\title{
Geochemical Tools and Paleoclimate Clues: Multi-Molecular and Isotopic Investigations of Tropical Marine Sediments and Alpine Ice
}

\author{
By \\ Matthew C. Makou \\ B.S., Binghamton University, 1997 \\ Submitted in partial fulfillment of the requirements for the degree of \\ Doctor of Philosophy \\ at the \\ MASSACHUSETTS INSTITUTE OF TECHNOLOGY \\ and the \\ WOODS HOLE OCEANOGRAPHIC INSTITUTION
}

February 2006

(C) 2006 Matthew C. Makou

All rights reserved.

The author hereby grants to MIT and WHOI permission to reproduce paper and electronic copies of this thesis in whole or in part and to distribute them publicly.

Signature of Author

Joint Program in Oceanography/Applied Ocean Science and Engineering
Massachusetts Institute of Technology
and Woods Hole Oceanographic Institution
February 2006

Certified by

Timothy I. Eglinton

Delia W. Oppo

Co-thesis Supervisor

Co-thesis Supervisor

Accepted by

J. Gregory Hirth

Chair, Joint Committee for Marine Geology and Geophysics Woods Hole Oceanographic Institution 


\section{CONTENTS}

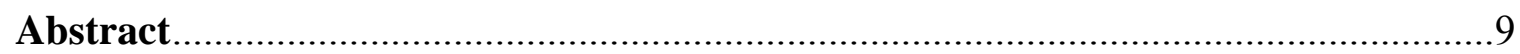

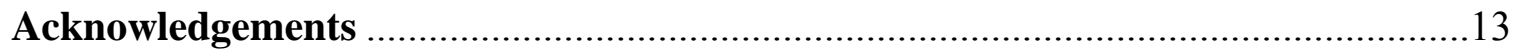

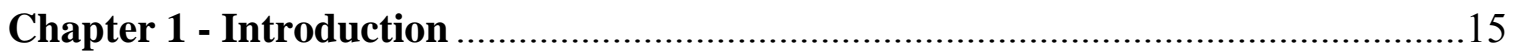

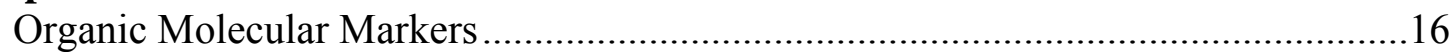

Advances in Analytical Capabilities .......................................................................18

Post-Glacial Tropical Climate.........................................................................19

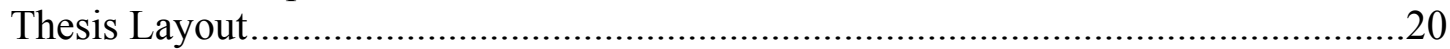

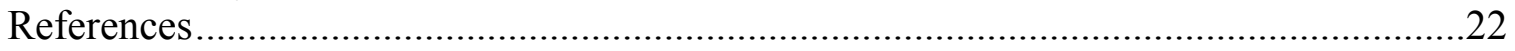

\section{Chapter 2 - Isotopic Records of Tropical Vegetation and Climate Change From} Terrestrial Vascular Plant Biomarkers Preserved in Cariaco Basin

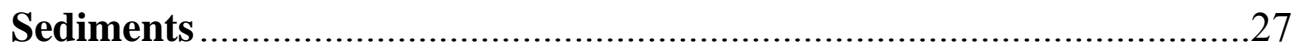

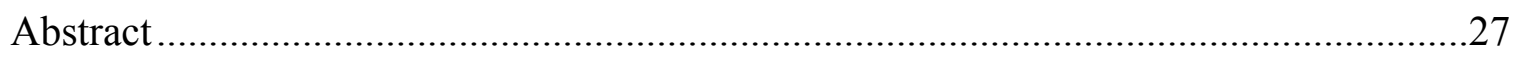

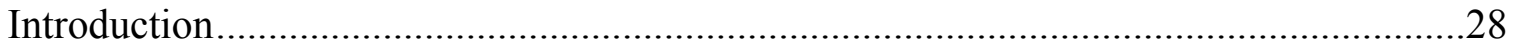

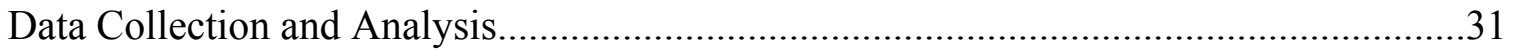

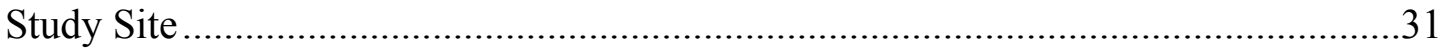

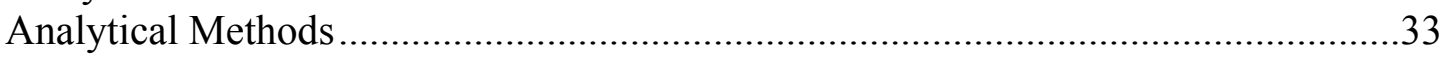

Statistical Analysis of Molecular Isotopic Data........................................................35

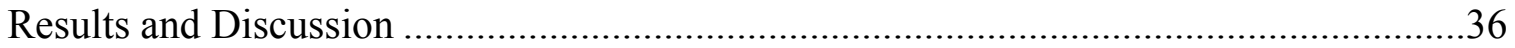

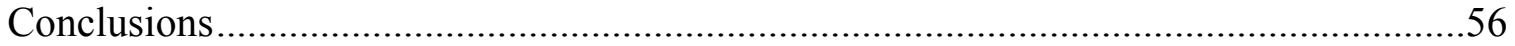

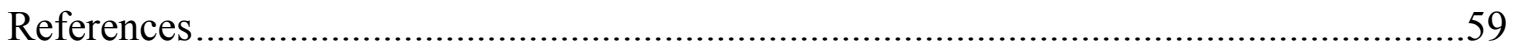

Chapter 3 - Investigation of Trace Lipids in Alpine Ice Cores …………………......65

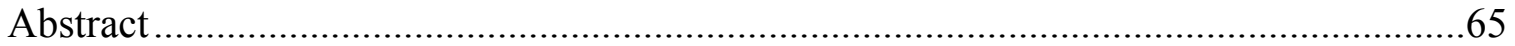

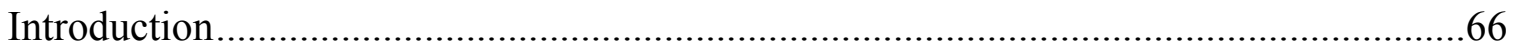

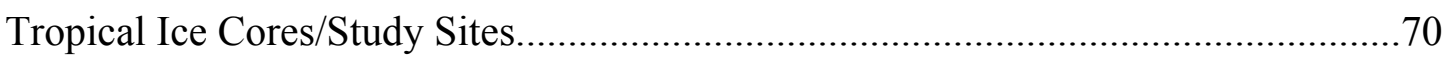

Previous Investigations of Biomarkers in Ice ..........................................................77

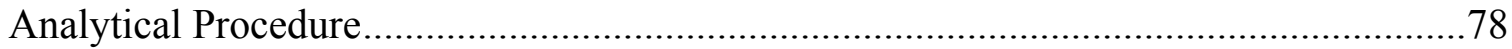

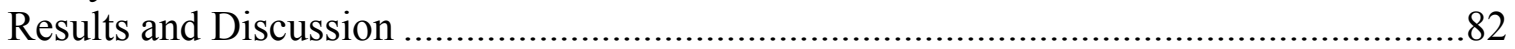

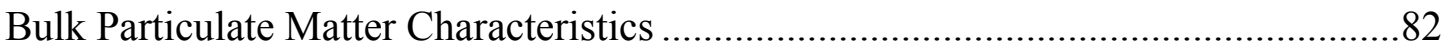

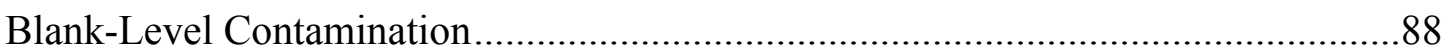

Biomarkers in Post-Industrial Samples..................................................................101

Alkyl Amides and Nitriles ...............................................................................101 


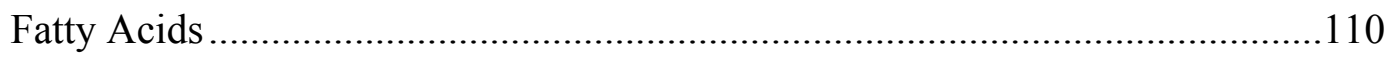

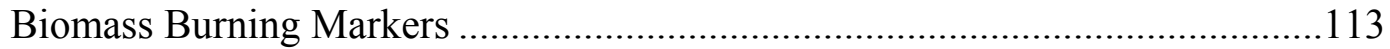

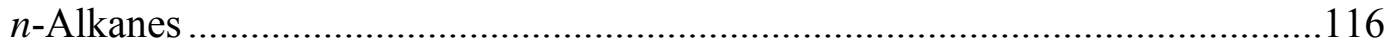

Comparison to Other Ice Core Studies ................................................................119

Biomarkers in Pre-Industrial Samples …………………...................................121

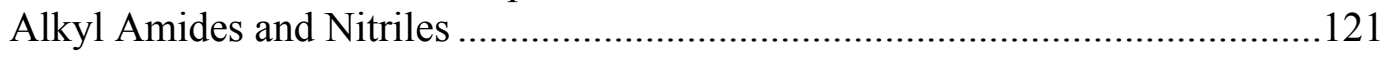

Fatty Acids ..........................................................................................124

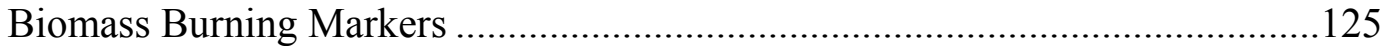

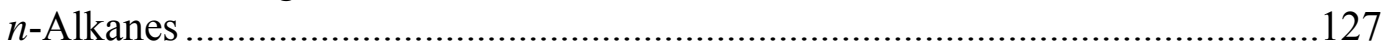

Controls on Biomarker Abundance in the Sajama Ice Core .....................................128

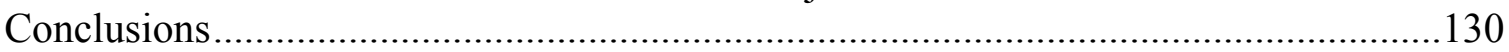

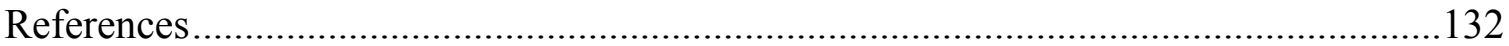

\section{Chapter 4 - Development of High-Resolution Multi-Molecular Stratigraphic} Records from Peru Margin Sediments .............................................137

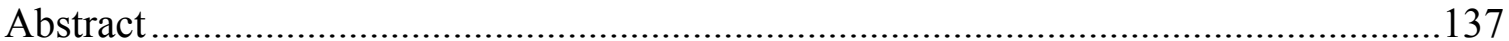

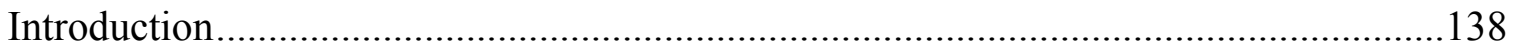

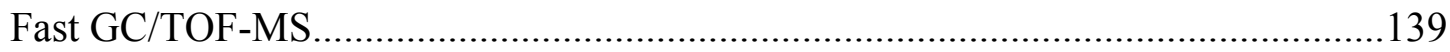

Peru Margin Study Site .................................................................................... 142

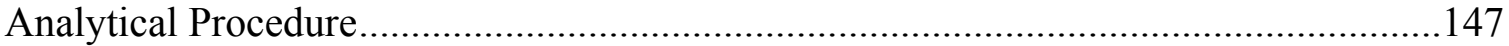

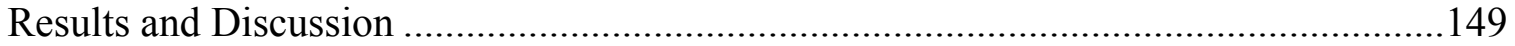

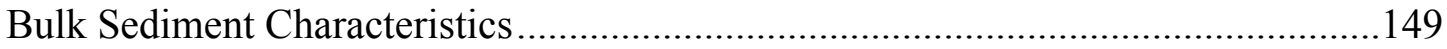

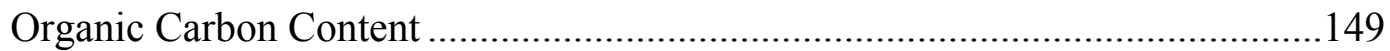

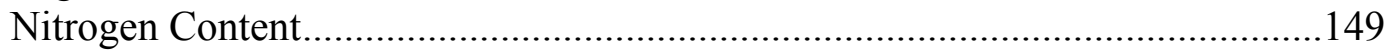

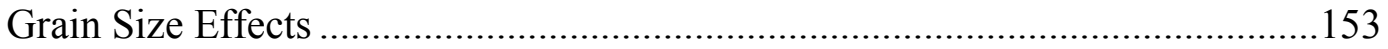

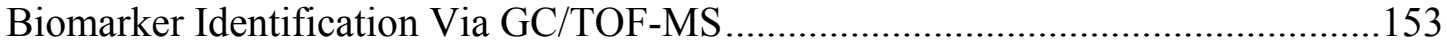

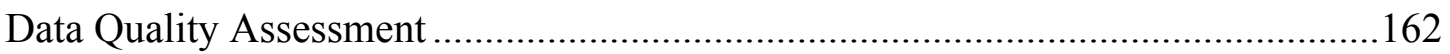

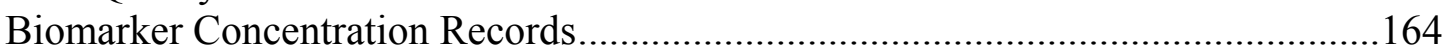

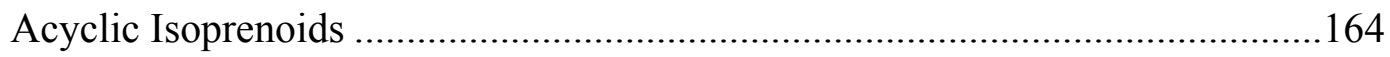

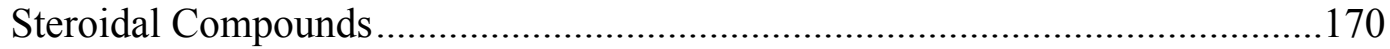

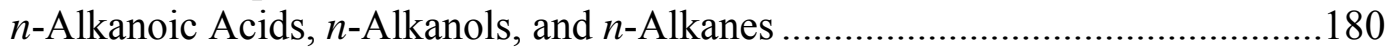

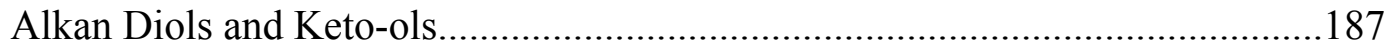

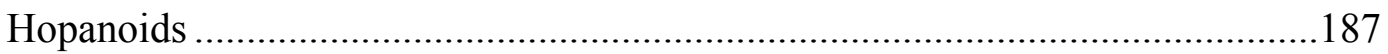

Biomarker Ratios ………………………………...................................190

Biomarker Records Normalized to Phytol ......................................................190

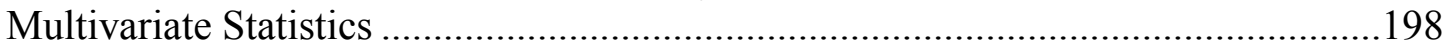

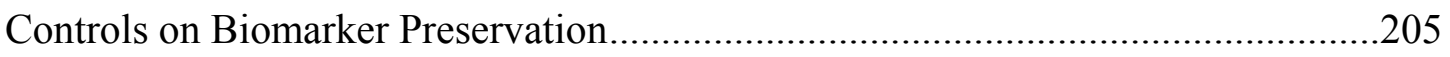

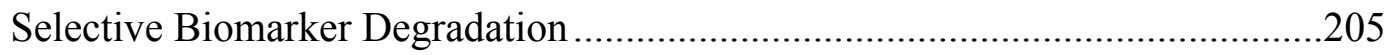

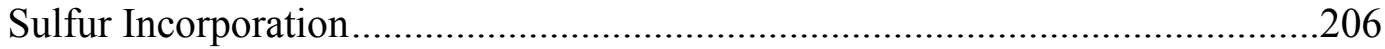

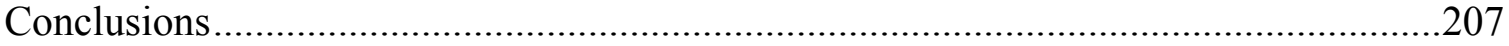

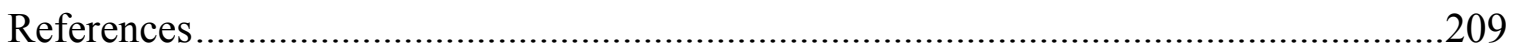




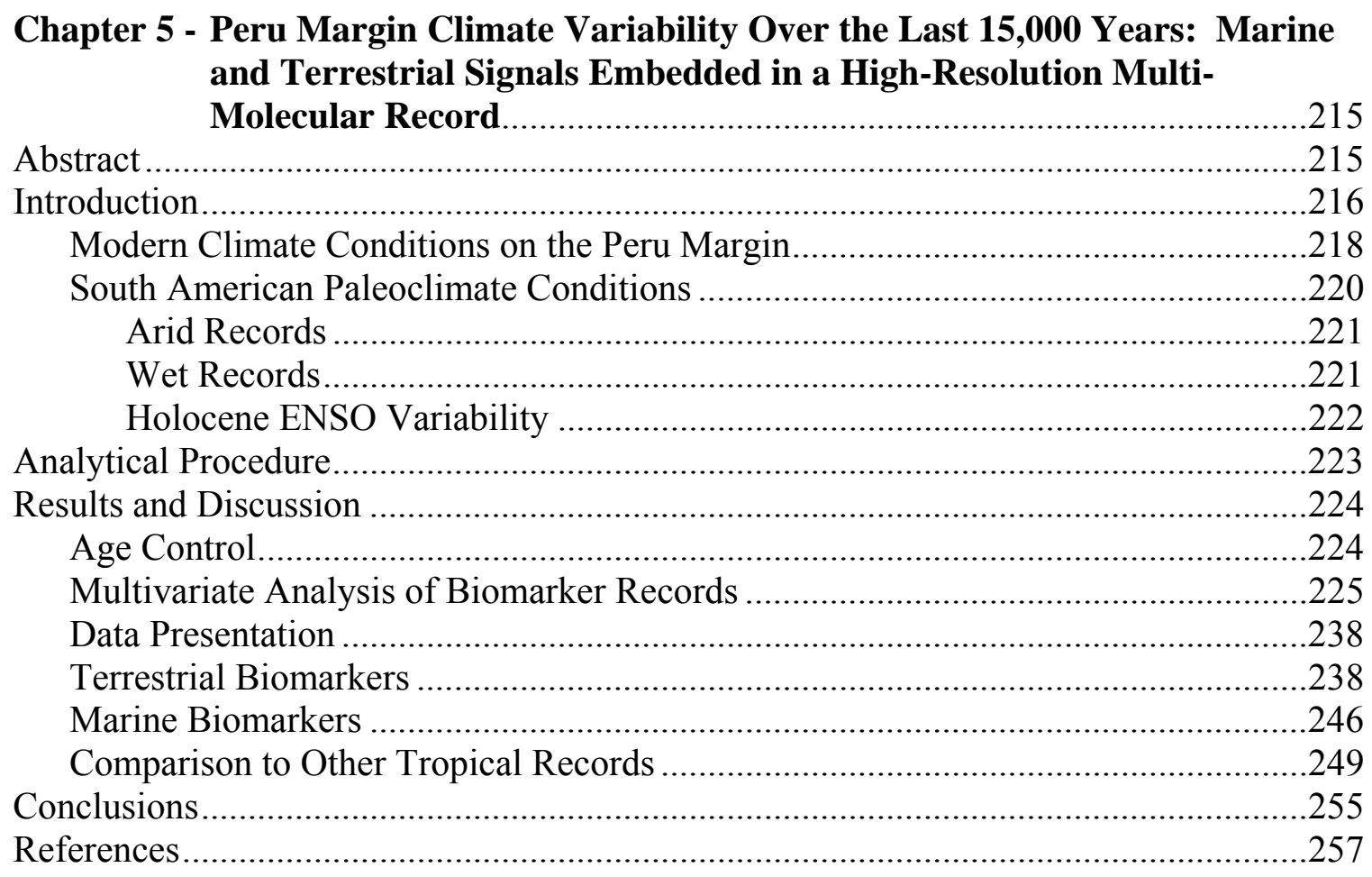

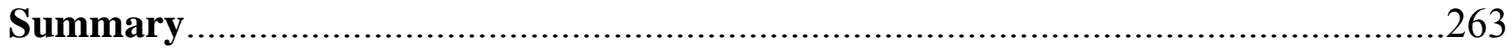

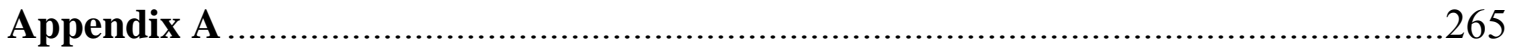

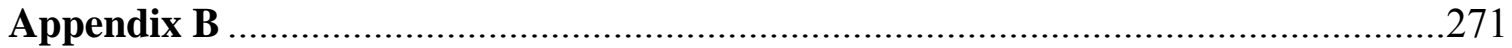

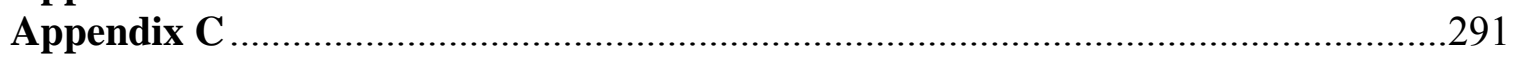




\section{Figures}

Figure 2-1

Figure 2-2

Figure 2-3

Figure 2-4

Figure 2-5

Figure 2-6

Figure 2-7

Figure 2-8

Figure 2-9

Figure 2-10

Figure 2-11

Figure 3-1 (a-d)

Figure 3-2 (a-c)

Figure 3-3

Figure 3-4

Figure 3-5 (a-b)

Figure 3-6

Figure 3-7

Figure 3-8

Figure 3-9

Figure 3-10

Figure 3-11 (a-b)

Figure 3-12

Figure 3-13

Figure 4-1

Figure 4-2

Figure 4-3

Figure 4-4

Figure 4-5

Figure 4-6 (a-b)

Figure 4-7

Figure 4-8

Figure 4-9

Figure 4-10

Figure 4-11
Cariaco Basin Fatty Acid Chromatograms

Cariaco Basin Fatty Acid Concentrations

Cariaco Basin Fatty Acid Average Chain Length

Cariaco Basin Fatty Acid $\delta D$

Cariaco Basin Fatty Acid Concentration and Isotopic Data for a

Preboreal and Glacial Sample

Cariaco Basin Fatty Acid $\delta^{13} \mathrm{C}$

Cariaco Basin Individual $\delta^{13} \mathrm{C}$ Measurements for Stacking Index

Cariaco Basin $\delta^{13} \mathrm{C}$ Indices

Cariaco Basin Individual $\delta D$ Measurements for Stacking Index

Cariaco Basin $\delta \mathrm{D}$ Indices

Cariaco Basin $\delta^{13} \mathrm{C}$ versus $\delta \mathrm{D}$

Ice Core Locations

Images of Sajama Particulate Matter

Molecule Structures

Alkyl Amide Concentrations in Modern Ice Core Samples

Ice Core $\left[\mathrm{C}_{18: 1}\right]$ versus [ $\left.\mathrm{C}_{22: 1}\right]$ Alkyl Amides and Nitriles

Alkyl Nitrile Concentrations in Modern Ice Core Samples

Ice Core Alkyl Amide $\mathrm{C}_{18: 1} / \mathrm{C}_{22: 1}$ versus Nitrile $\mathrm{C}_{18: 1} / \mathrm{C}_{22: 1}$

Ice Core Fatty Acid Concentrations, Modern Samples

Concentrations of Biomass Burning Marker Compounds in Modern and Pre-Industrial Ice Core Samples

Ice Core Total $n$-Alkane Concentrations

Puruogangri Ice Core Alkyl Amide and Nitrile Concentrations, Modern and 6 ka Samples

Sajama Ice Core $\delta^{18} \mathrm{O}$ and Dust

Sajama Ice Core Accumulation

Peru Margin Sample Location

Peru Margin Weight \% Organic Carbon

Peru Margin Carbon/Nitrogen

Peru Margin TIC (89 cm)

Peru Margin Fatty Acid (as FAME) EIC

Peru Margin $\mathrm{C}_{26} n$-Alkanol Chromatogram and Mass Spectrum

Peru Margin Sterol and Stanol EICs

Peru Margin Phytol Concentration

Peru Margin Phytol Concentration and Weight \% Organic Carbon

Peru Margin Pristane, Phytane, and Phytol Concentrations

Peru Margin Pristane, Phytane, and Phytol Concentrations Normalized to Organic Carbon

Figure 4-12 (a-b) Peru Margin Sterol Concentrations 
Figure 4-13

Figure 4-14

Figure 4-15

Figure 4-16

Figure 4-18(a-b)

Figure 4-19

Figure 4-20(a-b)

Figure 4-21

Figure 4-22

Figure 4-23

Figure 4-24(a-f)

Figure 4-25(a-b)

Figure 4-26(a-b)

Figure 5-1

Figure 5-2(a-b)

Figure 5-3(a-c)

Figure 5-4

Figure 5-5(a-c)

Figure 5-6

Figure 5-7

Figure 5-8

Figure 5-9

Figure 5-10

Figure 5-11

Figure 5-12

Figure 5-13
Figure 4-17

Peru Margin Sterol Concentrations Normalized to Organic Carbon Peru Margin Cholest-2-ene and Cholesta-3,5-diene Concentrations Peru Margin Cholesterol and Cholesterol Degradation Product Concentrations

Peru Margin Dinosterol and Dinostanol Concentrations

Peru Margin Dinosterol and Dinostanol Concentrations Normalized to Organic Carbon

Peru Margin $\mathrm{C}_{26}$ FAME and $\mathrm{C}_{26} n$-Alkanol Concentrations

Peru Margin $\mathrm{C}_{32}$ 1,15-alkan diol and $\mathrm{C}_{32}$ 15-keto-ol Concentrations

Peru Margin $\mathrm{C}_{16}$ and $\mathrm{C}_{18}$ FAME Concentrations

Peru Margin $\mathrm{C}_{32}$ 1,15-alkan diol and $\mathrm{C}_{32}$ 15-keto-ol Concentrations

Normalized to Organic Carbon

Peru Margin Hopanol Concentrations

Biomarker Ratios

Peru Margin Biomarker Concentrations Normalized to Phytol

Biomarker Factor Analysis

Biomarker Factor Analysis - Factor Scores for Individual Data Points Locations of South American Paleoclimate Records

Biomarker Data Set Factor Analysis

Factors 1, 2, and 3 - All Biomarkers Normalized to Organic Carbon Selected Biomarkers and Metals Factor Analysis - Factors 1 and 2

Factors 1, 2, and 3 - Selected Biomarkers Normalized to Organic Carbon and Metals Normalized to Al

Peru Margin $\mathrm{C}_{26}, \mathrm{C}_{28}$, and $\mathrm{C}_{30}$ Fatty Acid Concentrations Normalized to Organic Carbon

Peru Margin Fatty Acid $\delta^{13} \mathrm{C}$

Peru Margin Bulk Sediment $\delta^{13} \mathrm{C}$

Peru Margin $\mathrm{C}_{30}$ Fatty Acid Concentration and $\delta^{13} \mathrm{C}$

Peru Margin $\mathrm{C}_{30}$ Fatty Acid Concentration and Ti/Al

Peru Margin Cholesterol, Brassicasterol, and Dinosterol

Concentrations Normalized to Organic Carbon

Peru Margin Dinosterol Concentration and Inferred ENSO Variability Peru Margin Cholesterol Concentration and Eastern Tropical Atlantic Temperature Anomaly

\section{Tables}

Table 3-1

Table 4-1

Table 4-2
Ice Core Biomarker Concentrations (pg/ml)

Peru Margin Biomarker List

Data Quality Parameters for Individual Biomarkers 


\begin{abstract}
South American climate has undergone dramatic changes since the last glacial period, as evidenced from Cariaco Basin (Venezuelan coast) and Peru Margin marine sediment biomarker records. Compounds derived from vascular plant leaf waxes and delivered to the marine sedimentary environment, including long-chain $\left(\mathrm{C}_{24}-\mathrm{C}_{32}\right) n$ alkanoic acids, were used as proxies for terrestrial vegetation type, aridity, and atmospheric circulation. Marine biomarkers, such as sterols and phytol, were used to reconstruct productivity in the Peru Margin upwelling zone, where sedimentary conditions are not conducive to the preservation of foraminifera. Through the use of organic molecular isotopic techniques and multi-molecular stratigraphy, a great deal can be learned about communities of marine organisms and terrestrial plants that existed in the past and the environments in which they lived.

Vascular plant leaf wax carbon and hydrogen isotopic records were generated from $n$-alkanoic acids preserved in Cariaco Basin marine sediments. These records were compared to previously established pollen and climate records and were found to parallel local millennial-scale climate changes between the late Glacial and Preboreal periods, which were characterized by migrations of the inter-tropical convergence zone. Differences in $\delta \mathrm{D}$ between $\mathrm{C}_{16}-\mathrm{C}_{18}$ and $\mathrm{C}_{24}-\mathrm{C}_{30} n$-alkanoic acids suggest a marine source for the shorter chain lengths and a terrestrial source for the longer chains. Stacked $\delta D$ and $\delta^{13} \mathrm{C}$ records both exhibited isotopic enrichment during the late Glacial and Younger Dryas periods and depletion during the Bølling-Allerød and Preboreal periods. If interpreted as an aridity proxy, the $\delta \mathrm{D}$ record is in agreement with Cariaco Basin sediment grey scale records, suggesting that the late Glacial and Younger Dryas were more arid than the $\mathrm{B} \varnothing l$ ling-Allerød and Preboreal periods. $n$-Alkanoic acid $\delta^{13} \mathrm{C}$, which is a proxy for $\mathrm{C}_{3}$ versus $\mathrm{C}_{4}$ plant type, indicates that $\mathrm{C}_{3}$ plants predominated in this area of the tropics during warm and wet periods, such as the Bølling-Allerød and the Holocene, and $\mathrm{C}_{4}$ plants proliferated during cooler and more arid periods, such as the Glacial and Younger Dryas. The biomarker $\delta^{13} \mathrm{C}$ record agrees with pollen data previously developed from Cariaco Basin sediments, confirming that leaf wax compounds preserved in marine sediments can accurately record terrestrial vegetation changes.

Analytical methods utilizing stir bar sorptive extraction (SBSE) and thermal desorption were developed and applied to investigate lipid organic matter in a suite of alpine ice cores. These methods permit use of small volume (10-30 ml) samples, as would be required for high-resolution down-core analyses. SBSE involves using a polymer coated stir bar to extract organic matter from aqueous samples, after which it is
\end{abstract}


loaded directly into a thermal desorption unit and the organic matter transferred in its entirety to a gas chromatograph inlet. To test these methods and the organic content of tropical ice, post-industrial samples from two South American, two Asian, and one African ice core were analyzed. Compounds identified in the modern ice core samples included natural and anthropogenic biomarkers such as $n$-alkanes, $n$-alkanoic acids, $n$ alkyl amides and nitriles, polycyclic aromatic hydrocarbons (PAHs), and diterpenoids. Variability in the distributions of these compounds between different cores demonstrated that the lipid organic fraction in each core was representative of mostly local inputs. To further investigate natural inputs, several pre-industrial samples were analyzed from the Sajama ice core in the Andes and The Puruogangri core on the Tibetan Plateau. Inputs of terrestrial vegetation combustion biomarkers such as PAHs, diterpenoids, and alkyl amides were consistent with periods of enhanced aridity in each core. The results of this investigation demonstrate the utility of the methodology, which could now be applied to generate very high-resolution biomarker records from tropical ice cores.

Gas chromatography/time-of-flight mass spectrometry (GC/TOF-MS) was used to generate a high-resolution, multi-molecular organic biomarker record from Peru Margin sediments $\left(\sim 11^{\circ} \mathrm{S}, 252 \mathrm{~m}\right.$ water depth) for the last $15 \mathrm{ka}$. Because of their position beneath the oxygen minimum zone of a productive upwelling region, these sediments contain a wealth of compounds that can be exploited as paleoclimate indicators. TOF-MS and fast GC techniques allowed me to generate this record in a short amount of time and without employing the traditional suite of purification techniques. Before about $9 \mathrm{ka}$, organic carbon and biomarker concentration records exhibited similar variability, implying a forcing mechanism that affected input and/or preservation of both marine and terrestrial organic matter, such as large-scale climate change. Organic carbon and biomarker abundances then systematically increased throughout the Holocene and exhibited higher frequency variability, suggesting overall enhanced productivity from rapidly evolving planktonic communities. Similar patterns of variability between bacterial hopanol, sterol degradation product, and primary productivity biomarker records suggest that the productivity biomarkers are recording sea surface and water column processes, and are not significantly biased by sedimentary diagenesis. Low bound sulfur content in lipid extracts and a lack of observed sulfur-containing compounds argue against significant sulfurization and resultant biomarker sequestration in 1228D sediments. Factor analysis provided a statistical means of separating terrestrial and marine organic inputs, and reinforced the interpretations that very long chain $n$-alkanoic acids $\left(\mathrm{C}_{30}-\mathrm{C}_{32}\right)$ are terrestrially derived and sterol compounds primarily represent marine algal inputs. In all, the biomarker records suggest millennial-scale changes in upwelling strength superimposed on longer-term trends, with additional variability in contributions from specific precursors, such as dinoflagellates. Terrestrial leaf wax compounds also exhibited high-amplitude, millennial-scale variability, but with a different pattern of change than the marine inputs. GC/TOF-MS was shown to be a useful tool for generating high-resolution records of the type necessary to understand the relationships between biomarkers in a complex and sensitive depositional environment such as the Peru Margin. 
Climate signals embedded in the Peru Margin biomarker records provided clues as to the productivity and upwelling histories of the Peru Margin, as well as regional terrestrial vegetation. Elevated concentrations of marine biomarkers suggest enhanced upwelling and productivity from about $6.5 \mathrm{ka}$ to the present on the Peru Margin, with lower-amplitude millennial-scale variations occurring throughout this period. Enhanced dinosterol abundances after $6.5 \mathrm{ka}$ are consistent with greater occurrences and/or strength of El Niño, while concurrently enhanced upwelling suggests a parallel increase in La Niña activity. Similar timing of mid to late Holocene variability between Peru Margin marine biomarker records, a faunal sea surface temperature record from the eastern tropical Atlantic, and Andean paleoclimate records suggests strong climate links between these regions of the tropics, likely driven by broad-scale changes in El Niño and the Southern Oscillation (ENSO) and trade wind strength. The $\mathrm{C}_{30} n$-alkanoic acid, which is representative of vascular plant leaf wax inputs, exhibited millennial-scale variability superimposed on longer-term trends that may be related to aridity, assuming fluvial transport of terrestrial material. $n$-Alkanoic acid $\delta^{13} \mathrm{C}$ is generally enriched during periods of enhanced leaf wax abundance, consistent with increased inputs of $\mathrm{C}_{4}$ plant material at these times. 


\section{Acknowledgements}

I get by with a little help from my friends... - The Beatles

My most heartfelt thanks go to my wife, Alice, who has always supported my ambitions with an unwavering enthusiasm. I don't want to imagine the last six years without her love, patience, and encouragement. My parents inspired in me a love of nature and the mindset that makes me want to pick it apart. I guess when you take a kid to a quarry as part of a summer vacation you end up with a geologist. Ang, Val, and Chris have all helped in more ways than they know, as have my long time friends Dave, Dave, Mike, Mike, Scott, and Jim. My undergraduate advisor Tim Lowenstein has been a good friend and an inspiring guide through the world of geology. If he had not been kind enough to let me retake the midterm I slept through freshman year, I might have pursued my alternative academic path and ended up writing bad poetry instead of this thesis.

I am tremendously grateful to my graduate co-advisors, Delia Oppo and Tim Eglinton, for generously sharing their time and knowledge with me. I could readily see their care for my wellbeing as a student, scientist, and person in every talk we have ever had, and should I become an advisor myself, I will certainly use them as the example of how it is done best. Tim has been more than kind to let me pursue all of my research interests in his lab, even though many of them are proving to be less than fundable. Delia has been tremendously supportive and encouraging ever since I was a summer fellow, and especially when it was needed most. Konrad Hughen has been immensely helpful and encouraging ever since the first Cariaco Basin isotope analyses and I have benefited greatly from his wealth of knowledge about South American climate change and his enthusiasm for deciphering it. Lonnie Thompson has been extremely supportive, and has also generously shared his time and ice core samples, letting me pursue my greatest research interest with expert guidance. Thank you also to Roger Summons for chairing my thesis committee. I am grateful to other members of my generals and thesis proposal committees including Dan McCorkle, Maria Zuber, Jerry McManus, and Kerry Emanuel. I have enjoyed all the scientific discussions I have had with and classes I have taken from all the members of the WHOI and MIT paleoclimate groups. I have learned almost everything I know about organic geochemistry lab work through patient explanations and demonstrations from Daniel Montluçon, Nick Drenzek, Nao Ohkouchi, and Chris Reddy. Without the technical savvy of Daniel and Matt Lasater, neither the TOF-MS nor I would ever have worked. 
I know that my nostalgia for my time at WHOI will be defined by the friendships I have made here. Nick Drenzek has been a great friend, roommate, and listener to scientific ideas and tirades. Nick, Daniel Montluçon, and Helen White have always made Fye 111 seem more like a home to me than a place of work. I have enjoyed the camaraderie of all the JP students I have known, especially my fellow paleoclimate students. I've enjoyed all the time I have spent in shared offices with Rose Came and Mea Cook, classes with Kristy Dahl and Dave Lund, and I especially enjoy seeing us all graduating. Xie xie Luping Zou for being such a good teacher and friend all these years. It was incredibly generous of you to spend an hour each week teaching me Chinese so that I could impress my in-laws, and I always enjoyed the classes. I've had a great time everywhere I have lived over the last six years, so thank you to all my roommates from Cambridge, Oyster Pond, and School St.

Many individuals provided valuable assistance generating and analyzing data for this thesis. Li Xu prepared Cariaco Basin samples for isotopic analysis and John Hayes patiently shared his knowledge of isotopic systems and statistical treatment of data. Carl Johnson, Leah Houghton, and Sean Sylva provided IRMS analyses. Matt Higginson, Tim Herbert, Mark Altabet, and Jess Tierney generously shared Peru Margin age scale, $\delta^{15} \mathrm{~N}$, alkenone, and metals data for comparison with biomarker records. Lorraine Eglinton generated the microscope images of Sajama particulate matter. Thank you also to Olivier Marchal for the instructive discussions about multivariate analysis.

The Peru Margin research projects used samples and/or data provided by the Ocean Drilling Program (ODP). The ODP is sponsored by the U.S. National Science Foundation (NSF) and participating countries under the management of Joint Oceanographic Institutions (JOI) Inc. Funding for this research was provided by a Schlanger Ocean Drilling Fellowship, which is part of the NSF-sponsored U.S. Science Support Program (USSSP). An NSF grant to TIE (OCE-0402533) provided additional funding for the research presented in Chapters 3-5. Funding for the Cariaco Basin isotopic analyses was provided by the Frank and Lisina Hoch Endowed Fund and the Woods Hole Oceanographic Institution Director's General Discretionary Fund. 


\section{Chapter 1}

\section{Introduction}

Paleoclimate investigations performed on increasingly finer time scales have revealed that glacial-interglacial climate variability is punctuated by abrupt (millennialscale or shorter) events and transitions with far reaching effects (Ruddiman and McIntyre, 1981; Oeschger, 1985; Broecker and Denton, 1989; Lehman and Keigwin, 1992; Johnsen et al., 1992; Bond et al., 1993; Thompson et al., 1995; Behl and Kennett, 1996; Björck et al., 1996; Hughen et al., 1996; Thompson et al., 1998). A myriad of geochemical tools have been used to deduce this past climate variability, always with the aim of maximizing the amount of information that can be gained from samples comprising individual stratigraphic sequences. Typically, the proxies used to unveil abrupt climate changes have been those that are measurable at high temporal resolution, as can be achieved with foraminifera in marine sediments and ice core isotopic investigations. However, a wealth of paleoclimate information is also preserved in the form of sedimentary organic matter, the utility of which is limited mostly by preservation and the analytical capacity to isolate telling compounds.

As the field of organic geochemistry has progressed, developments in analytical technology and protocol have permitted a move from investigation of bulk geochemical properties to that of individual organic geochemical biomarkers, which are compounds attributable to a specific organism or class of organisms. Biomarker investigations enhance the amount of detailed information that can be gained about sources of organic 
matter inputs and the response of specific biota to environmental changes. Our growing appreciation for the utility of biomarkers as climate proxies has led to the incorporation of molecular organic geochemical tools into paleoclimate studies (e.g., Eglinton et al., 2000; Herbert et al., 2001; Zhao et al., 2003). However, for practical purposes imposed by analytical limitations, biomarker investigations typically involve lower-resolution records than the inorganic records they are compared to, or they are restricted to use of a small range of compounds.

In this thesis, recently developed analytical tools and techniques are employed and optimized to facilitate generation of high-resolution multi-molecular records from a variety of depositional environments, from those with substantial organic inputs and complex biomarker assemblages to those with only trace abundances of organic matter. In both cases, the goal is to develop a holistic understanding of environmental change by examining biomarkers from a wide range of sources, while reducing sample preparation and analysis times so that development of high-resolution proxy records becomes feasible. The resultant records would be amenable to abrupt climate change investigation and also application of common and informative interpretive tools such as multivariate and time series analyses.

\section{Organic Molecular Markers}

Over time, organic geochemical investigations of natural samples and cultures have identified an increasingly vast array of compounds and their sources. The extensive body of work that has been developed concerning the chromatographic and mass spectral characteristics of these biomarkers greatly facilitates their isolation, identification, and quantitation in environmental samples. In this thesis, a number of compounds derived from both marine and terrestrial sources were employed for paleoclimate investigation.

Vascular plant leaf waxes, which occur as a protective coating on the surfaces of leaves (Eglinton and Hamilton, 1967) and can be transported over long distances as aerosols (Gagosian and Peltzer, 1986), serve as useful terrestrial climate indicators (e.g. Ohkouchi et al., 1997; Huang et al., 1999; Freeman and Colarusso, 2001; Hughen et al., 
2004; Makou et al., in review). Leaf waxes are comprised of long-chain lipids, including $n$-alkanes, $n$-alcohols and $n$-alkanoic acids (fatty acids) (Eglinton and Hamilton, 1967; Kolattukudy, 1976). In general, these leaf wax compounds are well preserved in marine sediments (Prahl and Muehlhausen, 1989; Meyers, 1997), and the limited studies to date indicate that they are preserved in ice as well (Kawamura et al., 1996; Xie et al., 2000), where degradation by biological activity is expected to be less severe. Furthermore, their carbon and hydrogen isotopic composition can be used to infer $\mathrm{C}_{3}$ versus $\mathrm{C}_{4}$ plant contributions and $\delta \mathrm{D}$ of growth water (and thus possibly aridity), respectively (e.g. Sternberg, 1988; Hayes, 1993; Huang et al., 2000; Schefuß et al., 2003; Hughen et al., 2004; Makou et al., in review). Paired analysis of leaf wax compound abundance and isotopic composition promotes a more comprehensive understanding of changes in terrestrial vegetation and climate. Studies of leaf wax compounds in marine sediments are particularly telling when coupled with analyses of marine biomarkers in the same core, because the relative timings of marine and terrestrial climate changes can then be explored (Hughen et al., 2004).

In addition to leaf waxes, other compounds such as polycyclic aromatic hydrocarbons and diterpenoids can provide information about terrestrial vegetation and paleoclimate conditions. These compounds have been observed in smoke from biomass burning, and could thus be employed as a proxy for aridity through its effects on forest fire occurrence (e.g. Oros and Simoneit, 2001). Some of the terpenoid compounds produced through biomass burning may have the additional benefit of source specificity, potentially allowing identification of certain types of vegetation (e.g. conifers) (Oros and Simoneit, 2001).

Investigation of biomarkers in marine sediments derived from algal and bacterial sources can provide information about both climate and sedimentary processes. $\mathrm{C}_{37}$ methylketones are commonly used as a proxy for reproducing past sea surface temperatures (e.g. Sachs and Lehman, 1999; Herbert et al., 2001), but other compounds are also useful for describing characteristics of the marine environment such as primary productivity and extent of diagenesis. In particular, steroidal compounds are produced in 
abundance in the euphotic zone by phytoplankton and zooplankton and can sometimes be used to track inputs from specific producers, as is the case with 4-methylsterols and dinoflagellates (Boon et al., 1979; Piretti et al., 1997). Comparison of sterol abundances to that of those degradation products such as sterenes and steranes could provide information on the extent of degradation in the water column and sediments (Mackenzie et al., 1982). In addition to steroidal compounds, a wide range of other biomarkers, including acyclic isoprenoids, alkan diols and keto-ols, and short-chain fatty acids, among others, can also be used in sediments underlying productive areas as indicators of algal primary productivity (e.g. Volkman et al., 1998). Specific bacterial biomarkers such as hopanoids are useful for determining bacterial inputs, and thus the potential for bacterial diagenesis (e.g. Summons et al., 1999; Farrimond et al., 2000). All of these biomarkers are particularly informative when used in conjunction, thus providing the clearest picture of water column and sedimentary production and degradation of organic matter. Once sedimentary processes are understood, marine biomarker records could then be used to infer changes in climate, insofar as productivity is forced by environmental factors.

\section{Advances in Analytical Capabilities}

Very recent advances in instrumentation and analytical techniques facilitate generation of high-resolution multi-molecular records from both organic-rich depositional environments, such as those beneath upwelling systems, and those with only trace abundances of organic matter, such as ice fields. For example, fast-gas chromatography (GC) techniques, which reduce analysis times while increasing sensitivity, were employed in this thesis. Analyses were conducted using a recently developed gas chromatography/mass spectrometry (GC/MS) system that incorporates time-of-flight mass spectrometry (TOF-MS), and which is ideally suited for use with fastGC. TOF-MS provides many benefits, including increased resolution and increased sample throughput through reduced analysis times. Additionally, the elevated spectral acquisition rates inherent to the instrument permit quantitation of multiple molecular 
species in a single GC/TOF-MS analysis, even from short ( $\sim 10$ minute) runs that produce abundant interfering chromatographic peaks. In practice, these benefits enable development of parallel high-resolution stratigraphic records for a wide range of biomarkers in a short amount of time.

Another novel analytical technique was employed that permits easy extraction and quantitation of trace amounts of lipid organic matter in aqueous samples, such as melted ice. Stir bar sorptive extraction (SBSE) and thermal desorption are an alternative to solvent extraction of semi-volatile organic compounds from the aqueous matrix. In this technique, a glass stir bar coated with a chemically bonded absorbent phase is spun in an aqueous sample, during which time hydrophobic organic compounds, such as leaf waxes and PAHs, are partitioned onto it. After removing the stir bar from the sample, the sorbed organic matter is quantitatively transferred directly into the GC/TOF-MS inlet via thermal desorption. An important advantage to this approach for analysis of trace level compounds, such as those in ice, is that analytes are wholly transferred from the sample to the head of the chromatographic column. As with GC/TOF-MS analysis of sediment extracts, minimal sample pretreatment and rapid analysis times allow greatly enhanced sample throughput.

\section{Post-Glacial Tropical Climate}

Evidence from a variety of high-resolution paleoclimate studies suggests that tropical climate has undergone abrupt (millennial-scale or shorter) changes since the last glacial period, even during the Holocene (e.g. Thompson et al., 1995; Hughen et al., 1996; Thompson et al., 1998; deMenocal et al., 2000; Haug et al., 2001; Moy et al., 2002). In general, tropical climate is comprised of and influenced by several large-scale and interrelated systems, including El Niño and the Southern Oscillation (ENSO), regional monsoons, and migrations of the inter-tropical convergence zone (ITCZ). These systems are superimposed on general atmospheric and oceanic circulation patterns, and variations in their strength and position on seasonal and inter-annual time scales lead to steep regional gradients in climate characteristics such as aridity, temperature, and wind 
strength. Since the last glacial period, it is apparent that these systems have shifted between different modes of equilibrium, likely due to perturbations imposed by changes in tropical insolation and global climate (e.g. Clement et al., 2000; Liu et al., 2000; Haug et al., 2001; Koutavas et al., 2002; Moy et al., 2002).

Given the complexity of variability in tropical climate over the last $20 \mathrm{ka}$ and relationships between the phenomena that comprise it, the need arises for a dense network of high-resolution proxy records covering tropical oceans and landmasses. The various lines of inquiry pursued in this thesis are aimed at generating new information about tropical climate variability and the proxies used to investigate it, as well as developing new methodologies to achieve this goal. Once tropical climate variability in the past is better constrained, relationships with high-latitude climate variability can be further explored, ultimately allowing for investigation of causal mechanisms and climate signal propagation with greater certainty.

\section{Thesis Layout}

Chapter 2 of this thesis describes variability in terrestrial vascular plant inputs to the Cariaco Basin in northern South America. Plant leaf wax $\delta^{13} \mathrm{C}$ and $\delta \mathrm{D}$ are used to infer changes in vegetation assemblages and aridity from the last glacial to the Preboreal period. These analyses demonstrate that tropical vegetation in the study area responds to millennial-scale climate changes, and thus the carbon and hydrogen isotopic information embedded in plant wax biomarkers represents a valuable for tool for reconstructing past climate states.

In Chapter 3, SBSE and thermal desorption are used to investigate lipid biomarkers in tropical alpine ice cores, for which low ambient concentrations of organic matter generally preclude detailed analysis. The analytical scheme I employed allows the use of small volume samples, which are consistent with future generation of highresolution biomarker records from these cores. This preliminary study reveals that biomarkers are indeed preserved in ice and can be recovered by use of these methods. Differences in biomarker assemblages between ice core sites on different continents 
suggests that ice fields receive local or regional biomarker inputs of the sort useful for paleoclimate reconstruction. In particular, biomass burning indicators appeared to be correlated with aridity, and therefore might be used as a proxy for such.

In Chapters 4 and 5, GC/TOF-MS is used to generate high-resolution biomarker records from Peru Margin sediments in order to better constrain tropical climate variability at this location and understand delivery and preservation of sedimentary organic matter. Biomarker records from a wide array of sources provided information about diagenetic conditions and facilitated selection of biomarker records to be used for paleoclimate interpretation. Through their association with primary productivity and upwelling, sterol records provided clues about El Niño and La Niña variability over the last $15 \mathrm{ka}$. 


\section{References}

Behl R. J. and Kennett J. P. (1996) Brief interstadial events in the Santa Barbara basin, NE Pacific, during the past 60 kyr. Nature 379, 243-246.

Björck S., Kromer B., Johnsen S., Bennike O., Hammarlund D., Lemdahl G., Possnert G., Rasmussen T. L., Wohlfarth B., Hammer C. U., and Spurk M. (1996) Synchronized terrestrial-atmospheric deglacial records around the North Atlantic. Science 274, 1155-1160.

Bond G., Broecker W., Johnsen S., McManus J., Labeyrie L., Jouzel J., and Bonani G. (1993) Correlations between climate records from North Atlantic sediments and Greenland ice. Nature 365, 143-147.

Boon J. J., Rijpstra W. I. C., De Lange F., and De Leeuw J. W. (1979) Black Sea sterol a molecular fossil for dinoflagellate blooms. Nature 277, 125-127.

Broecker W. S. and Denton G. H. (1989) The role of ocean-atmosphere reorganizations in glacial cycles. Geochimica et Cosmochimica Acta 53, 2465-2501.

Clement A. C., Seager R., and Cane M. A. (2000) Suppression of El Niño during the mid-Holocene by changes in the Earth's orbit. Paleoceanography 15, 731-737.

deMenocal P., Ortiz J., Guilderson T., and Sarnthein M. (2000) Coherent high- and lowlatitude climate variability during the Holocene warm period. Science 288, 21982202.

Eglinton G. and Hamilton. (1967) Leaf epicuticular waxes. Science 156, 1322-1335.

Eglinton T., Conte M., Eglinton G., and Poynter J. (2000) Alkenone biomarkers gain recognition as molecular paleoceanographic proxies. Eos, Transactions, AGU 81, 253-260.

Farrimond P., Head I. M., and Innes H. E. (2000) Environmental influence on the biohopanoid composition of recent sediments. Geochimica et Cosmochimica Acta 64(17), 2985-2992.

Freeman K. H. and Colarusso L. A. (2001) Molecular and isotopic records of $\mathrm{C}_{4}$ grassland expansion in the late Miocene. Geochimica et Cosmochimica Acta $\mathbf{6 5}$, 1439-1454.

Gagosian R. B. and Peltzer E. T. (1986) The importance of atmospheric input of terrestrial organic matter to deep sea sediments. Organic Geochemistry 10, 661669. 
Haug G. H., Hughen K. A., Sigman D. M., Peterson L. C., and Röhl U. (2001) Southward migration of the intertropical convergence zone through the Holocene. Science 293, 1304-1308.

Hayes J. M. (1993) Factors controlling ${ }^{13} \mathrm{C}$ contents of sedimentary organic compounds: Principles and evidence. Marine Geology 113, 111-125.

Herbert T. D., Schuffert J. D., Andreasen D., Heusser L., Lyle M., Mix A., Ravelo A. C., Stott L. D., and Herguera J. C. (2001) Collapse of the California Current during glacial maxima linked to climate change on land. Science 293, 71-76.

Huang Y., Street-Perrott F. A., Perrott R. A., Metzger P., and Eglinton G. (1999) Glacialinterglacial environmental changes inferred from molecular and compoundspecific $\delta^{13} \mathrm{C}$ analyses of sediments from Sacred Lake, Mt. Kenya. Geochimica et Cosmochimica Acta 63, 1383-1404.

Huang Y., Dupont L., Sarnthein M., Hayes J. M., and Eglinton G. (2000) Mapping of $C_{4}$ plant input from North West Africa into North East Atlantic sediments.

Geochimica et Cosmochimica Acta 64, 3505-3513.

Hughen K. A., Overpeck J. T., Peterson L. C., and Trumbore S. (1996) Rapid climate changes in the tropical Atlantic region during the last deglaciation. Nature 380, $51-54$.

Hughen K. A., Eglinton T. I., Xu L., and Makou M. (2004) Abrupt tropical vegetation response to rapid climate changes. Science 304(5679), 1955-1959.

Johnsen S. J., Clausen H. B., Dansgaard W., Fuhrer K., Gundestrup N., Hammer C. U., Iversen P., Jouzel J., Stauffer B., and Steffensen J. P. (1992) Irregular glacial interstadials recorded in a new Greenland ice core. Nature 359, 311-313.

Kawamura K., Suzuki I., and Watanabe O. (1996) Ice core record of fatty acids over the past 450 years in Greenland. Geophysical Research Letters 23, 2665-2668.

Kolattukudy P. E. (1976) Chemistry and Biochemistry of Natural Waxes. Elsevier.

Koutavas A., Lynch-Stieglitz J., Marchitto T. M. J., and Sachs J. P. (2002) El Niño-like pattern in ice age tropical Pacific sea surface temperature. Science 297, 226-230.

Lehman S. J. and Keigwin L. D. (1992) Sudden changes in North Atlantic circulation during the last deglaciation. Nature 356, 757-762.

Liu Z., Kutzbach J., and Wu L. (2000) Modeling climate shift of El Niño variability in the Holocene. Geophysical Research Letters 27(15), 2265-2268. 
Mackenzie A. S., Brassell S. C., Eglinton G., and Maxwell J. R. (1982) Chemical fossils: The geological fate of steroids. Science 217(4559), 491-504.

Makou M. C., Hughen K. A., Xu L., Sylva S. P., and Eglinton T. I. (in review) Isotopic records of tropical vegetation and climate change from terrestrial vascular plant biomarkers preserved in Cariaco Basin sediments. Organic Geochemistry.

Meyers P. A. (1997) Organic geochemical proxies of paleoceanographic, paleolimnologic, and paleoclimatic processes. Organic Geochemistry 27, 213250 .

Moy C. M., Seltzer G. O., Rodbell D. T., and Anderson D. M. (2002) Variability of El Niño/Southern Oscillation activity at millennial timescales during the Holocene epoch. Nature 420, 162-165.

Oeschger H. (1985) The contribution of ice core studies to the understanding of environmental processes. In Geophysical Monograph, Vol. 33 (ed. C. C. Langway Jr., H. Oeschger, and W. Dansgaard), pp. 9-17.

Ohkouchi N., Kawamura K., and Taira A. (1997) Molecular paleoclimatology: reconstruction of climatic variabilities in the late Quaternary. Organic Geochemistry 27, 173-183.

Oros D. R. and Simoneit B. R. T. (2001) Identification and emission factors of molecular tracers in organic aerosols from biomass burning. Part 1. Temperate climate conifers. Applied Geochemistry 16, 1513-1544.

Piretti M. V., Pagliuca G., Boni L., Pistocchi R., Diamante M., and Gazzotti T. (1997) Investigation of 4-methyl sterols from cultured dinoflagellate algal strains. Journal of Phycology 33, 61-67.

Prahl F. G. and Muehlhausen L. A. (1989) Lipid biomarkers as geochemical tools for paleoceanographic study. In Productivity in the Oceans: Present and Past (ed. W. H. Berger, V. S. Smetacek, and G. Wefer), pp. 271-289. John Wiley \& Sons.

Ruddiman W. F. and A M. (1981) The North Atlantic Ocean during the last deglaciation. Palaeogeography, Palaeoclimatology, Palaeoecology 35, 145-214.

Sachs J. P. and Lehman S. J. (1999) Subtropical North Atlantic temperatures 60,000 to 30,000 years ago. Science 286, 756-759.

Schefuß E., Ratmeyer V., Stuut J. B. W., Jansen J. H. F., and Sinninghe Damsté J. S. (2003) Carbon isotope analyses of $n$-alkanes in dust from the lower atmosphere over the central eastern Atlantic. Geochimica et Cosmochimica Acta 67, 17571767. 
Sternberg L. d. S. L. (1988) D/H ratios of environmental water recorded by D/H ratios of plant lipids. Nature 333, 59-61.

Summons R. E., Jahnke L. L., Hope J. M., and Logan G. A. (1999) 2-Methylhopanoids as biomarkers for cyanobacterial oxygenic photosynthesis. Nature 400, 554-557.

Thompson L. G., Mosley-Thompson E., Davis M. E., Lin P. N., Henderson K. A., Coledai J., Bolzan J. F., and Liu K. B. (1995) Late-glacial stage and Holocene tropical ice core records from Huascarán, Peru. Science 269(5220), 46-50.

Thompson L. G., Davis M. E., Mosley-Thompson E., Sowers T. A., Henderson K. A., Zagorodnov V. S., Lin P. N., Mikhalenko V. N., Campen R. K., Bolzan J. F., Cole-Dai J., and Francou B. (1998) A 25,000-year tropical climate history from Bolivian ice cores. Science 282(5395), 1858-1864.

Volkman J. K., Barrett S. M., Blackburn S. I., Mansour M. P., Sikes E. L., and Gelin F. (1998) Microalgal biomarkers: a review of recent research developments. Organic Geochemistry 29, 1163-1179.

Xie S., Yao T., Kang S., Xu B., Duan K., and Thompson L. G. (2000) Geochemical analyses of a Himalayan snowpit profile: implications for atmospheric pollution and climate. Organic Geochemistry 31, 15-23.

Zhao M., Dupont L., Eglinton G., and Teece M. (2003) n-Alkane and pollen reconstruction of terrestrial climate and vegetation for $\mathrm{N}$. W. Africa over the last 160 kyr. Organic Geochemistry 34, 131-143. 


\title{
Chapter 2
}

\section{Isotopic Records of Tropical Vegetation and Climate Change From Terrestrial Vascular Plant Biomarkers Preserved in Cariaco Basin Sediments}

\begin{abstract}
Records of vascular plant leaf wax $\delta^{13} \mathrm{C}, \delta \mathrm{D}$, and average carbon chain length were generated from terrestrial biomarkers preserved in marine sediments from the Cariaco Basin. Leaf wax carbon and hydrogen isotopic records were compared to previously established local pollen and climate records and were found to parallel local millennial-scale climate changes between the late Glacial and Preboreal periods. The terrestrial biomarkers used consisted of $\mathrm{C}_{24}-\mathrm{C}_{32} n$-alkanoic acids, which are derived from vascular plant leaf waxes. Differences in $\delta \mathrm{D}$ between $\mathrm{C}_{16}-\mathrm{C}_{18}$ and $\mathrm{C}_{24}-\mathrm{C}_{30} n$-alkanoic acids suggest a marine source for the shorter chain lengths and a predominantly terrestrial source for the longer chains. For both $\delta \mathrm{D}$ and $\delta^{13} \mathrm{C}$, data from all terrestrial chain lengths were combined to produce single indices of isotopic change. Both of these records exhibited isotopic enrichment during the late Glacial and Younger Dryas periods and depletion during the Bølling-Allerød and Preboreal periods. $\delta \mathrm{D}$ is most likely a record of the hydrogen isotopic composition of environmental water used for plant growth, including the effects of evaporative enrichment within leaf spaces, and as such may act as a proxy for local aridity. In agreement with Cariaco Basin sediment grey scale records, $\delta \mathrm{D}$ suggests that the late Glacial and Younger Dryas were more arid than the BøllingAllerød and Preboreal periods. $n$-Alkanoic acid $\delta^{13} \mathrm{C}$, which is a proxy for $\mathrm{C}_{3}$ versus $\mathrm{C}_{4}$
\end{abstract}


plant type, indicates that $\mathrm{C}_{3}$ plants predominated in this area of the tropics during warm and wet periods, such as the Bølling-Allerød and the Holocene, and the relative abundance of $\mathrm{C}_{4}$ plants increased during cooler and more arid periods, such as the Glacial and Younger Dryas. The biomarker $\delta^{13} \mathrm{C}$ record agrees with pollen data previously developed from Cariaco Basin sediments, confirming that leaf wax compounds preserved in marine sediments can serve as sensitive indicators of terrestrial vegetation changes. Coupled carbon and hydrogen isotope measurements in plant leaf wax compounds provided valuable information about aridity and vegetation change in northern South America, and could thus be applied to other areas where less is known about the climate background.

\section{Introduction}

Organic compounds derived from terrestrial plants and preserved in marine sediments can be a useful tool for understanding the nature of past vegetation, and by inference, paleoclimate. Studies of vascular plant biomarkers, such as leaf waxes and lignin-derived phenols, in marine sediments have yielded information about changes in paleovegetation and atmospheric circulation (Rieley et al., 1991a, 1991b; Ohkouchi et al., 1997; Huang et al., 1999; Huang et al., 2000; Freeman and Colarusso, 2001; Schefuß et al., 2003).

I studied the carbon and hydrogen isotopic composition of vascular plant-derived compounds preserved in Cariaco Basin sediments, which have already yielded detailed records of local and high-latitude North Atlantic climate change during deglaciation, in order to determine the response of local vegetation to known millennial-scale climate variability. I demonstrate that terrestrial vegetation in this area is responsive to local climate change, and that different molecular-level analyses can be effectively combined to better understand the terrestrial vegetation signal embedded in the sedimentary record.

In the present study, vascular plant leaf waxes served as biomarkers (organic compounds that can be attributed to a specific organism or group of organisms). These particular compounds form a protective coating on the surfaces of leaves, helping to 
prevent physical damage and excessive water loss (Eglinton and Hamilton, 1967). Leaf waxes contain long-chain hydrocarbons, including $\mathrm{C}_{25}-\mathrm{C}_{33} n$-alkanes, which exhibit an odd-carbon-number predominance, and $\mathrm{C}_{24}-\mathrm{C}_{32} n$-alcohols and $n$-alkanoic acids (fatty acids), which exhibit an even-carbon-number predominance (Eglinton and Hamilton, 1967; Kolattukudy, 1976). The carbon number preference of these compounds aids in their analytical identification and source assignment. In general, these leaf wax compounds are well preserved in marine sediments (Prahl and Muehlhausen, 1989; Meyers, 1997).

Compound-specific isotopic analyses of leaf waxes reveal information about the nature of the source plants. Both carbon and hydrogen isotopes of leaf wax fatty acids were analyzed in the same samples in order to investigate changes in local terrestrial vegetation assemblages and the climate in which they grew. Plants that use different metabolic pathways during photosynthesis, such as $\mathrm{C}_{3}$ and $\mathrm{C}_{4}$ plants, exhibit different ranges of $\delta^{13} \mathrm{C}$ values in their organic tissue (e.g. Hayes, 1993). $\mathrm{C}_{4}$ plants are better adapted to arid and low $\mathrm{CO}_{2}$ environments than $\mathrm{C}_{3}$ plants, and while the $\mathrm{C}_{4}$ photosynthetic mechanism limits water loss, it also reduces carbon isotopic fractionation of atmospheric $\mathrm{CO}_{2}$ by the plant. Thus, $\mathrm{C}_{4}$ plant tissue is isotopically enriched in ${ }^{13} \mathrm{C}$ compared to $\mathrm{C}_{3}$ plants. Collister et al. (1994), for example, measured $\delta^{13} \mathrm{C}$ values of -10 to $-16 \%$ in the total leaf tissue of $\mathrm{C}_{4}$ plants and -25 to $-30 \%$ in $\mathrm{C}_{3}$ plants. Total surface lipid extracts were found to be depleted on average an additional $8 \%$ and $4 \%$ in $\mathrm{C}_{4}$ and $\mathrm{C}_{3}$ plants, respectively, and were shown to record isotopic values consistent with photosynthetic pathway. By measuring $\delta^{13} \mathrm{C}$ of leaf waxes from marine sediments, one can thus infer how the balance of $\mathrm{C}_{3}$ and $\mathrm{C}_{4}$ biomass in the region might have changed over time (Huang et al., 2000; Schefuß et al., 2003). However, changes in the carbon isotopic composition of leaf wax assemblages only broadly describe the relative influences of $\mathrm{C}_{3}$ and $\mathrm{C}_{4}$ vegetation. Due to the ranges of isotopic values observed in each type of plant, it is not possible to describe their past influences on the leaf wax record in a quantitative manner. As an interpretive tool, terrestrial vegetation regimes are divided into two broad categories designated "forest" and "grassland". Both contain $\mathrm{C}_{3}$ and $\mathrm{C}_{4}$ 
plants, but the forest end-member is dominated by $\mathrm{C}_{3}$ vegetation and low-latitude grasslands are identified by the enhanced presence of $\mathrm{C}_{4}$ vegetation.

Hydrogen isotopes have not been as extensively researched as carbon isotopes in vascular plant lipids, although $\delta \mathrm{D}$ of leaf waxes may provide information about plant type and growth climate. Sternberg (1988) found that for submerged aquatic plants in lakes, $\delta \mathrm{D}$ values of the plant lipids paralleled those of the lake water, although the plant values were consistently more depleted. The same relationship was not found for plant cellulose. Chikaraishi and Naraoka (2003) analyzed leaf wax $n$-alkane hydrogen isotopes for 33 terrestrial plants in Japan and Thailand and found $\delta \mathrm{D}$ values for $n$-alkanes of $-152 \pm 26 \%$ o for $\mathrm{C}_{3}$ angiosperms ( $-149 \pm 16 \%$ o for gymnosperms) and $-171 \pm 12 \%$ o for $\mathrm{C}_{4}$ plants. These results suggest that $\mathrm{C}_{3}$ and $\mathrm{C}_{4}$ plant leaf wax $\delta \mathrm{D}$ values may differ systematically, in which case $\delta \mathrm{D}$ values of leaf waxes in marine sediments could be used to differentiate between the two types of vegetation in a paleoclimate record. However, $\delta \mathrm{D}$ values in leaf waxes may be influenced by factors other than environmental water $\delta \mathrm{D}$, such as temperature and evapotranspiration, complicating the interpretation of $\delta \mathrm{D}$ paleoclimate results. Sternberg et al. (1984) observed roughly similar $\delta \mathrm{D}$ values for $\mathrm{C}_{3}$ and $\mathrm{C}_{4}$ plant saponifiable lipids, although only four types of each plant were analyzed and the study was not limited to specific compounds. Terwilliger et al. (2002) demonstrated that deuterium fractionation in leaf cellulose of different modern plant species is not predictable, with different plant species in the same geographic area exhibiting varying relationships between $\delta \mathrm{D}$ and elevation. In this study, hydrogen and carbon isotope measurements were performed on specific compounds in the same samples, enabling comparison of the leaf wax $\delta \mathrm{D}$ record with $\delta^{13} \mathrm{C}$, the latter being insensitive to changes in the hydrologic cycle. Additionally, only leaf wax fatty acids were used for this study, eliminating the influence of other plant-derived compounds that were created through different chemical pathways with different deuterium fractionation factors (Sessions et al., 1999).

Pollen records from the northern South American region imply that there were systematic shifts between forests and grassland as the mean climate state varied during 
the last deglaciation (van 't Veer et al., 2000; Rinaldi, 1996; Islebe et al., 1995; Leyden, 1985), likely owing to the enhanced ability of $\mathrm{C}_{4}$ plants to tolerate arid environments. The Cariaco Basin pollen record specifically shows an elevated amount of grass and herb pollen compared to forest taxa pollen during cold periods such as the Younger Dryas (YD) and Glacial, indicating that grasslands expanded during times when the Intertropical Convergence Zone (ITCZ) was shifted southward and the local climate was arid (Rinaldi, 1996). Forest vegetation, representative of $\mathrm{C}_{3}$ plants, exhibited greater pollen abundances during warm and wet periods, such as the Bølling-Allerød (B-A) and the Preboreal. The Colombian pollen record of van der Hammen and Hooghiemstra (1995) demonstrates the same pattern, indicating vegetation shifts on a regional scale. The biomarker results generated in this study will be compared to these pollen records to independently verify the utility of my methods for assessing paleovegetation.

\section{Data Collection and Analysis}

\section{Study Site}

The sediments used in this study were collected from the Cariaco Basin off the Venezuelan coast and contain annual laminations throughout the last deglaciation, extending back to 15 thousand years before present (kyr BP) (Overpeck et al., 1989; Peterson et al., 1991; Hughen et al., 1996a; Hughen et al., 1996b). Water in the Cariaco Basin is anoxic below $300 \mathrm{~m}$, enhancing organic matter preservation and eliminating bioturbation. Hughen et al. (1998) and Hughen et al. (2000) provided a reliable calendar age scale for Cariaco Basin sediments through varve counting and comparison of foraminiferal and tree ring radiocarbon records. Samples were obtained from piston cores PL07-56PC $\left(10^{\circ} 41.22^{\prime} \mathrm{N}, 64^{\circ} 58.07^{\prime} \mathrm{W} ; 810 \mathrm{~m}\right)$ and $58 \mathrm{PC}\left(10^{\circ} 40.60 ` \mathrm{~N}\right.$, $\left.64^{\circ} 57.70^{\prime} \mathrm{W} ; 820 \mathrm{~m}\right)$. These high deposition rate cores were collected from a saddle between the eastern and western sub-basins where there is minimal interference from turbidites or sediment slumping (Peterson et al., 1991), and where sediment redistribution due to advective processes should be minor (Mollenhauer et al., 2005). 
The annual climate cycle in northern South America, which is characterized by two distinct regimes, results in the yearly deposition of sedimentary laminae couplets, consisting of light-colored, plankton-rich and dark-colored, terrigenous mineral grain-rich layers (Hughen et al., 1996b). Annual migrations of the ITCZ produce a dry season with strong trade winds and enhanced coastal upwelling during Boreal winter, and a rainy season with diminished winds and upwelling during summer (Aparicio, 1986). The light layer is deposited during the upwelling season and the dark layer, including terrigenous silts, clays, and organic matter, is delivered during the rainy season via rivers that drain towards the basin.

In addition to seasonal changes, millennial-scale variations are observed in Cariaco Basin sediments. Relative reflectance, or grey scale, measured on fresh surfaces of split Cariaco Basin sediment cores correlates well with light laminae thickness, which records annual upwelling intensity (Hughen et al., 1996a). Grey scale and light laminae thickness show abrupt changes during the last deglaciation, indicating increased upwelling and trade wind strength during the YD and late Glacial periods, and reduced upwelling during the B-A and Preboreal periods. The former two periods are considered to reflect cool and arid conditions in northern South America and the latter two were warmer and wetter (Haug et al., 2001; Lea et al., 2003), consistent with millennial-scale northward and southward migrations of the mean seasonal ITCZ positions. The suite of Cariaco Basin deglacial climate changes correlate well with high-latitude Northern Hemisphere climate records, in particular the Greenland ice cores (Johnsen et al., 1992). General Circulation Model (GCM) simulations and abundance data for the planktonic foraminifer G. bulloides, which serves as an upwelling indicator, support the idea that upwelling in the Cariaco Basin is synchronous with reduced North Atlantic sea surface temperatures and increased zonal trade wind strength (Rind et al., 1986; Schiller et al., 1997; Black et al., 1999).

Several small rivers drain northern Venezuela and empty towards the Cariaco Basin, contributing terrestrial organic matter to the sediments. Two of the larger rivers presently drain areas with distinctly different plant communities. The Rio Tuy flows 
eastward along the mountainous coast and the Rio Unare flows northward through the savanna-like Llano. The vegetation in the high-elevation portion of the Rio Tuy drainage basin includes evergreen broadleaf rainforest and deciduous forest. The drainage basin of the Rio Unare consists mostly of unforested or sparsely forested grassland (UNEP, 2004). Thus, the vascular plant organic matter delivered to the Cariaco Basin through each of these rivers is expected to be different in character.

\section{Analytical Methods}

Lipid organic matter was extracted from eight freeze-dried sediment samples using a Dionex Accelerated Solvent Extraction system with methanol/dichloromethane (1:9), operating at a temperature and pressure of $100^{\circ} \mathrm{C}$ and 1000 p.s.i., respectively. The resultant total lipid extract was concentrated (Zymark Turbovap) and then separated via solid phase extraction (500mg aminopropyl sorbent in $6 \mathrm{ml}$ tubes). Neutral lipids eluted in the first fraction (7 $\mathrm{ml} \mathrm{1:9} \mathrm{acetone/dichloromethane)} \mathrm{and} n$-alkanoic acids eluted in the second fraction ( $8 \mathrm{ml} 2 \%$ formic acid in dichloromethane). The lipids in the acid fraction, including leaf wax $n$-alkanoic acids, were methylated using $14 \%$ boron trifluoride in methanol $\left(70^{\circ} \mathrm{C}\right.$ for 20 minutes $)$. The resulting fatty acid methyl esters (FAMEs) were extracted with hexane, dried with anhydrous sodium sulfate, and then purified via silica gel chromatography (5:95 ethyl acetate/hexane). Prior to analysis by gas chromatography (GC), a $\mathrm{C}_{36} n$-alkane standard was added to each sample.

All samples were initially analyzed via GC using an Agilent 6850 GC equipped with a split/splitless inlet, flame ionization detector (FID), and Agilent 6850 Auto Sampler. The inlet temperature was $300^{\circ} \mathrm{C}$. A CP Sil 5 CB capillary column $(60 \mathrm{~m}, 0.25$ mm i.d.) was used with hydrogen as the carrier gas. The samples were dissolved in toluene and run with a temperature program of: initial temperature $60^{\circ} \mathrm{C}(2 \mathrm{~min})$, ramped to $210^{\circ} \mathrm{C}$ at $25^{\circ} \mathrm{C} / \mathrm{min}$, then $4{ }^{\circ} \mathrm{C} / \mathrm{min}$ to $330^{\circ} \mathrm{C}$, held for $15 \mathrm{~min}$. FAMEs were positively identified via gas chromatography-mass spectroscopy (GC-MS) analysis performed on an Agilent 6890 Series GC coupled to an HP 5973 Mass Selective Detector. The GC-MS 
analyses were performed with a temperature program of: initial temperature $40^{\circ} \mathrm{C}(2$ $\min$ ), raised at $20^{\circ} \mathrm{C} / \mathrm{min}$ to 120 , then $5^{\circ} \mathrm{C} / \mathrm{min}$ to $320^{\circ} \mathrm{C}$, held for $15 \mathrm{~min}$.

Isotope ratio monitoring GC-MS (irm-GC-MS) was used to determine $\delta^{13} \mathrm{C}$ values for individual compounds. Measurements were performed on a Finnigan Delta ${ }^{\text {Plus }}$ stable isotope mass spectrometer with an attached HP 6890 GC and Finnigan GC combustion III interface. The temperature program used for irm-GC-MS was: $60^{\circ} \mathrm{C}(2 \mathrm{~min})$ ramped to $120^{\circ} \mathrm{C}$ at $30{ }^{\circ} \mathrm{C} / \mathrm{min}$, then $6{ }^{\circ} \mathrm{C} / \mathrm{min}$ to $340^{\circ} \mathrm{C}$, held for $15 \mathrm{~min}$. A DB5-MS column was used. Where sample size allowed, analyses were performed in duplicate or triplicate. $\delta^{13} \mathrm{C}$ values were determined relative to a reference gas $\left(\mathrm{CO}_{2}\right)$ of known isotopic composition, introduced in pulses during each run.

Hydrogen isotope ratios were measured on a Finnigan Delta ${ }^{\text {Plus }}$ XL isotope ratio mass spectrometer (IRMS) coupled to an Agilent 6890 GC via a Finnigan TC interface held at $1440^{\circ} \mathrm{C}$ (Burgoyne and Hayes, 1998). The $\mathrm{H}_{3}{ }^{+}$-factor for this instrument was measured daily by introducing square waves of $\mathrm{H}_{2}$ gas with constant $\delta \mathrm{D}$ and peak heights varying over a 10-fold range, and was typically $<4 \mathrm{ppm} \mathrm{mV}^{-1}$. Data were collected and corrected for contributions of $\mathrm{H}_{3}{ }^{+}$using the pointwise method of Sessions et al. (2001) and processed with Isodat NT software version 1.41 (ThermoFinnigan, Bremen).

Two types of standards were measured along with the Cariaco Basin samples in order to provide an estimate of instrumental error for hydrogen isotope measurements. A mixture of $\mathrm{C}_{16}-\mathrm{C}_{30} n$-alkanes ("external standards," obtained from the Biogeochemical Laboratories, Indiana University; http://php.indiana.edu/_aschimme/hc), with concentrations varying over a fivefold range were analyzed multiple times each day. Three $n$-alkanes $\left(n-\mathrm{C}_{15}, n-\mathrm{C}_{24}\right.$, and $\left.n-\mathrm{C}_{34}\right)$ were coinjected with each unknown sample. Two of these $\left(n-\mathrm{C}_{15}\right.$ and $\left.n-\mathrm{C}_{34}\right)$ were defined as standards, while the third $\left(n-\mathrm{C}_{24}, \delta \mathrm{D}=-\right.$ $55.4 \%$ ) was used to assess accuracy. The mean precision expressed as the pooled standard deviation of plant wax FAMEs was 4.6\%o. Based on the root mean square of $n$ $\mathrm{C}_{24}$ replicates $(\mathrm{n}=13)$, the accuracy estimate was $4.7 \%$. Reported $\delta \mathrm{D}$ values were normalized by regression of the IRMS values and the offline values for the $n-\mathrm{C}_{16}-\mathrm{C}_{30} n$ alkane mixture. All samples were run in duplicate for hydrogen isotopic analysis, with 
the exception of the sample at $12.2 \mathrm{kyr} \mathrm{BP}$, for which there was not enough material for a second measurement. Reported $\delta D$ values are averages of duplicate runs.

The $\delta^{13} \mathrm{C}$ and $\delta \mathrm{D}$ results have been corrected for the isotopic composition of the methyl group added to the compounds during methylation, ensuring that the reported values reflect the $\delta^{13} \mathrm{C}$ and $\delta \mathrm{D}$ of the original $n$-alkanoic acids. To accomplish this, a phthalic acid standard with known isotopic composition was methylated in the same manner as the samples, then measured and used to calculate the isotopic composition of the added methyl carbon and hydrogen. Average chain length (ACL) of $n$-alkanoic acids was computed from GC-FID peak areas using the formula: $\Sigma\left(\mathrm{C}_{\mathrm{i}} *_{\mathrm{i}}\right) / \Sigma \mathrm{C}_{\mathrm{i}}$, where $\mathrm{C}_{\mathrm{i}}$ is the peak area of an $n$-alkanoic acid of carbon chain-length i. Although analyses were performed on FAMEs, these compounds are referred to in the following text as fatty acids.

\section{Statistical Analysis of Molecular Isotopic Data}

To aid in the interpretation of trends in the leaf wax $\delta^{13} \mathrm{C}$ and $\delta \mathrm{D}$ records, all terrestrial fatty acid chain lengths $\left(C_{24}-C_{30}\right.$ for $\delta D ; C_{24}-C_{32}$ for $\left.\delta^{13} C\right)$ were combined into single indices of isotopic change using two statistical methods. These techniques were especially useful for the hydrogen isotope record, for which the magnitude of instrumental error approaches or exceeds the climate signal. Discrepancies in the trends of isotopic change between different chain lengths for both $\delta \mathrm{D}$ and $\delta^{13} \mathrm{C}$ are also addressed by my methods. First, the terrestrial fatty acid isotope records were "stacked". First, the mean chain length isotopic value was subtracted from each data point. The resultant values were then normalized to the standard deviation of the isotopic values determined for each specific chain-length fatty acid, removing any weighting bias of largely varying chains. In essence, this treats different chain length data points in the same depth interval as replicates of one inclusive isotopic measurement. As such, errors could be estimated for each depth interval by calculating the standard deviation of these "replicates". To generate the final stacked records, the mean of the normalized data for all terrestrial chain lengths was calculated for each depth interval. 
In generating the stacked records, I have assumed that all chain lengths are derived from the same source region or plant biome. That is, each fatty acid chain length, although normalized to standard deviation, is given the same weight in the stack. To avoid this assumption, mass-weighted average isotopic indices were also generated. For this statistical method, each isotopic result was multiplied by a weighting factor equivalent to the fractional abundance of its chain length compared to all terrestrial fatty acid chains in that sample. The results were then summed for each depth interval to produce a single result. If different terrestrial chain lengths were derived from different source plants, as suggested by the ACL record of Hughen et al. (2004), the weighting factors would favor the isotopic signal of the dominant producers. In this way, the massweighted average technique should reflect the isotopic character of the entire regional ecosystem better than the stacking technique. The error of these results, expressed as standard deviation of the mass-weighted average, was calculated from the variance, which is the sum for each depth interval of the fractional abundances of each fatty acid squared times the variance of the average isotopic results, plus the average results squared times the variance of the fractional abundance estimates.

\section{Results and Discussion}

Although it has been shown that leaf waxes can be transported long distances (e.g. halfway across the Pacific Ocean) by aeolian processes (Gagosian and Peltzer, 1986; Ohkouchi et al., 1997), a near-shore marine basin such as the Cariaco is expected to contain terrestrial organic matter that is derived primarily from regional or local sources. Hughen et al. (2004) plotted Cariaco Basin leaf wax fatty acid $\delta^{13} \mathrm{C}$ versus average chain length and found a bimodal distribution for different climate states that is not shared by African-source leaf waxes, indicating that the latter are not significant in Cariaco Basin sediments. Leaf wax compounds delivered through the rivers that feed the basin also contribute to the local terrestrial organic component in the sediments, although their residence time in soils prior to transport is unknown. Future molecular ${ }^{14} \mathrm{C}$-based studies may help clarify the path leaf waxes take from plant to depositional site, but for the 
purposes of this study, it is assumed that the leaf waxes are predominantly of local origin and experience a short terrestrial residence time. Additionally, seasonal cycles in leaf wax chemical composition and delivery to the basin are expected to average out through the time periods sampled, which are about 10-15 years per sediment interval (1.5-2.0 $\mathrm{cm})$.

A record of $\delta^{13} \mathrm{C}$ and $\delta \mathrm{D}$ variability in leaf wax fatty acids from Cariaco Basin sediments was obtained for the time period spanning the late Glacial through the Preboreal period (all analytical results are presented in Appendix A). Two samples each were selected from four different climate stages, including the Glacial, B-A, YD, and Preboreal. Initially, different classes of leaf wax compounds were analyzed, but only $n$ alkanoic acids, which were easily identified and isolated, were selected for this study. $n$ Alkanes and $n$-alkanols could not be used because of interference by petrogenic hydrocarbons, likely derived from seepage in the basin, or low abundances ( $n$-alkanols). Fatty acid homologues between $C_{16}$ and $C_{32}$ were analyzed. Longer chain $\left(\geq C_{24}\right)$ fatty acids are derived largely from terrestrial plants, whereas shorter carbon chain lengths may be derived from multiple sources, including aquatic productivity and heterotrophy (Meyers, 1997). Example chromatograms of Cariaco Basin fatty acids (as FAMEs) from the Glacial (14.7 kyr BP) and Preboreal (10.9 kyr BP) periods are shown in Figure 2-1. A strong even carbon number predominance is observed (CPI=4.9 for the $14.7 \mathrm{kyr} \mathrm{BP}$ sample), consistent with the distribution of these compounds in leaf waxes. Maximum fatty acid inputs occur at chain length $\mathrm{C}_{26}$ for the Glacial sample and $\mathrm{C}_{24}$ for the Preboreal sample. In general, chain length distributions appear to be shifted towards longer-chain fatty acids in the chromatograms from Glacial samples compared to the others.

Concentrations of fatty acids in Cariaco Basin sediment samples are shown in Figure 2-2. For all terrestrially derived chain lengths $\left(\mathrm{C}_{24}-\mathrm{C}_{32}\right)$, the lowest concentrations were recorded during the last Glacial and YD and higher concentrations occurred during the B-A and Preboreal periods. This trend suggests that leaf wax production decreased with increased aridity, leaf waxes were primarily transferred to the Cariaco Basin via fluvial transport, or terrestrial biomarkers were diluted by biogenic minerals resulting 
Figure 2-1

Cariaco Basin Fatty Acid Chromatograms

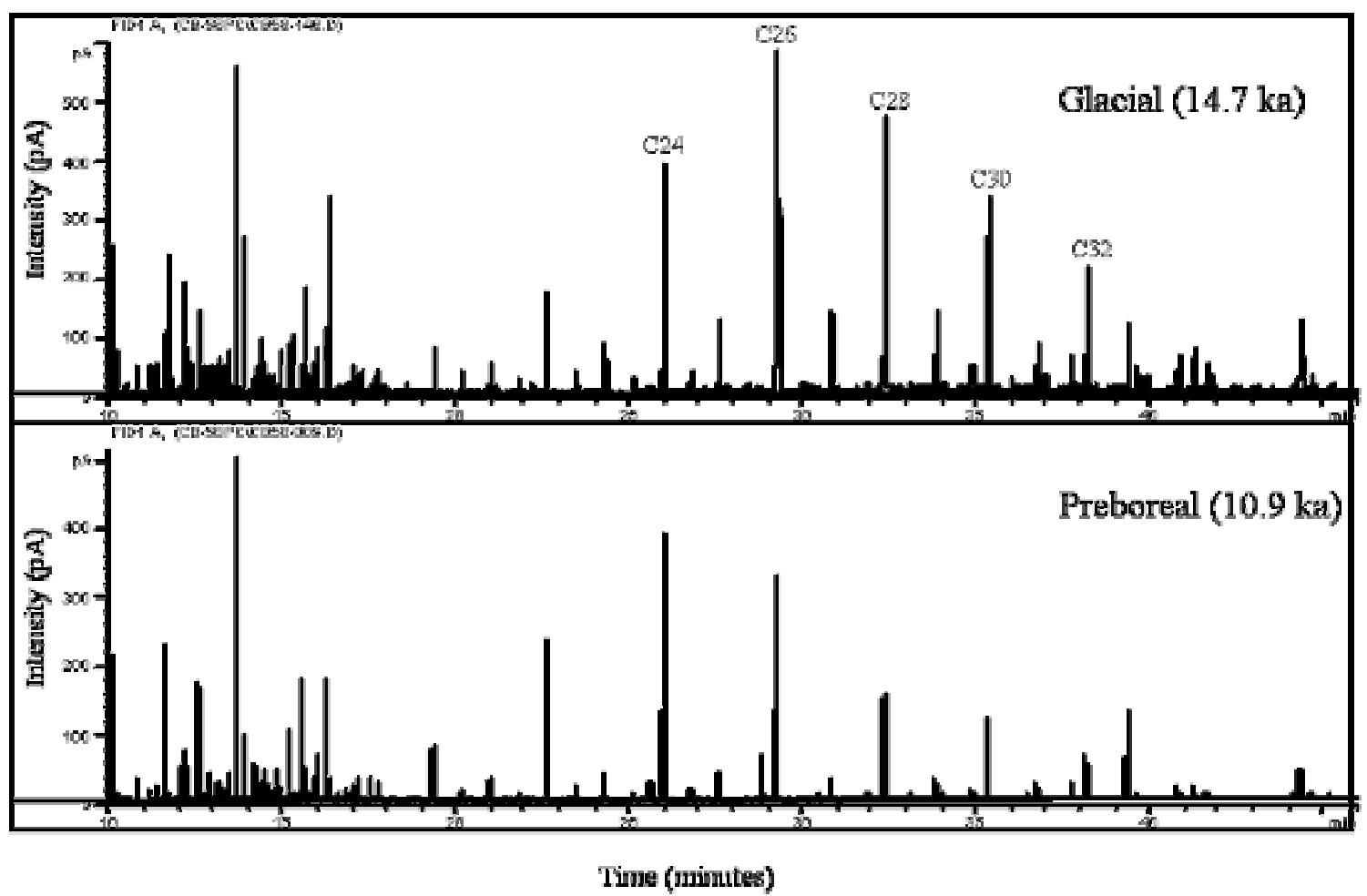

Chromatograms (GC-FID) of Cariaco Basin Glacial (top) and Preboreal (bottom) samples. Plant wax fatty acids (as methyl esters) appear as individual peaks $\left(\mathrm{C}_{24}-\mathrm{C}_{32}\right)$. FAME concentration was determined from peak areas referenced to an internal standard $\left(\mathrm{C}_{36}\right.$ n-alkane). 
Figure 2-2

Cariaco Basin Fatty Acid Concentrations

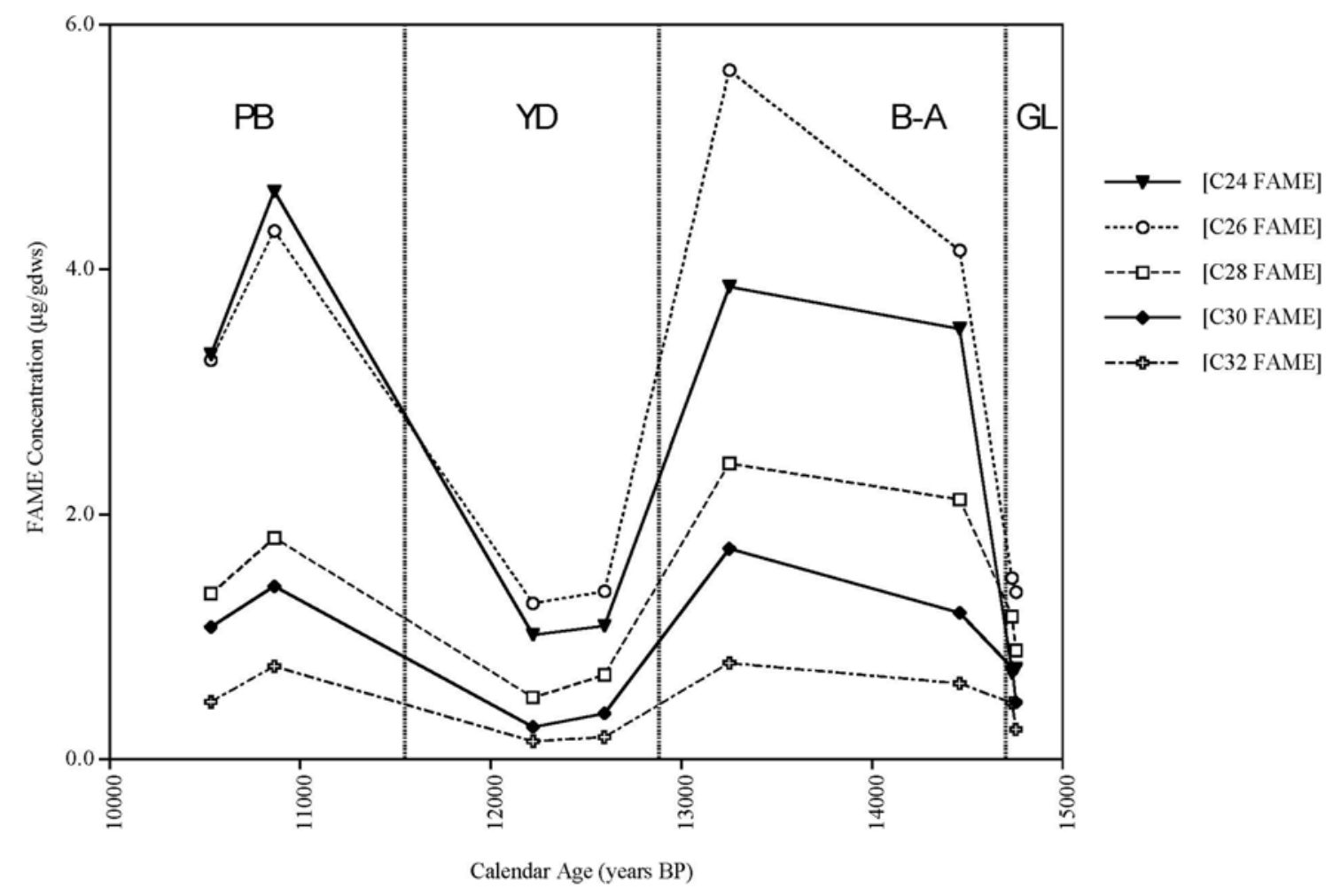

Concentration of individual Cariaco Basin FAMEs, reported as micrograms per gram dry weight sediment. Even chain lengths $\mathrm{C}_{24}-\mathrm{C}_{32}$ are plotted along with the climate periods of interest ( $\mathrm{GL}=\mathrm{Glacial}$; $\mathrm{B}-\mathrm{A}=\mathrm{B} ø$ lling-Allerød; $\mathrm{YD}=$ Younger Dryas; $\mathrm{PB}=$ Preboreal). 
from increased marine productivity during the YD and the last Glacial. The latter option is supported by the observation that overall sedimentation rates were greatest during the YD, driven by marine productivity (Hughen et al., 1996b). The ACL of $C_{24}-C_{32}$ fatty acids is presented in Figure 2-3. ACL values were greatest during the Glacial, intermediate from 14.5 to $12.6 \mathrm{kyr} \mathrm{BP}$, and lowest between 12.2 and $10.5 \mathrm{kyr} \mathrm{BP}$. Glacial values were 26.9 and 27.4, while ACL values for all other periods were less than 26.5 (estimated error of \pm 0.03 units). Although from adjacent sediment core samples with similar fatty acid concentrations, the two Glacial data points exhibit the greatest difference in ACL observed in sample pairs from the same climate period.

Cariaco Basin fatty acid $\delta D$ data are presented in Figure 2-4. The error for these measurements, expressed as the pooled standard deviation of all duplicate analyses, is $\pm 4.6 \%$ o. $\mathrm{C}_{32}$ results are not included in the analyses because the chromatographic peaks for this compound were not large enough to permit robust isotopic determination. $\mathrm{C}_{16}$ and $\mathrm{C}_{18}$ fatty acids, which are typically of marine origin, are depleted in deuterium compared to the leaf wax compounds $\left(\mathrm{C}_{24}-\mathrm{C}_{30}\right)$, as depicted for two samples in Figure 25. The $\mathrm{C}_{16}$ and $\mathrm{C}_{18}$ fatty acids averaged over all eight samples have $\delta \mathrm{D}$ values of $-183.1 \%$ and $-156.6 \%$, respectively, while $\mathrm{C}_{24}-\mathrm{C}_{30}$ fatty acids have average values between $-123.6 \%$ and $-105.0 \%$. This offset in $\delta \mathrm{D}$ suggests different sources for long and short chain lengths, as predicted, and supports the interpretation of $\mathrm{C}_{24}$ and longer fatty acids as terrestrial plant biomarkers. Cariaco Basin $C_{18}$ fatty acids have $\delta D$ values similar to $\mathrm{C}_{16}$ in the late YD and Preboreal, but trend towards more typically terrestrial values during earlier periods, possibly reflecting an increase through time in production of this specific compound by its marine precursor. Alternatively, this trend could reflect a shift in the balance between marine and terrestrial contributions of the $\mathrm{C}_{18}$ fatty acid or increasing preservation of the marine end member. Sauer et al. (2001) also noted greater variability in $\delta \mathrm{D}$ of short chain $n$-alkyl lipids than long chain, terrestrial homologues in lake sediments.

The different terrestrial chain lengths exhibit generally similar patterns of change, with enriched $\delta \mathrm{D}$ values observed in the late Glacial and again in the middle of the record 
Figure 2-3

Cariaco Basin Fatty Acid Average Chain Length

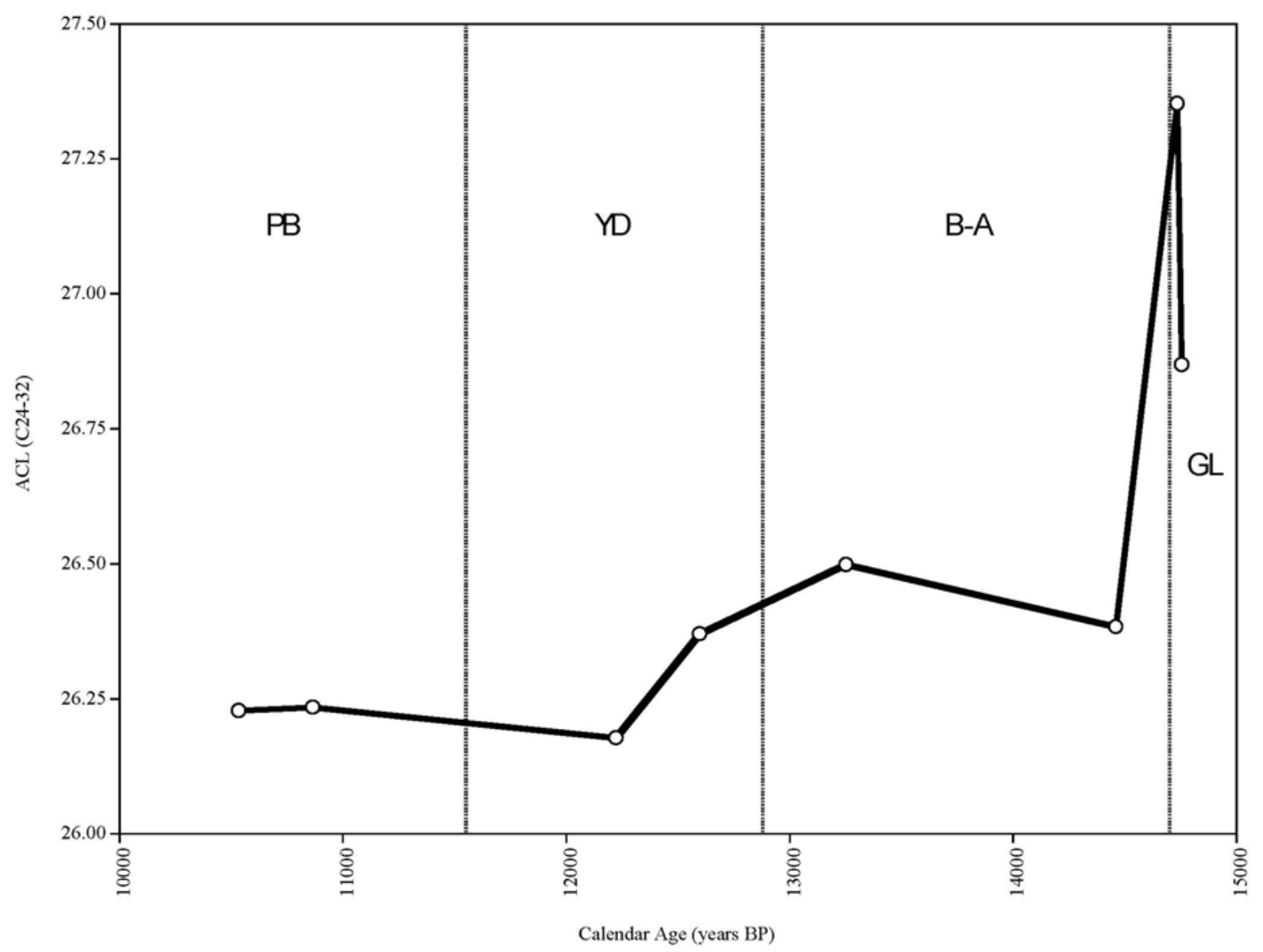

Average chain length (ACL) of $\mathrm{C}_{24}-\mathrm{C}_{32}$ FAMEs. 
Figure 2-4

\section{Cariaco Basin Fatty Acid $\delta D$}

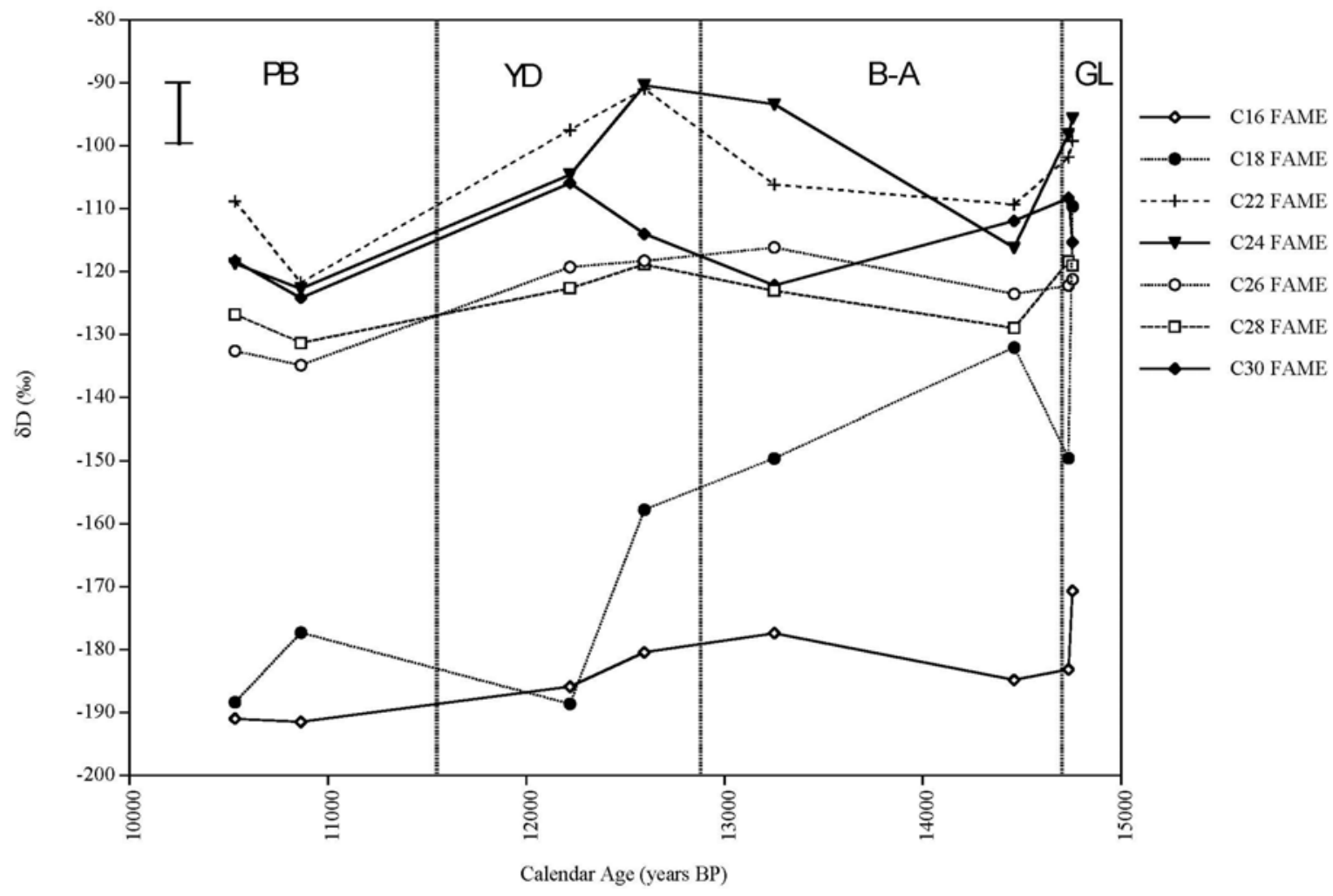

$\delta \mathrm{D}(\%)$ of individual FAMEs for chain lengths $\mathrm{C}_{16}-\mathrm{C}_{30}$. The $\mathrm{C}_{32}$ FAME is not plotted because the trace quantities of this compound present in the samples did not permit reliable $\delta \mathrm{D}$ determination via GC-IRMS. All data points are presented as averages of duplicate runs, with the exception of the $12.2 \mathrm{kyr}$ BP sample, for which the amount of sample material only permitted a single injection. The error bar $( \pm 4.6 \%)$ in the upper left corner of the figure represents the pooled standard deviation of all duplicate analyses. 
Figure 2-5

Cariaco Basin Fatty Acid Concentration and

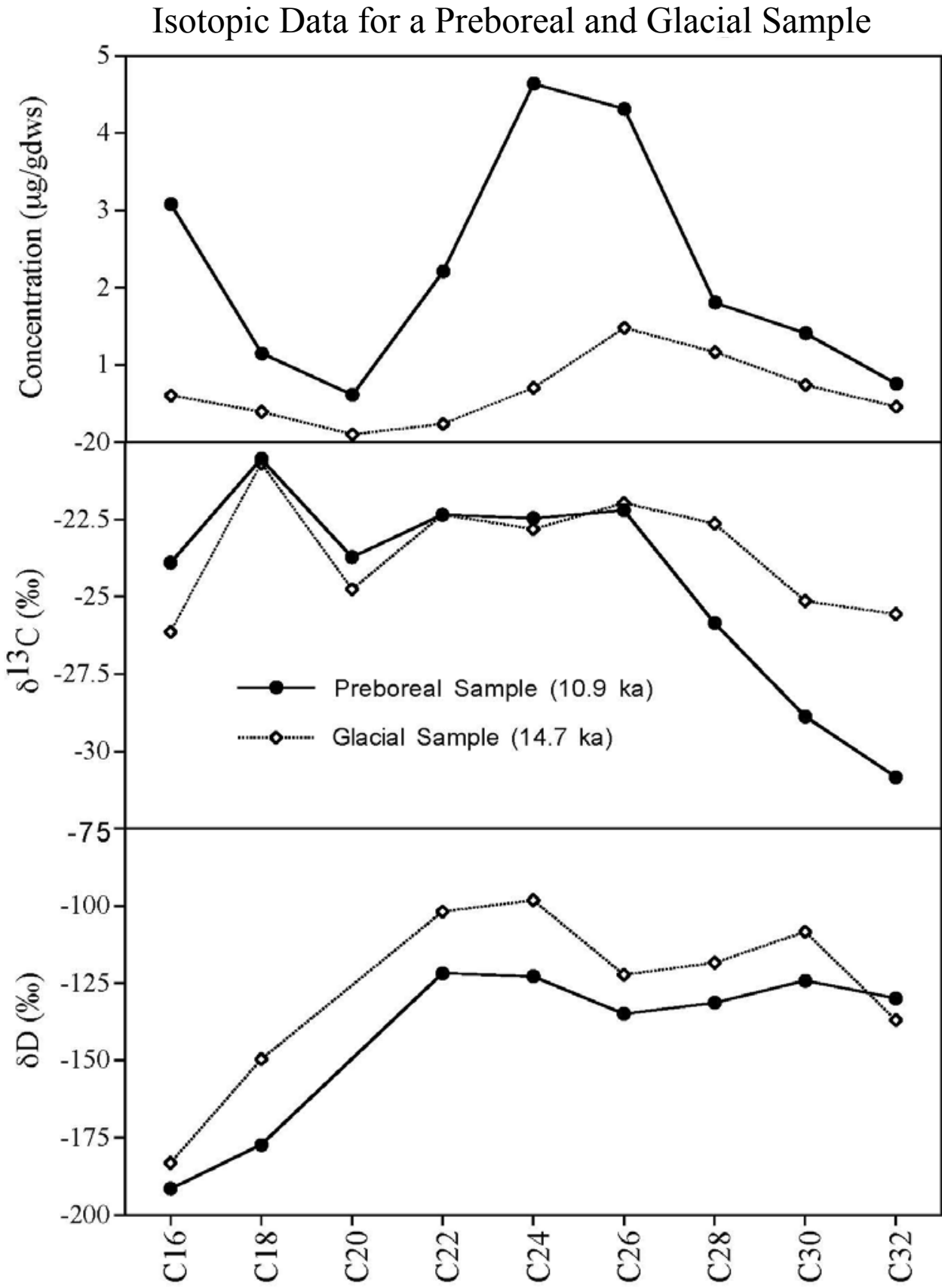

Chain Length

Specific fatty acid (as methyl ester) chain-length distribution and isotopic characteristics for a Preboreal and glacial period sample, each representing a different climate state in the Cariaco Basin region. Compound-specific concentrations (top panel), $\delta^{13} \mathrm{C}$ (middle panel), and $\delta \mathrm{D}$ (lower panel) are depicted. 
during the late B-A or YD, while Holocene values are generally depleted. The maximum range of variability of $\delta \mathrm{D}$ is $15.9 \%$ o for $\mathrm{C}_{30}$ fatty acids, $13.0 \%$ o for $\mathrm{C}_{28}, 18.7 \%$ ofor $\mathrm{C}_{26}$, and $32.3 \%$ ofor $\mathrm{C}_{24}$. For many of the chain lengths investigated, instrumental error (4.6\%o) eclipses point-to-point $\delta \mathrm{D}$ variability, precluding robust interpretation of the climate signal in individual homologues.

The fatty acid $\delta D$ results were compared to several other studies of hydrogen isotopes in modern terrestrial lipids. Sessions et al. (1999) found $\delta \mathrm{D}$ values between $-169 \%$ and $-150 \%$ o for marsh grass (Spartina alterniflora) odd-numbered leaf wax $n$ alkanes and values between $-166 \%$ and $-113 \%$ for carrot plant (Daucus carota) $n$ alkanes. Chikaraishi and Naraoka (2003) found average terrestrial plant long-chain $n$ alkane $\delta \mathrm{D}$ values between $-193 \%$ and $-115 \%$ for a wide range of species. The $\delta \mathrm{D}$ values obtained for leaf wax fatty acids in Cariaco Basin sediments were enriched compared to the $n$-alkane values reported in these studies. This discrepancy could be due to differences in the type of leaf wax compounds analyzed or may arise from differences in $\delta D$ of plant growth water in the various studies, each of which were conducted with samples from different continents. Additionally, Cariaco Basin sediments were collected from lower latitudes than most samples from the other studies. Although these studies demonstrate the large range of plant wax $\delta \mathrm{D}$ values found in nature, the difference in $\delta \mathrm{D}$ between Cariaco Basin long and short-chain fatty acids argues for a predominantly terrestrial origin for the long-chain homologues.

$\delta^{13} \mathrm{C}$ results for individual fatty acids, which are indicative of source plant type, are presented in Figure 2-6. The error for these measurements, determined as the pooled standard deviation of the samples measured in duplicate or triplicate, is $\pm 0.5 \%$. Inferred terrestrial fatty acid $\left(\mathrm{C}_{24}-\mathrm{C}_{32}\right) \delta^{13} \mathrm{C}$ values span a range of $-30.8 \%$ to $-21.1 \%$ o. $\delta^{13} \mathrm{C}$ values of the $C_{16}$ and $C_{18}$ fatty acids fall within or near the $\delta^{13} \mathrm{C}$ range of $C_{24}-C_{28}$, suggesting that some of these longer chain homologues have a marine derived component, or possibly that some terrestrial and marine organic inputs have similar $\delta^{13} \mathrm{C}$ values. However, the patterns of isotopic change observed in the short-chain fatty acids are distinct from those of $\mathrm{C}_{24}-\mathrm{C}_{32}$, reinforcing the interpretation of long-chain fatty acids 
Figure 2-6

Cariaco Basin Fatty Acid $\delta^{13} \mathrm{C}$

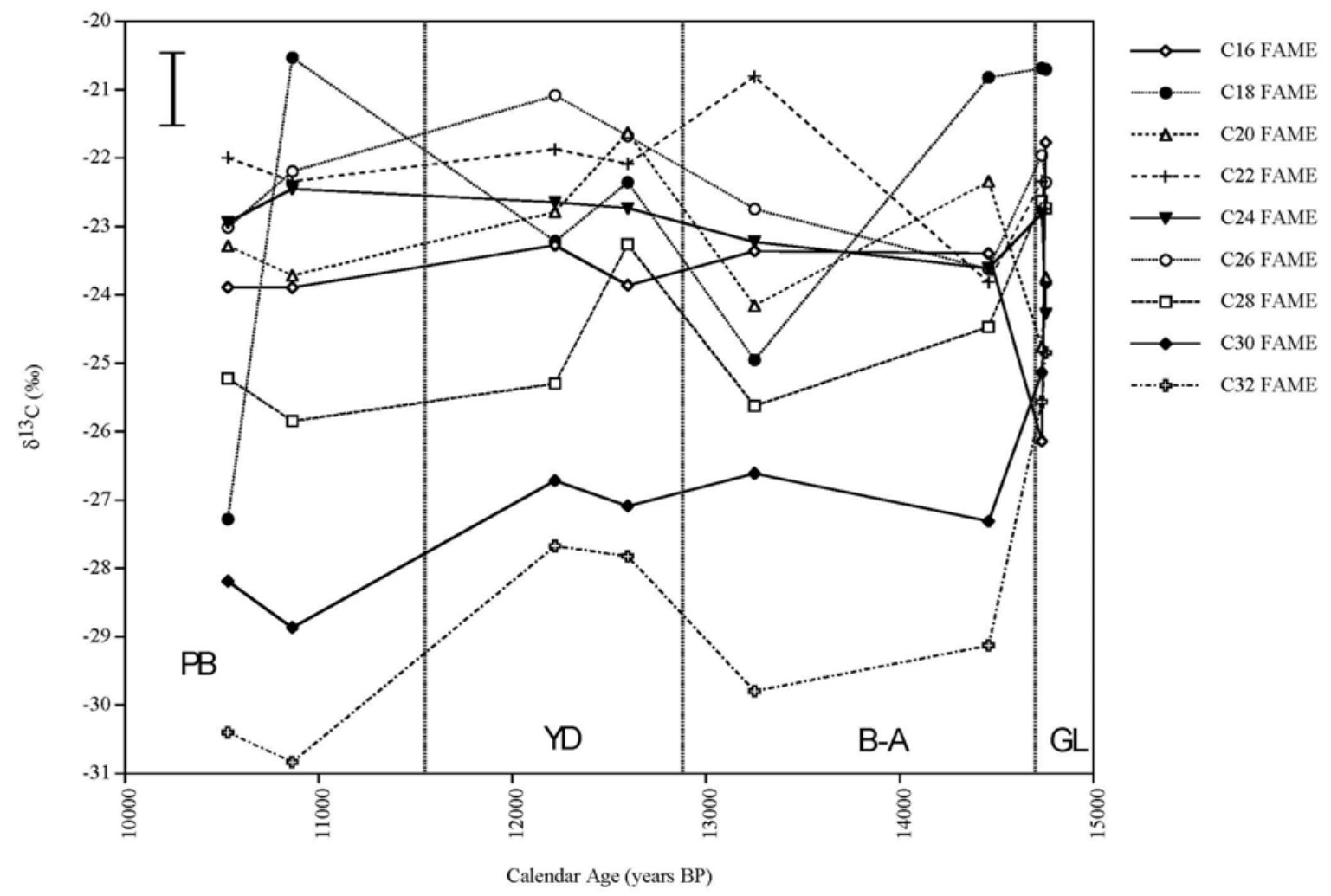

$\delta^{13} \mathrm{C}(\% \mathrm{o})$ of individual FAMEs for chain lengths $\mathrm{C}_{16}-\mathrm{C}_{32}$. The error bar $( \pm 0.5 \%$ ) in the upper left corner of the figure represents the pooled standard deviation of all replicate analyses. Where replicate measurements were performed, data points represent the mean $\delta^{13} \mathrm{C}$ value of those analyses. 
as predominantly terrestrial in origin. As with $\delta \mathrm{D}$, different terrestrial chain lengths exhibited somewhat different trends of $\delta^{13} \mathrm{C}$ change. However $\mathrm{C}_{28}-\mathrm{C}_{32}$ fatty acids were all generally enriched in ${ }^{13} \mathrm{C}$ during the late Glacial and midway through the record, and were generally depleted during the B-A and Preboreal periods (for example, see Figure 25). $\delta^{13} \mathrm{C}$ of the $\mathrm{C}_{30}$ and $\mathrm{C}_{32}$ fatty acids varied by greater than $5 \%$ between the late Glacial and the Preboreal.

The $\mathrm{C}_{26}$ through $\mathrm{C}_{32}$ fatty acids exhibited a trend of decreasing $\delta^{13} \mathrm{C}$ with increasing chain length, as observed for the glacial and Preboreal samples depicted in Figure 2-5. This same relationship has been observed in leaf wax $n$-alkanes of some modern plants (Collister et al., 1994; Nguyen Tu et al., 2004). A mixture of shorterchain contributions from predominantly $\mathrm{C}_{4}$ plants and longer-chain contributions from $\mathrm{C}_{3}$ plants could also produce this pattern in leaf waxes sampled from marine sediments. However, this hypothesis is not consistent with ACL records from the Cariaco Basin (Hughen et al., 2004) and southern Asia (Freeman and Colarusso, 2001), which exhibit the longest average chain lengths in samples with elevated $\delta^{13} \mathrm{C}$ values. In addition, modern spatial patterns in African leaf wax compounds show longer chain lengths associated with enriched $\delta^{13} \mathrm{C}$ (Schefuß et al., 2003).

The carbon isotope chain length index records show distinct variations in $\delta^{13} \mathrm{C}$ between climate states. Individual data points used to create the stacked record are shown in Figure 2-7 and the stacked record is presented in Figure 2-8 (top). Enriched $\delta^{13} \mathrm{C}$ values, which are taken to imply a higher $\mathrm{C}_{4} / \mathrm{C}_{3}$ source plant ratio, are observed in Glacial and YD samples, and comparatively depleted values are observed in B-A and Preboreal samples. Unfortunately, the large errors that arise during the normalization and stacking process preclude a robust paleovegetation interpretation of these trends. However, the same pattern of isotopic change is observed in the mass-weighted average record (Figure 2-8, bottom), for which the errors are smaller. The fact that the $\delta^{13} \mathrm{C}$ stacked and mass-weighted average records closely resemble each other argues for a common source region for all fatty acid chain lengths, as shifting chain length dominance appears to have no effect on the isotopic record. 
Figure 2-7

\section{Cariaco Basin Individual $\delta^{13} \mathrm{C}$ Measurements for Stacking Index}

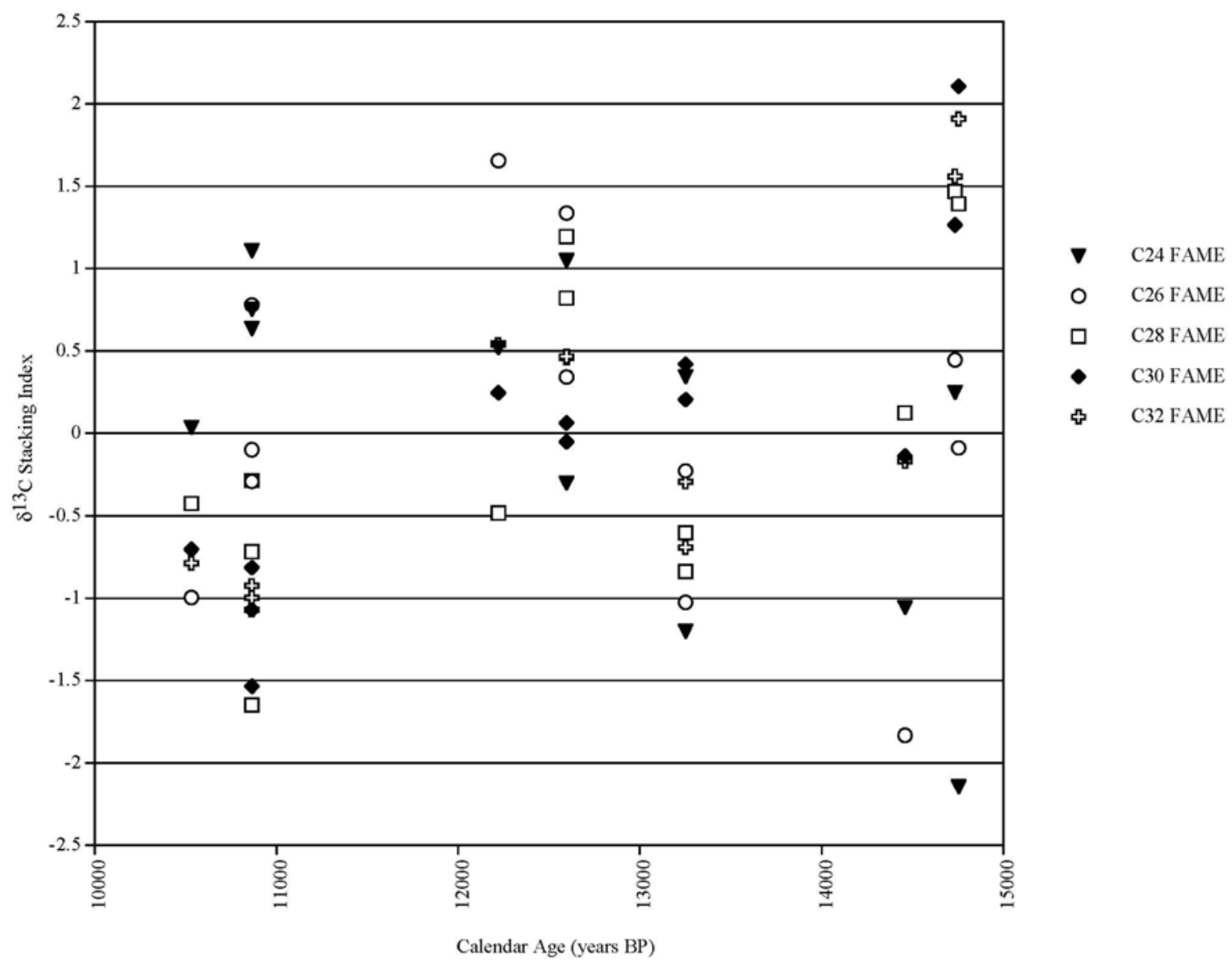

All FAME $\delta^{13} \mathrm{C}$ data $\left(\mathrm{C}_{24}-\mathrm{C}_{32}\right)$ that was used to make the stacked index record. Only chain lengths that are thought to be attributable to terrestrial vascular plants are used to make indices of overall isotopic change. Each data point has had the mean $\delta^{13} \mathrm{C}$ value (\%) for the associated chain length subtracted from it and has been normalized to the pooled standard deviation for that chain, giving rise to the "stacking index" value on the y-axis. Thus, chain length specific variability has been removed and data from different chain lengths for individual depth intervals can be plotted on the same scale. 
Figure 2-8

\section{Cariaco Basin $\delta^{13} \mathrm{C}$ Indices}

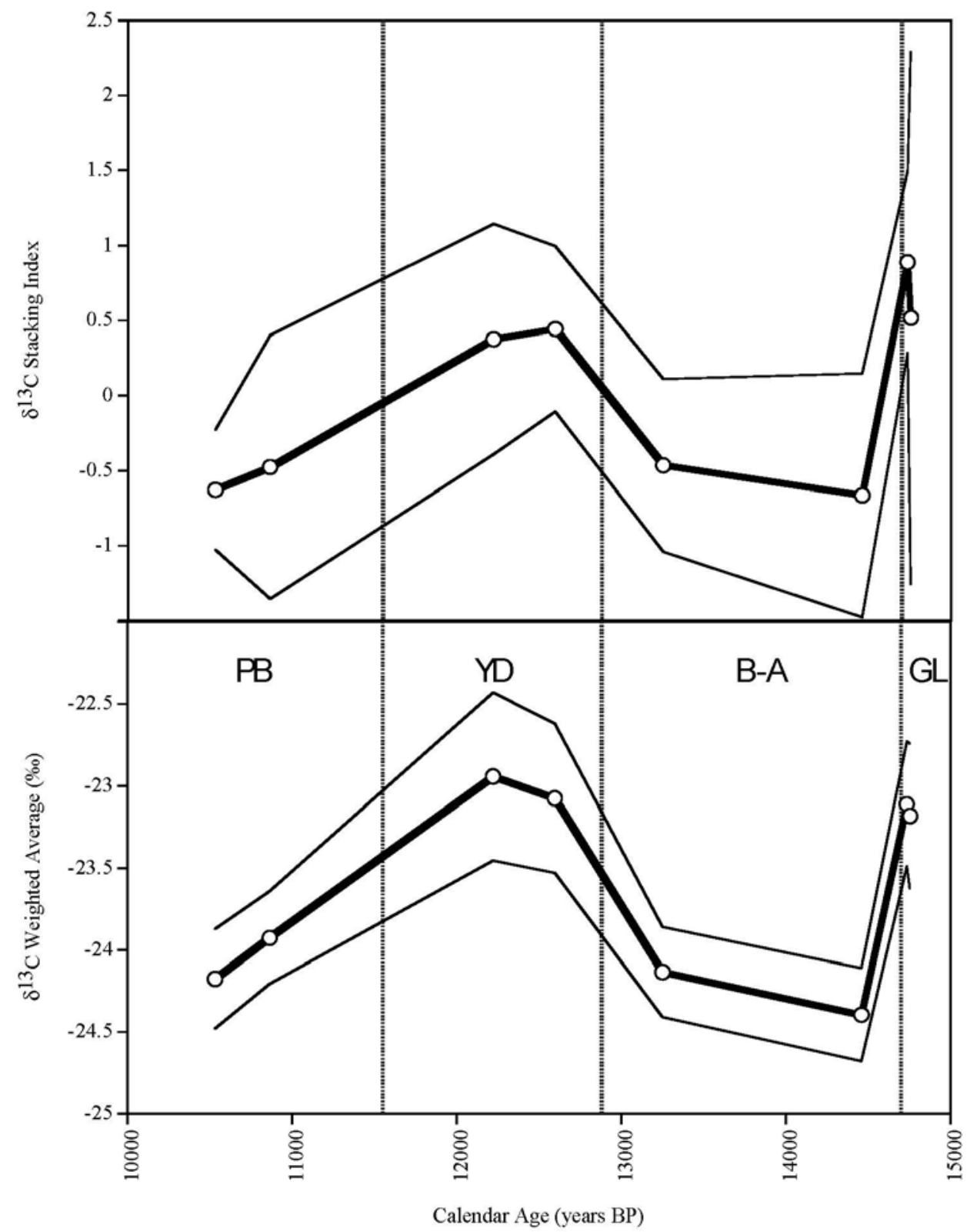

Carbon isotope combined indices for chain lengths $\mathrm{C}_{24}-\mathrm{C}_{32}$. Error bars are presented as thin black lines and are described in the statistical analysis section of the text. Top: Stacked $\delta^{13} \mathrm{C}$ isotopic index, generated from the data presented in Figure 2-7. Bottom: Mass-weighted average $\delta^{13} \mathrm{C}$ isotopic index. 
The most straightforward explanation for the leaf wax fatty acid $\delta^{13} \mathrm{C}$ trend is a shift in the balance between terrestrial vegetation regimes in favor of $\mathrm{C}_{4}$ grassland expansion during arid, cold periods. Carbon isotope data are consistent with a greater presence of $\mathrm{C}_{3}$ plants during the $\mathrm{BA}$ and Preboreal wet periods and an enhanced influence of $\mathrm{C}_{4}$ plants during the Glacial and YD. The Glacial and YD grassland expansion/forest reduction model is compatible with general $\mathrm{C}_{3}$ and $\mathrm{C}_{4}$ plant attributes and records of regional climate change. Supporting evidence is found in pollen records from northern South America (van ‘t Veer et al., 2000; Rinaldi, 1996; Islebe et al., 1995; Leyden, 1985), which exhibit relative reductions of forest inputs and increases in grassland inputs during the Glacial and YD periods.

As part of the above interpretation of the pollen and leaf wax records, I assume that changes in the measured variable represent changes in the relative biomass of contributing vegetation of certain types, and not changes in atmospheric circulation (wind trajectory), fluvial transport, or pollen production from individual plants. Unfortunately, the $\delta^{13} \mathrm{C}$ record is difficult to interpret in terms of absolute abundance changes of different plant communities due to a lack of information about the production rates of leaf waxes by different vegetation types, as well as the wide range of leaf wax carbon isotopic values for $\mathrm{C}_{3}$ and $\mathrm{C}_{4}$ end members.

An expansion of $\mathrm{C}_{4}$ vegetation in northern South America during the Glacial and YD periods could be explained by increased aridity, reduced temperature, or reduced atmospheric $\mathrm{CO}_{2}$ concentration. Trends in the Cariaco Basin leaf wax $\delta^{13} \mathrm{C}$ record parallel changes in the sediment grey scale and foraminiferal $\mathrm{Mg} / \mathrm{Ca}$ records (Lea et al., 2003), which track changes in terrestrial runoff (aridity, by inference) and sea surface temperature, respectively. In a Central American leaf wax $\delta^{13} \mathrm{C}$ study, Huang et al. (2001) demonstrated that $\mathrm{C}_{3} / \mathrm{C}_{4}$ plant distributions varied with local aridity, but not with global atmospheric $\mathrm{CO}_{2}$ concentration. Conversely, Street-Perrott et al. (1997) produced an East African high-altitude lake leaf wax record that exhibited an increase in $\delta^{13} \mathrm{C}$ prior to the estimated local aridity maximum, but in step with the deglacial Vostok $\mathrm{CO}_{2}$ increase, which argues for $\mathrm{CO}_{2}$ concentration as the deterministic factor for $\mathrm{C}_{4}$ plant 
expansion. Jolly and Haxeltine (1997) reached a similar conclusion by using a vegetation model to show that African $\mathrm{C}_{3}$ and $\mathrm{C}_{4}$ plant communities are more sensitive to temperature changes during periods of reduced atmospheric $\mathrm{CO}_{2}$ concentrations. However, these two studies that show sensitivity to atmospheric $\mathrm{CO}_{2}$ may be pertinent only to high-altitude biomes, and thus not appropriate for comparison to Cariaco Basin data. Indeed, the fatty acid $\delta^{13} \mathrm{C}$ results argue for a vegetation response to local climate conditions, such as aridity and/or temperature, rather than atmospheric $\mathrm{CO}_{2}$. The decrease in $\delta^{13} \mathrm{C}$ from the late Glacial to the $\mathrm{B}-\mathrm{A}$ is coincident with the rise in atmospheric $\mathrm{CO}_{2}$, but there is a similar $\delta^{13} \mathrm{C}$ trend for the YD to Preboreal warming, for which there is no such $\mathrm{CO}_{2}$ increase.

An explanation for the data that involves changes in plant physiology such as leaf wax production or leaf biomass, may be preferable to one that necessitates a change in the amounts of forest and grassland vegetation because changes in plant structure can occur on much shorter time scales than changes in whole vegetation regimes, possibly by several orders of magnitude (Cowling et al., 2001). Hughen et al. (2004) demonstrated that the Cariaco Basin vegetation signal lags local climate changes by about 25-50 years, which may be too short a time period for extensive changes in plant communities (Cowling et al., (2001) estimated 100 to 1,000 years for large shifts in vegetation). Cowling et al. (2001) used a vegetation model to show that the Amazonian forest canopy (in terms of the leaf area index) may have been reduced in density at the last glacial maximum rather than having been replaced by grassland. The authors hypothesized that forest extent may have been maintained through a reduction in evapotranspiration and photorespiration due to glacial cooling. If these model results are valid, there may not have been a reduction in the areal extent of the $\mathrm{C}_{3}$ plant biome that contributed leaf waxes to the Cariaco Basin, but rather a reduction in the canopy density or health of the forest vegetation. Under these circumstances, fewer $\mathrm{C}_{3}$ fatty acids would have been produced and delivered to the Cariaco Basin during the Glacial period because a reduced canopy density translates to a smaller contributing pool of leaf waxes. 
Variability in the mode of delivery of terrestrial organic material to the Cariaco Basin could also account for the observed variations in fatty acid $\delta^{13} \mathrm{C}$, obviating the need to call upon a change in vegetation structure or health. Since the Glacial period, changes in the seasonal cycle in northern South America were tied to changes in wind strength above the Cariaco Basin. Additionally, deglacial variations in precipitation and sea level rise may have affected the morphology and dynamics of the two rivers that drain into the basin. These changes would have impacted the delivery of leaf waxes from terrestrial plants and soils to the marine environment, although the manner in which they influenced the Cariaco Basin leaf wax record is unknown. Relative contributions of leaf waxes to the Cariaco Basin from aeolian and fluvial sources remain difficult to assess and have not been quantified. During the Glacial, the Rio Unare and Rio Tuy drained the additional portion of the continental shelf exposed by lowered sea level, which may have been vegetated by either plant type and contained soil organic matter derived from prior inputs, thus depositing terrestrial organic matter of uncertain origin and age in close proximity to the basin. Nevertheless, while an exposed shelf populated with $\mathrm{C}_{4}$ vegetation could explain the leaf wax $\delta^{13} \mathrm{C}$ decrease from the Glacial to the B-A, it could not account for subsequent changes, and thus is not likely the deterministic factor in $\mathrm{C}_{3}$ versus $\mathrm{C}_{4}$ plant leaf wax contribution to the sediments.

Although leaf wax $\delta^{13} \mathrm{C}$ values are mechanistically linked to source vegetation type, no such formal relationship has been determined for ACL. Some studies have suggested that ACL may be positively correlated with plant growth temperature (Gagosian and Peltzer, 1986; Rinna et al., 2002). The ACL record in this study, which exhibits the highest values during the Glacial period, is inconsistent with this proposed relationship. Chikaraishi and Naraoka (2003) directly sampled $22 \mathrm{C}_{3}$ and $7 \mathrm{C}_{4}$ species of vascular plants in Japan and Thailand and reported $n$-alkane ACL values. These $\mathrm{C}_{3}$ and $\mathrm{C}_{4}$ plants had mean ACL values of 29.65 and 31.14, respectively. A two-tailed Student's t-test was performed on these sample populations, and revealed that the mean $\mathrm{C}_{3}$ and $\mathrm{C}_{4}$ ACL values are significantly different for a $95 \%$ confidence level. This finding may not be relevant to my ACL record, though, because $n$-alkanes were measured instead of fatty 
acids and different ranges of $n$-alkane carbon chain lengths were used for different plant species. Furthermore, environmental variables that may influence ACL were not recorded as part of the Chikaraishi and Naraoka (2003) study. Schefuß et al. (2003) found differing distributions of plant wax $n$-alkanes on a longitudinal transect off the West African coast, in which a longer chain length $\left(\mathrm{C}_{31}\right)$ was dominant downwind of arid regions compared to wetter forested areas $\left(\mathrm{C}_{29}\right.$ dominated $)$. This finding supported their hypothesis that chain length is primarily influenced by aridity, in accordance with the role of leaf wax waxes in preventing moisture loss from plants.

Hughen et al. (2004) generated high-resolution plant wax fatty acid ACL and $\delta^{13} \mathrm{C}$ records from Cariaco Basin sediments spanning about 15-10 ka and observed that both variables changed in parallel with local mean climate state. Elevated ACL values were observed during periods of maximum $\delta^{13} \mathrm{C}$ and local aridity, implying that $\mathrm{ACL}$ could be indicative of $\mathrm{C}_{3}$ versus $\mathrm{C}_{4}$ plant type. Based on this relationship, the Cariaco Basin ACL record is consistent with enhanced $\mathrm{C}_{4} /$ reduced $\mathrm{C}_{3}$ plant contributions during the late Glacial period with an overall decrease in the $\mathrm{C}_{4} / \mathrm{C}_{3}$ plant ratio over time until $10.5 \mathrm{kyr}$ BP. However, this pattern of change is not observed in the $\delta^{13} \mathrm{C}$ record, for which the YD samples are not isotopically depleted enough to match the ACL trend. $\delta^{13} \mathrm{C}$ and $\delta \mathrm{D}$ from Cariaco Basin fatty acids imply greater $\mathrm{C}_{4}$ inputs and more arid conditions during this period, yet ACL values remain low, similar to B-A and Preboreal samples. Clearly, therefore, further interpretation of ACL data awaits more systematic studies of the relationship between plant physiology and chain length distribution.

Individual hydrogen isotope data points that were used to generate the stacked record are presented in Figure 2-9 and the stacked $\delta D$ record is shown in Figure 2-10 (top). The pattern of change observed in the stacked $\delta \mathrm{D}$ record is similar to that of the stacked $\delta^{13} \mathrm{C}$ record, with enriched isotopic values in Glacial and YD samples and depleted values in B-A and Preboreal samples. In this case, the errors compromise some of the climate signal, but the Glacial and Preboreal are still distinct, with the most depleted values occurring in the latter period. The hydrogen isotope mass-weighted average record (Figure 2-10, bottom) exhibits a trend similar to the stacked record, 
Figure 2-9

Cariaco Basin Individual $\delta D$ Measurements for Stacking Index

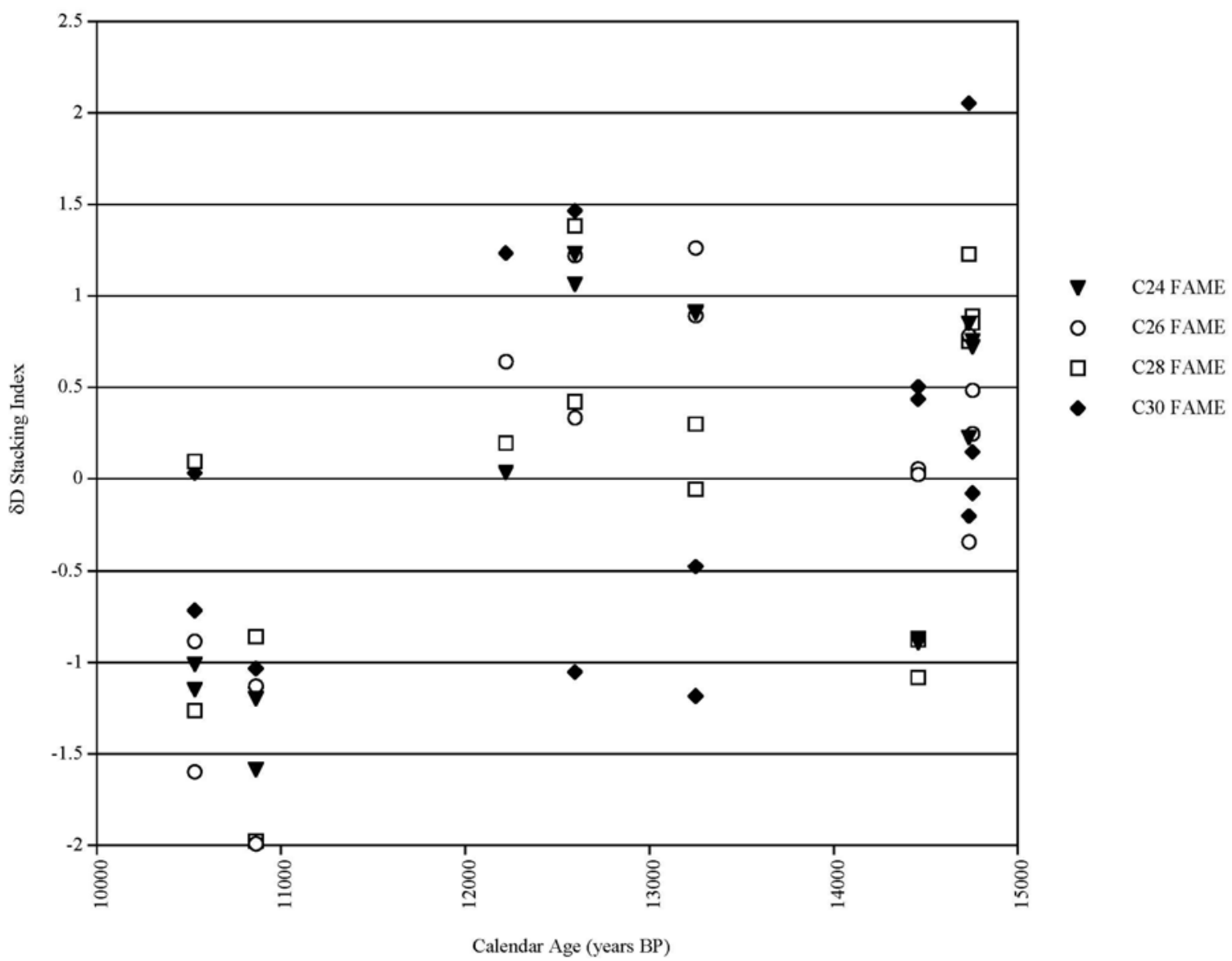

All FAME $\delta \mathrm{D}$ data $\left(\mathrm{C}_{24}-\mathrm{C}_{30}\right)$ that was used to create the stacked index record. The data are presented in the same manner as in Figure 2-7. 
Figure 2-10

Cariaco Basin $\delta \mathrm{D}$ Indices

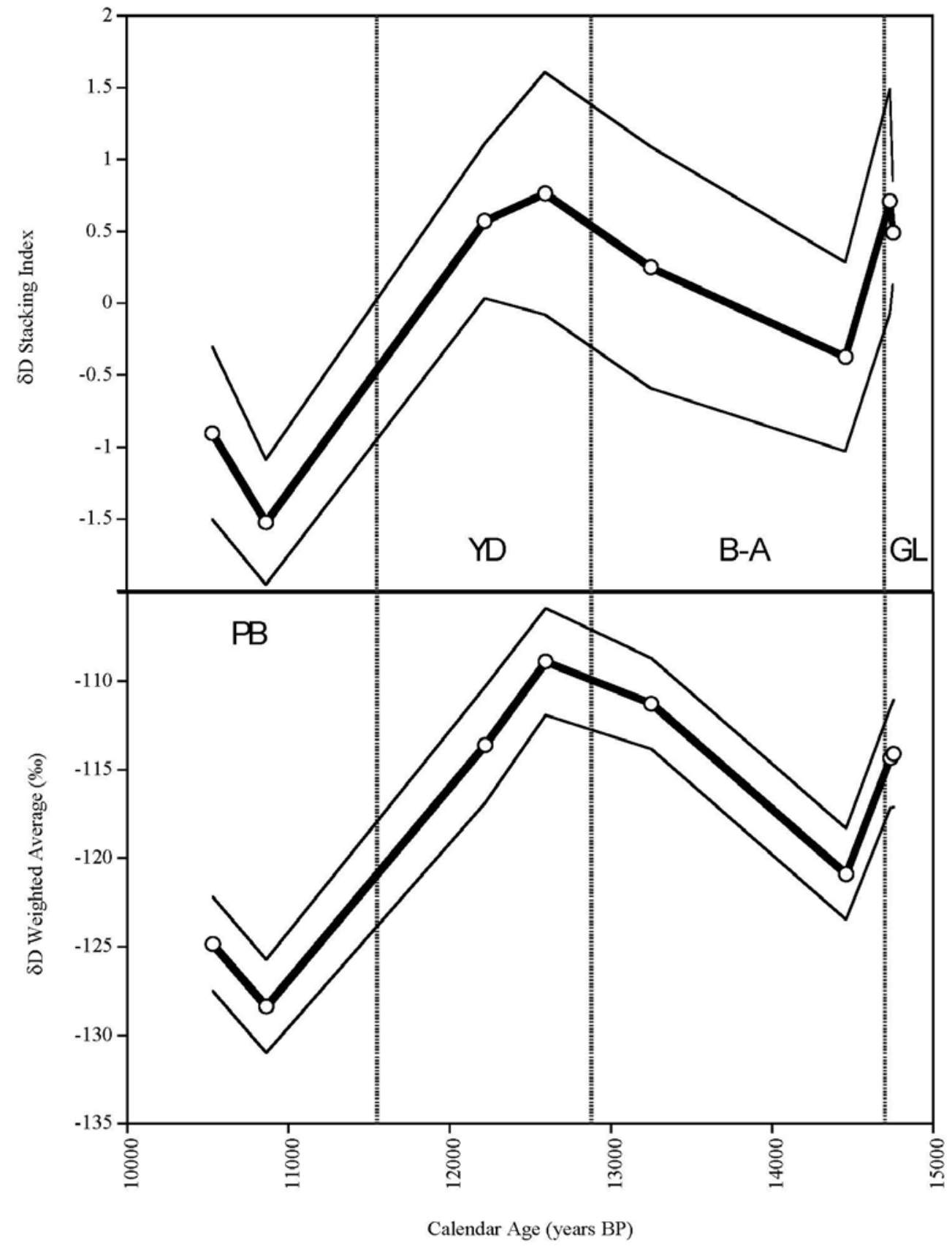

Hydrogen isotope combined indices for chain lengths $\mathrm{C}_{24}-\mathrm{C}_{30}$. Error bars are presented as thin black lines and are described in the statistical analysis section of the text. Top Stacked $\delta \mathrm{D}$ isotopic index, generated from the data presented in Figure 2-9. Bottom: Mass-weighted average $\delta \mathrm{D}$ isotopic index. 
although a few discrepancies are apparent. In both records, the earlier YD data point (12.6 kyr BP) is the most isotopically enriched, but it is closer in value to the Glacial data points in the stacked record. The $12.2 \mathrm{kyr}$ BP sample is enriched compared to the 13.3 kyr BP sample in the stacked record, but not in the mass-weighted average record, although these differences are within error estimates. Given the errors in the massweighted average $\delta D$ record, the Glacial, YD, and late B-A samples are distinctly enriched in deuterium, while the early B-A and Preboreal samples are comparatively depleted.

The pattern observed in the mass-weighted average hydrogen isotope record (Figure 2-10, bottom) may be explained by changes in the isotopic composition of meteoric or growth water, or possibly by changing $\mathrm{C}_{3} / \mathrm{C}_{4}$ plant contributions. Because the deuterium record parallels known changes in aridity, $\delta \mathrm{D}$ in Cariaco Basin leaf waxes is interpreted as a proxy for environmental water $\delta \mathrm{D}$, which is likely related to local aridity. This interpretation is consistent with the Sternberg (1988) finding that submerged aquatic plant lipid $\delta D$ values paralleled lake water $\delta D$. During the B-A and Preboreal periods, increased precipitation may have caused distillation of meteoric water reaching the vegetation source area, resulting in deuterium depletion in leaf waxes. Less precipitation during the Glacial period and YD would mean reduced distillation and therefore deuterium enrichment, as observed. An alternative interpretation of the combined $\delta \mathrm{D}$ record arises if $\mathrm{C}_{3}$ and $\mathrm{C}_{4}$ plants fractionate hydrogen isotopes differently during photosynthesis, and thus the $\delta \mathrm{D}$ record, like $\delta^{13} \mathrm{C}$, would be suggestive of changing terrestrial plant communities. At present, it is uncertain whether $\mathrm{C}_{3}$ and $\mathrm{C}_{4}$ plant leaf waxes have discernibly different $\delta \mathrm{D}$ values, although the results of Chikaraishi and Naraoka (2003) imply that $\mathrm{C}_{4}$ plant $n$-alkanes may exhibit greater deuterium fractionation with respect to meteoric water than those of $\mathrm{C}_{3}$ plants. My data do not support this finding because $\delta^{13} \mathrm{C}$ and $\delta \mathrm{D}$ follow the same trends of enrichment and depletion, meaning that periods of $\mathrm{C}_{3}$ dominance are characterized by the greatest deuterium fractionation. Due to this discrepancy and the current lack of a mechanism explaining differing hydrogen isotope fractionation for $\mathrm{C}_{3}$ and $\mathrm{C}_{4}$ photosynthetic mechanisms, an 
explanation for the $\delta \mathrm{D}$ data involving changes in the tropical hydrologic cycle is preferred.

Comparison of systematic changes measured in both isotopic systems reveals unique relationships between aridity and plant type for the climate periods studied. Leaf wax fatty acid $\delta \mathrm{D}$ versus $\delta^{13} \mathrm{C}$ is plotted in Figure 2-11. The mass-weighted average records were used for this plot because their errors were smaller in magnitude than those of the stacked records (considering error, the stacked records produced very similar results). The two isotope systems appear to record different climate phenomena, but can be directly compared because all measurements were performed on the same compounds. The Preboreal and B-A data points have similar $\delta^{13} \mathrm{C}$ values, which means $\mathrm{C}_{3}$ plant contributions, compared to $\mathrm{C}_{4}$, were maximal during these periods. A wide range of $\delta \mathrm{D}$ values were recorded during the Preboreal and B-A, implying variable aridity, although the Preboreal appears to have been the most arid period. The late B-A sample has similar $\delta \mathrm{D}$ composition to the samples from the Glacial and YD periods, both of which likely were arid based on sediment grey scale results (Hughen et al., 1996a). This sample (13.3 kyr BP) was collected from sediments that have a low grey scale value compared to the rest of the B-A and therefore may have been deposited during a period of brief aridity, thus explaining the enrichment in deuterium. Glacial and YD data points are enriched in $\delta^{13} \mathrm{C}$ and $\delta \mathrm{D}$. Considering error, these four data points are indistinguishable from one another on this plot. By inference, therefore, the late Glacial and YD were arid periods with a high $\mathrm{C}_{4} / \mathrm{C}_{3}$ plant input ratio.

\section{Conclusions}

Leaf wax carbon isotopic data indicate that terrestrial grassland and forest vegetation regimes south of the Cariaco Basin oscillated in parallel with local climate. $\mathrm{C}_{3}$ vegetation predominated during the arid and cool Glacial and YD periods, and $\mathrm{C}_{4}$ plants became more prominent during the wetter and warmer B-A and Preboreal periods. The Cariaco Basin leaf wax $\delta^{13} \mathrm{C}$ record shows the same pattern of change as several deglacial pollen records from northern South America, reinforcing the hypothesis that these 
Figure 2-11

Cariaco Basin $\delta^{13} \mathrm{C}$ versus $\delta \mathrm{D}$

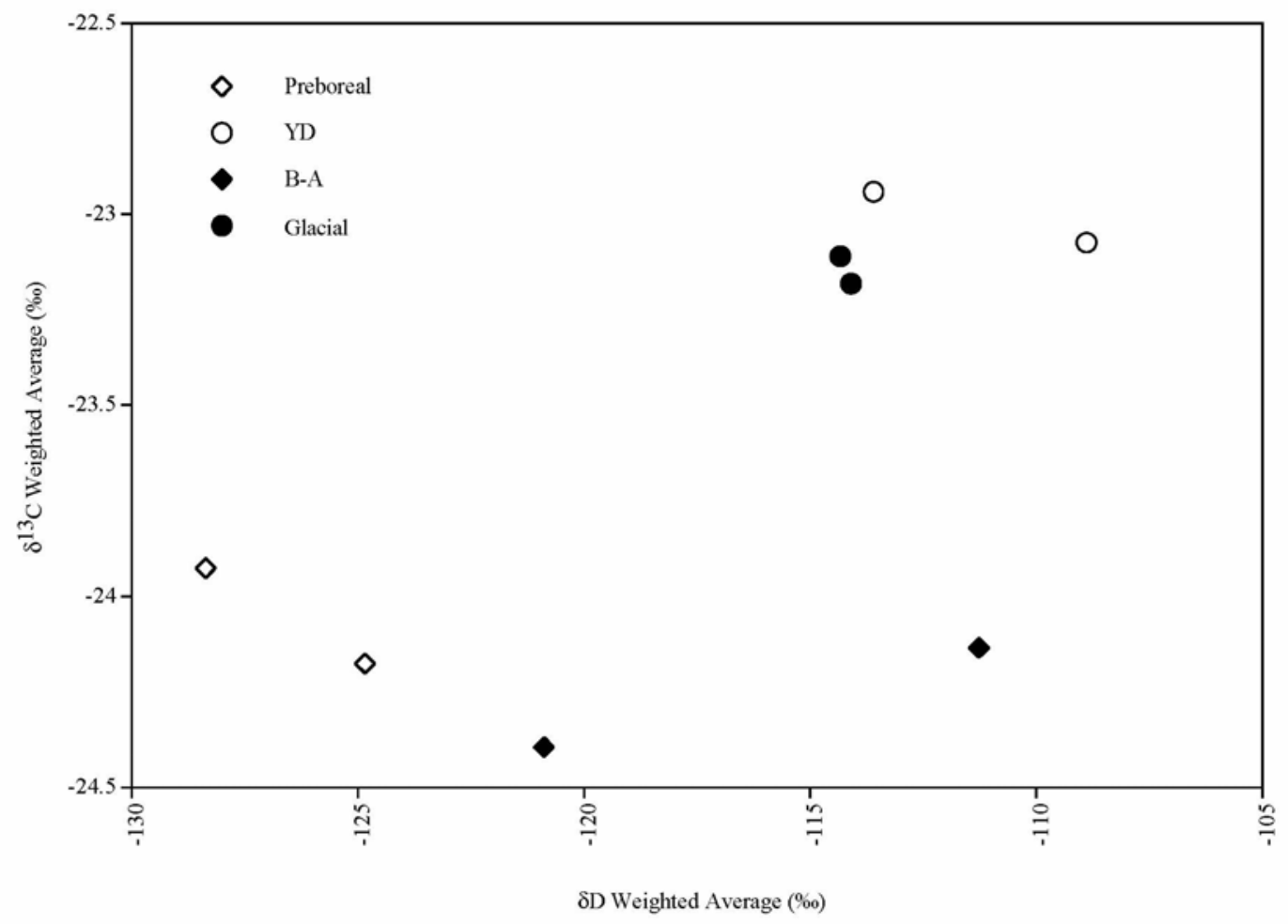

Mass-weighted average $\delta^{13} \mathrm{C}$ versus $\delta \mathrm{D}$. The climate periods of interest appear as different symbols. 
terrestrial biomarkers are faithful recorders of terrestrial vegetation change. A strong relationship was found between $\delta^{13} \mathrm{C}$ of leaf wax fatty acids and $\delta \mathrm{D}$, which is interpreted as a proxy for $\delta \mathrm{D}$ of environmental water at the time of leaf wax synthesis. Trends in $\delta \mathrm{D}$ confirm changes in aridity between the climate periods mentioned above. The relationship observed between both isotopic proxies would be expected if arid conditions provide a strong advantage for $\mathrm{C}_{4}$ over $\mathrm{C}_{3}$ plants. Similar studies in different locations would shed additional light on whether aridity is the deterministic climate factor for vegetation change, thus improving interpretations of other plant wax records. 


\section{References}

Aparicio, R., 1986. Upwelling along the southern coastal boundary of the Caribbean Sea: physical characterization, variability, and regional implications. MS thesis, Florida Institute of Technology, Melbourne.

Black, D.E., Peterson, L.C., Overpeck, J.T., Kaplan, A., Evans, M.N., Kashgarian, M., 1999. Eight centuries of North Atlantic Ocean atmosphere variability. Science 286, 1709-1713.

Burgoyne, T.W., Hayes, J.M., 1998. Quantitative Production of $\mathrm{H}_{2}$ by Pyrolysis of Gas Chromatographic Effluents. Anal. Chem. 70, 5136-5141.

Chikaraishi, Y., Naraoka, H., 2003. Compound-specific $\delta D-\delta{ }^{13} \mathrm{C}$ analyses of $n$-alkanes extracted from terrestrial and aquatic plants. Phytochemistry 63, 361-371.

Collister, J.W., Rieley, G., Stern, B., Eglinton, G., Fry, B., 1994. Compound-specific $\delta^{13} \mathrm{C}$ analyses of leaf lipids from plants with differing carbon dioxide metabolisms. Organic Geochemistry 21, 619-627.

Cowling, S.A., Maslin, M.A., Sykes, M.T., 2001. Paleovegetation simulations of lowland Amazonia and implications for neotropical allopatry and speciation. Quaternary Research 55, 140-149.

Eglinton, G., Hamilton, 1967. Leaf epicuticular waxes. Science 156, 1322-1335.

Freeman, K.H., Colarusso, L.A., 2001. Molecular and isotopic records of $\mathrm{C}_{4}$ grassland expansion in the late Miocene. Geochim. et Cosmochim. Acta 65, 1439-1454.

Gagosian, R.B., Peltzer, E.T., 1986. The importance of atmospheric input of terrestrial organic matter to deep sea sediments. Organic Geochemistry 10, 661-669.

Haug, G.H., Hughen, K.A., Sigman, D.M., Peterson, L.C., Röhl, U., 2001. Southward migration of the Intertropical Convergence Zone through the Holocene. Science 293, 1304-1308.

Hayes, J.M., 1993. Factors controlling ${ }^{13} \mathrm{C}$ contents of sedimentary organic compounds: Principles and evidence. Marine Geology 113, 111-125.

Huang, Y., Dupont, L., Sarnthein, M., Hayes, J.M., Eglinton, G., 2000. Mapping of $\mathrm{C}_{4}$ plant input from North West Africa into North East Atlantic sediments. Geochim. et Cosmochim. Acta 64, 3505-3513. 
Huang, Y., Street-Perrott, F.A., Metcalfe, S.E., Brenner, M., Moreland, M., Freeman, K.H., 2001. Climate change as the dominant control on glacial-interglacial variations in $\mathrm{C}_{3}$ and $\mathrm{C}_{4}$ plant abundance. Science 293, 1647-1651.

Huang, Y., Street-Perrott, F.A., Perrott, R.A., Metzger, P., Eglinton, G., 1999. Glacialinterglacial environmental changes inferred from molecular and compoundspecific $\delta^{13} \mathrm{C}$ analyses of sediments from Sacred Lake, Mt. Kenya. Geochim. et Cosmochim. Acta 63, 1383-1404.

Hughen, K.A., Eglinton, T.I., Xu, L., Makou, M., 2004. Abrupt tropical vegetation response to rapid climate changes. Science 304, 1955-1959.

Hughen, K.A., Overpeck, J.T., Lehman, S.J., Kashgarian, M., Southon, J., Peterson, L.C., Alley, R., Sigman, D.M., 1998. Deglacial changes in ocean circulation from an extended radiocarbon calibration. Nature 391, 65-68.

Hughen, K.A., Overpeck, J.T., Peterson, L.C., Anderson, R.F., 1996b. The nature of varved sedimentation in the Cariaco Basin, Venezuela, and its palaeoclimatic significance. In Kemp, A.E.S. (Ed.) Palaeoclimatology and Palaeoceanography from Laminated Sediments. Geological Society Special Publication 116. pp. 171183.

Hughen, K.A., Overpeck, J.T., Peterson, L.C., Trumbore, S., 1996a. Rapid climate changes in the tropical Atlantic region during the last deglaciation. Nature 380, 51-54.

Hughen, K.A., Southon, J.R., Lehman, S.J., Overpeck, J.T., 2000. Synchronous radiocarbon and climate shifts during the last deglaciation. Science 290, 19511954.

Islebe, G.A., Hooghiemstra, H., van der Borg, K., 1995. A cooling event during the Younger Dryas Chron in Costa Rica. Palaeogeography, Palaeoclimatology, Palaeoecology 117, 73-80.

Johnsen, S.J., Clausen, H.B., Dansgaard, W., Fuhrer, K., Gundestrup, N., Hammer, C.U., Iversen, P., Jouzel, J., Stauffer, B., Steffensen, J. P., 1992. Irregular glacial interstadials recorded in a new Greenland ice core. Nature 359, 311-313.

Jolly, D., Haxeltine, A., 1997. Effect of low glacial atmospheric $\mathrm{CO}_{2}$ on tropical African montane vegetation. Science 276, 786-788.

Kolattukudy, P.E., 1976. Chemistry and Biochemistry of Natural Waxes. Elsevier, Amsterdam. 
Lea, D.W., Pak, D.K., Peterson, L.C., Hughen, K.A., 2003. Synchroneity of tropical and high-latitude Atlantic temperatures over the last glacial termination. Science 301, 1361-1364.

Leyden, B.W., 1985. Late Quaternary aridity and Holocene moisture fluctuations in the Lake Valencia Basin, Venezuela. Ecology 66, 1279-1295.

Meyers, P.A., 1997. Organic geochemical proxies of paleoceanographic, paleolimnologic, and paleoclimatic processes. Organic Geochemistry 27, 213250 .

Nguyen Tu, T.T., Derenne, S., Largeau, C., Bardoux, G., Mariotti, A., 2004. Diagenesis effects on specific carbon isotope composition of plant $n$-alkanes. Organic Geochemistry 35, 317-329.

Ohkouchi, N., Kawamura, K., Taira, A., 1997. Molecular paleoclimatology: reconstruction of climatic variabilities in the late Quaternary. Organic Geochemistry 27, 173-183.

Overpeck, J.T., Peterson, L.C., Kipp, N., Imbrie, J., Rind, D., 1989. Climate change in the circum-North Atlantic region during the last deglaciation. Nature 338, 553557.

Peterson, L.C., Overpeck, J.T., Kipp, N.G., Imbrie, J., 1991. A high-resolution Late Quaternary upwelling record from the anoxic Cariaco Basin, Venezuela. Paleoceanography 6, 99-119.

Prahl, F.G., Muehlhausen, L.A., 1989. Lipid biomarkers as geochemical tools for paleoceanographic study. In Berger, W.H., Smetacek, V.S., Wefer, G. (Eds.), Productivity in the Oceans: Present and Past. John Wiley \& Sons. pp. 271-289.

Reiley, G., Collier, R.J., Jones, D.M., Eglinton, G., 1991a. The biogeochemistry of Ellesmere Lake, U.K. - I: Source correlation of leaf wax inputs to the sedimentary record. Organic Geochemistry 17, 901-912.

Reiley, G., Collier, R.J., Jones, D.M., Eglinton, G., Eakin, P.A., Fallick, A.E., 1991 b. Sources of sedimentary lipids deduced from stable carbon-isotope analyses of individual compounds. Nature 352, 425-427.

Rinaldi, M., 1996. Palynological evidence of the Younger Dryas event in a core of Cariaco Basin, northeastern Venezuela. Abstract, $30^{\text {th }}$ International Geological Congress, Beijing. 
Rind, D., Peteet, D., Broecker, W.S., McIntyre, A., Ruddiman, W., 1986. The impact of cold North Atlantic sea surface temperatures on climate: implications for the Younger Dryas cooling (11-10 k). Climate Dynamics 1, 3-33.

Rinna, J., Warning, B., Meyers, P.A., Brumsack, H.-J., Rullkötter, J., 2002. Combined organic and inorganic geochemical reconstruction of paleodepositional conditions of a Pliocene sapropel from the eastern Mediterranean Sea. Geochim. et Cosmochim. Acta 66, 1969-1986.

Sauer, P.E., Eglinton, T.I., Hayes, J.M., Schimmelmann, A., Sessions, A.L., 2001. Compound-specific D/H ratios of lipid biomarkers from sediments as a proxy for environmental and climatic conditions. Geochim. et Cosmochim. Acta 65, 213222.

Schefuß, E., Ratmeyer, V., Stuut, J.-B.W., Jansen, J.H.F., Sinninghe Damsté, J.S., 2003. Carbon isotope analyses of $n$-alkanes in dust from the lower atmosphere over the central eastern Atlantic. Geochim. et Cosmochim. Acta 67, 1757-1767.

Schiller, A., Miklajewicz, U., Voss, R., 1997. The stability of the North Atlantic thermohaline circulation in a coupled ocean-atmosphere general circulation model. Climate Dynamics 13, 325-347.

Sessions, A.L., Burgoyne, T.W., Hayes, J.M., 2001. Correction of $\mathrm{H}_{3}{ }^{+}$contributions in hydrogen isotope ratio monitoring mass spectrometry. Anal. Chem. $\mathbf{7 3}$ (2), 192-199.

Sessions, A.L., Burgoyne, T.W., Schimmelmann, A., Hayes, J.M., 1999. Fractionation of hydrogen isotopes in lipid biosynthesis. Organic Geochemistry 30, 1193-1200.

Simoneit, B.R.T., Chester, R., Eglinton, G., 1977. Biogenic lipids in particulates from the lower atmosphere over the eastern Atlantic. Nature 267, 682-685.

Sternberg, L. da S.L., 1988. D/H ratios of environmental water recorded by D/H ratios of plant lipids. Nature 333, 59-61.

Sternberg, L., Deniro, M.J., Ajie, H., 1984. Stable hydrogen isotope ratios of saponifiable lipids and cellulose nitrate from CAM, $\mathrm{C}_{3}$ and $\mathrm{C}_{4}$ plants. Phytochemistry 23, 2475-2477.

Street-Perrott, F.A., Huang, Y., Perrott, R.A., Eglinton, G., Barker, P., Khelifa, L.B., Harkness, D.D., Olago, D.O., 1997. Impact of lower atmospheric carbon dioxide on tropical mountain ecosystems. Science 278, 1422-1426. 
Terwilliger, V.J., Betancourt, J.L., Leavitt, S.W., Van de water, P.K., 2002. Leaf cellulose $\delta \mathrm{D}$ and $\delta^{18} \mathrm{O}$ trends with elevation differ in direction among cooccurring, semiarid plant species. Geochim. et Cosmochim. Acta 66, 3887-3900.

UNEP, 2004. Forests and Protected Areas of Venezuela. Compiled by Ravilious C., United Nations Environment Programme-World Conservation Monitoring Centre. http://www.unep-wcmc.org/forest/data/country/ven.htm.

van der Hammen, T., Hooghiemstra, H., 1995. The El Abra stadial, a Younger Dryas equivalent in Colombia. Quaternary Science Review 14, 841-851.

van 't Veer, R., Islebe, G.A., Hooghiemstra, H., 2000. Climatic change during the Younger Dryas chron in northern South America: a test of the evidence. Quaternary Science Reviews 19, 1821-1835. 


\title{
Chapter 3
}

\section{Investigation of Trace Lipids in Alpine Ice Cores}

\begin{abstract}
Making use of recently developed analytical tools, a broad array of organic compounds were extracted from small volumes of melted ice and quantified in order to assess anthropogenic and natural inputs to high-altitude ice fields. Stir bar sorptive extraction was used to isolate hydrophobic organic compounds from the aqueous samples in a form that could be quantitatively transferred to a gas chromatograph (GC) inlet via direct thermal desorption. Individual molecular markers (biomarkers) were identified and quantified using a GC coupled to a time-of-flight mass spectrometer. Benefits of this analytical approach include enhanced compound recovery and minimal contamination during handling, while maximizing the breadth of biomarker information that can be gained from a single analysis. Such advantages may enable measurement of biomarkers in ice core samples of a sufficiently reduced volume $(\leq 30 \mathrm{ml})$ so as to allow generation of high-resolution multi-molecular records.

Five post-industrial samples from alpine ice cores were examined in this manner in order to develop analytical methods and establish the utility of the approach. The samples include two from the Andes in South America, two from the Tibetan Plateau, and one from Mt. Kilimanjaro in East Africa. Biomarkers observed in these samples included $n$-alkanoic acids, $n$-alkyl amides and nitriles, polycyclic aromatic hydrocarbons, diterpenoids, and $n$-alkanes. These compounds suggest inputs from fresh vascular plant waxes, biomass burning products, and anthropogenic activities such as fossil fuel
\end{abstract}


utilization. The same analyses were also performed on five pre-industrial samples from two ice cores in order to assess concentration changes of biomarkers through time and the character of biomarker assemblages in the absence of anthropogenic contributions. Preindustrial investigations were performed on three samples from the Sajama ice core from the Bolivian Andes with ages of about $2 \mathrm{ka}, 5 \mathrm{ka}$, and the last glacial period, and two samples from the Puruogangri ice core from the Tibetan Plateau with ages of about $2 \mathrm{ka}$ and $6 \mathrm{ka}$. Polycyclic aromatic hydrocarbons and diterpenoids, such as were observed in modern Sajama ice samples, occurred in the two Holocene Sajama samples, but not in the last glacial sample. This finding, which indicates that byproducts of conifer burning were greatest during the Holocene, is consistent with arid conditions inferred from previous ice core research (Thompson et al., 1998). The Puruogangri 6 ka sample contained elevated concentrations of $n$-alkyl amides and nitriles, implying a natural source for these compounds, likely from biomass burning.

These results demonstrate the utility of my analytical methods for generating biomarker records from small volumes of melted ice. Using these techniques, it becomes feasible to generate multi-molecular stratigraphic records from tropical ice cores, expanding the amount of paleoclimate information they provide.

\section{Introduction}

Vascular plant derived biomarkers have been identified in many locations and environments and have been used to reconstruct changes in climate parameters such as vegetation type, atmospheric circulation, and aridity (e.g., Gagosian and Peltzer, 1986; Reiley et al., 1991a, 1991b; Ohkouchi et al., 1997; Huang et al., 1999, 2000; Freeman and Colarusso, 2001; Schefuß et al., 2003; Hughen et al., 2004; Makou et al., in review). A $\delta^{13} \mathrm{C}$ record of modern aeolian leaf wax compounds intercepted on Bermuda Island shows seasonal variability, indicating that biomarker transport and deposition occurs rapidly (Conte and Weber, 2002). Rapid deposition and excellent preservation characteristics of leaf wax lipids (Prahl and Muehlhausen, 1989) contribute the usefulness of these vascular plant biomarkers as paleovegetation indicators. Natural vascular plant 
products such as leaf waxes, and plant combustion byproducts such as polycyclic aromatic hydrocarbons (PAHs) occur in alpine and polar environments (Kawamura et al., 1996; Currie et al., 1998; Xie et al., 2000), but are generally an underutilized resource in ice cores due to their low ambient concentrations, which typically necessitate processing of kilogram quantities of ice for analysis.

In this study, I employed recently developed analytical technology to characterize and quantify a broad suite of organic biomarkers in ice core samples equivalent to $30 \mathrm{ml}$ or less, which are small enough to allow for future generation of high-resolution stratigraphic records. Stir bar sorptive extraction (SBSE) and thermal desorption (TD) were used to extract and concentrate organic matter from the melted ice and quantitatively transfer it to a GC coupled to a time-of-flight mass spectrometer (TOFMS), which provided the means to detect and resolve trace quantities of individual compounds in complex samples. This analytical scheme enhances the potential to quantify a broad spectrum of organic biomarkers in a sample of melted ice, making it ideally suited for investigation of ice cores, which are typically severely limited in amount of available sample material.

SBSE is performed by spinning a magnetic stir bar coated with an apolar polydimethylsiloxane (PDMS) phase in an aqueous sample, during which time dissolved organic analytes are partitioned into the phase through absorption (Baltussen et al., 1999). SBSE has been used successfully to analyze such compounds as fatty acids, amines, PAHs, and pesticides in aqueous samples (Kolahgar et al., 2002; Pfannkoch et al., 2003; Ochiai et al., 2004). The stir bars, which are produced by Gerstel under the name "Twister", are constructed of glass (10 mm long) coated with $24 \mu \mathrm{l}$ of a chemically bonded PDMS phase that is $0.5 \mathrm{~mm}$ thick. Baltussen et al. (1999) determined empirically that the detection limits of some volatile pollutants extracted via SBSE and analyzed via GC-MS were less than $0.1 \mathrm{ng} / \mathrm{L}$. This level of sensitivity should permit quantification of trace-level concentrations of biomarkers in alpine ice. Typically, SBSE is coupled with TD, which provides a means of transferring the sorbed organic matter from the stir bar to the inlet of a GC for subsequent separation and detection. After a 
sufficient extraction period, the stir bar is placed in a glass tube that is then introduced into a thermal desorption system, which is also manufactured by Gerstel (TDS2 ThermoDesorption System). The stir bar is heated under a He flow and the compounds in the stir bar phase are volatilized, transferred, and cryofocused onto a GC injector liner. Absorption into the non-reactive PDMS phase, rather than adsorption onto its surface, protects even unstable analytes from reaction in solution while allowing practically complete desorption at low temperatures (Baltussen et al., 1999).

There are several advantages of SBSE and TD that make them especially appropriate for analysis of biomarkers in ice. The high recovery and low detection limits for semivolatile compounds observed by Baltussen et al. (1999) ensure that even trace level concentrations of organic compounds, as are expected in alpine ice core samples, can be quantified using these methods. SBSE and TD also permit analysis of specific biomarkers with minimal sample handling. Traditionally, recovery of organic material from melted ice would involve use of solvents (e.g. liquid-liquid extraction) and subsequent sample concentration and transfer steps. Such procedures frequently result in sample loss or entrainment of contaminants that could interfere with the analytes during chromatographic analysis. With SBSE and TD, the analytes are sorbed into the stir bar within the sample matrix, after which they are transferred directly to a GC with minimal sample handling and no use of solvents. Finally, the analytes that are sorbed onto the stir bar are desorbed and transferred to the GC in their entirety, instead of as an aliquot, as is typical for GC injection from a solvent matrix. This benefit ensures maximum recovery of the biomarkers, aiding in analysis of trace biomarker concentrations.

TOF-MS is another recent analytical development that is ideally suited to investigating complex assemblages of biomarkers in environmental samples and for generating multi-molecular stratigraphic records. The TOF-MS used in this study is the Tempus, which was designed and manufactured by Thermo Electron Corporation. A TOF-MS is different from conventional mass spectrometers in that ions of a wide mass range (e.g. 50-650 amu) are essentially collected continuously, eliminating the need to scan across a range of mass-to-charge $(\mathrm{m} / \mathrm{z})$ values, as is necessary with quadrupole and 
other mass analyzers. After eluting from the GC column, compounds entering the Tempus are subject to bombardment with $70 \mathrm{eV}$ electron energy, causing them to fragment and ionize in a reproducible manner and ultimately forming the characteristic spectral patterns that are used to identify them. The resultant positive ions are focused at the base of flight tube, which is a rectangular box with the ion push-out region and the detector on either side of one end and a wire grid (reflectron) at the other end. The ions are ejected into the flight tube at a rate of $40 \mathrm{kHz}$ through an applied voltage differential. They travel through the flight tube in a parabolic path, aided by an electric potential applied to the wire grid, ultimately striking the microchannel plates that rest on top of the detector. An algorithm is used to differentiate between masses using the time that ions took to transverse the flight tube and the relationship $\mathrm{KE}=1 / 2 \mathrm{mv}^{2}$ (where $\mathrm{KE}=$ kinetic energy, $\mathrm{m}=$ mass, and $\mathrm{v}=$ velocity). A series of three stacked detectors, each of which detect different but overlapping ion input intensities, provide a linear response covering a range of concentrations that can approach 6 orders of magnitude (Lin et al., 2000).

Because the Tempus is capable of high spectral acquisition rates (up to 100 spectra/second), it can be used with fast-GC techniques, in which a rapid oven temperature ramp rate results in rapidly eluting chromatographic peaks. The narrow, sharp peaks produced by fast-GC improve the signal-to-noise ratio, thereby enhancing the detection and quantification of trace level concentrations of compounds.

A key attribute of GC/TOF-MS is the breadth of information that this mode of analysis yields. Because the TOF-MS simultaneously acquires all masses (i.e. it does not sequentially scan masses), full spectral information is continuously available. Thus, complex mixtures can be analyzed with minimal pre-treatment, reducing exposure to sources of laboratory contamination and allowing multiple molecular species to be monitored in a single run. Use of the Tempus in combination with SBSE and TD enhances the biomarker information that can be gained from a single measurement. GC/TOF-MS also offers high sensitivity. Detection limits for GC/TOF-MS systems have been determined to be equal to or less than 2 picograms of material (Lin et al., 2000), providing the potential to examine trace organic species, and/or to use smaller sample 
sizes. Additionally, the broad linear response characteristic of the Tempus allows for quantitation of trace and abundant compounds in the same sample. All of the qualities mentioned above lend themselves to analysis of biomarkers in ice cores, which are expected to occur in diverse assemblages, but generally present in very low concentrations.

\section{Tropical Ice Cores/Study Sites}

High-altitude tropical ice cores have yielded invaluable insights into variations in low-latitude climate since the last glacial period. This information has been gleaned through studies of oxygen isotopes, dust, and a range of other geochemical parameters (e.g. Thompson et al., 1985; Thompson et al., 1995; Thompson et al., 1998; Thompson et al., 2000a; Thompson et al., 2002). In South America, Asia, and other locations, these cores have been used to generate high-resolution proxy records and describe climate changes on a range of time scales, from glacial-interglacial and millennial to annual. As such, the network of tropical alpine ice cores provides the opportunity to investigate changes in tropical climate phenomena, such as El Niño and the southern oscillation (ENSO) and the monsoon systems, which may play a role in global climate (e.g. Wang et al., 1999; Lau and Nath, 2001). A wealth of geochemical information is encoded these cores, yet few efforts have been made to exploit their organic contents. In this study, I attempt to characterize the molecular biomarkers - compounds that are attributable to a specific organism or group of organisms - trapped in these cores, as well as other marker compounds derived from anthropogenic activities.

Dr. Lonnie Thompson of the Byrd Polar Research Center (Ohio State University) generously provided five post-industrial ice core samples and five pre-industrial samples, aged about 2 ka or greater, on which to develop and test my methods. The post-industrial samples, which for the purposes of this study will be termed "modern", were collected from the upper sections of the Huascarán and Sajama ice cores in the Andes, the Dasuopu and Puruogangri cores from the Tibetan Plateau, and Mt. Kilimanjaro in Africa (see Figure 3-1 and the table below). All of these samples were collected from below the firn 


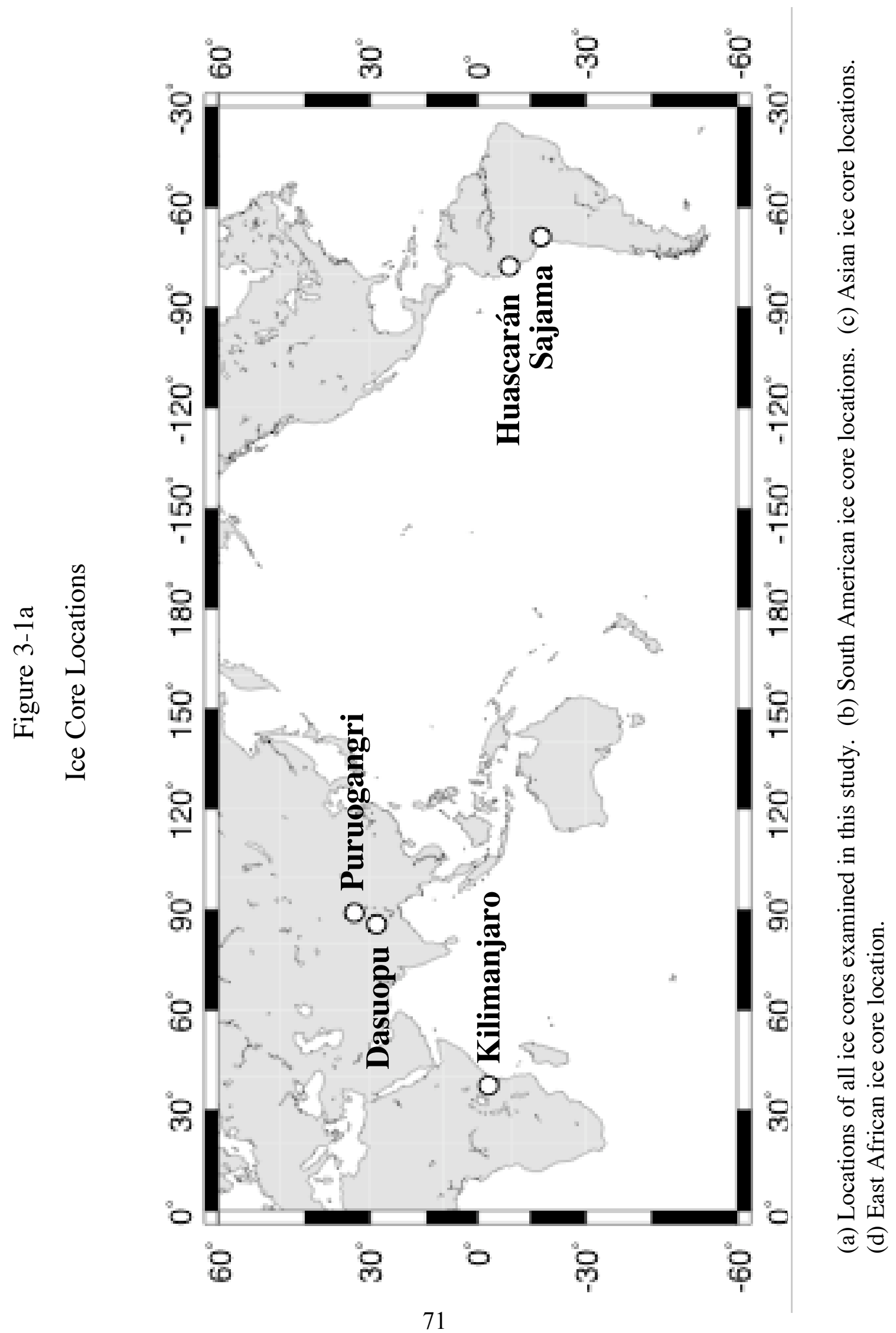


Figure 3-1b

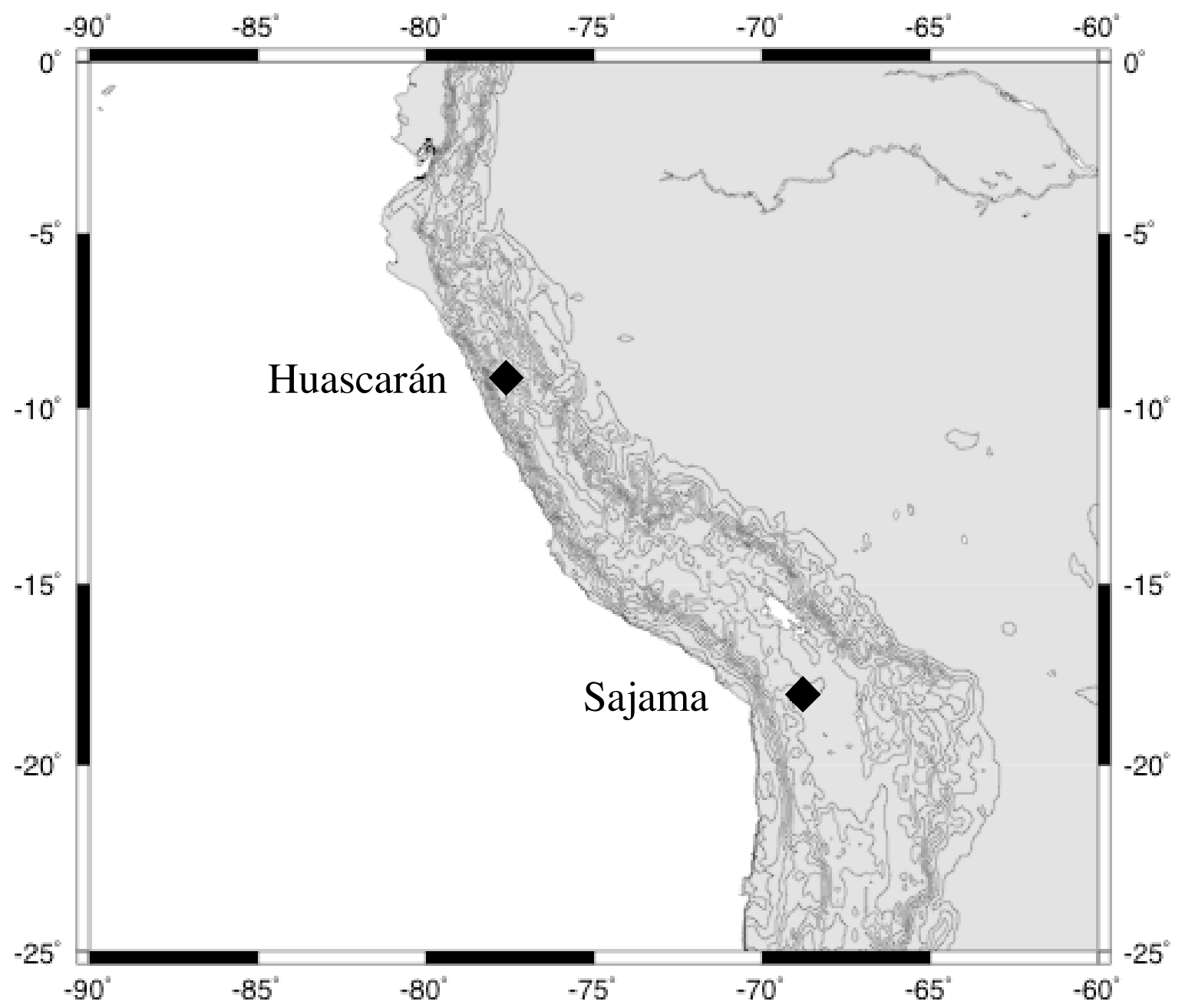


Figure 3-1c

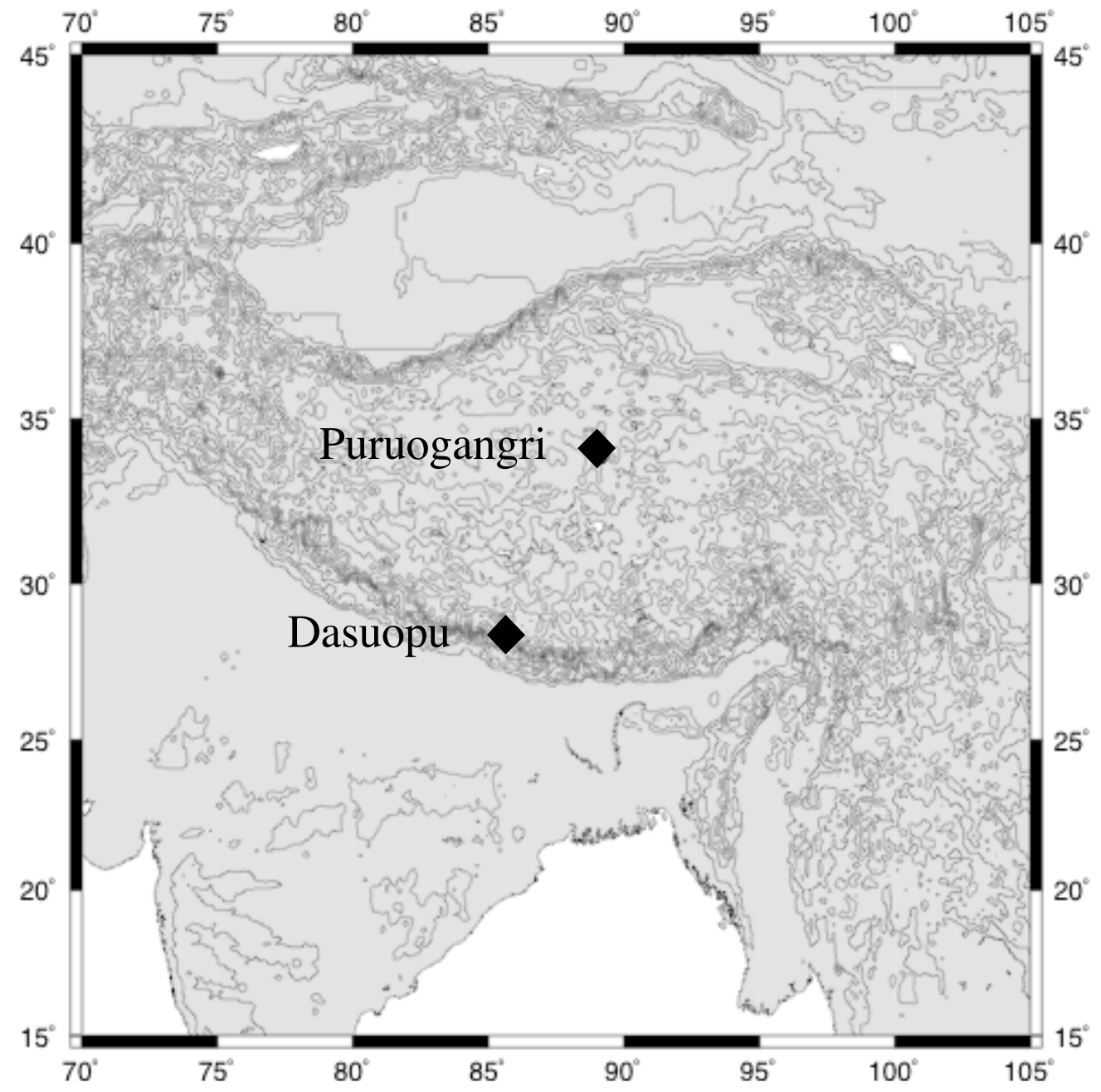


Figure 3-1d

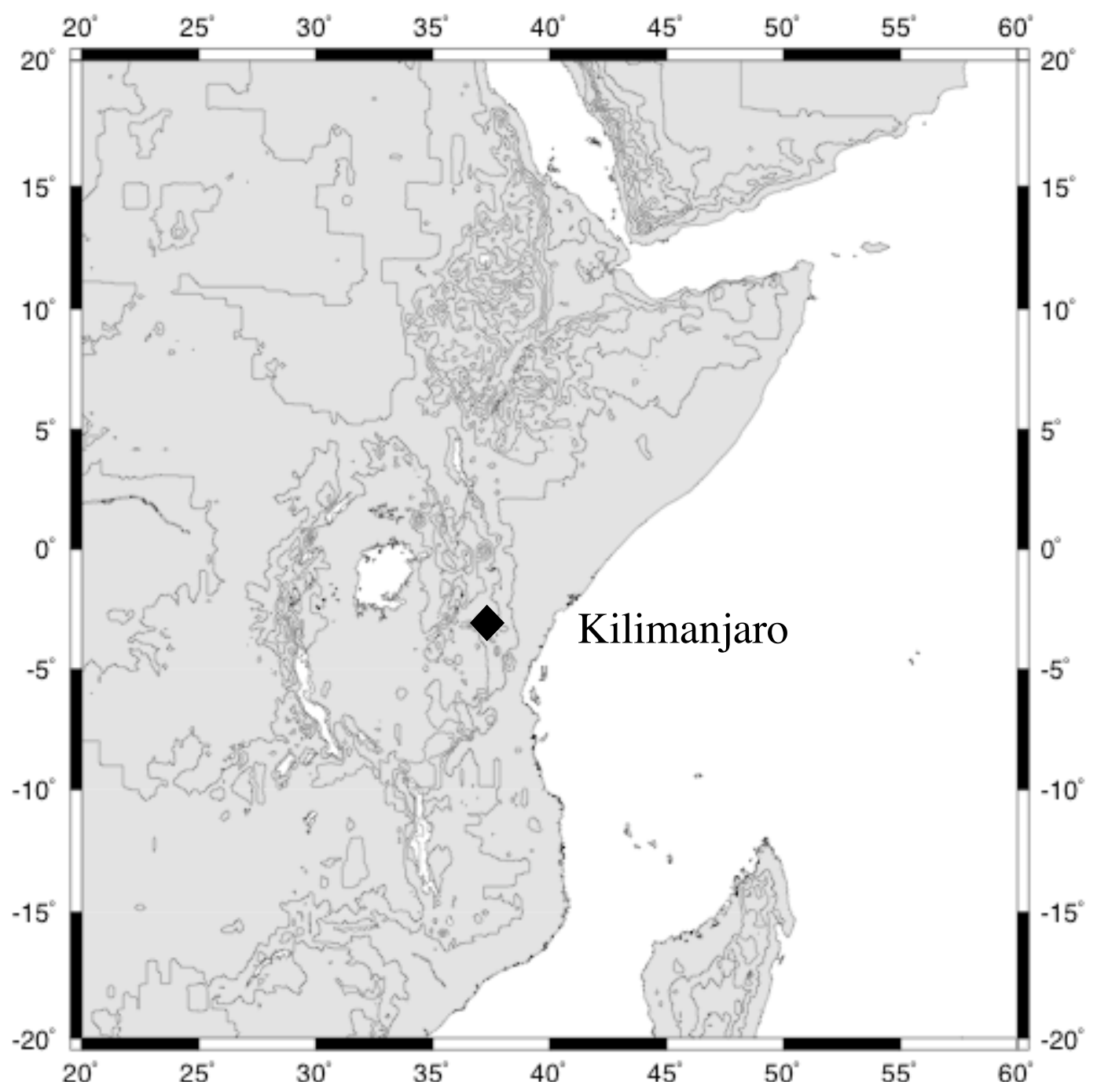


layer, and were thus out of contact with the atmosphere and organic aerosols at the time of coring. Furthermore, the ice was sampled from the center of core sections in order to minimize entrainment of contamination resulting from drilling or storage procedures (e.g. alcohol/water solutions that are sometimes used as a drilling lubricant for deeper core sections; anthropogenic activities at coring stations such as generator use). The preindustrial samples include two Holocene samples (approximate ages 2 and $5 \mathrm{ka}$ ) and one glacial sample from a Sajama ice core, as well as two Holocene samples (approximate ages 2 and $6 \mathrm{ka}$ ) from a Puruogangri ice core. The purpose of analyzing both modern and pre-industrial samples is to characterize biomarker assemblages in ice samples that have been affected by anthropogenic (i.e. petrogenic and pollutant) organic contributions and those that should contain purely natural biomarkers, especially those derived from terrestrial vegetation.

\begin{tabular}{|c|c|c|}
\hline Ice Core & $\begin{array}{c}\text { Location (Lat. Long. } \\
\text { Elev.) }\end{array}$ & Samples \\
\hline Huascarán & $\begin{array}{c}9^{\circ} 7^{\prime} \mathrm{S} ; 77^{\circ} 37^{\prime} \mathrm{W} \\
6048 \mathrm{~m}\end{array}$ & Modern: Core 2, Tubes $63 \& 6$ \\
\hline Sajama & $\begin{array}{c}18^{\circ} 6^{\prime} \mathrm{S} ; 68^{\circ} 53^{\prime} \mathrm{W} \\
6542 \mathrm{~m}\end{array}$ & $\begin{array}{l}\text { Modern: SB3, Tube } 62 \\
\sim 2 \text { ka: Core 2, Tube } 85 \\
\sim 5 \text { ka: Core 2, Tube } 95 \\
\sim \text { LGM: Core 2, Tube } 119\end{array}$ \\
\hline Puruogangri & $\begin{array}{c}33^{\circ} 55^{\prime} \mathrm{N} ; 89^{\circ} 5^{\prime} \mathrm{E} \\
6500 \mathrm{~m}\end{array}$ & $\begin{array}{l}\text { Modern: Core 1, Tube } 74 \\
\sim 2 \text { ka: Core 2, Tube } 153 \\
\sim 6 \text { ka: Core 2, Tube } 207\end{array}$ \\
\hline Dasuopu & $\begin{array}{c}28^{\circ} 23^{\prime} \mathrm{N} ; 85^{\circ} 43^{\prime} \mathrm{E} \\
7200 \mathrm{~m}\end{array}$ & Modern: Core 1, Tubes 52-54 \\
\hline Kilimanjaro & $\begin{array}{c}3^{\circ} 5^{\prime} \mathrm{S} ; 37^{\circ} 21^{\prime} \mathrm{E} \\
5893 \mathrm{~m}\end{array}$ & Modern: NIF Core 2, Tube 28 \\
\hline
\end{tabular}

The wide array of ice core geographic locations provides the opportunity to examine differences in biomarker content and concentrations in areas with different climates, vegetation, and anthropogenic influences. Airflow is easterly over the Peruvian and Bolivian Andes and moisture is primarily delivered from the Atlantic Ocean and Amazon Basin (Thompson et al., 1985; Thompson et al., 1995). Vegetation on the eastern slope of the Andes ranges from humid forest at low elevations to grasses and 
shrubs below the snowline (Hansen et al., 1984). Surface pollen samples collected near Laguna Junín, which is in the vicinity of the Huascarán core, at elevations of 4,400 to 4,900 m consisted mostly of Gramineae (grasses) with contributions from the shrub Ephedra, Compositae, and Alnus, which may have been transported from lower elevation forests (Hansen et al., 1984). On the Tibetan Plateau, atmospheric circulation changes seasonally, with the greatest moisture inputs from the South Asian Monsoon in summer and arid conditions, along with associated dust inputs, occurring during winter when winds are westerly (Thompson et al., 2000a). Liu et al., (1998) observe that trees are not present near the Dunde ice cap, which is on the northern edge of the Tibetan Plateau, and the local vegetation consists mostly of grasses, shrubs, and herbs. Ephedra pollen was observed in modern sections of the Dunde core and other dominant inputs were from Artemisia and Chenopodiaceae. Artemisia, which is characteristic of steppe vegetation, appeared to increase during periods of greater monsoon strength (Liu et al., 1998). Climate monitoring at the Northern Ice Field on Mt. Kilimanjaro showed that winds there are predominantly east-southeasterly (Thompson et al., 2002). Coastal Tanzanian vegetation upwind of Mt. Kilimanjaro includes many different species of Gramineae and trees (Muzuka, 1999).

Climate characteristics and variability may influence the biomarker patterns observed in the modern and pre-industrial ice core samples. Currently, the more northerly Huascarán ice core site receives greater moisture and lower dust inputs than the Sajama ice cap to the south, but the ice core paleoclimate records from these cores indicate that these conditions were reversed during the last glacial maximum (e.g. Thompson et al., 2000b). These widespread glacial/interglacial climate changes are associated with changes in the extent and type of terrestrial vegetation in South America (Hansen et al., 1984; Hughen et al., 2004; Makou et al., in review). Changes in ice accumulation rate would affect biomarker concentrations, and biomarker assemblages would be expected to change with changing proximity and type of vegetation. Additionally, changes in aridity would presumably affect delivery of biomarkers that are generated or liberated by biomass burning through, for example, facilitating or 
suppressing occurrences of forest fires. Pollen studies from the Junín area of the Peruvian Andes $\left(11^{\circ} \mathrm{S}\right)$ suggest a reduction in eastern forests during the last glacial period and an expansion of grasses and shrubs (Hansen et al., 1984). Similarly, reduced $\mathrm{NO}_{3}^{-}$ concentrations observed in the last glacial section of the Huascarán ice core may imply decreased vegetation, assuming that nitrogen species as aerosols in this region are primarily derived from tropical forests (Thompson et al., 1995). On the Tibetan Plateau, modern ice from the Dasuopu core, which is positioned farther south than Puruogangri (Figure 3-1c), is expected to receive greater inputs of anthropogenic pollutants due to its proximity to the Indian Subcontinent. Changes in pollen assemblages just after $5 \mathrm{ka}$ in the Dunde ice core suggest an increase in aridity, likely associated with a decrease in monsoon strength, and reduction in steppe vegetation from the early to the late Holocene (Liu et al., 1998). Such changes may also be observable as varying biomarker assemblages and concentrations. However, pollen records may differ slightly from those of vascular plant leaf waxes depending on the response of vegetation to environmental stimuli. Even though both substances are transported by wind and are subject to variability in atmospheric circulation, pollen is a measure of the reproductive activities of a plant community, while leaf wax production should be primarily a function of total leaf area (i.e. extent and/or density of vegetation).

\section{Previous Investigations of Biomarkers in Ice}

Several previous studies have confirmed the presence of molecular biomarkers in snow and ice, however large volumes of ice were typically required for these analyses. Kawamura et al. (1996) performed solvent extractions and lipid analyses (via GC and GC/MS) on Greenland ice core samples from the $16^{\text {th }}$ century to the present, and measured total $n$-alkanoic acid (fatty acid) concentrations of up to $105 \mathrm{ng} / \mathrm{g}$-ice for the $\mathrm{C}_{12}-\mathrm{C}_{32}$ homologues, although melt water samples of about $350 \mathrm{ml}$ were required. For PAHs, kilogram quantities of ice or snow have typically been required for conventional analysis (Peters et al., 1995; Masclet et al., 2000). Currie et al. (1998) measured concentrations of individual PAHs on as little as $120 \mathrm{~g}$ of contemporary Greenland snow 
using a combination of supercritical fluid extraction directly coupled to gas chromatography/mass spectrometry (GC/MS) with the quadrupole mass analyzer operating in selected ion monitoring (SIM) mode. While this approach is fairly sensitive, it negates the analysis of other molecular species and also involves analytical steps (e.g. filtration) that may entrain contaminants. Xie et al. (2000) identified anthropogenic and vascular plant derived compounds such as $n$-alkanes, $n$-alkanoic acids, and $n$-alkan-2ones in a Dasuopu snow pit sample. Their analytical approach, which involved adsorption of organic matter onto a solid phase and subsequent solvent extraction, required sample volumes greater than 20 liters; quantities that are incompatible with down-core ice studies.

The existence of vascular plant material that is observable to the naked eye or through microscopy in alpine ice cores also portends the presence of molecular biomarkers that are derived from the same source and similarly undergo aeolian deposition. Thompson et al. (1998) observed bark fragments and other plant material in the Sajama ice core as far back in time as the last glacial period. Liu et al. (1998) investigated pollen assemblages in the Holocene section of the Dunde ice cap core from the Qinghai-Tibetan Plateau, demonstrating centennial-scale variability in local vegetation and, by inference, regional moisture balance and temperature. Although pollen studies such as this provide specific information about source vegetation, mean ice sample volumes of over $400 \mathrm{ml}$ were required.

\section{Analytical Procedure}

All samples were transported from the Byrd Polar Research Center to the Woods Hole Oceanographic Institution in cleaned and combusted glass jars and were kept at or below freezing temperatures by shipping in a cooler with ice packs. Upon receipt, the samples were transferred immediately to a $-20^{\circ} \mathrm{C}$ freezer where they were stored frozen until analyzed. However, it was apparent that some of the samples partially ( 25\%) melted and refroze before arrival. Modern samples from individual sites, which were greater in volume than down-core samples, were homogenized and then split into 
samples of different volumes for separate analysis. To accomplish this, solvent-rinsed metal tools were used to chip the ice and transfer it to pre-washed and $\mathrm{HCl}$ - and solventrinsed $1 \mathrm{~L}$ Teflon bottles, which were then capped and the ice was allowed to melt completely at room temperature. Teflon bottles were chosen for their inertness in an effort to reduce the adhesion of polar species to vessel walls. For each post-industrial sample, 10, 20 and $30 \mathrm{ml}$ aliquots of melted ice were measured in a graduated cylinder and then decanted into separate pre-cleaned $40 \mathrm{ml}$ glass vials for SBSE. In addition, a 10 $\mathrm{ml}$ sample from Sajama and a $20 \mathrm{ml}$ sample from Kilimanjaro were run in duplicate. When decanting, care was taken to avoid entraining coarse particulate matter that had settled in the bottom of the Teflon bottles because organic matter associated with this material could not be recovered via SBSE. All of the samples contained at least minor amounts of visible solid material, although considerably more light and dark grains were observed in the Sajama post-industrial sample than in the others. The pre-industrial ice core samples were transferred directly to $40 \mathrm{ml}$ vials while still frozen. After melting, their volumes were estimated by comparison with known volumes of laboratory water in a separate $40 \mathrm{ml}$ vial. Blanks were created using purified (Milli-Q) water and were subjected to the same sample processing as the melted ice. One blank consisted of frozen Milli-Q water that was shipped along with the samples in order to assess contamination entrained during shipping and sub-sampling.

To improve SBSE recoveries, especially of polar compounds, methanol and $\mathrm{HCl}$ were added to each sample. An analysis of fatty acid $\left(\mathrm{C}_{16}-\mathrm{C}_{24}\right.$; even chain lengths) standards in solutions of varying methanol concentrations indicated that optimal SBSE recoveries occurred at about $25 \% \mathrm{CH}_{3} \mathrm{OH}$ (see Appendix B). Pfannkoch et al. (2003) demonstrated that a $\mathrm{pH}$ range of 3-5 was appropriate for extraction of several fatty acids of chain length $\mathrm{C}_{18}$ or less. Based on the results of this study and testing of fatty acid recoveries at different $\mathrm{pH}$ levels, a dilute $\mathrm{HCl} / \mathrm{Milli}-\mathrm{Q} \mathrm{H}_{2} \mathrm{O}$ solution was added dropwise to each sample until a $\mathrm{pH}$ of 3-4 was obtained. The $\mathrm{pH}$ of at least one sample from each ice core site was verified with $\mathrm{pH}$ paper. 
While the measures described above improve stir bar recovery of polar and hydrophobic compounds, discrimination against longer-chain fatty acids was observed during thermal desorption of standards dried in TD tubes. Even at very high concentrations ( $\sim 0.4 \mu \mathrm{g}$ on column), chain lengths greater than $\mathrm{C}_{22}$ were not quantifiable. However, when the same standard was transesterified and run under similar conditions, the longest chain lengths (up to $\mathrm{C}_{31}$ ) were readily observed as sharp chromatographic peaks. These results demonstrate that discrimination against large polar molecules is problematic for TD. Future analysis of compounds such as long-chain fatty acids and alcohols will necessarily involve a derivatization procedure.

Following methanol and $\mathrm{HCl}$ addition, one $10 \mathrm{~mm}$ Gerstel Twister stir bar was added to each sample, and the vials were capped. Before use, all stir bars were conditioned at $300^{\circ} \mathrm{C}$ under a He flow $(100 \mathrm{ml} / \mathrm{min})$ for 2 hours to remove any compounds retained from previous uses. All sample vials were placed on a Gerstel multi-position stir plate and the stir bars were rotated at $750 \mathrm{rpm}$ overnight at room temperature. All samples were stirred for at least 10 hours, which is more than sufficient for achieving maximal extraction (Popp et al., 2001; Montero et al., 2004). Results from a test in which the same ice core samples were extracted via SBSE twice sequentially demonstrated that almost all of the extractable organic matter in a sample is removed after one SBSE treatment. After removal from the stir plate, the stir bars were removed from their sample vials with clean forceps, shaken dry or nearly dry, and placed in clean glass desorption tubes ( $4 \mathrm{~mm}$ inside diameter, $178 \mathrm{~mm}$ long). All tubes were loaded onto a 20 position Gerstel TDSA autosampler, which inserted them sequentially into the TDS 2 thermal desorption device.

All analyses were performed using the Gerstel TDS 2 ThermoDesorption System, which was mounted on a TRACE GC (Thermo Electron Corp.) coupled with a Tempus TOF-MS (Thermo Electron Corp.). A Gerstel CIS3 GC inlet with cryo-cooling and a baffled glass liner, and an Agilent DB5-MS column (20 m length, $0.18 \mathrm{~mm}$ i.d., $0.18 \mu \mathrm{m}$ film thickness) were used. The run conditions were as follows: 
Tempus TOF-MS

- $10 \mathrm{spectra/second} \mathrm{acquisition} \mathrm{rate}$

- 50-650 amu mass range

TRACE GC

- Temperature program: $40^{\circ} \mathrm{C}$ initial temperature (held 1.0 minutes), increased $30^{\circ} \mathrm{C} /$ minute to final temperature of $320^{\circ} \mathrm{C}$ (held 5.0 minutes)

TDS 2

- Splitless flow; Desorption flow $=50 \mathrm{ml} / \mathrm{min}$

- He carrier gas

- Transfer line temperature $=325^{\circ} \mathrm{C}$

- Desorption temperature program: $30^{\circ} \mathrm{C}$ initial temperature (held 0.10 minutes), increased $60^{\circ} \mathrm{C} /$ minute to final temperature of $300^{\circ} \mathrm{C}$ (held 4.0 minutes)

CIS3

- Solvent venting. 1.0 minutes splitless time at beginning of $\mathrm{GC}$ run

- Temperature program: $-80^{\circ} \mathrm{C}$ initial temperature (held 0.10 minutes), increased $12^{\circ} \mathrm{C} /$ second to final temperature of $320^{\circ} \mathrm{C}$ (held 4.0 minutes)

All chromatographic peak areas were manually integrated for quantification using Xcalibur ${ }^{\circledR}$ software, and spectra of individual compounds were compared to the NIST/EPA/NIH Mass Spectral Library.

A number of TDS and GC inlet operational parameters can be adjusted to improve desorption efficiency and chromatography. Tests of standards recovered via SBSE and also directly placed onto desorption tube surfaces were performed in order to reveal the optimal run conditions for analyzing trace-level compounds in melted ice. A desorption flow rate of $50 \mathrm{ml} / \mathrm{min}(\mathrm{He})$ was selected to ensure complete desorption (pers. comm. E. Pfannkoch; full desorption may not be achieved at rates $<40 \mathrm{ml} / \mathrm{min}$ ), although other flow rates were also tested. Increasing the flow rate to as high as $75 \mathrm{ml} / \mathrm{min}$ did not improve response, and this elevated rate was not used due to concerns about discriminating against relatively volatile compounds. Increasing the transfer line temperature to $350^{\circ}$ was likewise not found to increase instrumental response. A wide range of final desorption temperatures and CIS3 inlet cryo-trapping initial temperatures were tested before choosing $300^{\circ}$ and $-80^{\circ} \mathrm{C}$, respectively, in order to optimize the response for anticipated compounds such as fatty acids and PAHs. Optimal temperatures may vary slightly depending on the analytes of interest. The TDS was operated in splitless mode to promote complete transfer of desorbed compounds to the CIS3 inlet, 
which was operated in solvent venting mode. It is not desirable to operate the CIS3 inlet entirely in splitless mode, because this will severely restrict desorption flow. The CIS3 inlet was splitless for one minute during rapid temperature ramping to promote complete transfer of analytes to the GC column. It is possible to increase this splitless time and thus analyte response, although doing so is undesirable because greater amounts of stir bar bleed would impact the chromatograms.

Modern ice core samples were run as at least three different volumes; 10, 20, and

$30 \mathrm{ml}$. For some samples, duplicates were prepared and analyzed, as well. Pre-industrial ice samples were run only once due to small volumes of available sample material. Standards of $n$-alkanes $\left(\mathrm{C}_{14}-\mathrm{C}_{19}, \mathrm{C}_{22}\right.$, and $\left.\mathrm{C}_{24}\right)$, fatty acids $\left(\mathrm{C}_{16}-\mathrm{C}_{24}\right.$ even chain lengths, $\mathrm{C}_{28}$, and $\mathrm{C}_{30}$ ), and PAHs (2-6 rings) were prepared in solutions of Milli-Q $\mathrm{H}_{2} \mathrm{O}, 25 \%$ methanol, and sufficient $\mathrm{HCl}$ to bring $\mathrm{pH}$ to 3-4, in order to mimic sample conditions (see Appendix B). The standards were then processed and analyzed in the same manner as the ice samples. The $n$-alkanes, fatty acids, and PAHs in the samples were quantified by comparison with these external standards. All other compounds, which were identified using the mass spectral library search and spectra in literature, were quantified by comparison with the standards mentioned above. Because authentic standards were not created for these compounds and individual response factors were not determined, their concentrations are only estimates. Nevertheless, relative concentrations of these analytes within the same compound class are relevant between samples.

\section{Results and Discussion}

\section{Bulk Particulate Matter Characteristics}

Many of the samples contained visible dust particles, which were most apparent in the larger volume modern samples. In the post-industrial samples, the solid matter was often dark in color, especially so in Sajama ice. Dark flecks were readily visible without magnification in the Sajama modern ice while it was still frozen. Magnified transmitted light images of a fraction of the solid material in the modern Sajama sample are presented in Figure 3-2. A wide range of sizes and types of solid material are present in this 
Figure 3-2a

Image of Sajama Particulate Matter

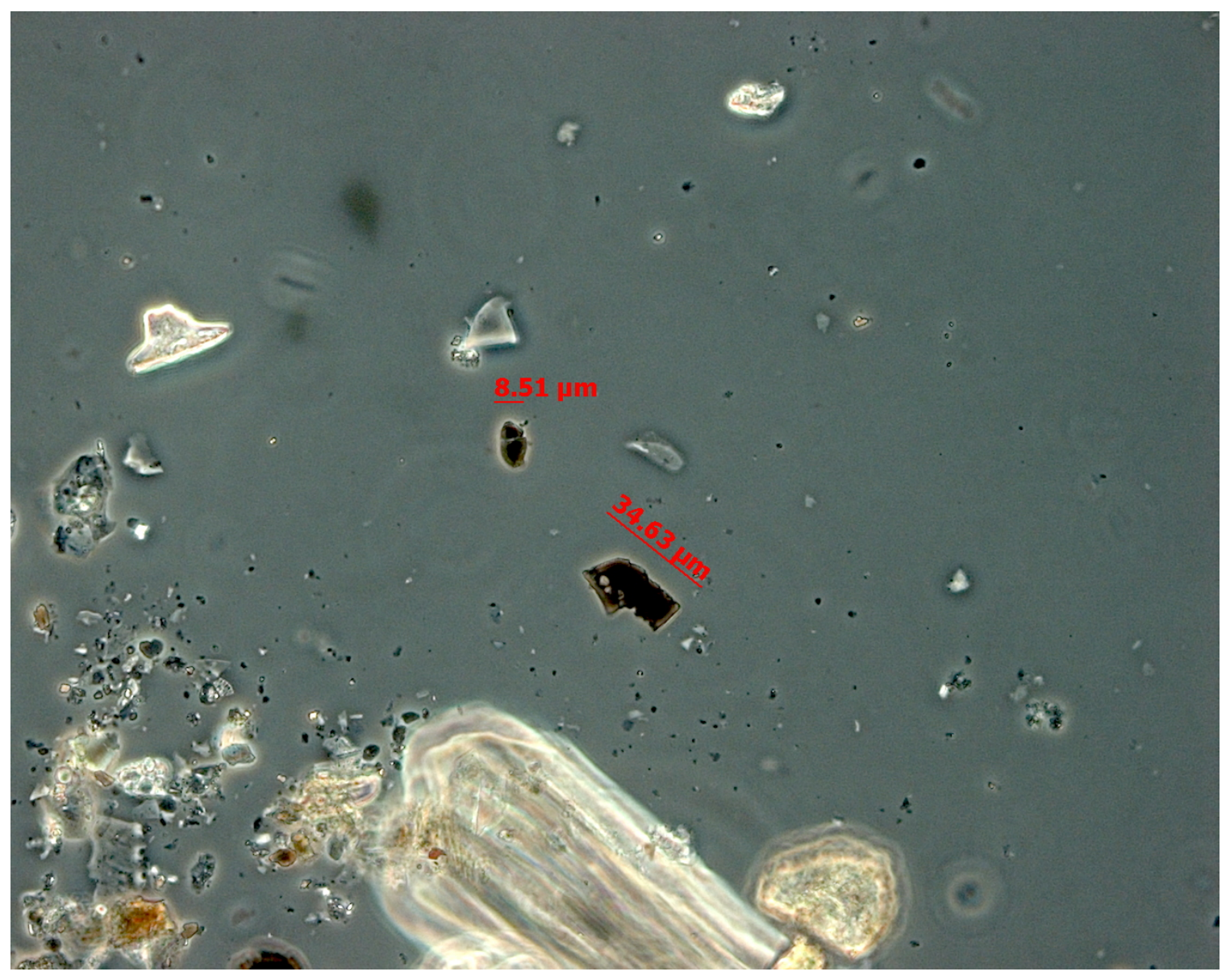

Transmitted light microscopy images. (a) Several types of particulate matter occur in the Sajama ice core sample. The light colored objects are mineral grains and the two dark colored particles in the center of the image are most likely inert organic matter. (b) The elongated, dark colored particle near the center of the image appears to be a vascular plant fragment. (c) The shading of this object implies that it is a mineral grain with bound organic matter. 
Figure 3-2b

Image of Sajama Particulate Matter

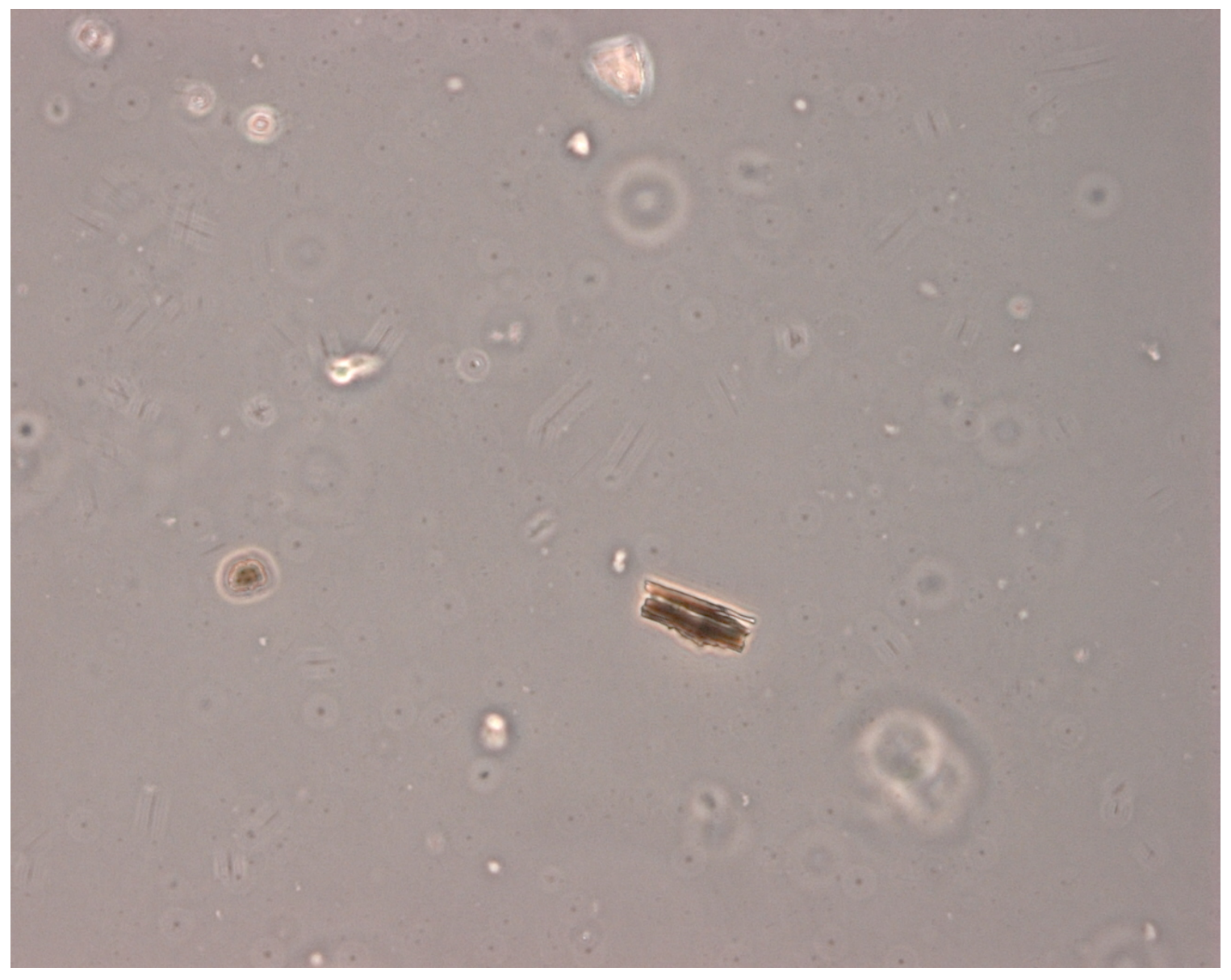


Figure 3-2c

Image of Sajama Particulate Matter

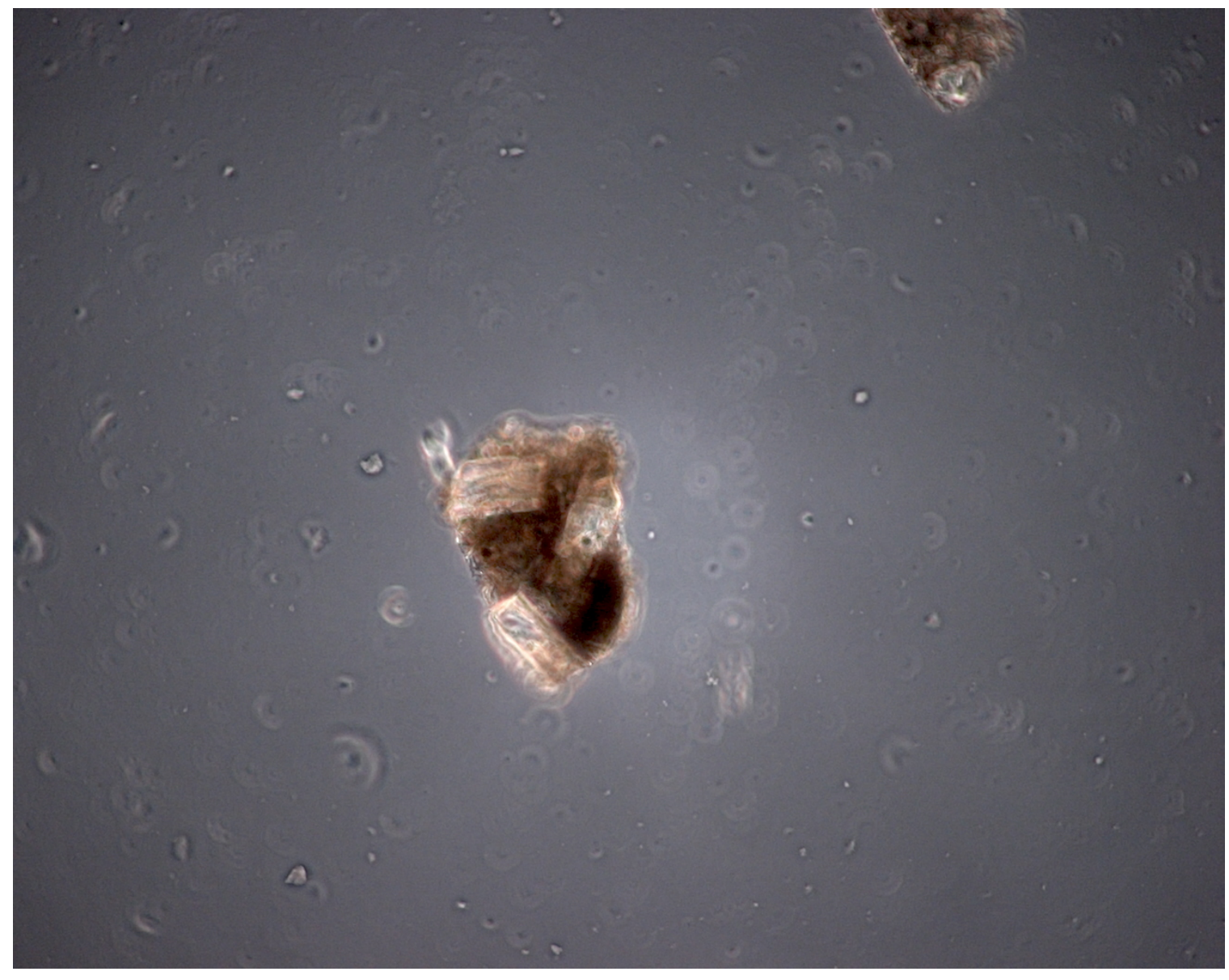


sample. Panel (a) depicts several large and many smaller mineral grains, as well as two distinct organic particles (sizes 8 and $35 \mu \mathrm{m}$ ), which, given their low light transmissivity, are likely to be macromolecular and recalcitrant. The $7 \mu \mathrm{m}$-long particle shown in panel (b) appears to be a woody plant fragment and the $10 \mu \mathrm{m}$-wide particle in the center of panel (c) appears to be a mineral grain with a darker coating of organic matter bound to it. The microscope investigation demonstrates that there are several types of particulate inorganic and organic material in the post-industrial Sajama ice core sample. They are most likely derived from a variety of sources such as fresh vegetation, anthropogenic activities, and proximal arid environments.

The presence of mineral grains in the ice samples presents a problem for successful extraction of organic matter via SBSE because some analytes could be tightly sorbed onto or associated with the solid material, reducing recovery by the Twister stir bar. To lessen this effect, the homogenized modern samples were decanted slowly into individual sample vials so as to minimize the amount of solid material entrained. Thus, organic matter occurring as inert, macro-molecular solids in the ice was not likely recovered or analyzed in this study via SBSE. Due to the small volumes of melted ice that were extracted, the pre-industrial ice samples analyzed were not expected to contain large amounts of mineral matter, nor was much observed.

A radiocarbon analysis was performed on the organic fraction of the particulate matter recovered by filtration from each modern ice sample in order to determine its age, which can be used to infer whether it consists of fresh or petrogenic material. Mineral and organic particulate material was collected from the five post-industrial melted ice core samples onto glass fiber filters, which were then combusted and the $\mathrm{CO}_{2}$ gas collected for analysis. The ice core particulates in each sample, which were filtered from approximately $300 \mathrm{ml}$ of melted ice, were visible and dark on the filters. The table below lists the amount of carbon evolved from each particulate sample and the results of the isotopic investigations: 


\begin{tabular}{cccccc}
\hline $\begin{array}{c}\text { Sample } \\
\text { (post-industrial) }\end{array}$ & $\begin{array}{c}\boldsymbol{\mu g} \text { Carbon } \\
\text { (in } \mathbf{3 0 0} \mathbf{~ m l} \\
\text { melted ice) }\end{array}$ & $\begin{array}{c}\text { Age } \\
(\mathbf{y r} \mathbf{B P})\end{array}$ & $\begin{array}{c}\text { Age Error } \\
(\mathbf{\pm} \text { yr BP) }\end{array}$ & $\begin{array}{c}\text { Fraction } \\
\text { Modern }\end{array}$ & $\begin{array}{c}\mathbf{8}^{\mathbf{1 3}} \mathbf{C} \\
(\boldsymbol{\%})\end{array}$ \\
\hline Huascarán & 32.0 & 2,200 & 240 & 0.76 & -20.8 \\
Sajama & 27.2 & 7,140 & 210 & 0.41 & \\
Kilimanjaro & 24.9 & 880 & 150 & 0.90 & \\
Dasuopu & 2.0 & & & & -24.8 \\
Puruogangri & 15.5 & & & & \\
\hline
\end{tabular}

An error during sample preparation likely resulted in the low $\mathrm{CO}_{2}$ recovery observed for the Dasuopu sample. Because about $25 \mu \mathrm{g}$ of carbon is required for radiocarbon determination by accelerator mass spectrometry (AMS), only the Huascarán, Sajama, and Kilimanjaro samples were analyzed for ${ }^{14} \mathrm{C}$. Sample abundances also permitted $\delta^{13} \mathrm{C}$ determination for the Huascarán and Puruogangri samples. All radiocarbon and carbon isotopic measurements described above were performed at the NOSAMS facility at the Woods Hole Oceanographic Institution.

The results of the radiocarbon investigation clearly demonstrate that a portion of the organic matter delivered to these cores in association with particulate matter consists of aged material, although whether this older fraction resulted from fossil fuel burning or weathering of soils and sediments is uncertain. The measured $\delta^{13} \mathrm{C}$ values are consistent with a wide range of sources, including vascular plant material, and are thus not deterministic in terms of source apportionment. The South American samples appear to contain a larger fraction of aged organic matter than the Kilimanjaro sample, perhaps because Mt. Kilimanjaro receives greater total inputs of fresh organic matter or because it is not situated in an area that receives significant inputs from anthropogenic activity. The Andean samples both contain substantial amounts of aged carbon, but Sajama contains a much greater fraction than Huascarán. Both cores are down-wind of the Amazon Basin, which is impacted by anthropogenic activity and thus represents a possible source of petrogenic dead carbon. However, the more arid conditions characteristic of the Sajama setting are expected to promote weathering of dessicated soils and sediments that may represent a source of pre-aged organic matter to the ice field. The substantial dust supply to the present Sajama site may thus represent an efficient delivery mechanism of natural 
aged carbon. The radiocarbon data are consistent with an interpretation of the visible black particulate matter observed in the modern Sajama ice as combusted fossil organic matter.

In summary, the radiocarbon data suggest that the composition of the particulate organic matter delivered to the post-industrial sections of ice cores is highly variable between sites, even those within the same mountain range. Thus, interpretations of biomarker information from this time period should be made with caution. Furthermore, although pre-industrial sections of cores are not expected to contain inputs associated with fossil fuel burning, the vegetation signal they contain may be biased by inputs from weathered soils and sediments. The results from the radiocarbon analyses are only pertinent to the filterable particulate material, which is generally not recoverable via SBSE and thus cannot be directly compared to the results of the present investigation. Currently, the distribution of organic matter in ice between particulate (both purely organic and mineral associated), colloidal, and dissolved phases is poorly understood. Much of the organic matter is expected to have been deposited in particulate or colloidal form, especially compounds that are associated with biomass burning and smoke, but may have subsequently dissolved. A portion of the suspended particulate and colloidal organic matter likely adsorbs to the stir bar, although the extent of this process is also uncertain. The radiocarbon results underscore the benefits of the biomarker approach, which aims to isolate compounds with specific sources for use as interpretive tools. However, detailed investigation of the biomarker content of particulate versus dissolved organic matter in these cores will be necessary before down-core records can be robustly interpreted.

\section{Blank-Level Contamination}

A number of the compounds investigated in this study were also detected in the blanks (concentrations are reported in Table 3-1). All blanks were created from Milli-Q $\mathrm{H}_{2} \mathrm{O}$ and were subjected to the same laboratory procedures as the samples (i.e. methanol and $\mathrm{HCl}$ addition, followed by SBSE). Biomarker concentrations from two different 
Table 3-1

Ice Core Biomarker Concentrations (pg/ml)

\begin{tabular}{|c|c|c|c|c|c|c|}
\hline I ce Core Sample & Volume (mI) & $C_{21}$ n-alkane & $C_{22} n$-alkane & $C_{23} n$-alkane & $C_{24} n$-alkane & $C_{25}$ n-alkane \\
\hline Sajama Modern & 10 & 263.1 & 858.7 & $2,730.5$ & $4,739.1$ & $5,212.6$ \\
\hline Sajama Modern ${ }^{1}$ & 10 & 171.6 & 675.2 & $2,202.0$ & $3,371.8$ & $3,476.5$ \\
\hline Sajama Modern & 20 & 87.3 & 298.2 & $1,166.4$ & $2,337.7$ & $2,515.4$ \\
\hline Sajama Modern & 30 & 143.8 & 333.0 & $1,295.1$ & $2,820.1$ & $3,075.1$ \\
\hline Sajama Modern ${ }^{2}$ & 40 & 94.0 & 279.5 & 834.3 & $1,812.6$ & $2,157.9$ \\
\hline Huascarán Modern & 10 & ND & 126.1 & 819.0 & $2,166.1$ & $2,807.0$ \\
\hline Huascarán Modern & 20 & ND & 85.7 & 648.6 & $1,353.6$ & $1,831.1$ \\
\hline Huascarán Modern & 30 & ND & 90.7 & 585.5 & $1,303.0$ & $1,744.1$ \\
\hline Puruogangri Modern & 10 & 25.1 & 60.4 & 153.0 & 253.6 & 283.9 \\
\hline Puruogangri Modern & 20 & 9.8 & 25.1 & 75.2 & 119.8 & 132.4 \\
\hline Puruogangri Modern & 30 & 15.5 & 33.8 & 128.3 & 311.8 & 439.5 \\
\hline Dasuopu Modern & 10 & 26.1 & 48.8 & 121.2 & 206.3 & 275.7 \\
\hline Dasuopu Modern & 20 & 16.4 & 33.1 & 92.9 & 176.3 & 241.5 \\
\hline Dasuopu Modern & 30 & 23.2 & 32.4 & 91.6 & 211.1 & 291.1 \\
\hline Kilimanjaro Modern & 10 & 76.7 & 106.4 & 169.4 & 354.0 & 260.3 \\
\hline Kilimanjaro Modern & 20 & 60.1 & 99.9 & 206.0 & 551.5 & 363.2 \\
\hline Kilimanjaro Modern ${ }^{1}$ & 20 & 105.7 & 257.1 & 487.2 & $1,168.7$ & 910.3 \\
\hline Kilimanjaro Modern & 30 & 64.5 & 177.9 & 335.9 & 902.1 & 680.0 \\
\hline Sajama 2 ka & 16.3 & 10.0 & 13.7 & 16.0 & 21.9 & 35.0 \\
\hline Sajama 5 ka & 15.5 & 24.0 & 54.1 & 152.3 & 348.7 & 613.6 \\
\hline Sajama Last Glacial & 15.5 & ND & 8.2 & 27.6 & 6.9 & 10.1 \\
\hline Puruogangri 2 ka & 12.8 & 3.1 & 4.5 & 14.0 & 19.8 & 21.6 \\
\hline Puruogangri 6 ka & 13 & ND & 52.9 & 186.2 & 622.1 & 920.5 \\
\hline $\mathrm{H}_{2} \mathrm{O}$ Blank $^{3}$ & 11.3 & 649.4 & $3,252.9$ & $19,656.2$ & $39,913.8$ & $60,161.3$ \\
\hline $\mathrm{H}_{2} \mathrm{O}$ blank $^{4}$ & 10 & 88.9 & 176.6 & 530.2 & 600.7 & 531.5 \\
\hline $\begin{array}{l}\text { Notes: } \\
\text { With the exceptions of } \\
\mathrm{ND}=\text { Not Detected } \\
{ }^{1} \text { Duplicate } \\
{ }^{2} \mathrm{Two} 20 \mathrm{ml} \text { samples an } \\
{ }^{3} \mathrm{Milli}-\mathrm{Q} \mathrm{H}_{2} \mathrm{O} \text { (ice) blank } \\
{ }^{4} \mathrm{Milli}-\mathrm{Q} \mathrm{H}_{2} \mathrm{O} \text { (aq) labora }\end{array}$ & $\begin{array}{l}\text {-alkane CPI and } \\
\text { lyzed together } \\
\text { shipped with sam } \\
\text { cory blank }\end{array}$ & $\mathrm{C}_{\max }$, and Fluorant & thene/Pyrene, all & reported biomarke & er values are in $p g$ & /ml. \\
\hline
\end{tabular}

Biomarker concentrations $(\mathrm{pg} / \mathrm{ml})$ for each sample and blank. Also listed are the $n$-alkane CPI and fluoranthene/pyrene ratio. 
Table 3-1 (cont)

Ice Core Biomarker Concentrations (pg/ml)

\begin{tabular}{|c|c|c|c|c|c|c|}
\hline I ce Core Sample & Volume (mI) & $\mathrm{C}_{26} \mathrm{n}$-alkane & $\mathrm{C}_{27}$ n-alkane & $\mathrm{C}_{28} \mathrm{n}$-alkane & $\mathrm{C}_{29}$ n-alkane & $C_{30} n$-alkane \\
\hline Sajama Modern & 10 & $4,097.0$ & $3,461.5$ & $2,865.5$ & $1,792.2$ & 801.9 \\
\hline Sajama Modern ${ }^{1}$ & 10 & $3,035.2$ & $2,744.0$ & $2,033.3$ & $1,354.8$ & 648.1 \\
\hline Sajama Modern & 20 & $2,334.8$ & $2,151.9$ & $1,816.9$ & $1,188.8$ & 692.1 \\
\hline Sajama Modern & 30 & $2,794.3$ & $2,434.8$ & $2,124.4$ & $1,329.6$ & 754.3 \\
\hline Sajama Modern² & 40 & $2,107.2$ & $1,823.3$ & $1,670.5$ & $1,012.7$ & 608.8 \\
\hline Huascarán Modern & 10 & $2,953.9$ & $2,913.0$ & $2,230.8$ & $1,407.2$ & 643.4 \\
\hline Huascarán Modern & 20 & $1,715.2$ & $1,660.0$ & $1,271.2$ & 882.4 & 406.2 \\
\hline Huascarán Modern & 30 & $1,704.5$ & $1,628.9$ & $1,220.2$ & 931.8 & 497.7 \\
\hline Puruogangri Modern & 10 & 225.5 & 222.6 & 222.7 & 147.5 & 95.4 \\
\hline Puruogangri Modern & 20 & 107.4 & 96.0 & 114.7 & 64.2 & 40.2 \\
\hline Puruogangri Modern & 30 & 407.0 & 363.2 & 534.9 & 174.9 & 99.5 \\
\hline Dasuopu Modern & 10 & 244.4 & 253.2 & 194.9 & 199.9 & 127.8 \\
\hline Dasuopu Modern & 20 & 209.7 & 207.4 & 165.6 & 123.3 & 87.6 \\
\hline Dasuopu Modern & 30 & 249.6 & 239.3 & 194.3 & 139.5 & 77.4 \\
\hline Kilimanjaro Modern & 10 & 194.8 & 175.0 & 192.5 & 140.1 & 95.4 \\
\hline Kilimanjaro Modern & 20 & 281.4 & 233.0 & 231.0 & 131.0 & 106.4 \\
\hline Kilimanjaro Modern ${ }^{1}$ & 20 & 745.7 & 617.0 & 678.7 & 269.9 & 176.2 \\
\hline Kilimanjaro Modern & 30 & 533.2 & 419.7 & 558.3 & 194.1 & 149.2 \\
\hline Sajama 2 ka & 16.3 & 35.7 & 44.0 & 31.0 & 32.5 & 12.3 \\
\hline Sajama 5 ka & 15.5 & 670.0 & 687.3 & 511.7 & 404.9 & 221.5 \\
\hline Sajama Last Glacial & 15.5 & 5.6 & 14.6 & 9.6 & 8.1 & 4.5 \\
\hline Puruogangri 2 ka & 12.8 & 17.1 & 22.8 & 22.1 & 20.6 & 10.5 \\
\hline Puruogangri 6 ka & 13 & 969.5 & $1,148.4$ & 743.5 & 508.1 & 316.8 \\
\hline $\mathrm{H}_{2} \mathrm{O}$ Blank $^{3}$ & 11.3 & $64,458.0$ & $70,874.7$ & $63,645.8$ & $55,757.5$ & $38,932.7$ \\
\hline $\mathrm{H}_{2} \mathrm{O}$ blank $^{4}$ & 10 & 370.3 & 352.5 & 214.0 & 161.8 & 107.9 \\
\hline
\end{tabular}


Table 3-1 (cont)

Ice Core Biomarker Concentrations (pg/ml)

\begin{tabular}{|c|c|c|c|c|c|c|}
\hline I ce Core Sample & Volume (mI) & $C_{31}$ n-alkane & $C_{32} n$-alkane & $C_{33}$ n-alkane & $\mathrm{C}_{34} \mathrm{n}$-alkane & Total $\mathbf{n}$-alkanes \\
\hline Sajama Modern & 10 & 480.0 & 308.8 & 182.0 & 100.7 & $27,893.4$ \\
\hline Sajama Modern ${ }^{1}$ & 10 & 413.8 & 291.8 & 167.2 & 87.5 & $20,672.7$ \\
\hline Sajama Modern & 20 & 402.4 & 192.2 & 134.4 & 74.8 & $15,393.2$ \\
\hline Sajama Modern & 30 & 463.5 & 211.0 & 114.6 & 75.9 & $17,969.4$ \\
\hline Sajama Modern ${ }^{2}$ & 40 & 350.0 & 163.9 & 83.7 & 60.7 & $13,059.2$ \\
\hline Huascarán Modern & 10 & 420.6 & 330.3 & 172.4 & 94.4 & $17,084.4$ \\
\hline Huascarán Modern & 20 & 302.0 & 169.8 & 129.2 & 75.4 & $10,530.5$ \\
\hline Huascarán Modern & 30 & 342.1 & 193.0 & 117.5 & 73.0 & $10,432.0$ \\
\hline Puruogangri Modern & 10 & 61.0 & 38.1 & 20.0 & ND & $1,808.8$ \\
\hline Puruogangri Modern & 20 & 26.5 & 16.9 & 7.2 & ND & 835.5 \\
\hline Puruogangri Modern & 30 & 83.8 & 69.5 & 31.8 & 17.0 & $2,710.4$ \\
\hline Dasuopu Modern & 10 & 117.3 & 53.7 & 31.0 & ND & $1,900.4$ \\
\hline Dasuopu Modern & 20 & 77.7 & 34.3 & 20.3 & 7.0 & $1,493.1$ \\
\hline Dasuopu Modern & 30 & 79.2 & 35.9 & 23.9 & 9.7 & $1,698.2$ \\
\hline Kilimanjaro Modern & 10 & 61.0 & 40.0 & 15.2 & ND & $1,880.8$ \\
\hline Kilimanjaro Modern & 20 & 86.1 & 47.2 & 23.2 & 13.2 & $2,433.4$ \\
\hline Kilimanjaro Modern ${ }^{1}$ & 20 & 134.4 & 126.8 & 59.8 & 36.5 & $5,774.0$ \\
\hline Kilimanjaro Modern & 30 & 91.5 & 53.5 & 27.1 & 14.2 & $4,201.3$ \\
\hline Sajama 2 ka & 16.3 & 14.4 & ND & ND & ND & 266.4 \\
\hline Sajama 5 ka & 15.5 & 196.7 & 109.0 & 66.0 & 24.8 & $4,084.4$ \\
\hline Sajama Last Glacial & 15.5 & 67.1 & 10.6 & ND & ND & 172.9 \\
\hline Puruogangri $2 \mathrm{ka}$ & 12.8 & 14.3 & 6.1 & ND & ND & 176.6 \\
\hline Puruogangri 6 ka & 13 & 242.0 & 143.6 & 71.5 & 28.3 & $5,953.5$ \\
\hline $\mathrm{H}_{2} \mathrm{O}$ Blank $^{3}$ & 11.3 & $23,967.5$ & $11,612.4$ & $4,781.7$ & $1,260.3$ & $458,924.1$ \\
\hline $\mathrm{H}_{2} \mathrm{O}$ blank $^{4}$ & 10 & 74.3 & 96.8 & 23.8 & ND & $3,329.3$ \\
\hline
\end{tabular}


Table 3-1 (cont)

Ice Core Biomarker Concentrations ( $\mathrm{pg} / \mathrm{ml})$

\begin{tabular}{|c|c|c|c|c|c|c|}
\hline I ce Core Sample & Volume ( $\mathrm{ml})$ & n -alkane CPI & n-alkane $C_{\max }$ & $\mathrm{C}_{12}$ Fatty Acid & $\mathrm{C}_{13}$ Fatty Acid & $\mathrm{C}_{14}$ Fatty Acid \\
\hline Sajama Modern & 10 & 1.03 & 25 & 526.9 & 95.2 & 686.5 \\
\hline Sajama Modern ${ }^{1}$ & 10 & 1.04 & 25 & 655.9 & 120.1 & 883.6 \\
\hline Sajama Modern & 20 & 0.99 & 25 & 338.4 & 81.0 & 588.9 \\
\hline Sajama Modern & 30 & 0.97 & 25 & 394.2 & 70.0 & 697.9 \\
\hline Sajama Modern ${ }^{2}$ & 40 & 0.95 & 25 & 385.4 & 50.3 & 642.1 \\
\hline Huascarán Modern & 10 & 1.00 & 26 & ND & ND & ND \\
\hline Huascarán Modern & 20 & 1.07 & 25 & ND & ND & ND \\
\hline Huascarán Modern & 30 & 1.05 & 25 & ND & ND & ND \\
\hline Puruogangri Modern & 10 & 1.02 & 25 & 611.8 & ND & ND \\
\hline Puruogangri Modern & 20 & 0.97 & 25 & 412.9 & ND & 218.0 \\
\hline Puruogangri Modern & 30 & 0.84 & 28 & $1,137.4$ & ND & 635.7 \\
\hline Dasuopu Modern & 10 & 1.17 & 25 & ND & ND & ND \\
\hline Dasuopu Modern & 20 & 1.09 & 25 & ND & ND & ND \\
\hline Dasuopu Modern & 30 & 1.10 & 25 & 223.2 & ND & 188.0 \\
\hline Kilimanjaro Modern & 10 & 0.91 & 24 & ND & ND & ND \\
\hline Kilimanjaro Modern & 20 & 0.83 & 24 & ND & ND & ND \\
\hline Kilimanjaro Modern ${ }^{1}$ & 20 & 0.81 & 24 & ND & ND & ND \\
\hline Kilimanjaro Modern & 30 & 0.76 & 24 & 172.0 & ND & 360.0 \\
\hline Sajama 2 ka & 16.3 & 1.33 & 27 & 147.5 & ND & ND \\
\hline Sajama 5 ka & 15.5 & 1.11 & 27 & 306.4 & ND & 159.7 \\
\hline Sajama Last Glacial & 15.5 & 2.81 & 31 & ND & ND & ND \\
\hline Puruogangri 2 ka & 12.8 & 1.20 & 27 & ND & ND & ND \\
\hline Puruogangri 6 ka & 13 & 1.07 & 27 & ND & ND & ND \\
\hline $\mathrm{H}_{2} \mathrm{O}$ Blank $^{3}$ & 11.3 & 1.06 & 27 & $6,704.7$ & ND & 173.6 \\
\hline $\mathrm{H}_{2} \mathrm{O}$ blank $^{4}$ & 10 & 1.13 & 24 & 181.1 & ND & 196.1 \\
\hline
\end{tabular}


Table 3-1 (cont)

Ice Core Biomarker Concentrations ( $\mathrm{pg} / \mathrm{ml})$

\begin{tabular}{|c|c|c|c|c|c|c|}
\hline I ce Core Sample & Volume (mI) & $\mathrm{C}_{15}$ Fatty Acid & $\mathrm{C}_{16}$ Fatty Acid & $\mathrm{C}_{18}$ Fatty Acid & $\mathrm{C}_{18: 1}$ Fatty Acid & $\mathrm{C}_{14}$ Alkyl Amide \\
\hline Sajama Modern & 10 & 192.3 & 800.9 & ND & $2,630.6$ & ND \\
\hline Sajama Modern ${ }^{1}$ & 10 & 244.6 & $8,529.4$ & $7,817.5$ & $1,823.0$ & ND \\
\hline Sajama Modern & 20 & 150.4 & $1,796.5$ & $3,058.9$ & $1,243.8$ & ND \\
\hline Sajama Modern & 30 & 158.9 & 353.6 & $1,381.1$ & $1,196.9$ & ND \\
\hline Sajama Modern² & 40 & 122.9 & 244.5 & 456.4 & $1,653.7$ & ND \\
\hline Huascarán Modern & 10 & ND & ND & ND & ND & ND \\
\hline Huascarán Modern & 20 & ND & ND & ND & ND & ND \\
\hline Huascarán Modern & 30 & ND & ND & ND & ND & ND \\
\hline Puruogangri Modern & 10 & ND & ND & ND & ND & 16.9 \\
\hline Puruogangri Modern & 20 & ND & 159.1 & ND & ND & 10.9 \\
\hline Puruogangri Modern & 30 & ND & $1,111.4$ & ND & ND & 44.7 \\
\hline Dasuopu Modern & 10 & ND & ND & ND & ND & 10.6 \\
\hline Dasuopu Modern & 20 & ND & ND & ND & ND & 7.8 \\
\hline Dasuopu Modern & 30 & ND & 267.4 & ND & ND & 9.7 \\
\hline Kilimanjaro Modern & 10 & ND & ND & ND & ND & 497.4 \\
\hline Kilimanjaro Modern & 20 & ND & ND & ND & ND & 399.8 \\
\hline Kilimanjaro Modern ${ }^{1}$ & 20 & ND & ND & ND & ND & $1,273.7$ \\
\hline Kilimanjaro Modern & 30 & ND & ND & ND & ND & 926.4 \\
\hline Sajama 2 ka & 16.3 & ND & 304.5 & ND & ND & ND \\
\hline Sajama 5 ka & 15.5 & ND & 442.8 & ND & ND & ND \\
\hline Sajama Last Glacial & 15.5 & ND & ND & ND & ND & ND \\
\hline Puruogangri 2 ka & 12.8 & ND & ND & ND & ND & ND \\
\hline Puruogangri 6 ka & 13 & ND & ND & ND & ND & 485.7 \\
\hline $\mathrm{H}_{2} \mathrm{O}$ Blank $^{3}$ & 11.3 & ND & ND & ND & ND & 48.7 \\
\hline $\mathrm{H}_{2} \mathrm{O}$ blank $^{4}$ & 10 & 47.8 & 536.7 & 269.0 & ND & ND \\
\hline
\end{tabular}


Table 3-1 (cont)

Ice Core Biomarker Concentrations ( $\mathrm{pg} / \mathrm{ml})$

\begin{tabular}{|c|c|c|c|c|c|}
\hline I ce Core Sample & Volume (mI) & $\mathrm{C}_{16: 1}$ Alkyl Amide & $\mathrm{C}_{16}$ Alkyl Amide & $\mathrm{C}_{18: 1}$ Alkyl Amide & $\mathrm{C}_{18}$ Alkyl Amide \\
\hline Sajama Modern & 10 & 62.9 & 338.7 & $2,967.4$ & 160.1 \\
\hline Sajama Modern ${ }^{1}$ & 10 & 39.6 & 216.1 & $1,981.5$ & 99.4 \\
\hline Sajama Modern & 20 & 28.9 & 276.2 & $2,234.6$ & 106.9 \\
\hline Sajama Modern & 30 & 26.9 & 201.9 & $1,828.8$ & 140.4 \\
\hline Sajama Modern² & 40 & 14.1 & 118.2 & 949.7 & 76.1 \\
\hline Huascarán Modern & 10 & ND & ND & ND & ND \\
\hline Huascarán Modern & 20 & 14.2 & 101.4 & 532.4 & 71.7 \\
\hline Huascarán Modern & 30 & 16.1 & 124.5 & 584.4 & 62.0 \\
\hline Puruogangri Modern & 10 & 11.7 & 64.2 & 449.8 & 27.0 \\
\hline Puruogangri Modern & 20 & 8.9 & 40.3 & 264.7 & 15.8 \\
\hline Puruogangri Modern & 30 & 25.5 & 149.3 & $1,026.8$ & 70.2 \\
\hline Dasuopu Modern & 10 & 3.0 & 45.9 & 148.6 & 15.6 \\
\hline Dasuopu Modern & 20 & 3.4 & 32.5 & 122.2 & 16.1 \\
\hline Dasuopu Modern & 30 & 8.4 & 67.3 & 339.9 & 25.1 \\
\hline Kilimanjaro Modern & 10 & 519.6 & $1,146.8$ & $5,361.7$ & 801.8 \\
\hline Kilimanjaro Modern & 20 & 398.1 & 963.0 & $5,270.8$ & 701.7 \\
\hline Kilimanjaro Modern ${ }^{1}$ & 20 & 967.4 & $2,392.9$ & $16,430.8$ & $1,680.6$ \\
\hline Kilimanjaro Modern & 30 & 813.5 & $2,060.9$ & $12,223.9$ & $1,575.6$ \\
\hline Sajama 2 ka & 16.3 & ND & ND & ND & ND \\
\hline Sajama 5 ka & 15.5 & ND & ND & ND & ND \\
\hline Sajama Last Glacial & 15.5 & ND & ND & ND & ND \\
\hline Puruogangri 2 ka & 12.8 & ND & ND & 19.9 & ND \\
\hline Puruogangri 6 ka & 13 & 870.0 & 637.6 & $7,063.2$ & 352.5 \\
\hline $\mathrm{H}_{2} \mathrm{O}$ Blank $^{3}$ & 11.3 & ND & 196.1 & 34.9 & ND \\
\hline $\mathrm{H}_{2} \mathrm{O}$ blank $^{4}$ & 10 & 13.5 & ND & 139.4 & ND \\
\hline
\end{tabular}


Table 3-1 (cont)

Ice Core Biomarker Concentrations (pg/ml)

\begin{tabular}{|c|c|c|c|c|c|}
\hline I ce Core Sample & Volume (mI) & $\mathrm{C}_{20: 1}$ Alkyl Amide & $C_{22: 1}$ Alkyl Amide & $C_{16: 1}$ Alkyl Nitrile & $\mathrm{C}_{16}$ Alkyl Nitrile \\
\hline Sajama Modern & 10 & 42.4 & $1,827.4$ & 6.2 & 14.2 \\
\hline Sajama Modern ${ }^{1}$ & 10 & 30.7 & $1,253.7$ & 8.3 & 9.0 \\
\hline Sajama Modern & 20 & 32.9 & $1,684.7$ & 3.3 & 10.1 \\
\hline Sajama Modern & 30 & 25.5 & $1,360.0$ & 4.7 & 10.2 \\
\hline Sajama Modern ${ }^{2}$ & 40 & 13.7 & $1,168.6$ & 3.9 & ND \\
\hline Huascarán Modern & 10 & ND & ND & ND & 4.4 \\
\hline Huascarán Modern & 20 & 5.0 & 305.4 & 2.2 & 7.1 \\
\hline Huascarán Modern & 30 & 5.6 & 390.5 & 3.7 & 7.3 \\
\hline Puruogangri Modern & 10 & 46.9 & 816.9 & 3.3 & ND \\
\hline Puruogangri Modern & 20 & 24.7 & 414.0 & 2.7 & 10.2 \\
\hline Puruogangri Modern & 30 & 55.7 & $2,337.9$ & 2.8 & 9.5 \\
\hline Dasuopu Modern & 10 & 3.8 & 199.1 & 3.5 & 4.7 \\
\hline Dasuopu Modern & 20 & 5.6 & 247.6 & 1.7 & 5.5 \\
\hline Dasuopu Modern & 30 & 8.8 & 474.5 & 2.6 & 15.7 \\
\hline Kilimanjaro Modern & 10 & 39.4 & 638.8 & 25.3 & 35.4 \\
\hline Kilimanjaro Modern & 20 & 33.7 & 662.9 & 21.5 & 33.8 \\
\hline Kilimanjaro Modern ${ }^{1}$ & 20 & 83.4 & $2,109.4$ & 75.6 & 79.4 \\
\hline Kilimanjaro Modern & 30 & 77.3 & $1,606.9$ & 41.8 & 63.6 \\
\hline Sajama 2 ka & 16.3 & ND & ND & ND & ND \\
\hline Sajama 5 ka & 15.5 & ND & ND & ND & 8.4 \\
\hline Sajama Last Glacial & 15.5 & ND & ND & ND & ND \\
\hline Puruogangri 2 ka & 12.8 & ND & ND & ND & ND \\
\hline Puruogangri $6 \mathrm{ka}$ & 13 & 31.0 & 293.8 & 62.6 & 32.4 \\
\hline $\mathrm{H}_{2} \mathrm{O}$ Blank $^{3}$ & 11.3 & ND & ND & ND & ND \\
\hline $\mathrm{H}_{2} \mathrm{O}$ blank $^{4}$ & 10 & ND & ND & ND & 18.2 \\
\hline
\end{tabular}


Table 3-1 (cont)

Ice Core Biomarker Concentrations (pg/ml)

\begin{tabular}{|c|c|c|c|c|}
\hline I ce Core Sample & Volume (mI) & $C_{18: 1}$ Alkyl Nitrile & $C_{22: 1}$ Alkyl Nitrile & N,N-dimethyloctanamide \\
\hline Sajama Modern & 10 & 113.6 & 38.5 & 233.7 \\
\hline Sajama Modern ${ }^{1}$ & 10 & 84.7 & 30.5 & 129.5 \\
\hline Sajama Modern & 20 & 71.0 & 30.6 & 132.7 \\
\hline Sajama Modern & 30 & 56.3 & 26.1 & 131.6 \\
\hline Sajama Modern² & 40 & 22.7 & 23.1 & 72.9 \\
\hline Huascarán Modern & 10 & ND & ND & ND \\
\hline Huascarán Modern & 20 & 35.7 & 41.4 & 2.8 \\
\hline Huascarán Modern & 30 & 30.4 & 34.4 & ND \\
\hline Puruogangri Modern & 10 & 55.1 & 85.0 & ND \\
\hline Puruogangri Modern & 20 & 31.5 & 52.3 & ND \\
\hline Puruogangri Modern & 30 & 50.0 & 86.7 & ND \\
\hline Dasuopu Modern & 10 & 19.7 & 35.1 & 35.3 \\
\hline Dasuopu Modern & 20 & 17.1 & 30.7 & 27.7 \\
\hline Dasuopu Modern & 30 & 27.4 & 37.5 & 41.7 \\
\hline Kilimanjaro Modern & 10 & 196.4 & 88.0 & 163.3 \\
\hline Kilimanjaro Modern & 20 & 174.9 & 67.0 & 155.4 \\
\hline Kilimanjaro Modern ${ }^{1}$ & 20 & 568.5 & 193.1 & 350.1 \\
\hline Kilimanjaro Modern & 30 & 361.0 & 90.0 & 358.8 \\
\hline Sajama 2 ka & 16.3 & ND & ND & ND \\
\hline Sajama 5 ka & 15.5 & ND & ND & ND \\
\hline Sajama Last Glacial & 15.5 & ND & ND & ND \\
\hline Puruogangri 2 ka & 12.8 & 9.9 & 8.6 & ND \\
\hline Puruogangri 6 ka & 13 & 261.7 & 73.7 & ND \\
\hline $\mathrm{H}_{2} \mathrm{O}$ Blank $^{3}$ & 11.3 & ND & ND & ND \\
\hline $\mathrm{H}_{2} \mathrm{O}$ blank $^{4}$ & 10 & 24.4 & ND & ND \\
\hline
\end{tabular}


Table 3-1 (cont)

Ice Core Biomarker Concentrations ( $\mathrm{pg} / \mathrm{ml})$

\begin{tabular}{|c|c|c|c|c|c|}
\hline I ce Core Sample & Volume ( $\mathrm{ml})$ & Fluoranthene & Pyrene & Fluoranthene/ Pyrene & Dehydroabietane \\
\hline Sajama Modern & 10 & 2.7 & 8.8 & 0.3 & 1.8 \\
\hline Sajama Modern ${ }^{1}$ & 10 & 3.3 & 11.0 & 0.3 & 5.4 \\
\hline Sajama Modern & 20 & 2.0 & 7.6 & 0.3 & 2.3 \\
\hline Sajama Modern & 30 & 1.8 & 8.2 & 0.2 & 3.0 \\
\hline Sajama Modern ${ }^{2}$ & 40 & 1.3 & 5.0 & 0.3 & 3.2 \\
\hline Huascarán Modern & 10 & ND & ND & ND & ND \\
\hline Huascarán Modern & 20 & 0.1 & 0.2 & 0.7 & ND \\
\hline Huascarán Modern & 30 & 0.2 & 0.2 & 1.1 & ND \\
\hline Puruogangri Modern & 10 & 0.4 & 0.5 & 0.8 & ND \\
\hline Puruogangri Modern & 20 & 0.2 & 0.3 & 0.6 & ND \\
\hline Puruogangri Modern & 30 & 0.3 & 0.6 & 0.6 & ND \\
\hline Dasuopu Modern & 10 & 1.4 & 1.5 & 0.9 & ND \\
\hline Dasuopu Modern & 20 & 1.7 & 1.8 & 1.0 & ND \\
\hline Dasuopu Modern & 30 & 2.2 & 2.3 & 1.0 & ND \\
\hline Kilimanjaro Modern & 10 & 2.0 & 7.7 & 0.3 & ND \\
\hline Kilimanjaro Modern & 20 & 1.7 & 6.1 & 0.3 & ND \\
\hline Kilimanjaro Modern ${ }^{1}$ & 20 & 2.2 & 8.5 & 0.3 & ND \\
\hline Kilimanjaro Modern & 30 & 2.3 & 8.6 & 0.3 & ND \\
\hline Sajama 2 ka & 16.3 & 0.2 & 0.3 & 0.9 & 1.5 \\
\hline Sajama 5 ka & 15.5 & 0.4 & 0.5 & 0.7 & 3.3 \\
\hline Sajama Last Glacial & 15.5 & ND & ND & ND & ND \\
\hline Puruogangri 2 ka & 12.8 & ND & ND & ND & ND \\
\hline Puruogangri 6 ka & 13 & 0.4 & 0.4 & 1.1 & ND \\
\hline $\mathrm{H}_{2} \mathrm{O}$ Blank $^{3}$ & 11.3 & 1.2 & 1.1 & 1.1 & ND \\
\hline $\mathrm{H}_{2} \mathrm{O}$ blank $^{4}$ & 10 & 0.4 & 1.0 & 0.4 & ND \\
\hline
\end{tabular}


Table 3-1 (cont)

Ice Core Biomarker Concentrations (pg/ml)

\begin{tabular}{|c|c|c|c|c|}
\hline I ce Core Sample & Volume (ml) & Tremetone & Sugiol & Dehydroabietic aldehyde \\
\hline Sajama Modern & 10 & 139.9 & ND & 0.9 \\
\hline Sajama Modern ${ }^{1}$ & 10 & 147.6 & 2.9 & 1.6 \\
\hline Sajama Modern & 20 & 95.0 & 1.8 & 1.3 \\
\hline Sajama Modern & 30 & 70.5 & 2.5 & 1.7 \\
\hline Sajama Modern² & 40 & 39.6 & 1.6 & 1.9 \\
\hline Huascarán Modern & 10 & ND & ND & ND \\
\hline Huascarán Modern & 20 & ND & ND & ND \\
\hline Huascarán Modern & 30 & 1.6 & ND & ND \\
\hline Puruogangri Modern & 10 & 9.6 & ND & ND \\
\hline Puruogangri Modern & 20 & 4.4 & ND & ND \\
\hline Puruogangri Modern & 30 & 5.7 & ND & ND \\
\hline Dasuopu Modern & 10 & ND & ND & ND \\
\hline Dasuopu Modern & 20 & 2.9 & ND & ND \\
\hline Dasuopu Modern & 30 & 2.0 & ND & ND \\
\hline Kilimanjaro Modern & 10 & 3.7 & ND & ND \\
\hline Kilimanjaro Modern & 20 & 2.2 & ND & ND \\
\hline Kilimanjaro Modern ${ }^{1}$ & 20 & 5.6 & ND & ND \\
\hline Kilimanjaro Modern & 30 & 2.8 & ND & ND \\
\hline Sajama 2 ka & 16.3 & 56.8 & 0.8 & 1.2 \\
\hline Sajama 5 ka & 15.5 & 102.2 & 3.2 & 3.5 \\
\hline Sajama Last Glacial & 15.5 & ND & ND & ND \\
\hline Puruogangri 2 ka & 12.8 & ND & ND & ND \\
\hline Puruogangri 6 ka & 13 & ND & ND & ND \\
\hline $\mathrm{H}_{2} \mathrm{O}$ Blank $^{3}$ & 11.3 & ND & ND & ND \\
\hline $\mathrm{H}_{2} \mathrm{O}$ blank $^{4}$ & 10 & ND & ND & ND \\
\hline
\end{tabular}


types of blanks are listed in Table 3-1. One was frozen in a sample jar and shipped with the ice samples in the cooler, after which it was sub-sampled as ice and analyzed along with the ice core samples. This blank should most accurately reflect contamination imparted to the samples during the entire sampling and analytical process. The other blank was never frozen, but was processed in the same manner as the samples were after they had melted, thus reflecting contamination strictly associated with the extraction methods. An important difference between the blanks and the samples is that the blanks were created from Milli-Q water, which the samples did not contain or ever come in contact with. Thus, the blanks may contain systematic contamination that is unique to laboratory water and is not present in melted ice. The water used to create them was decanted directly from a Milli-Q purification system and was not further distilled or solvent-extracted.

Blank contamination was most problematic for the $n$-alkanes, for which the total concentration $\left(\mathrm{C}_{21}-\mathrm{C}_{34}\right)$ in the frozen blank $(459 \mathrm{ng} / \mathrm{ml})$ was more than an order of magnitude greater than that of the sample with the next highest concentration $(28 \mathrm{ng} / \mathrm{ml}$; modern Sajama, $10 \mathrm{ml}$ ) and 62 times greater than the average value of all of the ice core samples. Given the poor solubility of $n$-alkanes in water, it is likely that the high blank values arose from entrainment of colloidal material, either on the stir bar surface or otherwise. Despite the trends that are observed in the $n$-alkane data from the modern ice core samples, the signal is well overridden by significant blank contamination for these compounds. It is not understood why the frozen blank contains such exceedingly high concentrations of $n$-alkanes, and although it casts doubt on all of the sample results for this compound class, it is not considered representative of typical levels of contamination. Total $n$-alkane concentrations in the laboratory blank, although lower, are still large enough to surpass the concentrations in most of the modern Asian and African samples and are less than an order of magnitude lower than those in the South American samples. The transported blank and the laboratory blank $n$-alkanes both exhibited a carbon preference index (CPI) of 1.1 and had a maximum response at chain lengths of 27 and 24, respectively, which are within the ranges obtained for the ice core samples. Many of the 
ice core samples with elevated $n$-alkane concentrations exhibited CPI values close to those of the blanks, suggesting that contamination may be present, but also that deviations from a CPI of 1.0-1.1 in other samples may reflect true depositional inputs. The presence of overwhelming $n$-alkane blank contamination precludes detailed interpretation of sample results even though they are often consistent with known climate and geographical characteristics.

Blank contamination affected several of the other compound classes, but not to the same extent as the $n$-alkanes. For example, the concentration of the $\mathrm{C}_{12}$ fatty acid in the frozen blank $(6.7 \mathrm{ng} / \mathrm{ml})$ was greater than any of the measured sample values, and blank concentrations were within an order of magnitude of mean measured sample values for the $\mathrm{C}_{14}-\mathrm{C}_{16}$ fatty acids. Alternatively, the $\mathrm{C}_{13}, \mathrm{C}_{18}$, and $\mathrm{C}_{18: 1}$ fatty acids were not impacted by excessive or problematic blank contamination. Of the alkyl amides, the shorter chain homologues $\left(\mathrm{C}_{14}, \mathrm{C}_{16: 1}, \mathrm{C}_{16}\right)$ exhibited the greatest blank contamination, but little or none was present for the longer chains. The $\mathrm{C}_{16}$ and $\mathrm{C}_{18: 1}$ alkyl nitrile results were compromised by blank contamination, but none was present for the $\mathrm{C}_{16: 1}$ or $\mathrm{C}_{22: 1}$ homologues, nor for N,N-dimethyloctanamide. The blank contamination observed for the amides and nitriles does not impact results from the Mt. Kilimanjaro core (and often for the Puruogangri 6 ka sample), for which measured concentrations were generally very high. Blank concentrations of the PAHs fluoranthene and pyrene were always greater than or within an order of magnitude of measured sample values. Of the PAH sample results, only the modern Sajama and Kilimanjaro sample values for pyrene were well above blank level. Although the trends in PAH abundance are often consistent with known climate conditions, the presence of large PAH concentrations in the blanks precludes detailed interpretation of the results. Other biomass burning marker compounds, such as the diterpenoids, were detected in the ice core samples but were not observed in the blanks, distinguishing them as the biomarkers of greatest utility in this study.

Several of the compounds detected in the blanks are typical laboratory contaminants, such as $n$-alkanes and fatty acids. However, the presence of less common 
contaminants such as the PAHs and several of the alkyl amides and nitriles suggests that some of the blank contamination may be due to sample carry over, most likely within the TDS, but possibly in the stir bars themselves. The TDS consists of a desorption chamber and a transfer line leading into the GC inlet, thus providing several surfaces on which compounds could collect and potentially carry over. Fatty acid, alkyl amide, and nitrile blank contaminants were generally biased towards the shorter chain length homologues, suggesting that lower-volatility compounds may be most readily entrained in subsequent samples. However, an assessment of stir bar carry over using standards revealed that the second analysis by TDS + GC/TOF-MS of a used stir bar produced a chromatogram typical of a conditioned, blank stir bar, thus suggesting that carry over is not problematic.

\section{Biomarkers in Post-Industrial Samples}

Post-industrial samples from five locations were examined to determine the nature of biomarker assemblages present at different locations around the tropics and subtropics, and to identify sites for which vascular plant and combustion biomarkers might prove useful for paleoclimate analysis. Several homologous biomarker series were present in these samples, including $n$-alkanes, $n$-alkanoic acids, and $n$-alkyl amides and nitriles, as well as a range of biomass burning marker compounds including PAHs and diterpenoids (see Table 3-1).

Alkyl Amides and Nitriles Alkyl amides (II; Figure 3-3) and nitriles (III) were major thermal desorption products of the organic matter in the modern ice core samples (see Table 3-1). $\mathrm{C}_{14}, \mathrm{C}_{16}$, and $\mathrm{C}_{18}$ alkyl amides were identified in almost all of the modern ice samples, as were the mono-unsaturated amides $\mathrm{C}_{16: 1}, \mathrm{C}_{18: 1}, \mathrm{C}_{20: 1}$, and $\mathrm{C}_{22: 1} . \mathrm{C}_{16}, \mathrm{C}_{16: 1}$, $\mathrm{C}_{18: 1}$, and $\mathrm{C}_{22: 1}$ alkyl nitriles were also positively identified in almost all of the modern ice core samples. The presence of the labile unsaturated amides and nitriles implies a high preservation potential for lipids in glacial ice. Although the samples contained a similar suite of alkyl amide and nitrile homologues, the distribution of these compounds varied with geographic location (see Figure 3-4). For both compound classes, $\mathrm{C}_{18: 1}$ and $\mathrm{C}_{22: 1}$ were the most abundant homologues, although the $\mathrm{C}_{18: 1} / \mathrm{C}_{22: 1}$ ratio varied. The $\mathrm{C}_{18: 1}$ and 
Figure 3-3

Molecule Structures

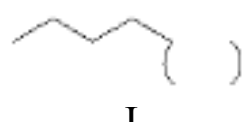

n-alkane

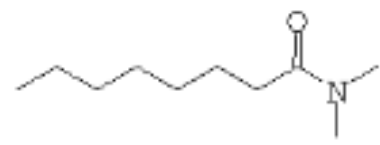

IV

N,N-dimethyloctanamide

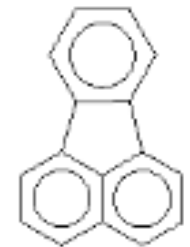

VII

pyrene

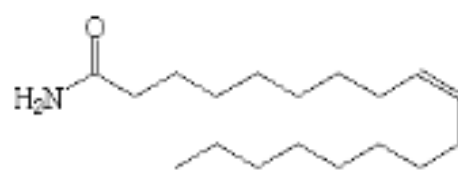

II

n-alkyl amide

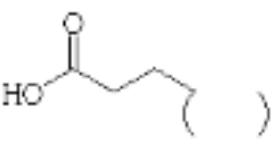

$\mathrm{V}$

fatty acid

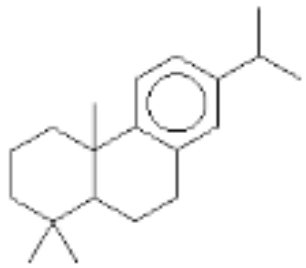

VIII dehydroabietane

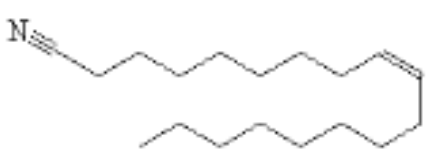

III

n-alkyl nitrile

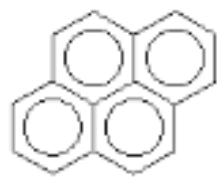

VI

fluoranthene

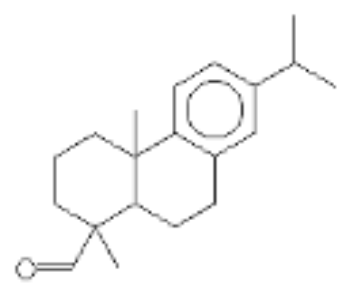

IX

dehydroabietic aldehyde

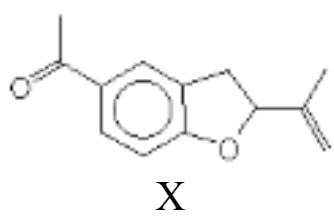

tremetone

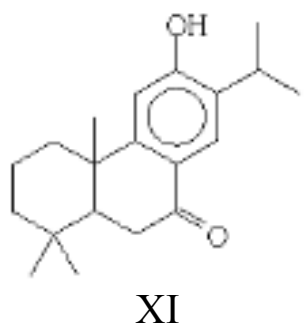

sugiol

Structures of organic molecules discussed in the text. 
Figure 3-4

Alkyl Amide Concentrations in Modern Ice Core Samples

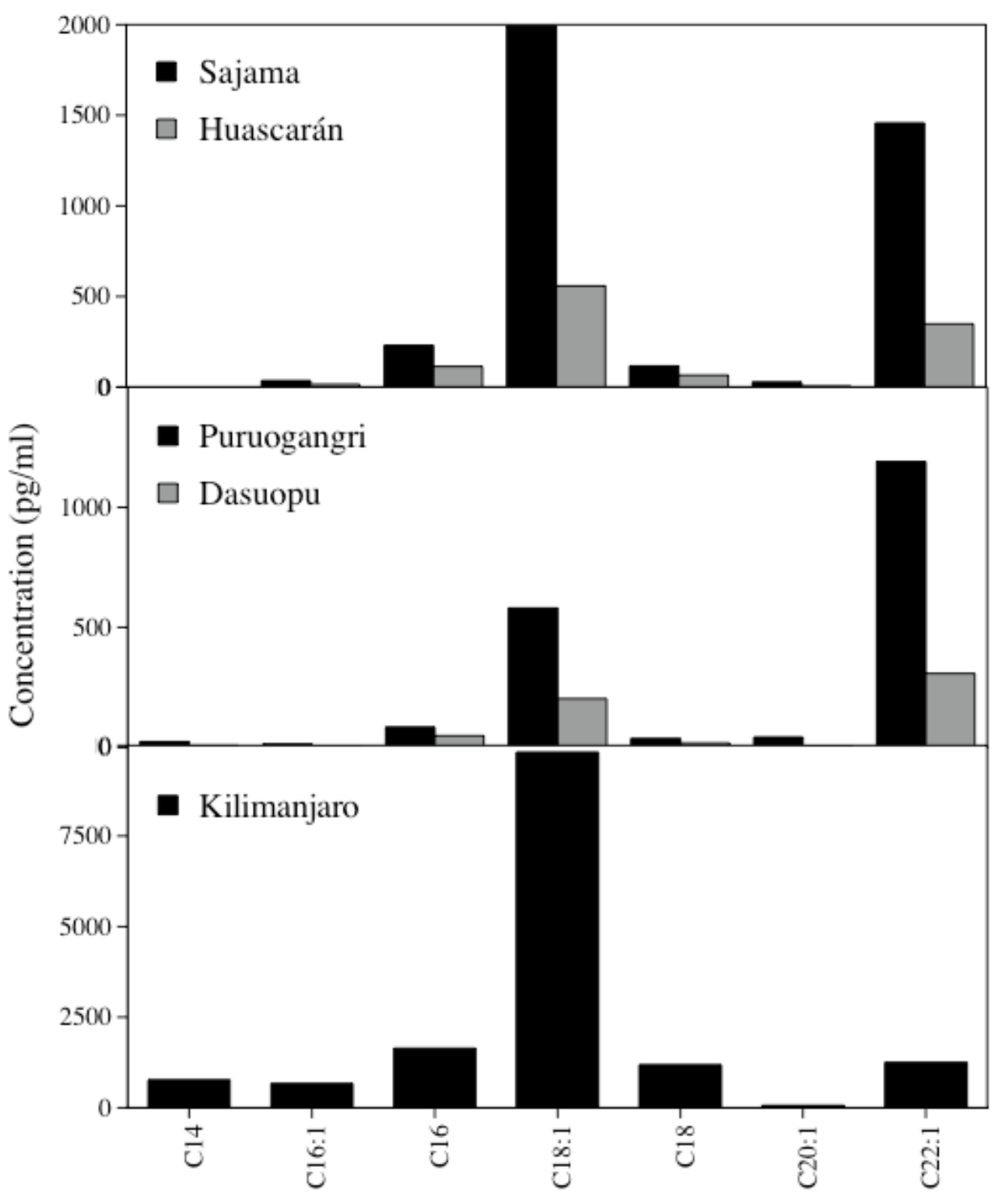

Alkyl Amide Homologue

Alkyl amide distributions in the modern ice core samples (average concentrations in $\mathrm{pg} / \mathrm{ml})$. 
$\mathrm{C}_{22: 1}$ amides and the $\mathrm{C}_{22: 1}$ nitrile were not strongly affected by blank contamination issues, but a relatively elevated blank level for the $\mathrm{C}_{18: 1}$ nitrile impacts interpretation of abundances of this compound for all modern samples except Kilimanjaro. For amides, the maximum $\mathrm{C}_{18: 1} / \mathrm{C}_{22: 1}$ ratio, expressed as the mean concentrations in the samples from a given location, occurred in the Kilimanjaro sample (7.83), while the South American modern ice samples had ratios slightly greater than 1 (1.37 and 1.60) and the two Asian samples exhibited values of only 0.49 and 0.66 . A similar pattern was observed for the nitriles, with the exception of the modern Huascarán sample, which had a $\mathrm{C}_{18: 1} / \mathrm{C}_{22: 1}$ ratio of less than 1 (0.87). Figure 3-5, which includes cross plots of alkyl amide and nitrile $\mathrm{C}_{18: 1}$ and $\mathrm{C}_{22: 1}$ concentrations, illustrates the unique distribution in the Kilimanjaro sample. Mean concentrations of amides were greatest in Kilimanjaro ice, for which $\mathrm{C}_{18: 1}$ was present at an estimated $9.8 \mathrm{ng} / \mathrm{ml}$. Mean concentrations of all amides measured in Sajama ice were 1.7 to 5.5 times greater than in Huascarán, and amides were similarly enriched in Puruogangri ice compared to Dasuopu. Alkyl nitrile concentrations were lower and more consistent between sites than the amides, although the maximum concentrations of nitriles also occurred in the Kilimanjaro samples. The elevated concentrations of alkyl amides and nitriles in Kilimanjaro and Sajama ice compared to other cores could be due to low overall ice accumulation rates or enhanced flux. Reduced ice accumulation rates would effectively enrich compounds in samples of constant volume, whereas increased accumulation would have a diluting effect.

With the exception of the Huascarán samples, for which relative abundances of $\mathrm{C}_{18: 1}$ and $\mathrm{C}_{22: 1}$ are different for alkyl amides and nitriles, the distributions of these two homologous series are similar in the modern ice samples, implying a common source (see Figure 3-6). Simoneit et al. (2003) observed nearly the same suite of amide and nitrile homologues in urban aerosol samples from Santiago, Chile as were identified in this study, and produced an amide and nitrile under laboratory conditions by hydrous pyrolysis of an alkanoic acid in the presence of ammonium bicarbonate. The authors suggested a reaction scheme whereby alkanoic acids, when combusted in the presence of ammonia, are converted to amides of similar chain length and then to nitriles upon further 
Figure 3-5a

Ice Core $\left[\mathrm{C}_{18: 1}\right]$ versus $\left[\mathrm{C}_{22: 1}\right]$ Alkyl Amides

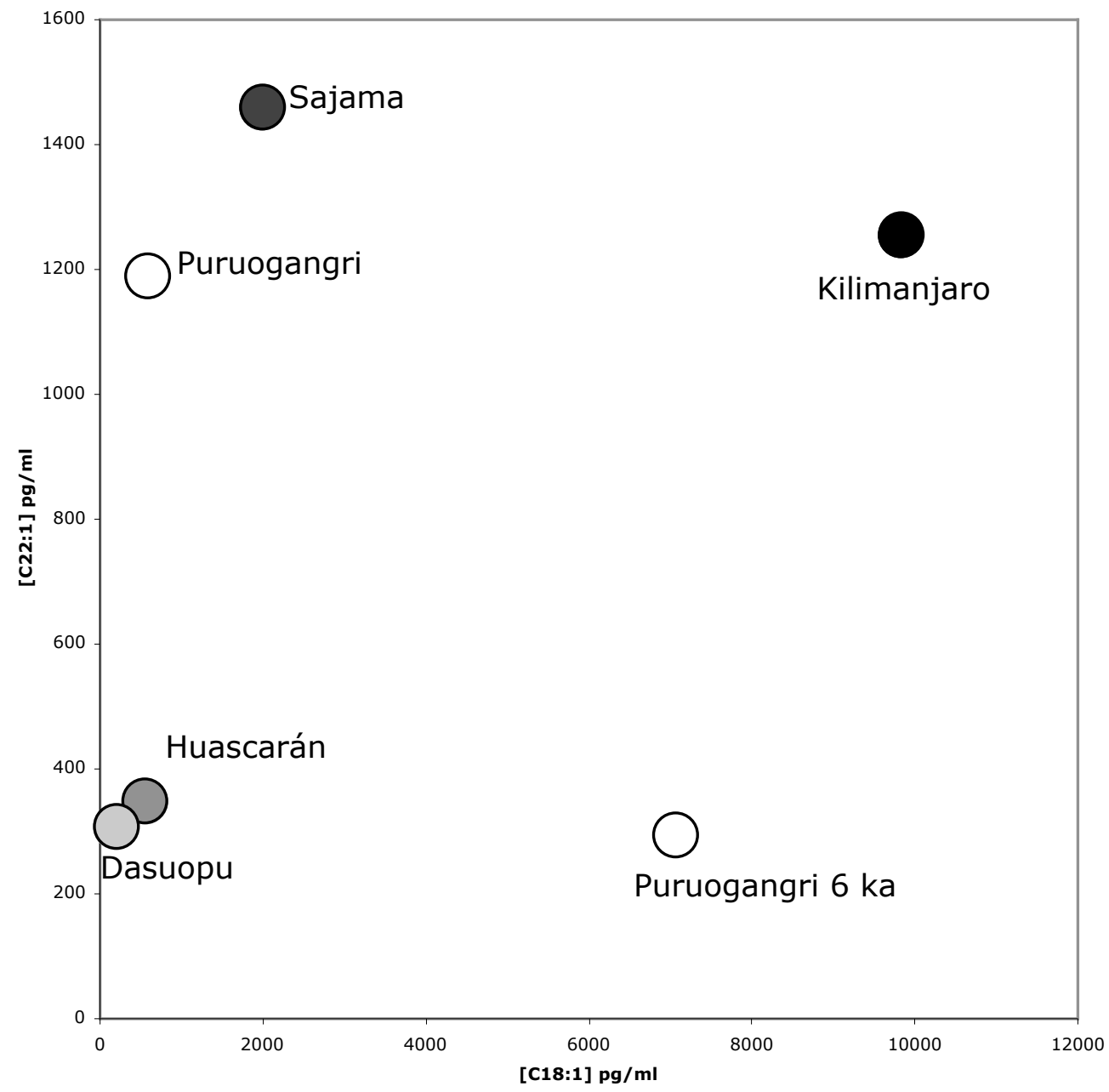

Plots of $\mathrm{C}_{18: 1}$ versus $\mathrm{C}_{22: 1}$ homologue average concentrations ( $\mathrm{pg} / \mathrm{ml}$ ) for alkyl (a) amides and (b) nitriles. Only the modern and Puruogangri 6 ka samples are depicted because the other samples did not contain appreciable amounts of these compounds. 
Figure 3-5b

Ice Core $\left[\mathrm{C}_{18: 1}\right]$ versus $\left[\mathrm{C}_{22: 1}\right]$ Alkyl Nitriles

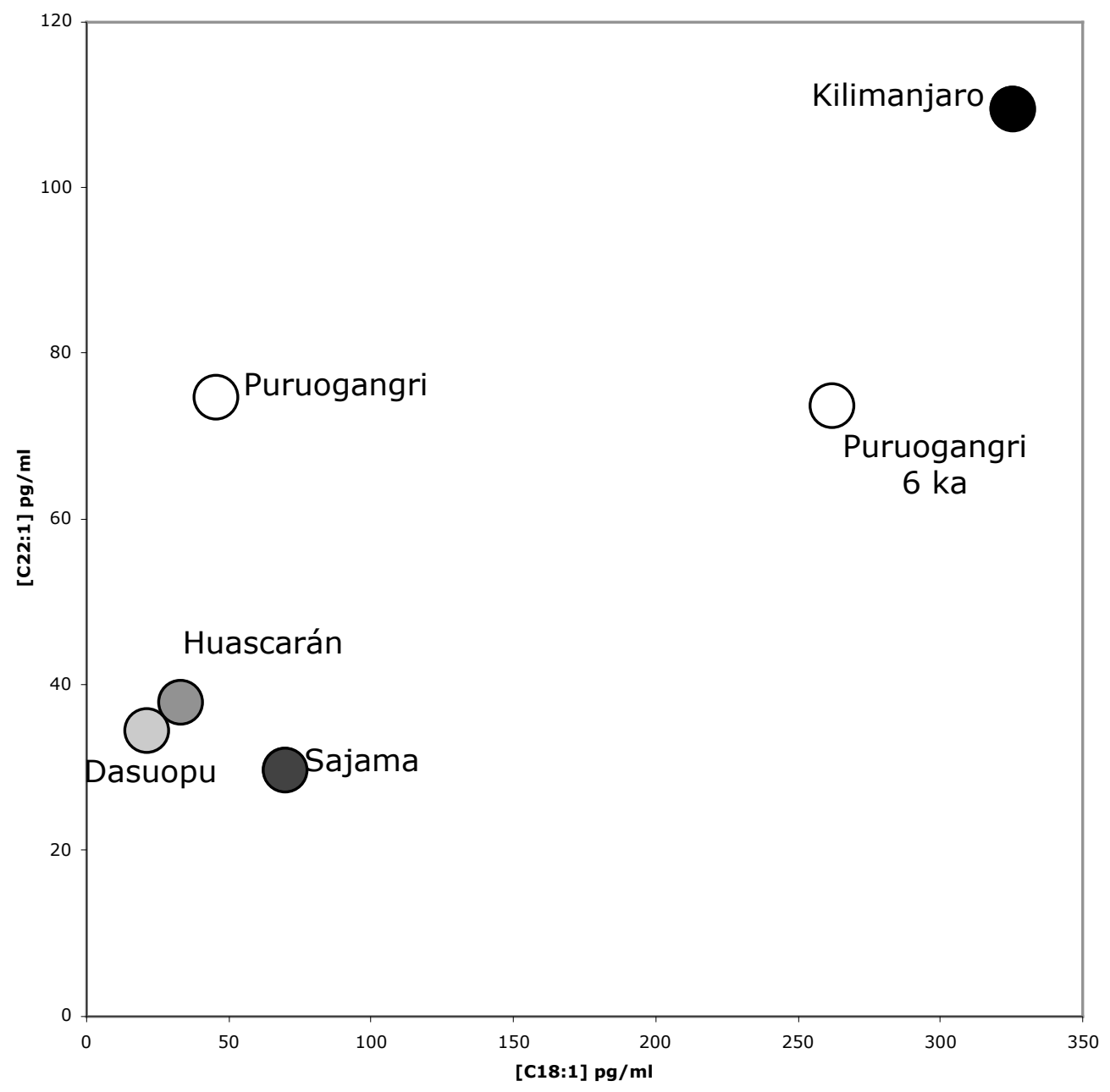


Figure 3-6

Alkyl Nitrile Concentrations in Modern Ice Core Samples

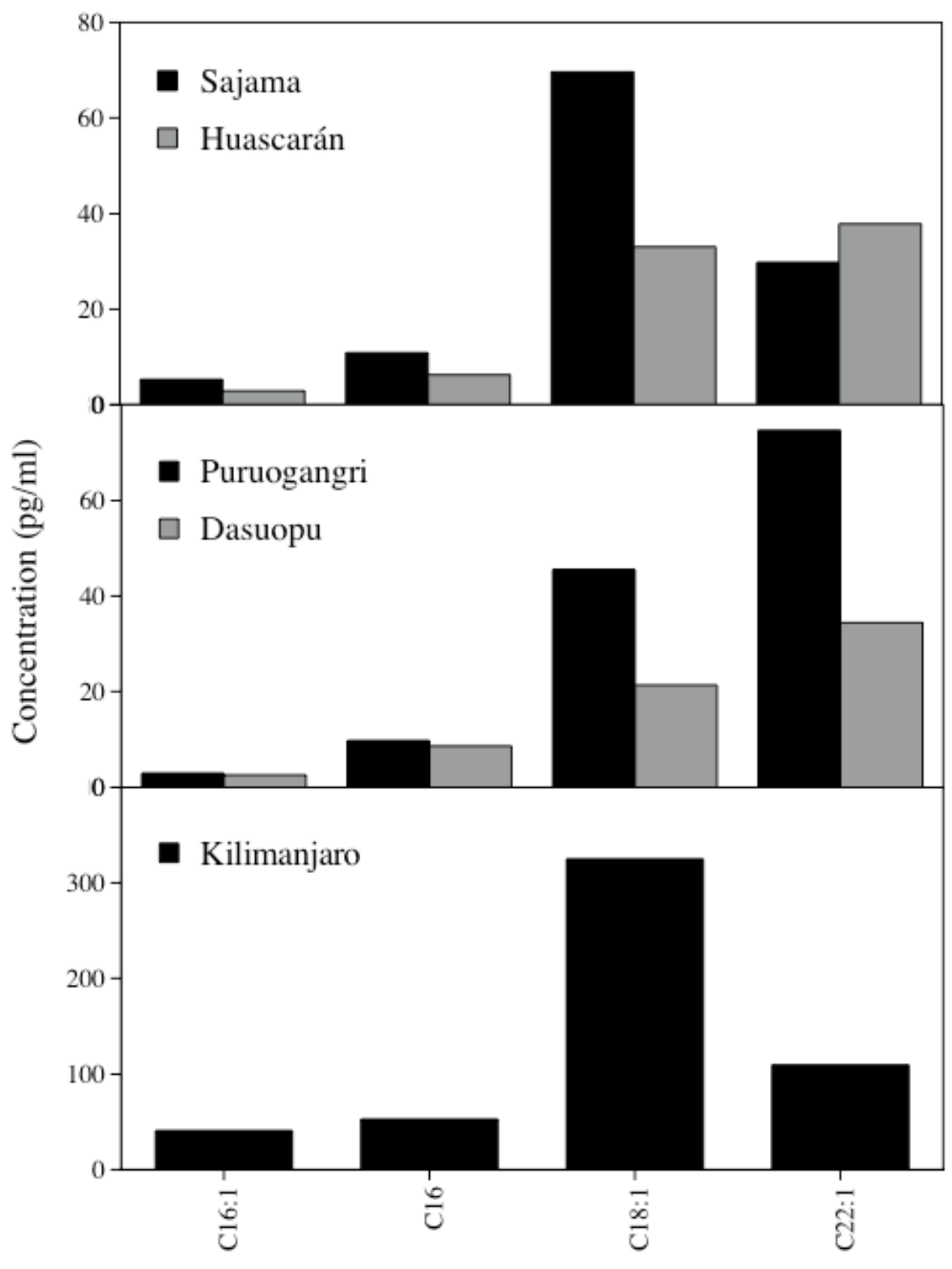

Alkyl Nitrile Homologue

Alkyl nitrile distributions in the modern ice core samples (average concentrations in $\mathrm{pg} / \mathrm{ml})$. 
combustion. Methyl alkamides of shorter chain lengths are also considered to be combustion byproducts in this process (Simoneit et al., 2003). Interestingly, N,Ndimethyloctanamide (IV), which is a $\mathrm{C}_{10}$ methyl alkamide, was identified in the modern ice samples from Sajama, Dasuopu, and Kilimanjaro, which exhibited a maximum concentration of $358.8 \mathrm{pg} / \mathrm{ml}$. Given that the alkyl amides and nitriles may form by combustion of alkanoic acids in the presence of ammonia, two likely sources of these compounds in modern aerosols are biomass burning and cooking (Simoneit et al., 2003). The amides and nitriles observed in the modern ice samples could have arisen from either of these sources. Alkyl amides and nitriles in Santiago aerosol samples that Simoneit et al. (2003) attributed to food preparation exhibited a great amount of the $\mathrm{C}_{22: 1}$ homologue compared to $\mathrm{C}_{18: 1}$, which was not the case for any of the ice core samples. However, no long-chain $\left(>\mathrm{C}_{24}\right)$ amides or nitriles were observed in the ice samples, which would have provided more conclusive evidence for a combusted plant source. The long-chain compounds may not have been detected because they were absent from the samples or because they experience discrimination during TD, as do the fatty acids. Homologous series of alkyl amide and nitrile standards were not analyzed as part of this study, but would provide information about response factors for these compounds and whether or not they could have been detected using the current methodology.

Samples from each continent have their own consistent distributions of alkyl amides and nitriles, with South American samples exhibiting greater concentrations of the $\mathrm{C}_{18: 1}$ amide than $\mathrm{C}_{22: 1}$, Asian samples demonstrating the opposite pattern, and amides in Kilimanjaro ice that are dominated by $\mathrm{C}_{18: 1}$. Figure 3-7, which plots alkyl amide and nitrile $\mathrm{C}_{18: 1} / \mathrm{C}_{22: 1}$ ratios against each other, demonstrates the differences in distribution at each site. With the exception of Huascarán, modern samples from different regions occur in different areas of the plot. Such specificity for each mountain range or mountain implies that ice in each location is receiving biomarker inputs from within its broad geographical setting, but not from other locations around the tropics. Variations in amide and nitrile distribution may arise from differences in the nature of combusted biomass or food preparation. Simoneit et al. (2003) only found high concentrations of these 
Figure 3-7

Ice Core Alkyl Amide $\mathrm{C}_{18: 1} / \mathrm{C}_{22: 1}$ versus Nitrile $\mathrm{C}_{18: 1} / \mathrm{C}_{22: 1}$

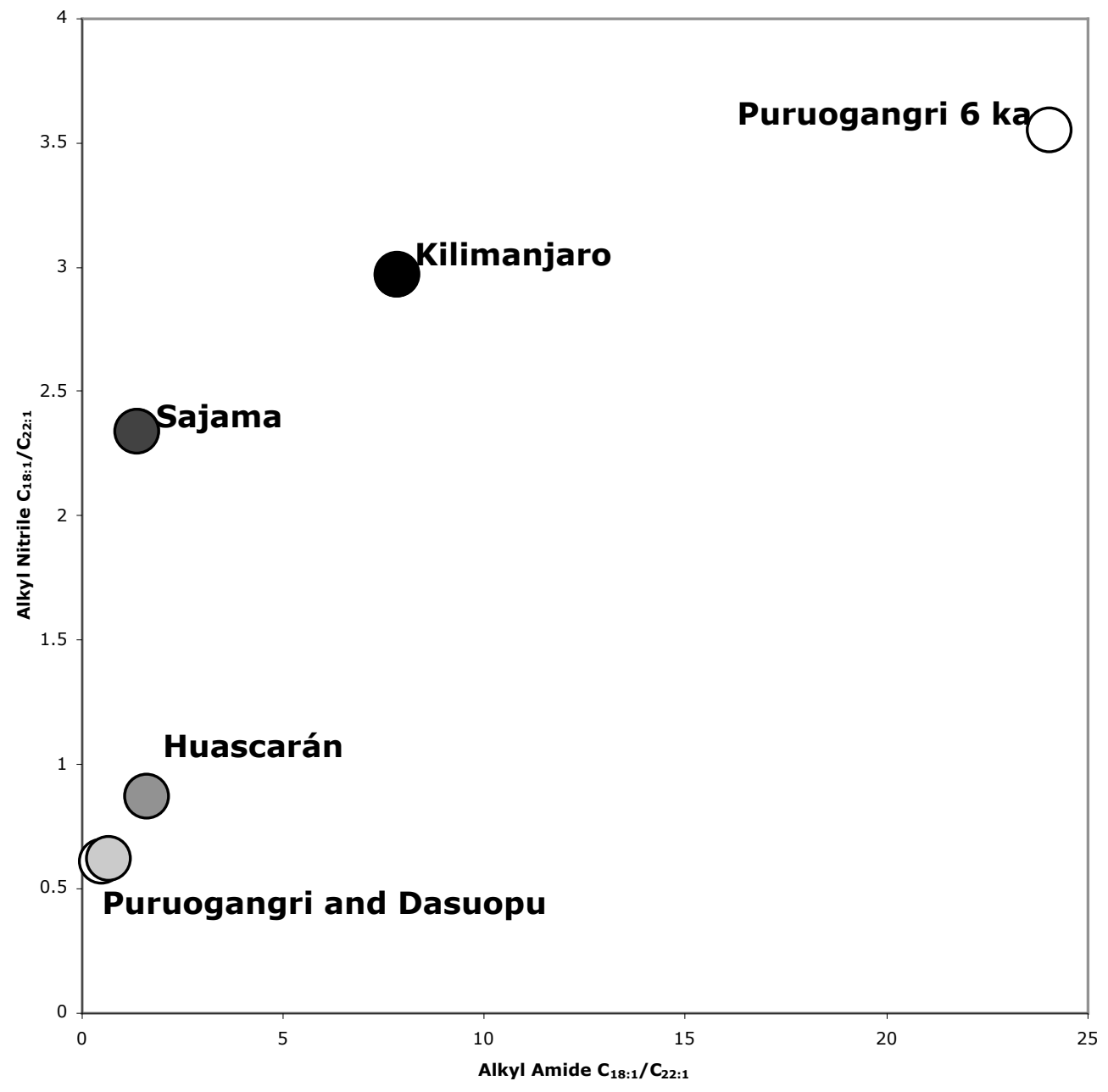

Plot of the $\mathrm{C}_{18: 1} / \mathrm{C}_{22: 1}$ homologue ratio (calculated from average concentrations) for alkyl amides versus nitriles. Only the modern and Puruogangri 6 ka samples are depicted because the other samples did not contain appreciable amounts of these compounds. 
compounds in aerosols at one sampling location in Santiago and not others, leading them to hypothesize that they came from a nearby source and were not dispersed throughout the city's air. Given the remote locations of the South American and Asian ice cores, food was not likely prepared immediately near to where the cores were collected except at the time of collection, during which time the ice I investigated was not in contact with the atmosphere. Additionally, the samples received only brief exposure to air in the laboratory during sample transfers and were stored in capped bottles or vials at all other times. These assumptions imply that combusted plant matter is the source of the amides, nitriles, and N,N-dimethyloctanamide in the modern ice samples. If so, a potential hypothesis to explain the different compound distributions between continents is that different types of vegetation burned upwind of the various ice core sites. For example, the South American cores may contain combusted plant material from Amazonian forest or higher-elevation evergreens, whereas Kilimanjaro would be expected to receive strong inputs of grassland biomarkers.

Fatty Acids Short-chain $\left(\leq \mathrm{C}_{18}\right)$ fatty acids (V) were identified consistently in the modern ice core samples from Sajama, and in some of the other post-industrial samples, as well. $\mathrm{C}_{12}-\mathrm{C}_{16}$, as well as $\mathrm{C}_{18}$ and $\mathrm{C}_{18: 1}$ fatty acids, were measured in Sajama samples (see Table 3-1). While no fatty acids were detected in samples from Huascarán, samples from both Asian sites were found to contain $\mathrm{C}_{12}, \mathrm{C}_{14}$, and $\mathrm{C}_{16}$ fatty acids, and one Kilimanjaro sample contained the $\mathrm{C}_{12}$ and $\mathrm{C}_{14}$ homologues (see Figure 3-8). Odd carbon number fatty acids were only detected in the Sajama samples. An average $\mathrm{CPI}\left(\mathrm{C}_{13}-\mathrm{C}_{16}\right.$; in this case CPI was calculated as $\Sigma_{\text {even }} / \Sigma_{\text {odd }}$ chain lengths) of 10.2 was calculated for these samples. These chain lengths and distributions are consistent with either a vascular plant leaf wax source or algal and bacterial sources. Detection of long-chain fatty acids would provide better evidence for a leaf wax source, but despite efforts to improve the efficiency of recovery and analysis of polar compounds using SBSE and TD, severe discrimination against fatty acids $>\mathrm{C}_{18}$ occurred during TD, as evidenced by repeated analysis of fatty acid standards (see Appendix B). Derivatization of fatty acids is difficult to achieve in aqueous solutions. An in situ ethylation was attempted with ice core 
Figure 3-8

Ice Core Fatty Acid Concentrations, Modern Samples

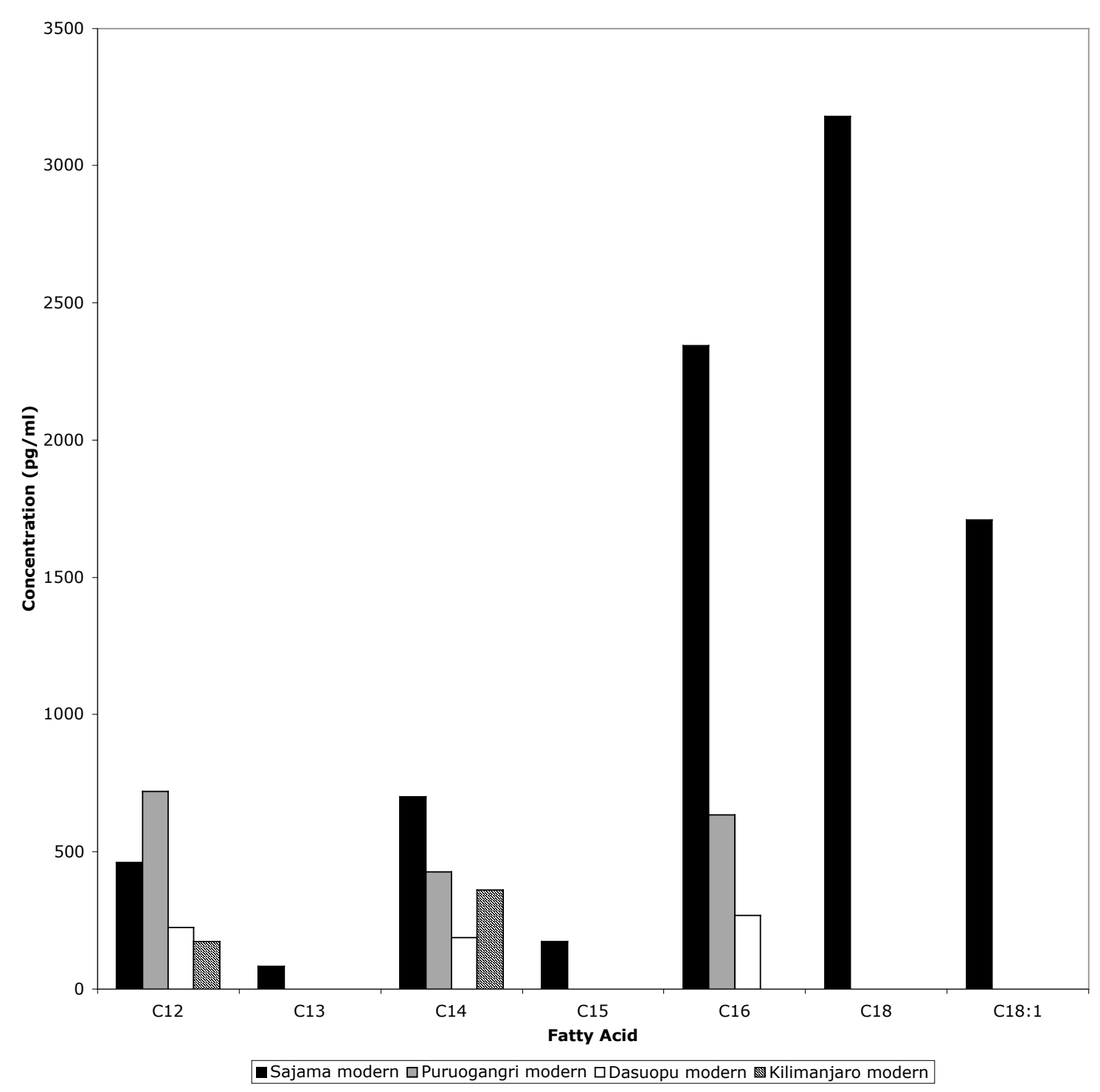

Fatty acid distributions in the modern ice core samples (average concentrations in $\mathrm{pg} / \mathrm{ml}$ ). Huascarán is not depicted because these compounds were not detected in any sample from there. 
samples using ethyl chloroformate as a derivatization agent (Husek, 1993), however the results obtained with standards and samples were not sufficiently different from the process blank results to warrant interpretation or further use of this method. Additional refinements to this or other derivatization methodologies may render the technique useful in future studies.

Fatty acids may not have been detected in Huascarán samples due to dilution resulting from elevated accumulation rates. In the Dasuopu and Kilimanjaro samples, the fatty acids were only detected in the largest sample splits $(30 \mathrm{ml})$ due to their low ambient concentrations. Fatty acids were detected in all modern Puruogangri samples, but the largest sample produced the greatest response in this case, as well. As was the case for the alkyl amides and nitriles, the Sajama sample exhibited the greater concentration of fatty acids in the Andean cores studied, and Puruogangri recorded the greater concentration of the two Asian cores.

Because all organic matter trapped in alpine ice is deposited by purely aeolian processes (small fragments of wood were even observed by microscope in the modern Sajama sample), leaf waxes are a likely source for the fatty acids. However, short-chain fatty acids are nearly ubiquitous in the environment, largely due to production by algae and bacteria. These compounds were not observed in the Huascarán ice core samples, demonstrating that if there are algal or bacterial sources, they do not affect all sites. Fatty acids of the chain lengths observed, like the alkyl amides and nitriles, are also produced during food preparation with seed oils (Simoneit et al., 2003). However, cooking oils are not a likely source for the fatty acids observed in the ice due to lack of local food preparation and consumption, and because of inconsistencies between concentrations of amides and fatty acids. For example, the greatest amide concentrations were observed in the Kilimanjaro samples, which contain relatively low concentrations of fatty acids and no $\mathrm{C}_{16}$ or $\mathrm{C}_{18}$ homologues. The $\mathrm{C}_{18: 1}$ fatty acid was also detected in Sajama samples at concentrations of up to $2.6 \mathrm{ng} / \mathrm{ml}$, but was not found in any other sample or blank. This compound, which is more labile than its saturated counterpart, is interpreted to be indicative of recent plant or algal biogenesis (Stephanou and Stratigakis, 1993; Abas et 
$a l ., 2004)$ and demonstrates the high preservation potential of lipids in glacial ice. The $\mathrm{C}_{18: 1}$ fatty acid, which occurs in the Sajama sample in concentrations roughly similar to $\mathrm{C}_{18}$, was not likely to have undergone aeolian transport over great distances or experienced long residence times in soil, as it would have been highly susceptible to oxidative degradation. The presence of this compound is consistent with a local vegetation biomarker source to the Sajama ice cap, such as high-altitude Andean grasses, shrubs, or conifers.

Biomass Burning Markers Other compounds indicative of biomass burning were identified in the modern ice samples, including the PAHs fluoranthene (VI) and pyrene (VII), dehydroabietane (VIII), dehydroabietic aldehyde (dehydroabietal) (IX), tremetone $(\mathrm{X})$, and sugiol (XI). Fluoranthene and pyrene were the only PAHs observed and reached maximum concentrations of 3.3 and $11.0 \mathrm{pg} / \mathrm{ml}$, respectively, both of which occurred in one Sajama sample. However, blank levels of these compounds (0.4-1.2 $\mathrm{pg} / \mathrm{ml}$ ) are sufficient to preclude detailed interpretation of PAH sample data for all but pyrene in the modern Sajama and Kilimanjaro samples. The interpretations explored below depend on the possibility that PAH contamination is inherent to the laboratory water used to create the blanks, and thus did not impact the ice core samples. Fluoranthene and pyrene are two of the major PAHs released during conifer combustion (Oros and Simoneit, 2001), but are not source-specific. For example, they have also been observed in coal smoke (Oros and Simoneit, 2000). However, other PAHs that were also detected in abundance in the coal smoke, such as phenanthrene and anthracenes, were not detected in any ice core sample. Especially in the post-industrial ice core samples, which should record both natural and anthropogenic organic inputs, the origin of the fluoranthene and pyrene is uncertain. Fluoranthene and pyrene were detected in all of the modern ice samples except for the smallest volume $(10 \mathrm{ml})$ Huascarán sample, with the greatest concentrations occurring in the Sajama, Dasuopu, and Kilimanjaro samples (see Figure 3-9). Concentrations of these compounds in the Huascarán and Puruogangri samples were below the levels observed in blanks. Low concentrations in the Huascarán core may be due to high rate of ice accumulation (i.e. dilution). In the absence of 


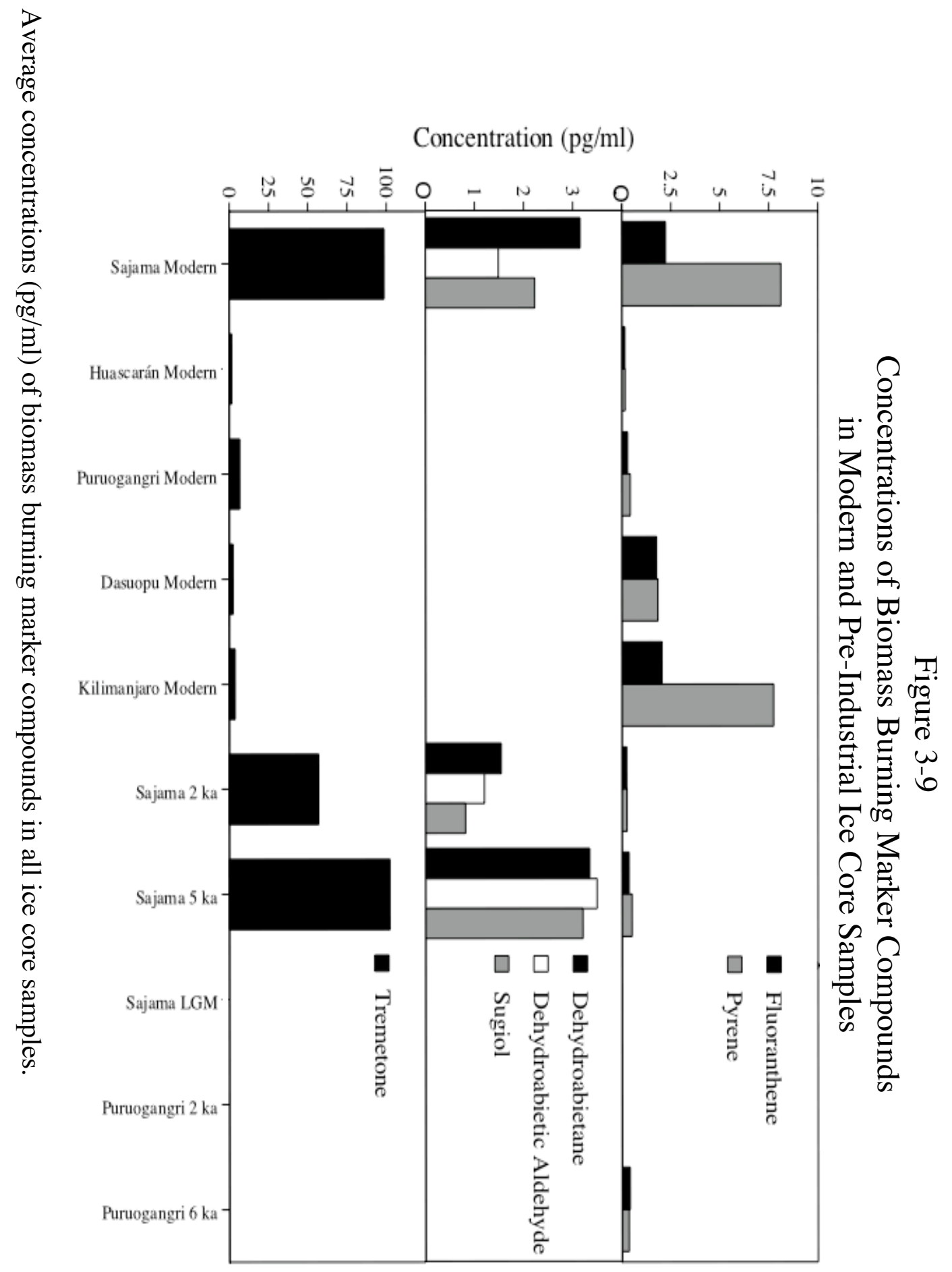


additional data, it remains uncertain whether the higher concentrations in the Sajama, Dasuopu, and Kilimanjaro cores result from enhanced biomass burning or anthropogenic activity in the areas upwind of these sites. The Dasuopu site, which is directly upwind of the Indian subcontinent during the summer, is poised to receive considerable organic inputs resulting from anthropogenic activities there. Fluoranthene and pyrene were detected by Simoneit et al. (1990) in Amazonian aerosols and by Abas et al. (1995) in smoke particulates from combusted Amazonian forest litter, confirming the existence of a possible source for the Andean ice core PAHs.

The diterpenoids dehydroabietane, dehydroabietic aldehyde, and sugiol were identified only in Sajama ice core samples and were not found in analytical blanks. Average estimated concentrations of these compounds in the modern Sajama samples were $3.2 \mathrm{pg} / \mathrm{ml}$ for dehydroabietane, $1.5 \mathrm{pg} / \mathrm{ml}$ for dehydroabietic aldehyde, and 2.2 $\mathrm{pg} / \mathrm{ml}$ for sugiol (see Figure 3-9). Because these compounds did not appear on the total ion chromatogram, the response factors applied to estimate their concentrations were necessarily selected from other compounds analyzed as standards that exhibited similar mass spectral characteristics (e.g. pyrene). Thus, their reported concentrations are estimates, but relative abundances are comparable between samples.

Oros and Simoneit (2001) detected dehydroabietane and dehydroabietic aldehyde in smoke particulates from combusted conifers, including types of fir, pine, hemlock, and spruce, in concentrations of up to $13.6 \mathrm{mg} / \mathrm{kg}$ of combusted material. Fine et al. (2004) also detected these two diterpenoids in emissions from softwoods combusted in wood stoves. Oros and Simoneit (2001) classify dehydroabietane as a naturally occurring compound in conifers and dehydroabietic aldehyde as an oxidation product, providing compelling evidence that biomass smoke contributions to high-altitude ice caps include natural resin compounds as well as those that have been thermally altered. Sugiol, which has a similar structure to dehydroabietane and is a common natural product in conifers, has been observed in seed cone extracts from the present-day cypress Taxodium distichum and fossil seed cone extracts from an Eocene Taxodium balticum and a Miocene Glyptostrobus oregonensis (Otto et al., 2002). 
The presence of sugiol, which is a polar and labile compound, suggests that other biomarkers that are derived from vascular plants through ablation or combustion could be preserved in alpine glaciers. The biomarkers identified in this study indicate that conifer combustion and subsequent aeolian smoke delivery is a source of trace organic material to the Sajama ice cap. Inputs of plant combustion biomarkers to this core, and not Huascarán, are consistent with the arid climate conditions around Sajama that could promote vegetation fires, implying that biomarker inputs to these sites derive from local sources.

Another compound identified (by mass spectral characteristics) in the modern ice core samples that potentially could be utilized as a terrestrial vegetation biomarker is 2,3dihydro-2-isopropenyl-5-benzofuranyl methyl ketone (tremetone). This compound was identified in samples from all five sites, but occurred in the greatest concentration in the Sajama samples. It was not detected in any blanks. The average concentration of tremetone in the modern Sajama samples was $98.5 \mathrm{pg} / \mathrm{ml}$, while samples from the other cores had concentrations between 1.6 and $9.6 \mathrm{pg} / \mathrm{ml}$ (see Figure 3-9). It has been identified in Brazilian propolis, which is a constituent of honeybee hives and originates from local vegetation (Banskota et al., 1998). Tremetone, which is a natural product, could have been volatilized from South American vegetation during combustion, and subsequently delivered to the Sajama ice field through aeolian transport of smoke particles, or it could have been simply deposited as part of a plant fragment. The fact that Sajama exhibited the highest concentrations of tremetone, and was also the only core to contain dehydroabietane, dehydroabietic aldehyde, and sugiol, indicates that it is most favorably positioned to receive inputs of organic matter derived from plants, possibly due to regional climate conditions or proximity to vegetation. Lower than average accumulation rates during the Holocene (Thompson et al., 1998) may aid in identification of these compounds in low volume samples.

n-Alkanes A series of $n$-alkanes (I, Figure 3-3) were identified in all of the samples and blanks analyzed, almost always spanning a range of carbon numbers from $\mathrm{C}_{21}$ to $\mathrm{C}_{34}$ or greater. These compounds are one of the principal components of the 
modern samples, occurring in individual concentrations of up to $5.2 \mathrm{ng} / \mathrm{ml}$ (see Appendix $\mathrm{B}$ for chromatogram). Interpretations of $n$-alkane abundance and distribution in the ice core samples are explored below, although severe blank contamination essentially obviates this endeavor. In that sense, these interpretations are idealistic and rely heavily on the possibility that blank contamination arises in a large part from the use of Milli-Q water.

Average total $n$-alkane concentrations are reported in Figure 3-10. Long-chain $n$ alkanes with a strong odd-to-even carbon number predominance are present in vascular plant leaf waxes (Eglinton and Hamilton, 1967; Kolattukudy, 1976), while a lack of carbon number preference is consistent with a petrogenic source (Mazurek and Simoneit, 1984). The $n$-alkane CPI was calculated for all samples and is presented in Table 3-1, as is the carbon number of maximum concentration $\left(\mathrm{C}_{\max }\right)$ in each sample. $\mathrm{CPI}$ was calculated by inserting chromatographic peak areas, which are a measure of concentration, into the formula: $\Sigma$ odd chains $\mathrm{C}_{21}-\mathrm{C}_{33} / \Sigma$ even chains $\mathrm{C}_{22}-\mathrm{C}_{34}$ (Mazurek and Simoneit, 1984). For all modern samples, CPI values varied between 0.76 and 1.17, implying that inputs of $n$-alkanes derived from anthropogenic petroleum use far outweighed contributions from plant leaf waxes.

Oros and Simoneit (2001) observed CPI values in $n$-alkanes isolated from conifer smoke that ranged from 0.5 for Ponderosa pine to 3.4 for Port Orford cedar combustion. They obtained an average CPI value of 1.3 for the six types of pine tree studied and 1.0 for the three types of fir. Thus, the $n$-alkane CPI values observed in the modern ice core samples are potentially also consistent with a combusted plant matter source. $n$-Alkanes in smoke from combusted Amazonian forest litter were found by Abas et al. (1995) to have a CPI of 3.6 with a $\mathrm{C}_{\max }$ of 29 or 31 . These Amazonian $\mathrm{C}_{\max }$ values are greater than most that were determined by Oros and Simoneit (2001) for North American conifers. An $n$-alkane $\mathrm{C}_{\max }$ of 25 was determined for most of the South American and Asian modern samples, while all Kilimanjaro samples had a value of 24 , possibly resulting from differences in the nature of the petrogenic or burned biomass source material between Kilimanjaro and the other samples, such as different fuel or plant type. This idea is 
Figure 3-10

Ice Core Total $n$-Alkane Concentrations

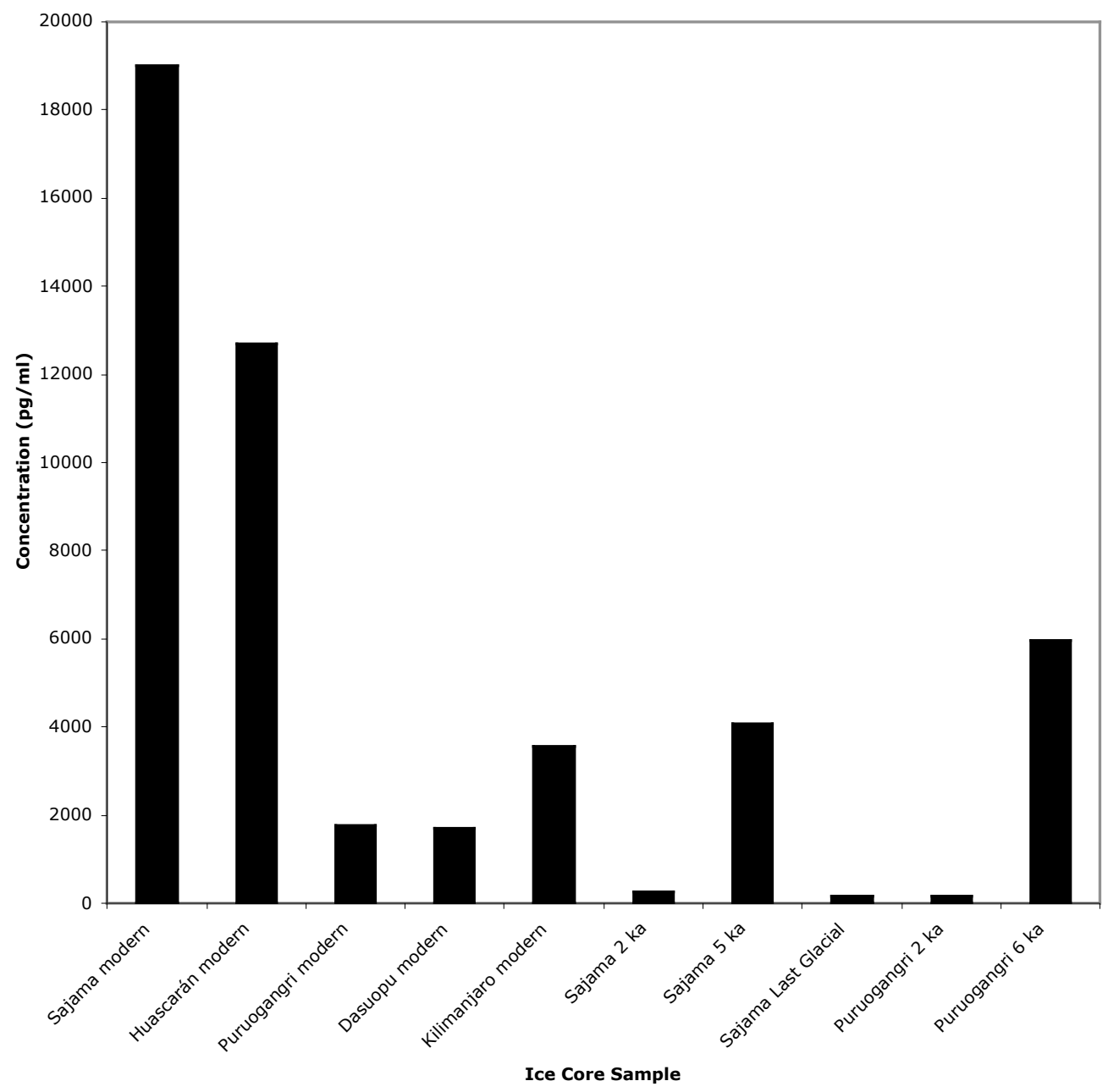

Average total $n$-alkane $\left(\mathrm{C}_{21}-\mathrm{C}_{34}\right)$ concentrations $(\mathrm{pg} / \mathrm{ml})$ in all ice core samples. 
supported by an average CPI value of only 0.83 for modern Kilimanjaro samples, compared to higher values in Sajama (0.99), Huascarán (1.04), Puruogangri (0.94), and Dasuopu (1.12) samples. If there were substantial contributions of vascular plant $n$ alkanes to the modern South American ice core samples, the lower $\mathrm{C}_{\max }$ values than combusted Amazonian forest litter may be reflective of inputs from coniferous plants growing at higher elevations rather than distant lowland forest.

Several other possible sources exist for the $n$-alkanes observed in the ice core samples, in addition to those discussed above. For example, pyrolysis of fatty acids $\left(\mathrm{C}_{4^{-}}\right.$ $\mathrm{C}_{12}$ ) under laboratory conditions has been shown to produce $n$-alkanes, and could thus represent another source of ice core hydrocarbons involving biomass burning (Leung et al., 1995). Also, Simoneit et al. (2005) demonstrated that $n$-alkanes with a strong even carbon number dominance are evolved during combustion of plastics. Phthalate compounds that were detected in the ice core samples suggest contributions from plastics, possibly resulting from atmospheric deposition, but more likely from laboratory or storage contamination. Dibutyl phthalate was also detected in blanks, but the postindustrial samples from Sajama, Kilimanjaro, and Dasuopu contained concentrations well in excess of blank levels. Contributions from combusted plastics via atmospheric deposition are expected to be minimal because the $n$-alkane homologues observed in the ice core samples did not demonstrate the even chain length preference described by Simoneit et al. (2005).

\section{Comparison to Other Ice Core Studies}

These results from biomarker analysis of modern ice core samples using SBSE and TD compare favorably to those of Xie et al. (2000), who analyzed organic matter in a Dasuopu snow pit spanning the time interval between the summers of 1996 and 1997. Based on $21 \mathrm{~L}$ to $25 \mathrm{~L}$ samples, they determined an average concentration of extractable organic matter of $45.4 \mathrm{ng} / \mathrm{ml}$, which is only about one order of magnitude greater than the total biomarker concentrations of the compounds recorded in this study from the Dasuopu sample. Their value is roughly comparable to my estimate of filterable (i.e. particulate or 
mineral-associated) organic carbon abundance in the modern Puruogangri sample, which is approximately $50 \mathrm{ng} / \mathrm{ml}$ (S. American samples are $100 \mathrm{ng} / \mathrm{ml}$ ). Thus, unlike the present biomarker investigation, the results of the Xie et al. (2000) study may reflect contributions from both dissolved and particulate organic carbon. Average total $n$-alkane concentration in the snow pit samples was $1.1 \mathrm{ng} / \mathrm{ml}$, which is similar to average values determined for the Asian (Puruogangri = 1.8; Dasuopu = $1.7 \mathrm{ng} / \mathrm{ml}$ ) and African $(3.6$ $\mathrm{ng} / \mathrm{ml}$ ) ice core samples, but about an order of magnitude less than values determined for the South American (Huascarán = 12.7; Sajama =19.0 ng/ml) samples. Xie et al. $(2000)$ observed $n$-alkane and $n$-alkanoic acid chain lengths similar those that I found, but they also detected compounds that I did not, including the isoprenoid hydrocarbons pristine and phytane, hopanes, and steranes. Given that I did not detect these other compounds, the biomarkers I did observe, which were deposited at an earlier time, may primarily reflect inputs from vascular plants and not petrogenic or bacterial sources. My results further demonstrate that various sites contain different biomarker assemblages that can potentially be used to infer inputs from specific (i.e. local or regional) sources.

Total fatty acid concentrations observed in the post-industrial ice core samples, as well as the other Sajama Holocene samples, are roughly comparable to those observed in Greenland ice over the last 400 years by Kawamura et al. (1996). Total fatty acid $\left(\mathrm{C}_{12^{-}}\right.$ $\mathrm{C}_{32}$ ) concentrations of 2-105 $\mathrm{ng} / \mathrm{ml}$ were determined throughout the Greenland record, while the results in this SBSE study spanned about 0.5 to $8.7 \mathrm{ng} / \mathrm{ml}$ for the $\mathrm{C}_{12}-\mathrm{C}_{18}$ and $\mathrm{C}_{18: 1}$ homologues combined. Although abundances in the alpine ice core samples are somewhat lower than in polar ice, the Kawamura et al. (1996) study included a greater range of fatty acid homologues and employed solvent extraction, which may have incorporated a greater amount of particulate organic matter than SBSE. Fluoranthene concentrations measured in Greenland snow pit samples $(0-4.6 \mathrm{ng} / \mathrm{ml})$ were generally much higher than those determined from post-industrial alpine ice samples in this study, often by greater than 3 orders of magnitude (Masclet et al., 2000). However, this Greenland study was performed on organic material filtered from melted snow, suggesting that PAHs may be strongly associated with particulate matter, and thus not 
entirely available through SBSE. The results of these polar studies and my tropical ice investigation demonstrate that some compounds of interest have a global distribution.

\section{Biomarkers in Pre-Industrial Samples}

Many of the biomarkers that were identified in the modern ice core samples were also found in ice from the pre-industrial era, where there are no contributions of anthropogenic pollutants. Organic matter in five pre-industrial ice core samples was investigated via SBSE and TD/GC/TOF-MS, including three samples from the Sajama ice core of approximate ages $2 \mathrm{ka}, 5 \mathrm{ka}$, and last glacial period, and two samples from the Puruogangri core of approximate ages $2 \mathrm{ka}$ and $6 \mathrm{ka}$. The greatest potential for impact from human activities on the organic content of these samples would be through biomass burning in the late Holocene, although this is assumed to be minor in comparison to naturally occurring fires. Ultimately, organic compounds in these samples should occur solely as a result of aeolian deposition of vascular plant matter, either fresh or combusted.

Alkyl Amides and Nitriles Alkyl amides and nitriles above blank level concentrations were observed in pre-industrial samples from the Puruogangri ice core, but not from Sajama. Abundances in the Puruogangri 6 ka sample generally exceeded blank level by an order of magnitude, with the exception of the $\mathrm{C}_{16}$ amide and nitrile. The full range of chain lengths that were detected in the modern samples were also found in the Puruogangri sample from $6 \mathrm{ka}$, although only the $\mathrm{C}_{18: 1}$ amide and the $\mathrm{C}_{18: 1}$ and $\mathrm{C}_{22: 1}$ nitriles were detected in the $2 \mathrm{ka}$ sample. Concentrations of these compounds were much greater in the Puruogangri 6 ka sample, with $\mathrm{C}_{18: 1}$ amide and nitrile values of 7.1 and 0.3 $\mathrm{ng} / \mathrm{ml}$, respectively. Although few amides or nitriles were detected in the 2 ka sample, those that were match those of greatest concentration in the 6 ka sample. N,Ndimethyloctanamide was not detected in any of the pre-industrial samples. The distributions of the alkyl amides and nitriles in the $6 \mathrm{ka}$ sample were different from those in the modern Puruogangri sample (see Figure 3-11). The $\mathrm{C}_{18: 1}$ homologue is by far the most abundant amide or nitrile in the older sample, whereas the $\mathrm{C}_{22: 1}$ amide and nitrile concentrations are about double $\mathrm{C}_{18: 1}$ in the modern sample. The amide and nitrile 
Figure 3-11a

Puruogangri Ice Core Alkyl Amide Concentrations, Modern and 6ka Samples

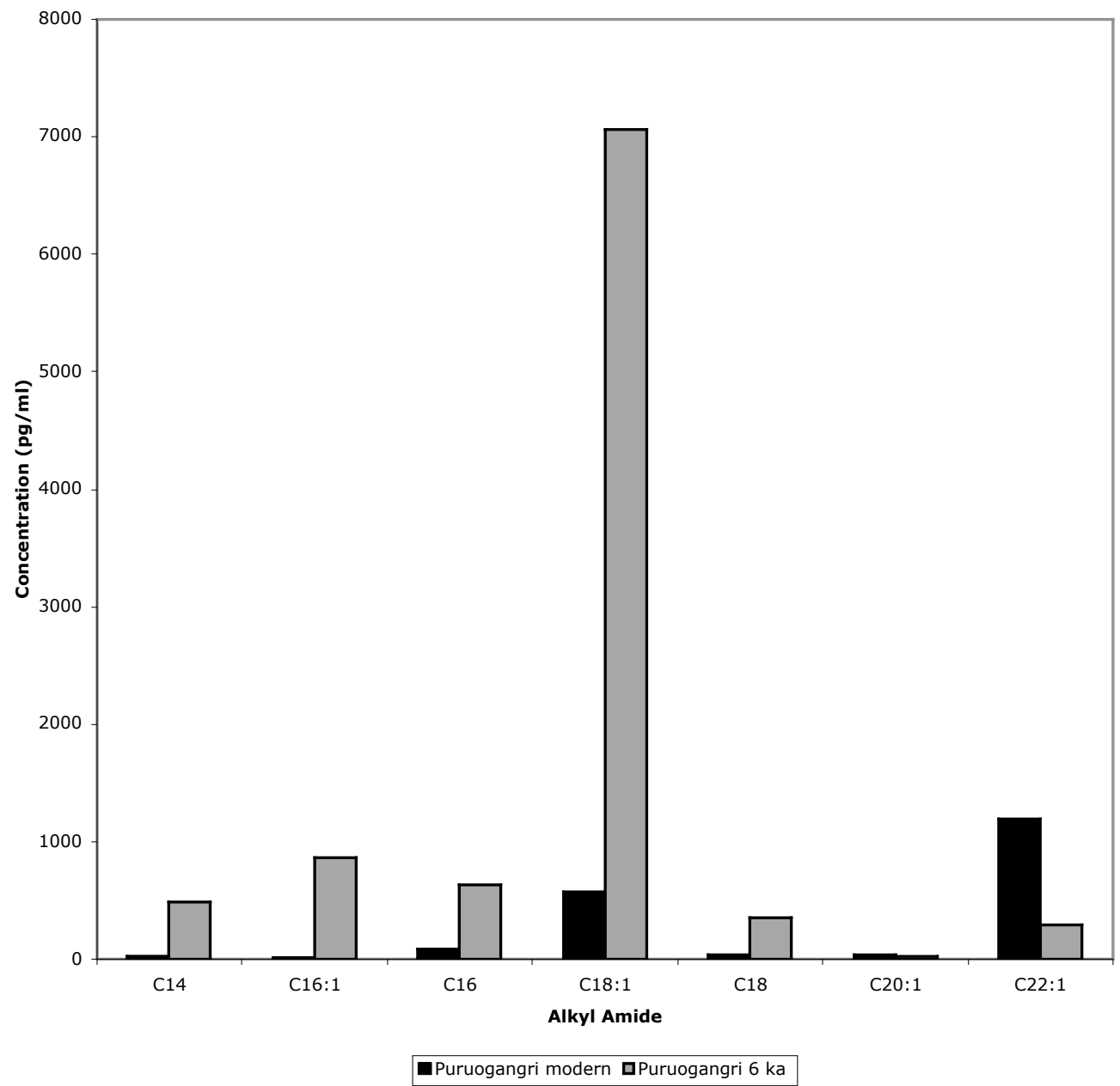

Alkyl (a) amide and (b) nitrile distributions in the modern and 6 ka Puruogangri ice core samples (average concentrations in $\mathrm{pg} / \mathrm{ml}$ ). Of the pre-industrial samples, these compounds were only detected in appreciable amounts in Puruogangri 6 ka. 
Figure 3-11b

Puruogangri Ice Core Alkyl Nitrile Concentrations, Modern and 6 ka Samples

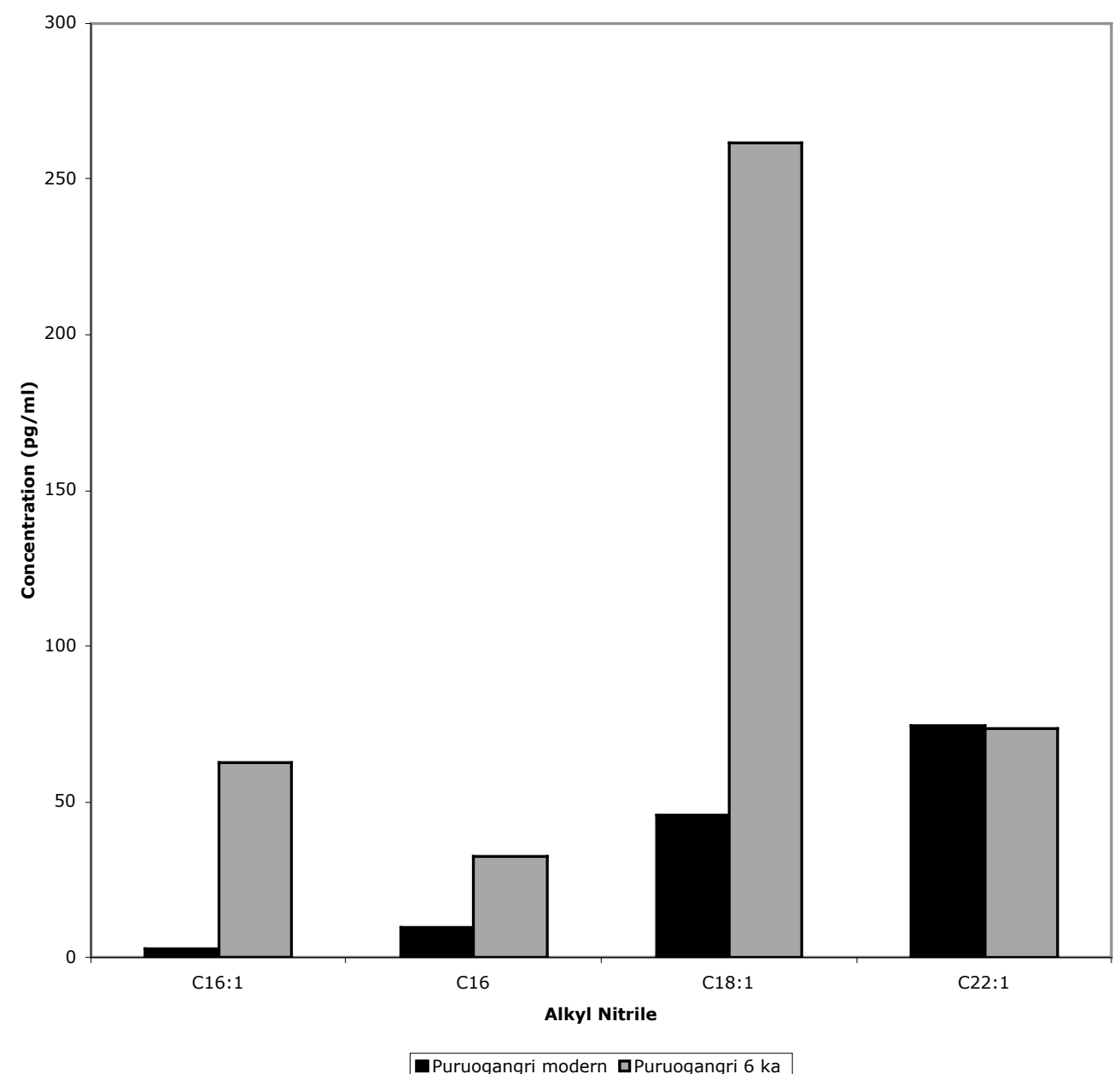


distributions in the Puruogangri 6 ka sample much more closely resemble those in the modern Kilimanjaro sample and are even similar in concentration (see Figures 3-5 and 37). The most probable source for these compounds in the Puruogangri 6 ka sample is combusted biomass, as there was almost assuredly no food preparation performed in the locale of the ice field at that time. The possibility remains that the sample was contaminated with aerosols generated during cooking at the time the core was collected, but this scenario is unlikely because the same concentrations were not observed in the Puruogangri 2 ka sample and the distribution of the homologues changed between the modern and older samples. One possible explanation for the different distribution observed at $6 \mathrm{ka}$ is a shift in vegetation type upwind of the site. The modern sample from Kilimanjaro, which closely resemble the Puruogangri 6 ka sample in amide and nitrile distribution, is likely heavily influenced by inputs from tropical grasses and scrub. By inference, the 6 ka distributions in Puruogangri could be explained by greater populations of grasses than today on the Tibetan Plateau. Indeed, Holocene pollen assemblages in the Dunde ice core indicate a relative expansion in steppe and a reduction in desert vegetation between about 10 and $5 \mathrm{ka}$ (Liu et al., 1998). Concentrations of the most abundant amides and nitriles in the 6 ka Puruogangri sample were 3-6 times greater than those in the modern Puruogangri samples. Oxygen isotopes in ice in the Guliya ice cap core $\left(35^{\circ} 17^{\prime} \mathrm{N}, 81^{\circ} 29^{\prime} \mathrm{E}, 6710 \mathrm{~m}\right)$ indicate that $6 \mathrm{ka}$ was around the time of the coolest and driest conditions during the Holocene on the Tibetan Plateau (Thompson et al., 1997). As with the Sajama samples, the Puruogangri biomarker concentrations are expected to be greatest during periods of reduced ice accumulation. Additionally, arid conditions set the stage for increased production of biomass burning indicators. One problem with the idea of grassland expansion at $6 \mathrm{ka}$ is that a reduction in desert should not be consistent with drier conditions on the Tibetan plateau and a decrease in monsoon strength, unless the summer monsoon front retreated across the Tibetan Plateau slowly throughout the Holocene, as suggested by Liu et al. (1998).

Fatty Acids The only fatty acids detected in the pre-industrial samples occurred in the Holocene samples from the Sajama ice core. The $\mathrm{C}_{12}$ and $\mathrm{C}_{16}$ homologues were 
identified in both samples but $\mathrm{C}_{14}$ was found only in the 5 ka sample. $\mathrm{C}_{18}$ and $\mathrm{C}_{18: 1}$ were not detected in any pre-industrial sample. All fatty acid concentrations in these samples were near or below blank level, indicating that they probably arose primarily from contamination, and thus precluding detailed interpretation of the results. However, only even carbon number homologues were detected, which would be consistent with a leaf wax source, and they were only found in the arid Holocene Sajama samples, consistent with the presence of other naturally derived compounds in the modern Sajama sample. The fatty acids in the pre-industrial samples presumably represent a mixture of natural inputs and contamination entrained in the laboratory or during core or sample handling.

Biomass Burning Markers The PAHs fluoranthene and pyrene were detected in the two Holocene Sajama samples and the Puruogangri 6 ka sample, but not in the LGM Sajama sample or the Puruogangri 2 ka sample. In the absence of anthropogenic inputs at these times, these compounds are expected to have been derived from biomass burning events. Fluoranthene and pyrene occur in very low concentrations in these samples, with maximum values of 0.4 and $0.5 \mathrm{pg} / \mathrm{ml}$, respectively (see Figure 3-9), which are below blank levels (avg. fluoranthene $=0.8$; pyrene $=1.1 \mathrm{pg} / \mathrm{ml}$ ). While these low concentrations negate robust quantitation and interpretation, the compounds do occur only in the samples that represent arid conditions in their geographic regions, as would be expected. In the last glacial Sajama sample and the 2 ka Puruogangri sample, both of which were deposited during warmer and wetter conditions, fluoranthene and pyrene were not detected at all, which was not the case even in the blanks. For practical purposes, it might therefore be more reasonable to compare the down-core ice samples to each other than to the blanks. The laboratory (Milli-Q) water that was used to create the blanks, but which did not contact the samples, may have contained PAHs, as evidenced by the observation that these compounds were present in the blanks, yet registered as non-detects in several samples. In the case of the pre-industrial samples, the occurrences of PAHs, although they exist in low concentrations, make sense with the ice core $\delta^{18} \mathrm{O}$ records (see Figure 3-12). I hypothesize that these PAHs may have been produced and deposited during arid periods due to greater occurrences of forest fires. 
Figure 3-12

Sajama Ice Core $\delta^{18} \mathrm{O}$ and Dust

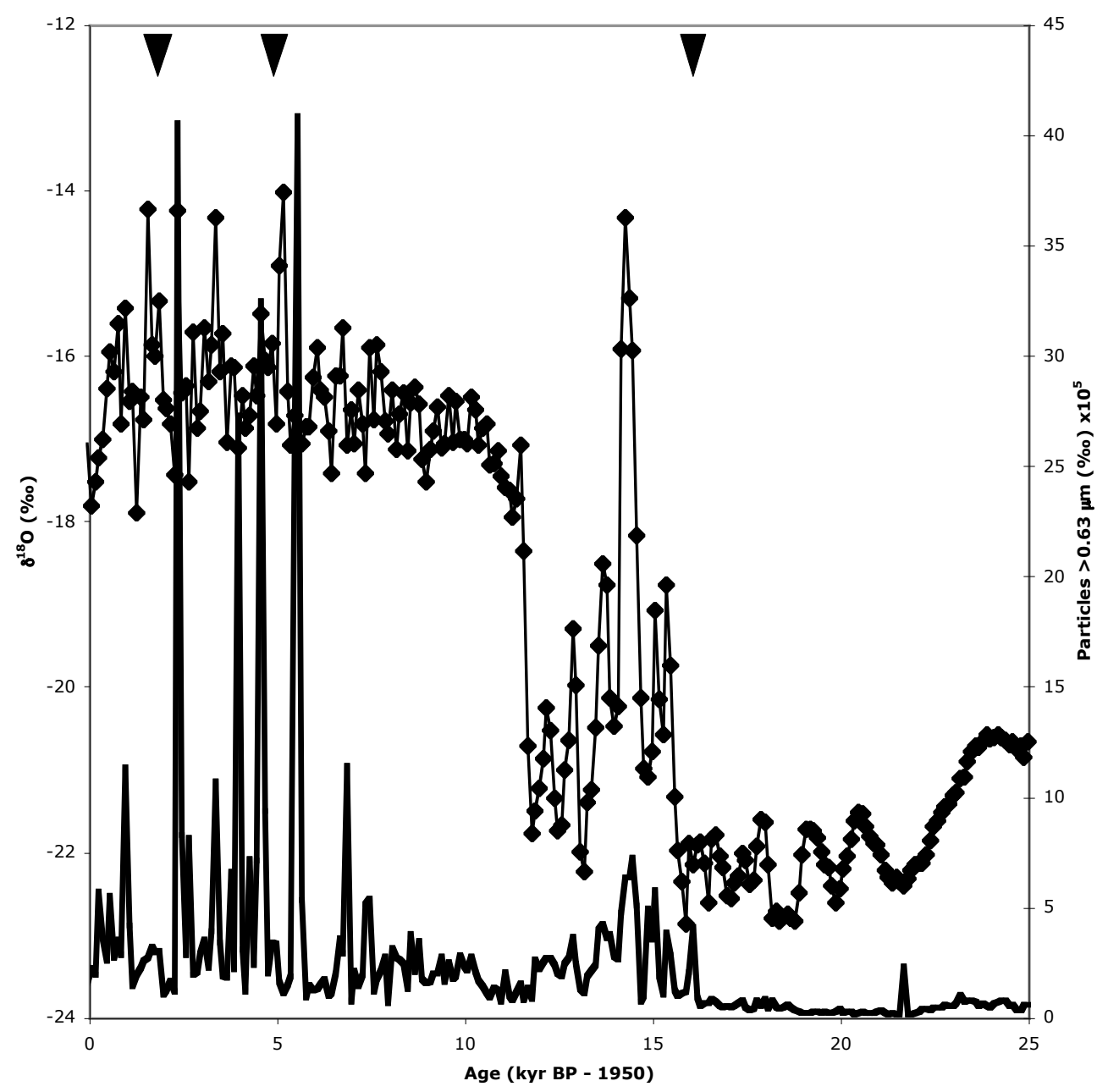

Sajama ice core $\delta^{18} \mathrm{O}$ (black diamonds) and dust (thick black line) records from Thompson et al. (1998). Inverted black triangles are approximate ages of the preindustrial ice core samples examined in this study. 
The distribution of the two PAHs in the modern samples is consistent between replicates and is different from the pre-industrial samples, which are always relatively enriched in fluoranthene. This difference in distribution may reflect a change in source from purely biomass burning in the pre-industrial samples to mixed natural and anthropogenic in the modern samples. The PAH distribution in the frozen and laboratory blanks is not constant (fluoranthene/pyrene $=0.4-1.1$ ).

Dehydroabietane, dehydroabietic aldehyde, sugiol, and tremetone were all detected in the two Holocene Sajama samples, but not in any other down-core sample, including the last glacial Sajama sample. Concentrations of the first three compounds listed above were low, ranging from about 0.8 to $3.5 \mathrm{pg} \mathrm{ml}$, with slightly higher concentrations in the $5 \mathrm{ka}$ than the 2 ka sample (see Figure 3-9). Estimated concentrations of tremetone were higher, with values of 56.8 and $102.1 \mathrm{pg} / \mathrm{ml}$ at $2 \mathrm{ka}$ and 5 ka, respectively (see Figure 3-9). Importantly, these compounds were not detected in any of the blanks. Because they were only abundant in the Sajama modern sample, it is fitting that they were detected in older Sajama samples as well, but not in Puruogangri ice. Their presence in Holocene but not last glacial ice is also consistent with known climate trends at Sajama, for which proxy records indicate that the mid to late Holocene climate was similar to present day conditions, whereas the last glacial period was much wetter and cooler.

$\boldsymbol{n}$-Alkanes All of the pre-industrial samples contained $n$-alkanes of carbon chain lengths $\mathrm{C}_{22}-\mathrm{C}_{31}$ or greater with total $n$-alkane concentrations ranging from 0.2 to 6.0 $\mathrm{ng} / \mathrm{ml}$ (see Figure 3-10). Although the concentrations in the pre-industrial samples are often similar to or below blank contamination levels, the $n$-alkanes in these samples exhibited distributional characteristics that are different from the blanks or the postindustrial samples. For example, all of the pre-industrial samples had a $\mathrm{C}_{\max }$ of 27 (the Sajama LGM sample had three major $n$-alkane peaks at $\mathrm{C}_{23}, \mathrm{C}_{27}$, and $\mathrm{C}_{31}$ ), whereas almost all of the modern South American and Asian samples had $\mathrm{C}_{\max }$ of 25. Also, all of the pre-industrial samples had $n$-alkane CPI values $>1.0$, which was the case for less than half of the modern samples. The 2 ka and LGM Sajama samples had CPI values of 1.3 
and 2.8, respectively, and the 2 ka Puruogangri sample had a CPI value of 1.2, all of which were greater than the CPI value of any post-industrial sample. These results imply that $n$-alkanes in the pre-industrial ice samples better represent fresh or combusted plant wax inputs, although laboratory or sampling contamination undoubtedly compromised the integrity of the signal, and thus render these interpretations dubious. Higher $n$-alkane concentrations in the Holocene Sajama samples compared to the last glacial sample and also in the older of the Puruogangri samples are consistent with inferred dryer conditions in the areas of these sites, and therefore lower ice accumulation rates and elevated dust inputs (Thompson et al., 1997; Thompson et al., 1998) (see Figures 3-12 and 3-13). Because similar sample volumes were extracted and analyzed in this study, biomarker enrichment is expected for periods of reduced ice accumulation.

\section{Controls on Biomarker Abundance in the Sajama Ice Core}

Several factors could have contributed to the discrepancy between plant biomarker concentrations in the Sajama glacial and Holocene samples, including increased ice accumulation rates in the glacial, changes in atmospheric circulation, and differences in the type or areal extent of vegetation upwind of the site. Enhanced ice accumulation, as occurred at Sajama during the last glacial period (Thompson et al., 1998), would effectively dilute biomarkers. Dust concentrations in Sajama are very low during the last glacial period (Thompson et al., 1998), implying that winds were reduced in this area, and thus aeolian transport of plant matter. A reduction in vascular plant inputs could also be achieved with a change in direction of the prevailing winds away from heavily vegetated areas. If cooler glacial temperatures reduced the amount of overall vegetation or lowered the tree line, the vegetation that is the source of these compounds may have moved far enough away from the ice cap to limit contributions. Another plausible explanation for a lack of biomarkers in the Sajama glacial sample may be that many of the biomarkers were delivered through smoke particulate matter and the wetter conditions during the last glacial period greatly reduced forest fire occurrences. 
Figure 3-13

Sajama Ice Core Accumulation

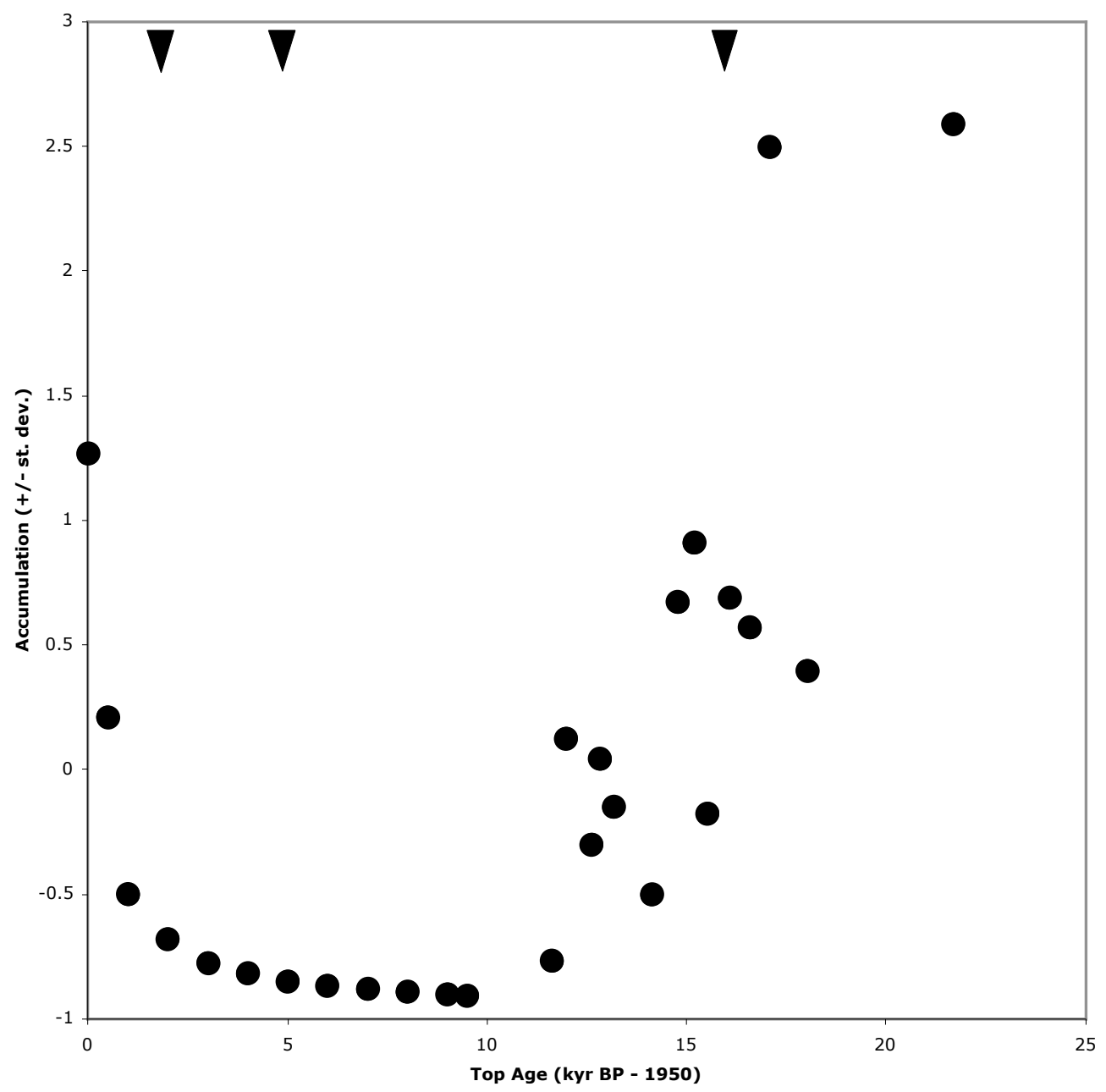

Sajama ice core accumulation estimates from Thompson et al. (1998). Inverted black triangles are approximate ages of the pre-industrial ice core samples examined in this study. 
The Sajama sample from the last glacial period is characterized by a lack of biomarkers and exhibits the lowest measured total $n$-alkane concentration of $173 \mathrm{pg} / \mathrm{ml}$. With the exception of the $n$-alkanes, all other biomarkers investigated in this study were not detected in this sample. One potential explanation for this observation is that elevated accumulation rates during the last glacial period diluted biomarker inputs and the associated wet conditions did not promote forest fires (see Figure 3-13). Another possible reason is degradation of organic matter within the ice. For example, PAHs are known to undergo photodegradation in natural waters, and among these compounds pyrene may degrade at a relatively high rate (Fasnacht and Blough, 2002). The ratio of fluoranthene to pyrene in the ice core samples is greater in the pre-industrial samples than the modern samples, supporting this argument, but also demonstrating by their presence some measure of resistance to degradation for at least $6 \mathrm{ka}$, possibly through association with black carbon. Potential effects of association with particulate matter on biomarker preservation are not known. With the range of samples investigated in this study, separation of degradation and climate signals cannot be achieved, but development of high-resolution biomarker records may address these issues.

\section{Conclusions}

The results of this investigation demonstrate that biomarkers are present in alpine ice cores in measurable quantities. The presence of the suite of biomarkers observed in this study in recent and down-core samples confirms the utility of SBSE, TD, and GC/TOF-MS for investigation of organic matter trapped in alpine ice. Biomarkers present in each of the ice cores can be used to address issues of climate change and anthropogenic pollution that are specific to each geographic location. Additionally, ice core biomarker studies can be used to investigate processes that affect the delivery of organic matter on a global scale. The results demonstrate that biomarker concentrations and distributions vary with regional climate conditions. Importantly, I have demonstrated the effectiveness of these methods with sample volumes of $30 \mathrm{ml}$ or less. These reduced volumes will allow for future generation of high-resolution, multi-molecular stratigraphic 
records that can be used to investigate changes in vegetation, atmospheric circulation, and aridity on time scales ranging from glacial/interglacial to annual. Continuing development of in-situ or on-stir-bar derivatization methods should further expand the amount of biomarker information available from single samples by negating the discrimination against polar compounds during TD. 


\section{References}

Abas M. R., Simoneit B. R. T., Elias V., Cabral J. A., and Cardoso J. N. (1995) Composition of higher molecular weight organic matter in smoke aerosol from biomass combustion in Amazonia. Chemosphere 30(5), 995-1015.

Abas M. R. B., Rahman N. A., Omar N. Y. M. J., Maah M. J., Samah A. A., Oros D. R., Otto A., and Simoneit B. R. T. (2004) Organic composition of aerosol particulate matter during a haze episode in Kuala Lumpur, Malaysia. Atmospheric Environment 38, 4223-4241.

Baltussen E., Sandra P., David F., and Cramers C. (1999) Stir bar sorptive extraction (SBSE), a novel extraction technique for aqueous samples: Theory and principles. Journal of Microcolumn Separations 11(10), 737-747.

Banskota A. H., Tezuka Y., Prasain J. K., Matsushige K., Saiki I., and Kadota S. (1998) Chemical constituents of Brazilian propolis and their cytotoxic activities. Journal of Natural Products 61, 896-900.

Conte M. H. and Weber J. C. (2002) Long-range atmospheric transport of terrestrial biomarkers to the western North Atlantic. Global Biogeochemical Cycles 16-4, 117.

Currie L. A., Dibb J. E., Klouda G. A., Benner B. A., Conny J. M., Biegalski S. R., Klinedinst D. B., Cahoon D. R., and Hsu N. C. (1998) The pursuit of isotopic and molecular fire tracers in the polar atmosphere and cryosphere. Radiocarbon $\mathbf{4 0}$, 381-390.

Eglinton G. and Hamilton. (1967) Leaf epicuticular waxes. Science 156, 1322-1335.

Fasnacht M. P. and Blough N. V. (2002) Aqueous photodegradation of polycyclic aromatic hydrocarbons. Environ. Sci. Technol. 36, 4364-4369.

Fine P. M., Cass G. R., and Simoneit B. R. T. (2004) Chemical characterization of fine particle emissions from the wood stove combustion of prevalent United States tree species. Environmental Engineering Science 21(6), 705-721.

Freeman K. H. and Colarusso L. A. (2001) Molecular and isotopic records of $\mathrm{C}_{4}$ grassland expansion in the late Miocene. Geochimica et Cosmochimica Acta 65, 1439-1454.

Gagosian R. B. and Peltzer E. T. (1986) The importance of atmospheric input of terrestrial organic matter to deep sea sediments. Organic Geochemistry 10, 661669. 
Hansen B. C. S., Wright J., H E, and Bradbury J. P. (1984) Pollen studies in the Junin area, central Peruvian Andes. Geological Society of America Bulletin 95, 14541465.

Huang Y., Street-Perrott F. A., Perrott R. A., Metzger P., and Eglinton G. (1999) Glacialinterglacial environmental changes inferred from molecular and compoundspecific $\delta^{13} \mathrm{C}$ analyses of sediments from Sacred Lake, Mt. Kenya. Geochimica et Cosmochimica Acta 63, 1383-1404.

Huang Y., Dupont L., Sarnthein M., Hayes J. M., and Eglinton G. (2000) Mapping of $C_{4}$ plant input from North West Africa into North East Atlantic sediments. Geochimica et Cosmochimica Acta 64, 3505-3513.

Hughen K. A., Eglinton T. I., Xu L., and Makou M. (2004) Abrupt tropical vegetation response to rapid climate changes. Science 304(5679), 1955-1959.

Husek P. (1993) Long-chain fatty acids esterified by action of alkyl chloroformates and analyzed by capillary gas chromatography. Journal of Chromatography, Biomedical Applications 615, 334-338.

Kawamura K., Suzuki I., and Watanabe O. (1996) Ice core record of fatty acids over the past 450 years in Greenland. Geophysical Research Letters 23, 2665-2668.

Kolahgar B., Hoffmann A., and Heiden A. C. (2002) Application of stir bar sorptive extraction to the determination of polycyclic aromatic hydrocarbons in aqueous samples. Journal of Chromatography A 963, 225-230.

Kolattukudy P. E. (1976) Chemistry and Biochemistry of Natural Waxes. Elsevier.

Lau N.-C. and Nath M. J. (2001) Impact of ENSO on SST variability in the North Pacific and North Atlantic: Seasonal dependence and role of extratropical sea-air coupling. Journal of Climate 14, 2846-2866.

Leung A., Boocock D. G. B., and Konar S. K. (1995) Pathway for the catalytic conversion of carboxylic acids to hydrocarbons over activated alumina. Energy \& Fuels 9, 913-920.

Lin L., Bukowski N., and Hughes J. (2000) Application of a wide-dynamic range $\mathrm{GC} / \mathrm{TOF}-\mathrm{MS}$ to routine quantitative analyses.

Liu K. B., Yao Z., and Thompson L. G. (1998) A pollen record of Holocene climatic changes from the Dunde ice cap, Qinghai-Tibetan Plateau. Geology 26, 135-138. 
Makou M. C., Hughen K. A., Xu L., Sylva S. P., and Eglinton T. I. (in review) Isotopic records of tropical vegetation and climate change from terrestrial vascular plant biomarkers preserved in Cariaco Basin sediments. Organic Geochemistry.

Masclet P., Hoyau V., Jaffrezo J. L., and Cachier H. (2000) Polycyclic aromatic hydrocarbon deposition on the ice sheet of Greenland. Part I: Superficial snow. Atmospheric Environment 34, 3195-3207.

Mazurek M. A. and Simoneit B. R. T. (1984) Characterization of biogenic and petroleum derived organic matter in aerosols over remote, rural, and urban areas. In Identification and Analysis of Organic Pollutants in Air (ed. L. H. Keith), pp. 353-370. ACS Symp., Ann Arbor Science/Butterworth Publishers.

Montero L., Popp P., Paschke A., and Pawliszyn J. (2004) Polydimethylsiloxane rod extraction, a novel technique for the determination of organic micropollutants in water samples by thermal desorption-capillary gas chromatography-mass spectrometry. Journal of Chromatography A 1025, 17-26.

Muzuka A. N. N. (1999) Isotopic compositions of tropical East African flora and their potential as source indicators of organic matter in coastal marine sediments. Journal of African Earth Sciences 28(3), 757-766.

Ochiai N., Sasamoto K., Kanda H., Yamagami T., David F., and Sandra P. (2004) Multiresidue method for determination of 85 pesticides in vegetables, fruits and green tea by stir bar sorptive extraction and thermal desorption GC-MS. Gerstel Application Notes Appnote 4/2004, 1-8.

Ohkouchi N., Kawamura K., and Taira A. (1997) Molecular paleoclimatology: reconstruction of climatic variabilities in the late Quaternary. Organic Geochemistry 27, 173-183.

Oros D. R. and Simoneit B. R. T. (2000) Identification and emission rates of molecular tracers in coal smoke particulate matter. Fuel 79, 515-536.

Oros D. R. and Simoneit B. R. T. (2001) Identification and emission factors of molecular tracers in organic aerosols from biomass burning. Part 1. Temperate climate conifers. Applied Geochemistry 16, 1513-1544.

Otto A., White J. D., and Simoneit B. R. T. (2002) Natural product terpenoids in Eocene and Miocene conifer fossils. Science 297, 1543-1545.

Peters A. J., Gregor D. J., Teixeira C. F., Jones N. P., and Spencer C. (1995) The recent depositional trend of polycyclic aromatic hydrocarbons and elemental carbon to the Agassiz Ice Cap, Ellesmere Island, Canada. Sci. Tot. Environ. 160/161, 167179. 
Pfannkoch E. A., Whitecavage J. A., and Kinton V. R. (2003) Stir bar sorptive extraction: Recovery of organic acids and amines. Gerstel Application Notes AppNote 5/2003, 1-7.

Popp P., Bauer C., and Wennrich L. (2001) Application of stir bar sorptive extraction in combination with column liquid chromatography for the determination of polycyclic aromatic hydrocarbons in water samples. Analytica Chimica Acta 436, $1-9$.

Prahl F. G. and Muehlhausen L. A. (1989) Lipid biomarkers as geochemical tools for paleoceanographic study. In Productivity in the Oceans: Present and Past (ed. W. H. Berger, V. S. Smetacek, and G. Wefer), pp. 271-289. John Wiley \& Sons.

Reiley G., Collier R. J., Jones D. M., and Eglinton G. (1991a) The biogeochemistry of Ellesmere Lake, U.K. - I: Source correlation of leaf wax inputs to the sedimentary record. Organic Geochemistry 17, 901-912.

Reiley G., Collier R. J., Jones D. M., Eglinton G., Eakin P. A., and Fallick A. E. (1991b) Sources of sedimentary lipids deduced from stable carbon-isotope analyses of individual compounds. Nature 352, 425-427.

Schefuß E., Ratmeyer V., Stuut J. B. W., Jansen J. H. F., and Sinninghe Damsté J. S. (2003) Carbon isotope analyses of $n$-alkanes in dust from the lower atmosphere over the central eastern Atlantic. Geochimica et Cosmochimica Acta 67, 17571767.

Simoneit B. R. T., Cardoso J. N., and Robinson N. (1990) An assessment of the origin and composition of higher molecular weight organic matter in aerosols over Amazonia. Chemosphere 21(10-11), 1285-1301.

Simoneit B. R. T., Rushdi A. I., Abas M. R., and Didyk B. M. (2003) Alkyl amides and nitriles as novel tracers for biomass burning. Environ. Sci. Technol. 37, 16-21.

Simoneit B. R. T., Medeiros P. M., and Didyk B. M. (2005) Combustion products of plastics as indicators for refuse burning in the atmosphere. Environ. Sci. Technol. 39, 6961-6970.

Stephanou E. G. and Stratigakis N. (1993) Oxocarboxylic and $\alpha, \omega$-dicarboxylic acids: Photooxidation products of biogenic unsaturated fatty acids present in urban aerosols. Environmental Science and Technology 27, 1403-1407.

Thompson L. G., Mosley-Thompson E., Bolzan J. F., and Koci B. R. (1985) A 1500-year record of tropical precipitation in ice cores from the Quelccaya Ice Cap, Peru.

Science 229, 971-973. 
Thompson L. G., Mosley-Thompson E., Davis M. E., Lin P. N., Henderson K. A., Coledai J., Bolzan J. F., and Liu K. B. (1995) Late-glacial stage and Holocene tropical ice core records from Huascarán, Peru. Science 269(5220), 46-50.

Thompson L. G., Yao T., Davis M. E., Henderson K. A., Mosley-Thompson E., Lin P. N., Beer J., Synal H. A., ColeDai J., and Bolzan J. F. (1997) Tropical climate instability: The last glacial cycle from a Qinghai-Tibetan ice core. Science 276(5320), 1821-1825.

Thompson L. G., Davis M. E., Mosley-Thompson E., Sowers T. A., Henderson K. A., Zagorodnov V. S., Lin P. N., Mikhalenko V. N., Campen R. K., Bolzan J. F., Cole-Dai J., and Francou B. (1998) A 25,000-year tropical climate history from Bolivian ice cores. Science 282(5395), 1858-1864.

Thompson L. G., Yao T., Mosley-Thompson E., Davis M. E., Henderson K. A., and Lin P. N. (2000a) A high-resolution millennial record of the South Asian Monsoon from Himalayan ice cores. Science 289(5486), 1916-1919.

Thompson L. G., Mosley-Thompson E., and Henderson K. A. (2000b) Ice-core palaeoclimate records in tropical South America since the Last Glacial Maximum. Journal of Quaternary Science 15(4), 377-394.

Thompson L. G., Mosley-Thompson E., Davis M. E., Henderson K. A., Brecher H. H., Zagorodnov V. S., Mashiotta T. A., Lin P. N., Mikhalenko V. N., Hardy D. R., and Beer J. (2002) Kilimanjaro ice core records: Evidence of Holocene climate change in tropical Africa. Science 298(5593), 589-593.

Wang L., Sarnthein M., Grootes P. M., and Erlenkeuser H. (1999) Millennial reoccurrence of century-scale abrupt events of East Asian monsoon: A possible heat conveyor for the global deglaciation. Paleoceanography 14(6), 725-731.

Xie S., Yao T., Kang S., Xu B., Duan K., and Thompson L. G. (2000) Geochemical analyses of a Himalayan snowpit profile: implications for atmospheric pollution and climate. Organic Geochemistry 31, 15-23. 


\title{
Chapter 4
}

\section{Development of High-Resolution Multi-Molecular Stratigraphic Records from Peru Margin Sediments}

\begin{abstract}
Time-of-flight mass spectrometry, coupled with fast gas chromatography, was used to identify a wide range of molecular markers in Peru Margin sediments from ODP Site 1228D. Detailed molecular stratigraphic records extending from the present to about $15 \mathrm{ka}$ were generated for specific biomarkers derived from terrestrial and marine sources. Prior to $9 \mathrm{ka}$, organic carbon, carbon/nitrogen, and many biomarker records varied in unison, implying a dominant forcing mechanism affecting production, delivery, and/or preservation of sedimentary organic matter. After $9 \mathrm{ka}$, biomarker and organic carbon concentrations increased and exhibited enhanced variability throughout the remainder of the Holocene. This period was marked by high frequency changes in marine and terrestrial organic carbon inputs, and in assemblages of marine primary producers. Different patterns of variability between independent biomarker records after $9 \mathrm{ka}$ and seemingly good preservation of labile compounds argue against a strong diagenetic or sediment redistribution overprint on the records. Concentration records of sterol degradation products and bacterial biomarkers were similar to those of compounds derived from marine algae, suggesting that in situ diagenesis is not substantial in these sediments. Very low organic-bound sulfur concentrations were measured in total lipid extracts and no sulfur bearing biomarkers were observed, suggesting that the biomarkers
\end{abstract}


used in this study are not biased by sulfur incorporation and resultant sequestration. Overall, these results suggest that 1228D sediments faithfully record water column and sediment surface processes, and can thus be used to investigate paleoclimate conditions over the time period studied. A multivariate analysis of the data was effective in separating marine and terrestrial contributions and supported the inference that the variability observed in the Peru Margin organic matter is predominantly due to marine processes, as would be expected in a productive upwelling area. The results demonstrate that the analytical scheme employed is useful for generating high-resolution biomarker records representing a wide variety of source organisms. The wealth of information provided by this approach is necessary to fully understand the relationships between biomarkers in complex and sensitive oceanic environments, such as the Peru Margin.

\section{Introduction}

Recently developed analytical technology provides organic geochemists with the opportunity to develop multi-molecular stratigraphic records that are comparable in resolution to those of other paleoclimate proxies such as foraminiferal carbonate $\delta^{18} \mathrm{O}$ and $\delta^{13} \mathrm{C}$. Time-of-flight mass spectrometry (TOF-MS; which can also denote time-of-flight mass spectrometer depending on sense) is a powerful tool that, when coupled with gas chromatography (GC; also gas chromatograph), enables rapid quantitation of a wide range of lipid biomarkers in a single sediment sample. Enhanced spectral acquisition rates ultimately permit the operator to reduce sample preparation and analysis times, and thus generate higher-resolution stratigraphic records. Marine and lacustrine sediments contain a wealth of geochemical information encoded in their organic fraction, although it occurs as a complex mixture that is most telling when separated and analyzed as individual molecular species. Successful identification and quantitation of the full scope of biomarkers present in sediments could provide information about input sources that span several trophic levels, permitting a more holistic interpretation of the biological processes contributing organic matter to the sediments. 


\section{Fast GC/TOF-MS}

Capillary column GC is an indispensable tool for lipid separation and analysis, but is limited in analytical potential by the type of detector it is paired with. Probably the most common detection device used in organic geochemical laboratories is the flame ionization detector (FID), which is simple, robust, and provides a linear response over a wide range of concentrations. However, the FID is limited in its utility in that it is only able to provide information about analyte concentration, and only reliably on peaks that are baseline-resolved. To identify and quantify compounds of interest, the analyst must already have an understanding of their elution order, usually obtained through analysis of external standards. To ensure valid results for specific biomarkers, organic rich samples must be purified using wet chemical techniques, which by nature exclude other compounds that may be of value. In essence, GC-FID analysis requires a priori knowledge of the biomarkers present in complex environmental samples and thus restricts the investigation to what the geochemist already expects or is familiar with.

Traditional types of mass selective detectors that are coupled with GC, such as quadrupole and ion trap instruments, add another dimension of analytical function in that they can be used to positively identify compounds as well as quantify them. Upon elution, compounds entering the MS are immediately ionized by electron impact or chemical methods, causing them to dissociate into charged fragments. The fragmentation pattern is reproducible and produces mass spectra that can be interpreted according to fundamental chemical principles and can be compared to those of authentic standards or to independent libraries, thus enabling identification of unknown compounds. Another benefit of using mass selective detectors arises from the ability to extract and view chromatograms of selected ions, whereby analyte peaks can be generated from representative ions and interfering ions can be removed. Using this feature, compounds of interest can be separately quantified from co-eluting peaks, ultimately reducing the necessary amount of sample pre-treatment and purification. The greatest drawback of traditional GC-MS systems is that they repeatedly scan across mass ranges, limiting 
spectral acquisition rates and demanding relatively slow elution times. Elution occurs continually, but only one ion mass is being collected by the MS at any given instant, by nature eliminating potentially valuable spectral information if chromatographic peaks are too narrow.

A new type of GC-MS system involving fast-GC and TOF-MS provides many of the advantages of traditional GC-MS instruments without the limitations described above. Rather than scanning across mass ranges to detect individual ions, the TOF-MS pulses groups of ions down a "flight tube" at $40 \mathrm{kHz}$ with the same initial energy, and then applies the time they take to traverse the flight path to the relationship $\mathrm{KE}=1 / 2 \mathrm{mv}^{2}$ to assign ion masses. The flight tube is simply a rectangular box with the ion push-out region and detector array on one of the sides and a wire grid with a constant applied voltage on the other. The ions travel a parabolic path from push-out region to detector, the length of which, and thus travel time, depends on the mass of the ion. The rapid ion transmission and signal processing in TOF-MS results in collection of an essentially continuous stream of ions and thus enables use of high spectral acquisition rates (up to 100 spectra/second). The TOF-MS manufactured by Thermo Electron Corp. (the Tempus) employs a series of three stacked detectors, each of which converts a different range of input intensities to spectral data, to produce a linear response that theoretically can span almost 6 orders of magnitude of analyte concentration (Lin et al., 2000). This detection system is exceptionally well suited to analysis of complex environmental samples in which widely varying biomarker concentrations are expected. A lower detection limit of about 2 pg of material on-column was established for the GC/TOF-MS I used, and sample overload occurred on the narrow-bore capillary column used before an upper boundary could be determined.

Fast-GC is a technique in which rapid oven temperature ramping is applied to a short, narrow-bore capillary column, resulting in quicker elution times and reduced run length compared to traditional GC methods. An important benefit of fast-GC is that it produces chromatograms with sharper, narrower peaks, effectively increasing signal-tonoise. Additionally, short run lengths (typically 10-15 minutes) provide the opportunity 
to increase sample throughput, facilitating development of high-resolution biomarker records. However, the peaks produced by fast-GC elute much closer together and are thus more likely to interfere with one another. Conventional GC-MS systems are thus ill suited detectors for fast-GC because their inherently slow scan rates (e.g. $\sim 1-10 \mathrm{~Hz}$ ) would under-sample peaks that are on the order of only one second wide, leading to poor quantitation. In contrast, TOF-MS is capable of fully resolving the narrow peaks produced by fast-GC and thus serves as an ideal mass selective detector for this application. Ultimately, the pairing of fast-GC techniques with the rapid spectral acquisition inherent to TOF-MS results in decreased analysis times and therefore greater sample throughput. A key benefit of this analytical approach is the ability to generate high-resolution molecular stratigraphic records of the type necessary to interpret abrupt environmental changes as recorded in sedimentary organic inputs. Additionally, the use of fast-GC with TOF-MS permits liberal measurement of sample replicates and external standards, improving biomarker quantitation in large sample sets.

In the present study of Peru Margin sediments, I avail myself of another important benefit of TOF-MS, which is the ability to identify and quantify a wide range of biomarkers in a single sample with minimal pre-treatment. Traditionally, total lipid extracts (TLEs) of environmental samples, especially organic-rich sediments, required separation of various biomarker classes by wet chemical methods into an array of fractions that would be analyzed individually. The number of fractions necessary generally depends on the complexity of the sample and the level of purity desired. Such is the case especially for GC-FID, for which compounds of interest must be free of coeluting peaks to achieve accurate quantitation. Separating the TLE into fractions and performing purification steps, often involving such procedures as silica gel column chromatography and urea adduction, is time consuming and can introduce contamination into the sample. For these reasons, molecular stratigraphic records are often of low temporal resolution or restricted to a particular class of compounds. Due to the unique ion transmission and mass recognition properties of the TOF-MS (i.e. that all ions are collected and none are lost due to scanning), full-range spectral information is available 
at every point on the chromatogram. Ultimately, this means that specific biomarkers peaks generated from characteristic ions can be isolated from exceedingly complex total ion chromatograms (TICs) even at the high spectral acquisition rates demanded by fastGC. Quadrupole GC-MS also provides the ability to monitor individual ions at an elevated sampling rate, but only when operating in selected ion monitoring mode, which is pre-programmed to ignore other ion inputs and thus restricts the number and type of biomarkers that can be identified in a single sample. TOF-MS provides the ability to examine a broader range of compounds in a TLE, even if they occur in widely different concentrations and co-elute with one another, thus obviating the need to purify or separate samples into fractions, which in turn greatly reduces sample preparation time, solvent usage, and chances of entraining contaminants.

\section{Peru Margin Study Site}

I employed GC/TOF-MS to examine the biomarker content of Peru Margin sediments that were collected during ODP Leg 201 at coring Site 1228D (Figure 4-1). This core was drilled nearby to ODP Leg 112 Site 680 on the outer continental shelf in

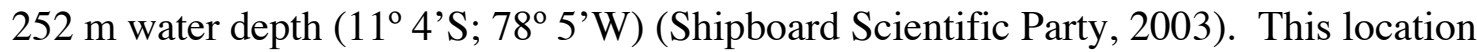
occurs in an area of perennial upwelling and associated high productivity, which is perhaps best known for its bountiful anchoveta population. In 1970, around which time the Peruvian upwelling region was the most productive fishery in the world, anchoveta catches surpassed 10 million tons (Cushing, 1981). Bruland et al. (2005) describe upwelled surface waters so replete with chlorophyll and biota that they appear "chocolate brown" in color. Although upwelling is not homogenous along the Peru Margin, Site $1228 \mathrm{D}$ is located within or adjacent to a modern cell of intense coastal upwelling and productivity (de Mendiola, 1981).

Upwelling of deep, nutrient-rich water on the Peru Margin and the resultant enhanced productivity are caused by stable regional atmospheric and oceanic circulation patterns. Perennial southeasterly alongshore trade winds produce an offshore flow to a depth of about $30 \mathrm{~m}$ (Smith, 1981). Smith (1981) observed a compensatory onshore flow 
Figure 4-1

\section{Peru Margin Sample Location}

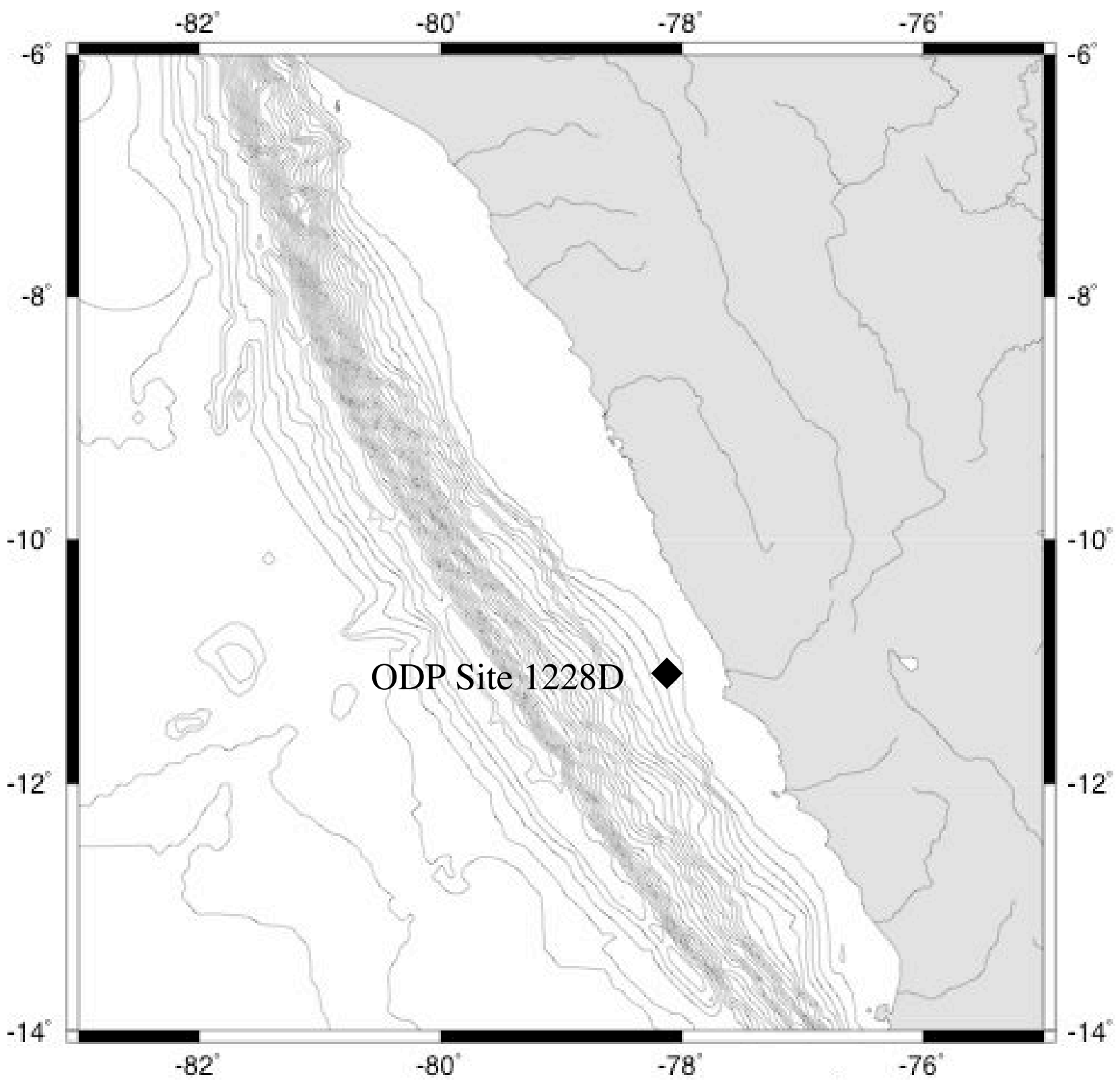

ODP Site 1228D coring location on Peru Margin outer shelf. 
below this layer to a depth of approximately $100 \mathrm{~m}$ with a maximum current velocity at about $60 \mathrm{~m}$ depth. The onshore flow waters are derived from the nutrient-rich, poleward flowing Peru Countercurrent (PCC), which impinges on the shelf to depths of $200 \mathrm{~m}$ or greater (Smith, 1983). It is the onshore flowing water that provides the nutrients that fuel coastal upwelling on the Peru Margin. The PCC lies just below the surface layer of wind-driven flow and reaches a maximum mean velocity of about $5 \mathrm{~cm} / \mathrm{sec}$ at depths of 40 to $80 \mathrm{~m}$ (Smith, 1981). However, Arthur et al. (1998) observed a poleward current at about $200 \mathrm{~m}$ depth $\left(12^{\circ} \mathrm{S}\right)$ with a velocity of $30 \mathrm{~cm} / \mathrm{sec}$, implying that the depth and strength of the PCC are variable. The PCC is strong enough to winnow and redeposit fine-grained shelf sediments such as those that organic matter is most commonly associated with. However, the surface sediments on the Peru shelf are often protected from the strong current by the presence of large microbial mats of sulfur oxidizing bacteria (McCaffrey et al., 1989; Arthur et al., 1998). Sediment winnowing is not expected to be problematic at site 1228D because it is located on the outer edge of the shelf, away from the core of the PCC, although it could be exposed to redeposited material from upstream. The shelf is most exposed to the PCC north of $11^{\circ} \mathrm{S}$ where it is much wider. A bulk organic carbon ${ }^{14} \mathrm{C}$ age of $630 \mathrm{yr} \pm 30$ was obtained for the $0-2 \mathrm{~cm}$ interval of a Peru Margin box core collected near 1228D (SJ1092 core BC153; 11 3.7'S, $78^{\circ} 4.4^{\prime} \mathrm{W} ; 250 \mathrm{~m}$ ) (pers. comm., T. Eglinton). This age implies that recent material is indeed preserved at the sediment surface and thus sediment redistribution is either not problematic, or occurs over short time scales.

A stable oxygen minimum zone (OMZ) bathes much of the outer shelf and slope on the Peru Margin and enhances organic matter preservation. Arthur et al. (1998) observed dissolved oxygen concentrations of less than $10 \mu \mathrm{mol} / \mathrm{kg}$ between depths of about 80 and $700 \mathrm{~m}$ at $12^{\circ} \mathrm{S}$. Besides inhibiting oxidation of sedimentary organic matter, these low oxygen conditions result in reduced benthic biological activity and bioturbation. No evidence of biological disturbance was observed in the top $3 \mathrm{~m}$ of 1228D. Based on benthic foraminiferal assemblages, Oberhänsli et al. (1990) inferred 
that there were no major changes in bottom water oxygenation at the location of $1228 \mathrm{D}$ during the time period examined in this study.

Primary productivity and upwelling, while patchy along the Peru Margin, are strong throughout the year with moderate seasonal dependence. Maximum phytoplankton concentrations occur in cells associated with strong upwelling and are generally located more to the north on the Peruvian coast in austral fall and winter, and to the south during spring and summer (de Mendiola, 1981). Overall phytoplankton cell densities were found to be slightly lower during the winter. Diatoms are the most prevalent phytoplankton in the Peru upwelling region, with only six species representing about $75 \%$ of the total population (de Mendiola, 1981). Dinoflagellates are also present in abundance, but are minor compared to diatoms. de Mendiola (1981) observed most of the important diatom and dinoflagellate species throughout the year, although individual species varied in abundance seasonally.

Despite the hyper-arid climate and sparse vegetation in western Peru, terrestriallyderived biomarkers have been identified in Peru Margin sediments and sea surface aerosol samples (Schneider and Gagosian, 1985; Volkman et al., 1987). Schneider and Gagosian (1985) estimated that less than $1 \%$ of the flux of two terrestrial biomarkers in the water column could be accounted for by aeolian deposition. Thus, the bulk of terrestrial inputs to the sediments are likely delivered through fluvial transport. Several rivers, including one directly to the east of Site 1228D, drain the western flank of the Andes (Figure 4-1) and could deliver terrestrial mineral and organic material to the Peru Margin. Indeed, several small fragments of what appeared to be vascular plant root material were observed during sampling of the 1228D core, and were also positively identified in Peru Margin sediments at about $15^{\circ} \mathrm{S}$ by McCaffrey (1990).

The upwelling, enhanced primary productivity, and low-oxygen conditions on the outer shelf and slope of the Peru Margin result in excellent preservation of organic matter, making this an optimal location for organic geochemical study. Arthur et al. (1988) examined surface sediments along two transects on the Peru margin and found a broad maximum in organic carbon content between depths of 75 and $350 \mathrm{~m}$, coincident 
with dissolved oxygen concentrations of less than $5 \mu \mathrm{mol} / \mathrm{kg}$. At Site $1228 \mathrm{D}$, the measured organic carbon content of near core-top sediments was about 11\%. Many different sedimentary biomarkers have been used in separate studies to examine production, preservation, and delivery of organic matter, as well as modern and paleoceanographic conditions on the Peru Margin (Farrington et al., 1988; Farrimond et al., 1990; McCaffrey et al., 1990; Bergamaschi et al., 1997; Higginson and Altabet, 2004). The studies to date demonstrate the complex nature of the sedimentary organic matter, owing to the tremendous diversity and amount of planktonic biota in the overlying water column. Sediments such as these are an ideal initial test for GC/TOFMS because its analytical utility entails reliable separation of individual compounds from complex mixtures fraught with chromatographic interferences.

Core 1228D was sampled from $4.5 \mathrm{~cm}$ to a maximum depth of $297.5 \mathrm{~cm}$. Throughout this interval, sediments were predominantly dark olive green to black diatomaceous silts and were nearly saturated at the core top, but lost water content with depth and were only moist at the bottom of the sampled section. A volcanic ash layer, which was not sampled, occurred between depths of 119.5 and $120.5 \mathrm{~cm}$. Foraminifera and what appeared to be vascular plant fragments and biogenic spines appeared sporadically in the core. Aside from the ash layer, the most prominent feature of the upper $3 \mathrm{~m}$ of $1228 \mathrm{D}$ was the presence of very coarse-grained mineral material $(0.5-3.0$ $\mathrm{cm}$ diameter) surrounded by sandy sediment between 276.5 and $280.5 \mathrm{~cm}$ depth. This material was most likely deposited in a much higher energy environment than the finegrained sediments above and below, possibly coincident with lower sea level during the last glacial period. It may consist of phosphorite nodules, as were observed in surface sediments at this water depth by Arthur et al. (1998), in which case the material could be indicative of winnowing by an unusually strong PCC. It is assumed that the presence of the coarse material represents a hiatus of unknown duration, and thus the few samples analyzed within and below this interval are not considered with the rest of the record, but serve only as clues to organic inputs under different depositional conditions. The uniform nature of the sediments above the hiatus and clearly defined ash layer argue 
against variable winnowing and re-deposition at $1228 \mathrm{D}$ as would be expected if the PCC strongly affected this depth and location. Although strength of upwelling, primary productivity, and delivery of organic matter are variable in location and time on the Peru Margin (e.g. Wakeham et al., 1984), the time period encompassed by each sediment sample ( $\sim 50$ years) should smooth out seasonal and El Niño scale episodic events and provide a reasonable estimate of average conditions. The age scale for $1228 \mathrm{D}$ is based on five alkenone and two bulk organic carbon AMS radiocarbon dates (Higginson and Altabet, 2004). Matthew Higginson and Mark Altabet (SMAST - UMASS Dartmouth) graciously provided the ${ }^{14} \mathrm{C}$ dates and corrected calendar ages. Alkenone ages were obtained at the Woods Hole Oceanographic Institution in conjunction with Timothy Eglinton and $\mathrm{Li} \mathrm{Xu}$. The age scale was adjusted based on correlation of $\delta^{15} \mathrm{~N}$ records between 1228D and several other shallow cores on the Peru Margin (Higginson and Altabet, 2004).

\section{Analytical Procedure}

Initially, the $1228 \mathrm{D}$ half-rounds were sub-sampled into two adjacent U-channel sleeves, one of which was archived. Prior to sampling, the core segments were shipped and stored under refrigeration to minimize loss of volatile or semi-volatile organic compounds and to suppress degradation processes. Samples were collected for this study from the original core segments around the void left by the U-channels. Several sections of the core, including the top $4.5 \mathrm{~cm}$, are not represented because large amounts of sediment had been removed previously for compound-specific radiocarbon analysis. Homogenous sediment samples were collected into clean $4 \mathrm{ml}$ vials in centimeter increments, after which they were freeze-dried and stored under refrigeration. Sediment samples from at least every other centimeter were prepared for analysis via GC/TOF-MS. The dry weight of these samples ranged from 0.14 to $1.55 \mathrm{~g}$, with an average of $0.40 \mathrm{~g}$.

Semi-volatile organic matter was extracted from the sediments via Accelerated Solvent Extraction (Dionex), in which a methanol/dichloromethane (1:9) mixture was introduced to each sample in three stages at $100^{\circ} \mathrm{C}$ and 1,000 p.s.i. The resultant TLEs, 
which were very dark green to black in color, were collected into $40 \mathrm{ml}$ vials and concentrated (Zymark Turbovap) to volumes of 1-2 ml. Enough activated $\mathrm{Cu}$ was added to each vial so that it was completely in contact with the TLE and then it was allowed to react for at least 12 hours in order to remove elemental S. 10\% of each TLE was removed to a $\mathrm{GC}$ vial with glass insert and was transesterified at room temperature using Meth-Prep 2 (Alltech), thus releasing ester-bound compounds and converting carboxylic acids to methyl esters. In particular, fatty acids were converted to their corresponding fatty acid methyl esters (FAMEs). Subsequently, the samples were silylated using BSTFA ( $+1 \%$ TMCS; Pierce) and pyridine $\left(60^{\circ} \mathrm{C}, 15 \mathrm{~min}\right)$. Prior to analysis, $\mathrm{C}_{23: 1}$ and $\mathrm{C}_{36} n$-alkane internal standards were added to each sample, all of which were ultimately analyzed in a solution of equal parts pyridine, BSTFA, and dichloromethane. $0.07 \%$ of each original TLE was injected $(1.0 \mu \mathrm{l})$ and analyzed via GC/TOF-MS. More than half of the samples were analyzed in duplicate and blanks and external standards consisting of FAMEs, silylated $n$-alkanols, and $n$-alkanes were run in between every 12 samples.

All analyses were conducted on a ThermoQuest TRACE GC with PAL autosampler and PTV injector coupled with a Thermo Electron Inc. Tempus TOF-MS. The PTV injector with $2 \mathrm{~mm}$ deactivated glass liner was run in solvent-split mode with a constant septum purge and a $0.4 \mathrm{ml} / \mathrm{min}$ constant He carrier gas flow, and the TRACE GC was equipped with a $10 \mathrm{~m}(0.10 \mathrm{~mm}$ i.d., $0.10 \mu \mathrm{m}$ film thickness $)$ Restek Rtx-1 column. The initial GC oven temperature was $40^{\circ} \mathrm{C}$, which was held for 3 minutes, after which the temperature was ramped at $75^{\circ} \mathrm{C} / \mathrm{min}$ to $120^{\circ} \mathrm{C}$ and $37^{\circ} \mathrm{C} / \mathrm{min}$ to a final temperature of $320^{\circ} \mathrm{C}$, which was maintained for 4 minutes. The Tempus TOF-MS was tuned and mass calibrated prior to the run and was operated at an acquisition rate of 20 spectra/second. The Xcalibur software package was used to process chromatographic and spectral data. The entire data set was automatically processed using the Xcalibur ICIS peak identification and area determination algorithm. Several types of useful lipid biomarkers were selected for analysis via this manner of data processing. Concentrations of FAMEs and $n$-alkanols were determined by comparison with authentic external standards analyzed at the same time as the samples and under the same conditions. 
Response factors for all other compounds were determined by comparing their chromatographic peaks in the TIC of a representative sample $(93 \mathrm{~cm})$ with that of the $\mathrm{C}_{36}$ $n$-alkane internal standard, and then adjusted for quantitation using the extracted ion chromatograms. Concentrations determined in this manner are not accurate due to coelution between compounds in the TIC, and should thus be considered as estimates. However, the chosen response factors were applied uniformly to each biomarker throughout the record and thus do not interfere with interpretation of patterns of variability in concentration. Total carbon, total organic carbon, and total nitrogen contents of each sediment sample, as well as total sulfur of a subset of TLEs, were determined via elemental analyzer (Carlo Erba EA1108). Results of GC/TOF-MS and other analyses are presented in Appendix C.

\section{Results and Discussion}

\section{Bulk Sediment Characteristics}

Organic Carbon Content Total organic carbon $\left(\mathrm{C}_{\text {org }}\right)$ varied between 2.0 and $14.6 \%$ in $1228 \mathrm{D}$ sediments with relative minima immediately overlying the hiatus $(\sim 14.7$ ka) and at about $9 \mathrm{ka}$ (see Figure 4-2). Values were generally greatest during the last 7 $\mathrm{ka}$, although the record is also most variable during this period. Sharp local minima are present at $0.5,1.4,4.0$, and $6.4 \mathrm{ka}$, and a broader local minimum is centered at about 2.0 ka. Biomarker contents were examined over the entire time period from the hiatus to the present, which, based on the variability observed in the percent $\mathrm{C}_{\text {org }}$ record, is expected to span several periods in which environmental conditions differed. Differences in sedimentary organic carbon content over this interval may be driven by changes in sea surface productivity, likely associated with upwelling strength, or preservation.

Nitrogen Content Total nitrogen was also measured in 1228D sediments and the $\mathrm{C} / \mathrm{N}$ ratio was determined (Figure 4-3). Before $9 \mathrm{ka}$, the $\mathrm{C} / \mathrm{N}$ record roughly resembles $\% \mathrm{C}_{\text {org }}$ with local minima in the oldest part of the record and at about 9 ka and higher values in between. The $\mathrm{C} / \mathrm{N}$ record is relatively stable after about $7.1 \mathrm{ka}$, implying that much of the biomarker variability during the Holocene is governed by changes in 
Figure 4-2

Peru Margin Weight \% Organic Carbon

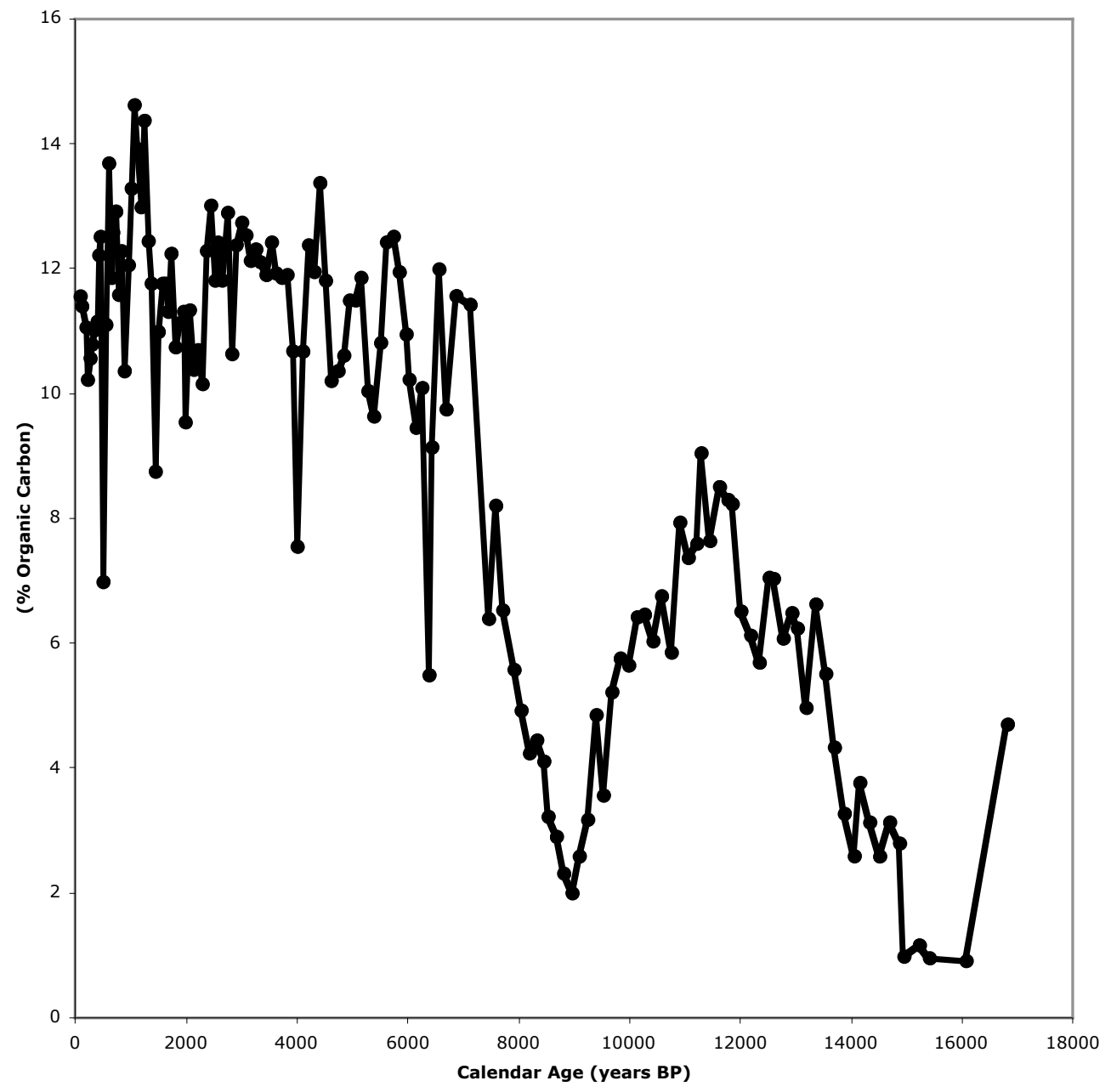

Organic carbon content (by weight \%) of 1228D sediments. 
Figure 4-3

Peru Margin Carbon/Nitrogen

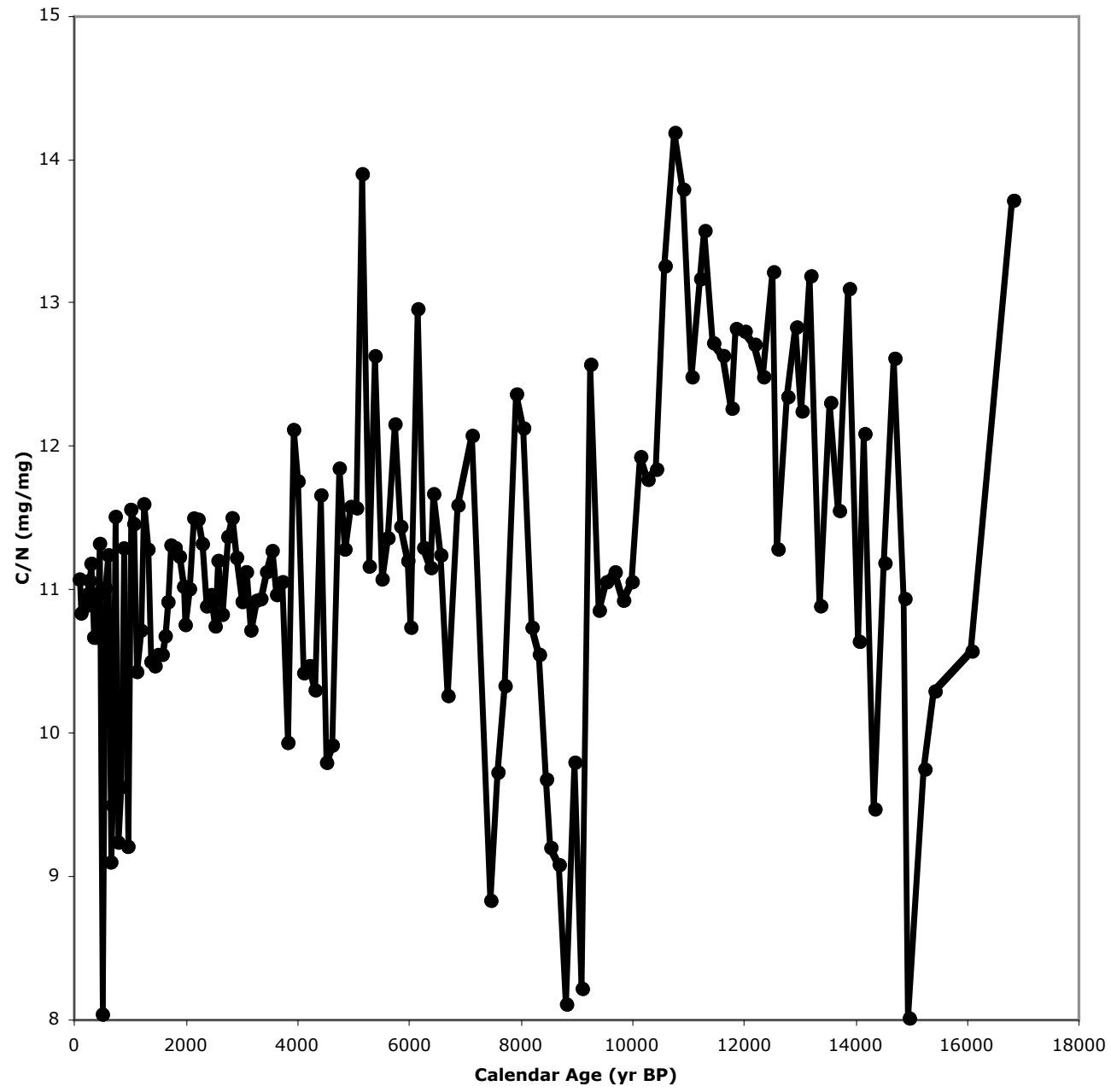

Carbon-to-nitrogen ratio $(\mathrm{C} / \mathrm{N})$ of $1228 \mathrm{D}$ sediments. 
composition of planktonic biota and not by any large changes in terrestrial versus marine inputs or preservation. A plot of total organic carbon versus total nitrogen revealed that there is little inorganic nitrogen present in sediments at Site 1228D throughout the record (y-intercept of linear trend line is approximately 0). Henrichs and Farrington (1984) measured lower $\mathrm{C} / \mathrm{N}$ in a core-top sample from the middle of the Peru Margin OMZ than in a nearby deeper core that was bathed in oxygenated bottom water ( 8.3 compared to 9.5). If this pattern were representative of greater organic matter degradation outside of the $\mathrm{OMZ}$, the low $\mathrm{C} / \mathrm{N}$ values observed at $9 \mathrm{ka}$ and early in the record would imply enhanced preservation. However, this inference is not borne out in the $\% \mathrm{C}_{\text {org }}$ record, which also has minima at these times. Indeed, Henrichs and Farrington (1984) observed that TOC and $\mathrm{C} / \mathrm{N}$ records within the top meter of Peru Margin sediments do not necessarily co-vary both within the $\mathrm{OMZ}$ and below it, suggesting that $\mathrm{C} / \mathrm{N}$ is influenced by factors other than just preservation. Reduced $\mathrm{C} / \mathrm{N}$ values at about 9 ka may be consistent with bacterial degradation of organic matter, which could simultaneously reduce sedimentary $\% \mathrm{C}_{\text {org }}$ and $\mathrm{C} / \mathrm{N}$. However, reduced concentrations of bacterial biomarkers at $9 \mathrm{ka}$ are not consistent with a discrete period of enhanced bacterial activity at this time. Alternatively, the low $\mathrm{C} / \mathrm{N}$ values may simply reflect reduced inputs from carbohydrate-rich (high $\mathrm{C} / \mathrm{N}$ ) organisms such as diatoms or the sulfur-oxidizing bacteria Thioploca.

Sellner et al. (1983) investigated phytoplankton assemblages and particulate organic matter (POM) $\mathrm{C} / \mathrm{N}$ in euphotic zone water samples from the Peru Margin, spanning recently upwelled near-shore waters to offshore advected surface water that had undergone nutrient drawdown. They observed that near-shore, nutrient-rich waters supported burgeoning diatom populations with a POM C/N of about 6 and high cell densities. Farther offshore, cell densities dropped, populations of dinoflagellates and zooplankton increased, POM C/N increased to above 8, and the lipid portion of POM increased. These results demonstrate that surface water processes related to upwelling and nutrient supply can have important effects on the nature of the lipid matter preserved the sediments and that $\mathrm{C} / \mathrm{N}$ variability can occur independently of preservation effects. 
Based on the results of Sellner et al. (1983), the C/N minima in the early, middle, and late parts of my record may represent a shift to more recently upwelled, nutrient-rich water over the site. In this case, the reduced POM lipid content determined by Sellner et al. (1983) for these conditions would be consistent with the reduced biomarker concentrations observed at these times, even in $\mathrm{C}_{\text {org }}$-normalized biomarker data. The $\mathrm{C} / \mathrm{N}$ values measured in $1228 \mathrm{D}$ (8.0-14.2) are greater than those described above for surface water POM, perhaps reflecting degradative processes and/or inputs of terrestrial vascular plant derived organic matter. Other processes such as winnowing and sediment redistribution may also have played a role in creating the event at about $9 \mathrm{ka}$.

Bergamaschi et al. (1997) recorded lower C/N values for Peru Margin grain sizes 50-500 $\mu \mathrm{m}$ compared to those $0.5-26 \mu \mathrm{m}$ (average values of $\sim 7$ compared to 10). Based on these results, which are consistent with absolute $\mathrm{C} / \mathrm{N}$ values, the low $\mathrm{C} / \mathrm{N}$ values in the record could also have resulted from the winnowing of fine-grained material.

Grain Size Effects In Peru Margin sediments, as in other settings, preservation of organic matter appears to be aided by association with mineral matter (Bergamaschi et al., 1997). Bergamaschi et al. (1997) found that much of the organic carbon in Peru Margin surface sediments (13\%31'S, $106 \mathrm{~m}$, bulk $\mathrm{C}_{\text {org }} 6.6 \%$ ) is associated with the 5-11 $\mu \mathrm{m}$ size fraction, which also presents the largest amount of surface area. They determined that the poorest preservation was in the $50 \mu \mathrm{m}$ size fraction, which provided relatively little surface area and could support only $1.5 \mathrm{Wt} \% \mathrm{C}_{\mathrm{org}}$. Above the hiatus, the minimum amount of $\mathrm{C}_{\text {org }}$ in $1228 \mathrm{D}$ sediments is $2.0 \%$, so preservation does not appear to be limited by grain size effects.

\section{Biomarker Identification Via GC/TOF-MS}

In order to test the ability of GC/TOF-MS to separate a wide range of biomarkers from a complex TLE, I investigated compounds from a variety of molecular classes that were expected to be present in Peru Margin sediments. TLEs were minimally treated prior to analysis so as not to eliminate any compounds of interest. A transesterification and silylation were performed to improve chromatography of compounds with functional 
groups, but no procedures were performed that separate a TLE into fractions by design, such as silica gel chromatography or urea adduction. GC run times were kept purposefully short (13.5 minutes) to increase signal and assess the capabilities of TOFMS used in conjunction with fast-GC for rapid sample throughput. The conditions of this study, namely the complexity of these organic matter-replete samples and the use of fastGC, were intended to test the methods under the highest degree of difficulty. Generation of a high-resolution, multi-molecular record from Peru Margin sediments using these simplified sample preparation methods demonstrates the utility of GC/TOF-MS and shows that this analytical scheme can be applied to samples from other locations and environments.

A GC/TOF-MS partial chromatogram from the $89 \mathrm{~cm}(\sim 2.6 \mathrm{ka})$ sample is presented in Figure 4-4 as an example. This sample was deposited during the late Holocene, which is characterized by increased input and/or preservation of organic matter $\left(12.4 \% \mathrm{C}_{\text {org }}\right)$. Figure $4-4$ is a total ion chromatogram (TIC), which is comprised of the summed responses of all ions collected during each acquisition event. This TIC is typical of all 1228D samples studied. Because ions are collected nearly continuously by the TOF-MS, the TIC is roughly analogous to a chromatogram produced by GC-FID. Many peaks are readily observable on the TIC although the elevated, shifting baseline represents an unresolved complex mixture (UCM) that obscures many compounds of interest, especially those occurring at low concentrations. The compounds in this complex sample often co-elute and are not fully resolved, rendering them difficult to quantify on the TIC. Indeed, many of the compounds of organic geochemical utility elute over a span of just 4 minutes, between 7 and 11 minutes, and their peaks are on the order of only 2 to 3 seconds wide. It would be possible to further reduce the GC run time, but the mixture of solvents used in this study (BSTFA, pyridine, and dichloromethane) produced a solvent peak that persisted past 7 minutes, so the initial temperature ramp was lengthened to provide adequate separation of low-volatility compounds from the solvent peak. 
Figure 4-4

Peru Margin TIC (89 cm)

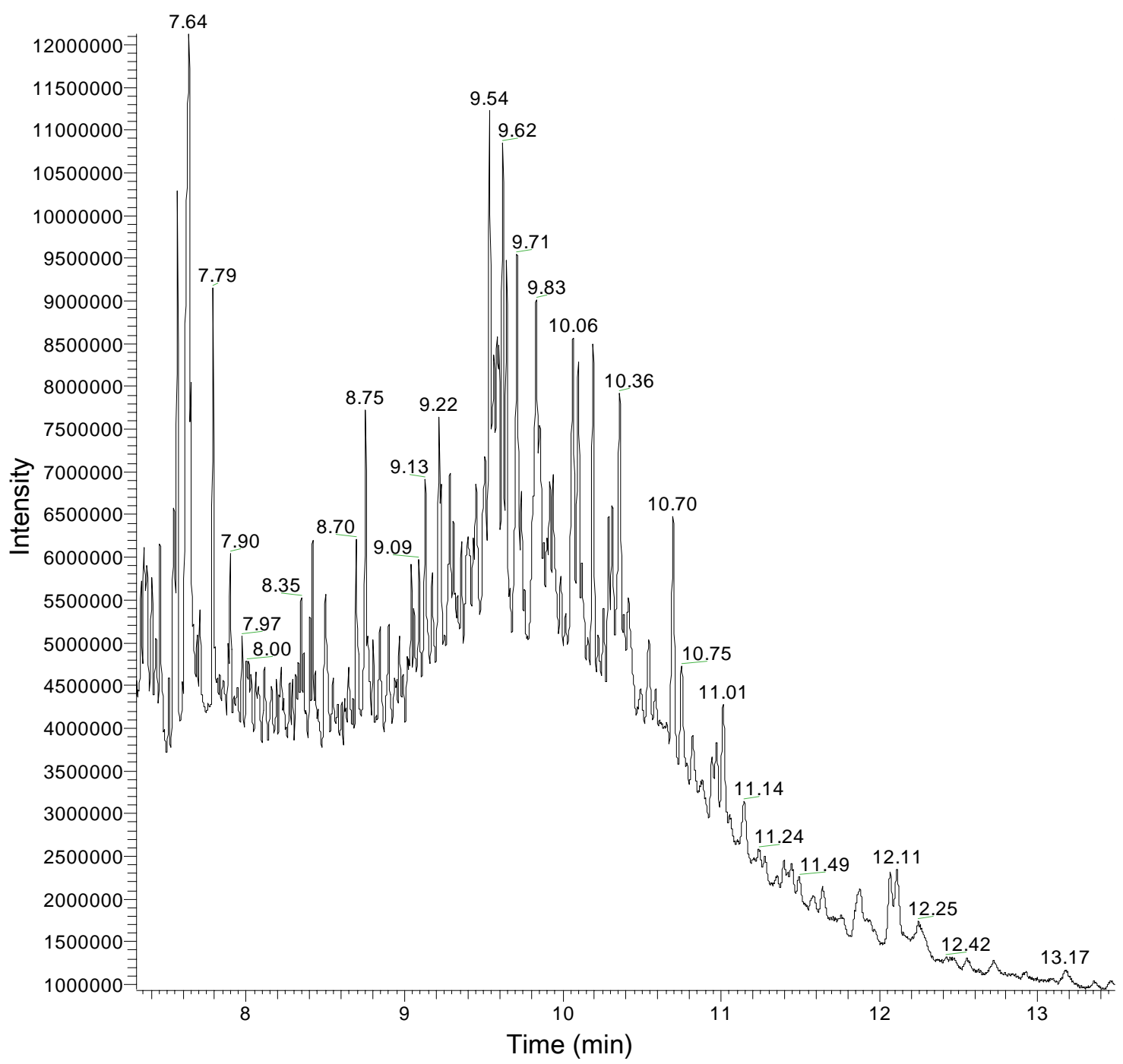

GC/TOF-MS total ion chromatogram of $89 \mathrm{~cm}$ sample. Sterols generally elute between 9.5 and 10.5 minutes. The broad solvent peak at the beginning of the run is not depicted. 
In order to identify and measure specific biomarkers in complex samples, extracted ion chromatograms (EICs) are generated from one or more ions that are representative of individual compounds or a class of compounds. For example, Figure 45 is an EIC of $\mathrm{m} / \mathrm{z} 74+87$, which is characteristic of FAMEs. In this manner, clean peaks with a stable baseline are culled from a noisy TIC. Unlike conventional mass spectrometers, the peaks generated by GC/TOF-MS contain comprehensive spectral information at all acquisition points, so even sub-second wide peaks could be faithfully identified and quantified from EICs. As a further example, Figures 4-6a and 4-6b exhibit the $\mathrm{C}_{26} n$-alkanol peak (EIC of $\mathrm{m} / \mathrm{z} 439$ ) from the $89 \mathrm{~cm}$ sample and its summed mass spectrum, respectively. The FAMEs and $n$-alkanols identified via EIC generally occur in low enough concentrations that they are not observable on the TIC, thus demonstrating the utility of this analytical method for "mining" biomarker information from parts of the chromatogram heavily impacted by the UCM. Figure 4-7 depicts EIC peaks of the individual sterols cholesterol, cholestanol, brassicasterol, $\beta$-sitosterol, and dinosterol, which all appear on the TIC, but not as baseline-resolved, quantifiable peaks. The utility of the broad-scale linearity provided by the stacked detector array is evident in the ability of the instrument to provide quantifiable peaks for both the low concentration $n$-alkanols and the enriched marine sterols. One drawback of the TOF-MS is that it appears to lose sensitivity at very high masses $(\mathrm{m} / \mathrm{z}>\sim 500)$. For this reason, I was not able to quantify the $\mathrm{C}_{37}$ unsaturated methylketones that have been used as a proxy for sea surface temperature, and that are typically some of the last compounds to elute using capillary GC.

Table 4-1 lists compounds that were positively identified in these Peru Margin sediments and their probable sources. The only biomarker shown on the table that proved difficult to isolate by EIC was the $\mathrm{C}_{28} n$-alkanol, for which all representative ions were present in the background spectrum at the time it eluted. The biomarkers chosen for this study were selected because they represent terrestrial and marine sources and a range of important source organism classes. A caveat about many of these compounds is that they are not exclusive to the sources that are listed, and thus interpretation of biomarker 
Figure 4-5

Peru Margin Fatty Acid (as FAME) EIC

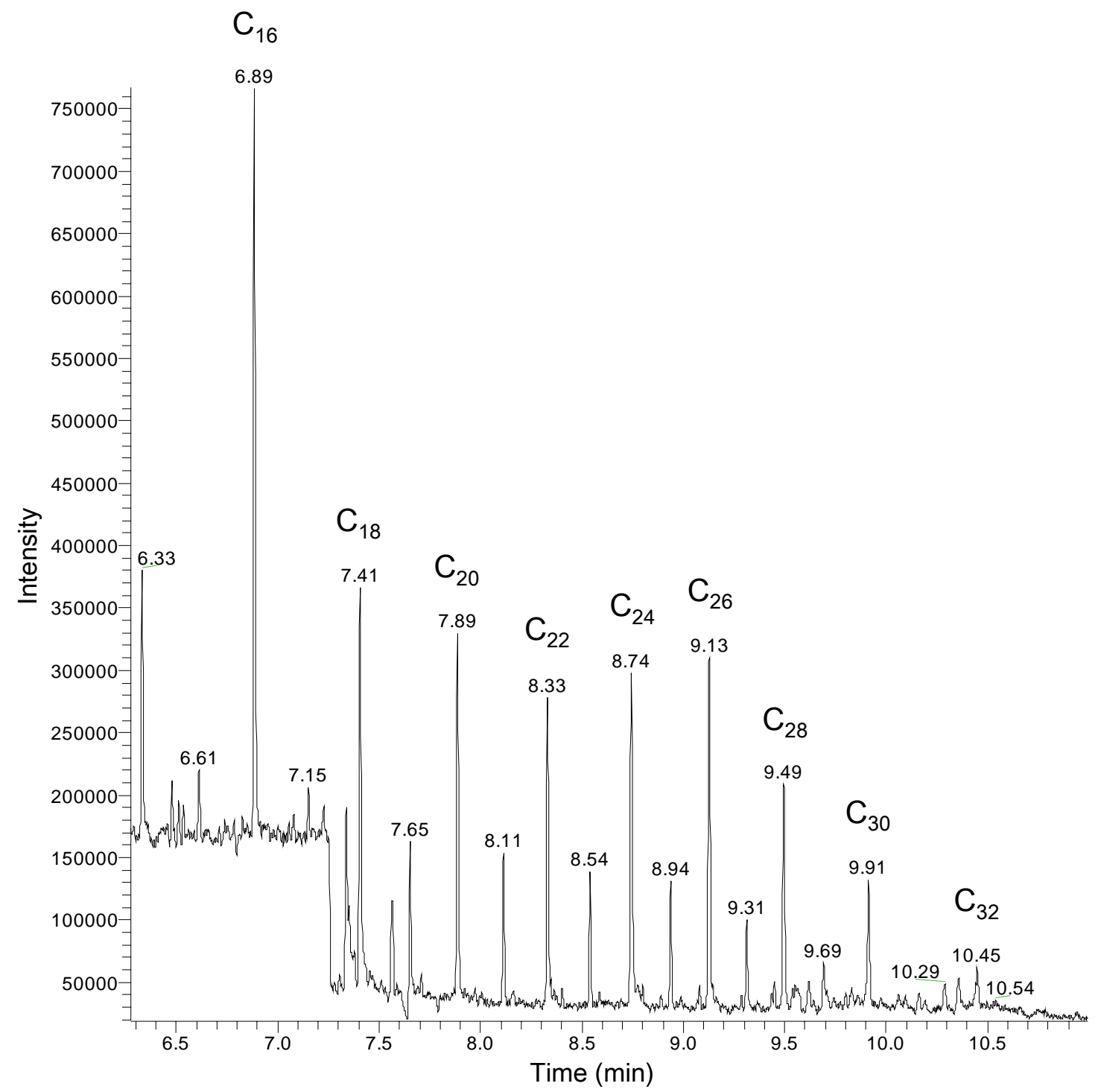

Extracted ion chromatogram $(\mathrm{m} / \mathrm{z}=74+87)$ of fatty acids, analyzed as methyl esters. Homologues $\geq \mathrm{C}_{24}$ with an even carbon number preference are indicative of terrestrial vascular plant inputs. 
Figure 4-6a

Peru Margin $\mathrm{C}_{26} n$-Alkanol (EIC, $\left.\mathrm{m} / \mathrm{z}=439\right)$

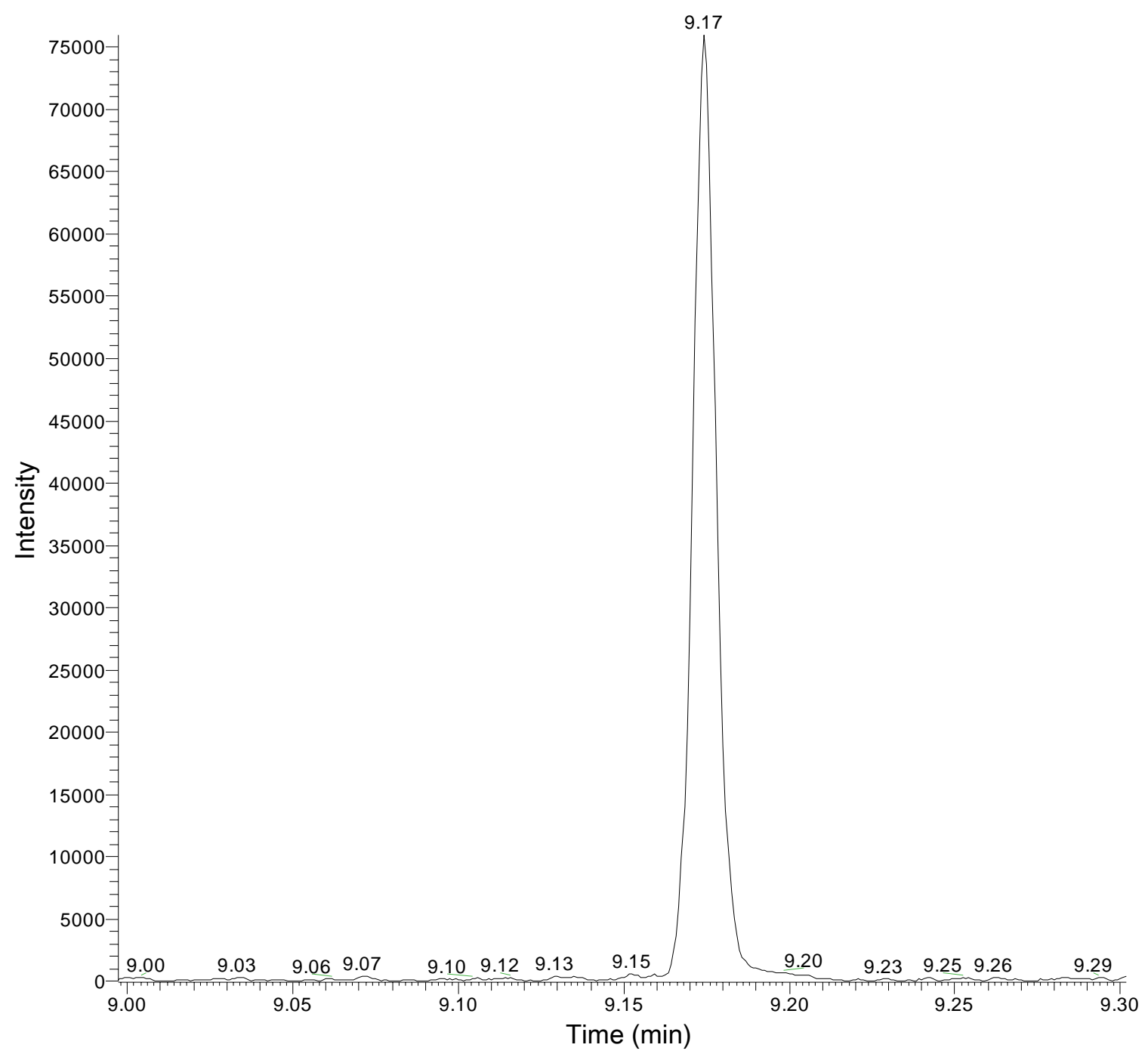

$\mathrm{C}_{26}$ n-alkanol (a) chromatographic peak (extracted ion chromatogram; $\mathrm{m} / \mathrm{z}=439$ ) and (b) characteristic mass spectrum $(89 \mathrm{~cm})$. 


\section{Figure 4-6b}

Peru Margin $\mathrm{C}_{26} n$-Alkanol Mass Spectrum

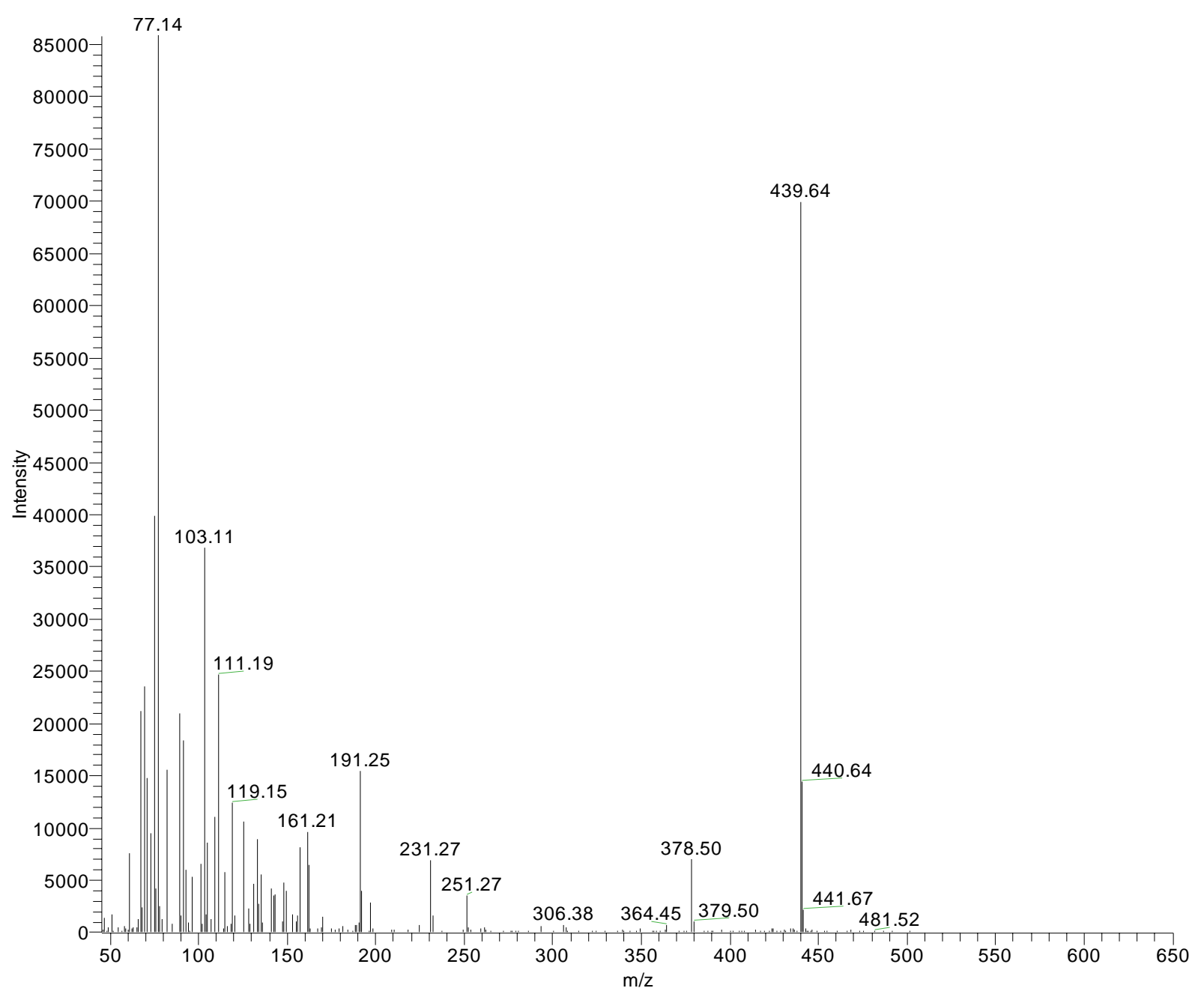


Figure 4-7

Peru Margin Sterol and Stanol EICs

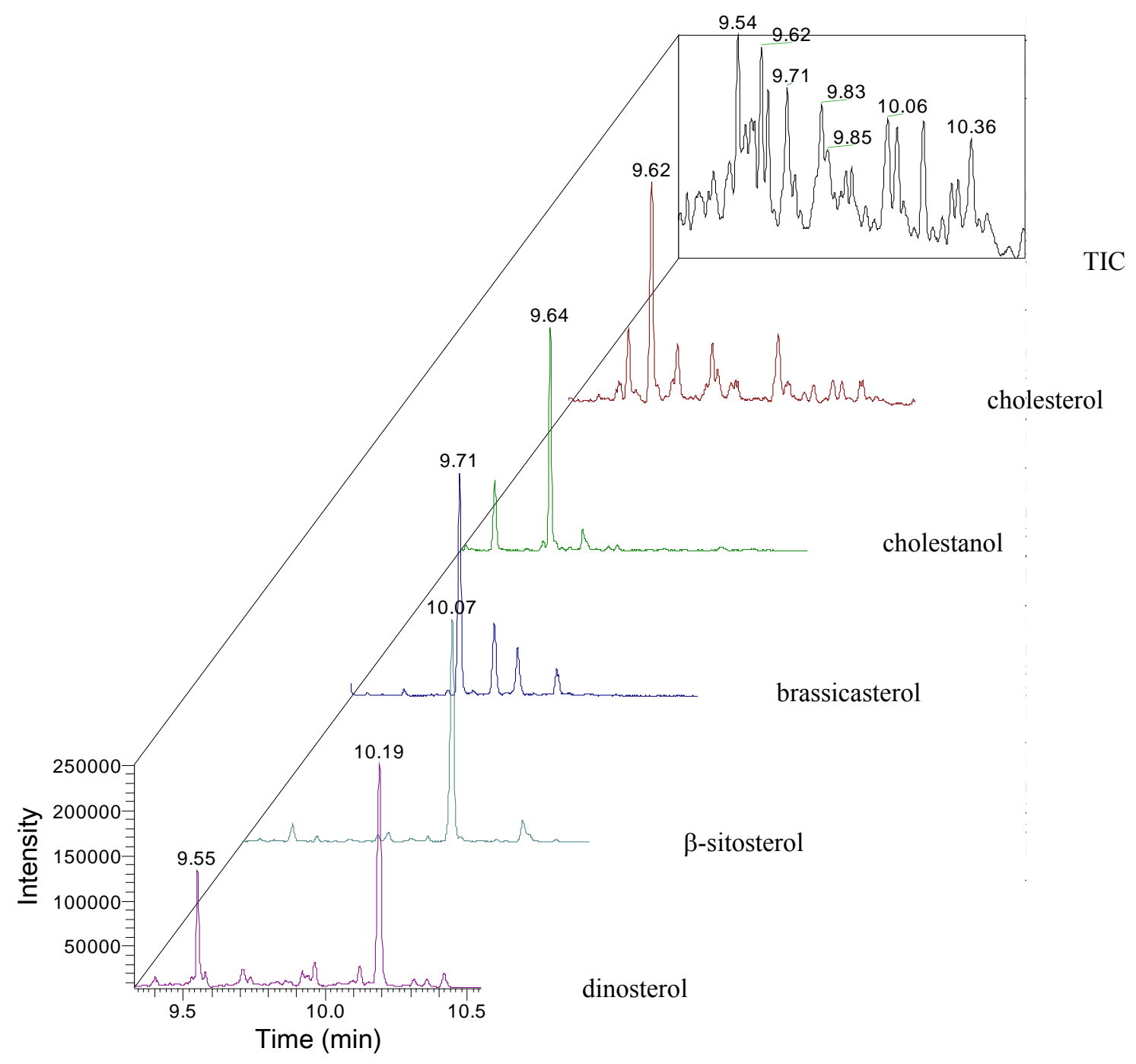

Total ion chromatogram and extracted ion chromatograms depicting cholesterol, cholestanol, brassicasterol, $\beta$-sitosterol, and dinosterol peaks $(89 \mathrm{~cm})$. 


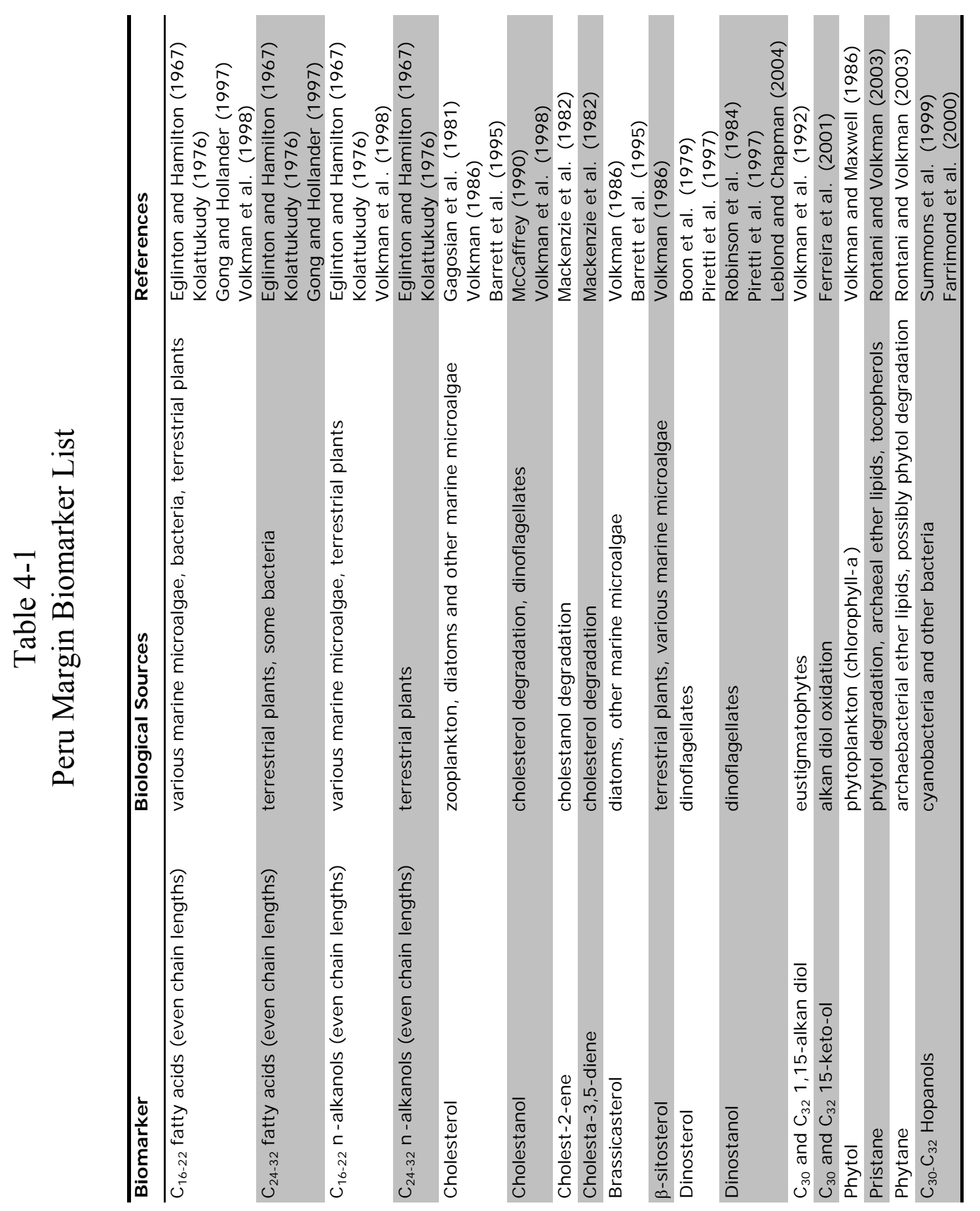


records must be tempered by the fact that they may be describing productivity of unanticipated or unknown source organisms. However, in Peru Margin sediments, it is reasonable to assume that organic inputs to the sediments are predominantly phytoplankton (esp. diatom) related or reflect heterotrophic consumption of algal biomass.

\section{Data Quality Assessment}

An important benefit of the enhanced speed of GC/TOF-MS analyses is the ease of including replicate analyses and blanks in long run sequences, which effectively improves data quality by providing a reliable estimate of instrumental error. Of the 100 samples reported in this study, 68 were analyzed in duplicate or triplicate. Also, 28 blanks were interspersed throughout the run. The error estimates and blank levels for each biomarker are reported in Table 4-2. Errors in biomarker concentration are reported as the pooled standard deviation of all replicate analyses in the data set. The variance of each replicate analysis was calculated and all of the individual variances were then summed and divided by the total number of replicates (duplicates were counted as one replicate measurement and triplicates were counted as two) to arrive at pooled variance. Pooled standard deviation was determined by calculating the square root of the pooled variance. Blank concentrations were determined by averaging the results of all blank measurements and applying the same response factors that were used to determine biomarker concentrations. Blank values are reported as the amount of the compound expected in an original TLE in order to put them on the same scale as the samples.

Error bars are depicted separately on plots of biomarker concentrations that are normalized to grams dry weight sediment (g dws), and are expressed as 2 times the pooled standard deviation ( \pm pooled standard deviation in $\mu \mathrm{g} / \mathrm{g} \mathrm{dws}$ ). In some cases, the errors can obscure low-amplitude, short-term variability (e.g. for $\mathrm{C}_{26}$ fatty acid, phytane, and cholesta-3,5-diene), but do not affect interpretation of high-amplitude changes or long-term trends. Blank concentrations are greatest for the $\mathrm{C}_{16}$ and $\mathrm{C}_{18}$ fatty acids, for which they average 0.38 and $0.37 \mu \mathrm{g}$, respectively. These values are $<39 \%$ of the 
Table 4-2

\section{Data Quality Parameters for Individual Biomarkers}

\begin{tabular}{lcc}
\hline Biomarkers & $\begin{array}{c}\text { Pooled Standard Deviation } \\
\text { ( } \boldsymbol{\mu g / g} \text { dws) }\end{array}$ & $\begin{array}{c}\text { Blank Concentration } \\
\text { ( } \boldsymbol{\mu g} / \mathrm{TLE})\end{array}$ \\
\hline $\mathrm{C}_{16}$ FAME & 2.7 & 0.38 \\
$\mathrm{C}_{18}$ FAME & 0.81 & 0.37 \\
$\mathrm{C}_{20}$ FAME & 0.74 & 0.0048 \\
$\mathrm{C}_{22}$ FAME & 0.69 & 0.0036 \\
$\mathrm{C}_{24}$ FAME & 1.2 & 0.0076 \\
$\mathrm{C}_{26}$ FAME & 2.2 & 0.015 \\
$\mathrm{C}_{28}$ FAME & 2.1 & 0.014 \\
$\mathrm{C}_{30}$ FAME & 2.0 & 0.016 \\
$\mathrm{C}_{32}$ FAME & $\mathrm{N} / \mathrm{A}$ & 0.0074 \\
$\mathrm{C}_{16}$ OH & 0.69 & 0.00088 \\
$\mathrm{C}_{18}$ OH & 0.32 & 0.0044 \\
$\mathrm{C}_{20}$ OH & 0.26 & 0.019 \\
$\mathrm{C}_{22}$ OH & 0.33 & 0.0011 \\
$\mathrm{C}_{24}$ OH & 0.27 & 0.00034 \\
$\mathrm{C}_{26}$ OH & 0.16 & 0.0016 \\
$\mathrm{C}_{30}$ OH & 0.11 & 0.0036 \\
$\mathrm{C}_{32}$ OH & 0.22 & 0.00014 \\
Cholesterol & 1.7 & 0.0048 \\
Cholestanol & 1.2 & 0.0067 \\
Brassicasterol & 1.6 & 0 \\
$\beta$-sitosterol & 1.9 & 0.018 \\
Dinosterol & 1.8 & 0.0017 \\
$\mathrm{C}_{32}$ 1,15 alkan diol & 3.3 & 0.064 \\
$\mathrm{C}_{32}$ 15 keto-ol & 0.57 & 0.0014 \\
Phytol & 4.4 & 0.0020 \\
Pristane & 0.88 & 0.033 \\
Phytane & 2.2 & 0.039 \\
Cholest-2-ene & 1.0 & 0.0092 \\
Cholesta-3,5-diene & 1.8 & 0.00050 \\
Dinostanol & 1.7 & 0.053 \\
$\mathrm{C}_{30}$ Hopanol & 1.2 & 0.056 \\
$\mathrm{C}_{31}$ Hopanol & 0.33 & 0.068 \\
$\mathrm{C}_{32}$ Hopanol & 0.7 & $\mathrm{~N} / \mathrm{A}$ \\
Cholesterol/Cholestanol & 0.93 & \\
$\mathrm{C}_{32}$ diol/keto-ol & & \\
\hline & & \\
\hline
\end{tabular}


measured response in the samples with the smallest $\mathrm{C}_{16}$ and $\mathrm{C}_{18}$ signals. For all other compounds analyzed in this study, average blank values are $0.07 \mu \mathrm{g}$ or less. These values are insignificant compared to concentrations detected in the samples and thus have no bearing on interpretation of the biomarker records. Blank results demonstrate that carry-over between individual analyses is not an issue of concern.

\section{Biomarker Concentration Records}

Acyclic Isoprenoids Phytol concentration records, reported as $\mu \mathrm{g} / \mathrm{g} d w s$ and as normalized to the amount of $\mathrm{C}_{\text {org }}$ extracted, are presented in Figure 4-8. Normalizing biomarker concentration records to the amount of $\mathrm{C}_{\text {org }}$ extracted essentially removes the dominant component of variability observed in the bulk $\mathrm{C}_{\text {org }}$ record and permits further interpretation of individual biomarker variability. The $\mathrm{C}_{\mathrm{org}}$-normalized phytol record is very similar to the original concentration record, suggesting that phytol is recording general primary productivity. The phytol records resemble that of $\% \mathrm{C}_{\text {org }}$ (Figure 4-9), as would be expected if the majority of the $\mathrm{C}_{\text {org }}$ deposited and preserved in Peru Margin sediments is derived from primary producers such as diatoms. Both the phytol and $\% \mathrm{C}_{\mathrm{org}}$ records exhibit similar patterns of change before $9 \mathrm{ka}$, with reduced concentrations in the oldest part of the record and again at about $9 \mathrm{ka}$ and relatively higher concentrations centered around $11 \mathrm{ka}$. After $9 \mathrm{ka}$, concentrations in both records increase to persistently elevated values and exhibit the greatest variability from about $7 \mathrm{ka}$ to the present.

Patterns of late Holocene variability are not the identical in the phytol and $\% \mathrm{C}_{\text {org }}$ records, although they contain some similar features. For example, the post-9 ka concentration increase does not have the same timing in both records. In the $\% \mathrm{C}_{\text {org }}$ record, the increase is sharper and begins in earnest immediately after $9 \mathrm{ka}$, whereas the comparable increase in the phytol concentration record is delayed and occurs in two stages at about 7.5 and $6.5 \mathrm{ka}$, potentially because phytol is very labile compared to other compounds and is poorly preserved before $7.5 \mathrm{ka}$ (Hoefs et al., 2002). With the exception of the point at $0.5 \mathrm{ka}$, the four sharp minima in the mid to late Holocene section of the $\% \mathrm{C}_{\text {org }}$ record are not reproduced in the phytol record. Similarly, many of the data 
Figure 4-8

Peru Margin Phytol Concentration

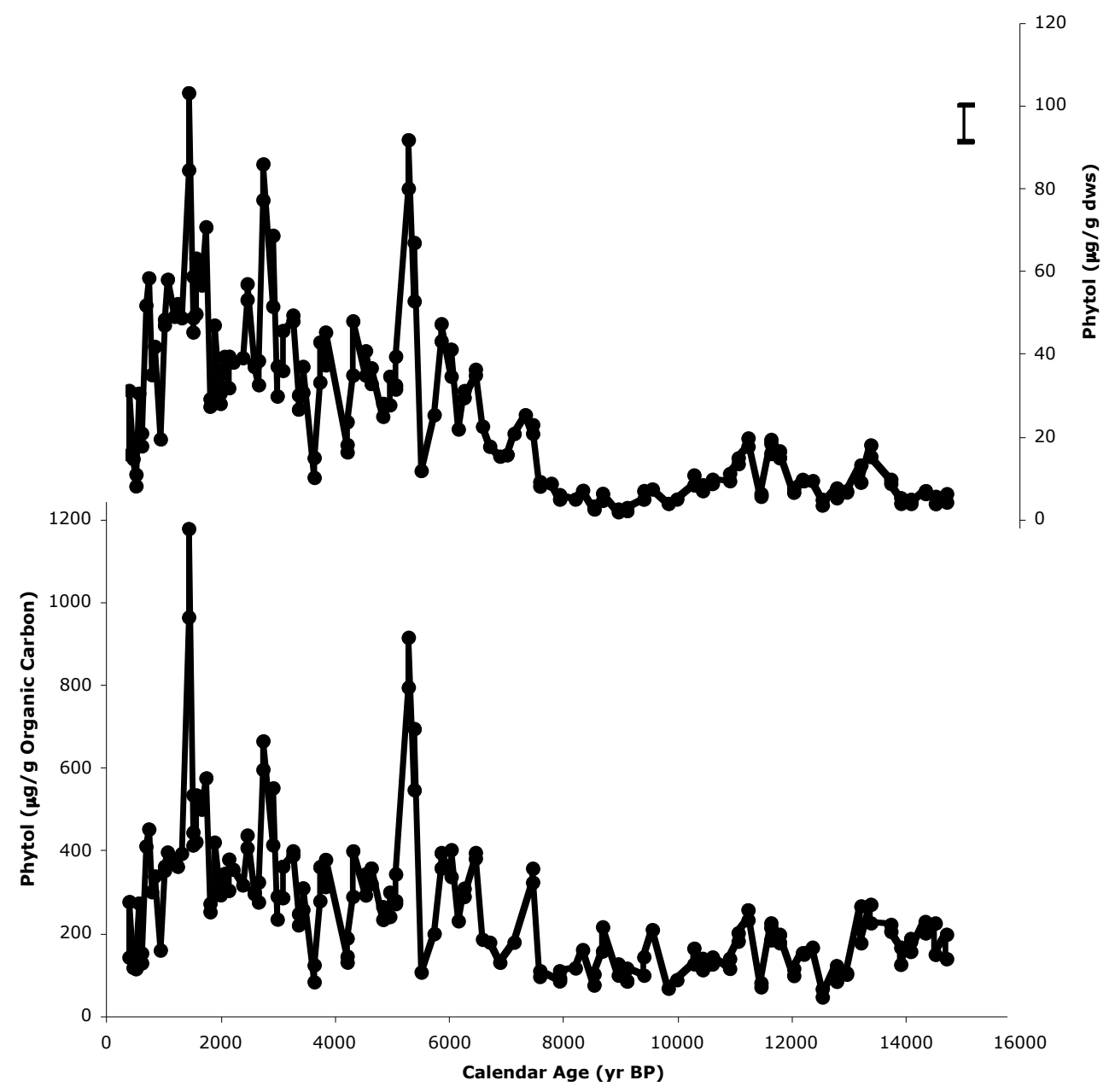

Phytol concentration records normalized to grams dry weight sediment (g dws) (upper plot) and organic carbon (lower plot). An error bar for the sediment-normalized plot is provided in the upper right corner. 
Figure 4-9

Peru Margin Phytol Concentration and Weight \% Organic Carbon

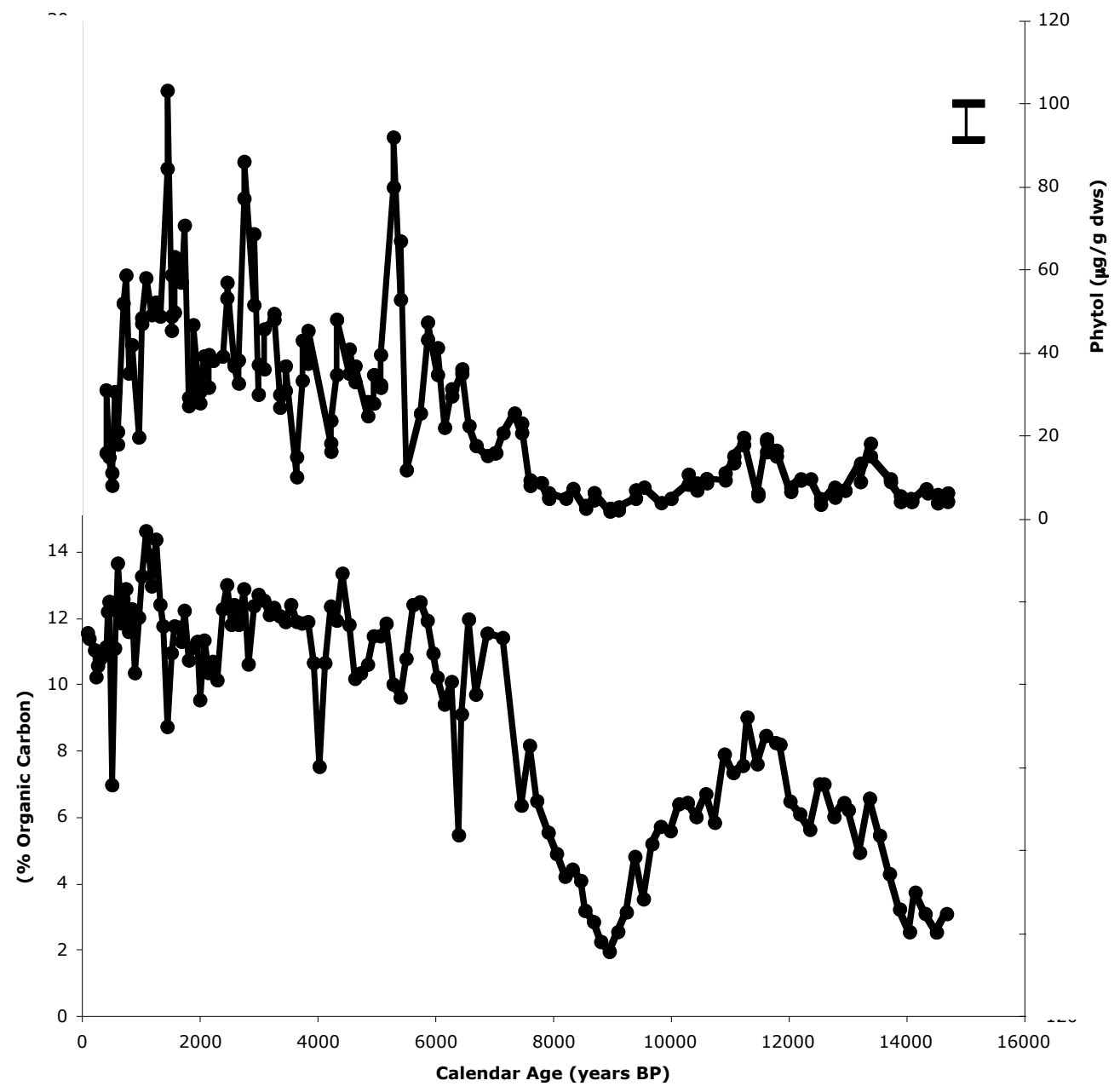

Phytol concentration record normalized to $\mathrm{g}$ dws (upper plot) and $\% \mathrm{C}_{\text {org }}$ (lower plot). Error bar applies to phytol plot. 
points representing maxima and minima in the phytol record are unremarkable in terms of $\% \mathrm{C}_{\text {org }}$. However, both records contain broad regions of reduced concentration at about $2 \mathrm{ka}$ and in the most recent part of the record. The relationship between phytol and $\% \mathrm{C}_{\text {org }}$ throughout the records implies a general dominant forcing on productivity or preservation, such as upwelling or bottom water oxygenation, with strong variability in the activities of specific precursor organisms, especially during the Holocene. Upwelling strength is a likely forcing mechanism for phytol and \%Corg variability because it can affect both productivity and preservation simultaneously, through surface nutrient supply and changes in demand on bottom-water oxygen, respectively.

In addition to phytol, pristane and phytane, which are potential degradation products of either phytol or archaebacterial ether lipids (Rontani and Volkman, 2003), were detected. These compounds exhibit similar patterns of variability whether they are normalized to $\mathrm{g}$ dws or $\mathrm{C}_{\text {org }}$ (Figures 4-10 and 4-11). Variability in the early part of the pristane and phytane records resembles that of phytol, although increasing phytol concentrations between about 7.5 and $5.8 \mathrm{ka}$ are not observed in the other records. After $5.3 \mathrm{ka}$, variability in all three records is similar and the sharp concentration maxima in the phytol record are also found in pristane and phytane. The overall similarities between the phytol, pristane, and phytane records suggest that variability in all of their concentrations is forced by large-scale processes, such as upwelling, that control their production and preservation. If oxidation were the dominant process controlling biomarker variability, one may expect to observe enhanced abundances of pristane during periods of low phytol concentration, which was not the case in the 1228D records. A possible model to explain the variability observed in the acyclic isoprenoid concentration records is that preservation potential in Peru Margin sediments is generally high and upwelling drives changes in algal and archaebacterial inputs alike. Highly branched isoprenoid alkenes, which can be employed as diatom molecular markers, were not detected, possibly due to selective degradation or reaction with sedimentary sulfur during early diagenesis (Sinninghe Damsté et al., 1999), although no evidence was found for the latter (see below). 
Figure 4-10

Peru Margin Pristane, Phytane, and Phytol Concentrations

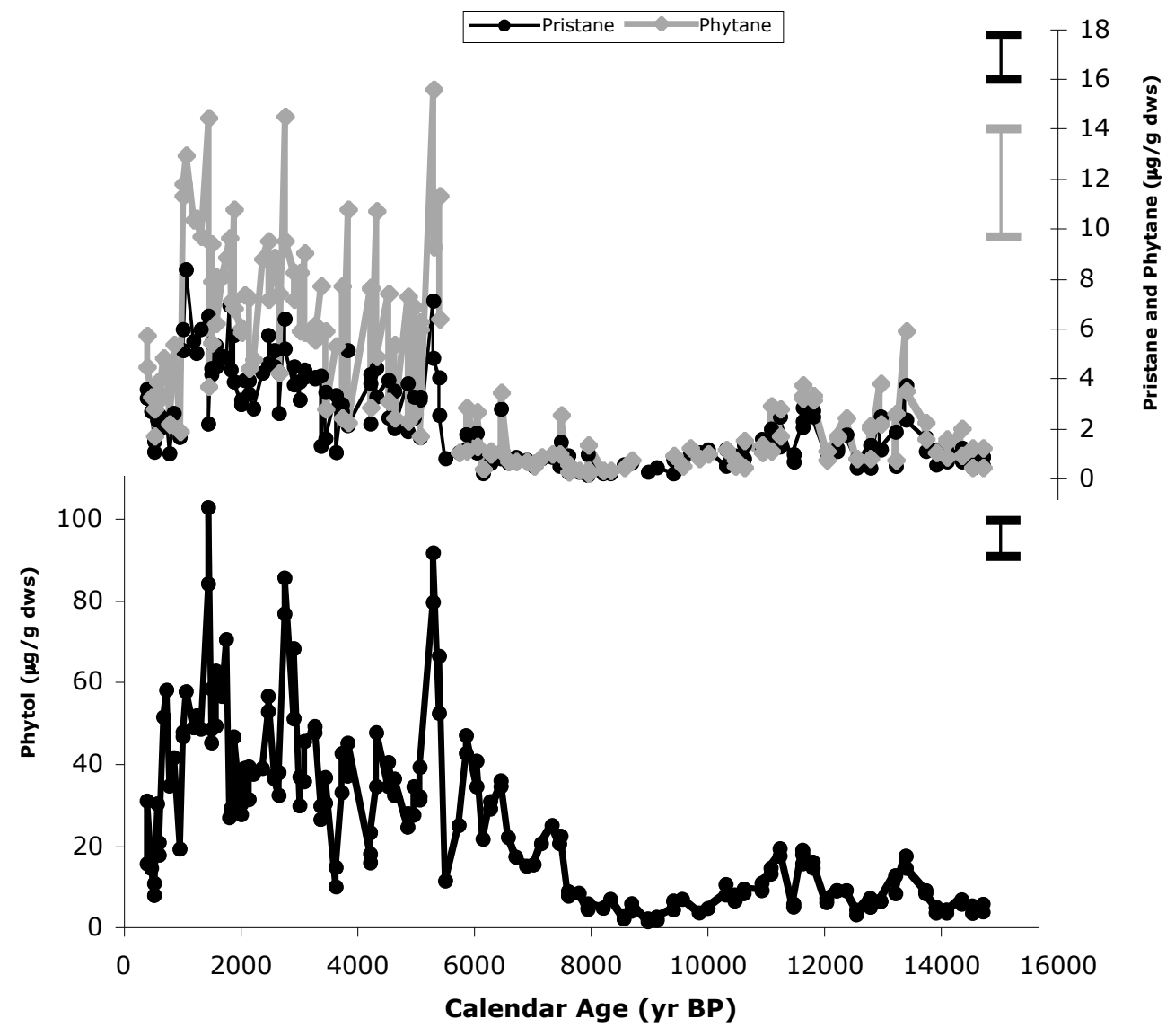

Pristane and phytane (upper plot) and phytol (lower plot) concentrations normalized to g dws. Error bars are provided for all three records. 
Figure 4-11

Peru Margin Pristane, Phytane, and Phytol Concentrations Normalized to Organic Carbon

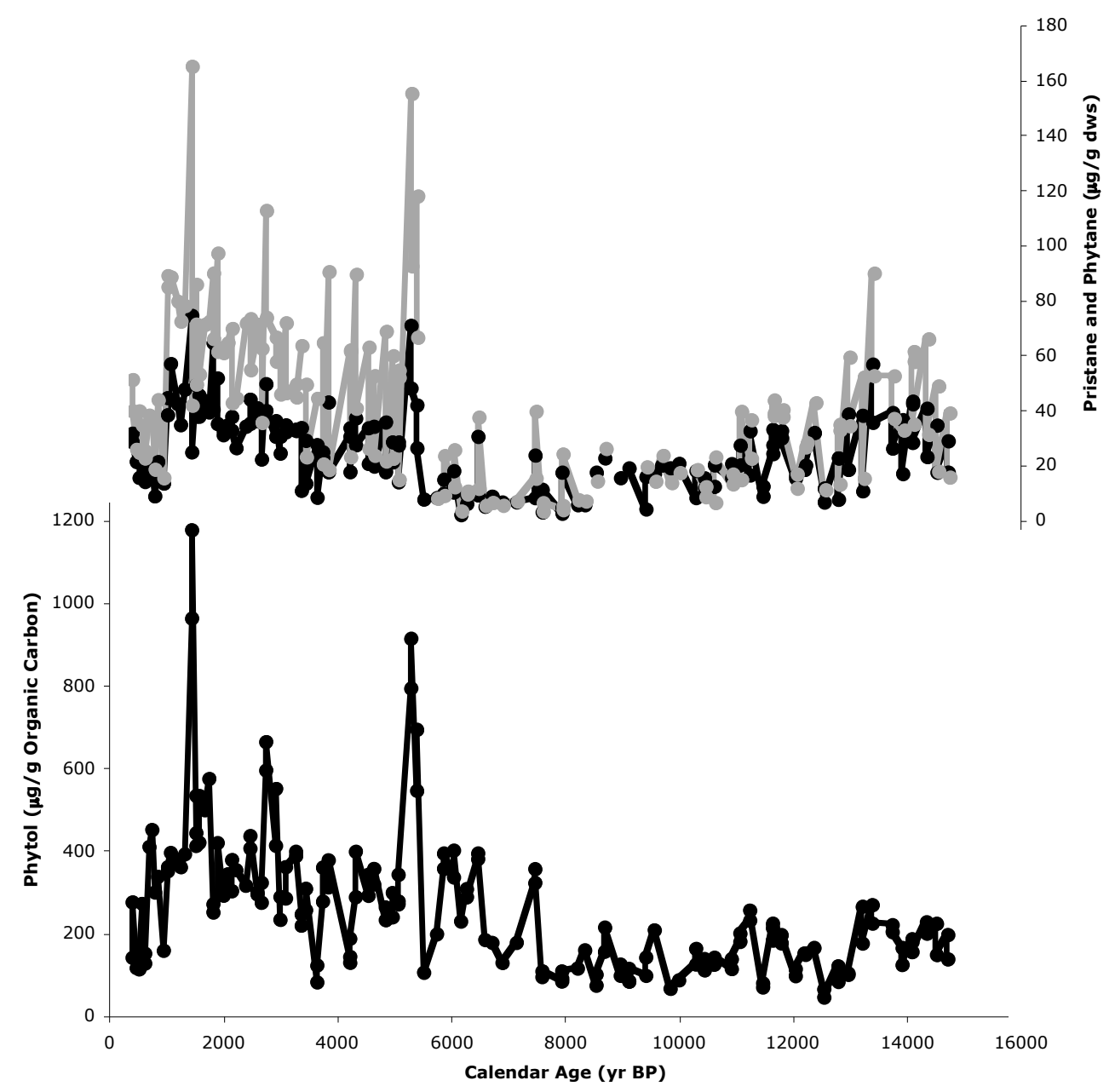

Pristane and phytane (upper plot) and phytol (lower plot) concentrations normalized to $\mathrm{C}_{\text {org. }}$. 
Steroidal Compounds Concentration records of many of the other compounds listed in Table 4-1 bear a broad resemblance to the $\% \mathrm{C}_{\text {org }}$ and phytol records (Figure 412), reinforcing the hypothesis that there is one dominant factor controlling productivity and/or preservation over the last $15 \mathrm{ka}$. For example, cholesterol and cholestanol, which vary in unison, strongly resemble the $\% \mathrm{C}_{\text {org }}$ and phytol records before $9 \mathrm{ka}$ and exhibit the same increase in concentration afterwards. Concentrations of these biomarkers are highly variable during the late Holocene, with a reasonably similar pattern of variability to $\% \mathrm{C}_{\mathrm{org}}$. Brassicasterol and $\beta$-sitosterol concentration records very strongly resemble those of cholesterol and cholestanol, implying commonalities between diatom productivity and overall surface activity, including zooplankton. Cholesterol is common to many marine phytoplankton and zooplankton and is interpreted as an integrator of total sea surface biota (Schouten et al., 1998). All of these sterols exhibit somewhat periodic variability beginning at $5.8 \mathrm{ka}$ with steadily greater and broader concentration peaks centered at 5.8, $4.5,2.5$, and $1.1 \mathrm{ka}$, and relative minima following each peak.

Plots of sterol concentration normalized to organic carbon (Figure 4-13) allow investigation of unique patterns of variability that may arise independently of overall organic matter delivery or preservation. Generally increasing concentrations after $9 \mathrm{ka}$ suggest that the planktonic biota producing these biomarkers are increasing in productivity over time even relative to bulk organic matter inputs. Alternatively, the biomarkers may be more labile than bulk $\mathrm{C}_{\text {org }}$ and are thus more degraded with depth (Hoefs et al., 2002). All of the sterol records except dinosterol exhibit a strong peak in the early part of the record at about $13.3 \mathrm{ka}$ that is not observed in the normalized phytol record, implying enhanced productivity of specific eukaryotic precursors at this time, as well.

The Peru Margin sediments used in this study were also examined for cholesterol degradation products in an effort to assess the preservation of steroidal biomarkers. Cholesta-3,5-diene and cholest-2-ene, which are degradation products of cholesterol and cholestanol (e.g. Mackenzie et al., 1982), respectively, were tentatively identified in all samples. A compound with spectral characteristics consistent with another cholestene 
Figure 4-12a

Peru Margin Cholesterol and Cholestanol Concentrations

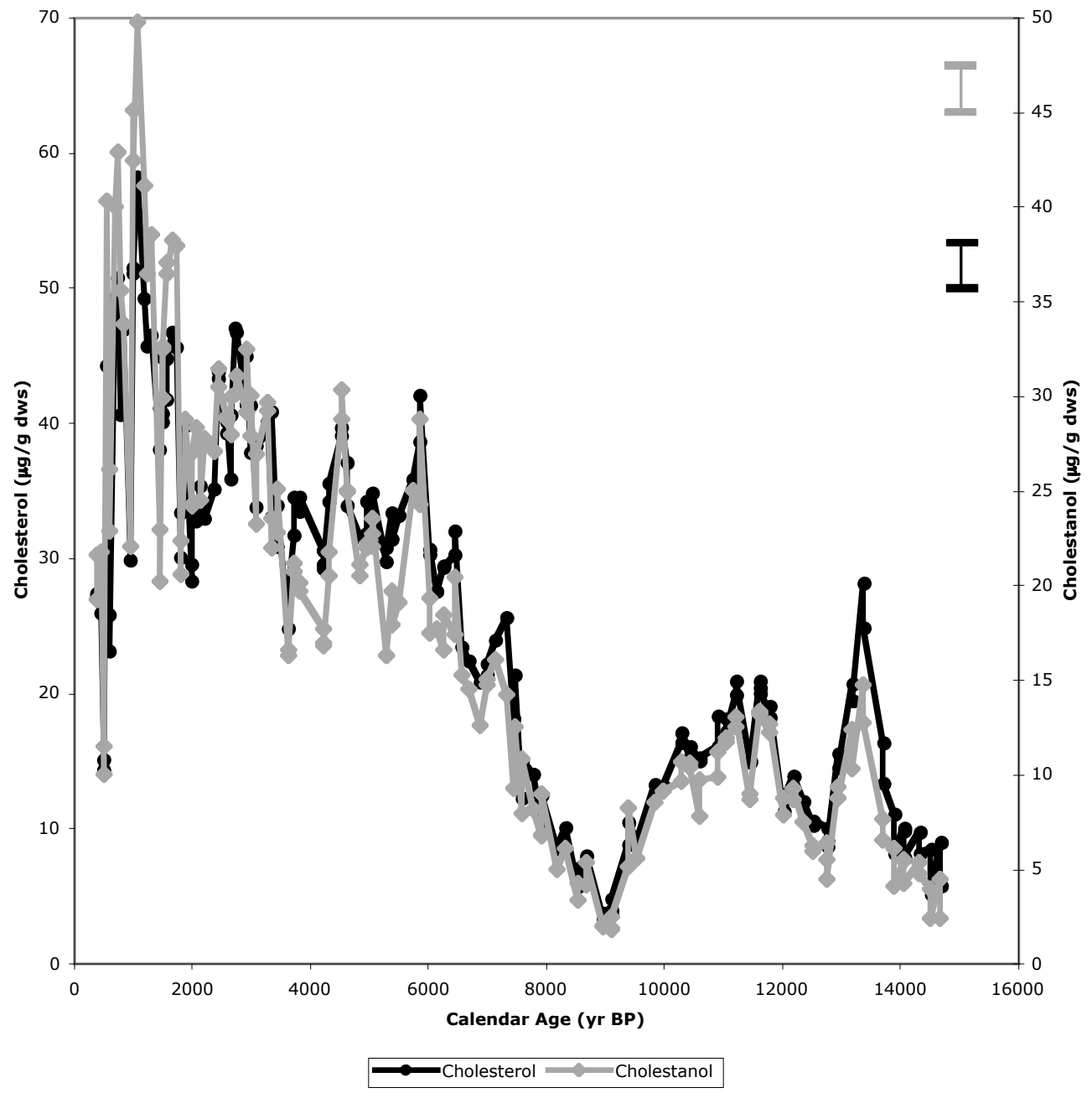

Sterol concentration records normalized to g dws. Error bars are provided for all compounds. 
Figure 4-12b

Peru Margin Brassicasterol and $\beta$-sitosterol Concentrations

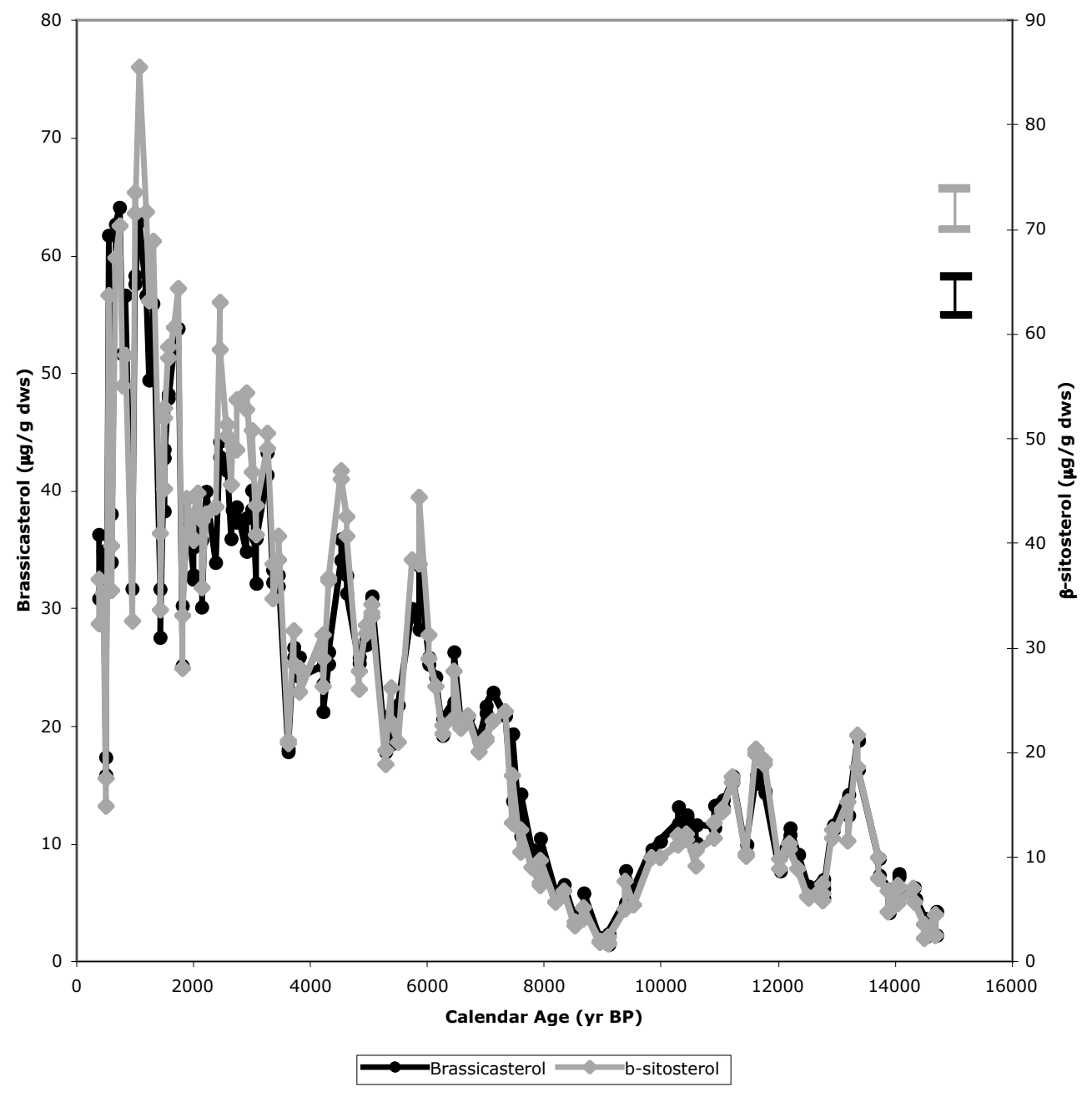


Figure 4-13

Peru Margin Sterol Concentrations Normalized to Organic Carbon

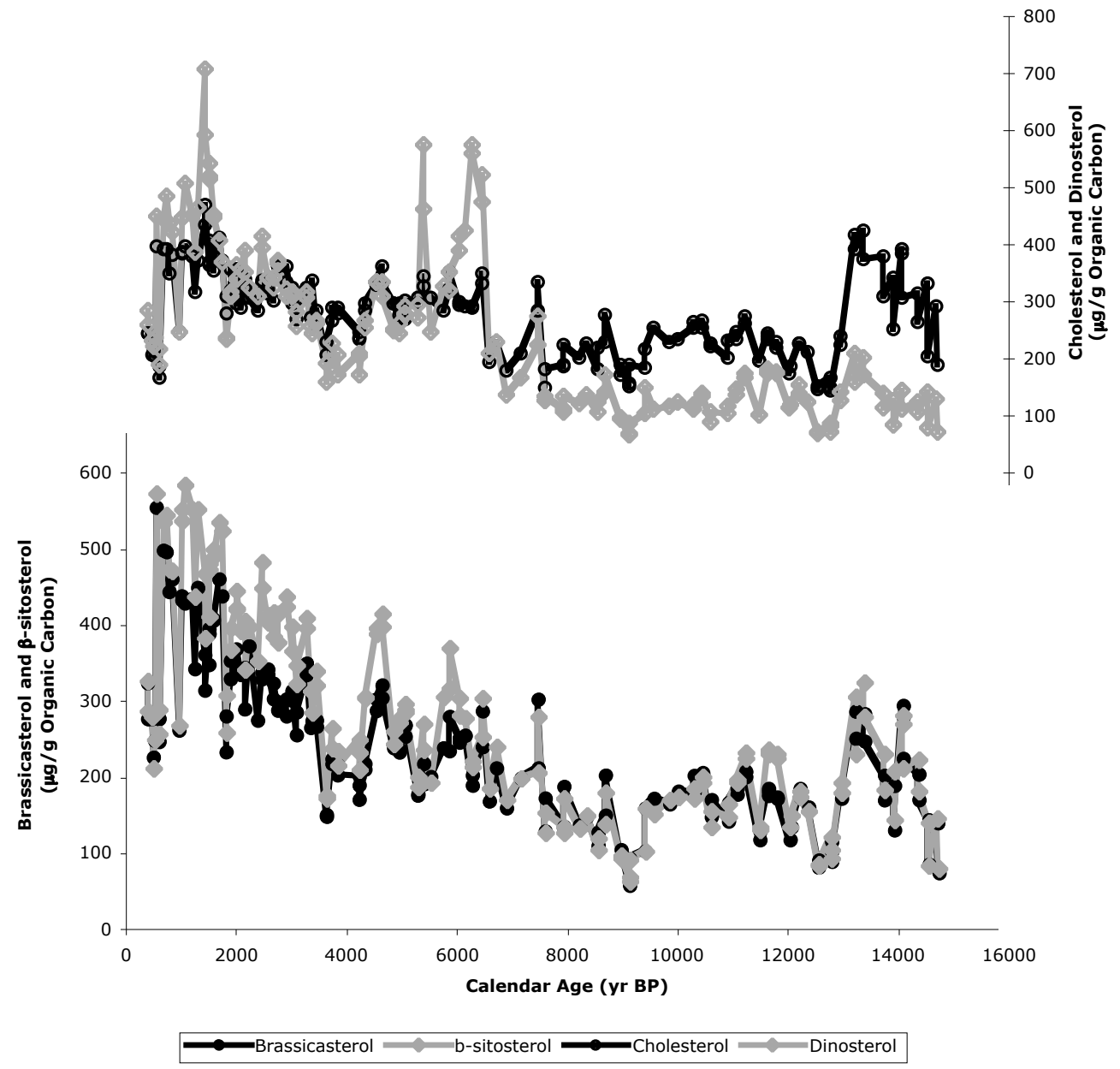

Cholesterol and dinosterol (upper plot) compared to brassicasterol and $\beta$-sitosterol (lower plot) concentration records normalized to $\mathrm{C}_{\text {org }}$. 
eluted immediately after cholest-2-ene, but could not be positively identified due to low response. The compound tentatively identified as cholesta-3,5-diene matches the mass spectrum of this compound in the spectral library, but elutes shortly after cholest-2-ene, which is not typical of compounds with additional unsaturation sites. If this compound is not cholesta-3,5-diene, its similar mass spectrum implies that it is very closely related structurally, and thus may still be derived from cholesterol diagenesis. The concentration records of cholesta-3,5-diene and cholest-2-ene are presented in Figure 4-14. The choice of normalization to either $\mathrm{g}$ dws or organic carbon does not affect interpretation of the records. Records of both compounds are similar to those of cholesterol and cholestanol in that they exhibit the same minima at about 14.5 and $9.0 \mathrm{ka}$, followed by gradually increasing concentrations throughout the remainder of the Holocene (Figure 4-15). The observation that the parent and degradation products have similar patterns of variability suggests good preservation of sterols in 1228D sediments. A hypothesis for this relationship is that degradation occurs chiefly in the water column and/or at the sediment surface, and the sedimentary record faithfully records changes in inputs. A number of other compounds related to cholesterol diagenesis (Mackenzie et al., 1982) including cholestanone, cholest-4-ene, cholest-5-ene, cholestane, and diacholestane were not detected, although either of these cholestenes could have been the small peak that eluted immediately after cholest-2-ene. The absence of these compounds, especially the heavily degraded sterane and diasterane forms, further supports the hypothesis that steroidal compounds are generally well preserved in 1228D sediments.

The record of dinosterol, which is characteristic of dinoflagellate inputs, is roughly similar to the other sterols, although its concentration record contains a unique early and intense peak at $6.3 \mathrm{ka}$ (Figure 4-13). Around this time, there may have been a change in environmental conditions that favored dinoflagellate productivity over diatoms. Currently, dinoflagellate productivity on the Peru Margin is greatest in the austral spring and summer when upwelling is relatively reduced in strength; dinoflagellate blooms have also been observed during El Niño conditions (de Mendiola, 1981). By extension, oceanographic conditions at $6.3 \mathrm{ka}$ may have been more characteristically El Niño- or 
Figure 4-14

Peru Margin Cholest-2-ene and Cholesta-3,5-diene Concentrations

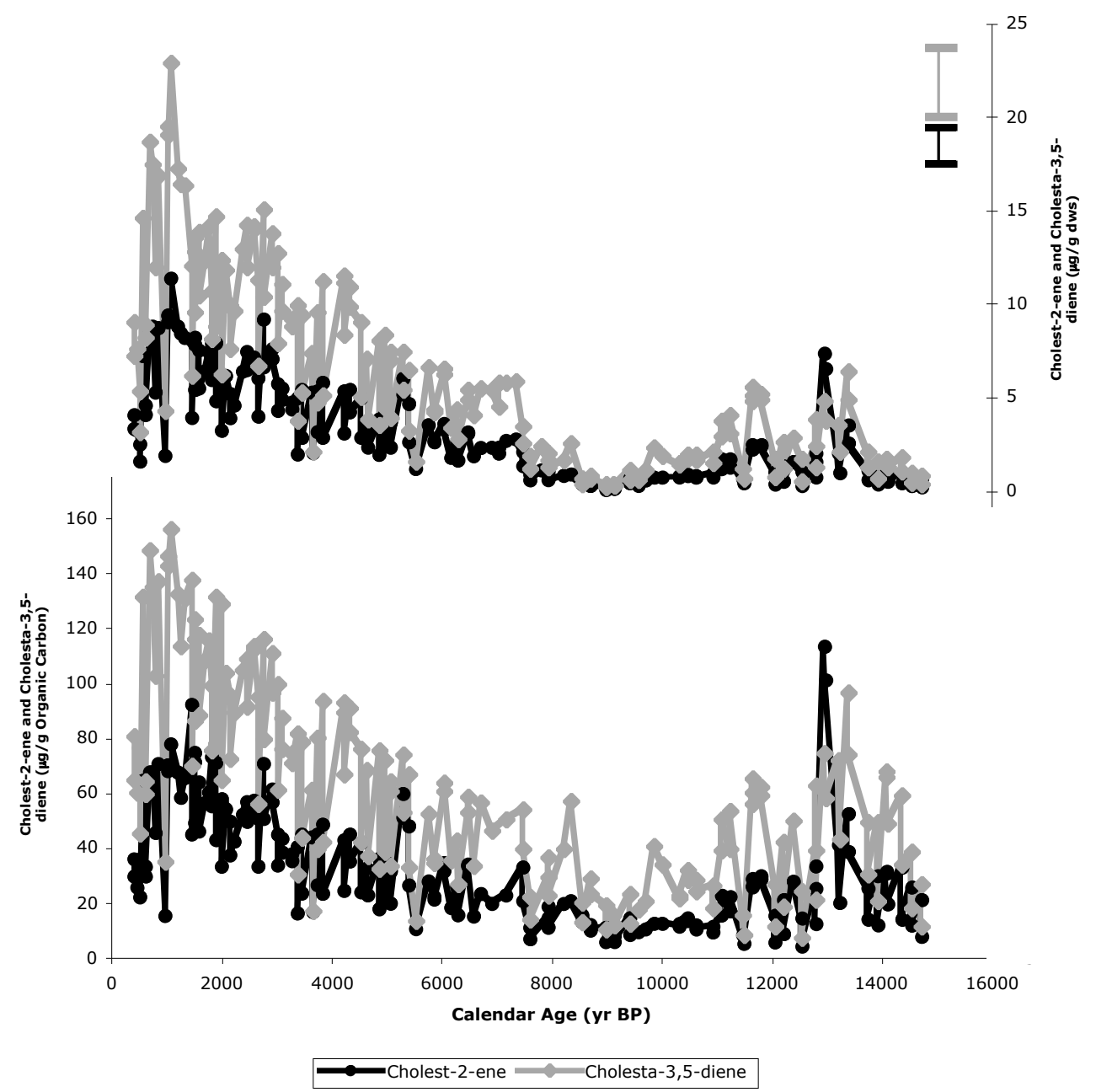

Cholest-2-ene and cholesta-3,5-diene concentrations normalized to g dws (upper plot) and $\mathrm{C}_{\text {org }}$ (lower plot). Error bars are provided for sediment-normalized data. 
Figure 4-15

Peru Margin Cholesterol and Cholesterol Degradation Product

Concentrations

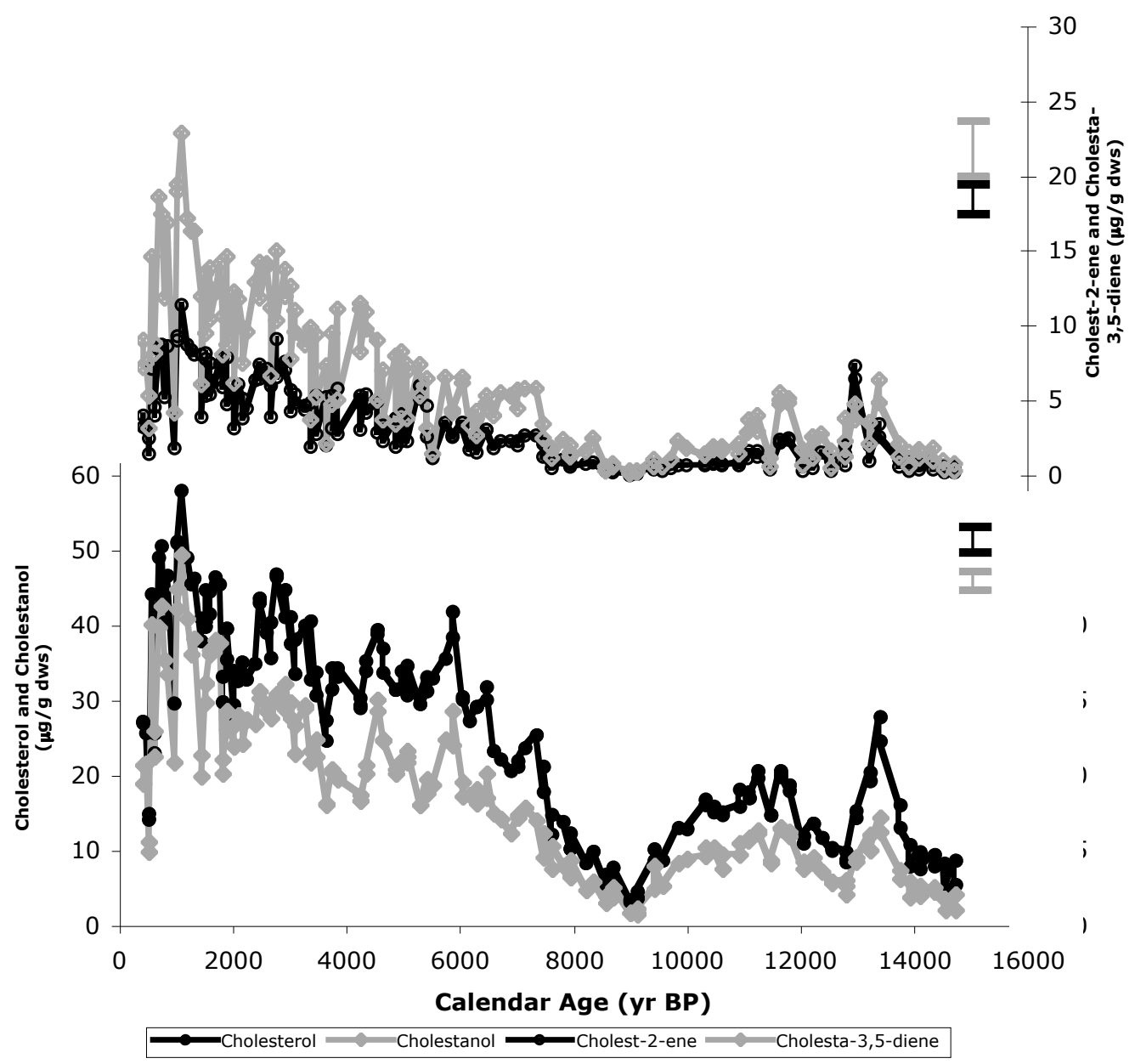

Cholest-2-ene and cholesta-3,5-diene concentrations (upper plot) and cholesterol and cholestanol concentrations (lower plot) normalized to g dws. Error bars are provided for all plots. 
summer-like, with a deeper mixed layer. Roughly similar to the results of this study, McCaffrey (1990) demonstrated that the greatest concentrations and variability of sterols occurred in the top $\sim 60 \mathrm{~cm}$ of a $1 \mathrm{~m}$ Peru Margin core and that dinosterol can vary independently of other sterols.

In addition to dinosterol, 1228D chromatograms were examined for the presence of other dinoflagellate marker compounds and dinosterol degradation products. Dinostanol, which is produced by at least several dinoflagellate species (Piretti et al., 1997), was routinely detected in 1228D sediments. Records of dinostanol and dinosterol normalized to $\mathrm{g} d w s$ and organic carbon are presented in Figures 4-16 and 4-17. Apart from higher amplitude variability in the earliest part of the $\mathrm{C}_{\text {org }}$-normalized record, the two records are similar. Interestingly, the dinostanol record bears a greater resemblance to brassicasterol and $\beta$-sitosterol concentration records than it does to dinosterol, most notably through the lack of the dramatic concentration increase centered at about $6.3 \mathrm{ka}$ that characterizes dinosterol. This notable absence in the dinostanol record is not likely due to diagenesis because dinostanol is expected to be more refractory than dinosterol. A more likely explanation for the differences between dinosterol and dinostanol is that they are derived from different sources. For example, dinostanol may have been produced by a different species of dinoflagellate than dinosterol, possibly one that occupies a different environmental niche, or dinostanol has a different algal source. Piretti et al. (1997) documented variability in the relative amounts of 4-methyl sterols produced by different species of dinoflagellate. The dinostanol concentration record is also subject to slightly greater inherent error than the records of other steroidal compounds because dinostanol often co-eluted with 4-methyl-24-ethylcholestan-3-ol, which has been detected in dinoflagellate culture experiments (Piretti et al., 1997) and has a nearly identical mass spectrum to dinostanol, rendering them difficult to separate via EIC. Because 4-methyl24-ethylcholestan-3-ol peaks were much smaller than those of dinostanol, they could not be quantified in this study. The 4-methyl steroidal ketones dinosterone and dinostanone, which were detected in a culture study of the dinoflagellate Pfiesteria piscicida (Leblond and Chapman, 2004), were not detected in 1228D sediments. Variations in 4- 
Figure 4-16

Peru Margin Dinosterol and Dinostanol Concentrations

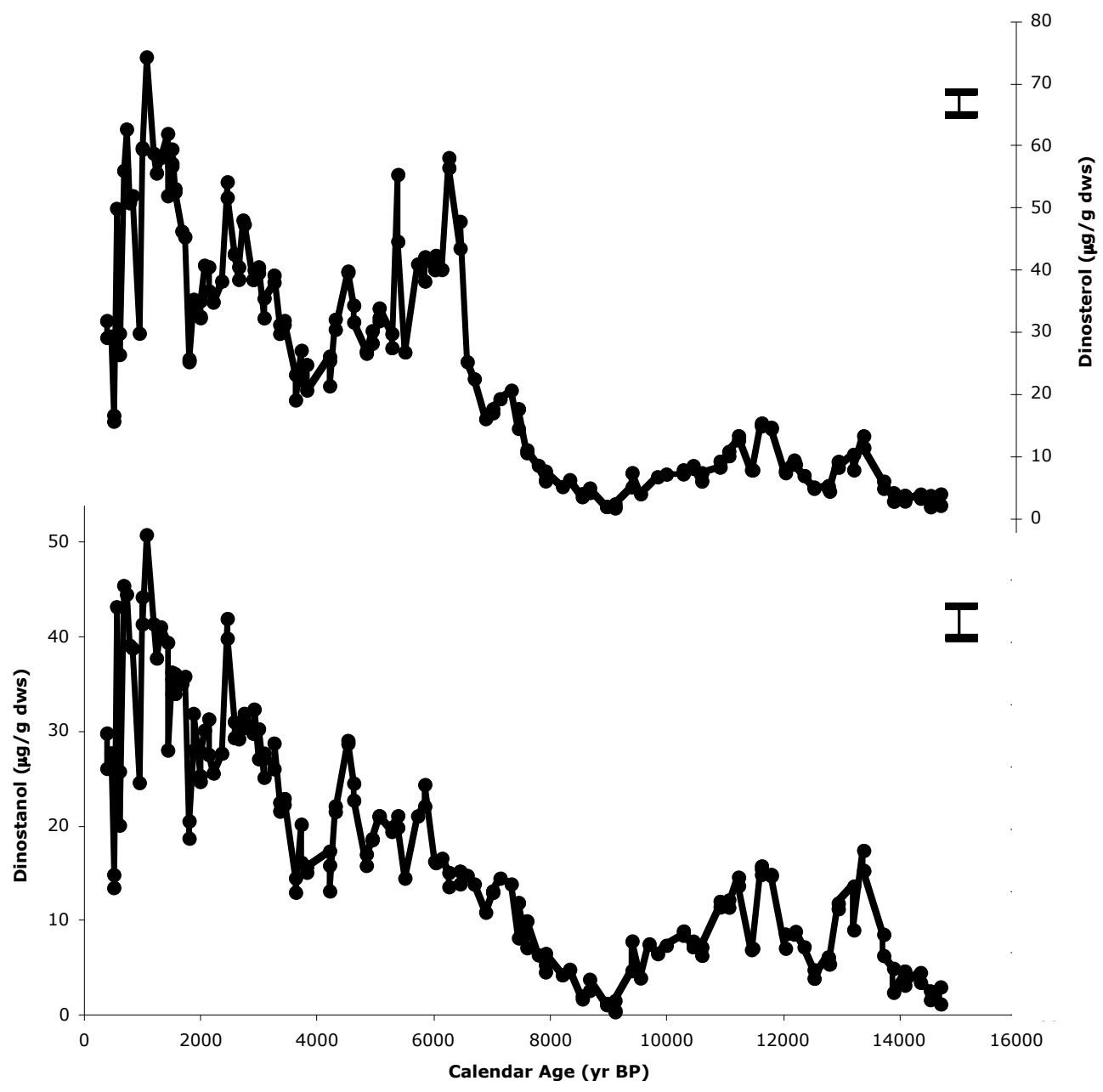

Dinosterol (upper plot) and dinostanol (lower plot) concentrations normalized to g dws. Error bars are provided for both plots. 
Figure 4-17

Peru Margin Dinosterol and Dinostanol Concentrations Normalized to Organic Carbon

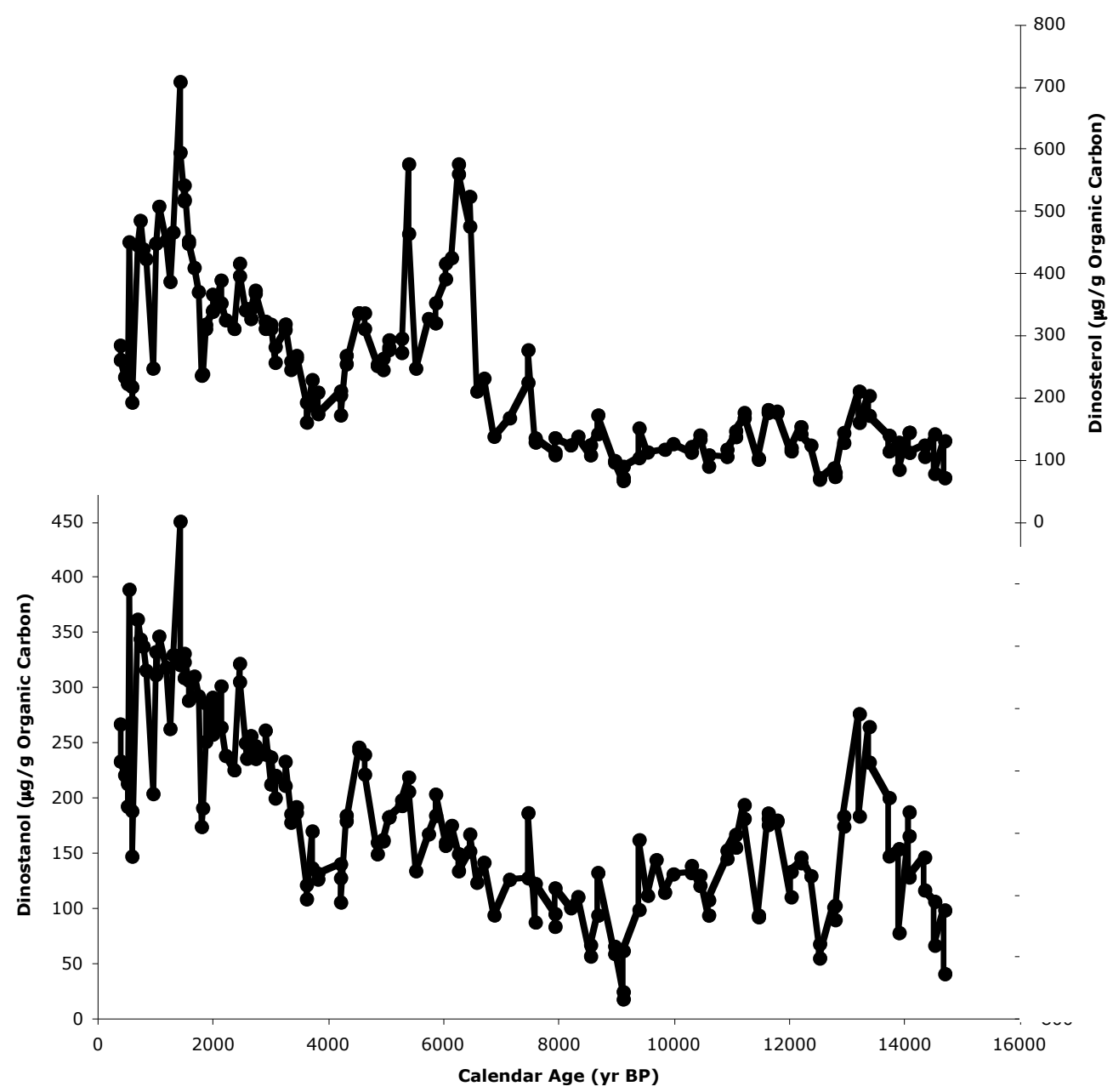

Dinosterol (upper plot) and dinostanol (lower plot) concentrations normalized to $\mathrm{C}_{\text {org }}$. 
methylsterols produced by different species of dinoflagellates may account for their absence. Dinosterane and $4 \alpha$-methyl-5 $\alpha$-cholest-2-ene (mass spectra obtained from Summons et al., 1987; Rechka et al., 1992), which are potential 4-methylsterol degradation products, also were not detected. The absence of these compounds points to excellent preservation of original dinoflagellate inputs, and thus supports unbiased interpretation of their stratigraphic records.

$\boldsymbol{n}$-Alkanoic Acids, $\boldsymbol{n}$-Alkanols, and $\boldsymbol{n}$-Alkanes The post-9 ka concentration increase is more dramatic in biomarker records of marine inputs than in that of the $\mathrm{C}_{26}$ fatty acid, which is presumably representative of terrestrial vascular plant inputs (Eglinton and Hamilton, 1967). However, the overall $\mathrm{C}_{26}$ fatty acid concentration record (/g dws) is roughly similar to $\% \mathrm{C}_{\mathrm{org}}$ and phytol in that there is a local minimum in the early part of the record and again at about $9 \mathrm{ka}$, followed by a trend of generally increasing concentration towards the present (Figure 4-18). Many specific features of the $\mathrm{C}_{26}$ fatty acid record do not match all of the marine records, though, such as the broad peak centered at about $6.9 \mathrm{ka}$. This peak is observed in the $\mathrm{C}_{26} n$-alkanol record, which is also likely derived, at least in part, from terrestrial vegetation, and the diol and keto-ol records (Figure 4-19), for which a common source is less obvious. Similarities between the records of long-chain fatty acids and $n$-alkanols, which are most likely derived from terrestrial vascular plants, and marine productivity indicators such as the $\mathrm{C}_{32}$ diol do not necessarily imply contributions from a marine source for the former compounds. Rather, large-scale climate processes likely affected production and/or delivery of both terrestrial and marine organic matter simultaneously.

Greater differences between marine and terrestrial biomarkers are observed for the $\mathrm{C}_{\text {org }}$ normalized data compared to the original concentration records. For example, the $\mathrm{C}_{26}$ fatty acid reaches a maximum normalized concentration at about $8.3 \mathrm{ka}$ when marine inputs still appear uniformly low (Figure 4-18). If the $\% \mathrm{C}_{\text {org }}$ record represents predominantly marine organic matter, as would be expected beneath the productive Peru upwelling zone, then this implies that greater relative inputs of terrestrial material occurred at this time. Average bulk $\delta^{13} \mathrm{C}$ values of $-21.3 \%$ throughout the record (see 
Figure 4-18a

Peru Margin $\mathrm{C}_{26}$ FAME and $\mathrm{C}_{26} n$-Alkanol Concentrations

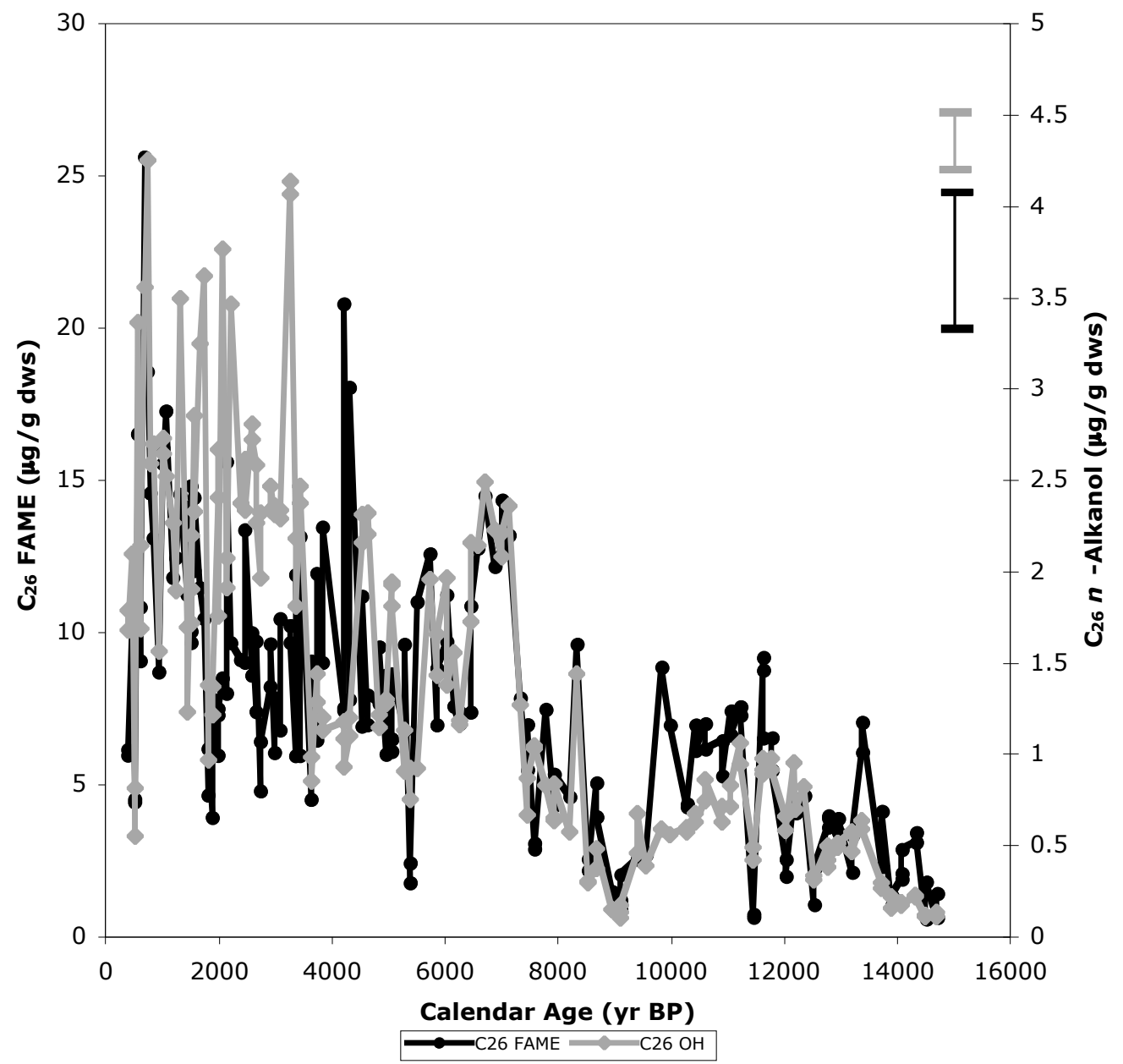

$\mathrm{C}_{26}$ fatty acid and $n$-alkanol concentrations normalized to $\mathrm{g}$ dws (a) and $\mathrm{C}_{\text {org }}$ (b). Error bars are provided for sediment-normalized data. 
Figure 4-18b

Peru Margin $\mathrm{C}_{26}$ FAME and $\mathrm{C}_{26} n$-Alkanol Concentrations Normalized to Organic Carbon

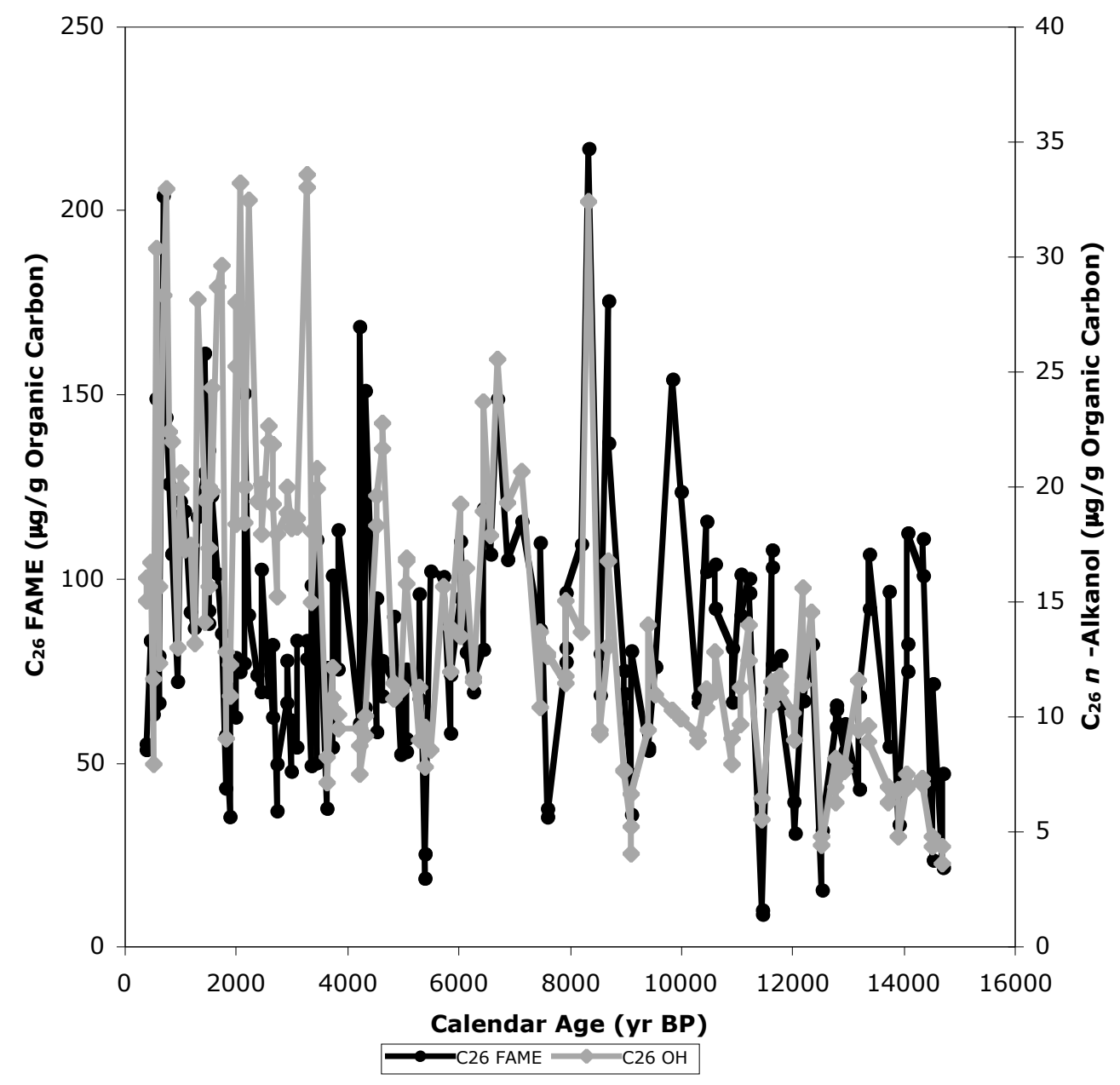


Figure 4-19

Peru Margin $\mathrm{C}_{32}$ 1,15-alkan diol and $\mathrm{C}_{32}$ 15-keto-ol Concentrations

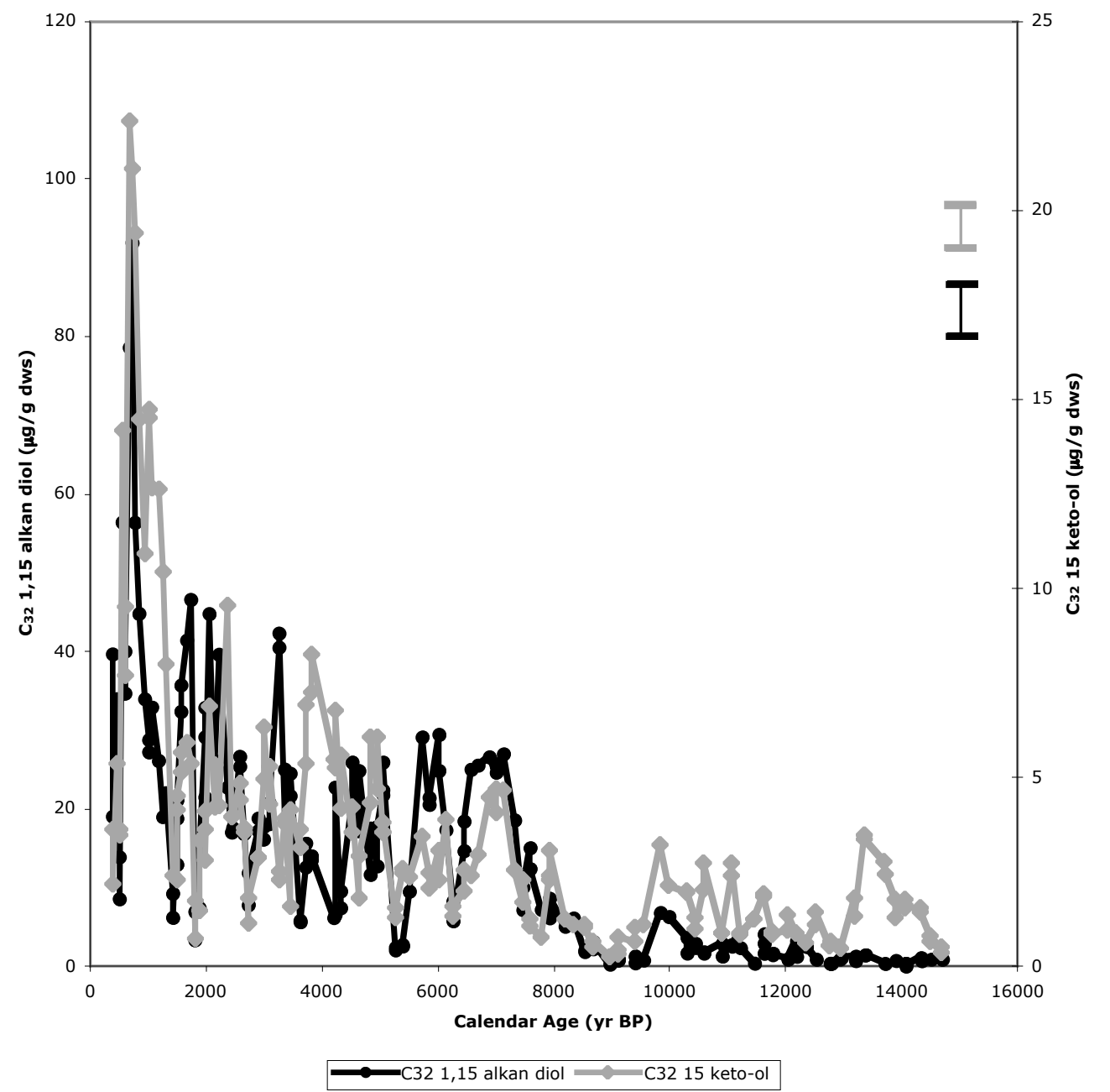

$\mathrm{C}_{32}$ alkan diol and keto-ol concentrations normalized to g dws. Error bars are provided for both records. 
Chapter 5) support a predominantly marine origin for organic matter in Peru Margin sediments. Longer-chain fatty acid homologues $\left(\geq \mathrm{C}_{26}\right)$ exhibited more depleted $\delta^{13} \mathrm{C}$ values than bulk organic matter (see Chapter 5), implying that they are indeed derived from a different (i.e. terrestrial) source.

The $\mathrm{C}_{16}$ fatty acid $\mathrm{C}_{\text {org }}$-normalized record is similar to the original concentration record, but the $\mathrm{C}_{18}$ fatty acid exhibits a sizable and broad new peak centered at about 8.7 $\mathrm{ka}$ and extending back through the $9 \mathrm{ka} \% \mathrm{C}_{\text {org }}$ minimum (Figure 4-20). These results imply a different source for the $\mathrm{C}_{18}$ fatty acid at this time, which is the only area of apparent dissimilarity between these two fatty acids. However, it is difficult to determine the nature of the source because $\mathrm{C}_{18}$ is common to many marine organisms and could also be derived from terrestrial vegetation. The $\mathrm{C}_{18}$ fatty acid is the only $\mathrm{C}_{\text {org }}$-normalized compound I observed with relatively increased concentration at $9 \mathrm{ka}$. McCaffrey et al. (1989) observed the $\mathrm{C}_{16}$, and to a lesser extent the $\mathrm{C}_{18}$, fatty acid in lipid extracts from the sulfur-oxidizing bacteria Thioploca, which is often found on the surface of sediments in the Peru Margin OMZ and may have been present at Site 1228D. However, the most abundant fatty acid in Thioploca is the unsaturated compound $\mathrm{C}_{16: 1}$ (McCaffrey et al., 1989), which was not detected in samples from Site $1228 \mathrm{D}$ at about $9 \mathrm{ka}$. The $\mathrm{C}_{16: 1}$ fatty acid is most likely not present in this interval because it is preferentially degraded, but possibly because Thioploca mats were not present. Ultimately, the source of the enhanced $\mathrm{C}_{18}$ fatty acid concentrations at 9 ka remains uncertain.

$n$-Alkanes were routinely detected in Peru Margin sediments, but were not reported due to suspicion of contamination. $n$-Alkane homologue distributions with a strong odd-carbon-number predominance can be utilized as vascular plant leaf wax biomarkers (e.g. Eglinton and Hamilton, 1967), but $n$-alkane distributions with little carbon number preference are suggestive of petrochemical contamination. The $n$-alkanes observed in this study all exhibited little or no carbon number preference. McCaffrey (1990) observed $n$-alkanes in the topmost $1 \mathrm{~m}$ of Peru Margin sediments with distributions that were consistent with leaf wax sources (CPI 3-8), so the absence of this distribution pattern in $1228 \mathrm{D}$ sediments suggests contamination, either intrinsic to the 
Figure 4-20a

Peru Margin $\mathrm{C}_{16}$ and $\mathrm{C}_{18}$ FAME Concentrations

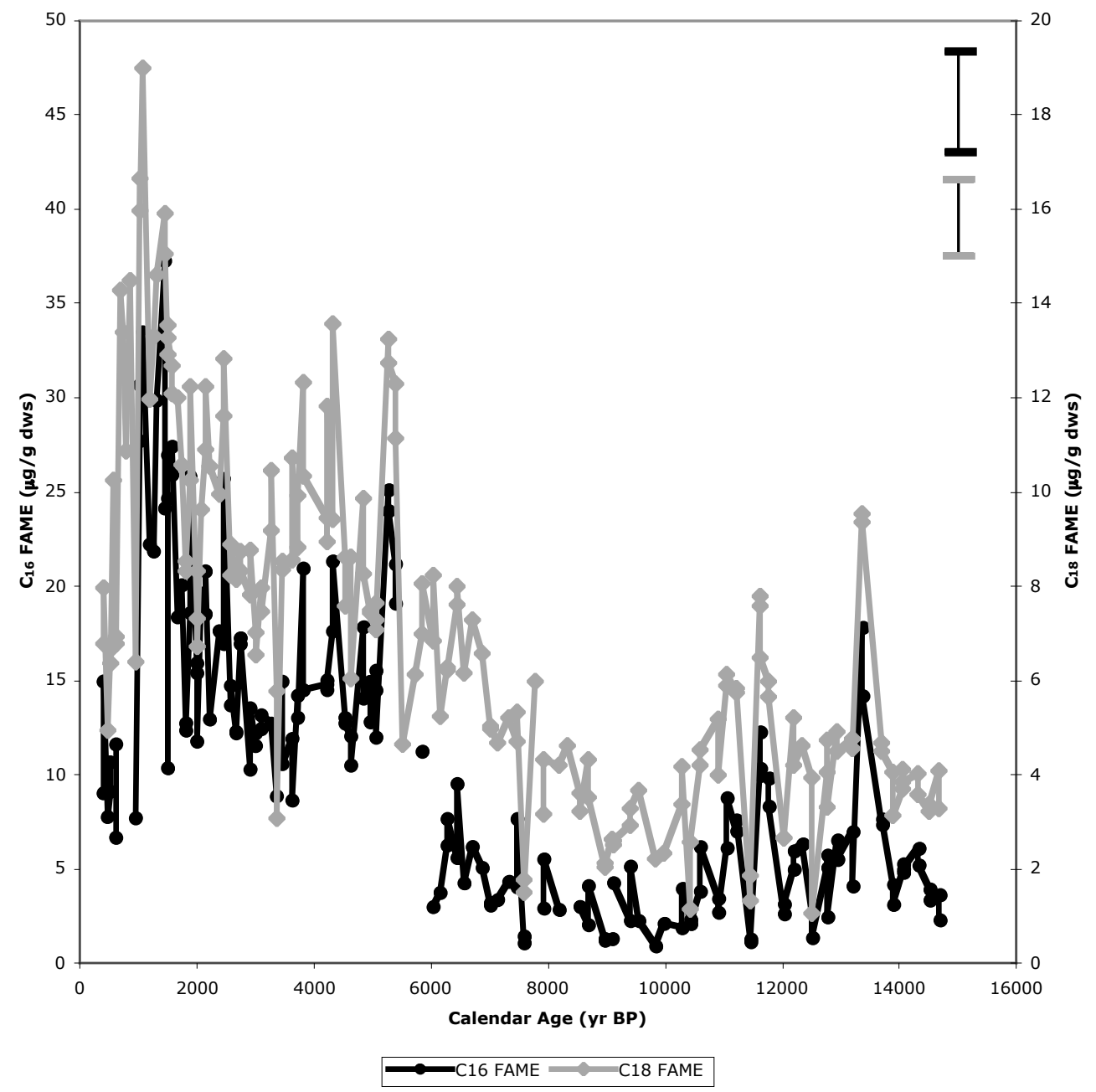

Short-chain $\left(\mathrm{C}_{16}\right.$ and $\left.\mathrm{C}_{18}\right)$ fatty acids normalized to $\mathrm{g}$ dws (a) and $\mathrm{C}_{\text {org }}(\mathrm{b})$. Error bars are provided for sediment-normalized data. 
Figure 4-20b

Peru Margin $\mathrm{C}_{16}$ and $\mathrm{C}_{18}$ FAME Concentrations Normalized to Organic Carbon

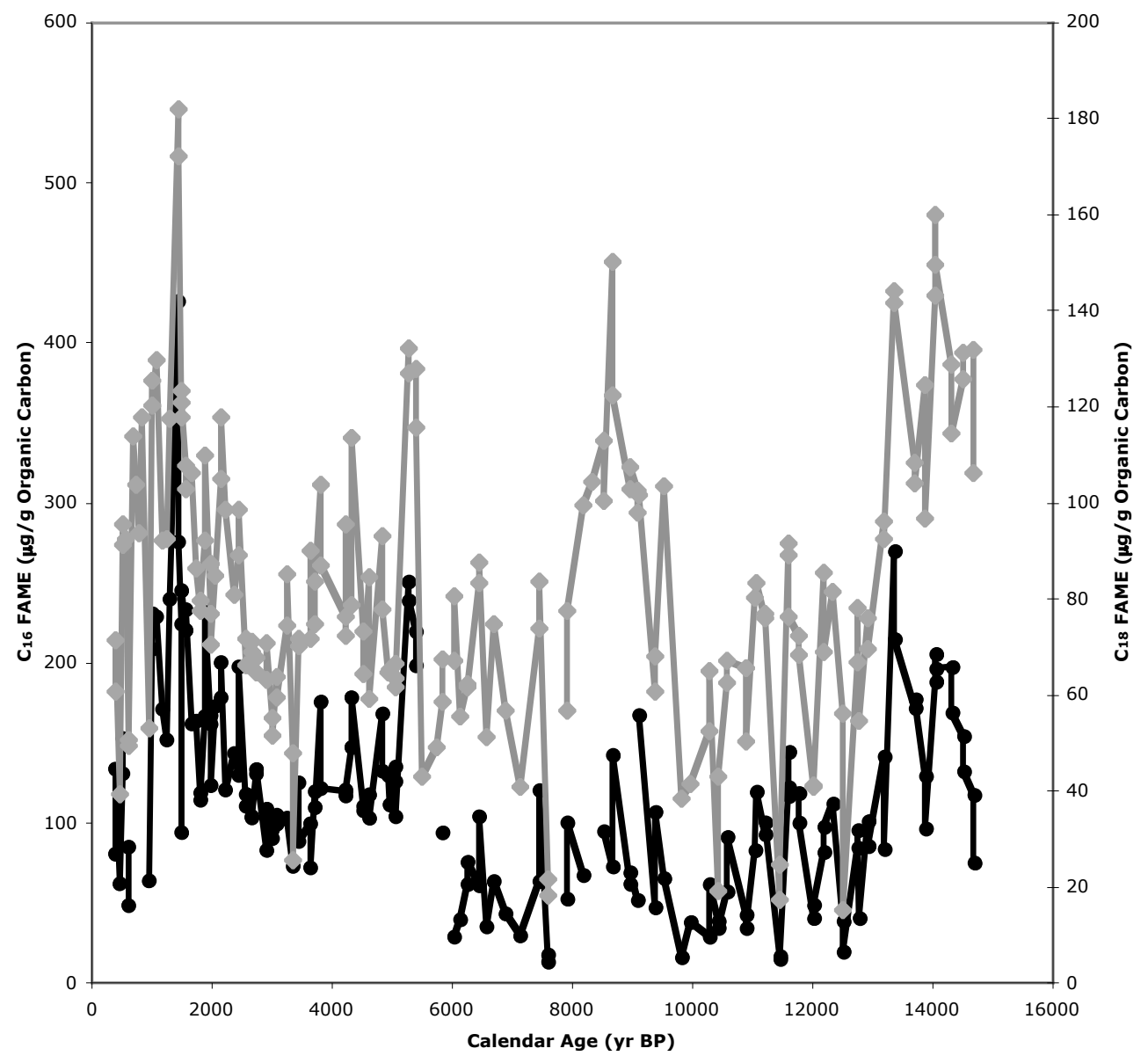

C16 FAME $\longrightarrow$ C18 FAME 
sediments or resulting from coring or laboratory practices, which overwhelms any leaf wax signal. Due to uncertainties about their source, $n$-alkanes were not employed as biomarkers in this study.

Alkan Diols and Keto-ols Other marine biomarkers, such as $\mathrm{C}_{16}$ and $\mathrm{C}_{18}$ fatty acids, $\mathrm{C}_{32}$ 1,15-alkan diol, and $\mathrm{C}_{32}$ 15-keto-ol exhibit concentration maxima late in the 1228D record, but display different variability than the sterols, once again indicating complex changes in the planktonic community over the past 9 ka (Figure 4-21). Interestingly, the $\mathrm{C}_{32}$ diol and keto-ol records are the only ones that have such a dominant peak at $0.7 \mathrm{ka}$. These records suggest that the putative precursors - eustigmatophytes (Volkman et al., 1992) - on the Peru Margin, among any other source organisms of longchain diols, respond to different environmental stimuli or exhibit different seasonal growth patterns than other primary producers, such as diatoms. Given uncertainties in the range of organisms that produce these compounds, the paleoenvironmental significance of variability in their records is difficult to determine.

Hopanoids $\mathrm{C}_{30}, \mathrm{C}_{31}$, and $\mathrm{C}_{32}$ hopanols (analyzed as trimethylsilyl derivatives), which are bacterial biomarkers, were detected in many of the samples analyzed in this study. The $\mathrm{C}_{30}$ and $\mathrm{C}_{32}$ hopanols generally occurred at higher concentrations than $\mathrm{C}_{31}$ (Figure 4-22). $\mathrm{C}_{33}$ hopanols could not be analyzed because the GC run ended prior to their expected elution time. The pattern of variability observed in the hopanol records generally parallels that of many of the marine algal marker compounds with elevated, highly variable concentrations throughout the Holocene after $9 \mathrm{ka}$, at which time there was a concentration minimum. These hopanols demonstrate the presence of bacteria in 1228D sediments, but the consistencies between the hopanol and algal biomarker records argue against sizable biasing of other biomarker records from bacterial degradation. Rather, bacterial inputs appear to match those of planktonic algae, suggesting that they are similarly derived from water column and/or sediment surface processes. Other common bacterial biomarkers such as fernene, diploptene, hop-17,21-ene, $17 \beta(H), 21 \beta(H)$-homohopane, and 28 -nor-17 $\alpha(H)$-hopane, some of which have been 
Figure 4-21

Peru Margin $\mathrm{C}_{32}$ 1,15-alkan diol and $\mathrm{C}_{32}$ 15-keto-ol Concentrations

Normalized to Organic Carbon

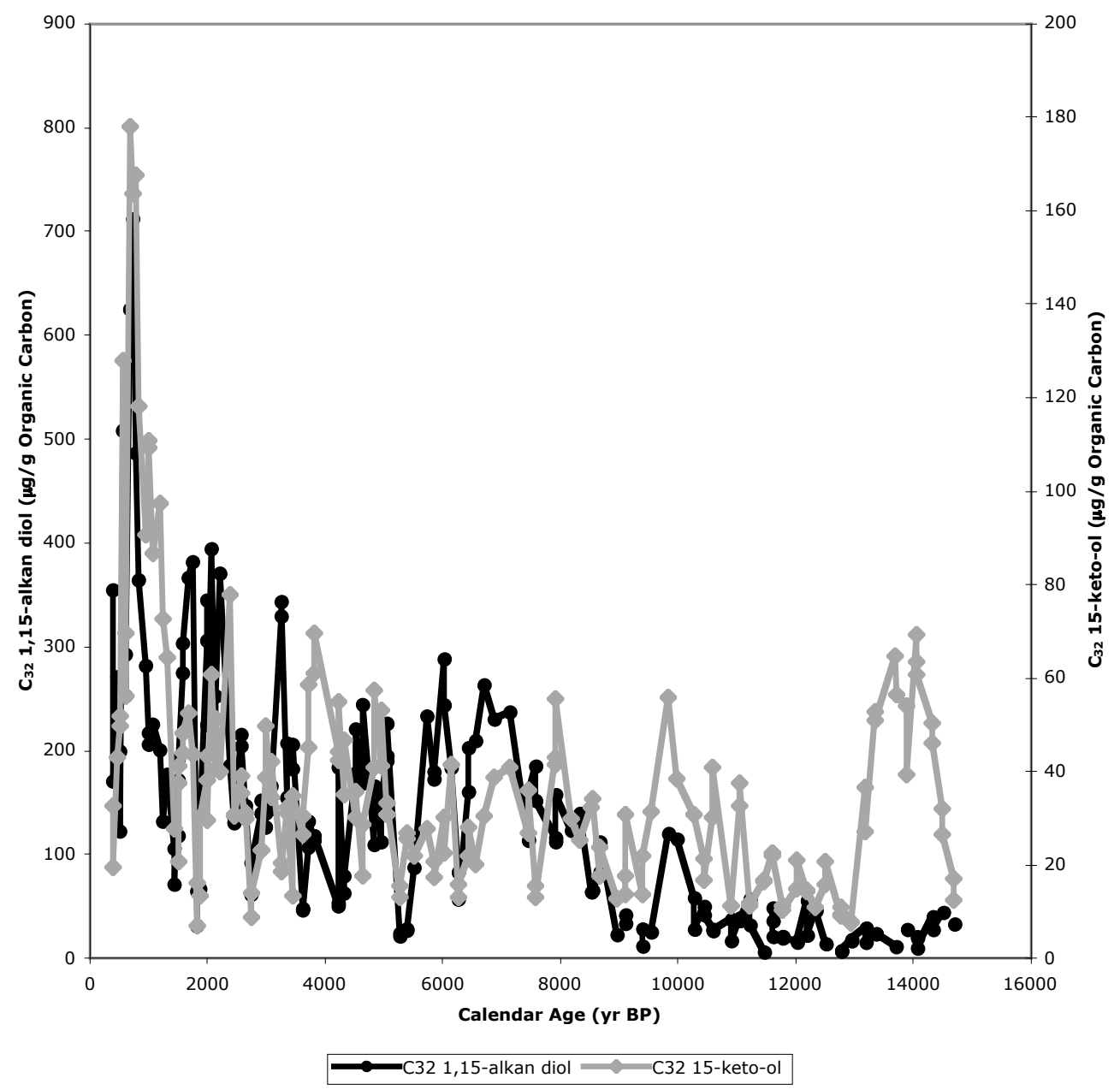

$\mathrm{C}_{32}$ alkan diol and keto-ol concentrations normalized to $\mathrm{C}_{\text {org }}$. 
Figure 4-22

Peru Margin Hopanol Concentrations

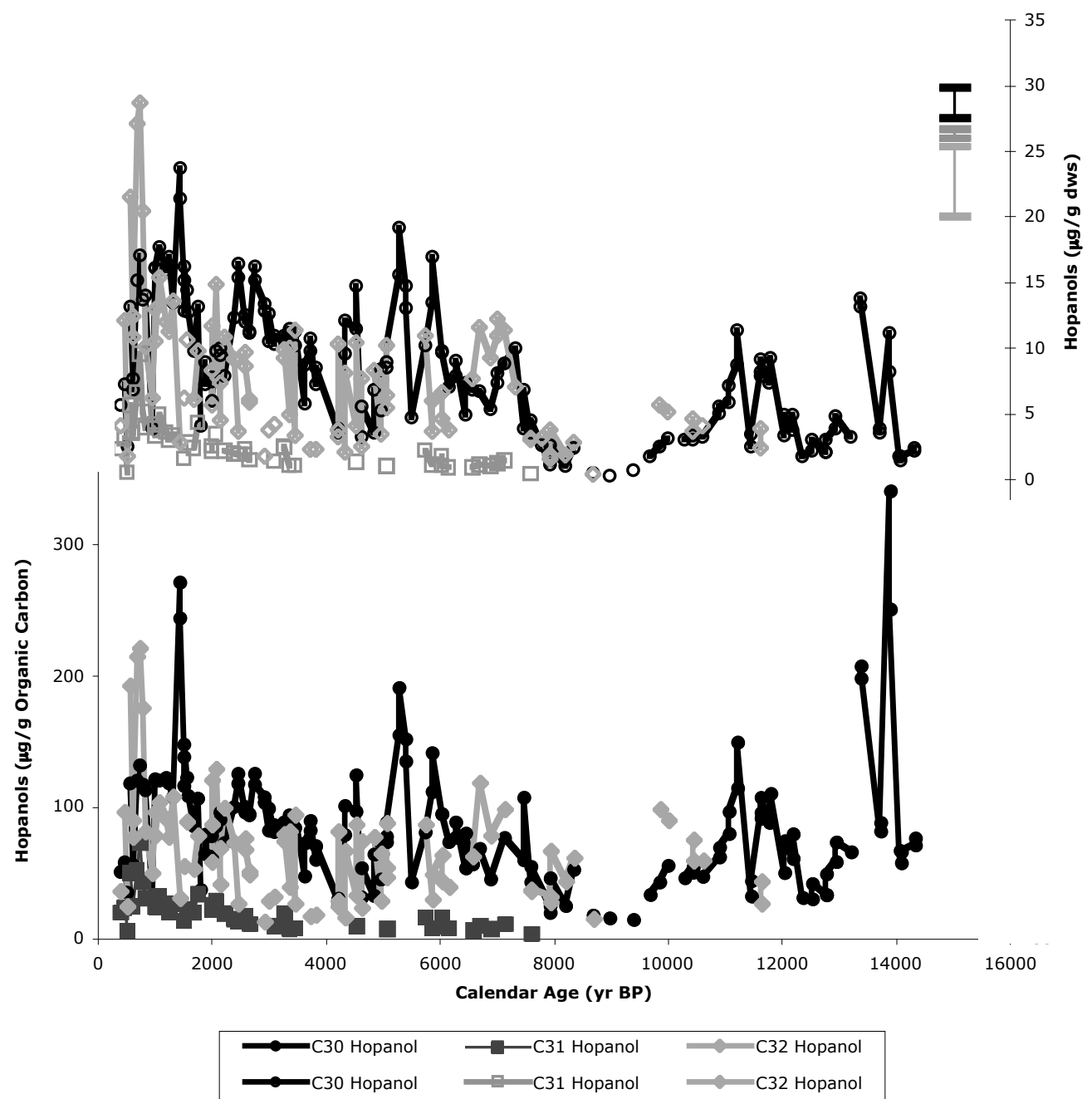

$\mathrm{C}_{30}-\mathrm{C}_{32}$ hopanol concentrations normalized to $\mathrm{g}$ dws (upper plot) and $\mathrm{C}_{\text {org }}$ (lower plot). Error bars are provided for sediment-normalized data. 
previously detected in other Peru Margin sediments (McCaffrey, 1990; ten Haven et al., 1990), were not detected in sediments from this study.

Biomarker Ratios The very strong relationship between cholesterol and cholestanol in Peru Margin sediments suggest that they may be related through production in common source organisms, or as parent and a daughter degradation product. Figure 4-23 depicts ratios of cholesterol/cholestanol and $\mathrm{C}_{32}$ 1,15-alkan diol/ $\mathrm{C}_{32}$ 15-keto-ol over the entire record. The sterol-to-stanol ratio shows moderate variability with a gradual decrease over time, possibly implying a change in source apportionment (e.g. a gradual decrease in zooplankton activity relative to phytoplankton), a change in distribution within a class of organisms, or better preservation in older sediments. Interestingly, two of the most prominent peaks in the record occur at 14.7 and $9.1 \mathrm{ka}$ when $\% \mathrm{C}_{\text {org }}$ was lowest. Assuming that the preservation potential was greatly reduced at these times, the cholesterol/cholestanol ratio appears to be insensitive to factors controlling organic matter degradation.

The $\mathrm{C}_{32}$ diol/keto-ol ratio, which is also used to infer changes in preservation, exhibits greater amplitude variability than cholesterol/cholestanol and a different pattern of change. The $\mathrm{C}_{32}$ 15-keto-ol may be a better proxy for degradation than cholestanol because it has fewer known biological sources that are not related to degradation (Ferreira et al., 2001). The $\mathrm{C}_{32}$ diol/keto-ol ratio suggests better preservation after $9 \mathrm{ka}$, consistent with the $\% \mathrm{C}_{\text {org }}$ and phytol records, and is highly variable throughout the rest of the Holocene. Between 9.0 and $3.6 \mathrm{ka}$, the diol/keto-ol ratio bears some similarity to the cholesterol record, implying a preservation overprint, but they take on a roughly opposite appearance after $3.3 \mathrm{ka}$, underscoring the complexity of changes in biota and upwelling on the Peru Margin during the late Holocene.

Biomarker Records Normalized to Phytol Figure 4-24 presents select biomarker records normalized to phytol concentration, which provides another way to investigate variability in specific compounds without a large productivity overprint. With the exception of dinosterol, which in this case probably provides an estimate of the dinoflagellate/diatom productivity ratio, the sterols show variability that is over- 
Figure 4-23

Biomarker Ratios

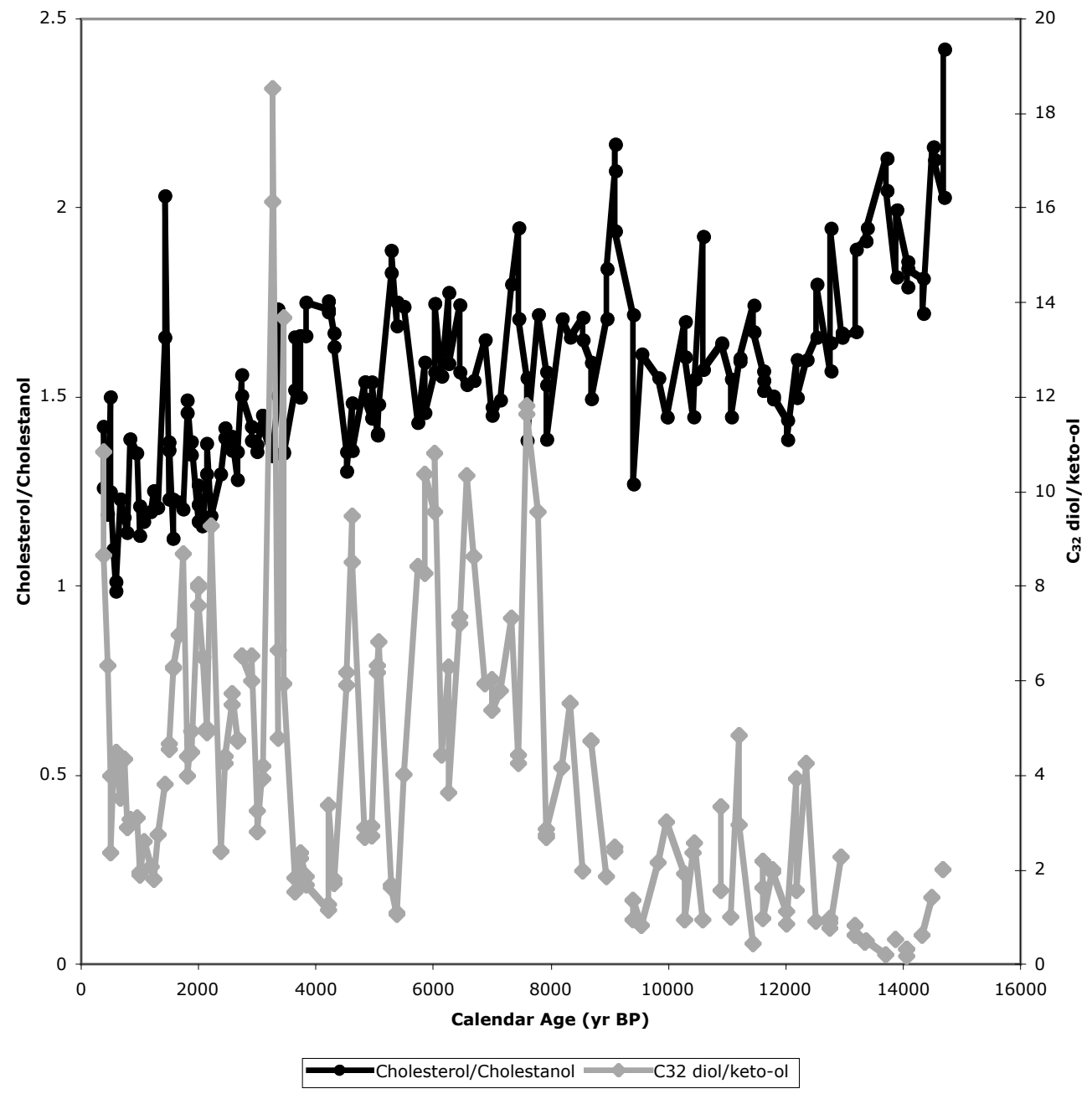

Biomarker ratios - cholesterol/cholestanol and $\mathrm{C}_{32}$ alkan diol and keto-ol. Increasing $\mathrm{y}$ axis values imply enhanced preservation. 
Figure 4-24a

Peru Margin Cholesterol and Cholestanol Concentrations Normalized to Phytol

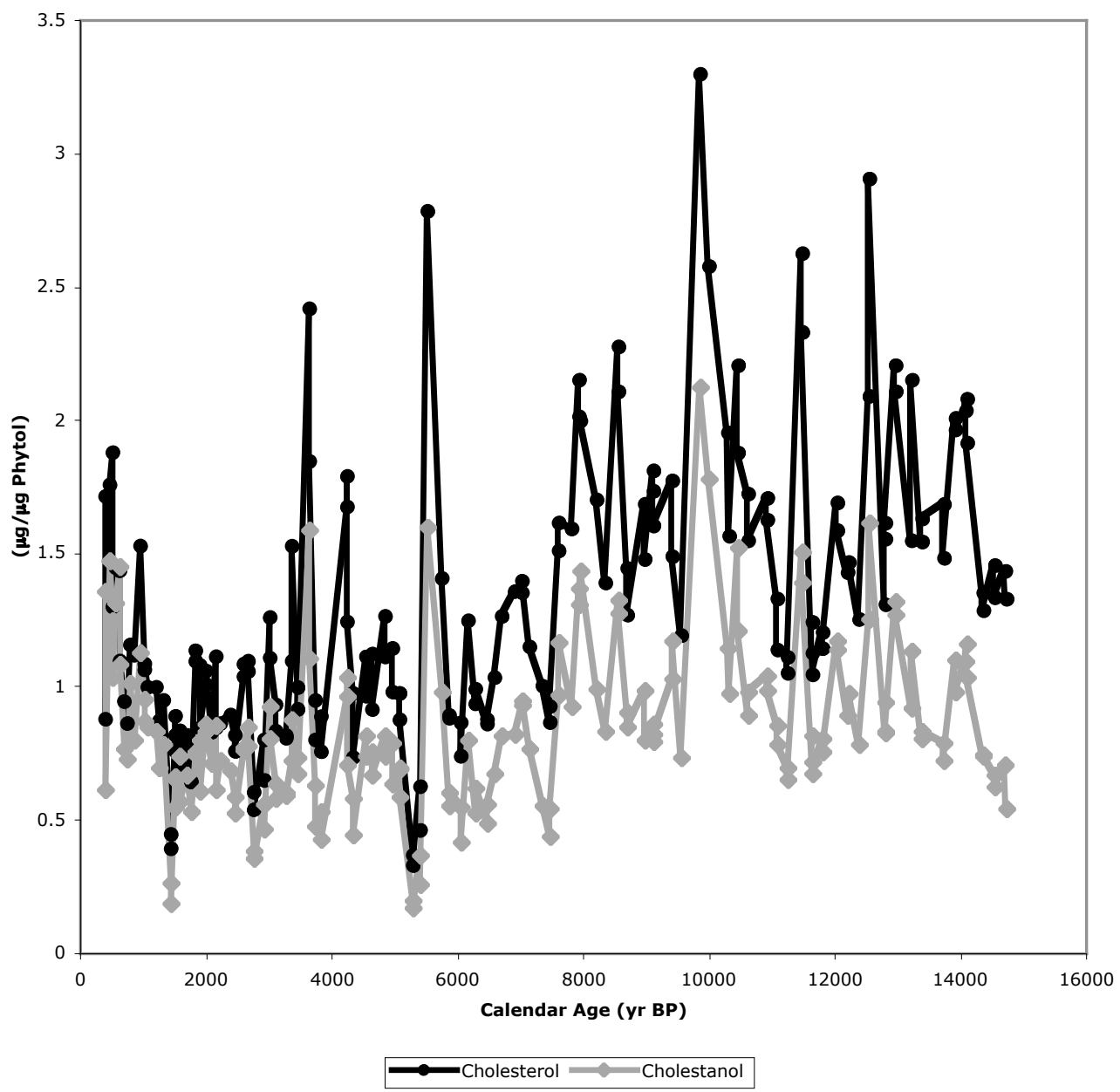

Biomarker concentration records normalized to phytol concentration. 
Figure 4-24b

Peru Margin Brassicasterol and $\beta$-sitosterol Concentrations Normalized to Phytol

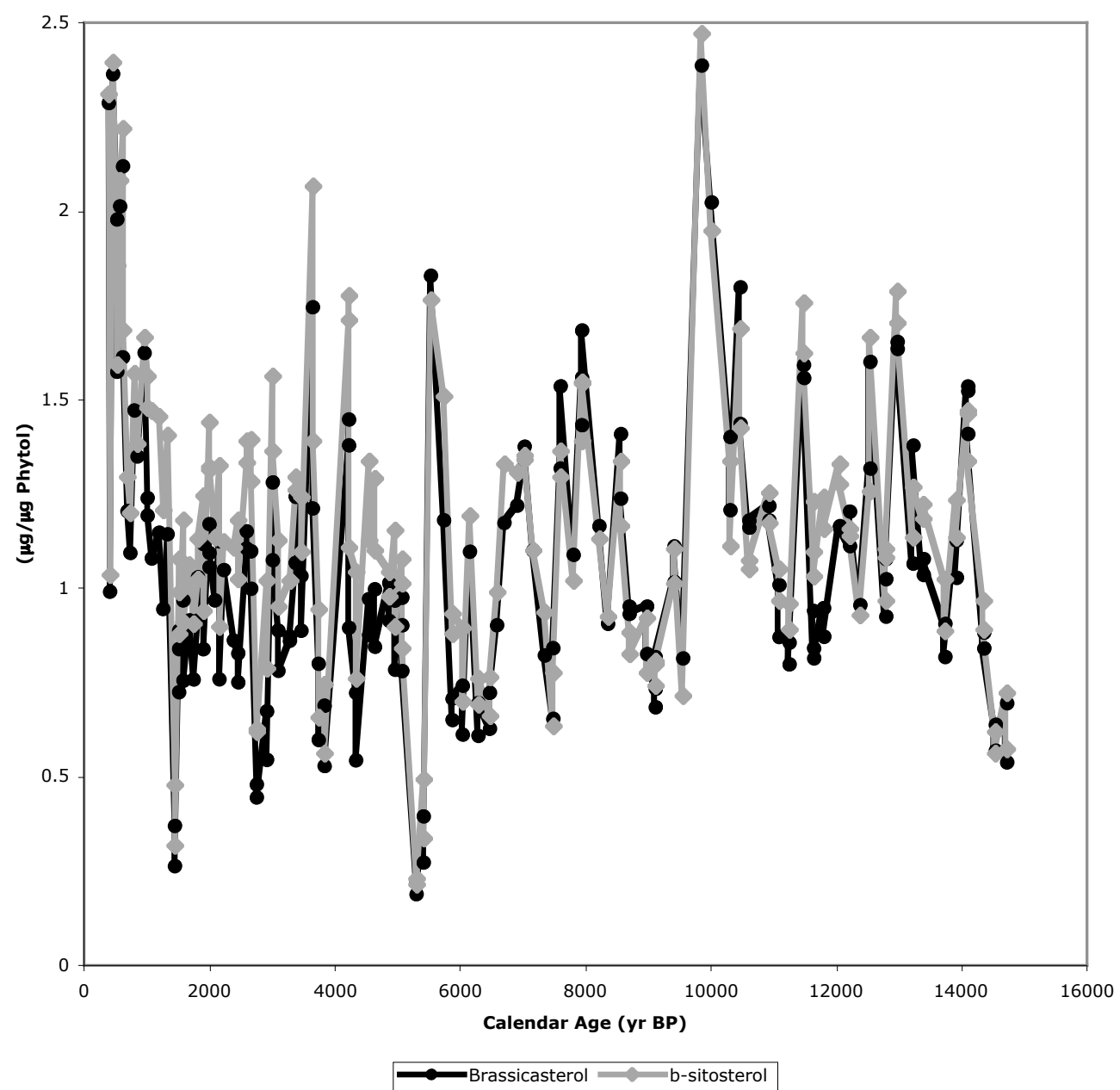


Figure 4-24c

Peru Margin Dinosterol Concentration Normalized to Phytol

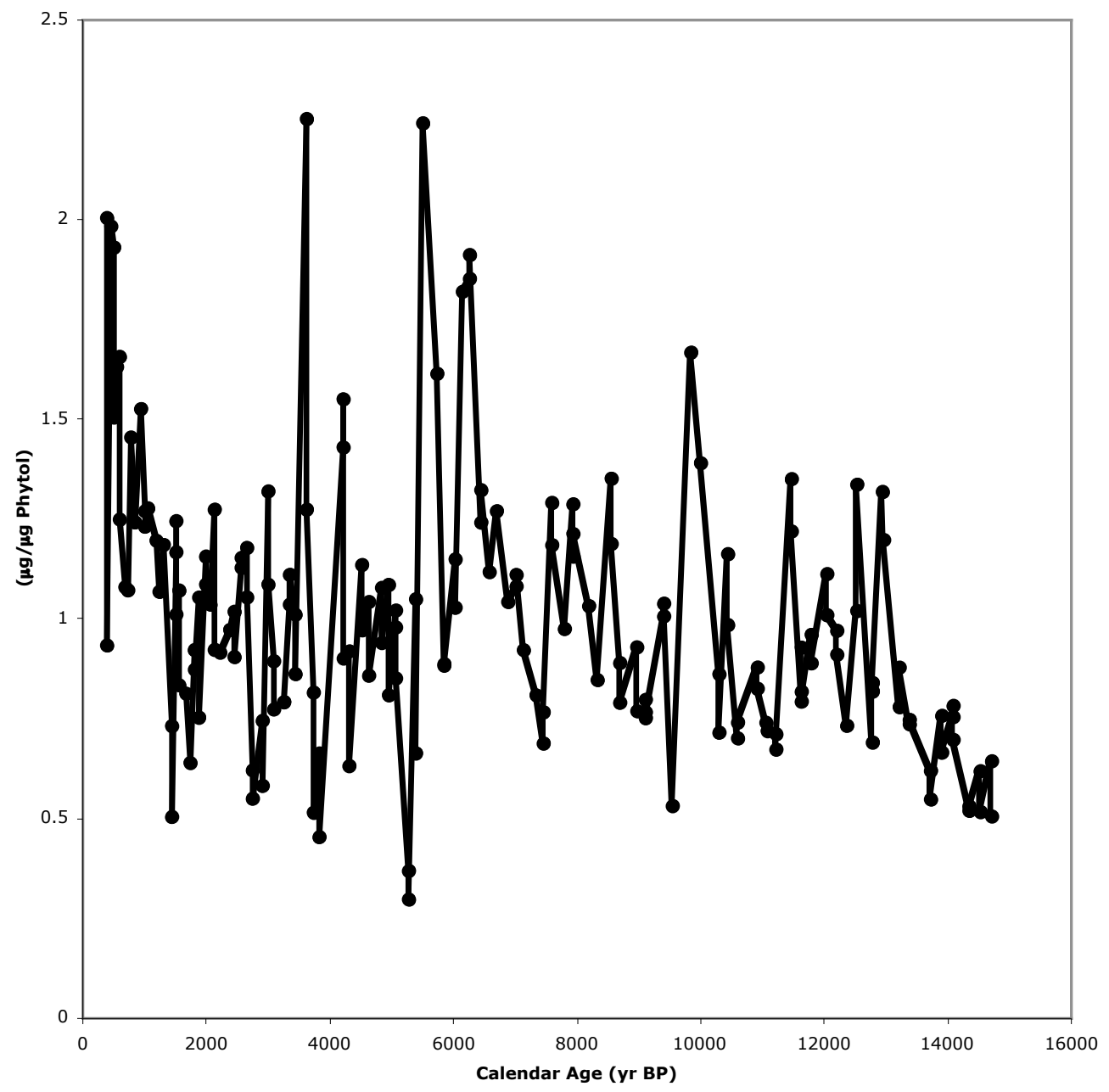


Figure 4-24d

Peru Margin $\mathrm{C}_{32}$ 1,15-alkan diol and $\mathrm{C}_{32}$ 15-keto-ol Concentrations Normalized to Phytol

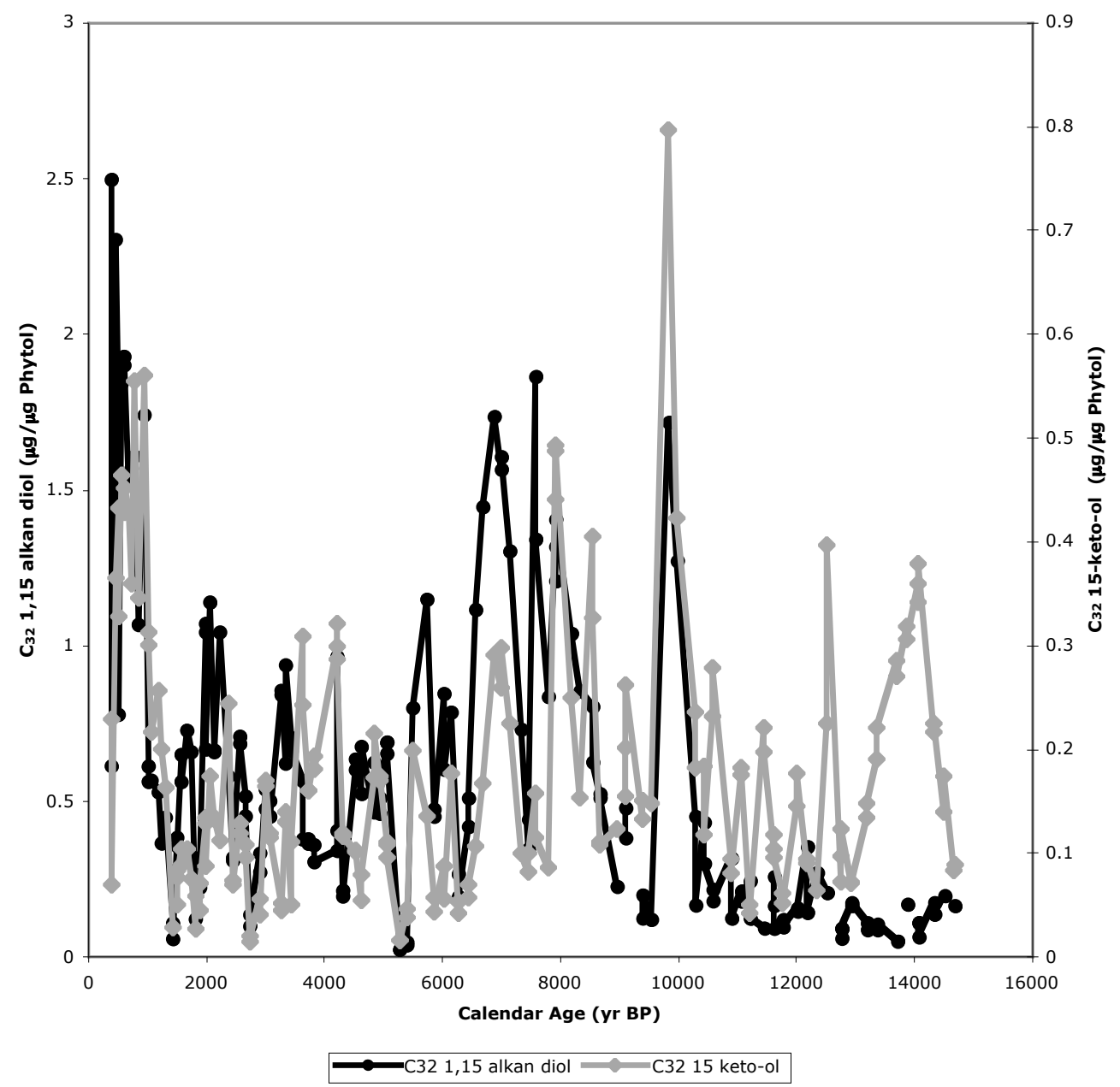


Figure 4-24e

Peru Margin $\mathrm{C}_{16}$ and $\mathrm{C}_{18}$ FAME Concentrations Normalized to Phytol

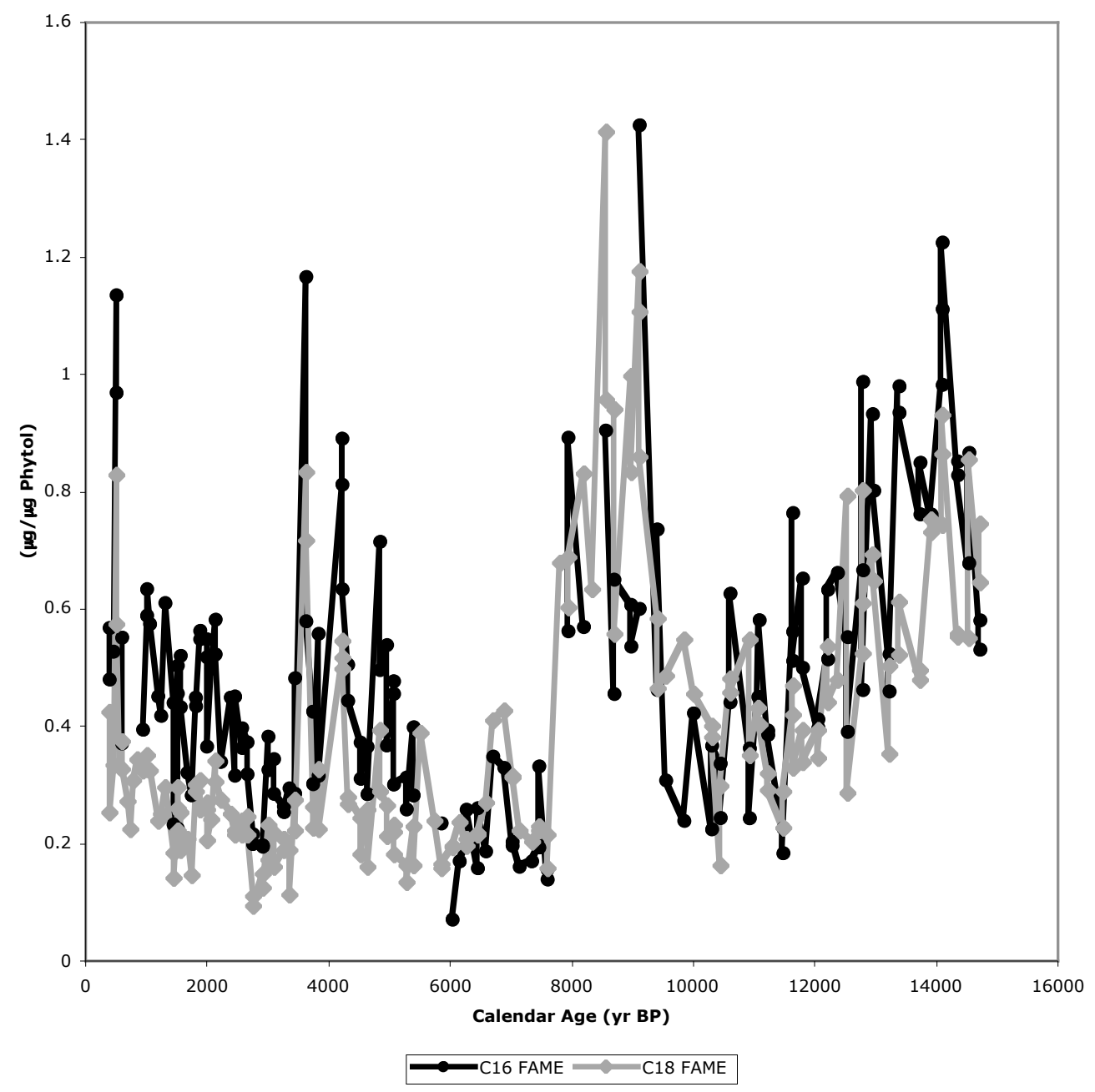


Figure 4-24f

Peru Margin $\mathrm{C}_{26}, \mathrm{C}_{28}$, and $\mathrm{C}_{30}$ FAME Concentrations Normalized to Phytol

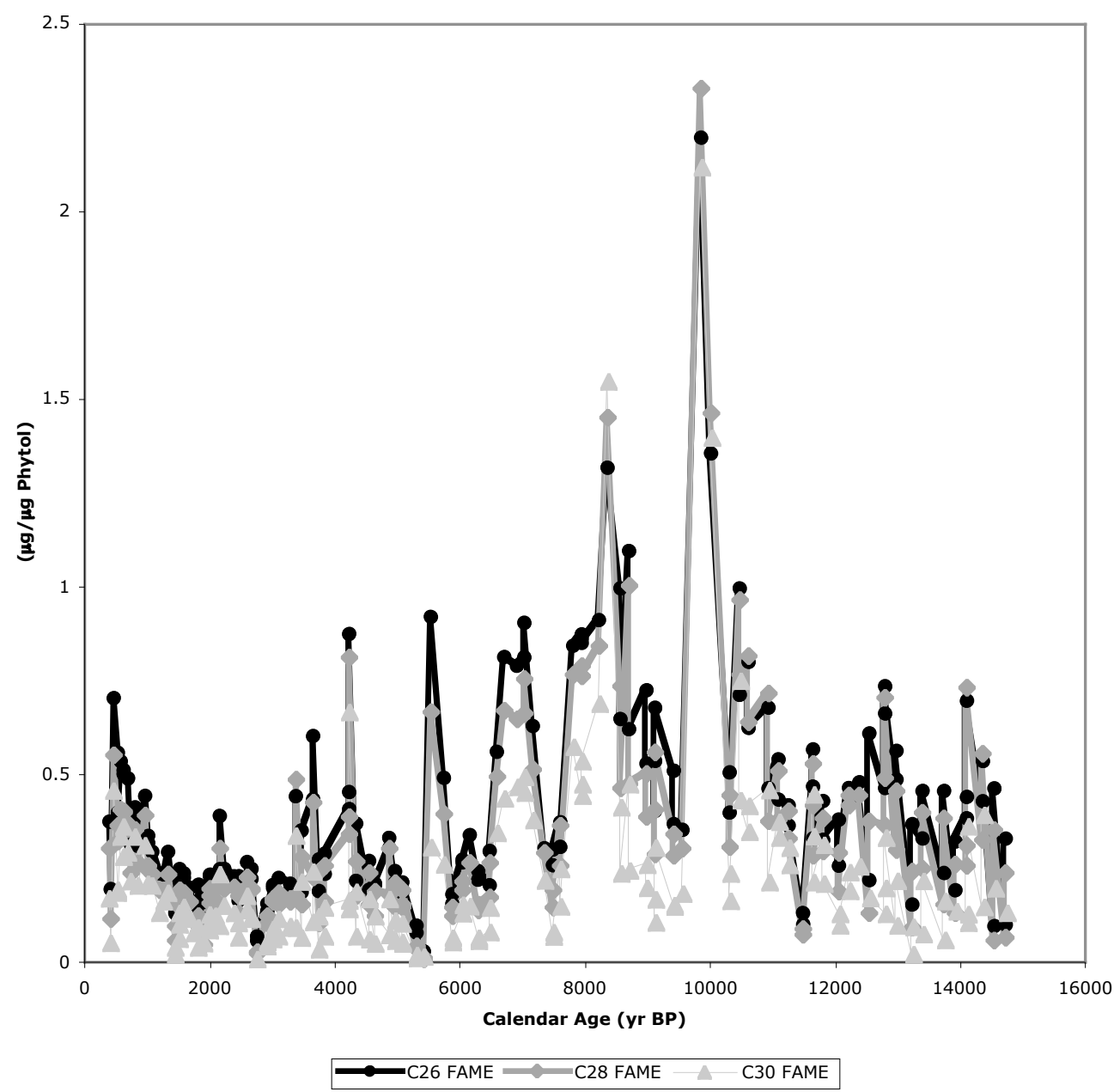


determined by the phytol normalization. The phytol-normalized dinosterol record implies that dinoflagellates exhibited increased productivity relative to diatoms at about $6.2 \mathrm{ka}$, and the original biomarker concentration records support this observation. Records of the $\mathrm{C}_{32}$ 1,15-alkan diol and $\mathrm{C}_{32}$ 15-keto-ol are similar to many of the sterol records, suggesting a possible diatom source for these compounds. The short-chain fatty acids $\left(\mathrm{C}_{16}\right.$ and $\left.\mathrm{C}_{18}\right)$ exhibit a somewhat different pattern of variability than the diatomrelated sterols, especially prior to $7.5 \mathrm{ka}$, implying contributions from other sources for these compounds. Again, the greatest inputs of the $\mathrm{C}_{18}$ fatty acid, and also the $\mathrm{C}_{16}$ fatty acid in this case, span the $9 \mathrm{ka}$ minimum in $\% \mathrm{C}_{\text {org }}$ and many of the biomarker records, possibly due to bacterial inputs or other marine sources. The long-chain, terrestrial vegetation derived fatty acid $\left(\mathrm{C}_{26}, \mathrm{C}_{28}\right.$, and $\left.\mathrm{C}_{30}\right)$ records exhibit a unique peak at $8.3 \mathrm{ka}$ when normalized to phytol. This peak is also evident in the $\mathrm{C}_{\text {org }}$ normalized $\mathrm{C}_{26}$ record, demonstrating enhanced inputs of terrigenous organic matter at this time.

\section{Multivariate Statistics}

Principal component analysis (PCA) and factor analysis were performed on all biomarker records (and \% $\mathrm{C}_{\text {org }}$ ) presented in this study in order to examine the relationships between different compounds and identify those that can be best applied to paleoclimate investigation. All statistical analyses were conducted using MATLAB software. To normalize the biomarker data, the covariance matrix was computed from an original matrix made up of 33 biomarkers and $\% \mathrm{C}_{\text {org }}$, with 176 observations (including replicates). The covariance matrix was then used in multivariate analyses. The first eigenvalue determined through PCA accounted for $97.4 \%$ of the variability in the biomarker records, with the next two accounting for 2.2 and $0.2 \%$. All subsequent eigenvalues combined accounted for about $0.1 \%$. The overwhelmingly large first eigenvalue almost certainly represents marine inputs, as would be expected for the diatom-dominated upwelling regime. The second may represent terrestrial leaf wax inputs to the sediments, which are expected to be small compared to marine inputs, but nonetheless refractory. 
Three factors were chosen for factor analysis, which was believed to be an appropriate number considering the large weighting on the first eigenvalue and subsequent rapid decrease observed in the PCA results; after the first three eigenvalues, the rest are virtually negligible. The factor analysis results are presented graphically in Figure 4-25, with the first (x-axis) and second (y-axis) factors plotted in 4-25a and the first and third in 4-25b. The individual compounds plot almost entirely in the first quadrant of the graph because the results have been rotated using the Varimax algorithm in MATLAB. As evidenced in Figure 4-25a, the first factor appears to define marine versus terrestrial contributions, with most of the marine-derived biomarkers (steroidal compounds, acyclic isoprenoids, short-chain fatty acids, $\mathrm{C}_{30}$ hopanol) plotting greater than 0.6 on the $\mathrm{x}$-axis and most of the terrestrial biomarkers (long-chain fatty acids and $n$ alkanols) plotting below this value. $\% \mathrm{C}_{\text {org }}$, which is expected to be heavily influenced by marine contributions, plots at an intermediate value. Further separation of the marinederived biomarkers is achieved with the second factor. All of the steroidal compounds plot at values greater than 0.4 on the $y$-axis and the acyclic isoprenoids, $\mathrm{C}_{16}$ and $\mathrm{C}_{18}$ fatty acids, $\mathrm{C}_{16} n$-alkanol, and $\mathrm{C}_{30}$ hopanol plot below this value. This result may be due to differences in source organisms, with steroidal compounds having been derived from algae and the other cluster of marine compounds from a combination of algae and bacteria. Alternatively, the differences between the marine biomarkers may have arisen from disparities in reactivity or particle association. Interestingly, dinostanol plots about as close to brassicasterol and $\beta$-sitosterol as it does dinosterol, reinforcing the hypotheses about this biomarker discussed earlier. The long-chain $\left(\geq \mathrm{C}_{22}\right)$ fatty acids and $n$-alkanols plot in clusters but separately, with the $n$-alkanols more heavily loaded on the second factor. The reason for this difference is not obvious because both types of compounds are expected to have a terrestrial plant leaf wax source (Eglinton and Hamilton, 1967), although it may have resulted from differences in reactivity between the alcohols and acids, or possibly analytical effects related to differing derivatization methods. The fact that the long-chain fatty acids plot separately from other marine-derived compounds supports their interpretation as terrestrial biomarkers. The $\mathrm{C}_{32}$ homologue, which is 
Figure 4-25a

Biomarker Factor Analysis - Factors 1 and 2

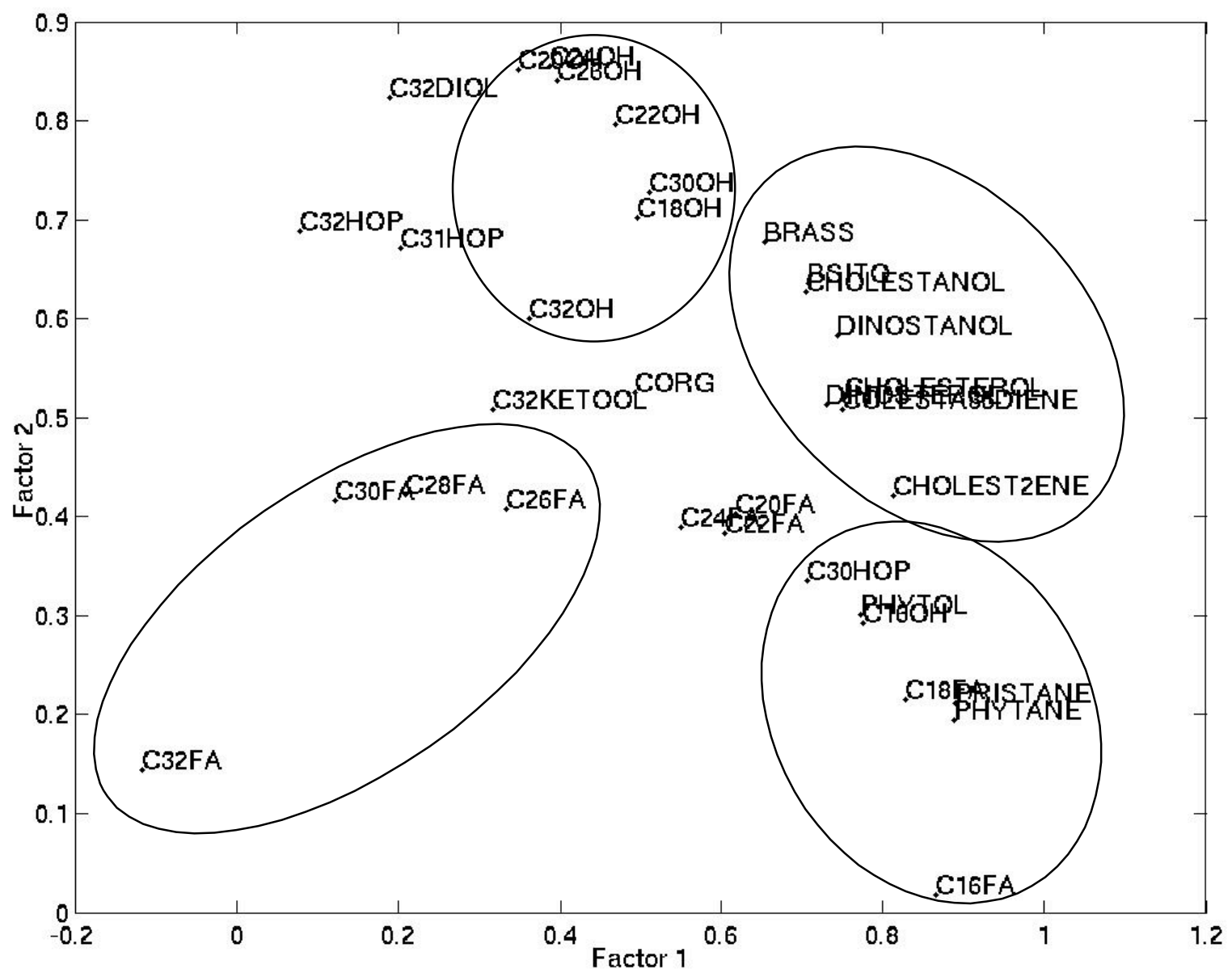

Factor analysis results plotted as factors 1 versus 2 (a) and 1 versus 3 (b). Encircled areas identify groups of similar biomarkers such as the steroidal compounds, other marine algal and bacterial biomarkers, fatty acids, and $n$-alkanols. In plot (b), the fatty acids are heavily loaded on factor three and the $n$-alkanols are not, which is the opposite of the pattern observed for factor two in plot (a). 
Figure 4-25b

Biomarker Factor Analysis - Factors 1 and 3

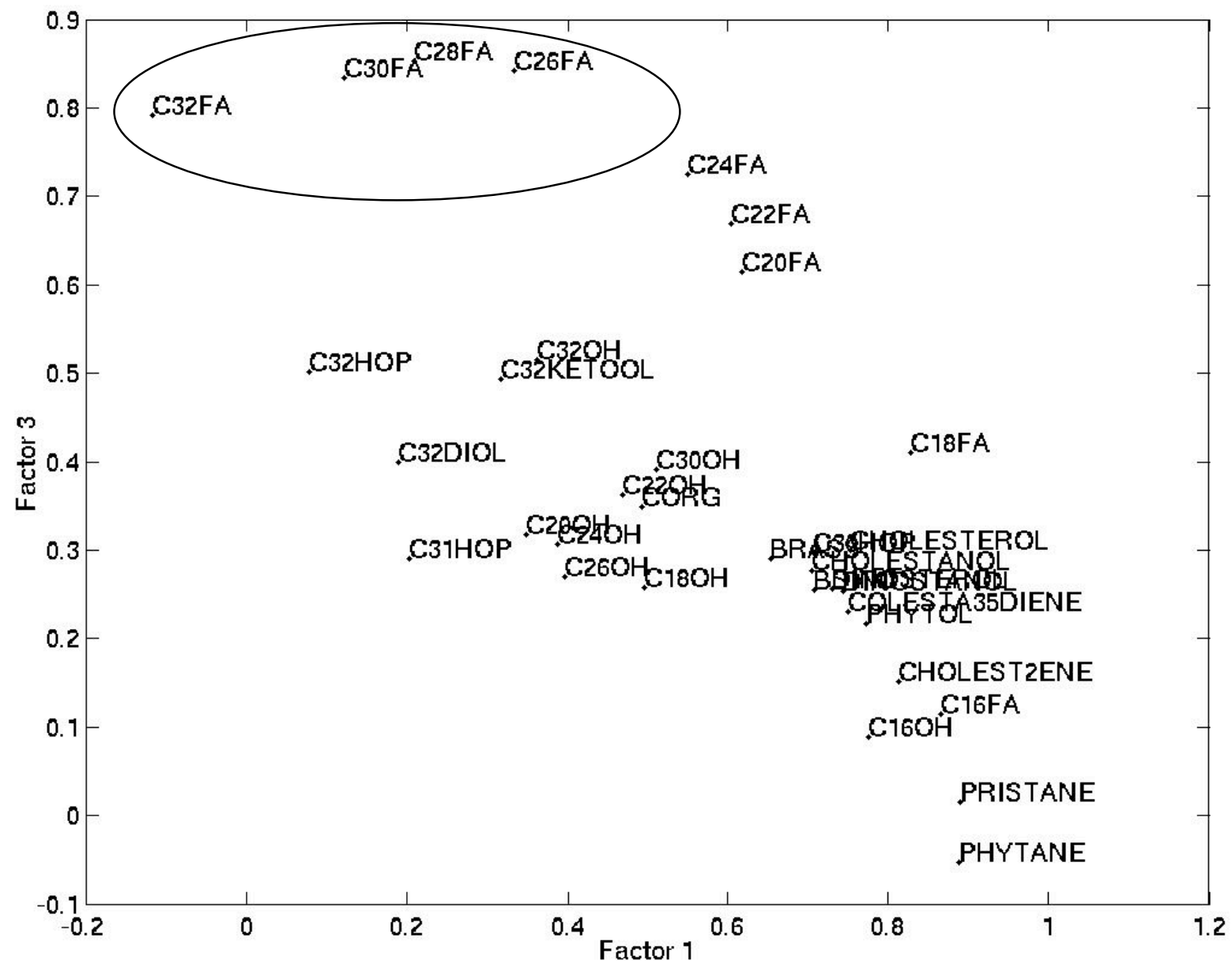


expected to be most purely terrestrial (see Chapter 5), plots lowest on the first factor and apart from all other compounds, reinforcing the assumption that it has no algal or bacterial sources in these sediments. Based on the results presented in Figure 4-25b, the third factor appears to separate the fatty acids and $n$-alkanols much as the second factor did, although in this case it is the fatty acids that are more heavily loaded. Again, the $\mathrm{C}_{32}$ fatty acid occupies a unique region of the plot. The third factor, which accounts for a very small fraction of the total variability, does not further separate the marine compounds as well as the second factor. Factor analysis also revealed that the $\mathrm{C}_{32}$ alkan diol and keto-ol and the $\mathrm{C}_{31}$ and $\mathrm{C}_{32}$ hopanols plot in different areas than the other marine compounds and are less heavily loaded on the first factor. The reason for this difference is not understood, as these compounds are almost assuredly derived from marine sources. Steroidal compounds that formed through diagenesis plot near their parent compounds, supporting the hypotheses that the original biomarkers are well preserved in Peru Margin sediments, the majority of degradation occurs in the water column or at the sediment surface, and the sedimentary records faithfully record water column processes.

Figure 4-26 plots the predicted factor scores for individual samples, with each point representing a specific depth. Replicate analyses are represented by a .01 or .02 designation after the depth in $\mathrm{cm}$. This analysis was conducted using the nonstandardized data as required in MATLAB, and thus is not entirely comparable to the factor analysis results, although it is expected to be similar based on the inherent similarities between the records. Replicate analyses generally plot near one another, consistent with assessments of low instrumental error. Almost all of the depths below $200 \mathrm{~cm}$, which represent ages older than about $9 \mathrm{ka}$, plot in the cluster of points centered at $x$ and $y$-axis values of about -0.5 . Shallower depth points are scattered throughout the plot, but are almost always more heavily loaded on factors 1 and/or 2. This pattern distinguishes between the generally low biomarker concentrations and variability observed prior to $9 \mathrm{ka}$ and the higher concentration and variability portion of the records following that time. Clearly, environmental conditions on the Peru Margin or in the sediments were different before and after this transition point. 
Figure 4-26a

Biomarker Factor Analysis - Factor Scores for Individual Data Points

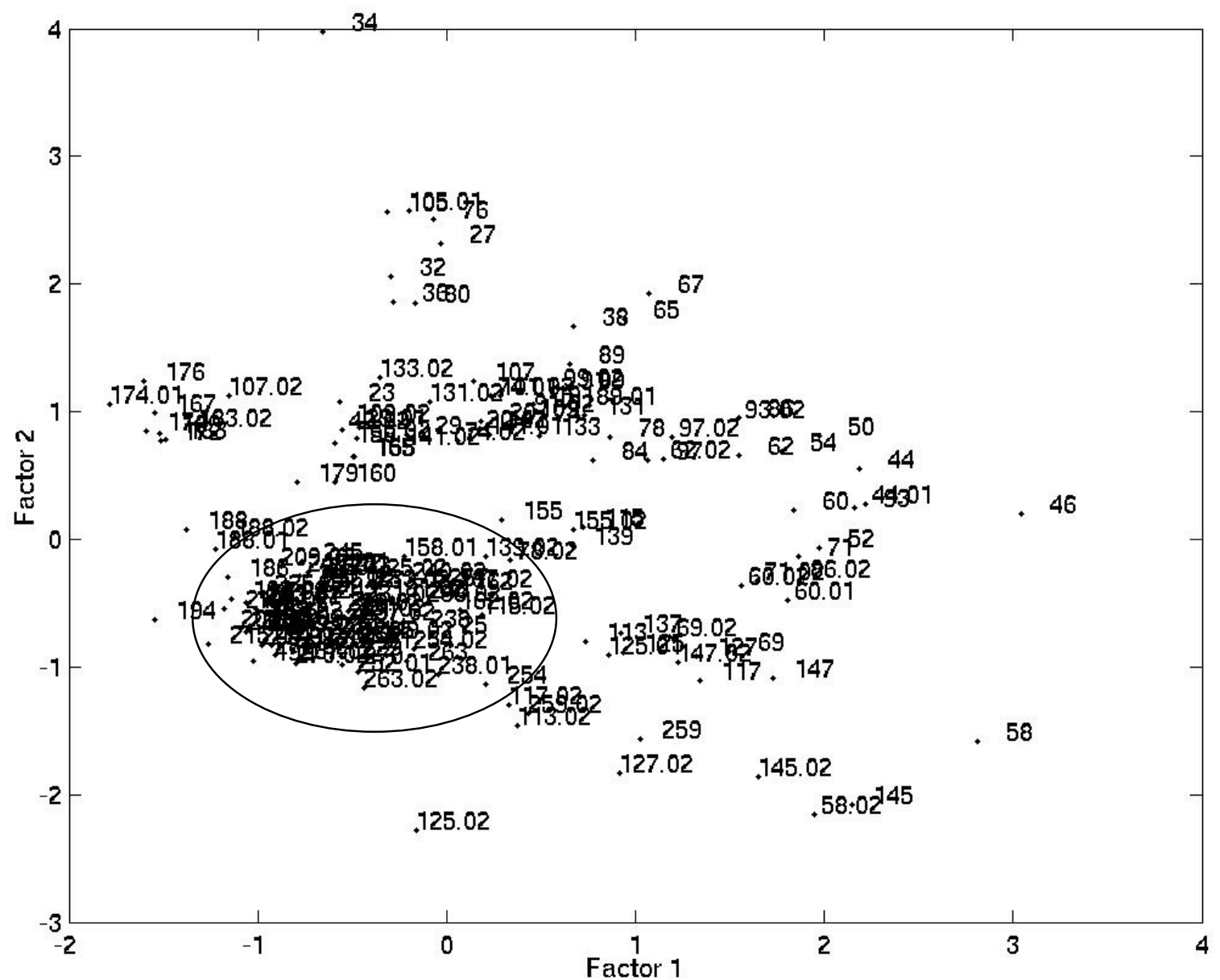

Predicted factor scores for individual sample depths (a). Plot (b) is an expanded view of the cluster of compounds encircled in plot (a). Values associated with each point are sample depth in $\mathrm{cm}$. Replicates are identified via .01 and .02 designations. The encircled area in (a) mostly includes depths below about $200 \mathrm{~cm}$. 
Figure 4-26b

Biomarker Factor Analysis - Factor Scores for Individual Data Points, Enhanced View of Clustered Data

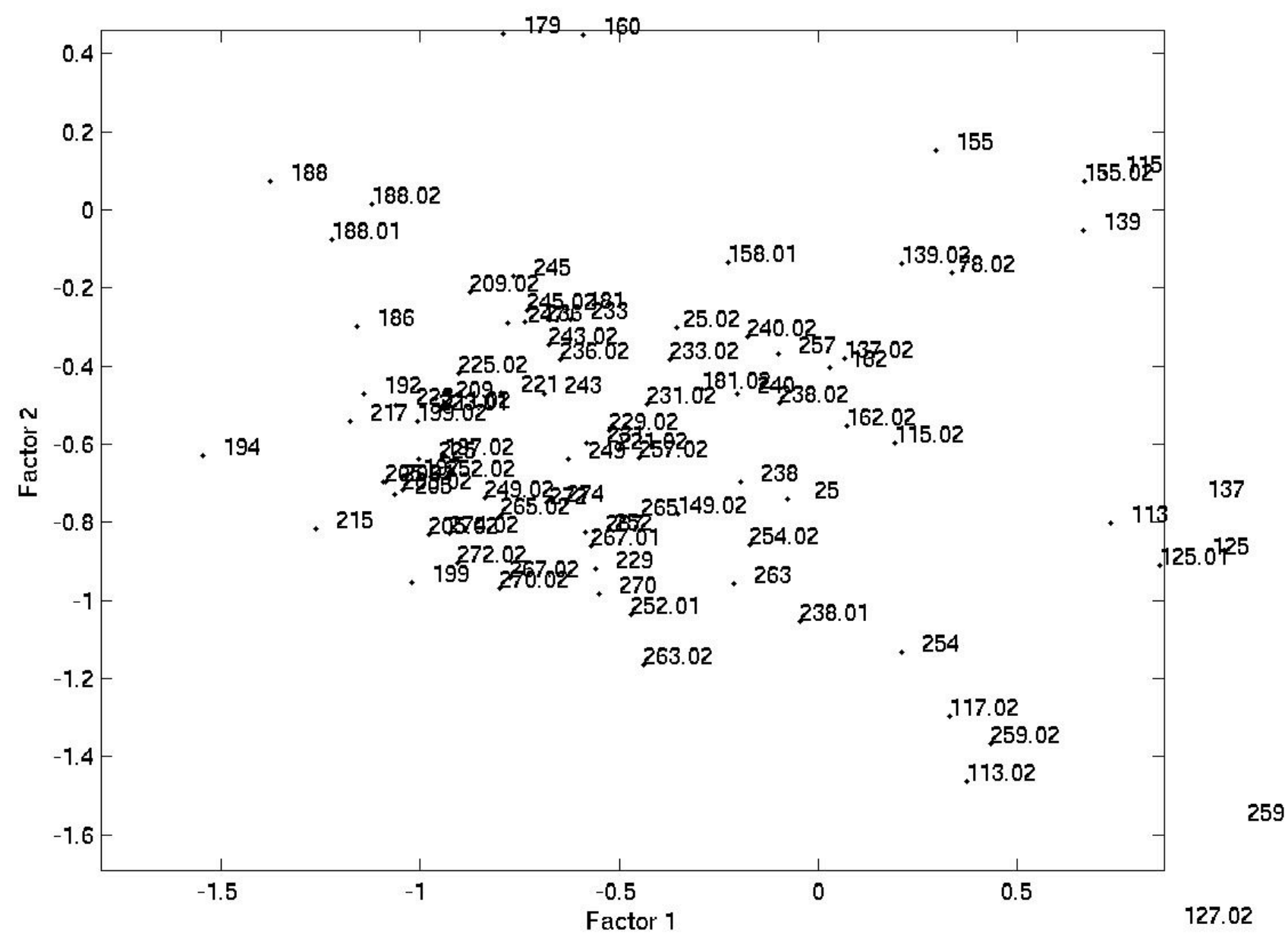


The results of the multivariate analysis performed on the 1228D biomarker data compare favorably with those of Yunker et al. (1995), who used PCA to identify different sources of organic matter to the Mackenzie shelf. As was the case for the factor analysis in the present study, the PCA performed on Mackenzie shelf sediments effectively distinguished between marine and terrestrially derived compounds. Additionally, both analyses provided the ability to detect lesser modes of variability that differentiated between marine compounds with potentially different sources, such as sterols and acyclic isoprenoids. These findings demonstrate the utility of multivariate analysis as a tool for understanding sources of individual compounds or classes of compounds to organic-rich environments.

\section{Controls on Biomarker Preservation}

Selective Biomarker Degradation Variability in biomarker records could result from changes in productivity or preservation of organic matter, potentially complicating paleoclimate interpretations. Of the sterols produced in Peru Margin surface waters, Gagosian et al. (1983) estimated that only 10-50\% were transported out of the euphotic zone and 1.5-6\% were incorporated into the sedimentary record. Based on similar biomarker and organic carbon profiles in two cores from the Peru Margin, one of which was well within the OMZ and the other of which was close to its shallow limit, Farrington et al. (1988) hypothesized that below the upper few centimeters, variability in the biomarker records resulted primarily from changes in productivity.

In order to test preservation in the $1228 \mathrm{D}$ records, they were compared to the study of Hoefs et al. (2002), who investigated differential biomarker degradation rates in a turbidite. According to their findings, the following Peru Margin biomarkers are arranged in order of preservation potential from greatest to least: $\mathrm{C}_{26}$ fatty acid $>$ cholestanol $>$ dinosterol $>$ phytol. Sinninghe Damsté et al. (2002) observed large differences in preservation efficiency between compounds that had been deposited within or outside of the OMZ on the Murray Ridge, and also identified differences in extent of degradation between compound classes. Their findings were similar to those of Hoefs $e t$ 
al. (2002) in that the $\mathrm{C}_{26}$ fatty acid and $\mathrm{C}_{32}$ alkan diol and keto-ol were generally better preserved than dinosterol. Although phytol and dinosterol are relatively labile under oxic conditions, their Peru Margin records both exhibit concentration peaks (per g dws) that are not observed in the $\mathrm{C}_{26}$ fatty acid record, and several dinosterol concentration peaks are likewise not represented in the cholestanol record. Excellent preservation of these more labile biomarkers strongly suggests that variability in the marine biomarker records is primarily a productivity signal, at least after $9 \mathrm{ka}$. By comparison with the findings of Sinninghe Damsté et al. (2002), the patterns observed in the Peru Margin records suggest that Site 1228D remained within the OMZ during the mid to late Holocene. Volkman et al. (1987) hypothesized that terrestrial organic matter may be preferentially preserved in Peru Margin sediments compared to marine organic matter. Although the $\mathrm{C}_{26}$ fatty acid exhibits unique concentration maxima, $\beta$-sitosterol, which is derived from both terrestrial and marine sources, strongly resembles other marine biomarker records instead of the $C_{26}$ fatty acid, implying that marine organic matter in $1228 \mathrm{D}$ does not strongly suffer from preferential degradation and a biased signal.

Sulfur Incorporation The lipid composition of Peru Margin sediments could be altered by sulfurization of functionalized compounds (Kohnen et al., 1991), effectively sequestering some biomarkers and thus biasing interpretation of stratigraphic records. However, the results of Eglinton et al. (1994) suggest that sulfur-bridging reactions do not appreciably affect organic matter degradation within at least the upper $68 \mathrm{~cm}$ of these sediments. To test for the presence of organically bound sulfur, a subset of 20 TLEs that had already been treated with activated $\mathrm{Cu}$ to remove free sulfur, and that span the entire depth range of $1228 \mathrm{D}$ sediments used in this study, was analyzed for total sulfur. The highest measured blank response eclipsed all of the sample values with the sole exception of the $257 \mathrm{~cm}$ sample, which was only $13 \%$ greater than blank level. Measured sample responses approached the lower analytical threshold of the instrument, demonstrating that the organically bound sulfur content of extractable lipids in 1228D sediments above the hiatus is negligible. As a further test for sulfurization of Peru Margin lipids, the chromatograms produced in this study were inspected for several lipid thiophenes and 
thiolanes that are generated through sulfur incorporation. The compounds 3-methyl-2(3,7,11-trimethyldodecyl)-thiophene and 3-(4,8,12-trimethyltridecyl)-thiophene, which were identified in deeper Peru Margin sediments (36.15 mbsf; Pliocene) by ten Haven et al. (1990), were not detected in 1228D sediments above the hiatus. Similarly, the thiophene and thiolane forms of highly branched isoprenoids identified by de las Heras et al. (1997) in oil shales were not detected. The absence of these compounds and appreciable amounts of bound sulfur in TLEs argues strongly against the sequestration of biomarkers through sulfurization in the sediments used in this study. Based on these findings, interpretation of 1228D biomarker records does not include influences from sulfurization.

\section{Conclusions}

Given the relationships between many of the biomarker records and the $\% \mathrm{C}_{\text {org }}$ and $\mathrm{C} / \mathrm{N}$ records, sedimentary organic matter on the Peru Margin appears to be recording different environmental phenomena before and after 9 ka. Prior to $9 \mathrm{ka}$, many of the biomarker records, including those of terrestrial organic matter, resemble each other and the $\% \mathrm{C}_{\text {org }}$ and $\mathrm{C} / \mathrm{N}$ records, implying a dominant process affecting all sedimentary organic matter, such as changes in bottom water oxygenation, sea level, or redistribution of shelf sediments. Alternatively, similarities between terrestrial and marine biomarkers may be due to large-scale climate processes that affect production and/or transport of organic matter from both environments. After $9 \mathrm{ka}$, biomarker records with different sources exhibit divergent and unique patterns of variability. Differences between biomarker records from different precursors, such as were observed for marine and terrestrially derived compounds, suggest that the mid to late Holocene sediments were not subjected to intense winnowing or redistribution, but accurately preserve the records of independent sources. Together, the biomarker records indicate that this time period on the Peru Margin was characterized by rapidly evolving, centennial-scale changes in the composition of planktonic communities, as well as variable delivery of terrestrial organic matter. These changes are likely governed by changes in regional climate conditions, in 
particular through their effect on upwelling strength. These issues will be further explored in Chapter 5.

The multi-molecular approach employed in this study allowed evaluation of the extent and nature of sedimentary diagenetic processes that could have impacted biomarker concentrations. Unique concentration maxima in records of labile biomarkers imply that the variability in these records is primarily related to productivity and not selective degradation. The records of cholesterol degradation products such as cholest-2ene and cholesta-3,5-diene (tentatively identified) were similar to those of their parent compounds, which were in turn similar to bacterial hopanol records. These relationships suggest that sterol diagenesis and bacterial activity are primarily water column or sediment surface processes. Low bound-sulfur contents of the total lipid extracts and the absence of thiophene and thiolane biomarkers demonstrate that biomarker sequestration due to sulfur incorporation does not impact the topmost $2.7 \mathrm{~m}$ of $1228 \mathrm{D}$ sediments. Together, these observations are taken as evidence that 1228D biomarkers faithfully record water column and surface sediment processes and are not heavily impacted by in situ diagenesis, thus reinforcing their utility as paleoclimate indicators.

The Peru Margin biomarker records presented in this study demonstrate the value of high-resolution biomarker analyses for interpreting sedimentary geochemical processes and paleoclimate variability. These concentration records exhibit highfrequency variability and abrupt changes, especially during the mid to late Holocene. Lower-resolution records might not fully capture these patterns of variability and thus bias interpretation of the records. GC/TOF-MS has proven to be an effective analytical tool for generating multi-molecular stratigraphic records from complex sediment samples. Biomarker records representing terrestrial and several trophic levels of marine inputs were generated from Peru Margin sediments with minimal laboratory preparation and analysis time. These very detailed records allow critical evaluation of how biomarker records relate to one another. 


\section{References}

Arthur M. A., Dean W. E., and Laarkamp K. (1998) Organic carbon accumulation and preservation in surface sediments on the Peru margin. Chemical Geology 152, 273-286.

Barrett S. M., Volkman J. K., Dunstan G. A., and LeRoi J.-M. (1995) Sterols of 14 species of marine diatoms (Bacillariophyta). Journal of Phycology 31, 360-369.

Bergamaschi B. A., Tsamakis E., Keil R. G., Eglinton T. I., Montluçon D. B., and Hedges J. I. (1997) The efffect of grain size and surface area on organic matter, lignin and carbohydrate concentration, and molecular compositions in Peru Margin sediments. Geochimica et Cosmochimica Acta 61(6), 1247-1260.

Boon J. J., Rijpstra W. I. C., De Lange F., and De Leeuw J. W. (1979) Black Sea sterol a molecular fossil for dinoflagellate blooms. Nature 277, 125-127.

Bruland K. W., Rue E. L., Smith G. J., and DiTullio G. R. (2005) Iron, macronutrients and diatom blooms in the Peru upwelling regime: brown and blue waters of Peru. Marine Chemistry 93, 81-103.

Cushing D. H. (1981) The effect of El Niño upon the Peruvian anchoveta stock. In Coastal Upwelling, Coastal and Estuarine Sciences 1 (ed. F. A. Richards), pp. 449-457. American Geophysical Union.

de las Heras F. X. C., Grimalt J. O., Lopez J. F., Albaigés J., Sinninghe Damsté J. S., Schouten S., and De Leeuw J. W. (1997) Free and sulphurized hopanoids and highly branched isoprenoids in immature lacustrine oil shales. Organic Geochemistry 27(1/2), 41-63.

de Mendiola B. R. (1981) Seasonal phytoplankton distribution along the Peruvian coast. In Coastal Upwelling, Coastal and Estuarine Sciences 1 (ed. F. A. Richards), pp. 348-356. American Geophysical Union.

Eglinton G. and Hamilton. (1967) Leaf epicuticular waxes. Science 156, 1322-1335.

Eglinton T. I., Irvine J. E., Vairavamurthy A., Zhou W., and Manowitz B. (1994) Formation and diagenesis of macromolecular organic sulfur in Peru margin sediments. Organic Geochemistry 22(3-5), 781-799.

Farrimond P., Poynter J. G., and Eglinton G. (1990) Molecular composition of sedimentary lipids off the Peru Margin, Leg 112. In Proc. ODP, Sci. Results, 112: College Station, TX (Ocean Drilling Program) (ed. E. Suess, R. von Huene, and e. al.), pp. 539-546. 
Farrimond P., Head I. M., and Innes H. E. (2000) Environmental influence on the biohopanoid composition of recent sediments. Geochimica et Cosmochimica Acta 64(17), 2985-2992.

Farrington J. W., Davis A. C., Sulanowski J., McCaffrey M. A., McCarthy M., Clifford C. H., Dickinson P., and Volkman J. K. (1988) Biogeochemistry of lipids in surface sediments of the Peru upwelling area at $15^{\circ} \mathrm{S}$. Organic Geochemistry 13(4-6), 607-617.

Ferreira A. M., Miranda A., Caetano M., Baas M., Vale C., and Sinninghe Damsté J. S. (2001) Formation of mid-chain alkane keto-ols by post-depositional oxidation of mid-chain diols in Mediterranean sapropels. Organic Geochemistry 32, 271-276.

Gagosian R. B., Nigrelli G. E., and Volkman J. K. (1983) Vertical transport and transformation of biogenic organic compounds from a sediment trap experiment off the coast of Peru. In Coastal Upwelling, Its Sediment Record, Part A: Responses of the Sedimentary Regime to Present Coastal Upwelling (ed. E. Suess and J. Thiede), pp. 241-272. Plenum Press.

Gong C. and Hollander D. J. (1997) Differential contribution of bacteria to sedimentary organic matter in oxic and anoxic environments, Santa Monica Basin, California. Organic Geochemistry 26(9/10), 545-563.

Henrichs S. M. and Farrington J. W. (1984) Peru upwelling region sediments near $15^{\circ}$ S. 1. Remineralization and accumulation of organic matter. Limnology and Oceanography 29(1), 1-19.

Higginson M. J. and Altabet M. A. (2004) Initial test of the silicic acid leakage hypothesis using sedimentary biomarkers. Geophysical Research Letters 31, L18303, doi:10.1029/2004GL020511.

Hoefs M. J. L., Rijpstra W. I. C., and Sinninghe Damsté J. S. (2002) The influence of oxic degradation on the sedimentary biomarker record I: Evidence from Madeira Abyssal Plain turbidites. Geochimica et Cosmochimica Acta 66(15), 2719-2735.

Kohnen M. E. L., Sinninghe Damsté J. S., and De Leeuw J. W. (1991) Biases from natural sulphurization in palaeoenvironmental reconstruction based on hydrocarbon biomarker distributions. Nature 349, 775-778.

Kolattukudy P. E. (1976) Chemistry and Biochemistry of Natural Waxes. Elsevier.

Leblond J. D. and Chapman P. J. (2004) Sterols of the heterotrophic dinoflagellate, Pfiesteria piscicida (Dinophyceae): Is there a lipid biomarker? Journal of Phycology 40, 104-111. 
Lin L., Bukowski N., and Hughes J. (2000) Application of a wide-dynamic range $\mathrm{GC} / \mathrm{TOF}-\mathrm{MS}$ to routine quantitative analyses.

Mackenzie A. S., Brassell S. C., Eglinton G., and Maxwell J. R. (1982) Chemical fossils: The geological fate of steroids. Science 217(4559), 491-504.

McCaffrey M. A., Farrington J. W., and Repeta D. J. (1989) Geochemical implications of the lipid composition of Thioploca spp. from the Peru upwelling region $-15^{\circ} \mathrm{S}$. Organic Geochemistry 14(1), 61-68.

McCaffrey M. A., Farrington J. W., and Repeta D. J. (1990) The organic geochemistry of Peru Margin surface sediments - I. A comparison of the C37 alkenone and historical El Niño records. Geochimica et Cosmochimica Acta 54(6), 1713-1724.

McCaffrey M. A. (1990) Sedimentary Lipids as Indicators of Depositional Conditions in the Coastal Peruvian Upwelling Regime, Ph. D. Thesis, WHOI/MIT Joint Program in Oceanography.

Oberhänsli H., Heinze P., Diester-Haass L., and Wefer G. (1990) Upwelling off Peru during the last 430,000 yr and its relationship to the bottom-water environment, as deduced from coarse grain-size distributions and analyses of benthic foraminifers at holes 679D, 680B, and 681B, Leg 112. In Proc. ODP, Sci. Results, 112: College Station, TX (Ocean Drilling Program) (ed. E. Suess, R. von Huene, and e. al.), pp. 369-390.

Piretti M. V., Pagliuca G., Boni L., Pistocchi R., Diamante M., and Gazzotti T. (1997) Investigation of 4-methyl sterols from cultured dinoflagellate algal strains. Journal of Phycology 33, 61-67.

Rechka J. A., Cox H. C., Peakman T. M., De Leeuw J. W., and Maxwell J. R. (1992) A reinvestigation of aspects of the early diagenetic pathways of 4-methylsterenes based on molecular mechanics calculations and the acid catalyzed isomerization of 4-methylcholest-4-ene. In Biological Markers in Sediments and Petroleum (ed. J. M. Moldowan, P. Albrecht, and R. P. Philp), pp. 42-57. Prentice-Hall.

Robinson N., Eglinton G., Brassell S. C., and Cranwell P. A. (1984) Dinoflagellate origin for sedimentary $4 \alpha$-methylsteroids and $5 \alpha(H)$-stanols. Nature 308, 439-442.

Rontani J.-F. and Volkman J. K. (2003) Phytol degradation products as biogeochemical tracers in aquatic environments. Organic Geochemistry 34, 1-35.

Schneider J. K. and Gagosian R. B. (1985) Particle size distribution of lipids in aerosols off the coast of Peru. Journal of Geophysical Research 90(D5), 7889-7898. 
Schouten S., Breteler W. C. M. K., Blokker P., Schogt N., Rijpstra W. I. C., Grice K., Baas M., and Sinninghe Damsté J. S. (1998) Biosynthetic effects on the stable carbon isotopic compositions of algal lipids: Implications for deciphering the carbon isotopic biomarker record. Geochimica et Cosmochimica Acta 62(8), 1397-1406.

Sellner K. G., Hendrikson P., and Ochoa N. (1983) Relationships between the chemical composition of particulate organic matter and phytoplankton distributions in recently upwelled waters off Peru. In Coastal Upwelling, Its Sediment Record, Part A: Responses of the Sedimentary Regime to Present Coastal Upwelling (ed. E. Suess and J. Thiede), pp. 273-287. Plenum Press.

Shipboard Scientific Party (2003) Site 1228. In D'Hondt, S.L., Jørgensen, B.B., Miller, D.J., et al., Proc. ODP, Init. Repts., 201, pp. 1-72 [CD-ROM]. Available from: Ocean Drilling Program, Texas A\&M University, College Station TX 778459547, USA.

Sinninghe Damsté J. S., Rijpstra W. I. C., Schouten S., Peletier H., van der Maarel M. J. E. C., and Gieskes W. W. C. (1999) A $\mathrm{C}_{25}$ highly branched isoprenoid alkene and $\mathrm{C}_{25}$ and $\mathrm{C}_{27} n$-polyenes in the marine diatom Rhizosolenia setigera. Organic Geochemistry 30, 95-100.

Sinninghe Damsté J. S., Rijpstra W. I. C., and Reichart G.-J. (2002) the influence of oxic degradation on the sedimentary biomarker record II. Evidence from Arabian Sea sediments. Geochimica et Cosmochimica Acta 66(15), 2737-2754.

Smith R. L. (1981) A comparison of the structure and variability of the flow field in three coastal upwelling regions: Oregon, Northwest Africa, and Peru. In Coastal Upwelling, Coastal and Estuarine Sciences 1 (ed. F. A. Richards), pp. 107-118. American Geophysical Union.

Smith R. L. (1983) Circulation patterns in upwelling regimes. In Coastal Upwelling, Its Sediment Record, Part A: Responses of the Sedimentary Regime to Present Coastal Upwelling (ed. E. Suess and J. Thiede). Plenum Press.

Summons R. E., Volkman J. K., and Boreham C. J. (1987) Dinosterane and other steroidal hydrocarbons of dinoflagellate origin in sediments and petroleum. Geochimica et Cosmochimica Acta 51, 3075-3082.

Summons R. E., Jahnke L. L., Hope J. M., and Logan G. A. (1999) 2-Methylhopanoids as biomarkers for cyanobacterial oxygenic photosynthesis. Nature 400, 554-557. 
ten Haven H. L., Littke R., Rullkötter J., Stein R., and Welte D. H. (1990) Accumulation rates and composition of organic matter in Late Cenozoic sediments underlying the active upwelling area off Peru. In Proc. ODP, Sci. Results, 112: College Station, TX (Ocean Drilling Program) (ed. E. Suess, R. von Huene, and e. al.), pp. 591-606.

Volkman J. K. (1986) A review of sterol markers for marine and terrigenous organic matter. Organic Geochemistry 9, 83-99.

Volkman J. K. and Maxwell J. R. (1986) Acyclic isoprenoids as biological markers. In Biological Markers in the Sedimentary Record (ed. R. B. Johns), pp. 1-42. Elsevier Science Publishing Company Inc.

Volkman J. K., Farrington J. W., and Gagosian R. B. (1987) Marine and terrigenous lipids in coastal sediments from the Peru upwelling region at $15^{\circ} \mathrm{S}$ : Sterols and triterpene alcohols. Organic Geochemistry 11(6), 463-477.

Volkman J. K., Barrett S. M., Dunstan G. A., and Jeffrey S. W. (1992) $C_{30}-C_{32}$ alkyl diols and unsaturated alcohols in microalgae of the class Eustigmatophyceae. Organic Geochemistry 18, 131-138.

Volkman J. K., Barrett S. M., Blackburn S. I., Mansour M. P., Sikes E. L., and Gelin F. (1998) Microalgal biomarkers: a review of recent research developments. Organic Geochemistry 29, 1163-1179.

Wakeham S. G., Farrington J. W., and Gagosian R. B. (1984) Variability in lipid flux and composition of particulate matter in the Peru upwelling region. Organic Geochemistry 6, 203-215.

Yunker M. B., Macdonald R. W., Veltkamp D. J., and Cretney W. J. (1995) Terrestrial and marine biomarkers in a seasonally ice-covered Arctic estuary - integration of multivariate and biomarker approaches. Marine Chemistry 49, 1-50. 


\title{
Chapter 5
}

\section{Peru Margin Climate Variability Over the Last 15,000 Years: Marine and Terrestrial Signals Embedded in a High-Resolution Multi-Molecular Record}

\begin{abstract}
A recently developed analytical approach - gas chromatography coupled with time-of-flight mass spectrometry (GC/TOF-MS) - was used to generate multi-molecular records from Peru Margin sediments ( $\left.11^{\circ} \mathrm{S} ; 252 \mathrm{~m}\right)$, which were then used to infer variability in upwelling, aridity, and El Niño and the Southern Oscillation (ENSO) over the last $15 \mathrm{ka}$. The Peru Margin, which is within the eastern tropical Pacific upwelling zone, is well situated to directly monitor changes in ENSO behavior over time. Factor analysis was used to examine relationships between the wide range of biomarker records produced via GC/TOF-MS, thus aiding in identification of specific compounds that are useful for paleoclimate investigation. Abundance records of dinosterol and cholesterol were used to infer variability in El Niño and La Niña, respectively, because they provide information about specific dinoflagellate inputs and upwelling strength in general. These sterol records imply reduced strength of both El Niño and La Niña from about 12.9 until an abrupt increase at $6.5 \mathrm{ka}$, and are punctuated by high-amplitude variability throughout. The increased frequency/intensity of La Niña during the mid-Holocene paralleled changes in El Niño. This description of the evolution of tropical Pacific climate during the Holocene contrasts with the paradigm that it instead varied between El Niño- and La Niña-like end-member states. Similarities between the Peru Margin cholesterol record
\end{abstract}


and the eastern tropical Atlantic sea surface temperature record of deMenocal et al. (2000) suggest that a strong and far-reaching tropical climate process affected upwelling at both locations over the last $15 \mathrm{ka}$. I hypothesize that upwelling at both sites was governed by changes in trade wind strength, which was in turn driven by ENSO variability. Similarities between the Peru Margin terrestrial and marine biomarker records and other Andean and South American records support the notion of broad-scale changes in tropical atmospheric circulation throughout the Holocene and earlier.

\section{Introduction}

The abundance of organic matter preserved in Peru Margin sediments results from perennial upwelling and a bottom water oxygen minimum zone (OMZ), and provides an excellent opportunity for paleoclimate study using high-resolution molecular stratigraphic records. Although many investigations have provided valuable insights into the nature of organic matter production, deposition, and preservation on the Peru Margin (Gagosian et al., 1983; Henrichs and Farrington, 1984; Volkman et al., 1987; Farrington et al., 1988; McCaffrey, 1990; Eglinton et al., 1994; Arthur et al., 1998), attempts at paleoclimate research have been limited by poor preservation of foraminifera. Existing regional climate records have demonstrated that the eastern tropical Pacific (ETP) (Koutavas et al., 2002) and western South America (e.g. Thompson et al., 1985; Thompson et al., 1995; Thompson et al., 1998; Abbott et al., 2000; Baker et al., 2001) are sensitive to climate changes on a variety of time scales, from glacial-interglacial to sub-decadal, which may be related to variations in ENSO. As described in the previous chapter, fastgas chromatography coupled with time-of-flight mass spectrometry (GC/TOF-MS) is an effective analytical tool for developing high-resolution, multi-molecular stratigraphic records from marine sediments. In this chapter, the biomarker records generated in Chapter 4 from ODP Site 1228D (Figure 5-1; 11 $4^{\prime} \mathrm{S} ; 7^{\circ} 5^{\prime} \mathrm{W}, 252 \mathrm{~m}$ ) will be used to infer changes in productivity and upwelling on the Peru Margin and delivery of terrestrial vascular plant matter to the sediments. These records span the last $14.7 \mathrm{ka}$, at a sampling 
Figure 5-1

Locations of South American Paleoclimate Records

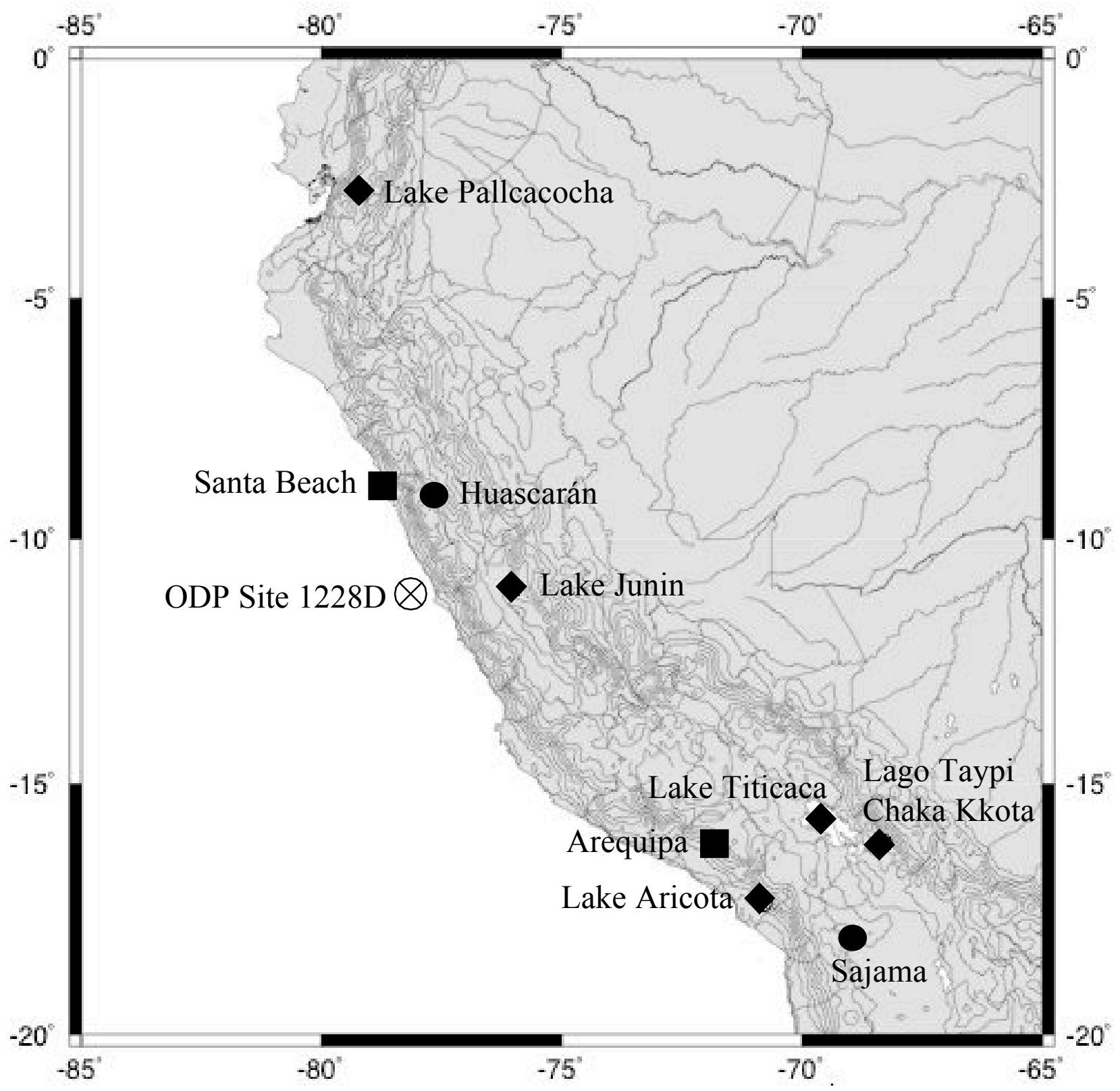

Locations of ODP Site 1228D and terrestrial paleoclimate records of interest. Rivers are shown and contours depict the extent of the Andes mountain range. Key: Ice core record; Lake record; $\bigotimes$ Marine sediment core; $\square$ Other records. 
resolution of about $100 \mathrm{yr}$ (true resolution is slightly lower because some sample results were discarded).

\section{Modern Climate Conditions on the Peru Margin}

The general patterns of oceanic and atmospheric circulation on the Peru Margin are described in detail in Chapter 4. Stable southeasterly trade winds along the coast result in offshore Ekman transport and upwelling of nutrient-rich waters derived from the poleward flowing Peru Countercurrent (PCC) (Smith, 1981). The strength of the PCC is variable but sometimes great enough to winnow fine-grained sedimentary material from shelf deposits. Site 1228D is located on the outer edge of the shelf and deeper than the strongest poleward flow, which predominantly impacts sediments deposited at less than $100 \mathrm{~m}$ on the broader shelf to the North (Smith, 1981; Arthur et al., 1998). The OMZ, which Arthur et al. (1998) observed between depths of about 80 and 700 m, effectively aids preservation of organic matter and inhibits the presence of benthic organisms that could cause bioturbation. Although the southeasterly winds and upwelling persist throughout the entire year on the Peru Margin, they are relatively enhanced during austral winter (Fahrbach et al., 1981; Strub et al., 1998). Alongshore upwelling-favorable winds are driven by the Pacific Subtropical Anticyclone and constrained by coastal topography. North of $\sim 5^{\circ} \mathrm{S}$, atmospheric circulation on the western South American margin is primarily driven by inter-tropical convergence zone (ITCZ) variability (Strub et al., 1998).

Diatoms dominate surface productivity on the Peru Margin throughout the year, although dinoflagellates, coccolithophores, and other algal species have been observed (de Mendiola, 1981; Sellner et al., 1983). de Mendiola (1981) determined phytoplankton cell densities of about $1 \times 10^{5}$ cells $\mathrm{L}^{-1}$ or greater throughout the year at $11^{\circ} \mathrm{S}$, with greater concentrations in austral summer and fall. During winter and spring, cells of maximum surface productivity were shifted to the North along the margin. These findings exemplify the patchy nature of Peru Margin productivity, which occurs in cells that vary in strength and location over time. Using sediment traps, Gagosian et al. (1983) 
estimated that 1.5 to $6 \%$ of the sterols produced in the euphotic zone achieve burial in Peru Margin sediments. These compounds were found to be predominantly diatom related and were delivered rapidly to the sediment surface in association with zooplankton fecal matter.

Terrestrial organic matter such as vascular plant derived biomarkers could be delivered to Peru Margin sediments by fluvial or aeolian processes. Schneider and Gagosian (1985) measured vascular plant waxes in Peru Margin marine aerosols and calculated that aeolian delivery could only account for a small fraction of the terrestrial lipids in the water column. By inference, the bulk of the terrestrial organic matter reaching the sediments may be delivered through the small rivers that drain the western flank of the Andes. Holmgren et al. (2001) observed that in southern Peru on the western Andean flank there is little vegetation below about 2,400 m. Above 2,400 m, vegetation grades from cacti and shrubs to grasses (found at $\sim 3,300-4,300 \mathrm{~m}$ ) with increasing elevation. Although the adjacent coast is hyper-arid and supports little vegetation (Holmgren et al., 2001), El Niño events have historically brought increased precipitation to parts of western Peru and drought conditions to the southeast part of the country (Quinn et al., 1987). El Niño related precipitation events near Site 1228D, such as those recorded at Lima (Quinn et al., 1987), would be expected to wash soils and fresh terrestrial plant matter onto the margin, where it is generally well preserved, possibly through association with mineral surfaces (Gagosian et al., 1983).

ENSO is characterized by zonal migrations of peak equatorial Pacific sea surface temperatures (SSTs) and associated convective regions, as well as changes in tropical Pacific atmospheric and oceanic circulation (e.g. Philander, 1989). The Peru Margin upwelling system is directly impacted by ENSO anomalies, given its low-latitude position and connection to the equatorial ocean circulation system. Although El Niño conditions are associated with a reduction in strength of the Pacific Subtropical Anticyclone, which drives atmospheric circulation over the Peru Margin, coastal winds remain strong enough to produce upwelling (Smith, 1983; Strub et al., 1998). However, a deeper thermocline results in upwelling of water that is relatively warm and low in 
nutrients (Strub et al., 1998). Concurrently, the strength of the PCC increases and warm waters are transported poleward (Smith, 1983). The ITCZ is deflected southward (to $\sim 5^{\circ} \mathrm{S}$ ) during El Niño, but not as far south as the study site (Strub et al., 1998).

It has long been thought that the increased stratification associated with El Niño events causes a reduction in primary productivity on the Peru Margin, and thus diminished carbon export to the sediments (e.g. Cushing, 1981; Henrichs and Farrington, 1984). Late $20^{\text {th }}$ century El Niño events have had disastrous effects on the Peruvian Anchoveta fishery (Escribano et al., 2004), and Henrichs and Farrington (1984) observed a correlation between strong El Niño events and reduced organic carbon content in Peru Margin sediments since the mid- $19^{\text {th }}$ century. However, detailed biological and geochemical studies of the 1997-1998 El Niño off northern Chile revealed a shift to smaller diatoms and zooplankton, but relatively stable primary productivity, especially in near-shore areas (Ulloa et al., 2001; Escribano et al., 2004). Furthermore, elevated dinoflagellate abundances and red tides have been associated with past El Niño events (de Mendiola, 1981; Quinn et al., 1987; Escribano et al., 2004). Caution must be taken when inferring ENSO variability from biomarker records, as the specific effects of El Niño on Peru Margin productivity and carbon export are not well understood. For example, McCaffrey et al. (1990) were not able to consistently resolve individual El Niño events in a 300-year Peru Margin alkenone-based sea surface temperature record, possibly as a result of low sampling resolution or sediment winnowing. However, their record appeared to identify periods of time since the late $17^{\text {th }}$ century marked by repeated strong events, as I hope to do in the present study.

\section{South American Paleoclimate Conditions}

Many terrestrial and marine paleoclimate records from western South America and the ETP exhibit different modes of variability during the last $15 \mathrm{ka}$, although the sense and geographic extent of these changes on a large scale is not fully constrained (see Figure 5-1 for locations). On a glacial-interglacial time scale, Andean ice core proxy records from Huascarán and Sajama imply a northward migration of the ITCZ and 
associated wet conditions after the last glacial period (Thompson et al., 1995; Thompson et al., 1998). Existing South American Holocene paleoclimate records generally fall into two categories; those that suggest an arid mid-Holocene and those that imply positive precipitation anomalies:

Arid Records Several proxy records including benthic and planktonic organism assemblages, carbonate content, and $\delta^{13} \mathrm{C}$ of total organic carbon, all from Lake Titicaca sediments, suggest a distinct period of lower lake levels from about 8.0-5.5 ka (Baker et al., 2001). Similarly, pollen and charcoal analyses of Lake Titicaca sediments provide evidence for a period of aridity, low lake levels, and increased occurrences of fire from about 8.0-3.1 ka, with peak aridity at about $5.5 \mathrm{ka}$ (Paduano et al., 2003). Estimates of lake water $\delta^{18} \mathrm{O}$ from sedimentary cellulose at Lago Taypi Chaka Kkota in Bolivia indicate the rapid onset of an arid period at $6.2 \mathrm{ka}$, which then lasted to about $2.3 \mathrm{ka}$ (Abbott et al., 2000).

Wet Records The Holocene portion of the Huascarán ice core $\delta^{18} \mathrm{O}$ record is relatively stable, but exhibits a broad maximum centered at about 6-8 ka, suggesting that this was the wettest part of the Holocene in the northern Andes. Rodent middens and their associated plant matter collected from the western Andean flank in southern Peru (Arequipa) suggest stable, relatively wet conditions from 9.6 to $2.8 \mathrm{ka}$ (Holmgren et al., 2001). Additionally, Placzek et al. (2001) determined that elevated lake levels at Lake Aricota in Peru occurred between about 6.1 (or earlier) and $2.7 \mathrm{ka}$. Interestingly, Lake Aricota is near Lake Titicaca, but is on the western edge of the Andes, while Lake Titicaca is on the Altiplano, which is closer to the eastern edge of the mountain range (Placzek et al., 2001). The opposite trends observed in the climate records from these two sites imply that steep climate gradients have existed within the narrow geographical range across the Andes. Beach ridge deposits at the outlet of the Rio Santa in Peru support the notion of a wet western Andes, suggesting enhanced fluvial discharge events prior to $6.7 \mathrm{ka}$ (Wells, 1996). Calcite $\delta^{18} \mathrm{O}$ records from Lake Junin, which is a highaltitude Andean lake at about the same latitude as Site 1228D, imply a peak in aridity at about $10 \mathrm{ka}$, followed by gradually increasing moisture to the present (Seltzer et al., 
2000). The pattern of variability in the Lake Junin record is different from the Lake Titicaca and Lago Taypi Chaka Kkota records in that the peak aridity is earlier and the climate appears to have gotten wetter while the others remained dry.

The discrepancies in aridity between the Altiplano and western Andes suggest that climate in western South America throughout the Holocene may have been governed by a wide range of factors, including, but not limited to, ITCZ migration, ENSO (Holmgren et al., 2001), and interactions between topography and atmospheric circulation. For example, a shift in seasonality could have strongly influenced this area, as moisture supply to the Altiplano is seasonally dependent and strong precipitation gradients are developed across the Andes (e.g. Vuille et al., 2000). ENSO in particular may have had an exceptional impact on Holocene climate change in the ETP and adjacent landmasses. The historical records of El Niño assembled by Quinn et al. (1987) contain evidence for ENSO related droughts in southeast Peru at Cuzco at the same time as heavy rainfall in the coastal city of Lima, consistent with the spatial disparities outlined above.

Holocene ENSO Variability Marine and terrestrial studies spanning a range of locations provide evidence for increasing El Niño intensity and/or frequency in South America during the later Holocene. The ETP sea surface temperature record of Koutavas et al. (2002) exhibits an abrupt increase just after $5 \mathrm{ka}$, possibly signifying a return to El Niño-like conditions after a prolonged ( $\sim 5 \mathrm{ka})$ cool period. Similarly, the Ecuadorian lake sedimentation records of Rodbell et al. (1999) and Moy et al. (2002) both suggest an abrupt increase in El Niño behavior at about $5 \mathrm{ka}$, as does the archaeological faunal assemblage evidence of Sandweiss et al. (1996). Sedimentary Ti and Fe records from the Cariaco Basin, which is impacted by ITCZ precipitation during boreal summer, imply a reduction in fluvial inputs throughout the later part of the Holocene, beginning at about $6.7 \mathrm{ka}$ (Haug et al., 2001). This observation is consistent with a southward migration of the ITCZ, which is in turn consistent with increased El Niño behavior.

Several modeling studies have implicated orbitally induced insolation changes in the tropical Pacific as the mechanism driving Holocene ENSO variability (Clement et al., 2000; Liu et al., 2000). Through interactions with the seasonal cycle, uniformly 
increased tropical insolation could potentially alter atmospheric and oceanic circulation across the tropical Pacific through favorable warming of waters in the west compared to those in the east, which may remain relatively cool due to perennial upwelling and atmospheric subsidence. The resulting increased zonal temperature gradient would enhance Walker circulation, trade wind strength, and ETP upwelling through a positive feedback loop, ultimately suppressing El Niño (Clement et al., 1999). Evidence for this phenomenon is provided by the records of Koutavas et al. (2002), which suggest reduced El Niño behavior during the mid-Holocene concurrent with a strong east-west SST gradient. Such a situation may have arisen in the early and mid-Holocene as a result of increased insolation during boreal summer (Clement et al., 2000), possibly through associated enhancement of the Asian monsoon system (Liu et al., 2000). Conversely, enhanced insolation during boreal winter, as occurs in the late Holocene, is expected to increase the likelihood and/or strength of El Niño events, as this is the season of reduced upwelling and warming in the ETP.

Existing records of ENSO behavior provide valuable clues about Holocene variability, but cover a restricted spatial extent compared to its broad fingerprint. Furthermore, they generally only reconstruct El Niño conditions, while La Niña variability is poorly understood. The biomarker records generated from Peru Margin sediments and described in Chapter 4 are well situated to study El Niño variability through its effects on primary productivity. Although the pattern of ENSO variability throughout the Holocene and its effect on the Peru Margin upwelling system are not fully understood, these biomarker records can provide a constraint on the dynamics of these complex systems and the extent of their impacts.

\section{Analytical Procedure}

The analytical methods used to generate biomarker concentration records via GC/TOF-MS are described in Chapter 4. To aid paleoclimate interpretation of biomarker records, $\delta^{13} \mathrm{C}$ of bulk sedimentary organic carbon and $n$-alkanoic acids (fatty acids; $\mathrm{C}_{16-32}$ ) were determined for 20 samples from 1228D. These samples span the length of the 
biomarker concentration records and are relatively evenly spaced. Fatty acids were isolated from an aliquot of total lipid extract via silica gel and amino propyl column chromatography. In each case, the fatty acids were eluted with dichloromethane $+2 \%$ formic acid. The fatty acids were then converted to fatty acid methyl esters (FAMEs) via methylation using methanol $+\mathrm{HCl}$ with a known isotopic composition. Compoundspecific $\delta^{13} \mathrm{C}$ measurements were performed using isotope ratio monitoring GC-MS and were conducted on a Finnigan Delta ${ }^{\text {Pus }}$ stable isotope mass spectrometer with an attached HP 6890 GC and Finnigan GC combustion III interface. Analyses were performed in triplicate and $\delta^{13} \mathrm{C}$ values were determined relative to $\mathrm{CO}_{2}$ reference gas of known isotopic composition, introduced in pulses during each run. FAME $\delta^{13} \mathrm{C}$ results were corrected for the carbon added during methylation. Isotopic investigation results are presented in Appendix C.

\section{Results and Discussion}

\section{Age Control}

Age control for 1228D is provided by five alkenone and two bulk organic carbon AMS radiocarbon dates, which are depicted on the biomarker concentration record figures. Few foraminifera are preserved in 1228D sediments, restricting radiocarbon investigations to organic matter. Higginson and Altabet (2004) applied a reservoir age correction of 420 years to create the age scale, and then adjusted the age model based on correlation of $\delta^{15} \mathrm{~N}$ records between 1228D and several other shallow cores on the Peru Margin. Uncertainties in alkenone-based age scales can arise from the association of molecular organic matter with fine-grained sedimentary material, as demonstrated by discrepancies between alkenone and foraminiferal radiocarbon records from the same sample site (Mollenhauer et al., 2003). Age scale uncertainties arising from redistribution of fine-grained material may be problematic on the Peru Margin due to the presence of the intermittently strong PCC. However, a bulk organic carbon ${ }^{14} \mathrm{C}$ age of $630 \mathrm{yr} \pm 30$ determined from core-top sediments collected near 1228D (pers. comm., T. Eglinton) demonstrates that the sediment surface at this location on the Peru Margin is 
comprised of recently deposited organic material. Additionally, the 1228D age model benefits from comparison of nitrogen isotope records with other cores that have foraminiferal radiocarbon age scales (Higginson and Altabet, 2004).

\section{Multivariate Analysis of Biomarker Records}

Multivariate analyses were conducted on the organic carbon-normalized biomarker records in order to examine statistical relationships between individual compounds and determine the primary modes of variability in 1228D sediments. Initially, a principal components analysis (PCA) was performed using all of the biomarker concentration records. Using the raw concentration data, the first three eigenvalues accounted for $65.4,16.1$, and $5.5 \%$ of the total variance (subsequent eigenvalues accounted for $<4 \%$ ). Using the covariance matrix of the data set instead, which is a rational choice considering the wide range of sources of organic matter to the Peru Margin, the first eigenvalue accounted for much more of the total variance $(89.5 \%$; the second and third accounted for 8.8 and 1.0\%, respectively). Most of the biomarkers did not have high loadings on either of the first two principal components. The sterols, stanols, phytol, and $\mathrm{C}_{32}$ alkan diol were loaded on the first principal component to a greater extent, and thus accounted for a very large part of the variability in the entire data set. Ultimately, PCA was only able to resolve these compounds and their overwhelming marine signal, and thus provided limited useful information to aid in interpretation.

Factor analysis, which does not inherently account for all of the variability in the data set, proved to be a better method for examining the relationships between classes of compounds. Factor analysis allowed closer examination of the patterns of variability that were different from those observed in the sterol records. Each analysis was performed using the covariance matrix calculated from the $\mathrm{C}_{\mathrm{org}}$-normalized concentration data set, and three factors were used. Three factors were chosen because the PCA results demonstrated that the first three eigenvalues accounted for nearly all of the total variability. Computations were performed using MATLAB software and all results were 
rotated using the Varimax algorithm. The results of the factor analysis of the entire biomarker data set are presented in Figure 5-2 as plots of factor 1 versus factors 2 and 3 .

Using the $\mathrm{C}_{\mathrm{org}}$-normalized data, factor 2 provided separation of typically marine and terrestrial organic matter, with marine biomarkers (e.g. sterols, acyclic isoprenoids, and short-chain fatty acids and $n$-alkanols) plotting at high values. Factor 1 appeared to separate marine compounds derived from algal (higher loadings) sources from those that may be derived from bacterial or a combination of algal and bacterial sources (lower loadings). $n$-Alkanoic acids and $n$-alkanols were also separated by factor 1 . The biomarker groupings are the same as those observed in the factor analysis performed in Chapter 4 on sediment-normalized data, although the first and second factors have been transposed. Normalizing the data to organic carbon has reduced the dominance of the marine signal and transferred it from the first to the second factor. The long-chain fatty acids $\left(\geq \mathrm{C}_{26}\right.$ ) have uniquely low loadings on factor 2 , supporting the inference that they are derived primarily from terrestrial vascular plant sources. Chain lengths systematically increase as loadings decrease, suggesting that the higher chain lengths are more purely terrestrial. The third factor separates the fatty acids from other compounds, with the possible exception of the $\mathrm{C}_{30}$ and $\mathrm{C}_{32} n$-alkanols, which are also probably derived from terrestrial sources.

The predicted factor scores are presented in Figure 5-3 in the depth domain. These factor scores were necessarily computed using the raw concentration data rather than the covariance matrix. The first factor exhibits some of the variability common to the sterol records, such as the minima at $9 \mathrm{ka}$ and later in the Holocene, but is also strongly influenced by other compounds, particularly the $n$-alkanols. Phytol, the $\mathrm{C}_{30}$ hopanol, and the $\mathrm{C}_{16} n$-alkanol are moderately loaded on factor 1 , but other compounds with the $\mathrm{OH}$ functional group are very strongly loaded. Factor 1 likely describes preservation effects specific to this class of compounds. Factor 2 appears to represent dominantly marine inputs and the pattern of variability in the down-core factor scores strongly resembles that of individual marine biomarker records. The sharp concentration increase observed in sterol records at about $6.5 \mathrm{ka}$ is represented in factor 2 , as are the 
Figure 5-2a

Biomarker Data Set Factor Analysis - Factors 1 and 2

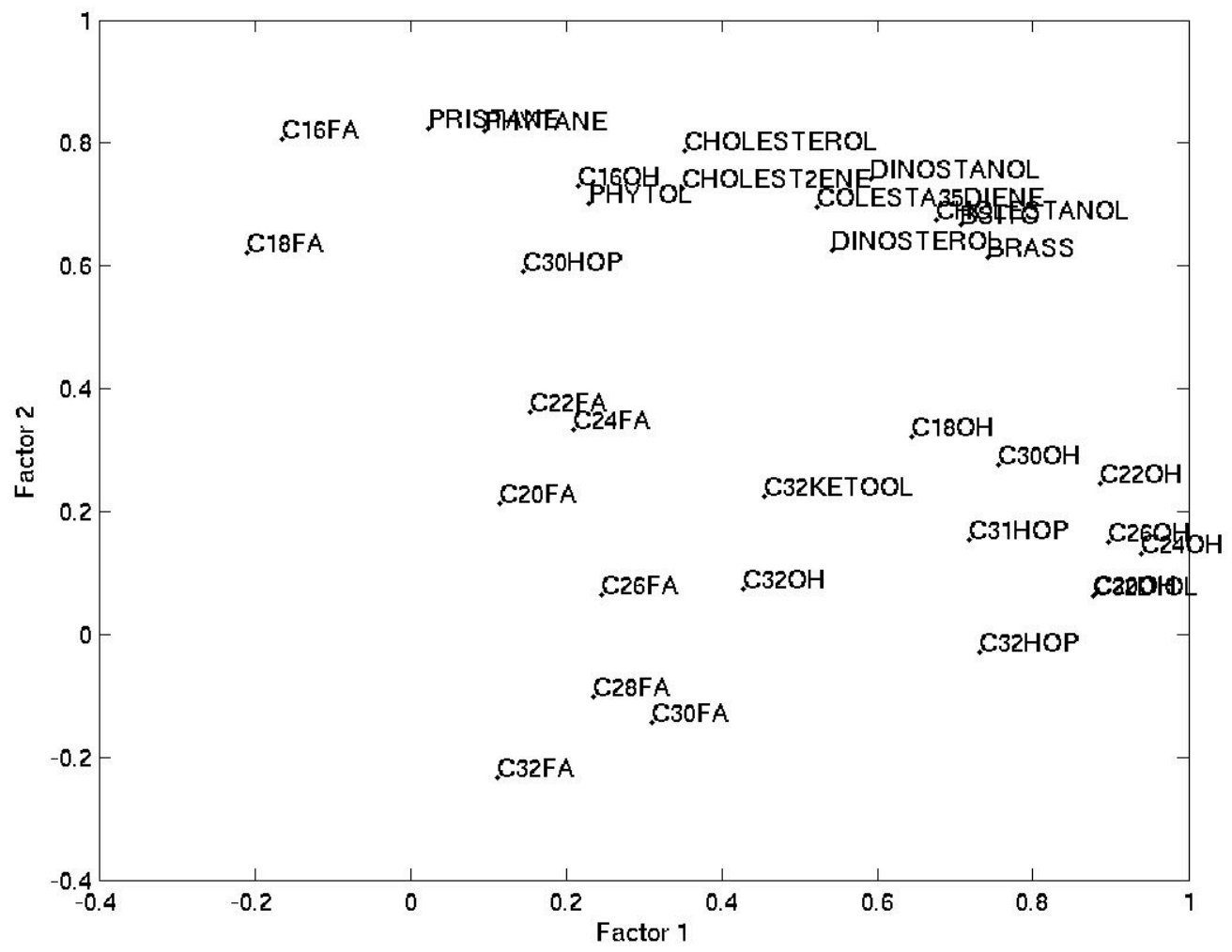

Factor analysis results for the entire biomarker data set normalized to organic carbon. Factor 1 versus factor 2 is depicted in (a) and factor 1 versus factor 3 is depicted in (b). 
Figure 5-2b

Biomarker Data Set Factor Analysis - Factors 1 and 3

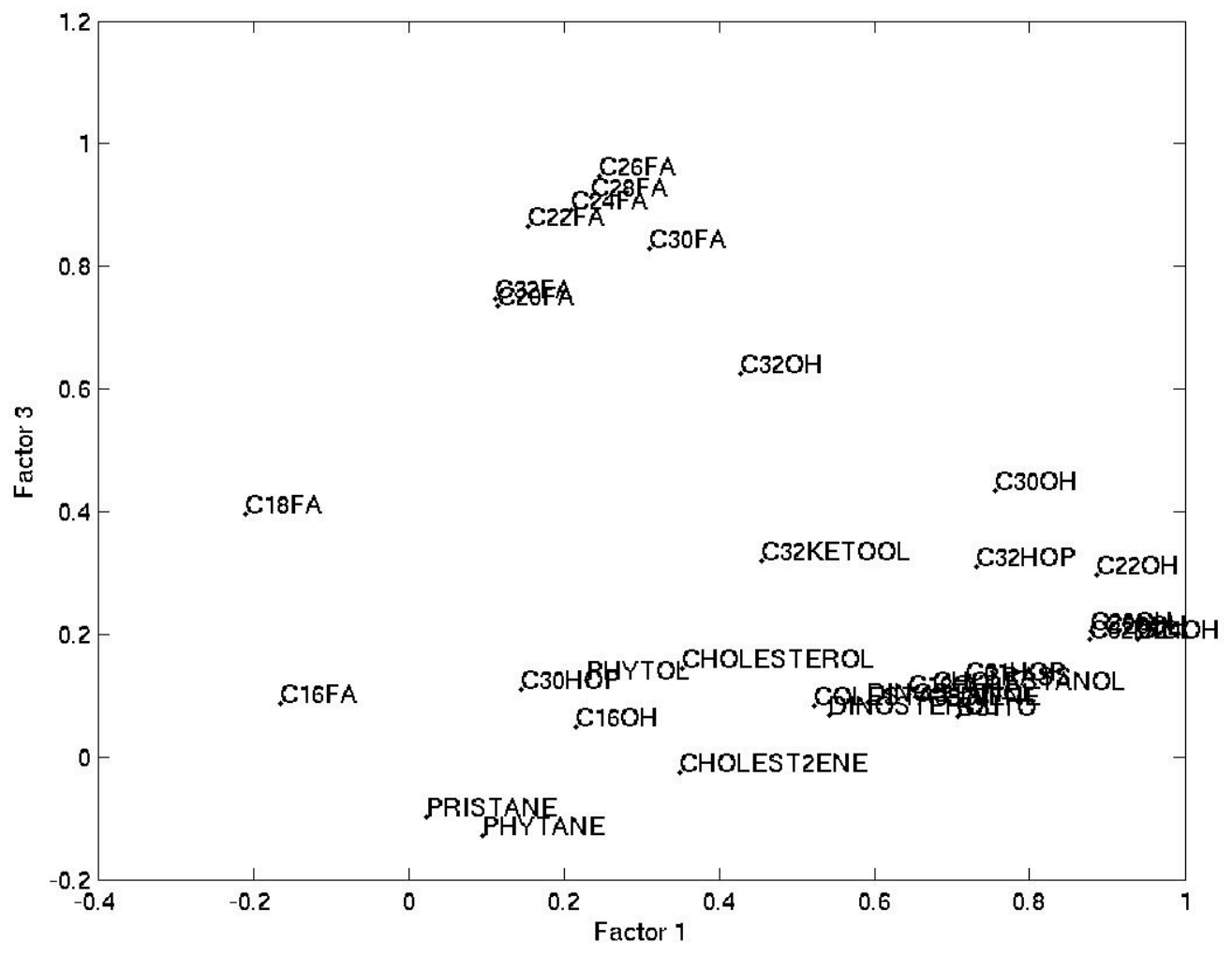


Figure 5-3a

Factor 1 - All Biomarkers Normalized to Organic Carbon

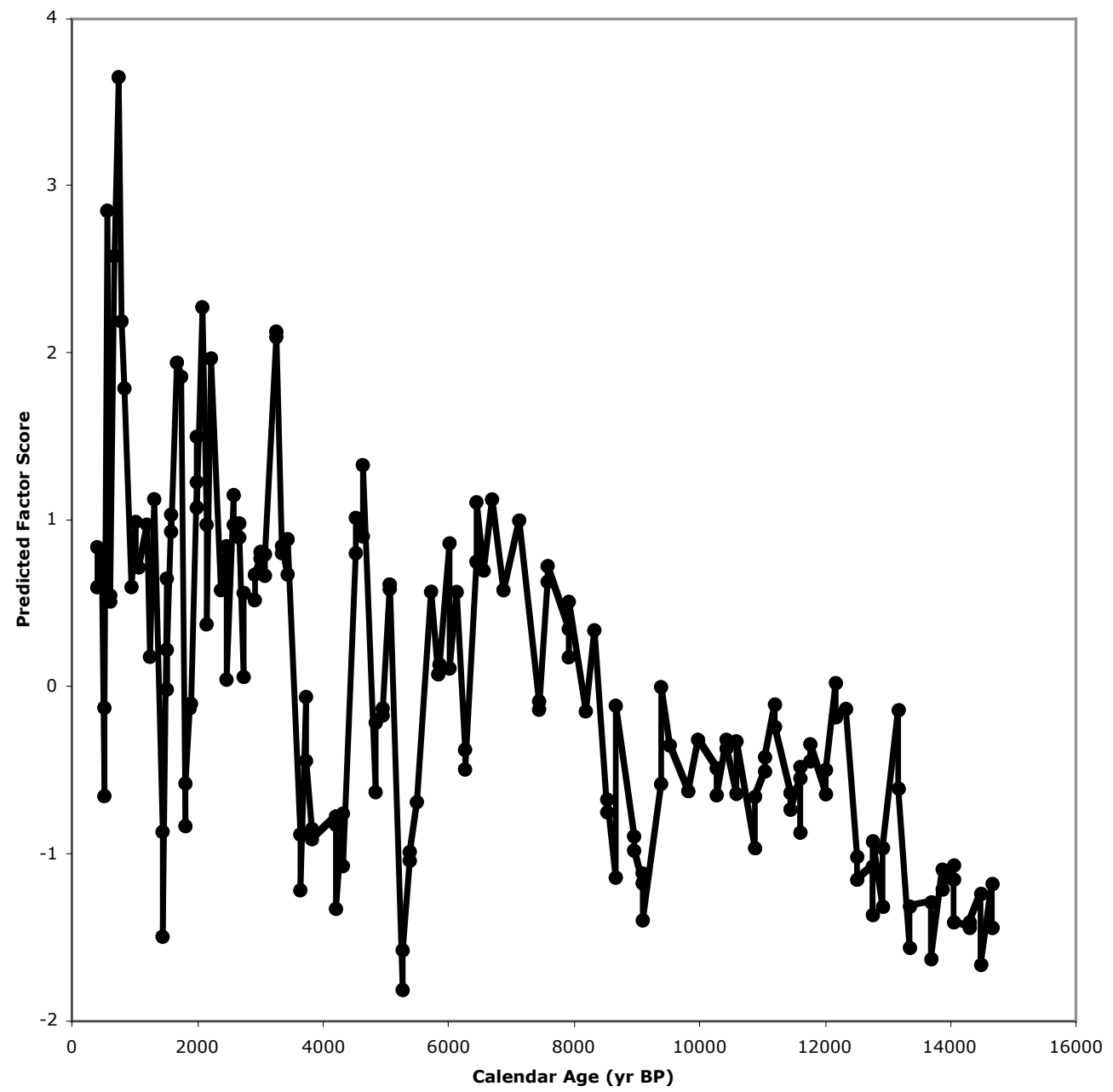

Predicted factor scores for the individual samples in the biomarker data set normalized to organic carbon. Factor 1 is presented in (a), factor 2 in (b), and factor 3 in (c). 
Figure 5-3b

Factor 2 - All Biomarkers Normalized to Organic Carbon

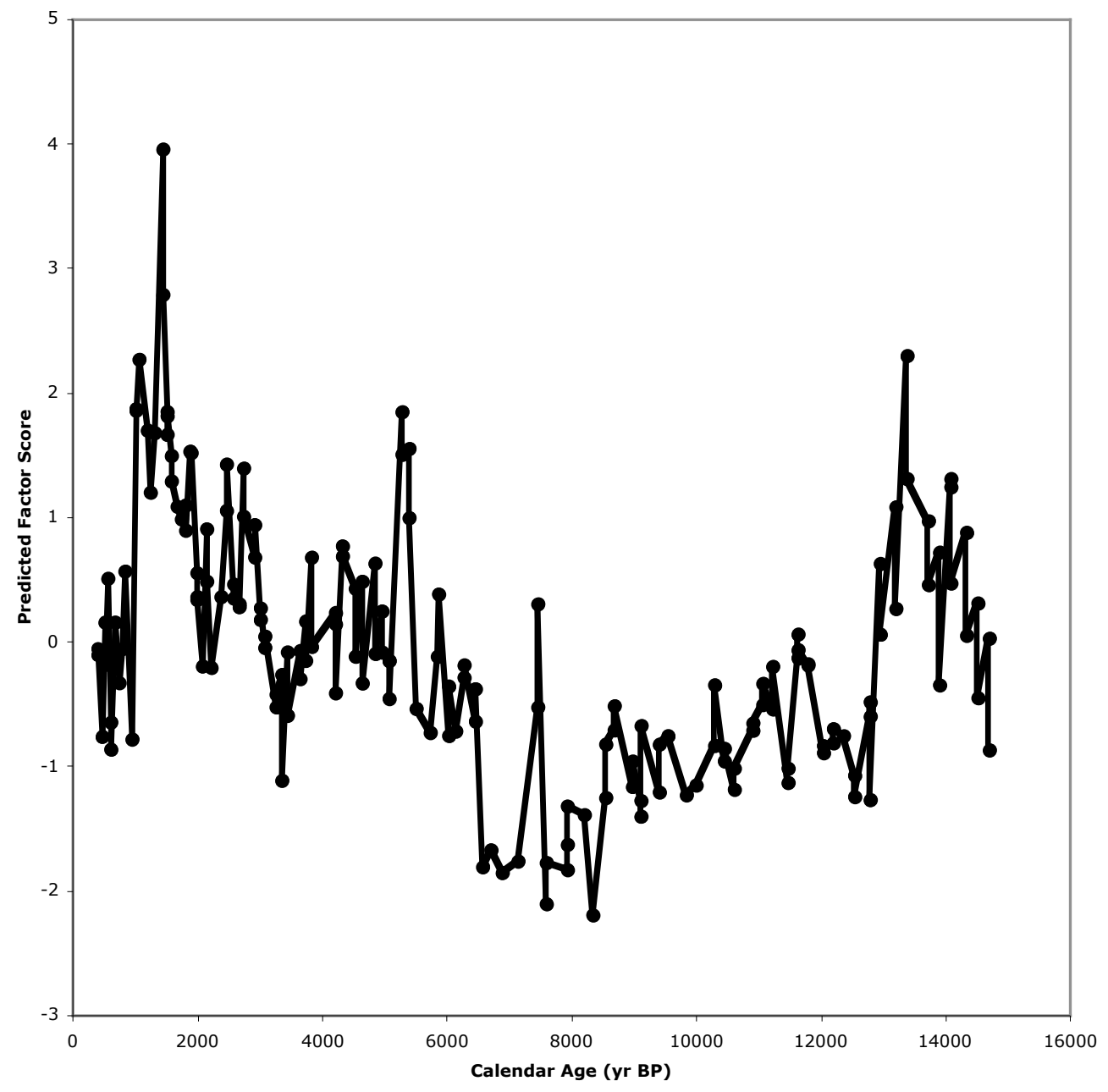


Figure 5-3c

Factor 3 - All Biomarkers Normalized to Organic Carbon

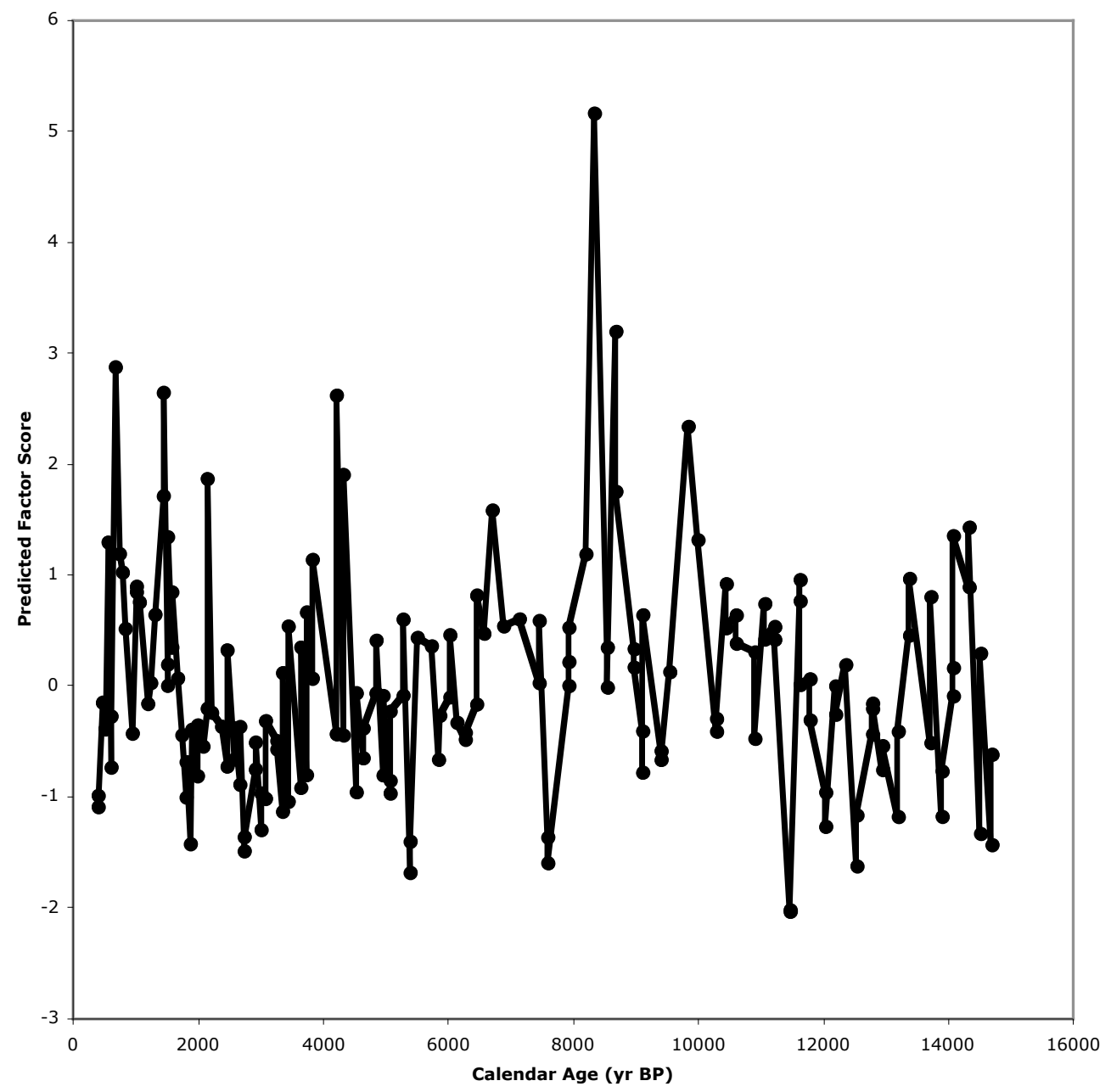


abrupt decreases at about 12.9 and $1 \mathrm{ka}$, and the negative excursion at $2 \mathrm{ka}$. Factor 3 , which closely resembles the concentration records of the long-chain fatty acids $\left(\geq C_{26}\right)$, represents terrestrial vascular plant inputs.

Factor analysis was also performed on a data set that was comprised of a subset of biomarkers representing various source organism classes, as well as the concentration record of $\mathrm{C}_{37}$ methylketone, which is a marker compound for coccolith productivity, and several trace metal records $\left(\mathrm{C}_{37}\right.$ and metals data courtesy of T. Herbert and J. Tierney). The particular set of biomarker records used was selected to include roughly equal numbers of compounds from each grouping in the factor analysis performed on all the biomarkers together. By this approach, I hoped to reduce the extent to which variability in the records of individual compounds is overshadowed by the marine algal signal. All the biomarker data were normalized to organic carbon, and the metals data were linearly interpolated to match my sample depths and were normalized to Al. The $\mathrm{C}_{37}$ methylketone record, which was developed by T. Herbert, was similarly interpolated and divided by the weight $\% \mathrm{C}_{\text {org }}$ values reported in Chapter 4 to normalize the data. A factor analysis was performed using the covariance matrix calculated from this data subset so that the disparate group of proxies could be analyzed together. The results are presented in Figure 5-4. All marine biomarkers are highly loaded on factor 1, but not on factor 2, and the converse is true for the terrestrial compounds. Ti, which is indicative of purely terrestrial inputs, plots very low on both factors, apart from all other compounds. Of all the biomarkers, the $\mathrm{C}_{30}$ and $\mathrm{C}_{32}$ fatty acids plot closest to Ti on factor 1, supporting the inference that they are derived from terrestrial sources. The terrestrial fatty acids may be loaded slightly higher on factor 1 than Ti because they have been subjected to some measure of degradation during transport and deposition, whereas Ti has not.

Marine derived compounds, which represent a variety of algal and bacterial sources, plot as a cluster along with the metals Fe, Si, V, Zn, and Mo (Figure 5-4). Among other metals, Fe and V have been observed as porphyrin substitution components in the geologic record (Barwise and Roberts, 1984; Bonnett et al., 1984). Thus, it is not surprising that these metals plot near phytol, which is another chlorophyll degradation 
Figure 5-4

Selected Biomarkers and Metals Factor Analysis - Factors 1 and 2

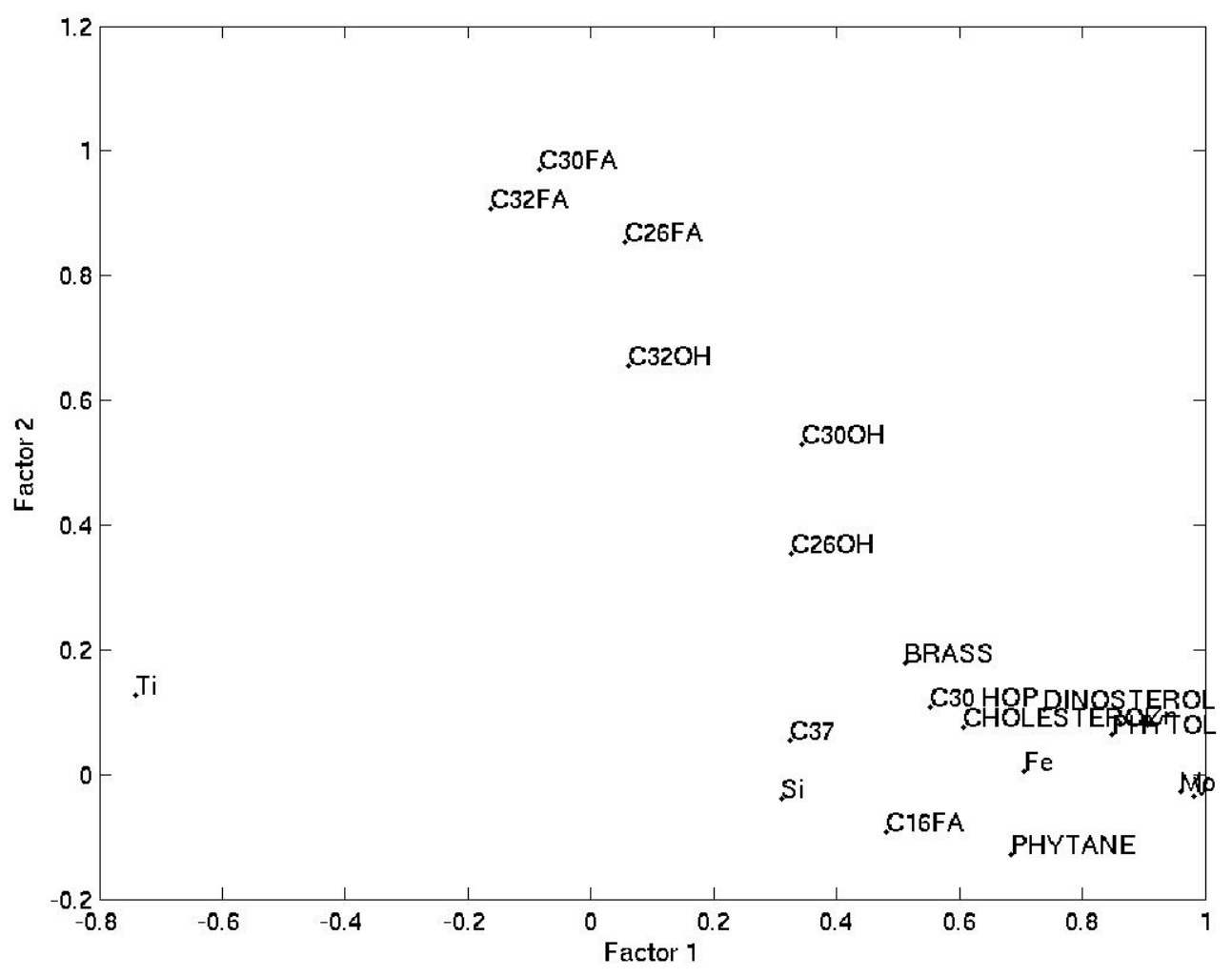

Factor analysis results for the data set containing selected biomarkers (normalized to $\mathrm{C}_{\text {org }}$ ), metals (normalized to $\mathrm{Al}$ ), and the $\mathrm{C}_{37}$ methylketone. Factor 1 is plotted versus factor 2 . 
product. Si is a nutrient and is associated with diatom productivity, and thus plots near the sterols. With the exception of the terrestrially derived $\mathrm{Ti}$, all of the metals appear to be strongly associated with large-scale marine productivity/preservation processes on the Peru Margin. The $\mathrm{C}_{37}$ methylketone, which is a marker for coccolith productivity, also plots in the same group as the other marine compounds, suggesting that its abundance is governed by roughly the same processes as other primary producers.

The predicted biomarker scores from the biomarker and metal subset were calculated using the non-standardized data instead of the covariance matrix and are presented in Figure 5-5. The factor 1 record contains many of the features common to the marine biomarker records, such as the minimum at $9 \mathrm{ka}$ and greater abundances and higher amplitude variability afterwards. The large peaks observed in the latter part of the Holocene in the factor 1 record are prominent features in the phytol and many of the metals records, suggesting that they represent variability in total chlorophyll production and/or preservation. As evidenced in Figure 5-4, the first factor appears to separate marine and terrestrial variability. The factor 2 record strongly resembles the pattern of variability observed in the long-chain fatty acid records, and thus represents the terrestrial mode of variability, which became more evident because some of the marine biomarkers were removed for this factor analysis. Factor 3 is highly variable and is difficult to interpret.

The results discussed above demonstrate how factor analysis can be an effective tool for describing relationships between proxy records in a large data set such as the one presented here. The factor analysis performed on the entire biomarker data set separated the data based on source organism classes, providing a framework for confident interpretation of paleoenvironmental changes. The biomarkers discussed later in this chapter were selected based on their groupings and factor loadings. For example, the factor analysis supported the hypotheses that the $\mathrm{C}_{30}$ and $\mathrm{C}_{32}$ fatty acids provide the most reliable terrestrial signal, and cholesterol can be used as an integrator of variability for a wide range of surface biota. The metals and $\mathrm{C}_{37}$ methylketone data added to the analysis are coherent with the model that variability in $1228 \mathrm{D}$ sediments is primarily controlled by 
Figure 5-5a

Factor 1 - Selected Biomarkers Normalized to

Organic Carbon and Metals Normalized to Al

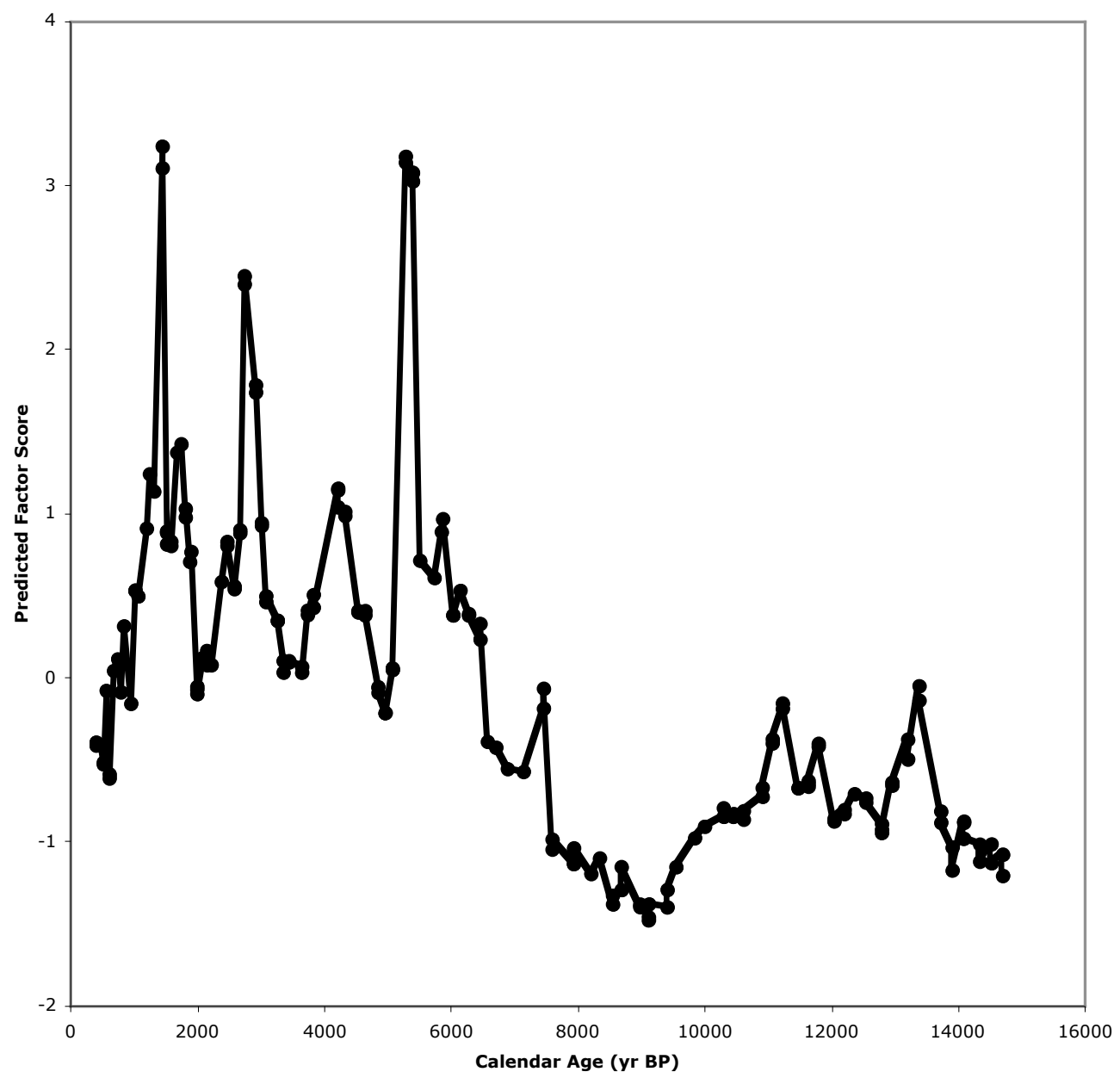

Predicted factor scores for the data set including selected biomarkers (normalized to $\mathrm{C}_{\mathrm{org}}$ ), metals (normalized to $\mathrm{Al}$ ), and the $\mathrm{C}_{37}$ methylketone. Factor 1 is presented in (a), factor 2 in (b), and factor 3 in (c). 
Figure 5-5b

Factor 2 - Selected Biomarkers Normalized to Organic Carbon and Metals Normalized to Al

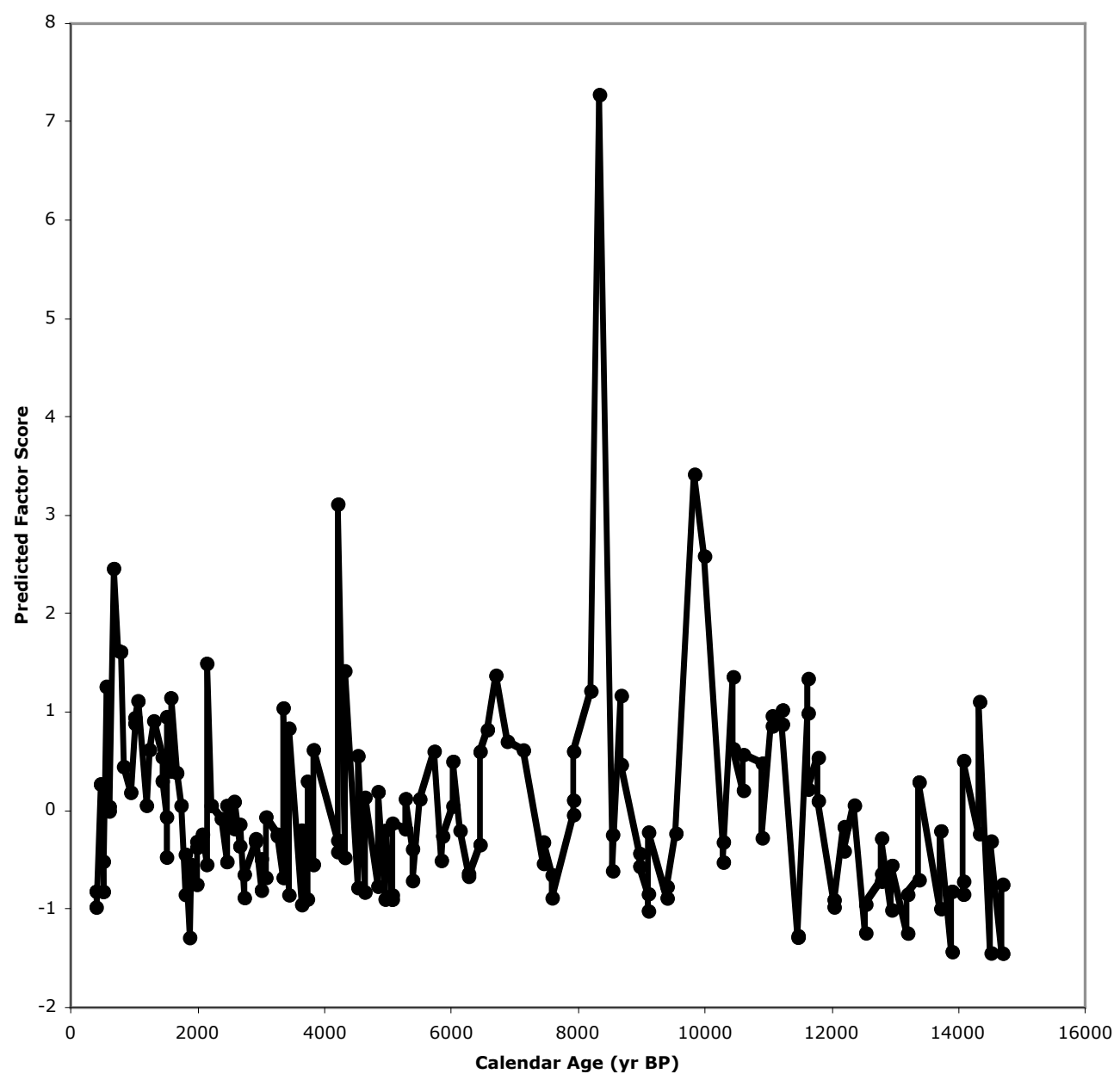


Figure 5-5c

Factor 3 - Selected Biomarkers Normalized to

Organic Carbon and Metals Normalized to Al

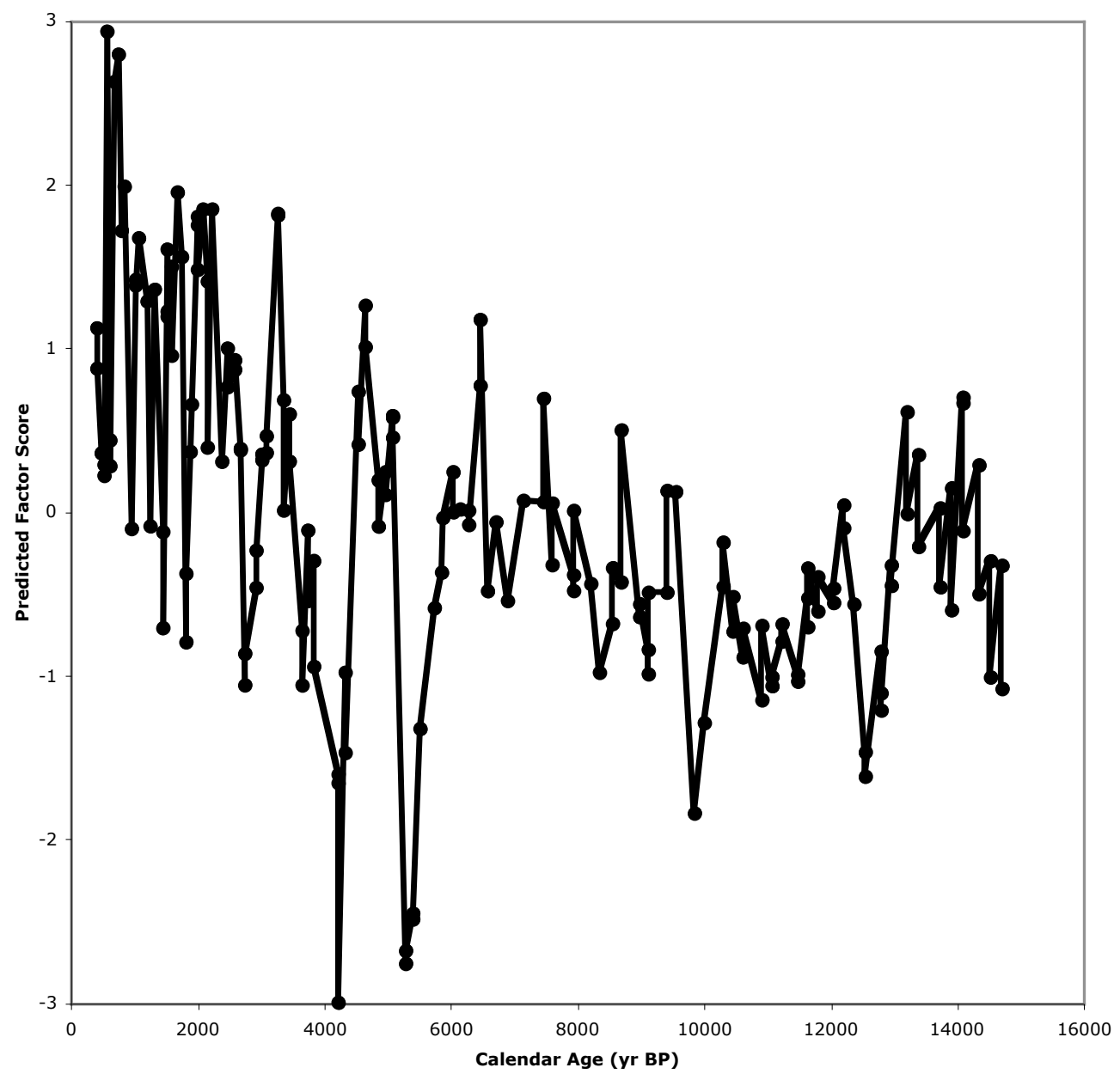


large-scale processes that influence productivity and/or preservation. Upwelling strongly influences both of these variables simultaneously and thus emerges as the likely environmental control.

\section{Data Presentation}

All of the biomarker abundance records presented in this chapter have been normalized to the amount of organic carbon extracted from individual sediment samples in order to highlight unique patterns of variability in biomarkers derived from different source organisms, and to minimize the overprint of bulk organic carbon delivery and preservation. For presentation purposes, all of the records have been smoothed with a three-point running average. However, the multivariate analyses described above were performed using the original (not smoothed) data.

\section{Terrestrial Biomarkers}

Fatty acids of chain lengths greater than $\mathrm{C}_{24}$ were interpreted as terrestrial vascular plant leaf waxes (Eglinton and Hamilton, 1967). The smoothed records of the $\mathrm{C}_{26-30}$ even-chain-length fatty acid concentrations are shown in Figure 5-6. Abundances of these biomarkers were highly variable throughout the record and provide evidence of millennial-scale variations in the input of terrestrial material to the Peru Margin over the last $15 \mathrm{ka}$. The millennial-scale variability is superimposed on longer-term trends defined by generally elevated terrestrial inputs from about 11.6 to $6.6 \mathrm{ka}$ and again from 1.6 to $0.5 \mathrm{ka}$, compared to the periods spanning 14.0 to $12.0 \mathrm{ka}$ and 6.3 to $1.7 \mathrm{ka}$, when inputs were lower. A large input peak occurred at $8.3 \mathrm{ka}$, which, given errors in age estimates, could overlap with the $8.2 \mathrm{ka}$ event described by Alley et al. (1997) in Greenland ice core records. The Costa Rican stalagmite record of Lachniet et al. (2004) provides evidence for a tropical expression of the 8.2 ka event, marked by a brief period of increased aridity. The timing of this long-chain fatty acid concentration peak may be fortuitous, though, considering that typically more pronounced climate events such as the Younger Dryas are not evident in my record. 
Figure 5-6

Peru Margin $\mathrm{C}_{26}, \mathrm{C}_{28}$, and $\mathrm{C}_{30}$ Fatty Acid Concentrations

Normalized to Organic Carbon

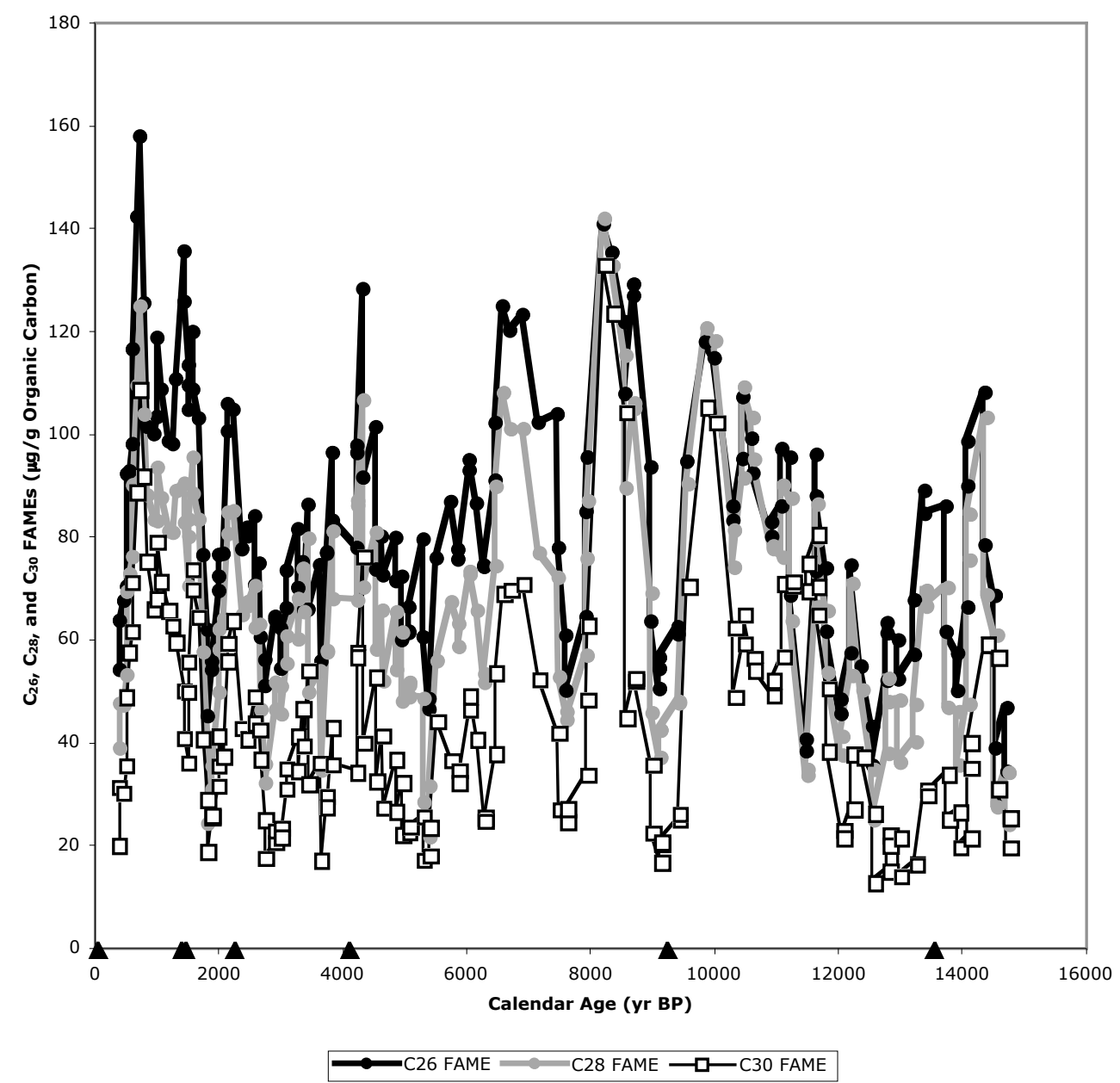

Peru Margin $\mathrm{C}_{26}, \mathrm{C}_{28}$, and $\mathrm{C}_{30}$ fatty acid (analyzed as methyl esters) concentration records normalized to organic carbon and smoothed with a 3-point running average. Black triangles represent radiocarbon dates. 
The fatty acid carbon isotope record also exhibits a large signal at $8.3 \mathrm{ka}$ and matches some of the long-term variability in the $\mathrm{C}_{30}$ abundance record. Figure 5-7 depicts the $\delta^{13} \mathrm{C}$ records of several chain lengths and Figure 5-8 shows bulk sediment $\delta^{13} \mathrm{C}$ values. Careful selection of fatty acid chain lengths for interpretation of terrestrial inputs is particularly important on the Peru Margin, where algal and bacterial sources may confound isolation of the terrestrial signal. The $\mathrm{C}_{30}$ chain length was selected for paleoclimate interpretation of the plant wax carbon isotopic signal. Its $\delta^{13} \mathrm{C}$ values are adequately separated from those of the $\mathrm{C}_{18}$ fatty acid and bulk sediments, which are most likely representative of predominantly marine organic inputs. $\mathrm{C}_{32} \delta^{13} \mathrm{C}$ would also have been an appropriate choice for the same reason, but the chromatographic peaks for this chain length were smaller than for $\mathrm{C}_{30}$, and therefore isotopic determinations were prone to greater error. Although the $\mathrm{C}_{26}$ and $\mathrm{C}_{28}$ fatty acids exhibited a similar pattern of concentration variability to $C_{30}$, their $\delta^{13} \mathrm{C}$ values approached those of $C_{18}$, suggesting that they may be in part derived from marine sources, and thus precluding their use as terrestrial vascular plant proxies. The $\mathrm{C}_{30}$ fatty acid $\delta^{13} \mathrm{C}$ record is presented in Figure 5-9 along with its smoothed concentration record. $\delta^{13} \mathrm{C}$ varies roughly in parallel with concentration between about 9 and $4 \mathrm{ka}$. A large peak in $\delta^{13} \mathrm{C}$ occurs at $8.3 \mathrm{ka}$ and another smaller peak is present at $6.7 \mathrm{ka}$, both coincident with concentration peaks.

Differences in photosynthetic mechanisms between $\mathrm{C}_{3}$ and $\mathrm{C}_{4}$ plants give rise to differing isotopic compositions, with $\mathrm{C}_{4}$ plants exhibiting enriched $\delta^{13} \mathrm{C}$ values relative to $\mathrm{C}_{3}$ plants (e.g. Collister et al., 1994). A potentially troubling aspect of the 1228D leaf wax $\delta^{13} \mathrm{C}$ record lies in the depleted baseline values, which are typical of $\mathrm{C}_{3}$ vegetation. Using the average $\delta^{13} \mathrm{C}$ values of leaf wax $n$-alkanes determined by Collister et al. (1994) $\left(\mathrm{C}_{3}=-35 \%\right.$; $\left.\mathrm{C}_{4}=-21 \%\right)$ as end-members, the most depleted values $(\sim-33 \%$ ) observed in the $1228 \mathrm{D} \mathrm{C}_{30}$ fatty acid record around 10-12 ka represent $\mathrm{C}_{3}$ plant contributions of about $86 \%$. In general, the arid environment on the Peru Margin would not be hospitable to large populations of these types of plants. However, very localized clusters of $\mathrm{C}_{3}$ plants could be associated with the rivers draining the western flank of the Andes. A detailed 
Figure 5-7

Peru Margin Fatty Acid $\delta^{13} \mathrm{C}$

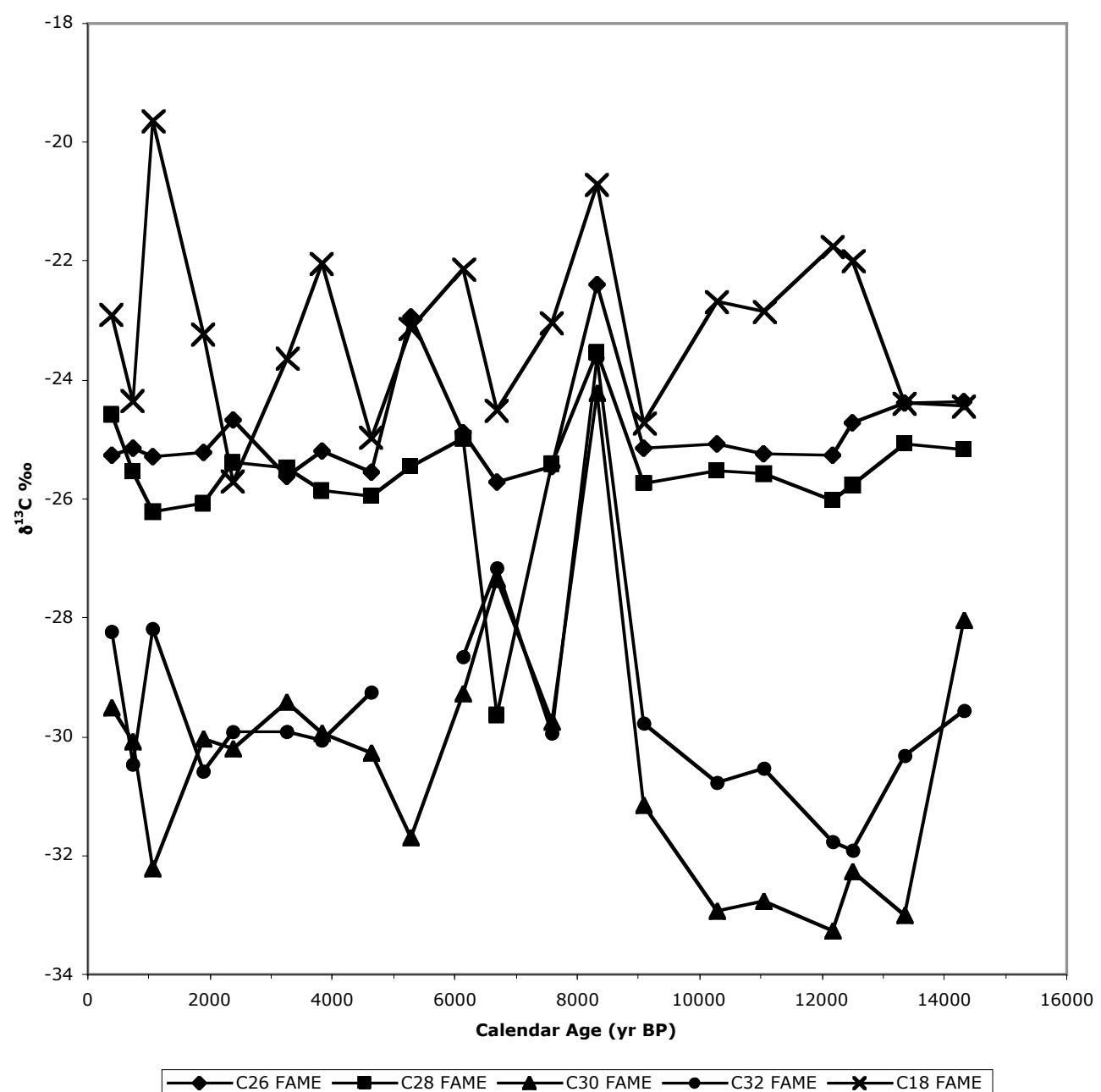

$\delta^{13} \mathrm{C}$ of various Peru Margin fatty acid (as methyl ester) chain lengths. 
Figure 5-8

Peru Margin Bulk Sediment $\delta^{13} \mathrm{C}$

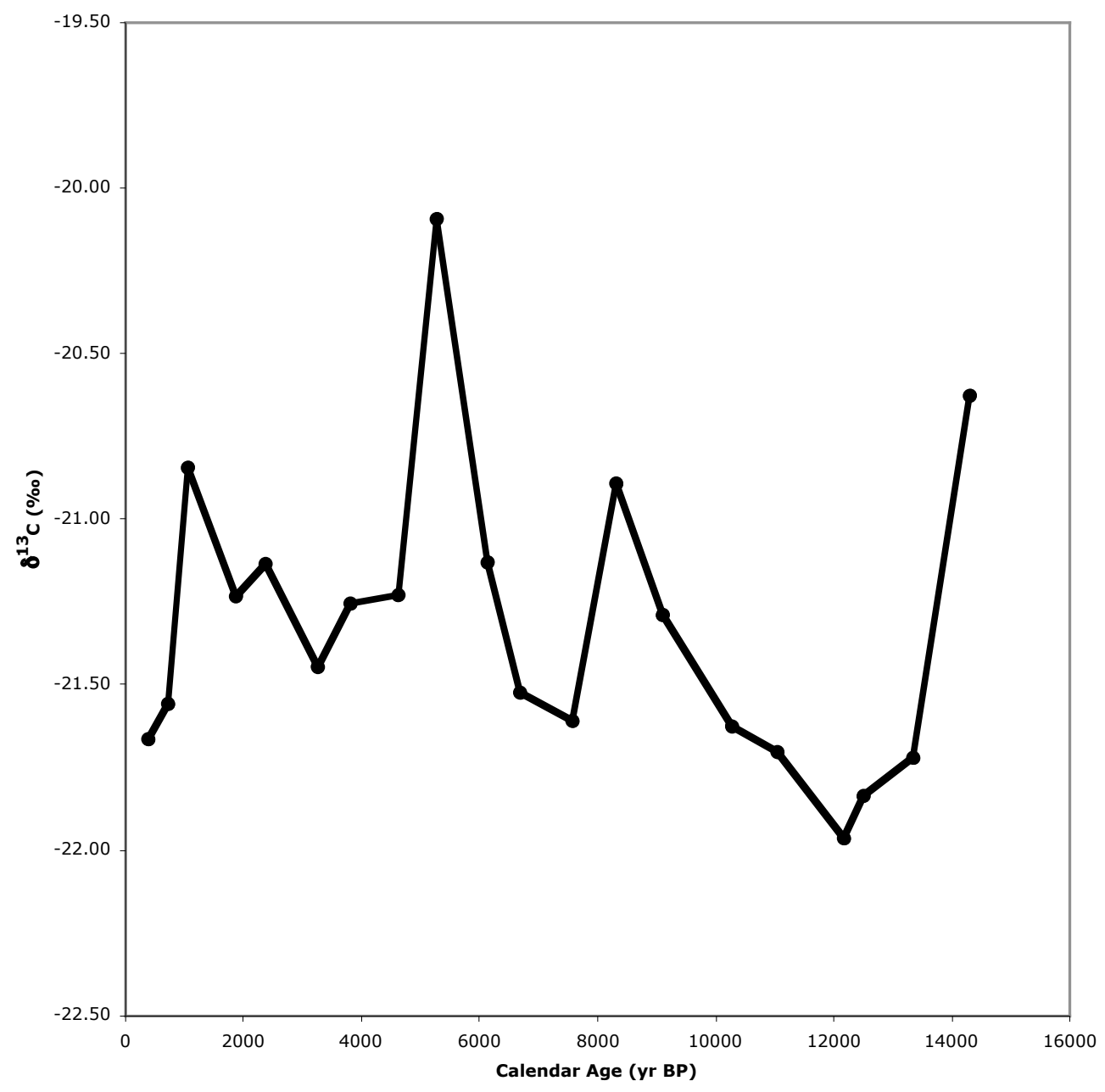

$\delta^{13} \mathrm{C}$ of Peru Margin bulk sediments. Samples are the same as those selected for compound specific $\delta^{13} \mathrm{C}$. 
Figure 5-9

Peru Margin $\mathrm{C}_{30}$ Fatty Acid Concentration and $\delta^{13} \mathrm{C}$

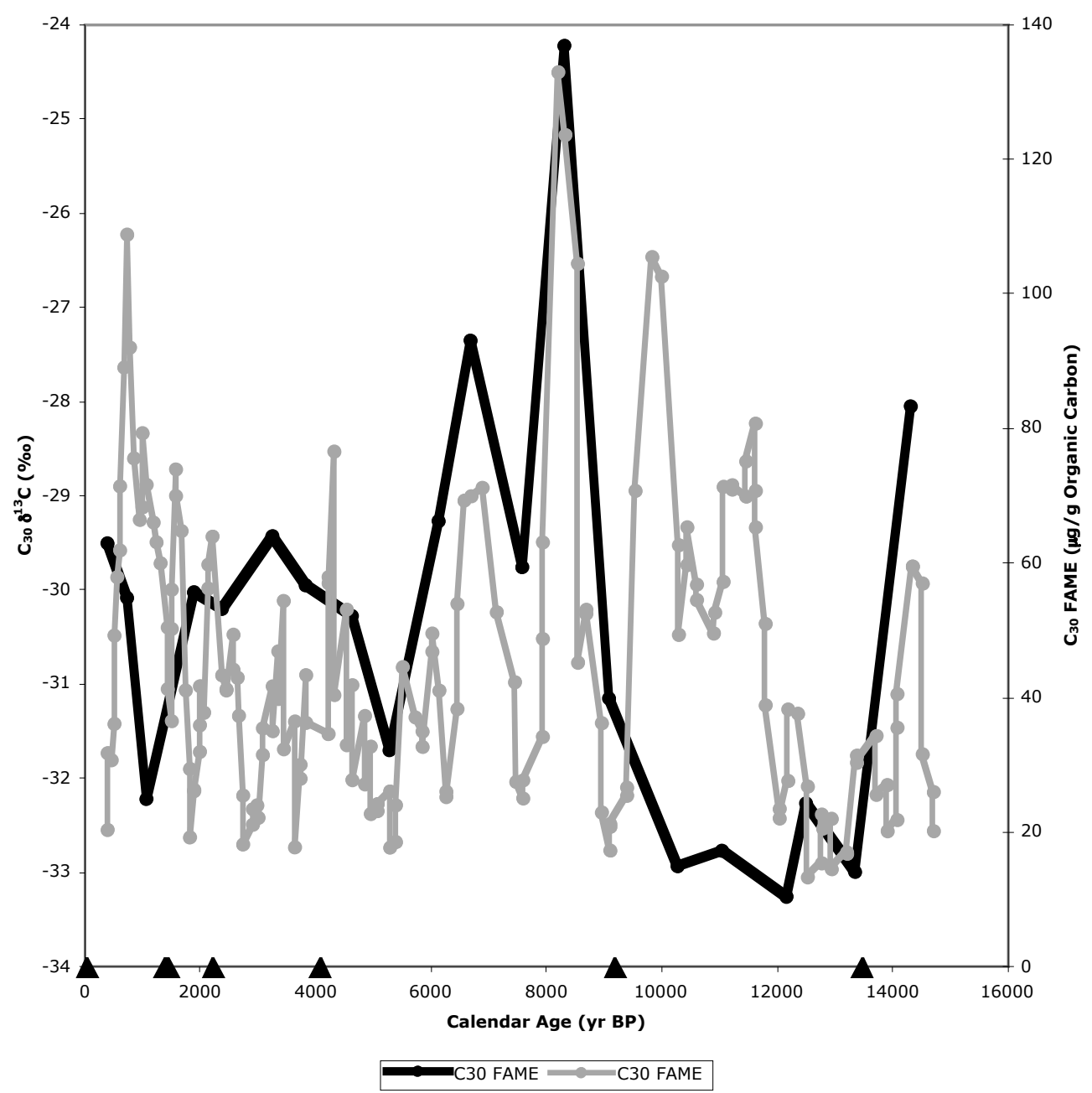

Peru Margin $\mathrm{C}_{30}$ fatty acid (analyzed as methyl ester) concentration (normalized to organic carbon and smoothed) and $\delta^{13} \mathrm{C}$ records. Black triangles represent radiocarbon dates. 
understanding of the organic matter transported by these rivers would aid interpretation of Peru Margin leaf wax $\delta^{13} \mathrm{C}$ records.

Possible explanations for the variability observed in the $\mathrm{C}_{30}$ fatty acid records include influences from marine sediment redistribution, such as long-shore transport, and variability in aeolian transport of terrestrial organic and mineral material throughout the past $15 \mathrm{ka}$. The former option is unlikely because the marine biomarker records, when normalized to organic carbon, exhibit different variability than the terrestrial records. Also, in order to produce the wide range of $\delta^{13} \mathrm{C}$ values observed in the record by sediment redistribution alone, great transport distances would likely have been required. Although present day aeolian deposition of organic matter on the Peru Margin is thought to be minimal (Schneider and Gagosian, 1985) and atmospheric circulation is relatively stable, conditions in the past may have been more variable. Contributions of leaf wax compounds via aeolian versus fluvial processes are difficult to assess with the suite of biomarkers used in this study, but future examination of the lignin content of the sediments may serve to constrain these variables. Pending a greater understanding of leaf wax transport to the Peru Margin, the interpretations provided below are somewhat speculative in that they hinge on the assumption that fluvial deposition has been continually dominant over aeolian transport.

The $\delta^{13} \mathrm{C}$ peak at $8.3 \mathrm{ka}$ likely represents an abrupt and intense input of $\mathrm{C}_{4}$ plant material, of the type consistent with high-elevation grasses. Assuming that terrestrial organic matter is delivered to Peru Margin sediments largely through fluvial processes, the 8.3 ka concentration spike observed in the $\mathrm{C}_{30}$ fatty acid record potentially represents the largest Holocene fluvial event. A Ti/Al record from these same sediments (Tierney et al., 2004) (Figure 5-10) also peaks at $8.3 \mathrm{ka}$, confirming enhanced delivery of terrestrial mineral matter at this time. Such occurrences could be caused by enhanced precipitation or melt water runoff from the western Andes, and could be consistent with wetter and/or warmer conditions. A simple hypothesis to explain the $\mathrm{C}_{30}$ fatty acid concentration and $\delta^{13} \mathrm{C}$ peaks at $8.3 \mathrm{ka}$ is that enhanced fluvial transport bore an abundance of leaf waxes from high-altitude, $\mathrm{C}_{4}$ plant-rich environments to the Peru Margin, as opposed to lower 
Figure 5-10

Peru Margin $\mathrm{C}_{30}$ Fatty Acid Concentration and Ti/Al

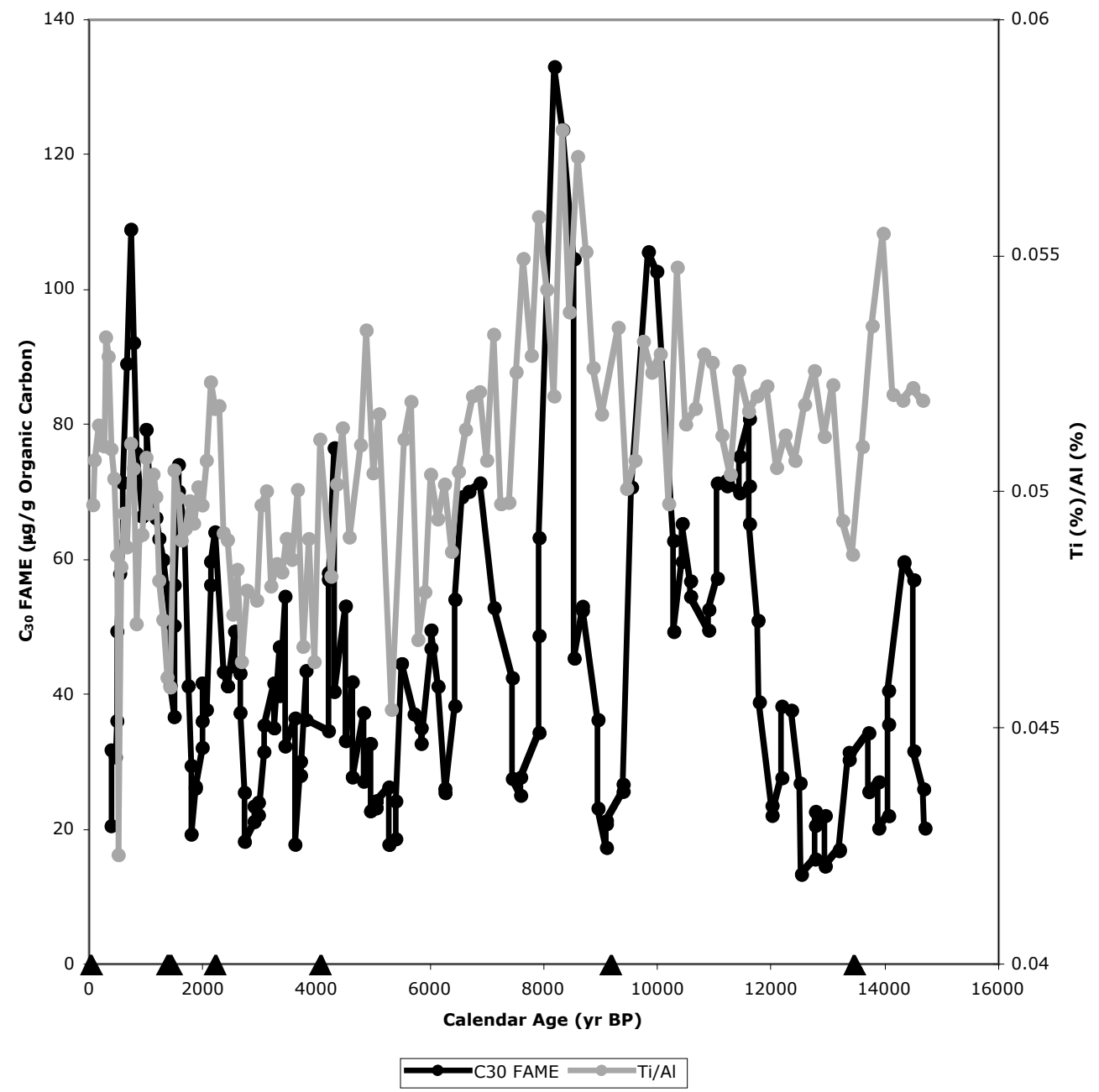

Peru Margin $\mathrm{C}_{30}$ fatty acid (analyzed as methyl ester) concentration record (normalized to organic carbon and smoothed) and Ti/Al (Tierney et al., 2004). 
altitude $\mathrm{C}_{3}$ plants that may be localized in river valleys and more typically delivered to the core site. An alternative explanation for the $\delta^{13} \mathrm{C}$ peak involves expansion of $\mathrm{C}_{4}$ plant populations that contribute organic matter to the marine environment. Vegetation on the hyper-arid Peruvian coast and western Andean flank is sparse and environmentally stressed, and is thus probably more sensitive to climate changes. For example, a minor increase in precipitation would be expected to have more of an effect on vegetation at this location than it would in the Amazonian forest. Thus, an increase in precipitation at 8.3 ka could have resulted in rapid expansion of plant populations and simultaneously increased delivery of terrestrial organic matter to Peru Margin sediments.

\section{Marine Biomarkers}

Figure 5-11 presents several Peru Margin marine algal-derived sterol concentration records that have been normalized to sedimentary organic carbon and smoothed. Cholesterol is interpreted as an integrator of total primary productivity and zooplankton activity in surface waters (Schouten et al., 1998). Brassicasterol most likely represents diatom inputs in Peru Margin sediments, and dinosterol is indicative of dinoflagellate inputs (see Table 4-1 for marine biomarker sources). Increased concentrations of these compounds are consistent with enhanced production in the water column and enhanced preservation, both of which would be symptomatic of increased upwelling on the Peru Margin. The mean upwelling signal is perhaps best interpreted from the cholesterol record, given that it represents a wide range of marine biota.

The cholesterol record suggests enhanced upwelling before about $13 \mathrm{ka}$ and again from about $6.5 \mathrm{ka}$ to the present. There are sharp transitional boundaries at 12.9 and 6.5 ka, between which times upwelling appears to be uniformly reduced. There are several

sharp decreases in concentration during the mid to late Holocene centered at about 5.1, $3.9,1.8$, and $0.6 \mathrm{ka}$. Of these events, the one centered at about $3.9 \mathrm{ka}$ is the most prolonged and the one at $0.6 \mathrm{ka}$ exhibits the greatest amplitude of change. These two events are prominent in the other sterol records, as well. The brassicasterol record is roughly similar to cholesterol prior to about $9 \mathrm{ka}$, with greater differences evident 
Figure 5-11

Peru Margin Cholesterol, Brassicasterol, and Dinosterol

Concentrations Normalized to Organic Carbon

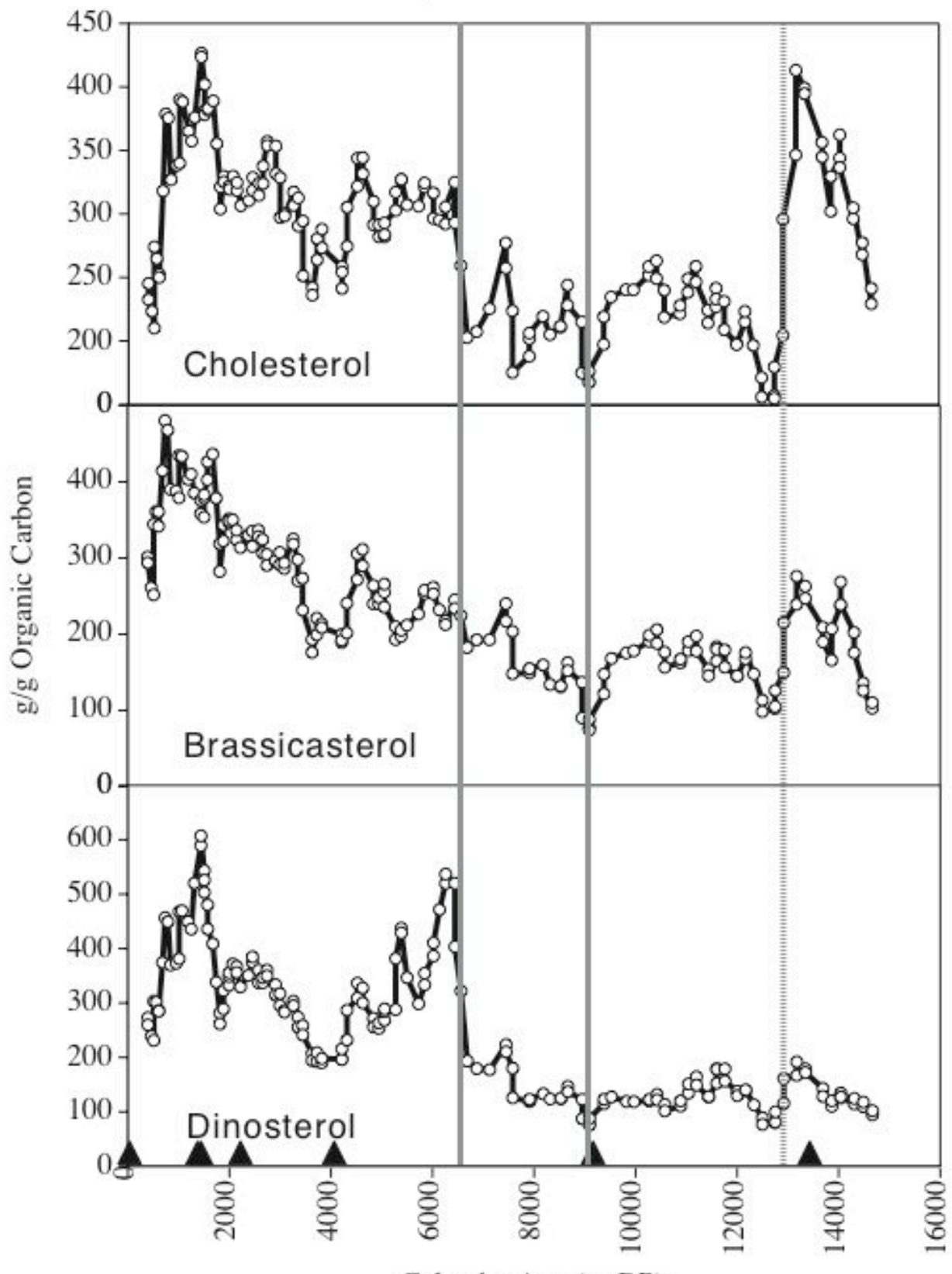

Calendar Age (yr BP)

Peru Margin sterol concentration records normalized to organic carbon and smoothed. Black triangles represent radiocarbon dates. 
afterwards. Brassicasterol concentrations increase gradually between 9 and $0.6 \mathrm{ka}$ with moderate variability, suggesting a steady increase in upwelling and diatom productivity. The increase at $6.5 \mathrm{ka}$ is not as sharp as in the cholesterol record, and the minima during the Holocene are similarly not as prominent. Differences between these sterol records probably arise from changes in phytoplankton communities and the activities of zooplankton over time. Even at present, phytoplankton species composition and centers of maximum productivity are variable on short time scales. Due to the wide range of sources it encompasses, I argue that the cholesterol record should serve as the best indicator of total surface biota activities, and thus should serve as the best upwelling indicator.

The dinosterol abundance record exhibits pronounced millennial-scale variability superimposed on a broader trend that is comparable to that of the other sterol records. Pronounced maxima occur at 6.5 and $1.4 \mathrm{ka}$, suggesting enhanced upwelling at these times, marked by particularly favorable conditions for dinoflagellate productivity. Variability in the early part of the record is lower amplitude than that observed for the other sterols. The unique high-amplitude features of the dinosterol record likely arise from differences between dinoflagellates and diatoms in terms of optimal growth conditions (e.g. nutrient requirements). As discussed earlier, the enhanced presence of dinoflagellates and the occurrence of red tides are consistent with the austral summer season and El Niño conditions. As such, the dinosterol concentration increase at $6.5 \mathrm{ka}$ may represent the onset of persistent El Niño events or enhanced summer seasonality. Abbott et al. (2000) present the summer insolation curve for $20^{\circ} \mathrm{S}$, which increases from about $8 \mathrm{ka}$ to the present, possibly signifying increasingly favorable conditions for dinoflagellates on the Peru Margin. Mid to late Holocene increases in the concentrations of the other marine biomarkers examined in Chapter 4 may have similarly arisen from increasing summer insolation at this time.

Altogether, the marine biomarker abundance records from 1228D suggest frequent changes in intensity and duration of upwelling events (in this case, the term "upwelling event" does not represent a single short-lived occurrence, but rather 
discernable millennial-scale mean states) on the Peru Margin during the last $15 \mathrm{ka}$. Upwelling was generally greatest between about 14.5 and $13.2 \mathrm{ka}$, and again during the Holocene from 6.5 to $1.0 \mathrm{ka}$, in contrast to the period spanning 12.8 to $6.6 \mathrm{ka}$ during which time upwelling appears to have been uniformly reduced. Transitions between these different upwelling states are abrupt (centennial-scale). Higher-frequency variability is superimposed on the long-term trend, with evidence of inhibited upwelling strength at about 5.1, 3.9, 1.8, and $0.6 \mathrm{ka}$. Interestingly, the similarities between the dinosterol and cholesterol abundance records suggest parallel variability between El Niño and upwelling. This correlation at first appears problematic because El Niño may have the effect of reducing upwelling and associated primary productivity, although these relationships are not fully understood. However, individual interpretations of these sterol records can be rectified if upwelling was also influenced by occurrences of La Niña, during which enhanced trade winds may have intensified upwelling. I suggest a model whereby enhanced El Niño conditions result in increased dinosterol inputs, while similarly stronger and/or more frequent La Niña events promote upwelling and thus elevated cholesterol inputs. In this manner, the 1228D dinosterol and cholesterol abundance profiles may have resulted from simultaneously enhanced El Niño and La Niña conditions, respectively, after $6.5 \mathrm{ka}$.

\section{Comparison to Other Tropical Records}

Based on the Peru Margin dinosterol and cholesterol records developed in this study, I hypothesize that stronger and/or more frequent El Niño and La Niña events occurred after $6.5 \mathrm{ka}$. These records also suggest a reduction in both El Niño and La Niña activity during the mid-Holocene, which has previously been identified as generally La Niña-like (Koutavas et al., 2002). My findings are consistent with the studies of Holocene ENSO variability discussed in the introduction, which infer enhanced El Niño occurrence in the late Holocene. However, in that it involves a parallel strengthening of La Niña, my proposed scenario adds a new facet to constructs that portray tropical Pacific climate as having varied between El Niño and La Niña end-member states. My findings 
support the model results of Clement et al. (1999), which exhibit paired variability between NINO3 warm and cold events over the last $70 \mathrm{ka}$, with increased occurrences of both in the late Holocene. The authors attribute the parallel variability to a reduced effect of the seasonal cycle on solar forcing and non-linearities in the climate system.

The 1228D dinosterol abundance record strongly resembles the Lake Pallcacocha sedimentation record of Moy et al. (2002), which was interpreted as a record of El Niño occurrence. Lake Pallcacocha ( $2^{\circ} 46^{\prime} \mathrm{S}, 79^{\circ} 14^{\prime} \mathrm{W} ; 4,200 \mathrm{~m}$ ) is a high-altitude lake in the Ecuadorian Andes and is located well North of Site 1228D on the Peru Margin, although both areas could be influenced by El Niño-related precipitation. The results of Moy et al. (2002), which are calculated as the number of El Niño events in a century, are compared to the 1228D dinosterol abundance record in Figure 5-12. Both records are remarkably similar in that they show a large initial increase at about $6.5 \mathrm{ka}$, a broad minimum centered at $4 \mathrm{ka}$, and similar high-amplitude variability from about $2 \mathrm{ka}$ to the present. The dinosterol record constrains the timing of El Niño onset in the mid-Holocene on the Peru Margin and the pattern of subsequent variability, and confirms the El Niño link inferred by Moy et al. (2002).

Peru Margin sterol abundance records are similar to the lake water $\delta^{18} \mathrm{O}$ estimates of Abbott et al. (2000) from the eastern Andes, which imply a dramatic increase in aridity at about 6.2 ka followed by generally increasing moisture towards the present. Abrupt $\delta^{18} \mathrm{O}$ depletions, which are consistent with wetter conditions, occurred at about $5 \mathrm{ka}$ or just prior, $4 \mathrm{ka}, 2 \mathrm{ka}$, and between 1 and $0.5 \mathrm{ka}$. Based on the 1228D age scale, the timing of these events is nearly identical to the mid to late Holocene negative excursions in the sterol records, which are interpreted as evidence for reduced upwelling (Figure 511). Because the moisture source to the eastern Andes is the Atlantic Ocean, the similar timing between reductions in Peru Margin upwelling and the wet events on the Altiplano signifies a broad climate process that spans the ETP and Atlantic Oceans.

Additional evidence for large-scale tropical climate events during the Holocene arises through comparison of the Peru Margin sterol records with the eastern tropical Atlantic (ODP Site 658C; $20^{\circ} 45^{\prime} \mathrm{N}, 18^{\circ} 35^{\prime} \mathrm{W}, 2263 \mathrm{~m}$ ) faunal sea surface temperature 
Figure 5-12

Peru Margin Dinosterol Concentration and Inferred ENSO Variability

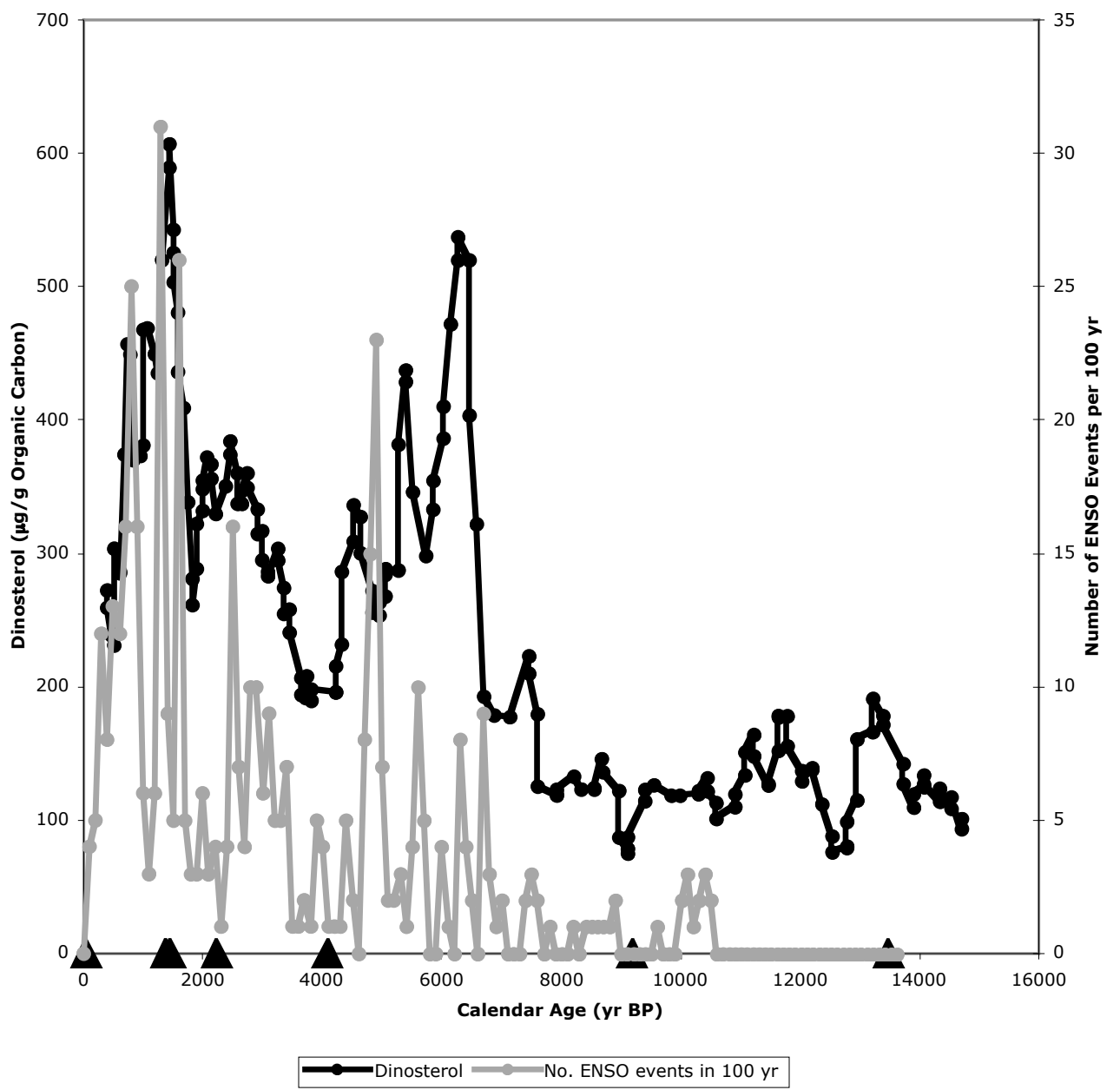

Peru Margin dinosterol concentration record (normalized to organic carbon and smoothed) plotted with the Lake Pallcacocha sediment record of Moy et al. (2002). Black triangles represent radiocarbon dates. 
estimates of deMenocal et al. (2000). Interestingly, the Site 658 core exhibits a sedimentation hiatus from 17.4 to $14.3 \mathrm{ka}$, the upper age of which is similar to the end of the $1228 \mathrm{D}$ hiatus, which occurred at about $14.7 \mathrm{ka}$. It is unlikely that both hiatuses result from sea level changes, as $658 \mathrm{C}$ is situated at $2263 \mathrm{~m}$ depth. Cholesterol abundance $\left(\mathrm{C}_{\mathrm{org}}\right.$-normalized and smoothed) is plotted with the warm temperature anomaly record of deMenocal et al. (2000) in Figure 5-13. The sense of the two plots is reversed, with increasing y-axis values consistent with greater upwelling on the Peru Margin and reduced upwelling off of West Africa. The two records are similar prior to the cholesterol concentration increase at $6.5 \mathrm{ka}$, and again from about $2 \mathrm{ka}$ to the present. From 6.5 to $2 \mathrm{ka}$, the scale of variability in both records is similar, but the timing is somewhat different. Starting with the 6.5 ka rapid cholesterol concentration increase, abrupt events may occur about 1 ka earlier on the Peru Margin, although age scale uncertainties preclude detailed interpretation of the relative timing of these events. deMenocal et al. (2000) attributed the abrupt sea surface cooling events during the mid to late Holocene to southward advection of cool northern Atlantic waters, suggesting a link between the tropics and North Atlantic on millennial time scales. Alternatively, the cooling events could signify periods of increased upwelling.

The Peru Margin and eastern tropical Atlantic upwelling systems are both influenced by equatorial circulation regimes, particularly the trade winds, which drive upwelling at both locations. As is the case on the Peru Margin, upwelling at the location of Site 658 is perennially strong. Immediately to the south, upwelling become seasonal and is strongest during boreal winter, although it is stronger during summer north of $25^{\circ} \mathrm{N}$ (e.g. Fütterer, 1983). I hypothesize that variability in the equatorial wind system produces the observed changes in upwelling strength at both locations. Inherent to my interpretations is the assumption that over the last $15 \mathrm{ka}$ the upwelling at Site 658 was generally strongest during boreal winter, as it presently is to the south. At present, El Niño events are associated with a westerly zonal surface wind anomaly during boreal winter from about $15^{\circ} \mathrm{N}$ to $30^{\circ} \mathrm{N}$ over much of the Atlantic (NOAA-CIRES, 2004), consistent with a weakening of the winds that cause upwelling. La Niña wind anomalies 
Figure 5-13

Peru Margin Cholesterol Concentration and Eastern Tropical Atlantic Temperature Anomaly

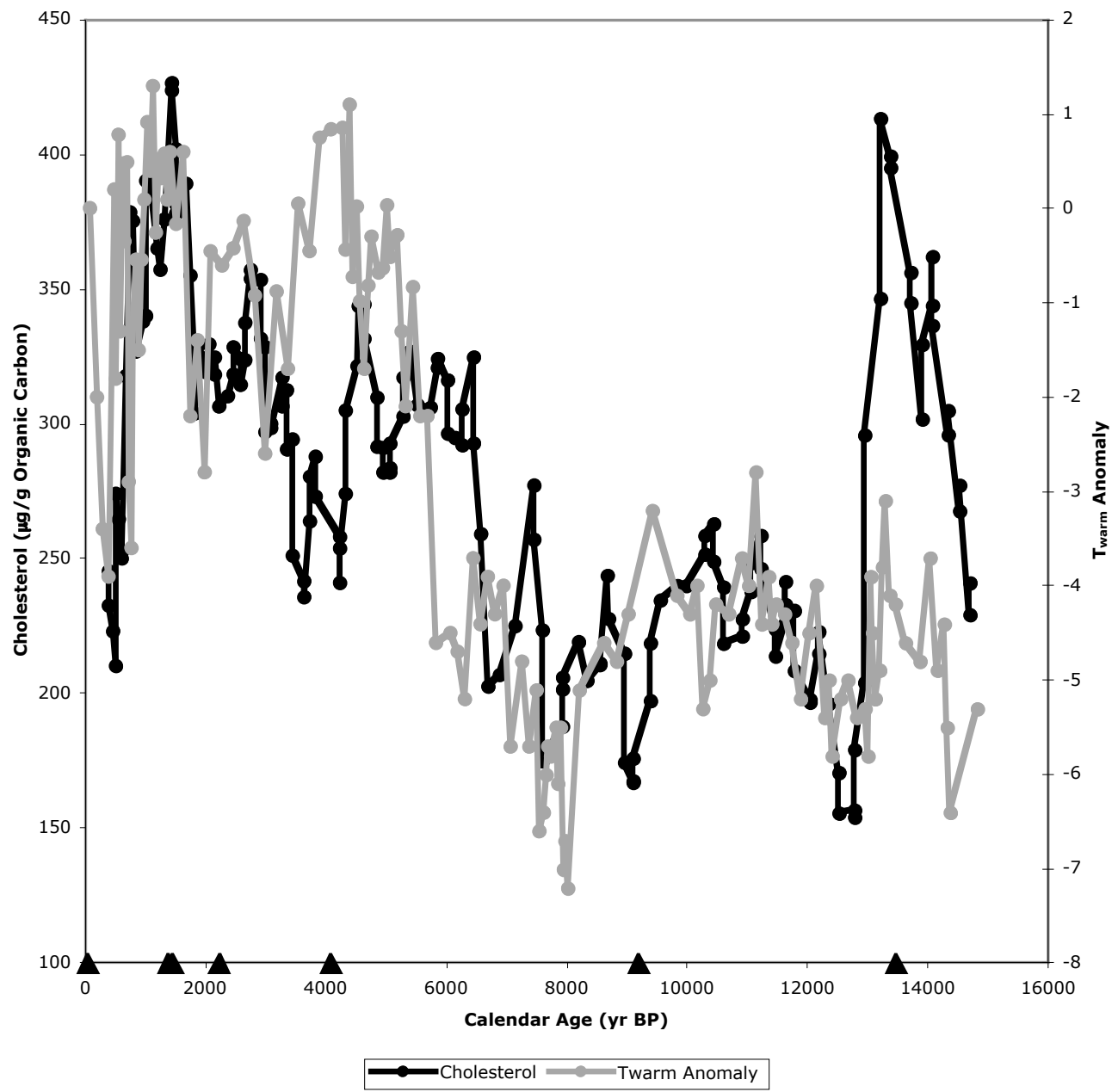

Peru Margin cholesterol concentration record (normalized to organic carbon and smoothed) plotted with the eastern tropical Atlantic $\mathrm{T}_{\text {warm }}$ anomaly record of deMenocal et al. (2000). Black triangles represent radiocarbon dates. 
in the same area and season are small. By this mechanism, the enhanced El Niño and La Niña conditions in the late Holocene inferred from the Peru Margin biomarker records could have resulted in, or been associated with, weakened winter zonal winds in the eastern tropical Atlantic, and thus reduced upwelling strength at Site 658. This hypothesis and the many similarities between the Peru Margin and Site 658 records imply that ENSO variability had far-reaching effects around the tropics and may have been the dominant mode of tropical climate variability during the Holocene.

Similar pacing of climate events between the Peru Margin, the eastern Andes, and the eastern tropical Atlantic could also be explained through other atmospheric connections than straightforward ITCZ migration. Zhou and Lau (1998) provide evidence for a South American monsoon, which could result in increased precipitation on the Altiplano and strengthened North Atlantic equatorial trade winds. The authors suggest that monsoon related upper-tropospheric flow would be established from the Altiplano towards northwest Africa, crossing the equator. The actions of the South American monsoon identified by Zhou and Lau (1998) may explain the climate links between the eastern tropical Atlantic and Altiplano, although effects on Peru Margin upwelling have not been established. Regardless, the similarities between Peru Margin marine biomarker records and other studies strongly suggest a role for the ETP in tropical Holocene climate variability.

Assuming predominantly fluvial delivery of terrestrial organic matter, the pattern of variability in the $1228 \mathrm{D}$ leaf wax fatty acid abundance records suggests relatively arid conditions from about 6.3 to $1.7 \mathrm{ka}$. Periods of enhanced fluvial inputs occurred between 11.6 and $6.6 \mathrm{ka}$, and again from about 1.6 to $0.5 \mathrm{ka}$. These results are also consistent with the aridity proxy records of Abbott et al. (2000) from Lago Taypi Chaka Kkota in the eastern Andes. Interestingly, the leaf wax aridity signal is thus out of phase with the western Andean paleoclimate records described in the introduction, which generally suggest wet conditions at about the same time as reduced $\mathrm{C}_{30}$ fatty acid inputs. These observations underscore the complexity of Holocene climate variability in this area of South America and support the hypothesis that steep aridity gradients were present in the 
Andes, likely as a result of interactions between the ITCZ, ENSO, and large-scale (i.e. circum-tropical or global) climate processes. An incomplete understanding of terrestrial organic matter sources, as discussed above, precludes further interpretation of the leaf wax records.

\section{Conclusions}

Peru Margin biomarker records have provided valuable clues about tropical climate variability throughout the Holocene. The high-resolution records generated via GC/TOF-MS afforded an opportunity to study changes in organic inputs from a variety of sources on an appropriate time scale for interpreting abrupt climate events. The wide range of biomarker records used in this study provided the ability to monitor paleoclimate conditions on the Peru Margin from a variety of perspectives. Variability in marine and terrestrial biomarker proxy records permitted inferences about changes in upwelling strength, ENSO conditions, and aridity throughout the last $15 \mathrm{ka}$.

Sterol abundance records imply that upwelling strength on the Peru Margin was variable on orbital and millennial time scales, particularly so after $6.5 \mathrm{ka}$, at which time there was a rapid increase in sterol concentrations. Dinosterol, which is a marker for dinoflagellate inputs and was employed as an El Niño proxy, demonstrated similar variability to other sterol records, although it exhibited a higher-amplitude increase at 6.5 ka. The dinosterol record implies the onset of enhanced El Niño conditions at about 6.5 ka, similar to the Ecuadorian Lake Pallcacocha sedimentation record of Moy et al. (2002). Parallel variability between the cholesterol upwelling and dinosterol El Niño proxy records suggests a simultaneous increase in La Niña strength/frequency after 6.5 ka. My findings imply that the tropical Pacific during the Holocene did not necessarily vary between El Niño- and La Niña-like end-member states, but rather between stronger and weaker overall ENSO states.

$n$-Alkanoic acid abundance and carbon isotope records demonstrate millennialscale variability in total inputs of terrestrial organic matter and $C_{3}$ versus $C_{4}$ plant inputs, possibly associated with changes in delivery, vegetation, aridity, or a combination of all 
three parameters. If interpreted as a measure of fluvial inputs, the leaf wax fatty acid abundance records suggest a pattern of aridity change that has been inferred from other Andean climate records. However, disparities between these records and others in the same geographic area demonstrate that steep zonal and meridional precipitation gradients may have existed across the Andes during the last $15 \mathrm{ka}$.

Strong relationships between climate records from throughout the Andes, a site in the eastern tropical Atlantic, and the Peru Margin suggest the existence of a far-reaching tropical climate process that is characterized by strong mid to late Holocene millennialscale variability and is reasonably independent of North Atlantic climate. ENSO arises as the most likely driving mechanism through its effects on tropical atmospheric circulation. Further studies of Holocene tropical climate variability will help test this hypothesis by providing constraints on the strength and timing of the ENSO signal at various locations. Additionally, comparison with extra-tropical studies will shed light on the relationships between ENSO and global climate. 


\section{References}

Abbott M. B., Wolfe B. B., Aravena R., Wolfe A. P., and Seltzer G. O. (2000) Holocene hydrological reconstructions from stable isotopes and paleolimnology, Cordillera Real, Bolivia. Quaternary Science Reviews 19, 1801-1820.

Alley R. B., Mayewski P. A., Sowers T., Stuiver M., Taylor K. C., and Clark P. U. (1997) Holocene climatic instability: A prominent, widespread event $8200 \mathrm{yr}$ ago. Geology 25, 483-486.

Arthur M. A., Dean W. E., and Laarkamp K. (1998) Organic carbon accumulation and preservation in surface sediments on the Peru margin. Chemical Geology 152, 273-286.

Baker P. A., Seltzer G. O., Fritz S. C., Dunbar R. B., Grove M. J., Tapia P. M., Cross S. L., Rowe H. D., and Broda J. P. (2001) The history of South American tropical precipitation for the past 25,000 years. Science 291, 640-643.

Barwise A. J. G. and Roberts I. (1984) Diagenetic and catagenetic pathways for porphyrins in sediments. Organic Geochemistry 6, 167-176.

Bonnett R., Burke P. J., Czechowski F., and Reszka A. (1984) Porphyrins and metalloporphyrins in coal. Organic Geochemistry 6, 177-182.

Clement A. C., Seager R., and Cane M. A. (1999) Orbital controls on the El Niño/southern oscillation and the tropical climate. Paleoceanography 14(4), 441456.

Clement A. C., Seager R., and Cane M. A. (2000) Suppression of El Niño during the mid-Holocene by changes in the Earth's orbit. Paleoceanography 15, 731-737.

Collister J. W., Rieley G., Stern B., Eglinton G., and Fry B. (1994) Compound-specific $\delta^{13} \mathrm{C}$ analyses of leaf lipids from plants with differing carbon dioxide metabolisms. Organic Geochemistry 21(6/7), 619-627.

Cushing D. H. (1981) The effect of El Niño upon the Peruvian anchoveta stock. In Coastal Upwelling, Coastal and Estuarine Sciences 1 (ed. F. A. Richards), pp. 449-457. American Geophysical Union.

de Mendiola B. R. (1981) Seasonal phytoplankton distribution along the Peruvian coast. In Coastal Upwelling, Coastal and Estuarine Sciences 1 (ed. F. A. Richards), pp. 348-356. American Geophysical Union. 
deMenocal P., Ortiz J., Guilderson T., and Sarnthein M. (2000) Coherent high- and lowlatitude climate variability during the Holocene warm period. Science $\mathbf{2 8 8}$, 21982202.

Eglinton G. and Hamilton. (1967) Leaf epicuticular waxes. Science 156, 1322-1335.

Eglinton T. I., Irvine J. E., Vairavamurthy A., Zhou W., and Manowitz B. (1994) Formation and diagenesis of macromolecular organic sulfur in Peru margin sediments. Organic Geochemistry 22(3-5), 781-799.

Escribano R., Daneri G., Farías L., Gallardo V. A., González H. E., Gutiérrez D., Lange C. B., Morales C. E., Pizarro O., Ulloa O., and Braun M. (2004) Biological and chemical consequences of the 1997-1998 El Niño in the Chilean coastal upwelling system: a synthesis. Deep-Sea Research II 51, 2389-2411.

Fahrbach E., Brockmann C., Lostaunau N., and Urquizo W. (1981) The northern Peruvian upwelling system during the ESACAN experiment. In Coastal Upwelling, Coastal and Estuarine Sciences 1 (ed. F. A. Richards), pp. 134-145. American Geophysical Union.

Farrington J. W., Davis A. C., Sulanowski J., McCaffrey M. A., McCarthy M., Clifford C. H., Dickinson P., and Volkman J. K. (1988) Biogeochemistry of lipids in surface sediments of the Peru upwelling area at $15^{\circ}$ S. Organic Geochemistry 13(4-6), 607-617.

Fütterer D. K. (1983) The modern upwelling record off northwest Africa. In Coastal Upwelling: Its Sediment Record, Part B: Sedimentary Records of Ancient Coastal Upwelling (ed. J. Thiede and E. Suess), pp. 105-121. Plenum Press.

Gagosian R. B., Nigrelli G. E., and Volkman J. K. (1983) Vertical transport and transformation of biogenic organic compounds from a sediment trap experiment off the coast of Peru. In Coastal Upwelling, Its Sediment Record, Part A: Responses of the Sedimentary Regime to Present Coastal Upwelling (ed. E. Suess and J. Thiede), pp. 241-272. Plenum Press.

Haug G. H., Hughen K. A., Sigman D. M., Peterson L. C., and Röhl U. (2001) Southward migration of the intertropical convergence zone through the Holocene. Science 293, 1304-1308.

Henrichs S. M. and Farrington J. W. (1984) Peru upwelling region sediments near $15^{\circ}$ S. 1. Remineralization and accumulation of organic matter. Limnology and Oceanography 29(1), 1-19. 
Higginson M. J. and Altabet M. A. (2004) Initial test of the silicic acid leakage hypothesis using sedimentary biomarkers. Geophysical Research Letters 31, L18303, doi:10.1029/2004GL020511.

Holmgren C. A., Betancourt J. L., Rylander K. A., Zeballos H., Linares E., and Quade J. (2001) Holocene vegetation history from fossil rodent middens near Arequipa, Peru. Quaternary Research 56, 242-251.

Koutavas A., Lynch-Stieglitz J., Marchitto T. M. J., and Sachs J. P. (2002) El Niño-like pattern in ice age tropical Pacific sea surface temperature. Science 297, 226-230.

Lachniet M. S., Asmerom Y., Burns S. J., Patterson W. P., Polyak V. J., and Seltzer G. O. (2004) Tropical response to the $8200 \mathrm{yr}$ B. P. cold event? Speleothem isotopes indicate a weakened early Holocene monsoon in Costa rica. Geology 32, 957-960.

Liu Z., Kutzbach J., and Wu L. (2000) Modeling climate shift of El Niño variability in the Holocene. Geophysical Research Letters 27(15), 2265-2268.

McCaffrey M. A. (1990) Sedimentary Lipids as Indicators of Depositional Conditions in the Coastal Peruvian Upwelling Regime, Ph. D. Thesis, WHOI/MIT Joint Program in Oceanography.

McCaffrey M. A., Farrington J. W., and Repeta D. J. (1990) The organic geochemistry of Peru Margin surface sediments - I. A comparison of the C37 alkenone and historical El Niño records. Geochimica et Cosmochimica Acta 54(6), 1713-1724.

Mollenhauer G., Eglinton T. I., Ohkouchi N., Schneider R. R., Müller P. J., Grootes P. M., and Rullkötter J. (2003) Asynchronous alkenone and foraminifera records from the Benguela Upwelling System. Geochimica et Cosmochimica Acta 67(12), 2157-2171.

Moy C. M., Seltzer G. O., Rodbell D. T., and Anderson D. M. (2002) Variability of El Niño/Southern Oscillation activity at millennial timescales during the Holocene epoch. Nature 420, 162-165.

NOAA-CIRES Climate Diagnostics Center (2004) El Niño and La Niña anomalies. http://www.cdc.noaa.gov/cgi-bin/ENSO/enso.pl

Paduano G. M., Bush M. B., Baker P. A., Fritz S. C., and Seltzer G. O. (2003) A vegetation and fire history of Lake Titicaca since the Last Glacial Maximum. Palaeogeography, Palaeoclimatology, Palaeoecology 194, 259-279.

Philander G. (1989) El Niño and La Niña. American Scientist 77, 451-459. 
Placzek C. and Quade J. (2001) Holocene lake-level fluctuations of Lake Aricota, southern Peru. Quaternary Research 56, 181-190.

Quinn W. H., Neal V. T., and de Mayolo S. E. A. (1987) El Niño occurrences over the past four and a half centuries. Journal of Geophysical Research 92(C13), 1444914461.

Rodbell D. T., Seltzer G. O., Anderson D. M., Abbott M. B., Enfield D. B., and Newman J. H. (1999) An 15,000-year record of El Niño-driven alluviation in southwestern Ecuador. Science 283, 516-520.

Sandweiss D. H., Richardson III J. B., Reitz E. J., Rollins H. B., and Maasch K. A. (1996) Geoarchaeological evidence from Peru for a 5000 years B.P. onset of El Niño. Science 273, 1531-1533.

Schneider J. K. and Gagosian R. B. (1985) Particle size distribution of lipids in aerosols off the coast of Peru. Journal of Geophysical Research 90(D5), 7889-7898.

Schouten S., Breteler W. C. M. K., Blokker P., Schogt N., Rijpstra W. I. C., Grice K., Baas M., and Sinninghe Damsté J. S. (1998) Biosynthetic effects on the stable carbon isotopic compositions of algal lipids: Implications for deciphering the carbon isotopic biomarker record. Geochimica et Cosmochimica Acta 62(8), 1397-1406.

Sellner K. G., Hendrikson P., and Ochoa N. (1983) Relationships between the chemical composition of particulate organic matter and phytoplankton distributions in recently upwelled waters off Peru. In Coastal Upwelling, Its Sediment Record, Part A: Responses of the Sedimentary Regime to Present Coastal Upwelling (ed. E. Suess and J. Thiede), pp. 273-287. Plenum Press.

Seltzer G., Rodbell D., and Burns S. (2000) Isotopic evidence for late Quaternary climatic change in tropical South America. Geology 28, 35-38.

Smith R. L. (1981) A comparison of the structure and variability of the flow field in three coastal upwelling regions: Oregon, Northwest Africa, and Peru. In Coastal Upwelling, Coastal and Estuarine Sciences 1 (ed. F. A. Richards), pp. 107-118. American Geophysical Union.

Smith R. L. (1983) Peru coastal currents during El Niño: 1976 and 1982. Science 221, 1397-1399.

Strub P. T., Mesías J. M., Montecino V., Rutllant J., and Salinas S. (1998) Coastal ocean circulation off western South America. In The Sea, Vol. 11 (ed. A. R. Robinson and K. H. Brink), pp. 273-313. John Wiley \& Sons, Inc. 
Thompson L. G., Mosley-Thompson E., Bolzan J. F., and Koci B. R. (1985) A 1500-year record of tropical precipitation in ice cores from the Quelccaya Ice Cap, Peru.

Science 229, 971-973.

Thompson L. G., Mosley-Thompson E., Davis M. E., Lin P. N., Henderson K. A., Coledai J., Bolzan J. F., and Liu K. B. (1995) Late-glacial stage and Holocene tropical ice core records from Huascarán, Peru. Science 269(5220), 46-50.

Thompson L. G., Davis M. E., Mosley-Thompson E., Sowers T. A., Henderson K. A., Zagorodnov V. S., Lin P. N., Mikhalenko V. N., Campen R. K., Bolzan J. F., Cole-Dai J., and Francou B. (1998) A 25,000-year tropical climate history from Bolivian ice cores. Science 282(5395), 1858-1864.

Tierney J., Cleaveland L., Herbert T., and Altabet M. (2004) Metal deposition along the Peru Margin since the last glacial maximum: Evidence for regime change at $\sim 6$ ka. AGU Fall Meeting.

Ulloa O., Escribano R., Hormazabal S., Quiñones R. A., González R. R., and Ramos M. (2001) Evolution and biological effects of the 1997-98 El Niño in the upwelling ecosystem off northern Chile. Geophysical Research Letters 28(8), 1591-1594.

Volkman J. K., Farrington J. W., and Gagosian R. B. (1987) Marine and terrigenous lipids in coastal sediments from the Peru upwelling region at $15^{\circ} \mathrm{S}$ : Sterols and triterpene alcohols. Organic Geochemistry 11(6), 463-477.

Vuille M., Bradley R. S., and Keimig F. (2000) Interannual climate variability in the Central Andes and its relation to tropical Pacific and Atlantic forcing. Journal of Geophysical Research 105(D10), 12447-12460.

Wells L. E. (1996) The Santa Beach Ridge Complex: Sea-Level and progradational history of an open gravel coast in central Peru. Journal of Coastal Research 12, 117.

Zhou J. and Lau K.-M. (1998) Does a monsoon climate exist over South America? Journal of Climate 11, 1020-1040. 


\section{Summary}

The contributions of this thesis arise in a large part from the application of recently developed analytical techniques to paleoclimate and organic geochemistry problems. Specifically, development and application of gas chromatography/time-offlight mass spectrometry (GC/TOF-MS), stir bar sorptive extraction (SBSE), and thermal desorption (TD) techniques to molecular stratigraphic research sets the stage for generation of high-resolution multi-molecular records from ice and sediment cores. The methods have been adapted to the specific interests of this thesis, but can be further applied to research in many different environments to address a wide range of paleoclimate and organic geochemistry questions.

Several key findings resulted from this thesis work, and addressed questions about the nature of organic compounds preserved in ice and behavior of El Niño and La Niña since the last glacial period. Investigation of the hydrophobic lipid fraction of alpine ice samples revealed the presence of compounds related to biomass burning that appeared to vary with paleo-aridity conditions in the Sajama ice core. These compounds, which included polycyclic aromatic hydrocarbons (PAHs) and diterpenoids, could thus be used to generate high-resolution proxy records of forest fire occurrences. Sterol records from Peru Margin sediments provided information about upwelling and dinoflagellate productivity over the last $15 \mathrm{ka}$, which was then used to infer variability in El Niño and La Niña, respectively. The results implied that the strength and/or frequency of both El Niño and La Niña were diminished throughout the early Holocene and increased abruptly at about $6.5 \mathrm{ka}$. The following time period was marked by generally enhanced activity of both phenomena with superimposed millennial-scale variability. These findings reinforce previous ideas of El Niño behavior during the Holocene, but suggest a new mode of La Niña variability. When compared with other tropical 
paleoclimate studies, the Peru Margin results suggest broad-scale changes in Holocene tropical climate, likely associated with ENSO and trade wind variability.

Several analytical challenges remain with respect to the techniques used in this thesis, largely pertaining to the measurement of biomarkers in ice. A priority for further studies will be reducing the blank level contamination. The results described in Chapter 3 suggest that a large part of the contamination may arise from the laboratory water used for the blank samples. A detailed investigation of the organic content of the Milli-Q water, methanol, and $\mathrm{HCl}$ used for these analyses is warranted, as is further consideration of carryover both on the stir bars and within the TD system itself. Improvements to SBSE efficiency may be achieved through addition of salt to sample solutions and through use of Teflon vials as extraction vessels in order to reduce adhesion of analytes to vial walls. These techniques will be explored before further down-core analyses proceed. Lastly, development of an effective in situ derivatization procedure will increase the analytical window afforded by SBSE and TD/GC/TOF-MS by allowing identification and quantification of polar analytes, such as long-chain $\left(\geq C_{24}\right)$ fatty acids, and a wider range of biomass burning indicators.

Future research arising from this thesis involves continuing improvement of the analytical techniques, and their further application to paleoclimate problems. Identification of biomarkers in ice via SBSE and TD/GC/TOF-MS sets the stage for development of high-resolution down-core records. Records such as these could provide information about abrupt changes in atmospheric circulation, forest fire frequency, vegetation characteristics, and anthropogenic activities. The high-resolution multimolecular stratigraphic records generated via GC/TOF-MS can be applied to a variety of different settings or problems, including marine and lacustrine sediments. Consistent with the aim of this thesis, these types of organic geochemical records could be used to further constrain tropical climate variability throughout the Holocene and earlier, providing a more detailed understanding of climate processes that affect human life and endeavors and may play a strong role in future climate change stemming from rising atmospheric $\mathrm{CO}_{2}$ levels. 
Appendix A 


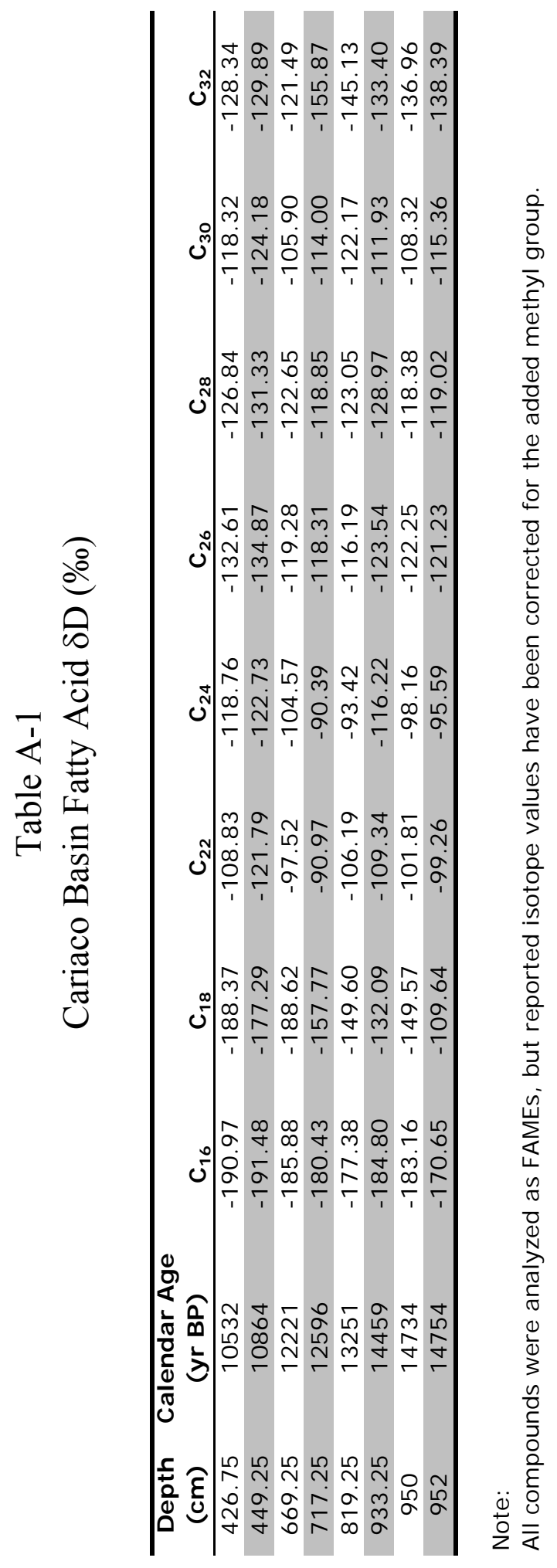




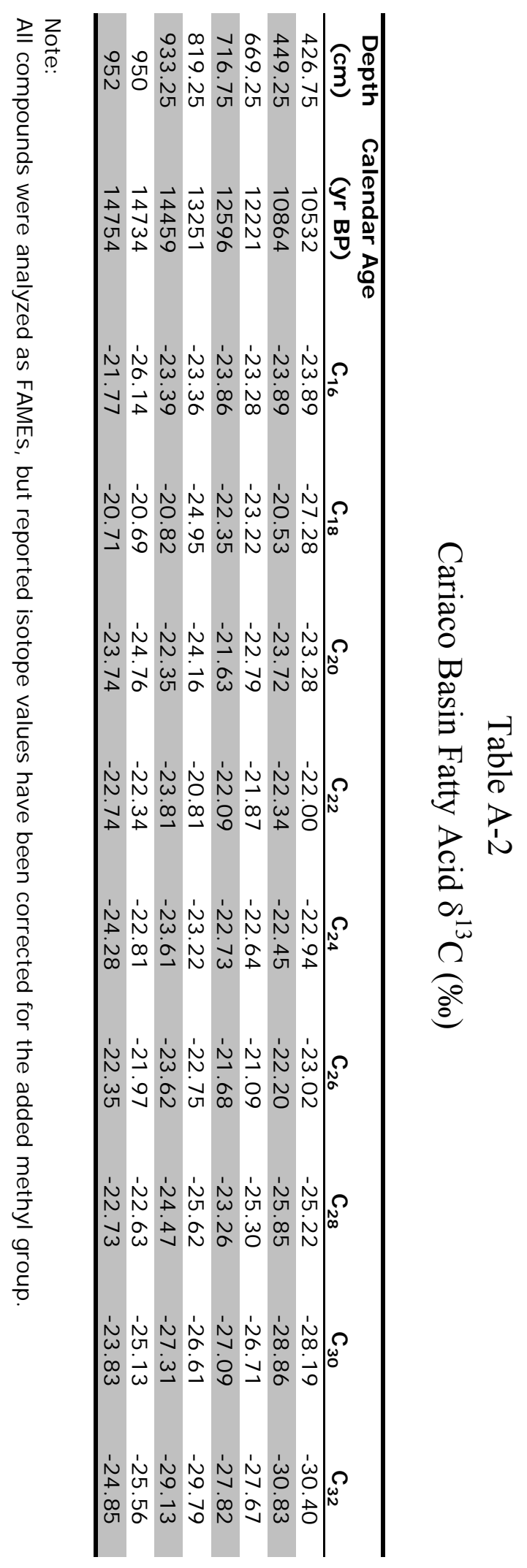




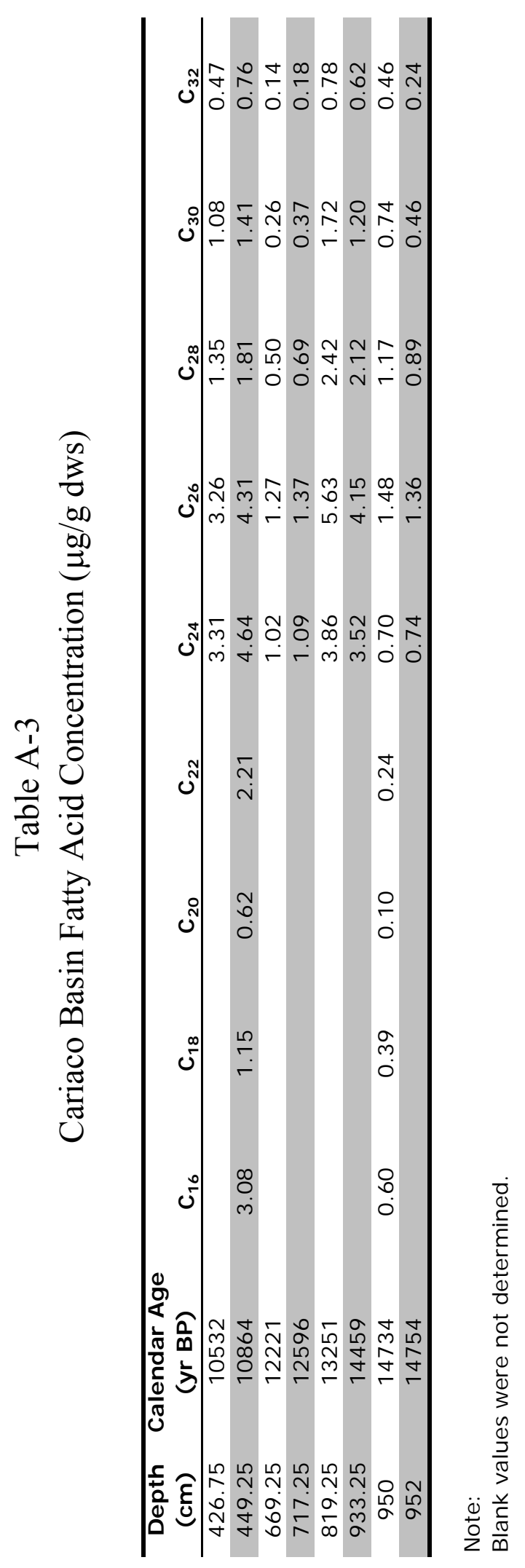


Appendix B 
Figure B-1

Twister Recovery of Free Fatty Acids for Varying \% $\mathrm{MeOH}$

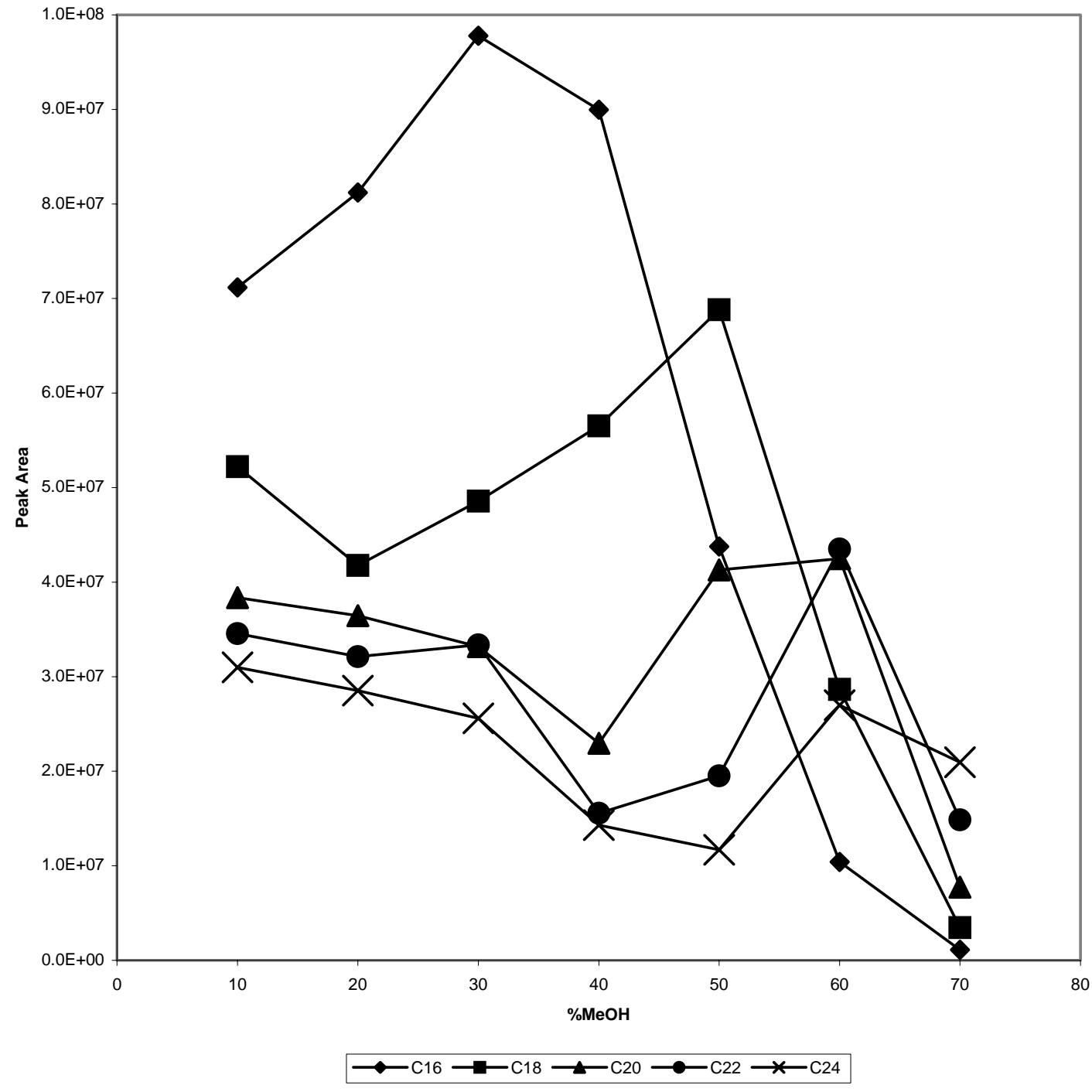


Figure B-2

Ice Core External Standard Chromatogram

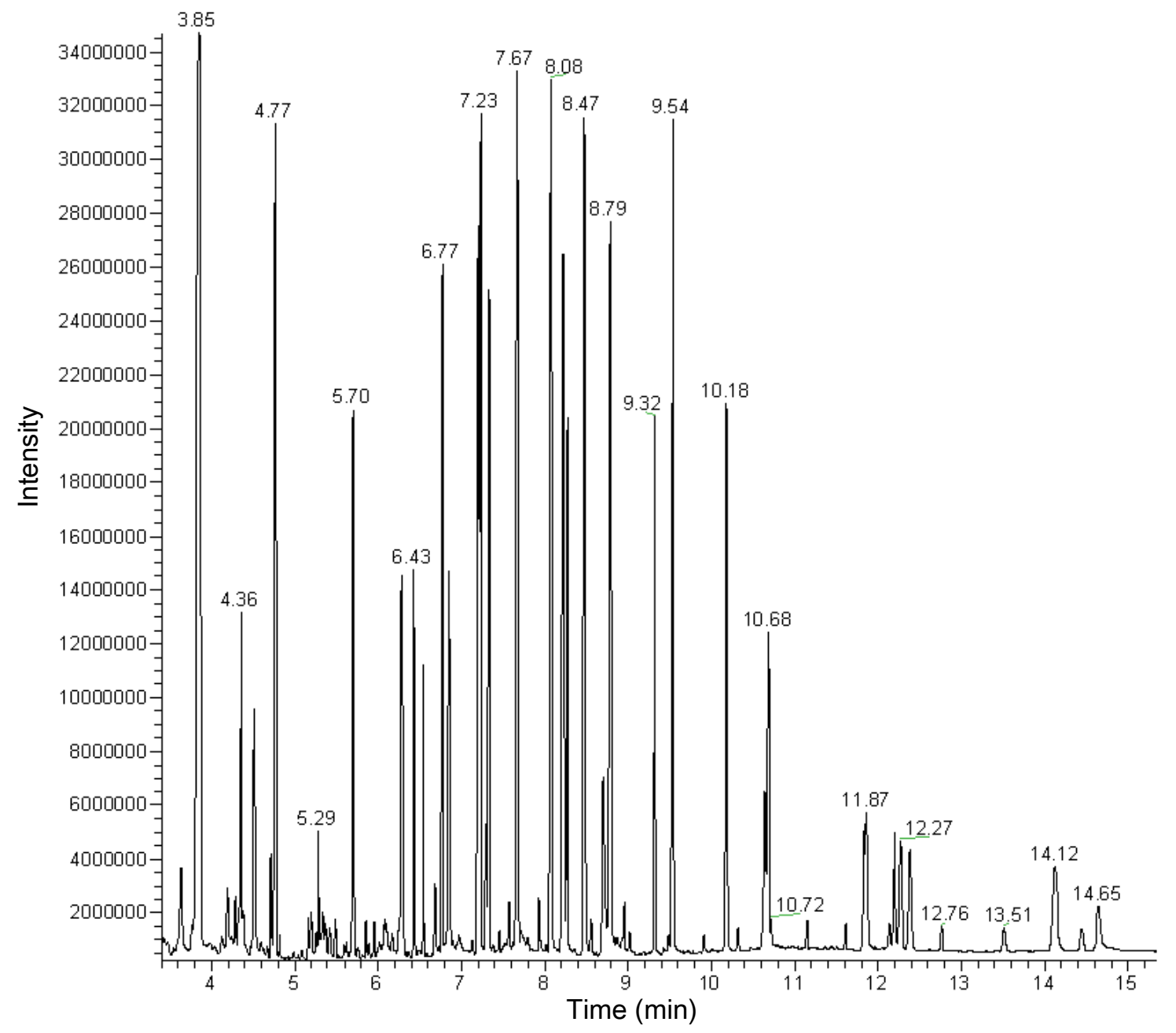


Figure B-3

Sajama Ice Core $n$-Alkane EIC

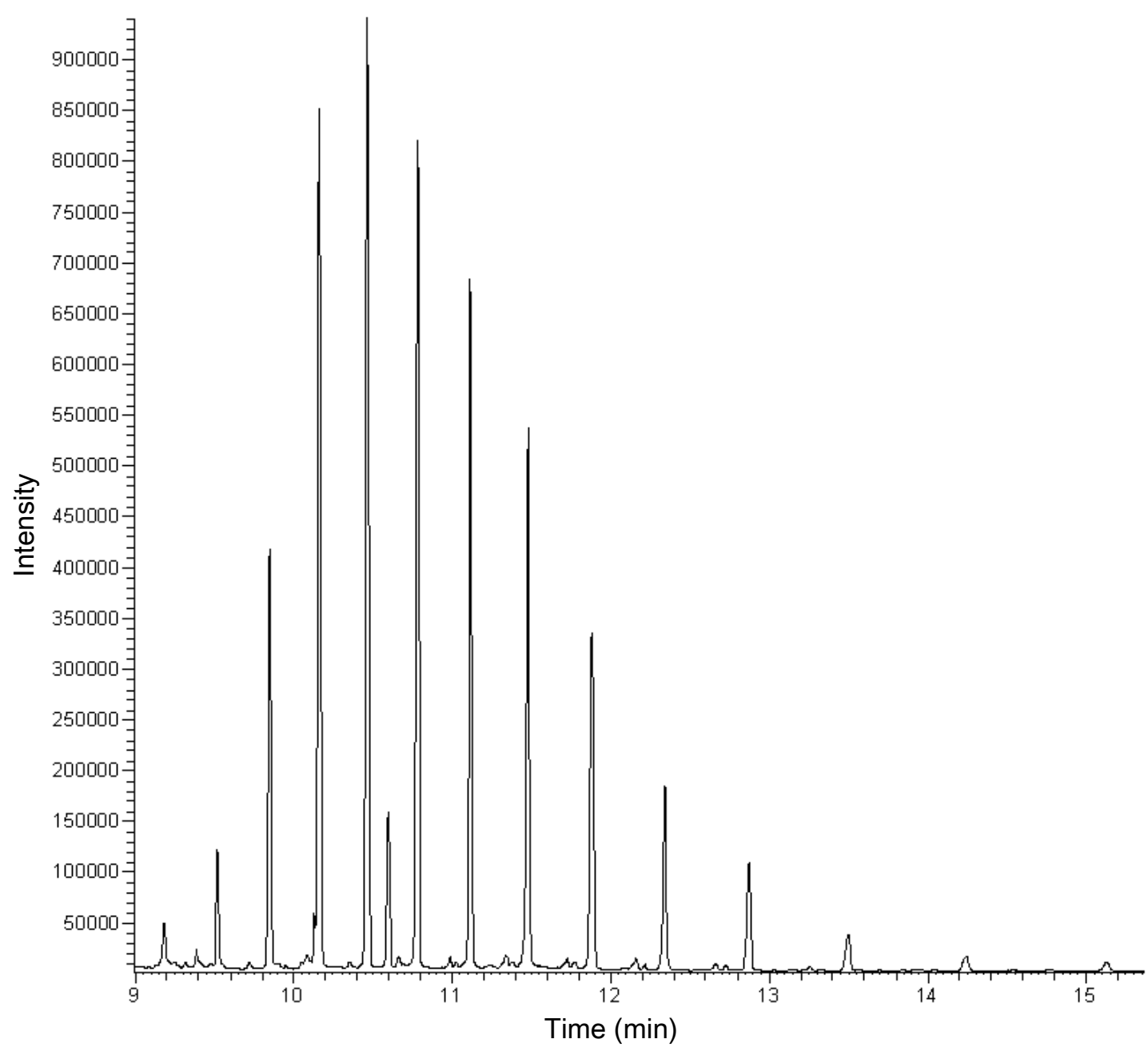


Figure B-4a

Free Fatty Acid Standard

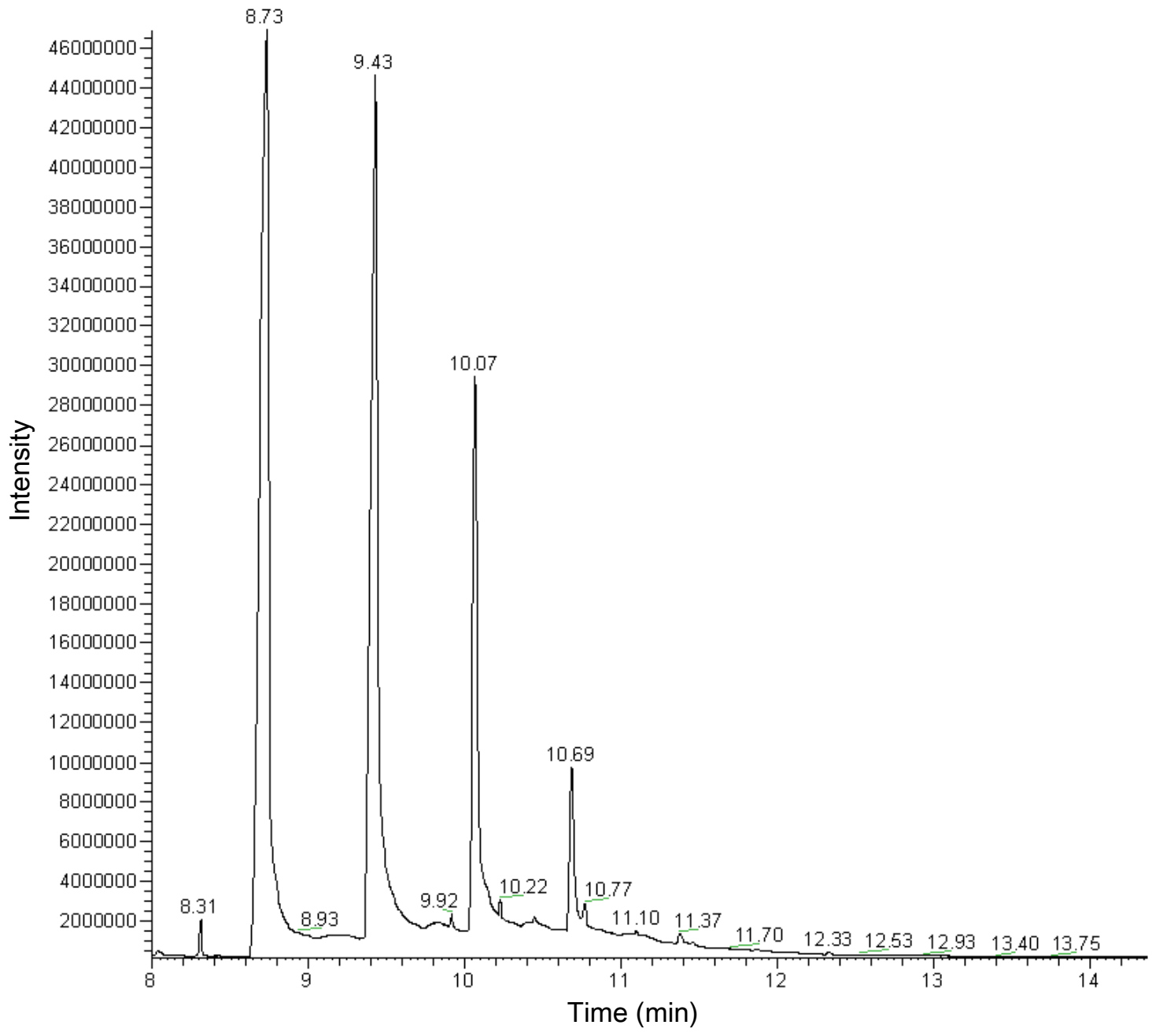


Figure B-4b

Fatty Acid Standard Analyzed as Methyl Esters

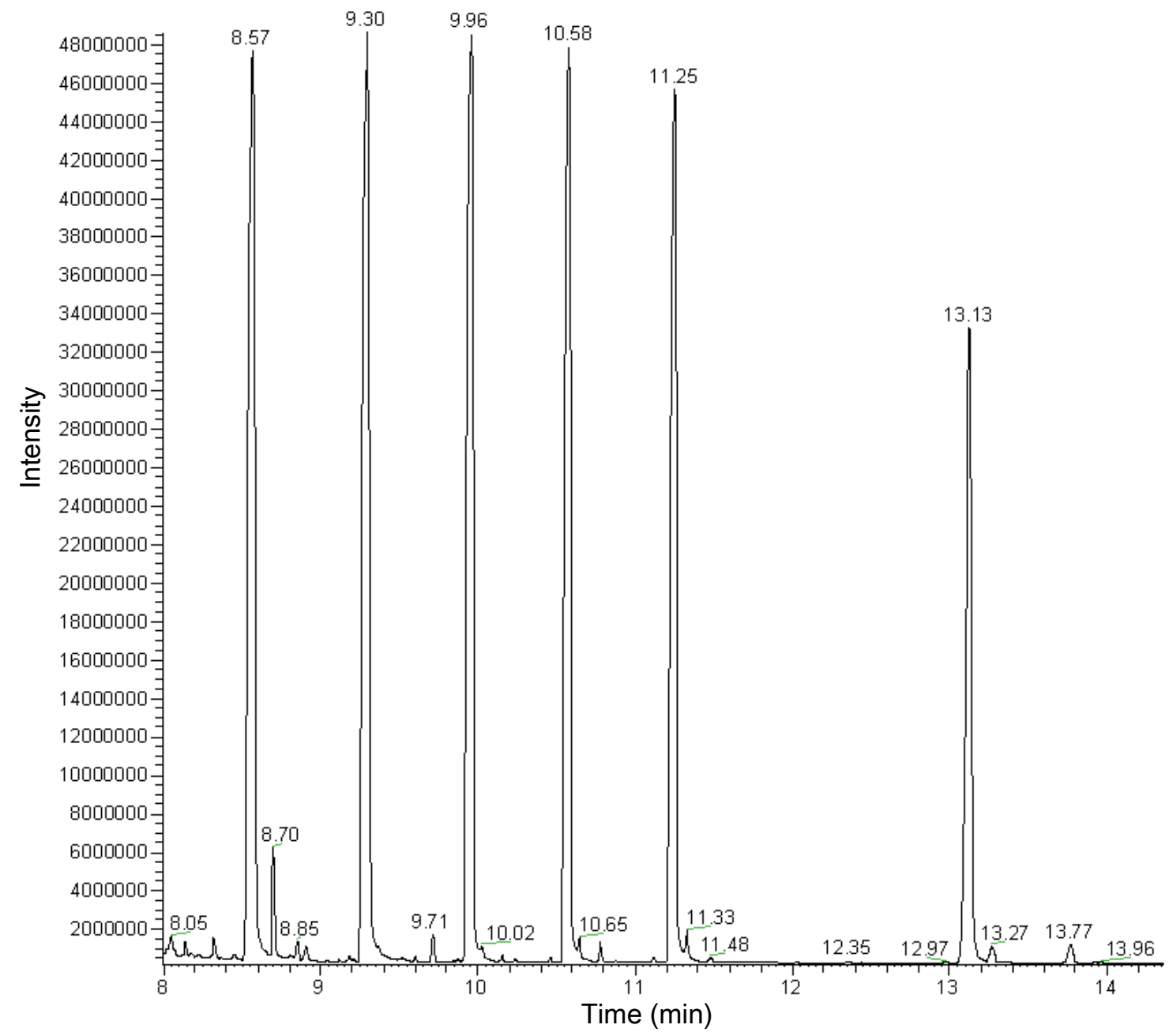


Figure B-5a

Thermally Desorbed Filter, Huascarán Modern Sample

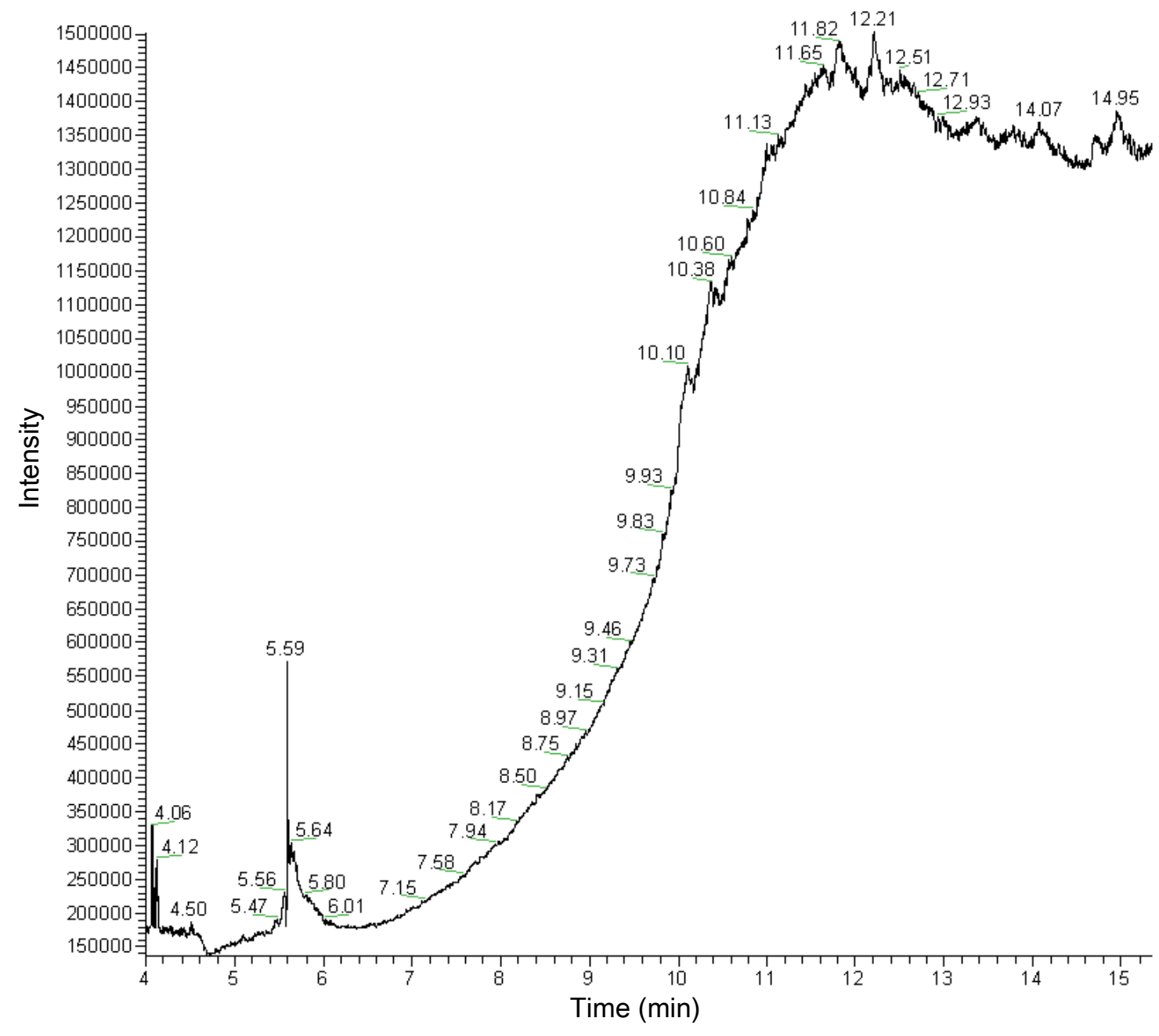


Figure B-5b

Thermally Desorbed Filter, Sajama Modern Sample

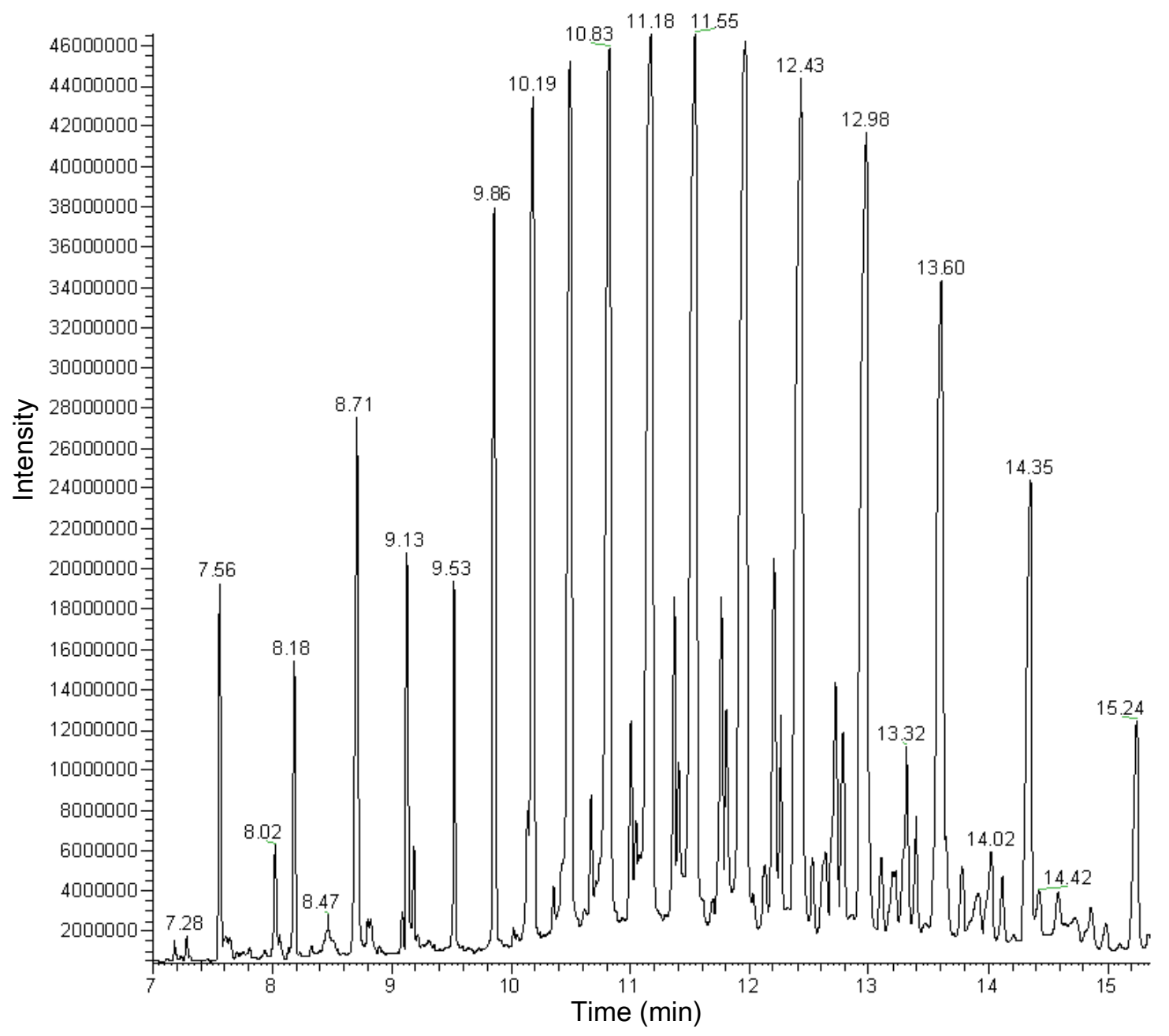


Ice Core Biomarker Mass Spectra (as Analyzed) 


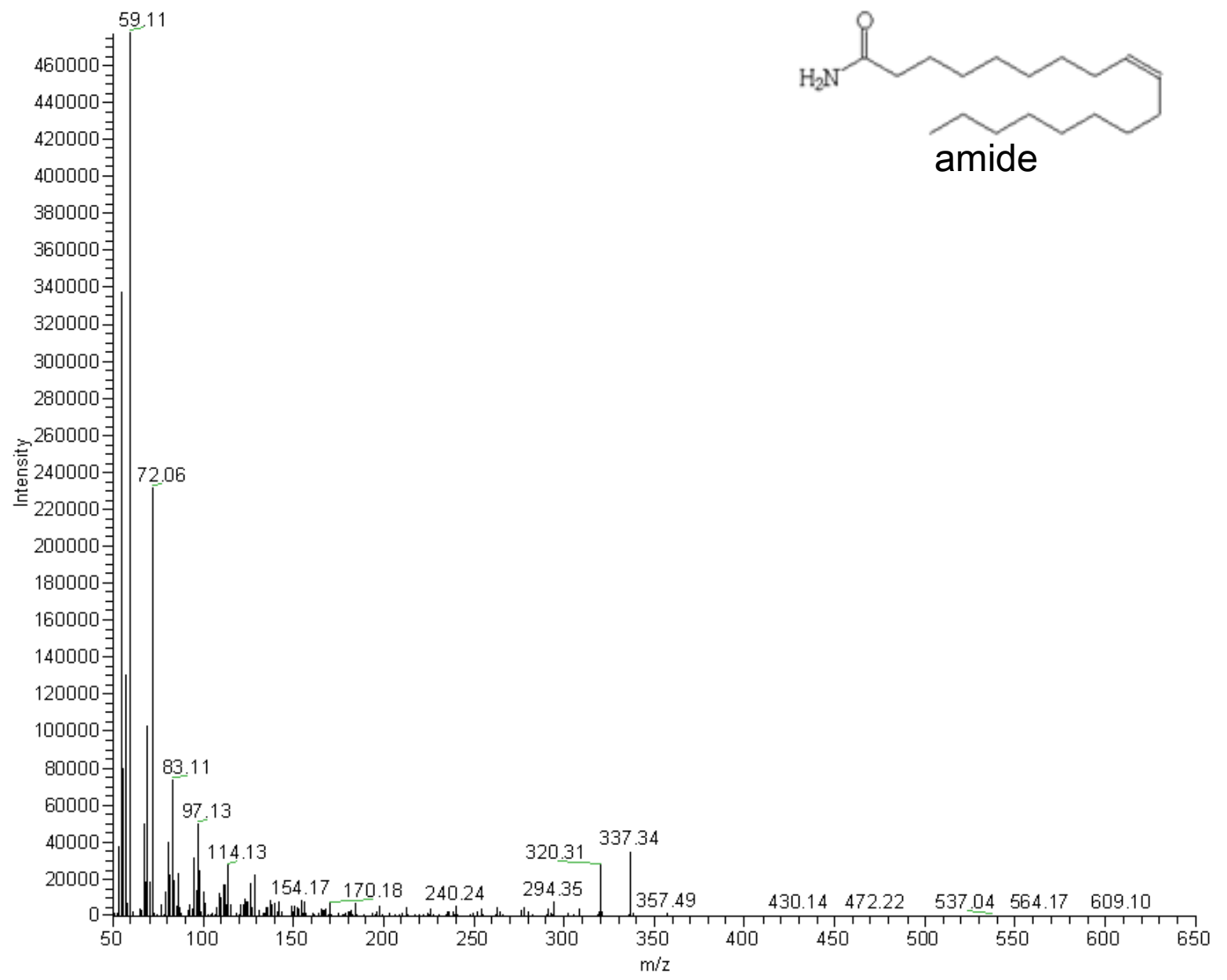




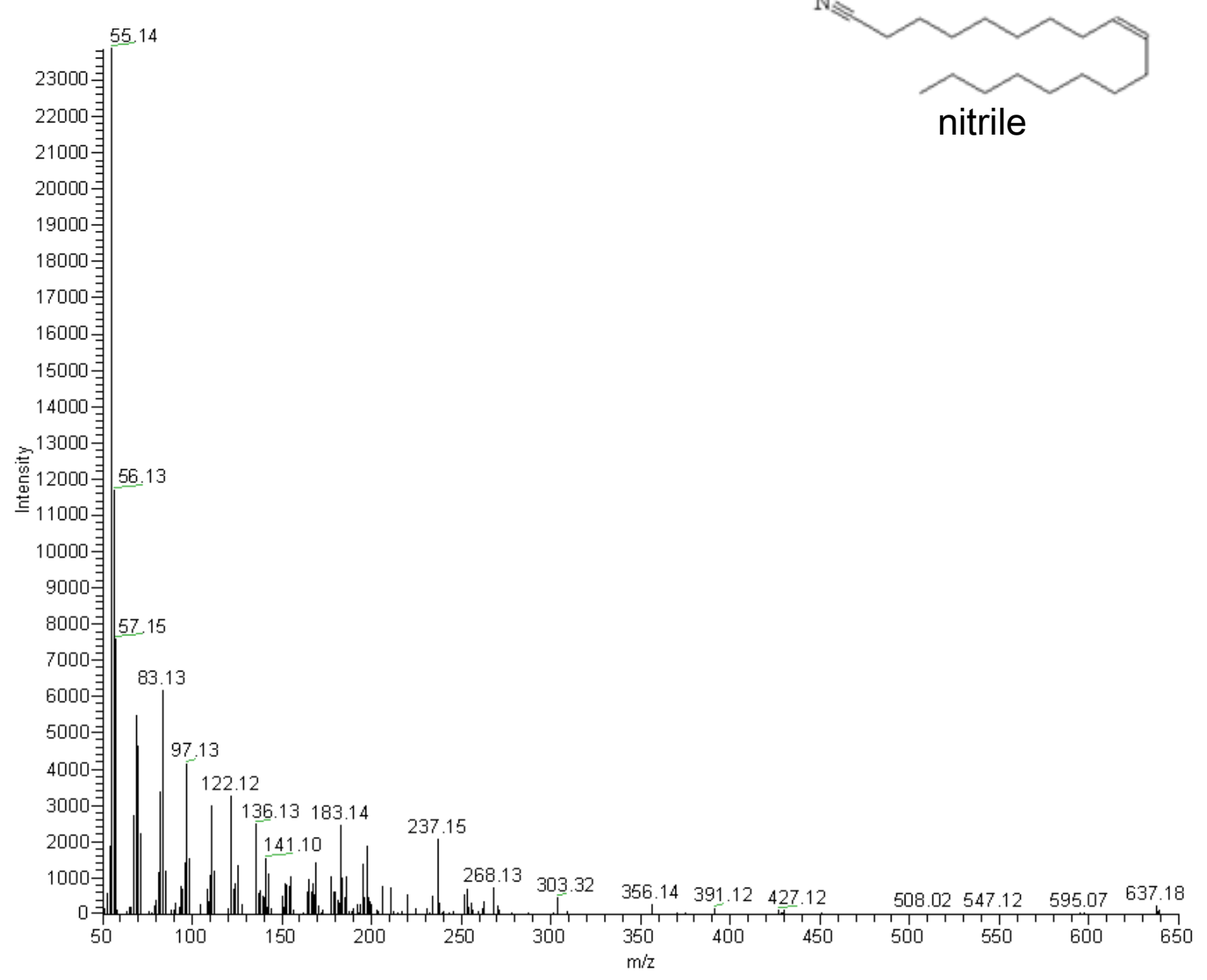




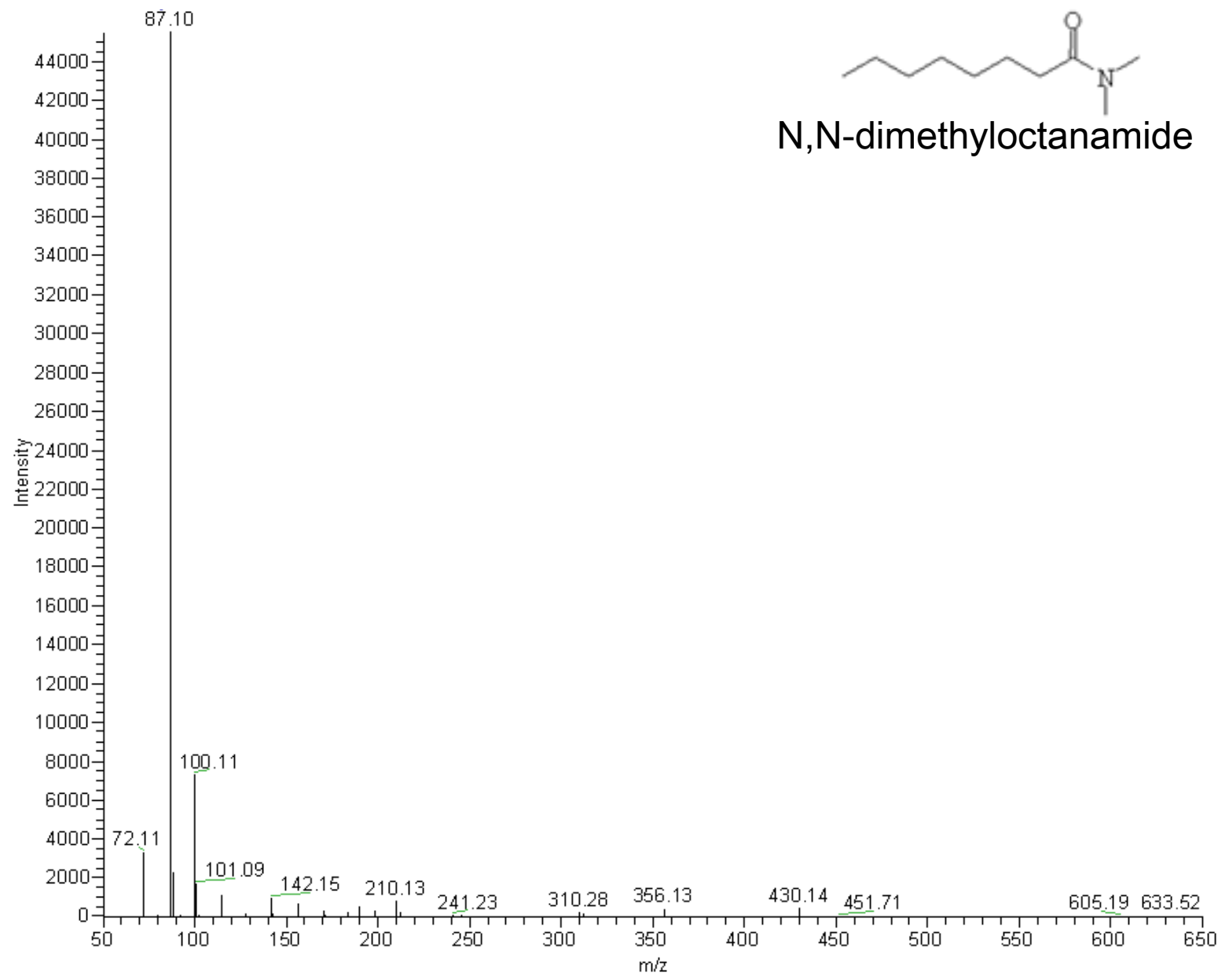




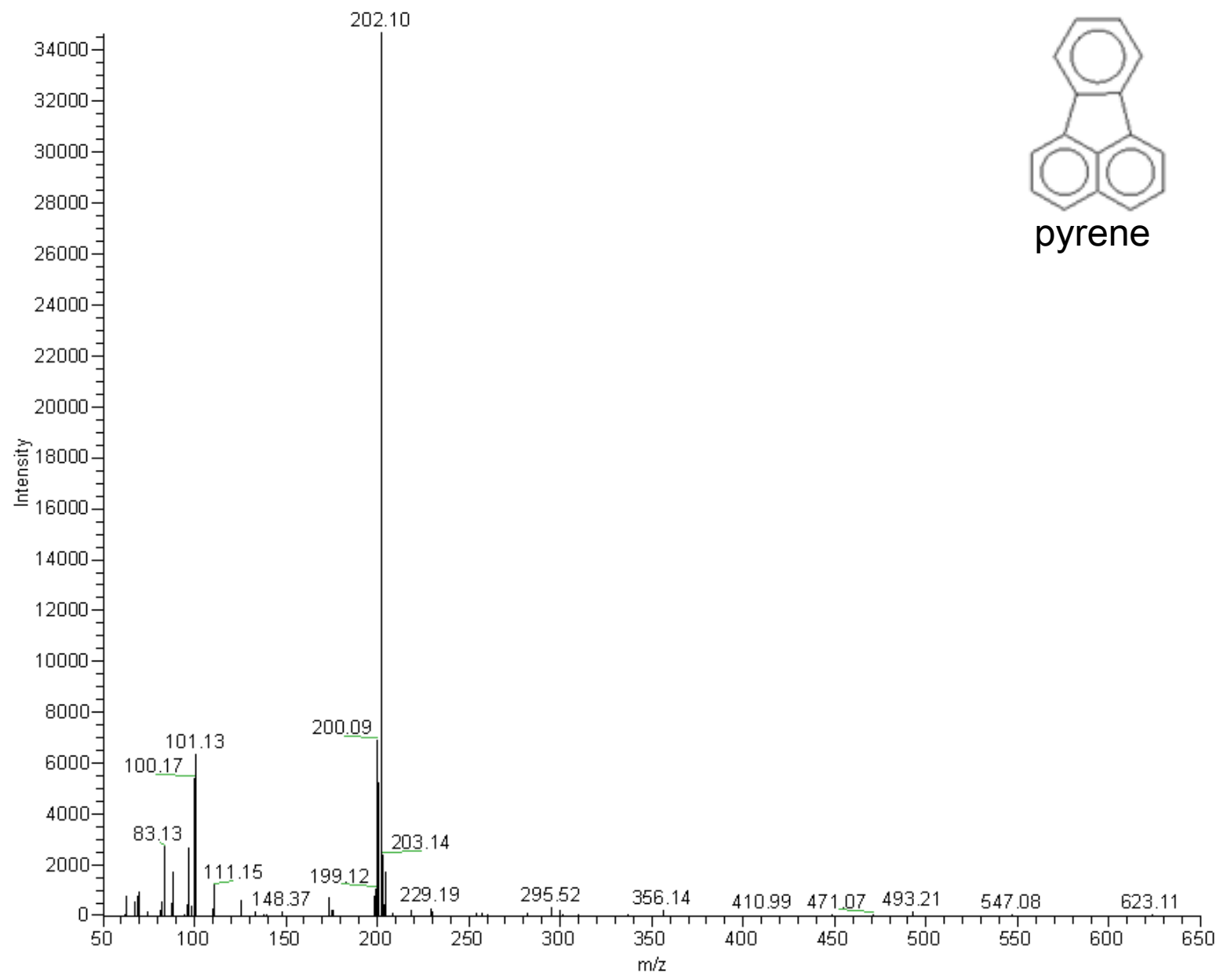




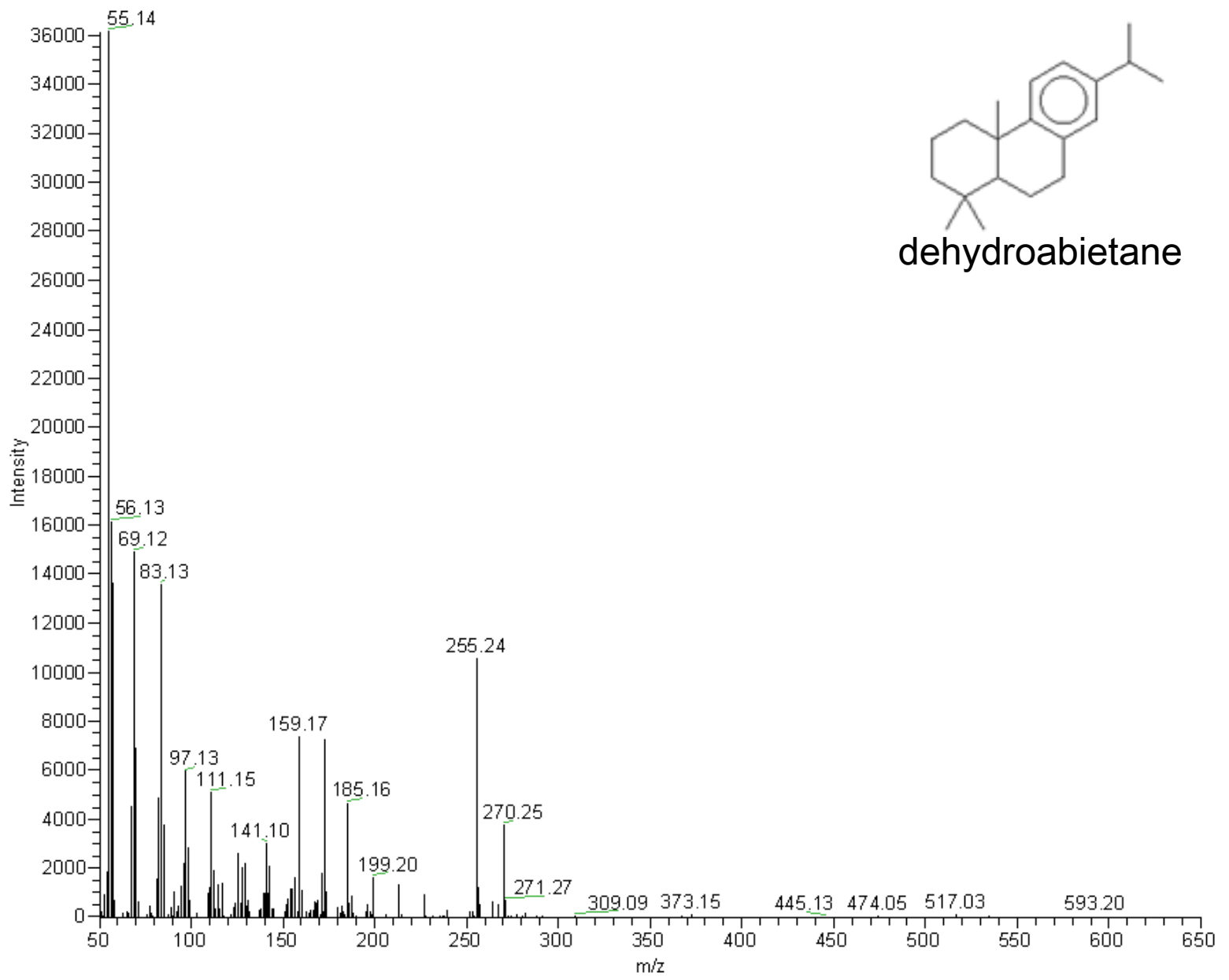




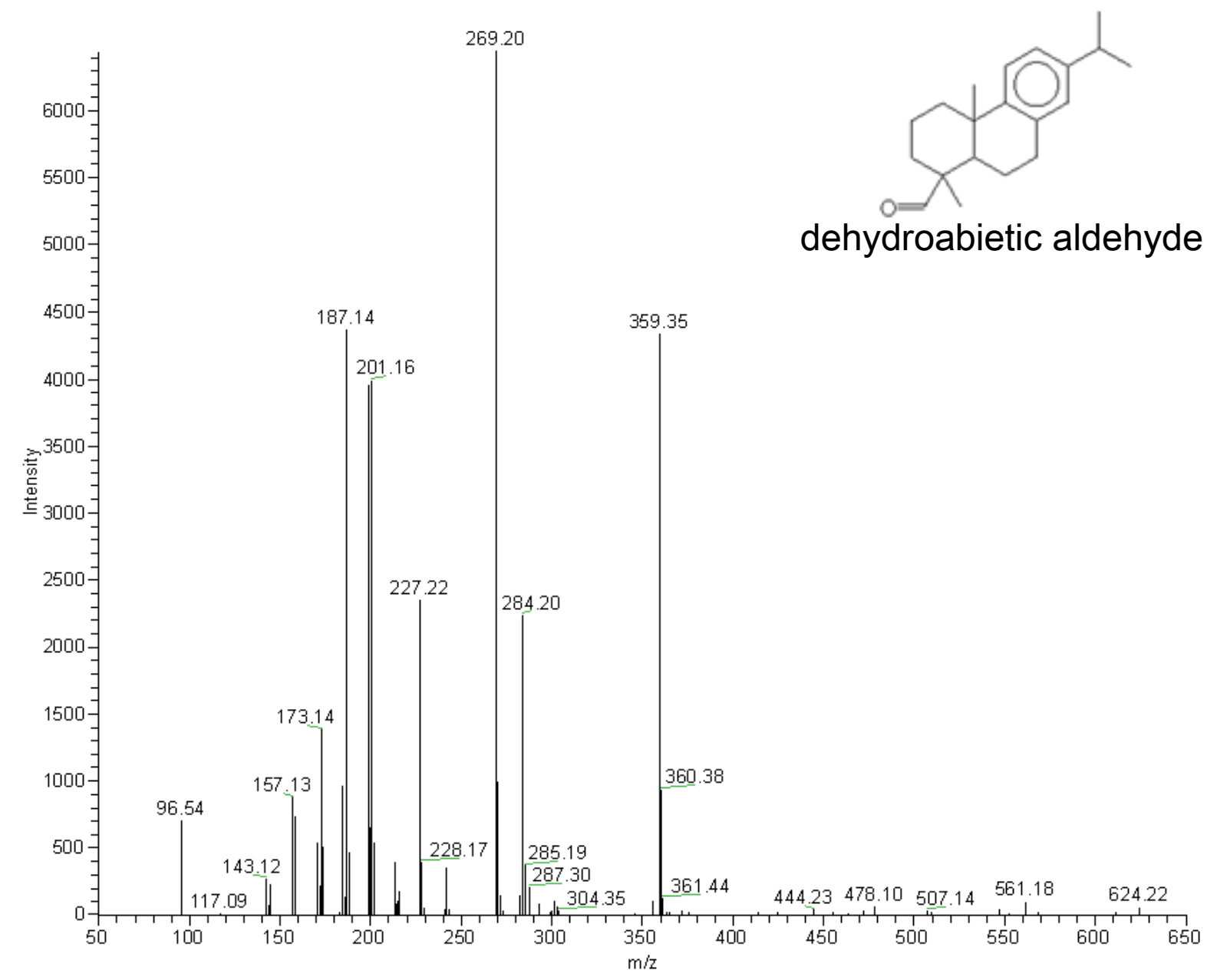




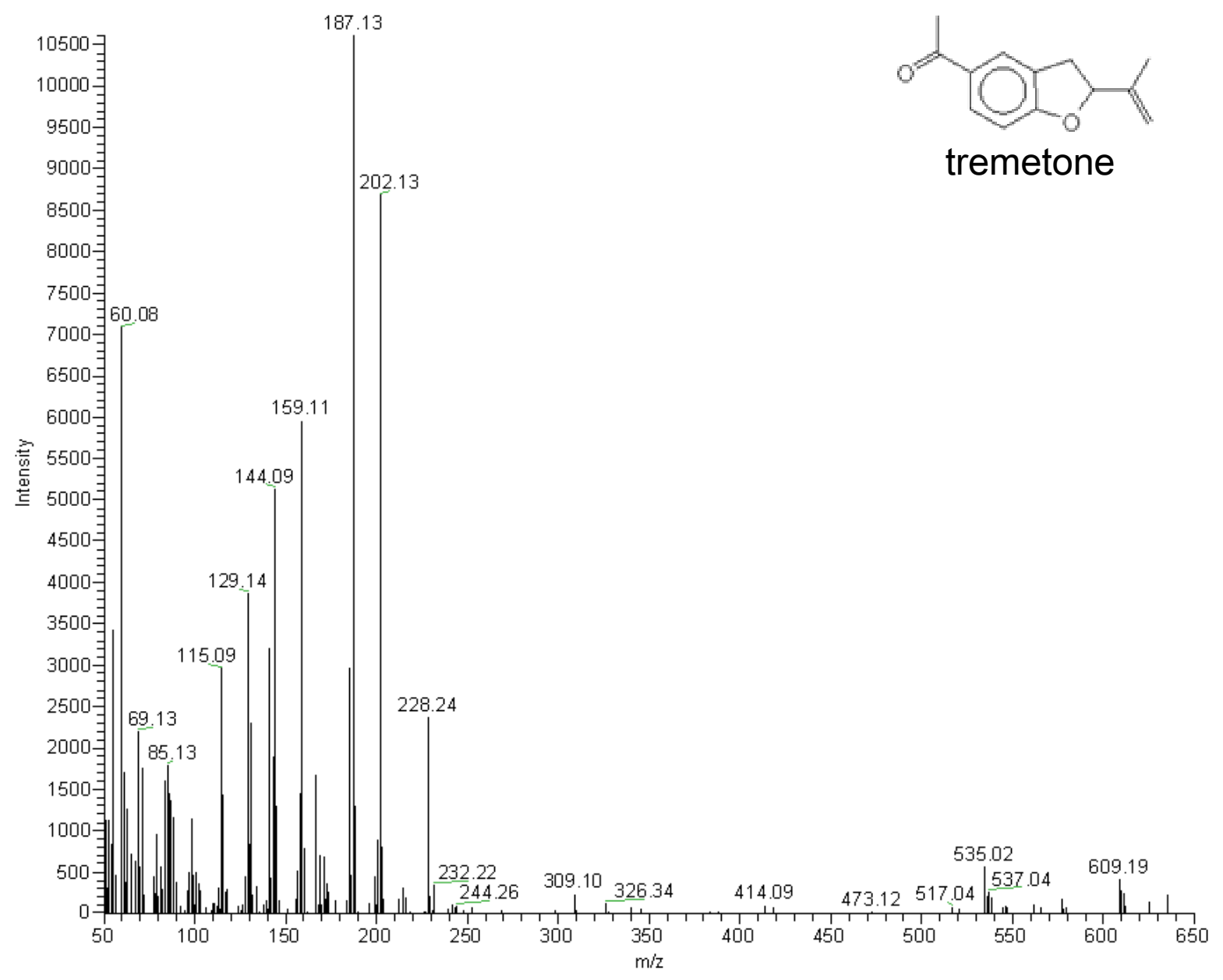




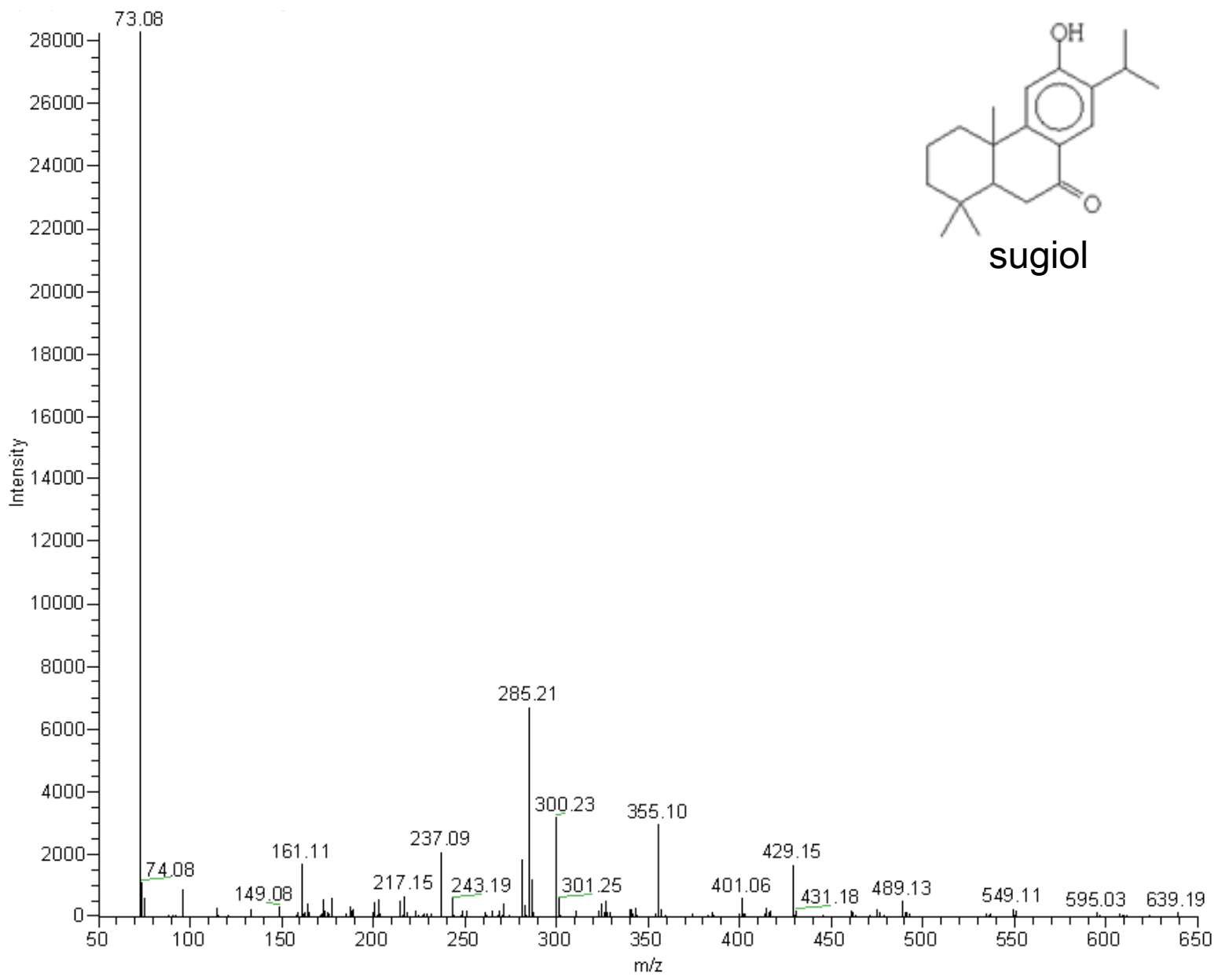


Appendix C 


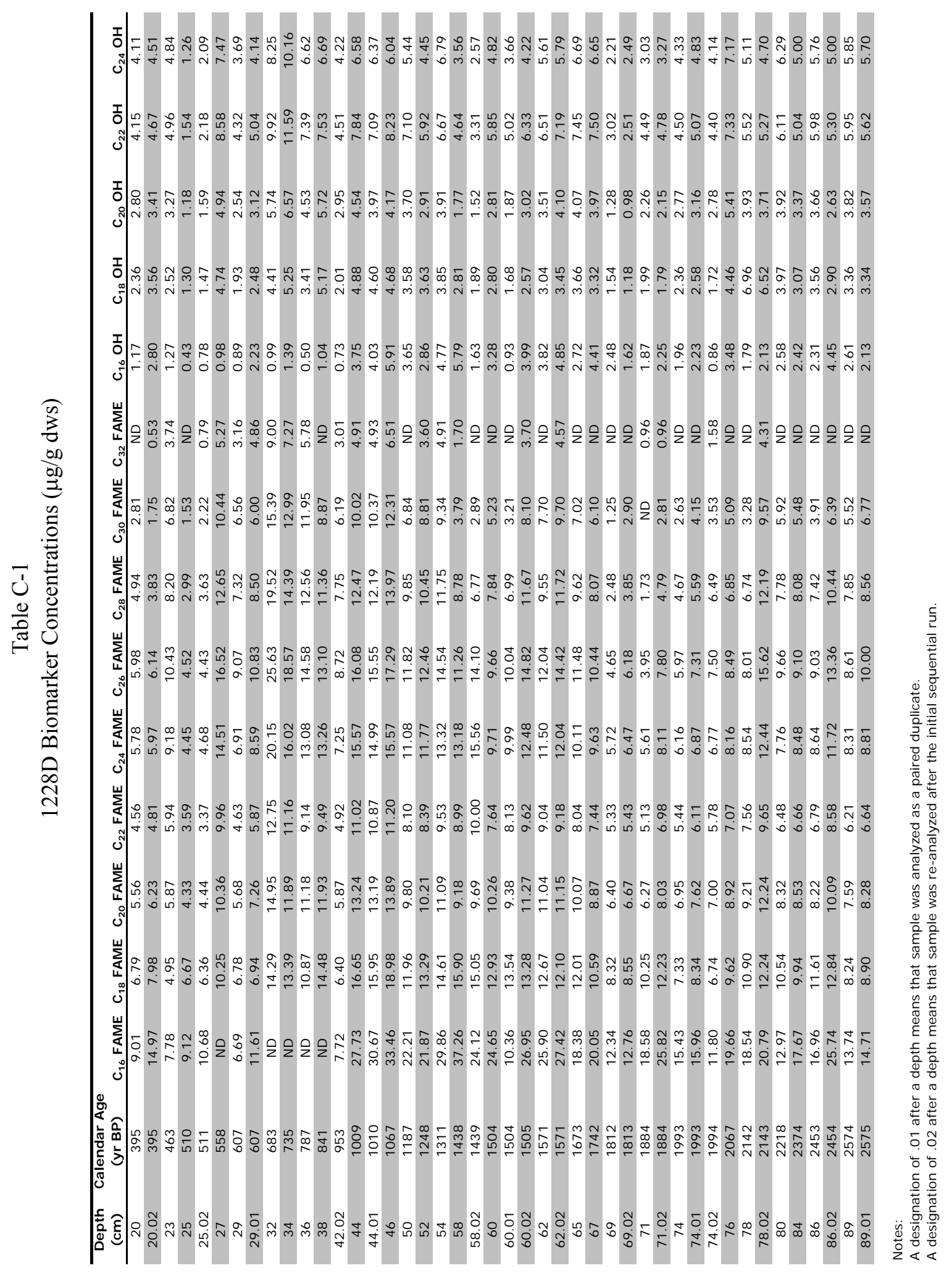




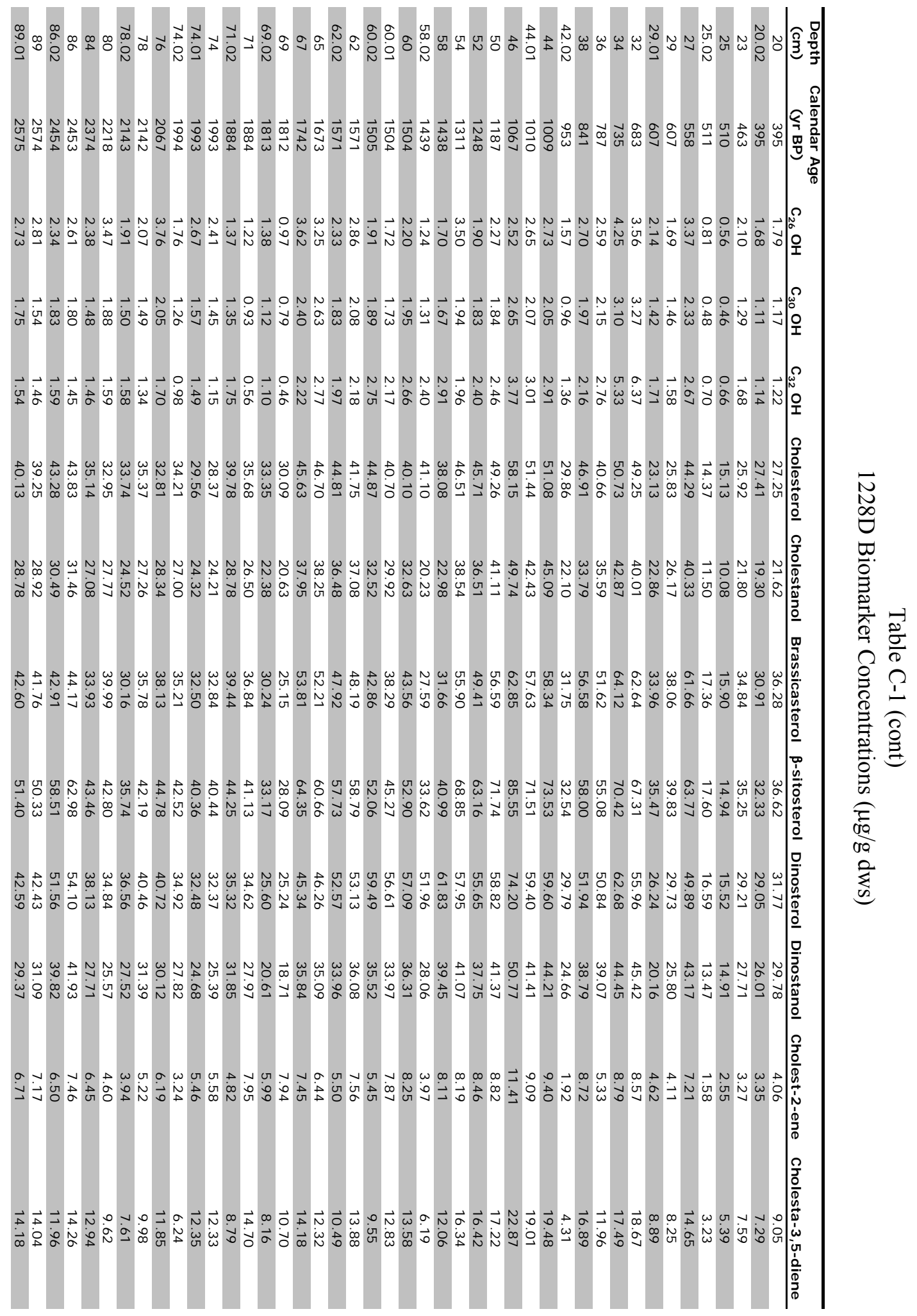




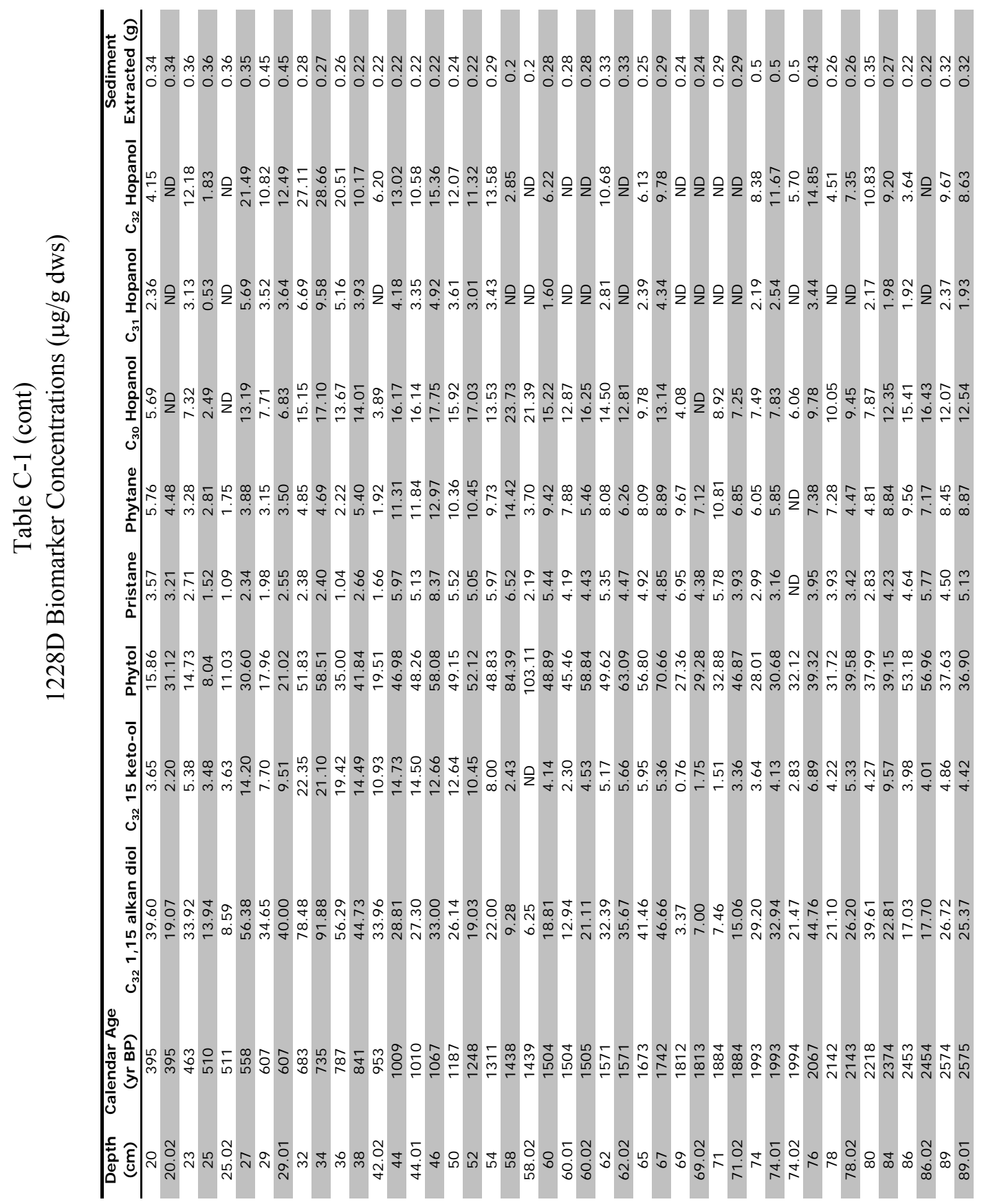




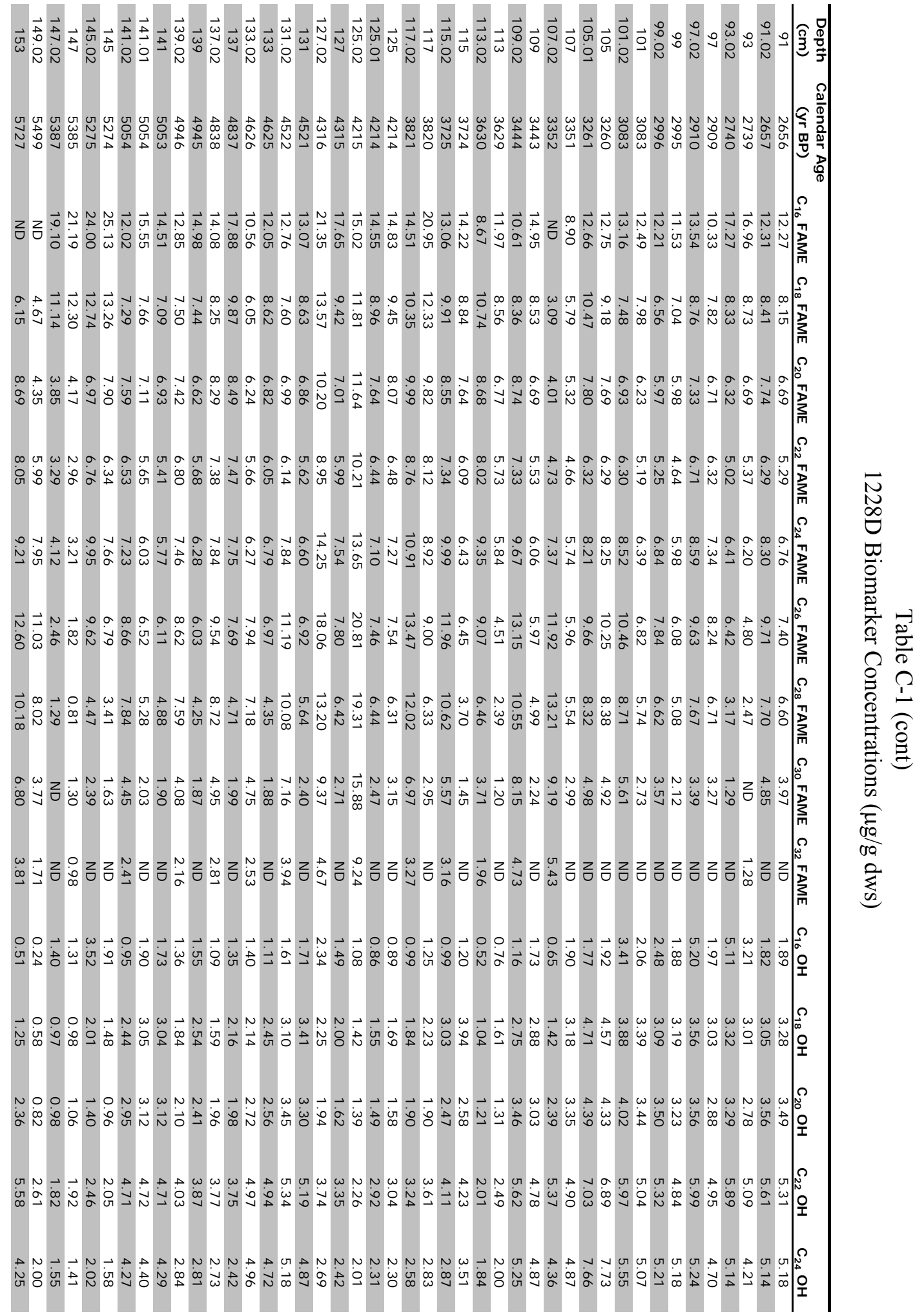




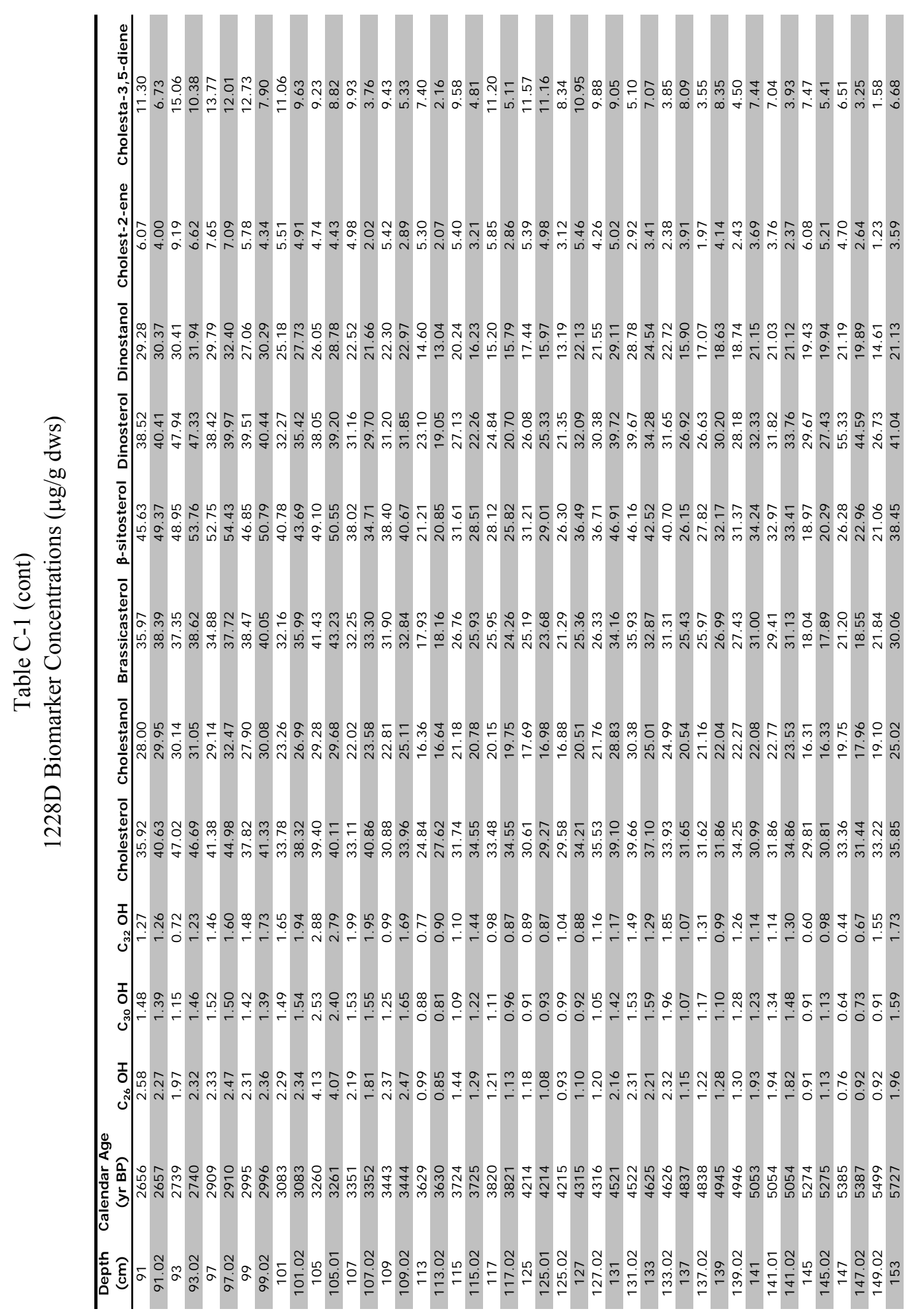




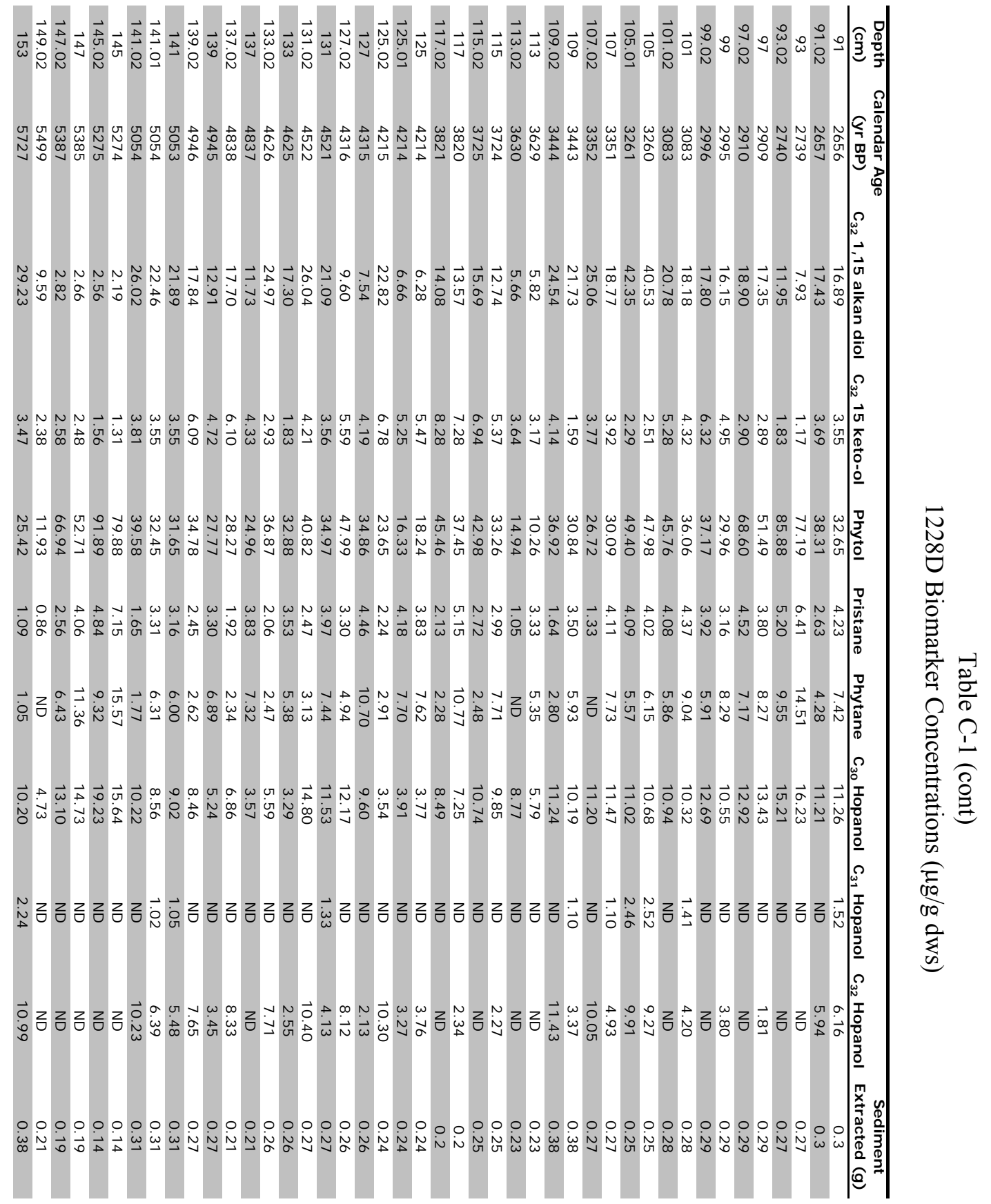




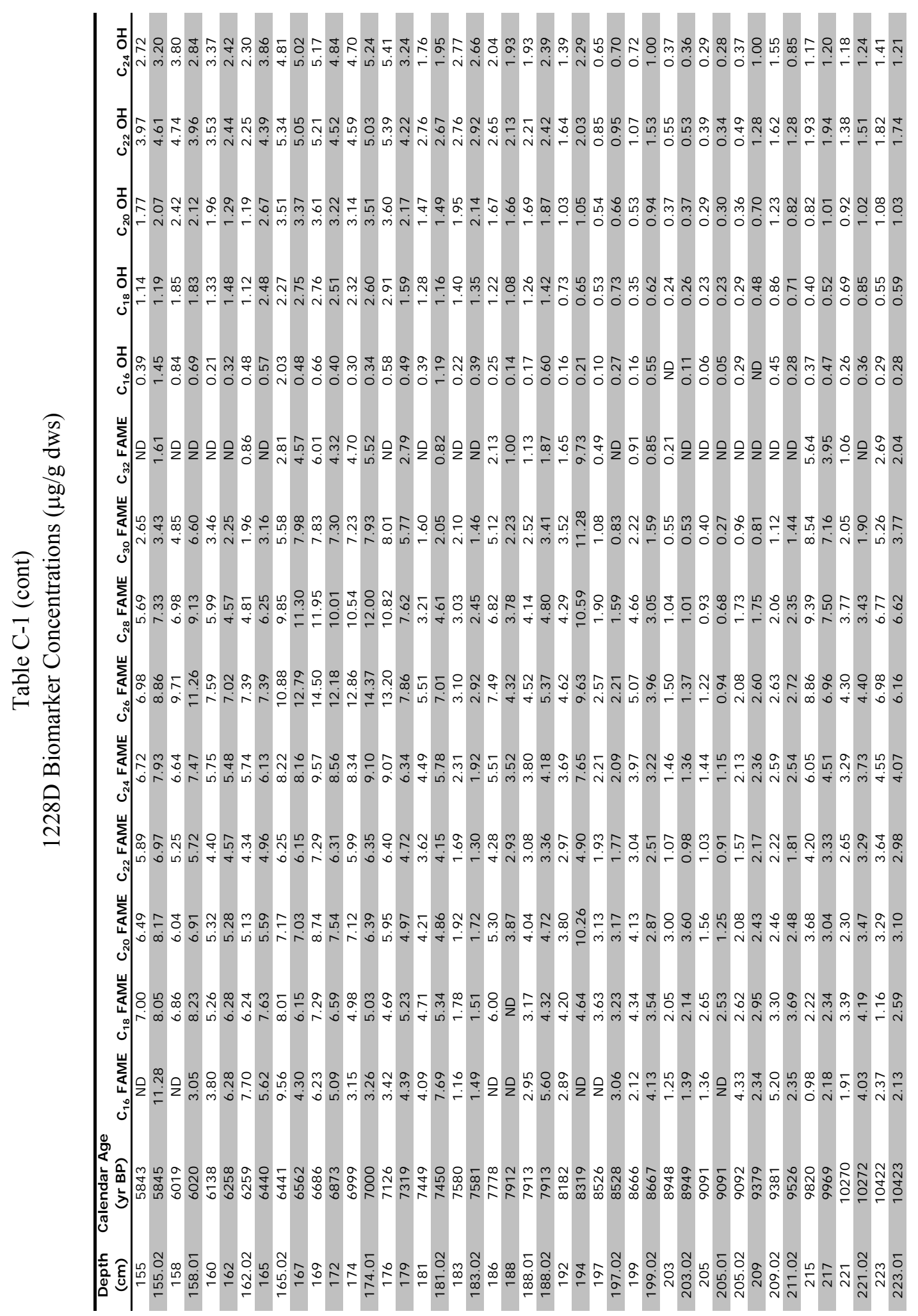




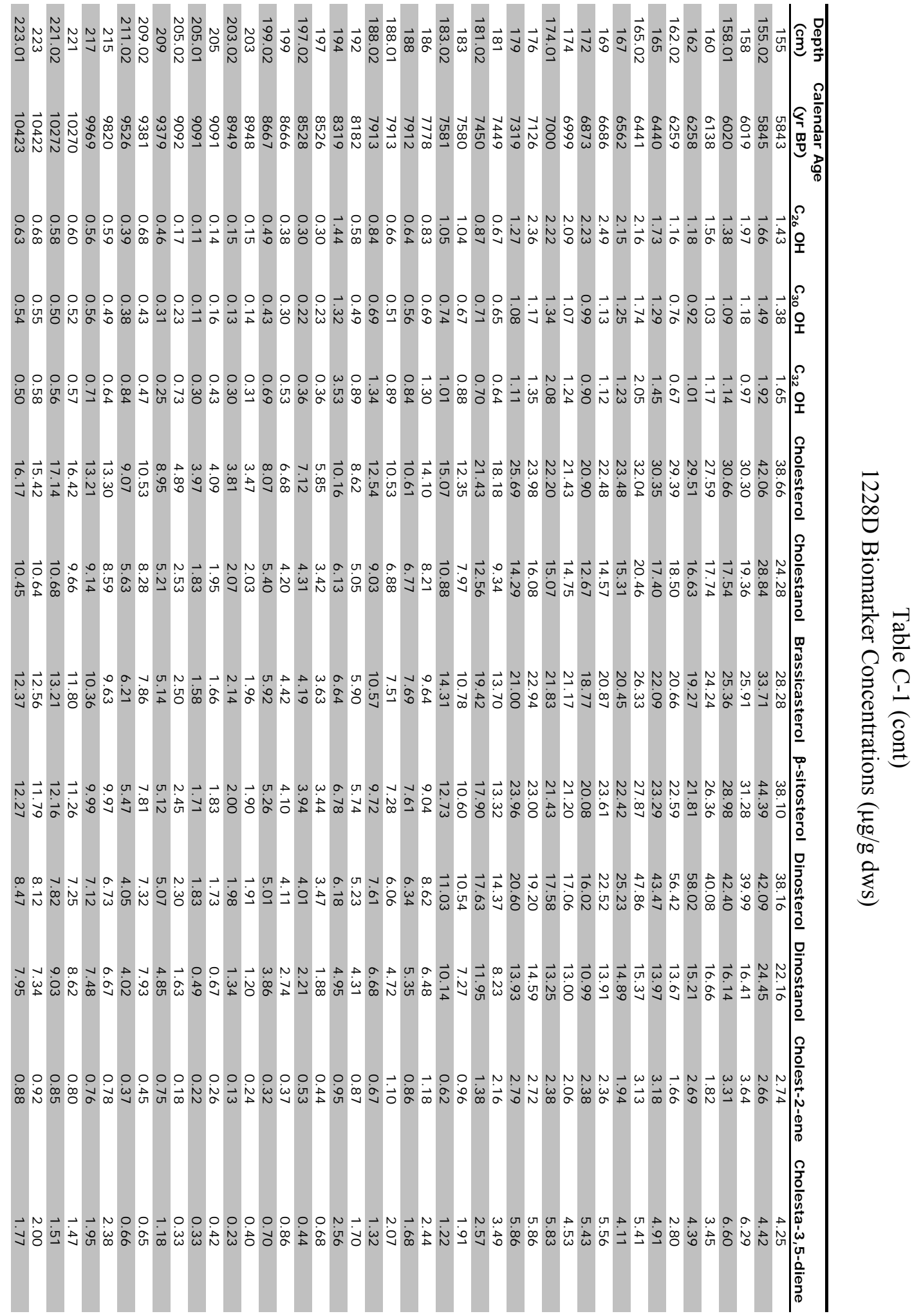




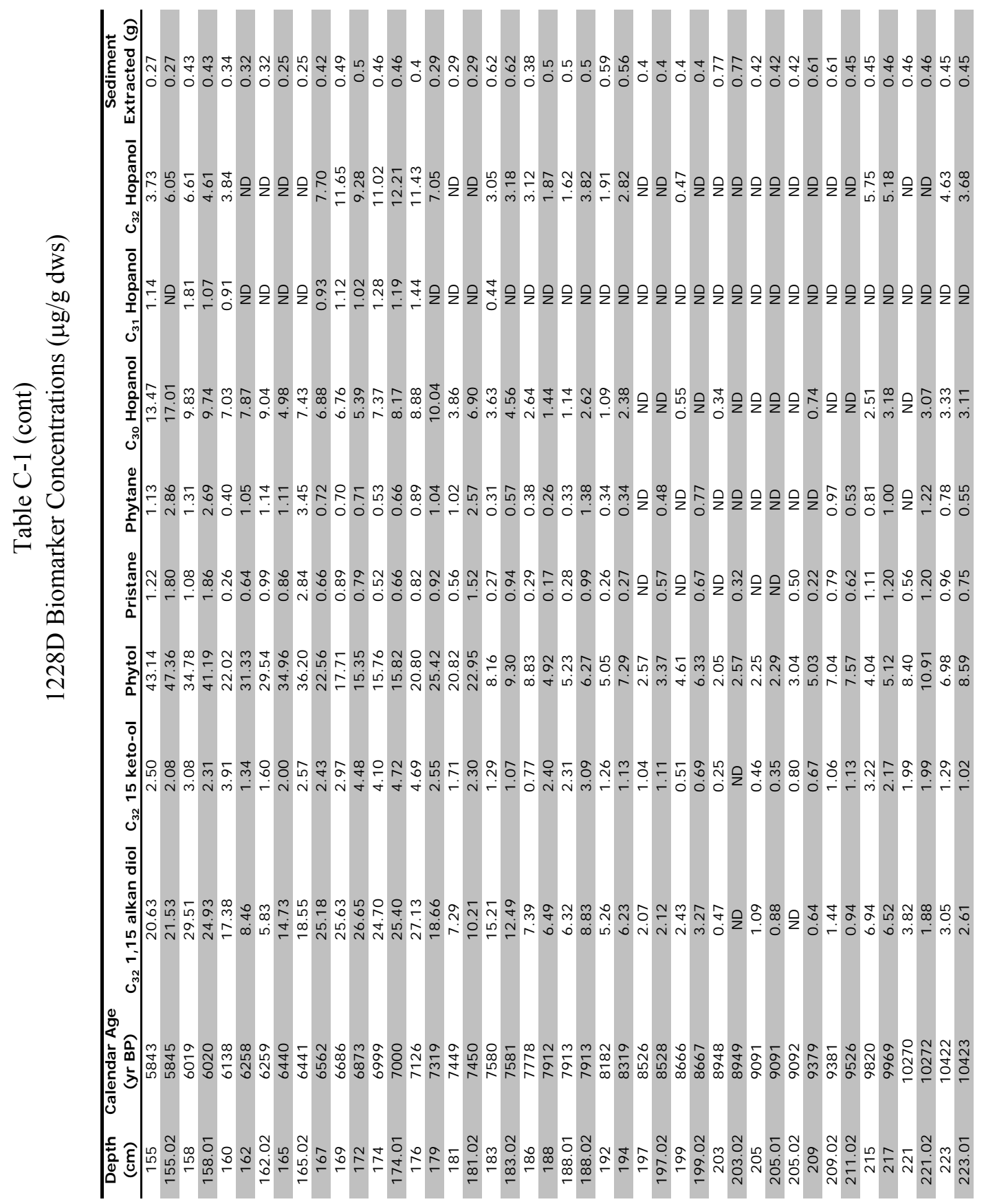




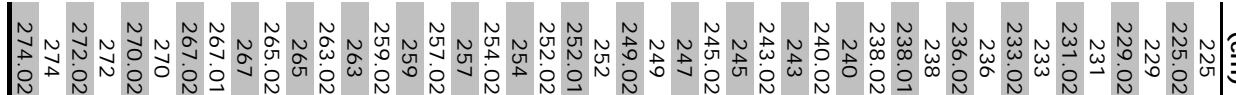

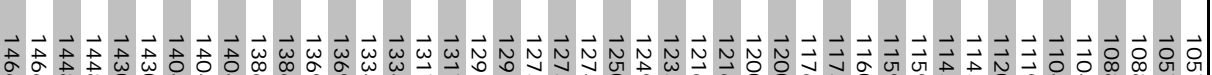

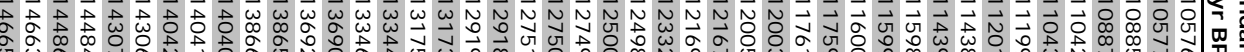

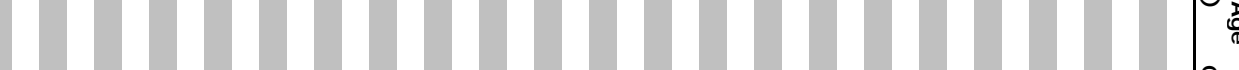

N

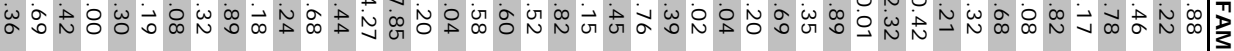

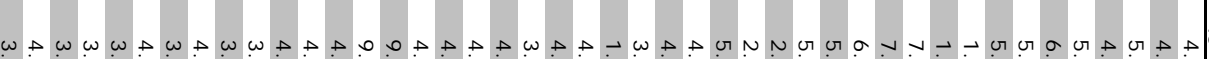

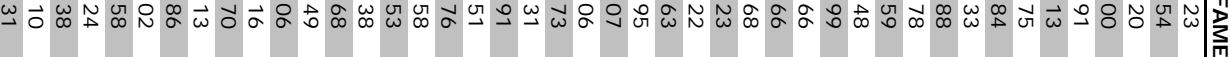

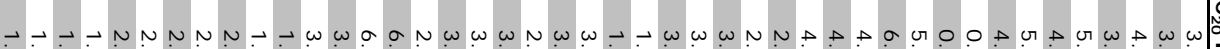

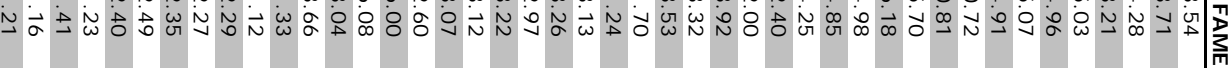

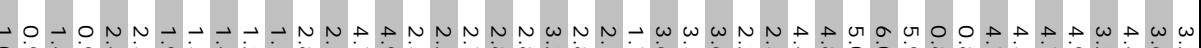

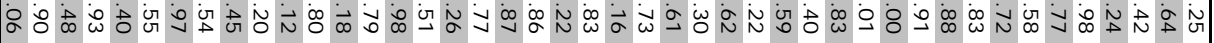

Ho ron

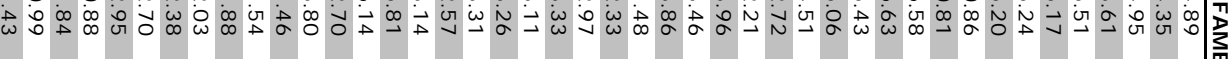

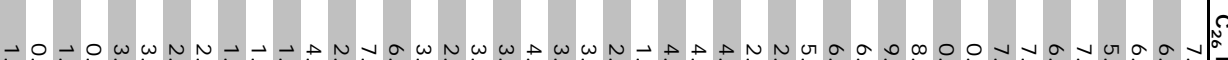

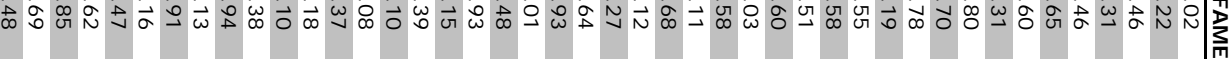

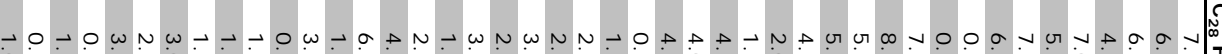

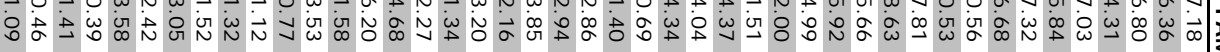

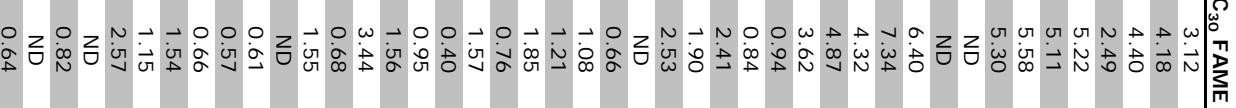

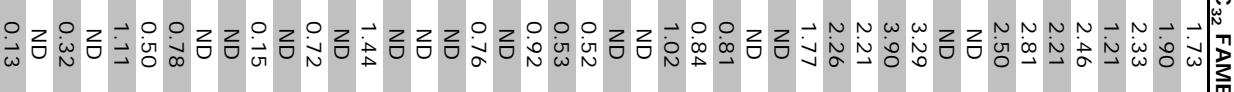

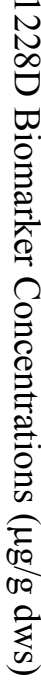

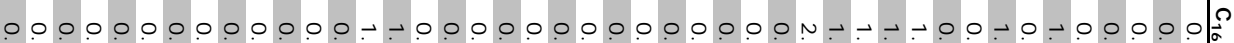

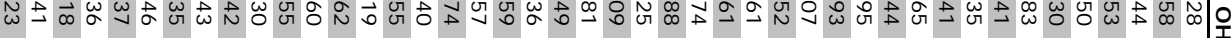

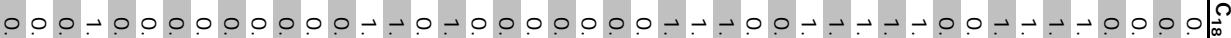

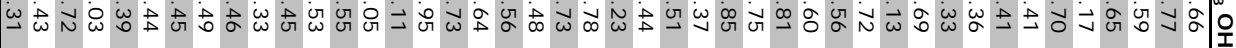

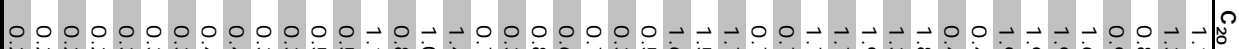

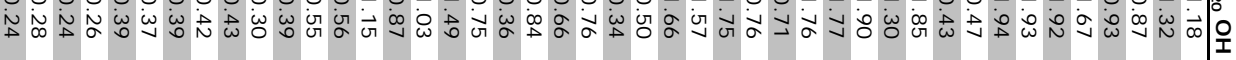

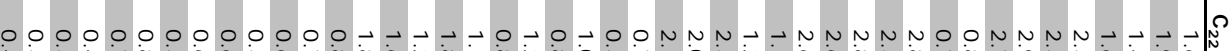

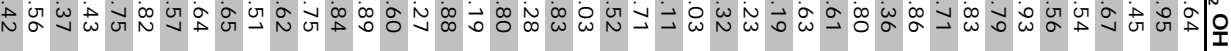

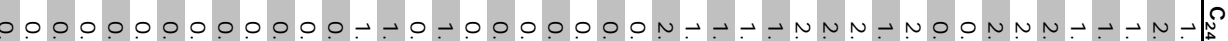

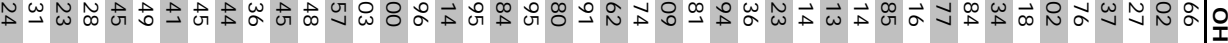




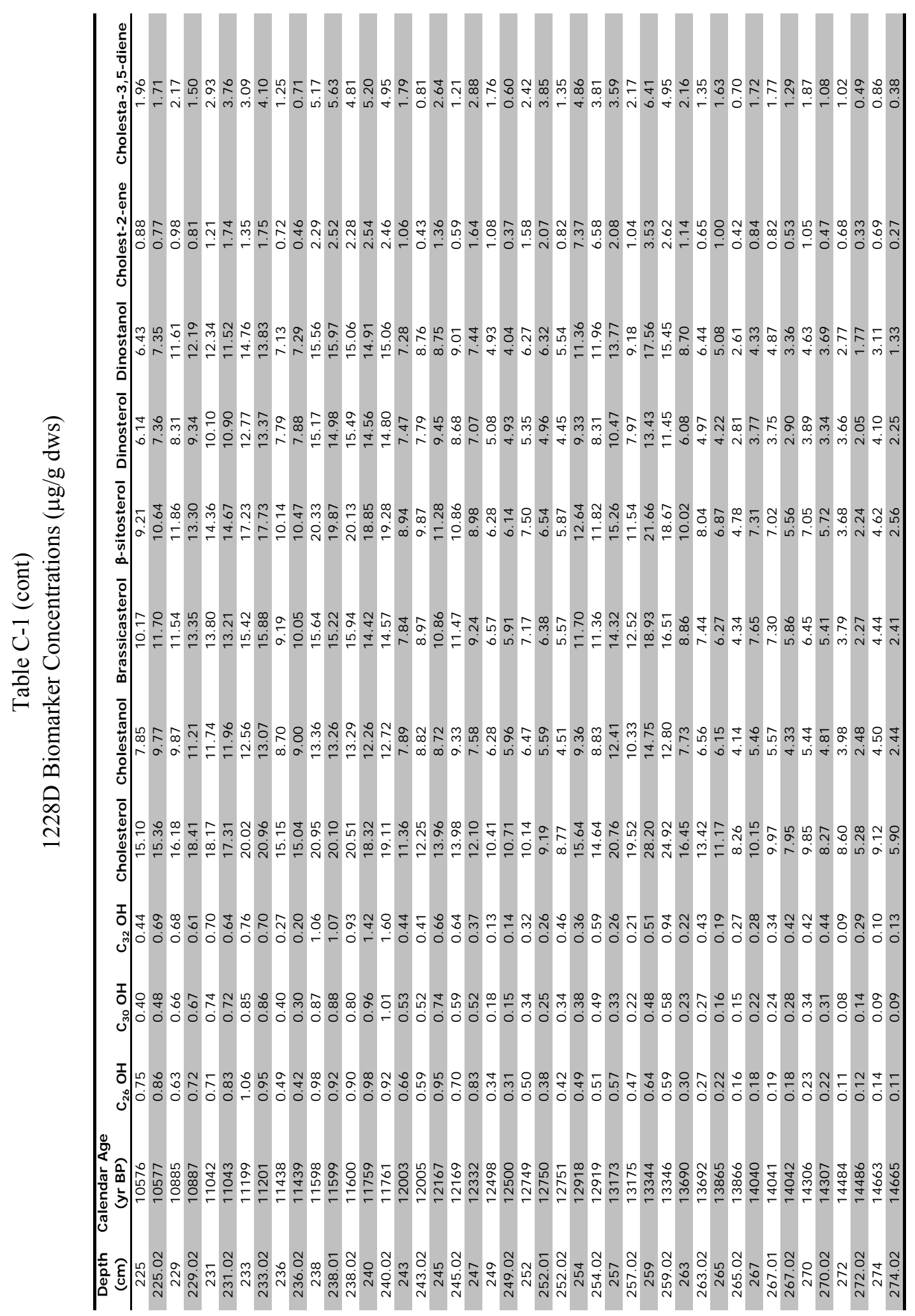




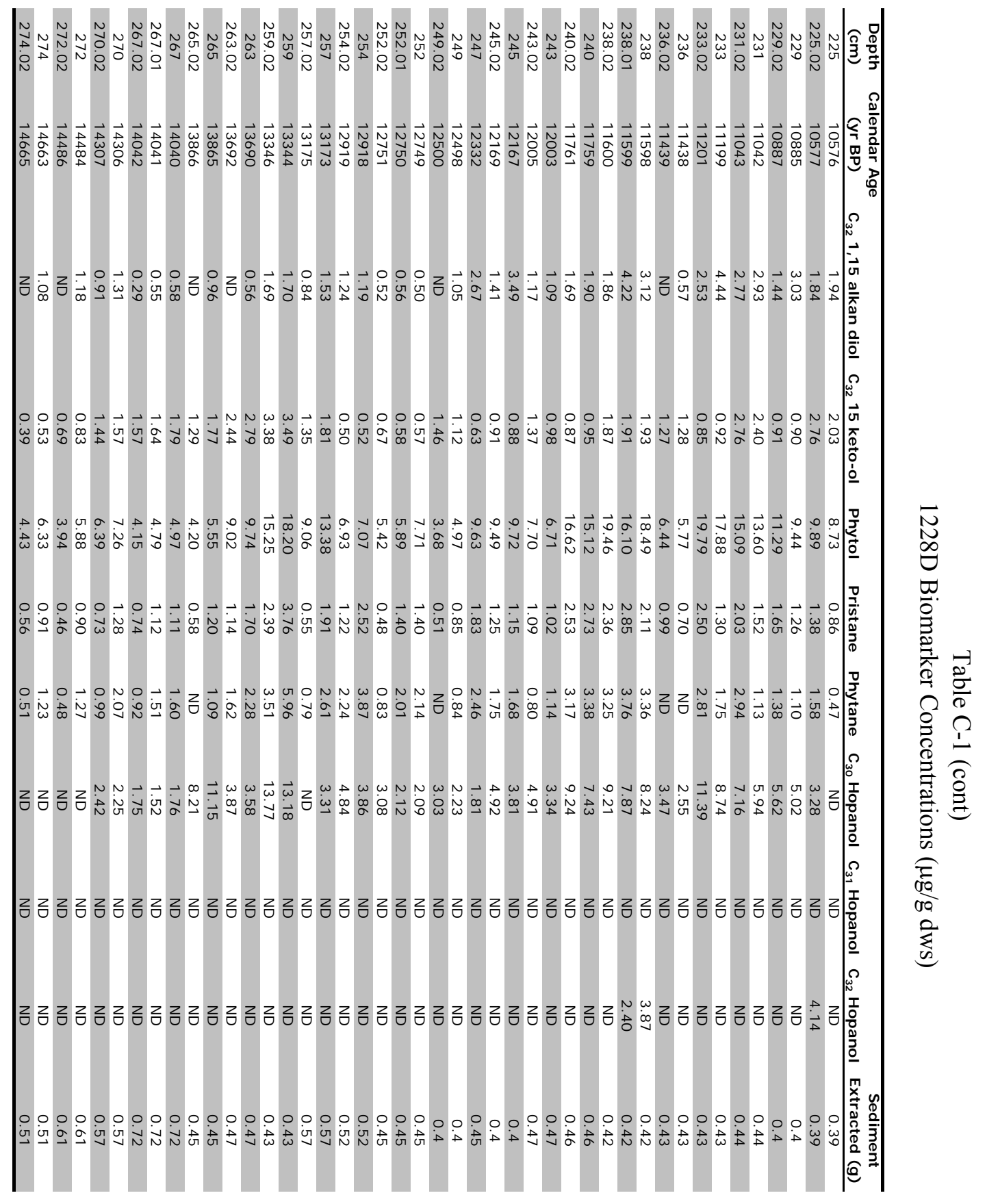


Table C-2

1228D Weight \% Organic Carbon and C/N

\begin{tabular}{|c|c|c|c|}
\hline $\begin{array}{l}\text { Depth } \\
\text { (cm) }\end{array}$ & $\begin{array}{c}\text { Calendar Age } \\
\text { (yr BP) }\end{array}$ & $\begin{array}{c}\text { Weight \% Organic } \\
\text { Carbon }\end{array}$ & C/ N \\
\hline 5 & 88 & 11.55 & 11.07 \\
\hline 7 & 126 & 11.38 & 10.83 \\
\hline 11 & 204 & 11.04 & 10.88 \\
\hline 12 & 224 & 10.21 & 10.96 \\
\hline 14 & 265 & 10.56 & 11.06 \\
\hline 16 & 307 & 10.77 & 11.18 \\
\hline 18 & 350 & 11.00 & 10.67 \\
\hline 20 & 395 & 11.15 & 10.67 \\
\hline 22 & 440 & 12.21 & 10.97 \\
\hline 23 & 463 & 12.51 & 11.32 \\
\hline 25 & 510 & 6.97 & 8.03 \\
\hline 27 & 558 & 11.09 & 11.01 \\
\hline 29 & 607 & 13.67 & 11.24 \\
\hline 31 & 657 & 11.85 & 9.10 \\
\hline 32 & 683 & 12.56 & 9.50 \\
\hline 34 & 735 & 12.90 & 11.51 \\
\hline 36 & 787 & 11.58 & 9.24 \\
\hline 38 & 841 & 12.27 & 9.62 \\
\hline 40 & 896 & 10.36 & 11.28 \\
\hline 42 & 952 & 12.05 & 9.20 \\
\hline 44 & 1009 & 13.28 & 11.56 \\
\hline 46 & 1067 & 14.62 & 11.45 \\
\hline 48 & 1127 & 13.92 & 10.42 \\
\hline 50 & 1187 & 12.98 & 10.72 \\
\hline 52 & 1248 & 14.37 & 11.60 \\
\hline 54 & 1311 & 12.42 & 11.28 \\
\hline 56 & 1374 & 11.75 & 10.50 \\
\hline 58 & 1438 & 8.74 & 10.47 \\
\hline 60 & 1504 & 10.98 & 10.54 \\
\hline 62 & 1571 & 11.75 & 10.55 \\
\hline 64 & 1638 & 11.75 & 10.68 \\
\hline 65 & 1673 & 11.31 & 10.92 \\
\hline 67 & 1742 & 12.23 & 11.31 \\
\hline 69 & 1812 & 10.73 & 11.29 \\
\hline 71 & 1884 & 11.13 & 11.23 \\
\hline 73 & 1956 & 11.30 & 11.02 \\
\hline 74 & 1993 & 9.54 & 10.75 \\
\hline 76 & 2067 & 11.33 & 11.01 \\
\hline 78 & 2142 & 10.38 & 11.49 \\
\hline 80 & 2218 & 10.69 & 11.49 \\
\hline 82 & 2296 & 10.15 & 11.31 \\
\hline 84 & 2374 & 12.28 & 10.88 \\
\hline 86 & 2453 & 13.01 & 10.97 \\
\hline 88 & 2534 & 11.80 & 10.74 \\
\hline 89 & 2574 & 12.41 & 11.20 \\
\hline 91 & 2656 & 11.81 & 10.83 \\
\hline 93 & 2739 & 12.89 & 11.36 \\
\hline 95 & 2824 & 10.63 & 11.50 \\
\hline
\end{tabular}


Table C-2

1228D Weight \% Organic Carbon and C/N

\begin{tabular}{|c|c|c|c|}
\hline $\begin{array}{l}\text { Depth } \\
(\mathrm{cm})\end{array}$ & $\begin{array}{c}\text { Calendar Age } \\
\text { (yr BP) }\end{array}$ & $\begin{array}{c}\text { Weight \% Organic } \\
\text { Carbon }\end{array}$ & $\mathbf{C} / \mathbf{N}$ \\
\hline 97 & 2909 & 12.37 & 11.22 \\
\hline 99 & 2995 & 12.72 & 10.92 \\
\hline 101 & 3083 & 12.53 & 11.12 \\
\hline 103 & 3171 & 12.11 & 10.72 \\
\hline 105 & 3260 & 12.31 & 10.92 \\
\hline 107 & 3351 & 12.09 & 10.94 \\
\hline 109 & 3443 & 11.89 & 11.12 \\
\hline 111 & 3535 & 12.41 & 11.27 \\
\hline 113 & 3629 & 11.92 & 10.96 \\
\hline 115 & 3724 & 11.84 & 11.05 \\
\hline 117 & 3820 & 11.89 & 9.93 \\
\hline 119 & 3917 & 10.67 & 12.12 \\
\hline 121 & 4015 & 7.54 & 11.75 \\
\hline 123 & 4114 & 10.66 & 10.41 \\
\hline 125 & 4214 & 12.36 & 10.47 \\
\hline 127 & 4315 & 11.94 & 10.30 \\
\hline 129 & 4417 & 13.36 & 11.66 \\
\hline 131 & 4521 & 11.79 & 9.79 \\
\hline 133 & 4625 & 10.20 & 9.92 \\
\hline 135 & 4730 & 10.36 & 11.84 \\
\hline 137 & 4837 & 10.60 & 11.28 \\
\hline 139 & 4945 & 11.47 & 11.57 \\
\hline 141 & 5053 & 11.48 & 11.57 \\
\hline 143 & 5163 & 11.85 & 13.89 \\
\hline 145 & 5274 & 10.03 & 11.16 \\
\hline 147 & 5385 & 9.62 & 12.63 \\
\hline 149 & 5498 & 10.79 & 11.07 \\
\hline 151 & 5612 & 12.42 & 11.36 \\
\hline 153 & 5727 & 12.50 & 12.15 \\
\hline 155 & 5843 & 11.93 & 11.44 \\
\hline 157 & 5960 & 10.94 & 11.20 \\
\hline 158 & 6019 & 10.21 & 10.73 \\
\hline 160 & 6138 & 9.44 & 12.95 \\
\hline 162 & 6258 & 10.08 & 11.29 \\
\hline 164 & 6379 & 5.49 & 11.15 \\
\hline 165 & 6440 & 9.13 & 11.66 \\
\hline 167 & 6562 & 11.98 & 11.24 \\
\hline 169 & 6686 & 9.73 & 10.26 \\
\hline 172 & 6873 & 11.56 & 11.59 \\
\hline 176 & 7126 & 11.41 & 12.07 \\
\hline 181 & 7449 & 6.37 & 8.83 \\
\hline 183 & 7580 & 8.19 & 9.73 \\
\hline 185 & 7712 & 6.52 & 10.33 \\
\hline 188 & 7912 & 5.57 & 12.36 \\
\hline 190 & 8047 & 4.92 & 12.13 \\
\hline 192 & 8182 & 4.23 & 10.73 \\
\hline 194 & 8319 & 4.44 & 10.55 \\
\hline 196 & 8457 & 4.10 & 9.67 \\
\hline
\end{tabular}


Table C-2

1228D Weight \% Organic Carbon and C/N

\begin{tabular}{|c|c|c|c|}
\hline $\begin{array}{l}\text { Depth } \\
\text { (cm) }\end{array}$ & $\begin{array}{c}\text { Calendar Age } \\
\text { (yr BP) }\end{array}$ & $\begin{array}{c}\text { Weight \% Organic } \\
\text { Carbon }\end{array}$ & $\mathrm{C} / \mathrm{N}$ \\
\hline 197 & 8526 & 3.21 & 9.20 \\
\hline 199 & 8666 & 2.89 & 9.08 \\
\hline 201 & 8806 & 2.30 & 8.11 \\
\hline 203 & 8948 & 1.99 & 9.80 \\
\hline 205 & 9091 & 2.58 & 8.21 \\
\hline 207 & 9234 & 3.17 & 12.56 \\
\hline 209 & 9379 & 4.84 & 10.85 \\
\hline 211 & 9525 & 3.56 & 11.05 \\
\hline 213 & 9672 & 5.21 & 11.12 \\
\hline 215 & 9820 & 5.75 & 10.92 \\
\hline 217 & 9969 & 5.63 & 11.05 \\
\hline 219 & 10119 & 6.41 & 11.92 \\
\hline 221 & 10270 & 6.45 & 11.76 \\
\hline 223 & 10422 & 6.03 & 11.84 \\
\hline 225 & 10576 & 6.75 & 13.25 \\
\hline 227 & 10730 & 5.85 & 14.18 \\
\hline 229 & 10885 & 7.92 & 13.79 \\
\hline 231 & 11042 & 7.36 & 12.48 \\
\hline 233 & 11199 & 7.58 & 13.17 \\
\hline 234 & 11279 & 9.03 & 13.50 \\
\hline 236 & 11438 & 7.62 & 12.72 \\
\hline 238 & 11598 & 8.50 & 12.63 \\
\hline 240 & 11759 & 8.28 & 12.26 \\
\hline 241 & 11840 & 8.21 & 12.82 \\
\hline 243 & 12003 & 6.50 & 12.80 \\
\hline 245 & 12167 & 6.12 & 12.70 \\
\hline 247 & 12332 & 5.67 & 12.48 \\
\hline 249 & 12498 & 7.04 & 13.21 \\
\hline 250 & 12581 & 7.03 & 11.28 \\
\hline 252 & 12749 & 6.06 & 12.34 \\
\hline 254 & 12918 & 6.47 & 12.83 \\
\hline 255 & 13003 & 6.24 & 12.24 \\
\hline 257 & 13173 & 4.95 & 13.18 \\
\hline 259 & 13344 & 6.61 & 10.88 \\
\hline 261 & 13517 & 5.49 & 12.30 \\
\hline 263 & 13690 & 4.32 & 11.54 \\
\hline 265 & 13865 & 3.26 & 13.09 \\
\hline 267 & 14040 & 2.58 & 10.63 \\
\hline 268 & 14128 & 3.75 & 12.09 \\
\hline 270 & 14306 & 3.12 & 9.47 \\
\hline 272 & 14484 & 2.58 & 11.18 \\
\hline 274 & 14663 & 3.11 & 12.61 \\
\hline 276 & 14844 & 2.78 & 10.94 \\
\hline 277 & 14934 & 0.97 & 8.00 \\
\hline 280 & 15208 & 1.16 & 9.75 \\
\hline 282 & 15391 & 0.94 & 10.29 \\
\hline 289 & 16042 & 0.90 & 10.57 \\
\hline 297 & 16802 & 4.69 & 13.71 \\
\hline
\end{tabular}




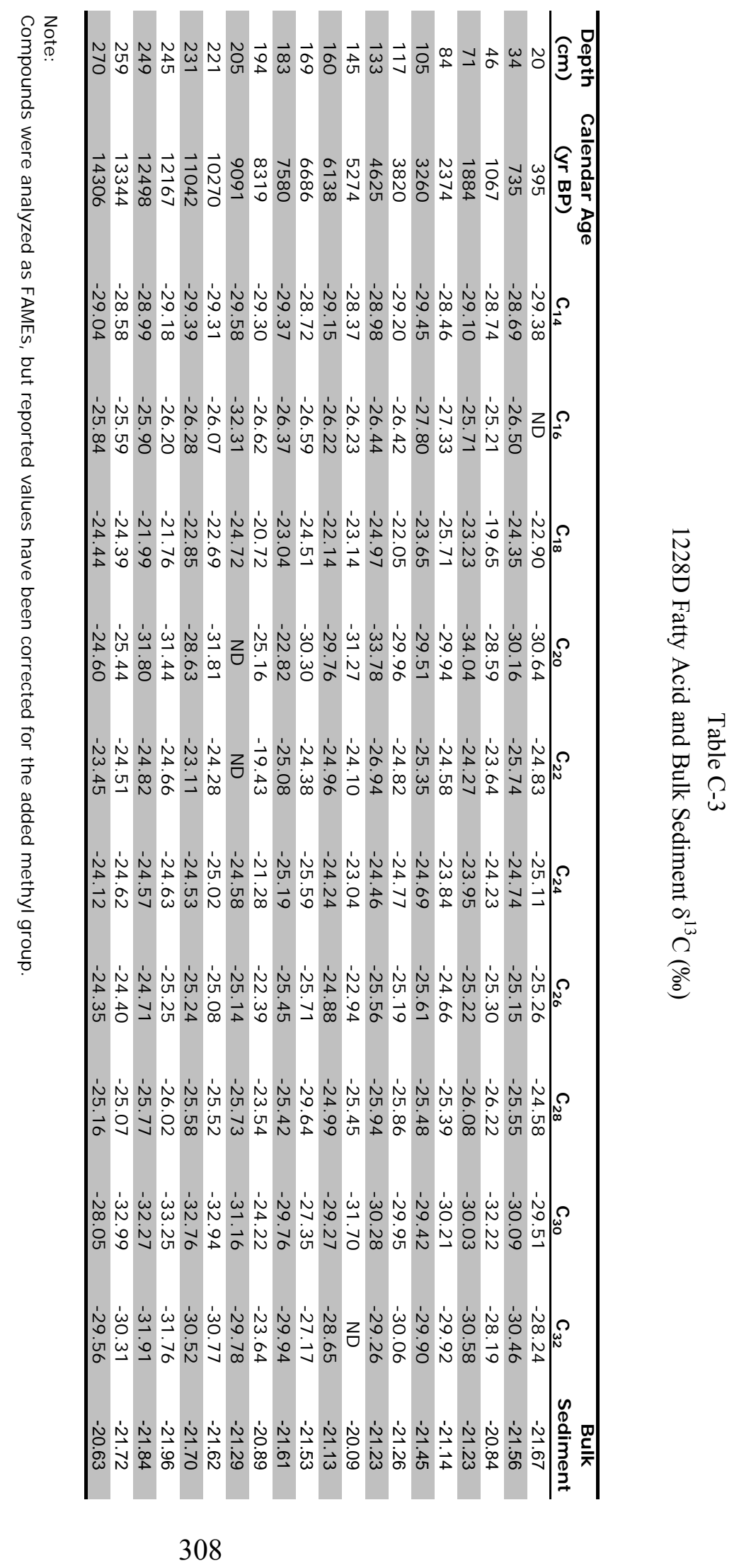

